\title{
ANNETTE FÖRSTER
}

\section{WOMEN IN THE SILENT CINEMA}

\section{Histories of Fame and Fate}

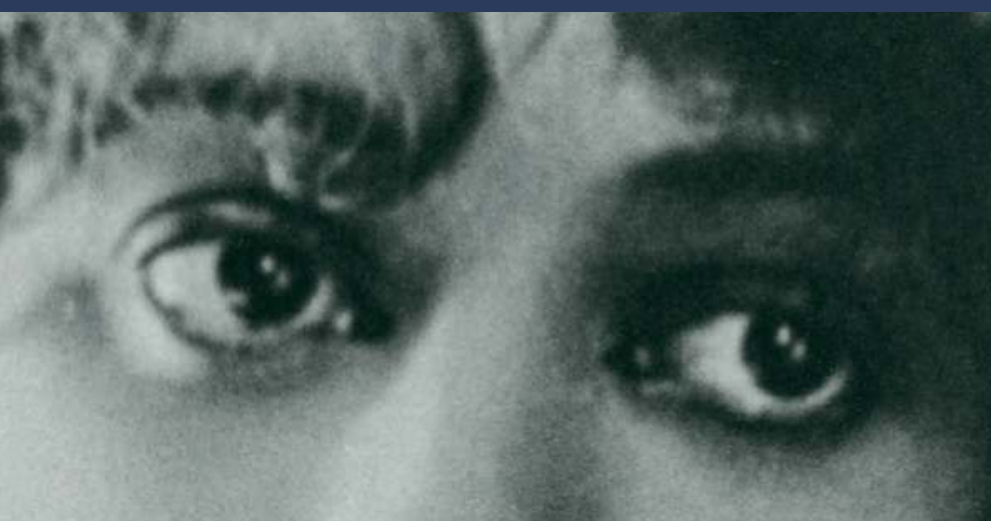


WOMEN IN THE SILENT CINEMA 


\section{FRAMING FilM}

FRAMING FILM is a book series dedicated to theoretical and analytical studies in restoration, collection, archival, and exhibition practices in line with the existing archive of EYE Filmmuseum. With this series, Amsterdam University Press and EYE aim to support the academic research community, as well as practitioners in archive and restoration.

\section{SERIES EDITORS}

Giovanna Fossati, EYE Filmmuseum \& University of Amsterdam, the Netherlands

Leo van Hee, EYE Filmmuseum

Frank Kessler, Utrecht University, the Netherlands

Patricia Pisters, University of Amsterdam, the Netherlands

Dan Streible, New York University, United States

Nanna Verhoeff, Utrecht University, the Netherlands

\section{EDITORIAL BOARD}

Richard Abel, University of Michigan, United States Jane Gaines, Columbia University, United States Tom Gunning, University of Chicago, United States Vinzenz Hediger, Goethe University Frankfurt, Germany

Martin Koerber, Deutsche Kinemathek, Germany Ann-Sophie Lehmann, University of Groningen, the Netherlands

Charles Musser, Yale University, United States

Julia Noordegraaf, University of Amsterdam, the Netherlands

William Uricchio, Massachusetts Institute of Technology, United States

Linda Williams, University of California at Berkeley, United States 


\section{ANNETTE FÖRSTER \\ WOMEN IN THE \\ SILENT CINEMA}

Histories of Fame and Fate 


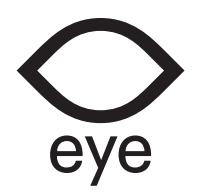

Published by EYE Filmmuseum / Amsterdam University Press

Cover illustration:

Top: Nell Shipman in BAREE, SON OF KAZAN (fragment, see page 329)

Middle: Musidora, publicity portrait (fragment, see page 136)

Bottom: Adriënne Solser in an unidentified film (fragment, see page 98)

Cover design and lay-out: Magenta Ontwerpers, Bussum

Amsterdam University Press English-language titles are distributed in the US and Canada by the University of Chicago Press.

$\begin{array}{ll}\text { ISBN } & 9789089647191 \\ \text { e-ISBN } & 9789048524518 \text { (pdf) } \\ \text { DOI } & 10.5117 / 9789089647191 \\ \text { NUR } & 670\end{array}$

(C) A. Förster / Amsterdam University Press B.V., Amsterdam 2017

All rights reserved. Without limiting the rights under copyright reserved above, no part of this book may be reproduced, stored in or introduced into a retrieval system, or transmitted, in any form or by any means (electronic, mechanical, photocopying, recording or otherwise) without the written permission of both the copyright owner and the author of the book.

Every effort has been made to obtain permission to use all copyrighted illustrations reproduced in this book. Nonetheless, whosoever believes to have rights to this material is advised to contact the publisher. 


\section{TABLE OF CONTENTS}

INTRODUCTION 9

The Method of Writing Careerographies 11

Archival and Other Sources 15

Nell Shipman in the Archives 16

Musidora in the Archives 17

Adriënne Solser in the Archives 19

Note on the usage of Dutch and French names for genres and on translations 20

\section{PART I ADRIËNNE SOLSER, THE NETHERLANDS}

ADRIËNNE SOLSER ON THE DUTCH POPULAR STAGE 25

The Formative Years, 1885-1904 25

Pioneering Comedians in the Dutch Variété 26

The Years of Achievement, 1904-1914 38

New Entertainment Genres and Blurry Boundaries 39

Entr'acte: Solser's Repertoire and Stage Persona 46

The Years of Character Comedy, 1914-1920 55

Adriënne Solser as the Amsterdam Folk Woman 56

Stage History of Amsterdam Folk Characters 58

ADRIËNNE SOLSER AND THE DUTCH SILENT CINEMA 73

Interaction On-stage and On-screen, 1896-1930 73

Mixed Programs in Dutch Variétés and Cinemas 73

Staging Films: Lecturing 80

Dutch Comic Film Production until 192083

Reviewing Interaction Between Stage and Screen 90

Dutch Comic Film during the 1920 s 92 
Adriënne Solser as an On- and Off-screen Film Performer 92 A Difficult Choice 105 Adriënne Solser's Production Company, 1924-1928 106 Solser's Live Act and the Bet-character 116 Solser's Career in the Cinema 131 Epilogue 132

\section{PART II MUSIDORA, FRANCE}

MUSIDORA ON THE FRENCH POPULAR STAGE 137

Jeanne Roques Becoming Musidora, 1906-1912 137

Musidora's Early Acting Career $\mathbf{1 4 2}$

French Popular Stage Genres 143

Musidora in Music-hall and the Parisian Revue, 1912-1914 145

6 | Of Vedettes and "their" Genres 148

Musidora in the Parisian Revue 151

Revue and Film 162

Musidora's Writings and Charicatures 166

Conditions of Musidora's Stage Career by $1914 \quad 167$

MUSIDORA AND THE FRENCH SILENT CINEMA 169

Musidora as an Actress at Gaumont, 1914-1916 169

Feuillade's Dramas and Comic Films with Musidora 173

Coexistence Cinema and Stage Performance 188

Ciné-vaudevilles and Stage Vaudeville 192

Feuillade's Serials with Musidora 210

Musidora as an Actress, 1916-1918 236

Musidora Speaking about Acting in LA VAGABONDE 240

Musidora Writing, Directing, Acting and Producing Films, 1919-1924 245

VICENTA (1920) 246

POUR DON CARLOS (1921) 249

SOLEIL ET OMBRE (1922) 263

LA TERRE DES TAUREAUX (1924) 271

Epilogue 278

\section{PART III NELL SHIPMAN, NORTH AMERICA}

NELL SHIPMAN ON THE AMERICAN POPULAR STAGE 283

Nell Shipman's Stage Career, 1907-1911 283

Entr'acte: Some Reflections on the Memoirs as a Source 289

The Climax of the Stage Period 293 
The Barrier as Northwest Drama 296

Nell Shipman's Options and Choices, 1911-1912 298

NELL SHIPMAN AND THE AMERICAN SILENT CINEMA 305

Nell Shipman as a Scenarist, 1912-1917 305

UNDER THE CRESCENT: Series and Novel 309

Scenario "The Last Empire" 312

Nell Shipman Acting for the Camera, 1915-1918 314

Actress at Vitagraph 316

James Oliver Curwood's Northwest Dramas 329

Back to Nell Shipman's Career: Options and Choices, 1918335

The Shipman-Curwood Film Producing Company, 1918-1920 336

From "Wapi the Walrus" to BACK TO GOD's COUNTRY 341

Nell Shipman Acting with Animals 361

Nell Shipman's Options and Choices, 1919-1920 370

Nell Shipman Writing, Directing, Acting in and Producing Films, 1920-1925 373

A BEAR, A BOY AND A DOG 374

SOMETHING NEW and THE TRAIL OF THE ARROW 376

THE GIRL FROM GOD'S COUNTRY 386

"I packed my Toys and Moved North" 393

THE GRUBSTAKE as Nell Shipman's Magnum Opus 400

Nell Shipman's Options and Choices, 1924-1925 423

Epilogue 425

IN CONCLUSION 427

Abbreviations 431

Notes 433

Career Overviews $\quad 527$

Adriënne Solser 527

Musidora 530

Nell Shipman 533

Acknowledgments 539

Illustration Credits 543

Index 545 



\section{Introduction}

This book presents the careers and oeuvres of three women filmmakers from the silent era, and two of them for the first time comprehensively in English language scholarship. Adriënne Solser, a comic actress and a producer of mixed stage and film shows in The Netherlands, is virtually unheard of in international scholarship. Musidora derived her fame in international film history and feminist theory from her roles as the female criminal in French crime series, but the large body of comic films in which she acted or the three dramas and the mixed stage and film production which she directed in France deserve much more consideration than they have so far received. With Nell Shipman, a Canadian born actress and filmmaker who used to work in the United States, the reverse is the case: the films she produced and directed were indeed the subject of historical and feminist research, but her acting career on the American popular stage or in the cinema were not. In this book, I reconstruct the full range of each career, as actresses and filmmakers in the silent cinema and as actresses in early twentieth century stage entertainment. Each career, moreover, is situated in its historical and national context. The oeuvres discussed each include an array of stage performances, a set of leading roles in films directed and produced by others, and a number of feature films and shorts produced and (co-) directed by the woman filmmaker in question. Each woman's work additionally encompasses a variety of writings, including novels, short fiction and scenarios (in the case of Musidora and Shipman), notes for the live accompaniment of films (Solser), self-presentations in the contemporary press as well as memoirs and reminiscences written in retrospect (Musidora and Shipman). The result is an exciting and compelling triple journey through bygone cultural worlds from the vantage point of the women at work in them, including the dramas and the humor, the endurance and the pragmatism, the accomplishments and the hard- 
ships; in short: the histories of fame and fate that theatre and film careers during the silent era epitomize.

The careers of the three actresses and women filmmakers bear significant parallels. This was an era in which filmmakers learned their métier in practice, so many worked as actresses before they endeavored to produce and direct films. Solser, Musidora and Shipman each had achieved a degree of fame on the stage and on the screen before they took the entrepreneurial and artistic risks involved in establishing their own film companies. Another shared element was that they usually cast themselves in the leading roles in the films they produced. Additionally, at the time, none of the three used to claim the directing credit of these films for herself alone. A final significant parallel follows from the diverse historical cultural contexts of entertainment in which each built her career. The Netherlands had a relatively small and unstable film production in the silent era, but a thriving national popular theatre. France and the United States were leading film producing countries that exchanged their world hegemony during the Great War. Whereas in the US the popular stage suffered from the advent of the cinema, in France it continued to prosper alongside and in interaction with it. The questions opened up by the parallels among these three women broaden the scope of issues to be accounted for in comparison with the questions raised if only one of the three women were considered. The emphasis shifts, for instance, from one woman's filmmaking practices and accomplishments to the significance of their stage and screen acting, and by consequence, to these women's views of the acting métier and of the role of a film's director. The parallels also prompt a historical contextualisation of the ambitions and aspirations that motivated the twists and turns of the versatile careers under scrutiny and called attention to the national stage and film genres that proved pivotal to them. The shifting relationships between the stage and the cinema, last but not least, demanded substantial research into the professional models, options and choices these women had in the entertainment business in the first decades of the twentieth century and in which regards their careers epitomized those of other women, or men, in the country in which it occurred.

Through reconstructing the professional itinerary of each actress/filmmaker, histories of the Dutch, French, and American popular stage and film cultures of the first decades of the twentieth century are provided from the vantage point of the women at work in them. These historical contexts are considered in their dynamics of change and interaction as well as in their cultural specificity. Each career move is understood as interacting with shifts within media and among disciplines. The various components of the oeuvres are studied in relation to these shifts, as well as in terms of their internal continuities and discontinuities. The general thesis that this book defends, is 
that women's careers and oeuvres make a difference to histories of the silent cinema and of the early twentieth century popular theatre, because they may highlight and exemplify practices and genres in popular cultures of the time that otherwise remain largely obscured.

\section{The Method of Writing Careerographies}

What is provided in the process, I propose to call "careerographies": reconstructions of careers that have occurred in a given time and a given place and that have materialized in oeuvres, which comprise a number of roles on stage and on screen, of films and of writings. In each "careerography", the professional itinerary and components of the oeuvre of an actress/filmmaker is historicized and contextualized. For that aim, the research has focused on the material, intertextual and interdisciplinary conditions of each career and oeuvre separately. "Careerographies" are multilayered and interdisciplinary, as well as affirmative and non-hierarchical; they do not necessarily privilege cinema over other disciplines and media and they reflect the spirit of the times in professionalism, entrepreneurial practices and shifts within and among a range of disciplines and media.

Because Solser was relegated to the margins of film history and of feminist research, and Shipman's and Musidora's presences were confined to one aspect of their oeuvres, it was my concern to develop an alternative for the hierarchies that underpin such perspectives. Instead of presupposing that the films directed by these women were more prone to historical and feminist scrutiny than the roles they had acted, or vice versa, and instead of assuming that the stage acting was not related to their work in the cinema, or vice versa, I investigated the three components of each career from a non-hierarchical perspective. This research strategy opened up the possibility to approach each career and oeuvre analogous to how early cinema is considered in modern day film history, that is to say as "a site of shifts and struggles, of roads not taken and paths unexpectedly crossing," ${ }^{1}$ to cite Thomas Elsaesser's summarizing words about this broad and innovative field of investigation. It implies that I consider both continuous and discontinuous relations and developments within and around each career and oeuvre.

Two further strategies advocated by Elsaesser have guided my general approach. One concerns the application in early film history of "a demotion of intrinsic filmic evidence." ${ }^{2}$ Although film analysis has been an indispensable tool, it was by no means the only one. It could not be, especially for the stage acting components of the careers, because to stage performances films obviously were less relevant than stage texts and reviews. For their screen careers, 
moreover, film viewing was only an option insofar as prints were extant or accessible and a substantial number were not. This awareness invited the inclusion of a wide variety of sources in the investigation, for establishing what Elsaesser has called "the media-intertext" ${ }^{3}$ of the careers and oeuvres. Another strategy concerns the approach to this non-filmic material, both primary and secondary. In the research, I have taken literal the call by Robert Allen to "suspect every biography and check every monograph." ${ }^{4}$ have understood this suspicion and need for checking as applying to the establishment of facts and what can count as evidence, as well as to the relation of a particular text with the discourse of which it was, or now is, part. Both strategies have prompted extensive archival research for contemporary documents and for textual sources pertinent to the careers and oeuvres under scrutiny.

The importance of examining cultural specificity in popular cultures in relation to the marginalization of the work of women derives from Giuliana 12 Bruno's momentous study on the Neapolitan woman filmmaker Elvira Notari. ${ }^{5}$ Bruno connects the historic eclipse of the films of Notari not only to the long scholarly neglect of Italian silent cinema, but also to "the disregard within this period of the regional, local, and differential Neapolitan production, grounded in a popular culture." Bruno's micro-history of Notari draws attention to the fact that popular cultures are at once historically and culturally-that is to say, nationally, regionally or locally-specific. This insight became an important tool to understand the distinct choices for genres and aesthetics made by Solser, Musidora and Shipman individually.

During the research in France and the Netherlands, it became apparent that for Musidora and Solser not only the screen acting, but also the stage acting, was an important component of their careers, if only because neither had abandoned live performing once they had begun acting for the camera. That both of them continued acting live on-stage gave me the inkling that this was not an idiosyncrasy but rather a symptom of something significant. The inkling turned into a conjecture when I came across Eric de Kuyper's passionate call for more research into the relation between silent film and the popular stage instead of re-invoking time and again the struggle of cinema to set itself free from its theatrical heritage. ${ }^{7}$ De Kuyper argues that the nineteenth century popular stage had much more in common with the cinema of the 1910 s than the focus on film specificity and differentiation allows for and that concepts such as "realism," "spectacle," and "mise-en-scène" constitute continuities between the two rather than that they can be claimed for film in particular. The emphasis on the competition between film and theatre emanates, according to De Kuyper, from a shortage of knowledge of the popular theatre of the late nineteenth century in film scholarship. This plea for an affirmative approach to the theatrical heritage in the cinema of the 1910s has 
inspired my discussion of both Solser's and Musidora's oeuvres and, eventually, of Shipman's too. This affirmative approach permitted substantial forms of obscured popular culture to surface, most notably of Dutch and French popular stage genres and of an American popular theatre and literary genre. It also allowed for establishing the pertinence of each genre to the oeuvres to which it gave shape, and to examine the role each actress/filmmaker played in the migration of the genres from one discipline or medium to another.

In the first two decades of the twentieth century, stage and film production in the three countries constituted an open and dynamic field of entertainment business. This openness and dynamism stimulated a "get up and go attitude," as Marsha McCreadie encapsulated it in the introduction to her study on American women screen writers. ${ }^{8}$ One of these screen writers, Anita Loos, whose career began in the 1910s, articulated the pragmatism behind this attitude:

during those early years we had little respect for a métier that we looked down on as a mere passing fad. [...] Those of us whom the movies were making rich, were bent only on cashing in before the craze died out. ${ }^{9}$

The "get up and go attitude" can be found in the many loose affiliations and switches between companies and collaborators in the careers of the actresses/ filmmakers under scrutiny. Some "fads" did pass quickly in the swiftly changing fields of stage and film entertainment of the time, and each of the three women experienced the fading of styles and genres that their acting careers had been thriving on. On the other hand, none of them was a "first" in her profession, certainly not as popular stage and screen actresses, but not even as women filmmakers; each had female predecessors and colleagues. Nonetheless, all three were self-taught professionals in a range of métiers that constantly changed and demanded new or extra skills. In addition, acting and directing are rarely autonomously executed crafts and usually require collaboration with others. The collective nature of both the work and the profession demanded research into models and teams. The professional dynamism required investigation into the historically and culturally specific conditions of the subsequent métiers that each of the women chose.

The interest in screen acting likewise borrows from Heide Schlüpmann's research on the silent film actress Asta Nielsen. Schlüpmann analyses how Nielsen in her early films distinguished her physical acting before the camera from her acting within the diegesis. In so doing, Nielsen created a specific relation to spectators, in that she made them aware of their presence in the auditorium and that she addressed them as female narrators. ${ }^{10}$ The distinction made by Schlüpmann between diegetic and extra-diegetic acting and the 
agency ascribed to the actress proved to be a useful tool for analysing the relations with the camera and with spectators created by the actresses in question and the forms of address they developed.

The non-hierarchical treatment of the three components of each career, the study of obscured popular genres, the non-oppositional relation of the actresses/filmmakers with the popular cultures in which they worked and the investigation of historically and culturally specific conditions of stage acting, screen acting, and film making invited an intertextual pragmatic of examining preceding and concurrent texts. Also in this regard, Bruno's study on Notari has been inspirational, particularly in its insistence that the nature of a research subject determines its approach. ${ }^{11}$ While Bruno was faced with a largely lost body of films, I dealt with a mixture of available and missing material. Among the missing material, then, are the stage roles, various screen roles and several films belonging to the oeuvres of each actress and filmmak-

14 er. Like Bruno, who draws from Gérard Genette's theory of intertextuality ${ }^{12}$ I have retraced these missing elements with the help of paratextual material: reviews, autobiographical statements by the actresses/filmmakers, synopses, scenarios, novelizations, and preceding texts such as novels and stories from which the works were adapted.

My curiosity, however, was for something different than the women's "fictional 'scene of writing'," as Bruno articulates her understanding of Notari's unclaimed authorship. ${ }^{13}$ Driven by the awareness that Musidora and Shipman had been established authors, producers and directors at the time, I searched for knowledge of the choices each actress/filmmaker made as a craftswoman on the stage and in the cinema: how they adopted, adapted and reworked crafts, genres, styles, and subject matter. I have not only done so in related texts, but in the films and the roles as well. This required a more pragmatic method than theoretically reconstructed authorship would have permitted. For that reason, I probed the material from a Bakhtinian angle, as explained by Robert Stam:

Dialogism refers to the relation between the text and its others not only in the relatively crude and obvious forms of an argument-polemics and parody - but also in much more diffuse and subtle forms that have to do with overtones, pauses, implied attitude, what is left unsaid or is to be inferred. ${ }^{14}$

Implied attitude, what is left unsaid or is to be inferred were often highly pertinent for interpreting a statement. Moreover, Bakhtinian translinguistics allows for an understanding of authorship that deviates from originating or creating authors, as in auteurism, or from the textual authorship desired by 
spectators as in cultural theory. Bakhtin's authors are "existing in, and even in some measure created by, dialogue." 15 They are permeated and permeable with preceding and concomitant texts, which are consistently taken as "utterances," as discursive rather than as signifying practices. ${ }^{16}$ Also, Bakhtin's understanding of textuality is not restricted to spoken words or written texts, but "applies by extension to the relation between languages, literatures, genres, styles and even entire cultures." ${ }^{17}$ Notwithstanding, authors are concrete and apparent in history, as, for instance, the writer to whom Bakhtin devoted his book Rabelais and his world. "But in order to understand [Rabelais]," Bakhtin argues, "we must read him with the eyes of his contemporaries; we must see him against the thousand-year-old tradition that he represents." 18 Even though the traditions that the actresses and women filmmakers in this book epitomize are not that old, reading their careers and oeuvres with the eyes of their contemporaries became an important tool to understand the options and choices of these women filmmakers within the popular cultures in which their work took shape and which their work helped to shape. This tool allows for acknowledging the historical distance between the modernday researcher and the just one-century-old traditions and genres relevant to the oeuvres of these women filmmakers that often appear, however, as no less unfamiliar to us than Rabelais' world.

My first and foremost intention is to delineate Adriënne Solser's, Musidora's, and Nell Shipman's aspirations and preferences, their professional options and choices in the swiftly changing fields of entertainment of the first decades of the twentieth century, and how they fared with and in them. My aim is to clarify the skills, views, risks and achievements involved, as well as the obstinacy, the courage, and the faith that brought them now fame, now twists of fate. Above all, I hope that my fondness of Solser, Musidora and Shipman and my delight in their performances shines through on every page.

\section{ARCHIVAL AND OTHER SOURCES}

In search for films, personal documents, autobiographies, trade papers, newspapers, magazines and other relevant material, I consulted film archives and film collectors, a radio archive, film, theatre, and general libraries and municipal archives, as well as family members in the Netherlands, France, and the United States. The silent and archival film festivals Le Giornate del Cinema Muto in Pordenone and Il Cinema Ritrovato in Bologna, moreover, offered key opportunities to watch in projection and with appropriate accompaniment archival prints of films from the contexts of the oeuvres. Over the years, the internet became an increasingly important source of primary documents 
such as hard-to-access film magazines and local newspapers. The material retrieved is copious and extremely diverse, and will be discussed in due detail in the main text; however, some specific finds and some details of the investigative work may illuminate its substance and pertinence to the subjects of inquiry.

\section{Nell Shipman in the Archives}

Nell Shipman is the only one of the three women filmmakers whose papers were assembled in a collection, together with eight of her extant feature-length and short films. The Nell Shipman Archive is housed in the Albertsons Library of Boise State University in Boise, Idaho and contains a wealth of material. ${ }^{19}$ The host of published and unpublished autobiographic utterances, factional and fictional, as well as the correspondence was pivotal for my research. Shipman's memoirs, moreover, were published posthumously by the head of The Hemingway Western Studies Center, the late Tom Trusky, who established the collection. These memoirs are rare in three respects: first, for my research, Shipman's memoirs were the only one's available for consult-Musidora's were not and Solser's do not exist-; second, Shipman's memoirs were published as she had written them, in her candid, witty and astute style; third, the memoirs attest to a view that brings to mind modern-day approaches to silent cinema history, as Shipman speaks in terms of " $[\mathrm{m}]$ any broken threads going, seemingly nowhere; but some running straight, so their ends are traceable to their beginnings." ${ }^{20}$ This view and Shipman's penchant for self-reflection made her memoirs a rich source for my discussion of her career.

Nell Shipman's son Barry was already critically ill when he granted me two brief interviews at his home in San Bernardino, California about a month before he died at age eighty-four. Despite his condition, he was willing to answer my questions and to share his personal impressions of his mother and her work. I have gratefully incorporated them in my discussion of Shipman's treatment of genre.

Shipman's personal papers have been supplemented with documentation gathered by Trusky from contemporary trade papers, fan magazines, and eyewitnesses. Given the scope of the project, additional investigation was nonetheless due, most notably of trade papers such as Moving Picture World and New York Dramatic Mirror. Further research concerned Shipman's career as a stage actress. Over the course of time, more digitized local newspapers became available for download; additionally, complete transcriptions of novels - in which Shipman had acted in adaptations thereof-also became available. This permitted to reassess historically a sub-genre of popular literature, 
theatre and cinema that appeared more than pertinent to Nell Shipman's career and oeuvre.

I had several opportunities to watch films from Shipman's oeuvre on video and DVD, but, most significantly, in projection. My first encounter with three of her films was in the invaluable historic program section of the Festival International de Films de Femmes in Créteil, near Paris, in 1989. In 1992, I included BACK TO GOD'S COUNTRY in a guest program in the former Nederlands Filmmuseum (now: EYE Filmmuseum). Since then, the film has been provided with a new musical score composed by Lindsay Cooper, with which it has been released on DVD by the Idaho Film Collection. Other preserved Shipman films were projected for me at Boise State University, and are now likewise available on DVD. Especially with silent films, watching them in projection on a big screen is often necessary to fully grasp the atmosphere, pictorial qualities, and narrative logic of these films.

Musidora in the Archives

Musidora's career and oeuvre required basic investigation. Two French publications of the 1970 s extensively discuss her career, one written by the film historian and Feuillade-connoisseur Francis Lacassin, the other by filmmaker and radio film critic Patrick Cazals. ${ }^{21}$ They made me aware of Musidora's career on-stage and on-screen, as well as of a vast body of writings about and by her. I gratefully took these publications as guides, but additionally undertook week-by-week, page-by-page examinations of the most important French film periodicals of the era in film libraries and archives in Paris, Brussels, Ghent and Amsterdam. In addition to reviews on Musidora's films, some periodicals contained self-statements about her experiences in acting and filmmaking, including short stories and semi-fictional accounts, that appeared to be highly pertinent to my search for Musidora's own views. Additional writings by Musidora were published in Cazals, which became a valuable primary source in this regard as well. The Fonds Musidora at the Bibliothèque du Film (BiFi), moreover, contained notes in Musidora's handwriting on one of her films that significantly influenced my impression of it. From the archives of Radio Suisse Romande, tapes were obtained of radio lectures that Musidora had given in the 1940 .

In the Bibliothèque Nationale de France, Département des Arts du Spectacle in Paris, I consulted various files relevant to Musidora's career, among which a collection of synopses allowed for a reassessment of the comic films in which Musidora had acted at Gaumont. Most important for the research on Musidora's stage-acting career appeared the daily for the performing arts, 
Comoedia, as well as the Collection Rondel, which contains programme booklets and reviews of revues in which Musidora had acted. A pivotal source for understanding the Parisian popular stage of the time proved a series of articles by musicologist Louis Laloy in the contemporary magazine of classical and popular music, La Revue Musicale S.I.M..

From Musidora's screen-acting career, I had access to the episode films LES VAMPIRES (on screen at the Nederlands Filmmuseum and in Le Giornate del Cinema Muto, as well as on video) and JUDEx (on screen at the Festival International de Films de Femmes in Créteil and on the editing table at the Cinémathèque Royale in Brussels). Over the years, moreover, one Musidora production after the other re-surfaced in French archives, including SOLEIL ET OMBRE at the Cinémathèque française in Paris and Fort de Saint-Cyr, as Well as LA TERRE DES TAUREAUX and POUR DON CARLOS at the Centre National de la Cinématographie in Bois d'Arcy. I was also able to view several short sub18 jects with Musidora as an actress at the Cinémathèque Gaumont in Neuillysur-Seine. These subjects included the only surviving Feuillade film farce with Musidora in the cast, LAgOURDETTE GENTLEMAN CAMBRIOLEUR. Thanks to the restoration of the film by the Cineteca di Bologna and the Gaumont Pathé Archives, I was able to include it in an homage to Musidora in Il Cinema Ritrovato at Bologna in 2011. The fragment of LE RÉVEIL DE L'ARTISTE, finally, was rediscovered by the Parisian film restoration company Lobster Film. As for the latter three films - POUR DON CARLOS, LAGOURDETTE GENTLEMAN CAMBRIOLEUR and LE RÉVEIL DE L'ARTISTE - , this is the first book in which they are discussed in due detail.

When Musidora died unexpectedly in 1957, she had been working for eleven years at the Cinémathèque française, as the head of the Press and Documentation Department and as the documentarian of the Commission des Recherches Historiques, which was an oral history project for documenting early and silent cinema initiated by Henri Langlois. Musidora was assigned to organize the sessions and to transcribe the taped discussions, the minutes of which are being preserved at the BiFi in Paris. They did not contain a session on Musidora's self-produced films, only incidental remarks. She had donated prints of her films to the Cinémathèque, and was busy creating a file on Colette, but had kept most of her personal papers at her home in Bois-Le-Roi. ${ }^{22}$ This is where Lacassin at the end of the 1960s, and Cazals a decade later, were able to consult Musidora's scrapbooks and correspondence. Patrick Cazals informed me, moreover, that soon after he had begun writing his book, Musidora's only son Clément Marot had an accident that incapacitated him. Since then, Musidora's collection seems to be inaccessible. By consequence, on Musidora's options and choices quite a bit remained and remains to be inferred. 
Adriënne Solser's daughter, the film editor Lien d'Oliveyra, died before I started the research on her mother. The founder of the Nederlands Filmmuseum, the late Jan de Vaal, had himself searched for papers of Solser's and found that none were retrievable, as he assured me when I told him of my plans to include her in this project. In 1992, the Filmmuseum acquired the small collection that now constitutes the "Archief Adriënne Solser en Lien D'Oliveyra 1904-1952". The Solser part of it consists largely of notebooks with handwritten texts of songs, duets, and monologues that Solser used to deliver on stage and with her films. It also contains a scrapbook with press clippings about a tour throughout the Netherlands in the early 1930s that Solser made with two of her films. In all its scantiness, the material eventually appeared of high pertinence to establish Solser's stage and screen persona and her practice of performing live with her films.

This was also how the material was used by the EYE Filmmuseum for the restoration of two of Solser's films. Not only were two surviving prints reconstructed, but also Solser's performances with them. Among a group of musicians commissioned to develop appropriate live accompaniment with silent films were the pianist Stefan Ram and the jazz-singer Jet Pit. From the notebooks and through lip-reading, Jet Pit reconstituted the songs and the spoken text with which Solser used to accompany the films. I have been able to watch more than once the show she makes of it, at the Amsterdam cinema Tuschinski with a local public akin to the one for which it was intended and at the Festival International de Films de Femmes at Créteil with an international women's audience. Each time it was an event, a cross-media show with great appeal to a public appreciative of Amsterdam or farcical humour. To attend these shows fundamentally informed my research on and impression of Solser's style and practice.

In order to retrace Adriënne Solser's career on stage and in cinema, I followed a procedure akin to the one developed for Musidora's, although their film historic reputation differed considerably. If Musidora was time and again adulated as the star of Feuillade's serials, Solser's work in retrospect was estimated not cinematic enough to be taken seriously. To my surprise and delight, however, this was not the case in her times: film periodicals and newspapers reviewed her films and performances with regard for their specific qualities and conditions of reception. On this basis, I began to surmise that, at the time, there had been a more appropriate way of savouring Solser's work than if approached from a perspective of cinematic quality or film per se. My focus became to establish the material, interdisciplinary and intertextual conditions on which this work could thrive and survive well into the 1930s, which 
led me to inquire into the traditions of popular stage forms and genres from which it drew. However, the history of the genres and forms pertinent to Solser's oeuvre appeared to be largely unwritten, so that on these too, archival research was necessary. Various sources have been of pivotal importance to this research: the files of the Stadsarchief Amsterdam relating to individuals, to theatres, and to stage performances, which included press clippings and handbills; the files on revue writers and popular stage critics in the collection of the TIN (the former Theater Instituut Nederland); the local newspaper Rotterdamsch Nieuwsblad, of which I did a day-by-day, page-by-page examination of the years 1883-1920 in the Gemeentearchief Rotterdam; the invaluable filmography of Dutch silent fiction OfJoy and Sorrow established by the late Geoffrey Donaldson; and a theatre and film paper of the 1910s that hitherto has been rarely consulted by historians of the popular stage and the cinema: De Theatergids. Geïllustreerd Dagblad voor Tooneel, Muziek en Beeldende Kunsten.

Note on the usage of Dutch and French names for genres and on translations

In the parts on Solser and Musidora, I have chosen to retain the names for genres of entertainment and performances as they were in the Netherlands and in France at the time. This is motivated by the fact that such names are often untranslatable in their cultural and historic specificity and that the same names refer to different phenomena as they were current in different entertainment cultures. For reasons of comprehensibility, moreover, nonEnglish titles of films, plays, and performances have been translated. These translations are mine, unless stated otherwise. 



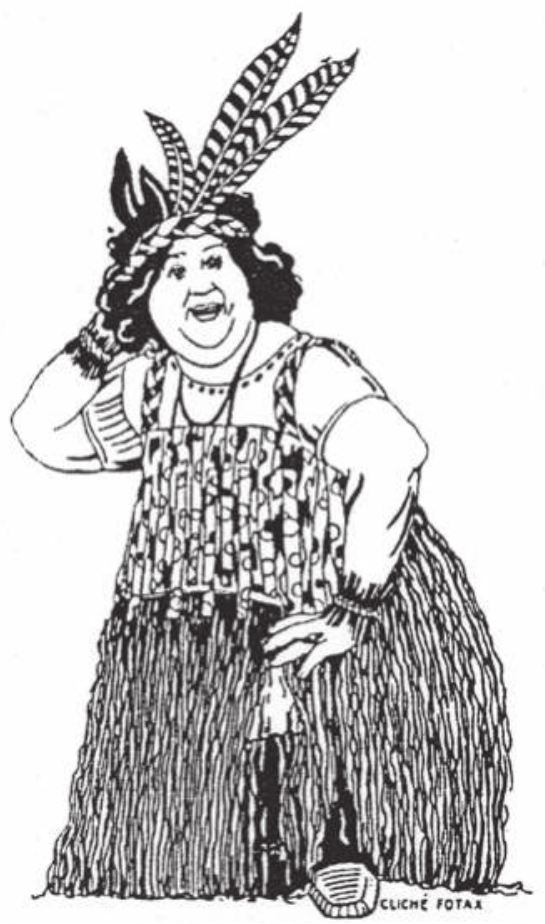

Adriënne Solser. Caricature from an advertisement of BET ZIT IN DE PENARIE, Nieuw Weekblad voor de Cinematografie, 25 January 1929. 


\section{PART I ADRIËNNE SOLSER THE NETHERLANDS}




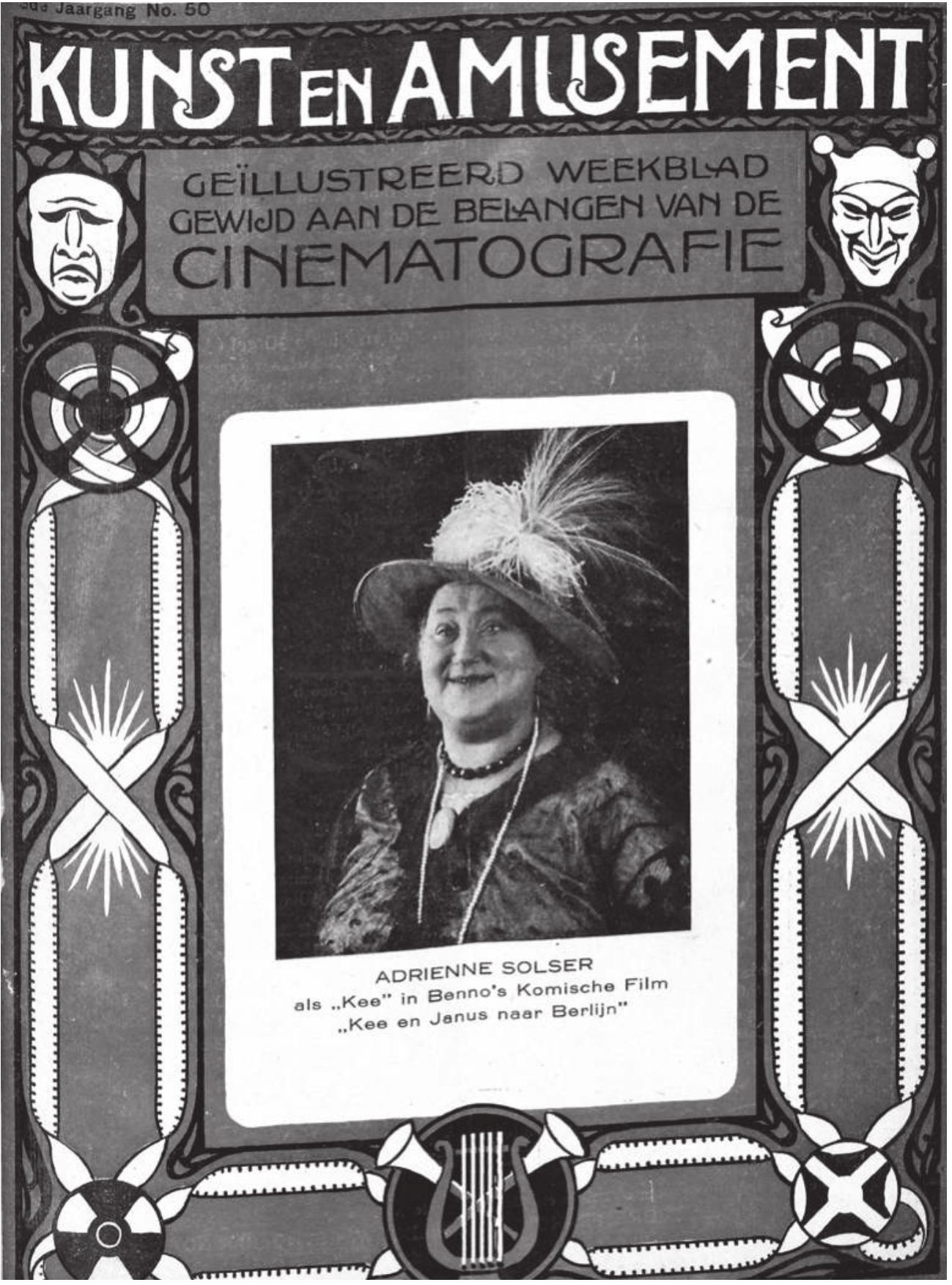

Fig. I.1: Adriënne Solser's portrait on the cover of

Kunst en Amusement, 15 December 1922. 


\section{Adriënne Solser on the Dutch Popular Stage}

\section{THE FORMATIVE YEARS, 1885-1904}

During the first two decades of Adriënne Solser's career, from the 1880 s through 1904, popular stage entertainment became professional and turned into a booming business in the Netherlands, as in most developed countries. The boom was enhanced by the advent of variété, revue, cabaret, and cinema. Solser's career parallels this development in the sense that, in those years, she became a professional and respected soubrette in the Dutch variété. The oldest verses from her repertoire preserved at the EYE Filmmuseum date from 1904; if this was indeed the year when she began to collect and copy her repertoire-rather than that preceding notebooks were lost-, this is a sign that she was reaching professional maturity. Sources such as advertisements in local newspapers and the program leaflets of theaters where she used to perform testify to her increasing prominence by 1905, and as such, they provide more adequate means to reconstruct Solser's career than the extremely scarce remarks in newspaper reports and the virtually absent reviews in other periodicals, even up to 1912. Additional illuminating source material is contextual and relates to two of her brothers, who were major players in the business; to some of her female colleagues; and, finally, to issues pertaining to the entertainment business in general. In this weaving of a contextual fabric around the few available facts and figures, the contours and conditions of Adriënne Solser's early professional years will be reconstructed.

Around 1900, Dutch variété did not differ significantly from the French music-hall, American vaudeville, or the German Spezialitäten-Programm. These various terms designated the kind of entertainment that targeted an audience that consisted of a mix of classes, sexes, and ages. These performances were presented in posh halls built or rebuilt especially for the purpose of staging 
series of awe-inspiring and entertaining performances. Such an evening, or matinee, program was composed of a number of distinct short acts, usually including a trained-animal routine, acrobatics, a clown act, as well as comic, musical, and vocal performances. Throughout the industrializing world, such miscellaneous programs were instrumental to introducing film to mass audiences, and thus it was that Dutch variété programs began featuring a standard film act in 1896. ${ }^{1}$ The films shown during this period were of foreign origin, like the bulk of the specialiteiten, the Dutch term for the individual acts or attractions. The owner of one Amsterdam variété-theater ventured into filmmaking by 1899 , but this was exceptionally early. ${ }^{2}$ Variété programs in the Netherlands used to feature German, English, French, and American acts, while Dutch comic actors and actresses travelled to Berlin, Brussels, London, Paris, New York, and to "Nederlandsch Indië", the colonial term for what is now Indonesia. Adriënne Solser reportedly performed in Belgium towards the

26 end of the 1890s, and her repertory notebooks contain French translations and German versions of several verses. ${ }^{3}$

The regular staging of untranslated French and German plays and operettas before and around the turn of the century, as advertised in newspapers, suggests that theater audiences were presumed to understand the two languages that surround the small country of the Netherlands. This assumption, together with the international orientation of Dutch variété, initially generated some reservations towards Dutch comedians, who, by the turn of the century, had nonetheless managed to secure the goodwill of directors and audiences because the latter better understood the subtleties in humorous texts in their own language. ${ }^{4}$ If Dutch performers and their texts were to satisfy an increasingly fastidious audience, they would have to meet the standards upheld by the international attractions. This goal had been achieved convincingly by the early 1910s, a time when audiences downright demanded to see and hear Dutch artists perform. ${ }^{5}$

\section{Pioneering Comedians in the Dutch Variété}

The first generation of male and female comedians in the Netherlands, including Adriënne Solser, became popular during the 1880 os and $1890{ }^{6}{ }^{6}$ Advertisements in newspapers reveal, furthermore, that both female and male Dutch comedians became an indispensable element in the variété program after the turn of the century. The size of the font used to advertise them illustrates that they had become the popular stage's biggest attractions by 1910. The best of Dutch comedians, though-including, during the 1900s, Chrétienni and Louisette, Louis and Rika Davids, Louise Fleuron and the duo Solser en Hesse, with 
Adriënne's brother Lion-were crowd-pleasers from the beginning. Adriënne Solser herself attained such a status by 1908 .

Aside from Adriënne and Lion, another sister, Josephine, and two more brothers, Michel and Louis, were active on the variété stage before the turn of the century. ${ }^{7}$ With Adriënne, Louis, and Lion carrying on after 1900, the Solser family was one of several groups of relatives and their spouses who, together, largely constituted the acting stock of Dutch popular theater and variété. The largest and most renowned families were the Davids' and the De la Mars.

The former family included, the variété, cabaret, and revue artist Louis Davids, who initially performed with his sister Rika until he formed a comical duo with a second sister, Henriëtte (who went by the stagename Heintje) in

Fig. I.2: Adriënne Solser in the early 1900 s. Publicity portrait by C. Bethlehem, Den Helder

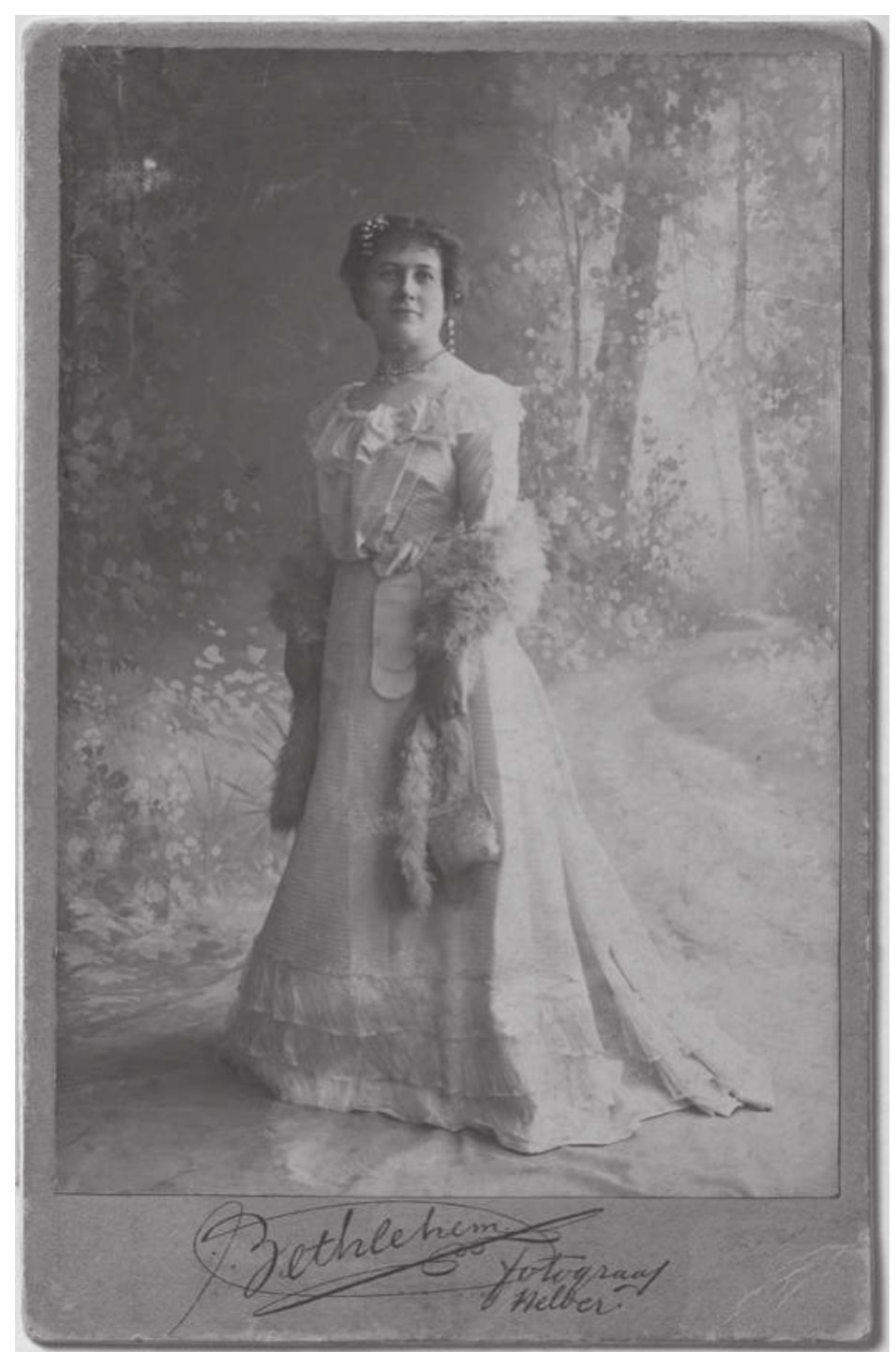


1912. Heintje married the entertainment critic Philip Pinkhof, who, under the nom de plume Rido, wrote many successful revues, in some of which Adriënne Solser performed as well. Heintje Davids went on to become one of the top revue stars in the Netherlands after the First World War and also acted in films. The central figure of the latter family, the De La Mars, was the actor, comedian, and stage director Napoleon de la Mar, known as Nap in the vernacular, one of the five children of the actor Charles de la Mar and the actress Rika Kley. During the 1910s, Adriënne Solser appeared in revues and cabaret programs with Nap and Chris de la Mar. A further influential family in the fields of the legitimate and the popular stage, as well as in cinema, was the Bouwmeester clan, with, at its center, Louis Bouwmeester Sr. and his sister Theo, two of the most celebrated theater actors of their day. ${ }^{8}$ And then there was the Van Dommelen family: the brothers Frits, Jan, and Louis, and their sister Caroline. Caroline (or Caro), was the most versatile of them: she alternated between the legitimate stage, cabaret, revue, and film, and also directed films.

While many of these actors continued to collaborate with their relatives throughout their careers, the Solsers, apart from occasionally standing in for each other, did so only at the very beginning. In fact, they began performing within their parents' company, which toured the province of Zuid-Holland during the 1870 s and 1880 ..${ }^{9}$ Michel, the third child born in 1865, allegedly made his acting debut at age five or six; ${ }^{10}$ and Adriënne, born in 1873, was reported to have sung on stage at age ten. ${ }^{11}$ Together with Josephine (18631928), about whom not much more is known than that she performed as a soubrette with Michel, their brother Louis (1868-1944), and their mother, the actress Engelina Hartlooper (1835-1920), they were the artistes of the troupe managed by the father, Johannes Solser (1833-1893), "who went by the name of Van der Vank". ${ }^{12}$ The youngest of the children, Lion (1877-1915), was sent to theater school and began his career in an operetta at age sixteen. The Solser or Van der Vank troupe originally concentrated on "koeplet-zingen", that is to say, singing mischievous verses and telling jokes, with which they toured towns and villages and performed at the fairgrounds or on Sunday evenings. ${ }^{13}$ The Dutch entertainment historian Jacques Klöters has described the hardships of the itinerant actors, who generally lacked education and accordingly had a low social status; who had to meet the audience demand of offering as much variety as possible, ceaselessly creating and rehearsing new acts and gags; and for whom traveling over unpaved roads, often with several performances in different towns in a single day, must have been very tiresome. Their low social status was complemented by their free way of life, Klöters adds, by unlawful marriages with children being born out of wedlock as a rule. ${ }^{14}$ The Solser parents did indeed follow this custom: father Johannes acknowledged five children in 1876, three years after Adriënne, at that moment the youngest, 
Fig. I.3: Michel Solser. Publicity portrait by S. van der Zijl, Amsterdam.

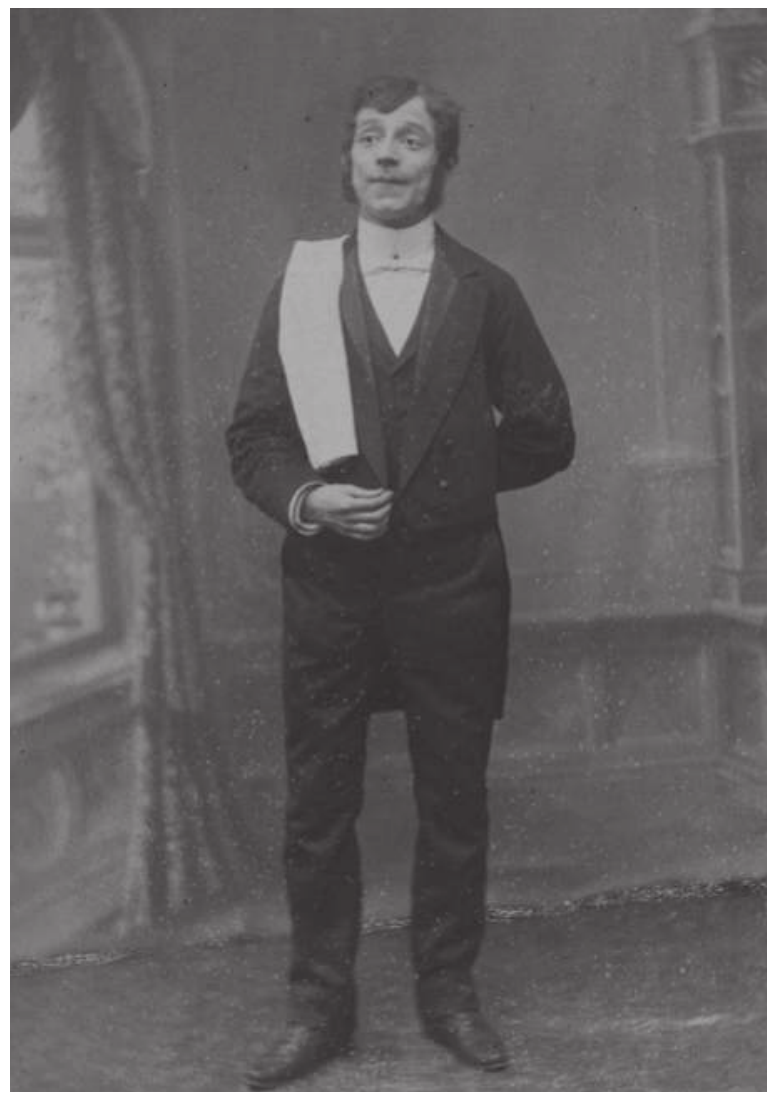

had been born. ${ }^{15}$ By comparison, Adriënne's love life was not as whimsical as Klöters believes it to have been ${ }^{16}$ - even though none of her three marriages were everlasting, her children were legitimate. Whether Adriënne Solser enjoyed any further education than what she learned from stage experience is not known, yet she had sufficient command of German and French to deliver her verses and monologues abroad.

The first of the family to be discovered for the emerging variété circuit was Michel Solser. In 1886, the variété-theater owner Carl Pfläging launched him at the contemporary temples of entertainment, the Doon in Rotterdam and the Paleis voor de Volksvlijt in Amsterdam, after which the program-manager Wittkower Gerson contracted him in 1887 to the Amsterdam café-concert Victoria (known as the "Vic" in the vernacular). ${ }^{17}$ It was there that Michel Solser earned his legendary reputation as the most brilliant comedian in the country. ${ }^{18}$

As those were the transitional years of variété in the Netherlands, before the opening of the posh variété-theaters, it was to the surprise of tout Amsterdam 
that a previously nondescript place like the Vic, located in a grubby neighborhood and surrounded by infamous bars and café-concerts, managed to attract large numbers of the so-called better public, who would come at midnight to attend a show built around a sketch with the title "De revue" (The revue). ${ }^{19}$ The fact that the Vic continued to thrive on Michel Solser's glory for a time-after Michel Solser and his company left the Vic in 1892 and he died of tuberculosis the following year-is indicative of his impact both on the Vic and the scene in Amsterdam. The Vic, however, lost its prominence before the turn of the century $^{20}$ and its building was demolished in 1911, when playwright Herman Heyermans, under his nom de plume Samuel Falkland, paid tribute to Michel Solser with an utterly graphic depiction:

Solser was the soul of the Vic. Solser died. Solser, the giant, the titanic, who endeavored from within the variété to demonstrate to the entirety of stage actors of our self-satisfied country how to act with ingenuity, how to use the most beautiful parts of the human body: the face, the facial muscles, the eyes, the mouth-Solser, the most excellent caricaturist, psychologist, performer, acrobat, as well as comic and tragic actor of the century-Solser, who carried on his bony shoulders a globe of a hundred worlds filled with grotesque creatures and wretches in agony, who climbed the veneered steps of the painted backdrop and carried in his flimsy coffer farces, dramas and tragedies-Solser, who spoke all languages, Mephistopheles and Faust in one, a fine artist and a critic. ${ }^{21}$

None of the existing accounts of Michel Solser's career mentions whether his sisters and brothers were contracted together with him or if he just brought them along, so the precise moment of Adriënne's debut in Amsterdam remains uncertain. The date is equally irretrievable from advertisements in newspapers, because the Vic did not name the supporting artistes, and dates are often missing from the program leaflets preserved, as is the case with a rare surviving leaflet featuring Adriënne Solser. ${ }^{22}$ In December 1887, the advertisements began singling out Michel's and Josephine's names, and in October 1888 , a series of little sketches was announced featuring Michel Solser "and family" ${ }^{23}$ Later advertisements for the sketch "De Revue" only featured Michel Solser. ${ }^{24}$ It seems that the sketch was delivered more than a thousand times with, apart from its main attraction, a variable cast, in which Adriënne may have appeared. ${ }^{25}$ The surviving program leaflet, in which Adriënne Solser is featured as delivering an Anna Judic song and in a duo act together with Lion Solser in the specialiteitenprogramma which preceded "De revue", only unspecified "Kunstenaars en Kunstenaressen", (male and female artistes) in the supporting cast for the sketch. 


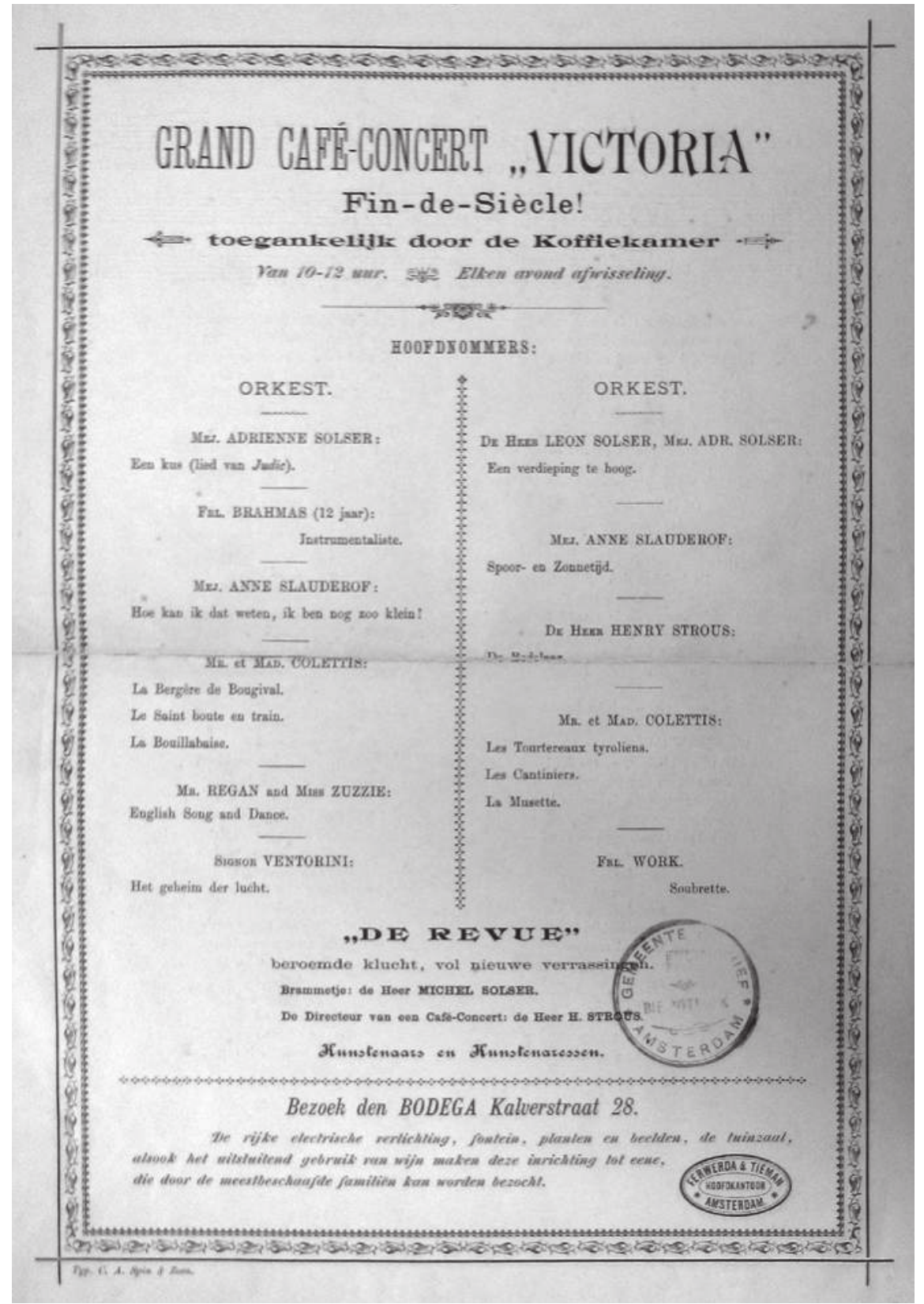

Fig. I.4: Earliest traceable performance of Adriënne Solser. Undated program leaflet from the café-concert Victoria. 
If Adriënne Solser did not fiddle with the dates when she celebrated the thirtieth anniversary of her stage career in April 1919, then her debut at the Vic ought to be dated to 1889, as was suggested in the advertisement with the program announcement "Wat Adriënne Solser zong in 1889" ${ }^{26}$ (what Adriënne Solser sang in 1889). Only five years after this jubilee, however, she was already announcing her fortieth anniversary on stage. ${ }^{27}$ With a little leniency, this can be taken as a retrospective upgrading of her years with the parental troupe, that is to say, if the anniversary was not merely held for publicity's sake. At any rate, the date of her Amsterdam debut is rather obscured by such jubilee announcements, although she did perform more than once at the Vic. ${ }^{28}$

Like her female colleagues and contemporaries Louise Fleuron and Emilie Culp, Adriënne Solser usually performed solo, ${ }^{29}$ while other soubrettes preferred to work in duos, such as Louisette with her "teacher" Chrétienni and Rika Davids with her brother Louis. Men also worked in duos, like Lion

32 Solser with Piet Hesse, to cite but one of many instances. At bookings aside from the Vic, Josephine Solser regularly appeared together with Michel, ${ }^{30}$ who did so with his friend Chrétienni as well. One characteristic of Michel Solser was his insistence on working as an itinerant comedian, for it allowed him to earn more money to support the family-his wife, his siblings and parents. ${ }^{31}$ It remains unclear whether he or someone else served as a model for Adriënne in this regard, but she obviously upheld a similar principle. This even goes for the part of her career prior to the turn of the century, when she, as well as her brothers, was an occasional performer at the Frascati-Schouwburg in Amsterdam, which mainly staged operettas and boulevard comedies. Adriënne Solser's involvement in some of those productions can be positively established from Frascati's program leaflets, which reveal, by the same token, that she was definitely not a stock member of the playhouse. ${ }^{32}$ In Adriënne Solser's offstage life during the 18 gos there occurred several events that may have made her reluctant to enter into regular engagements. Within one decade, she went to live abroad, married twice, and gave birth to three or possibly four children, in May 1893, January 1896, July 1897, and August 1898, respectively. ${ }^{33}$ The middle two were born in Pretoria, South Africa, where Solser lived for about three years with her then-husband, the doctor and pharmacist Louis-Joseph Boesnach; and if there was indeed a fourth child, it may have been born during her stage tour through Belgium. ${ }^{34}$ The appearances of Adriënne Solser at the Frascati-Schouwburg, in January 1895 and April 1900, then, do seem to demarcate the beginning and the end of her stay(s) abroad.

Adriënne Solser was a soubrette, which is a profession that has evolved considerably throughout its history and taken on more than one name accordingly. In a 1902 reference to a solo performance, Solser was advertised and reviewed as "Miss Adriënne Solser, the international chanteuse who enthralls 
with impish songs and much, much more". ${ }^{35}$ Alex de Haas, a historian with first-hand experience, ${ }^{36}$ has explained that the term chanteuse belonged to the café-concert, a precursor of the professional and respectable variété, that is to say, to a place like the Vic. Earlier, such tingeltangels (honky-tonks), had been frequented by male revelers and bar-flies seeking voyeuristic and drinking pleasures, and if women accompanied them, they were usually prostitutes or at least considered to be such. Performances staged at such cafés were first and foremost meant to boost consumption:

As soon as the pianist had played the opening march and overture, they came parading onto the stage like a flock of geese while singing the ceremonial entry song, and subsequently settled themselves, sprawling but with grace, on the beautiful plush chairs which were placed in a semicircle on the stage. Thus they formed the conventional corbeille, a flower-basket arrangement, which stayed on throughout the show as a living backdrop, firstly to enliven the setting, secondly to have at hand an encouraging chorus for every refrain, and thirdly (and this was their main function!) to entice the posh revelers in the audience to treat the ladies to rounds of drinks and thereby increase the consumption returns. ${ }^{37}$

The women's stage act was called "Bühne-zitten", (stage sitting) and Solser's anniversary program of 1919 suggested that she too had participated in this rather humiliating act..$^{38}$ The chanteuses among the women, then, used to take turns in singing verses, a routine which demanded more of their miming than of their vocal or acting abilities:

The chanteuses, soubrettes, and sentimental singers, who during the variété years still counted as top of the bill, launched "risqué" frivolities with impish and seductive little signs and a gentle abundance of promising winks. ${ }^{39}$

Thus, the clichéd image of the female entertainer in the time before variété

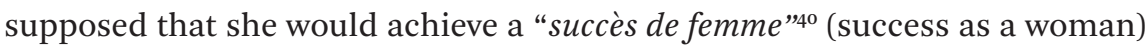
instead of being noticed for her presentation or performance. Nevertheless, both Klöters and Haas have emphasized that-although the Vic was by no means a classy variété-theater-the Vic had shifted from a honky-tonk to a relatively decent place where female performers were not expected to act as dance-hall hostesses. The program leaflet of the Vic does indeed give the impression of a café-concert program, with songs and sketches meant to be watched and listened to.

The preserved program leaflet contains not only the program but also the 
translated text and the music of the Anna Judic song which Solser delivered in the Vic: "Een Kus" (A Kiss). ${ }^{41}$ The song text reviews various kinds of kisses: lover's stolen kisses, children's innocent kissing, the mechanical kissing of married couples, and a soubrette's blown kisses. There is no refrain, but an alternating rhythm of full sentences and shorter lines, and in the middle of the latter the direction "kus-kus" (kiss, kiss) is repeatedly printed in italics, as if to suggest that this was to be enacted rather than sung or said. At the end, it reads a few times: "kushand" (blown kiss).

In the review of Solser's performance from which I quoted earlier, the addendum "and much, much more" still evoked the old atmosphere, as did the title "Miss", redolent of availability, while in fact Solser was in the midst of her second marriage..$^{22}$ Thus the writer discerned impishness in Solser's performance and his review is the only one I have encountered that did so. The site of the performance was the impermanent "Grand Spectacle Concert Varié" 34 pitched at the Rotterdam fair,43 but just like the Vic, a 1902 fair constituted a transitional stage between the old risqué setting and a more decent contemporary decor. The fact that the reporter on this occasion noticed and appreciated Adriënne Solser's verses may indicate that the emancipation of the chanteuse, that is to say, her transformation into the soubrette, had taken place. Not only the womanly presence mattered now, but the text and the acting as well.

All the same, the soubrette as a phenomenon never entirely rid herself of her dubious reputation: for example, the columnist who defended and advocated for the variété's eagerness for respectability, even in 1917 still considered it indispensable to contrast the soubrette's image with her off-stage life. The article stated that the soubrette, for the sake of her job, "drinks and [...] talks about immoral things and [...] enjoys dirty jokes; she has friends and vices: in short, she embodies Vileness". ${ }^{44}$ As soon as she is through with the performance, however, she goes home to take care of her bedridden husband and little child, whom she supports with her wages. Arguing in a similar manner, Alex de Haas has insisted on the gap between the soubrette's off- and onstage lives, while he further pointed out that "even the texts of the songs they delivered were actually of an almost virginal virtuousness, and they preferred songs with a wholesome moral ending". 45

Klöters, on the other hand, does not disentangle the image and the reality of female performers in the variété. ${ }^{46}$ In the case of Adriënne Solser, he has confused this reputation with her life by stating: "both her comical talent and her career were as erratic as her love life". ${ }^{47}$ Whatever one may think of her love life, it does not correlate with her professional career, which was stable and consistent throughout. The contemporary public's insistence on the decency of female comedians, whether sanctimonious or not, also parallels the discourse on the new standards of decency to which the variété was confining 
itself in those years. In this sense, one could say that women performers were instrumental and exemplary in the attempt to heighten popular entertainment. The shift from chanteuse to soubrette entailed that women invent a new craft for themselves and that they make use of a range of skills and talents aside from coquettishness. In this light, the legacy of philandering ascribed to soubrettes largely appears to be a product of the enduring historical imaginations of men. One should likewise take with a grain of salt Klöter's suggestion that it was preferred to apply the term soubrette to "gay, coquettish, young women's parts" and that, with the pioneering soubrettes' aging, their names faded in favor of their younger colleagues. ${ }^{48}$ The careers of Louise Fleuron, Louisette, ${ }^{49}$ and Adriënne Solser, among others, do not validate such age norms for women. Although they indeed began performing when young, they remained active as soubrettes for as long as Dutch variété remained popular.

The word "soubrette" originates from the French, but it was not used in French music-hall..$^{50}$ The Encyclopaedia Britannica defines it as a comic female character that became popular in the comic opera and the operetta of the eighteenth century. "Most often of an independent nature, the soubrette demonstrated a nonconformist attitude coupled with a down-to-earth approach and native humour." ${ }^{1}$ The Dutch dictionary Van Dale specifies it as a light soprano part (usually a chambermaid's role) in a comic opera or as a lead in an operetta,,$^{52}$ yet does not refer to the specific use of the term in the Dutch variété, in which, interestingly enough, the soubrette's main characteristics, lyrical bent, folk humor, and independence, were perpetuated.

Within the Dutch variété, with its family-based audience and attention to what happened on stage, a soubrette's performance formed an act in its own right. In both its prominence within the program structure and its attractiveness to the public, it was equivalent to the act of her male counterpart, the karakterkomiek or salonkomiek (the character or gentleman comedian). Female and male comedians used to deliver comic monologues, little sketches, gags, and quodlibets, or coupletten (verses); such acts highlighted the artist's comic and vocal delivery and acting abilities, although, with the advent of cabaret after the turn of the century, the subtlety and poignancy of the verses gradually began to draw more critical attention. As a warning to those who never witnessed such performances and to historians who try to comprehend them through the texts alone, Alex de Haas has pointed out the ephemeral condition of the comedian's act:

those soubrettes, chanteuses, character comedians, duos, and the like, were excellent stage actors who "delivered" their verses and for whom the texts merely functioned as directions as in the commedia dell'arte, ergo, merely as bases to build their ingenious creations upon. ${ }^{53}$ 
Haas was more specific concerning female performers and their qualities in his necrology of Adriënne Solser's contemporary and colleague Louise Fleuron, who

embodied all that the genre required: a figure built to launch the regal ladies' fashions between 1900 and 1915, a beautiful and striking face, a pair of expressive eyes, a highly evocative facial expression, and a warm voice, voluminous enough to fill the largest halls. ${ }^{54}$

In addition, he praised Fleuron's comic versatility, her capability "to make much of small nothings" and her sense "for what would work well". ${ }^{55}$ Skills such as these were a necessity, and because the acts were normally short, the actor also needed to capture her or his audience and carry it away from the very first minute:

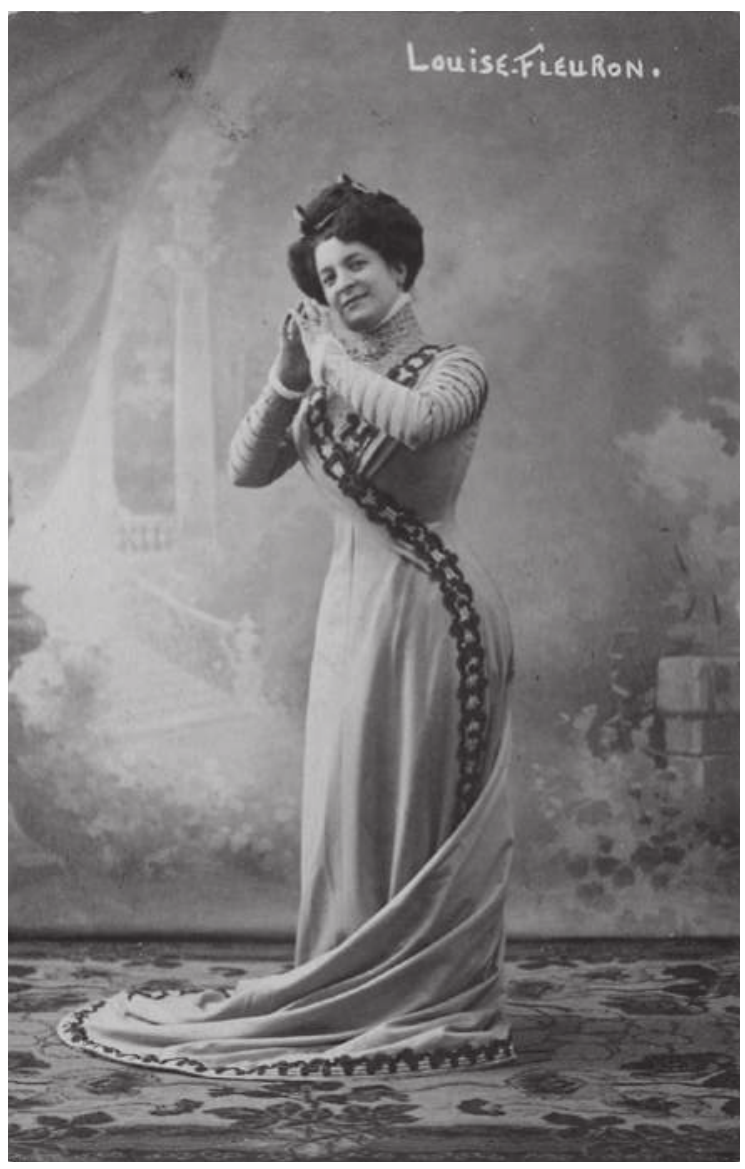

Fig. I.5: Louise Fleuron. Publicity portrait by W. Ganter, Rotterdam. 
True female humorists, imitators of life, satirical singers, are rare. That kind of art needs a certain quick and buoyant jollity, a casual delivery of cheerful satire, which excludes all subjectivity. [...] The cabaret and variété actress is [...] alone and first needs to establish contact, become the centre of attention, take us into a sphere of flippant jokes and jests, which is her one and only "aim." In her genre, she has to be an "instigator" whose performance is decisive from the start..$^{6}$

The ability to mould the audience to her or his will and the enduring efficacy of the performance were what made a performer into a "born artiste", an epithet also bestowed upon Adriënne Solser:

For one thing is certain: Mrs. Solser knows the audience [...] inside out. She knows very well how to capture the attention in a full house, and to hold it right until the last adventure of the humorous duo from the Jordaan. Only born artistes can do this. ${ }^{57}$

Among male comedians, two "genres" could be distinguished around the turn of the century. The character comedians, like Michel and Lion Solser, made use of a type recognizable from his farcical garb and attributes and whose point of view allowed them to magnify his naiveté and render it comical. They were followed by - and, in retrospect, contrasted with - the gentleman comedians, like Chrétienni and the later Louis Davids, who appeared in stylish frocks and accompanied their verses with elegant gestures and dance steps; thus, resembled modern cabaret artists. Klöters does not distinguish between the different genres for soubrettes, or supposes that they adapted themselves to the style of the gentleman comedian..$^{8}$ If, however, we compare with each other the five leading soubrettes at the turn of the century, Emilie Culp, ${ }^{59}$ Anna Slauderof, Louise Fleuron, Louisette, and Adriënne Solser, the first distinction to be made is that in their performances either the vocal or the acting was emphasized. The gezangs-soubrette Culp ${ }^{60}$ and the operette-soubrette Slauderof were vocalists with acting talent, while the others were entertaining actresses with good voices. Fleuron and Louisette were soubrettes compatible with the type of the gentleman comedian, while Solser also ventured into farce and character comedy. She indeed did so in 1900, albeit not as a soubrette but in a comic operetta about an Amsterdam phenomenon called Hartjesdag, the evening and night before the annual fair in mid-August when, from time immemorial, everybody, including women and children, used to get drunk and stagger along the streets, particularly in the working-class neighborhood of the Jordaan. ${ }^{61}$ Adriënne Solser played one of those women, named Kee, Trui, or Ka, as was typical for the neighborhood, and in a review, the actors 
earned compliments for the liveliness of the impersonations. ${ }^{62}$ As will become apparent, this typical female figure from Amsterdam will dutifully accompany Adriënne Solser throughout her stage and cinema career.

\section{THE YEARS OF ACHIEVEMENT, 1904-1914}

Before the war, Rotterdam was the centre of popular entertainment in the Netherlands. ${ }^{63}$ The acts and plays of Dutch comedians often premiered in the harbor city before reaching the country's capital, Amsterdam. Adriënne Solser's "latest creation", for instance, was advertised for its run at the Grand Théâtre in Amsterdam in 1912 as being the "big success at the Casino Variété in Rotterdam". ${ }^{64}$ The names of the specialiteitentheaters were frequently bracketed together with the name of the program-manager in charge, who 38 received credit for making sophisticated and exquisite choices in programming. ${ }^{65}$ Between 1904 and 1914, Adriënne Solser made appearances on several of these stages, most notably in the Casino Soesman and Circus Pfläging in Rotterdam, the Scala in The Hague, and the Grand Théâtre Van Lier and the Panopticum in Amsterdam. This alone already places her at the top of the variété artistes during those years. However, while bookings at the big variététheaters were necessary for earning and sustaining fame and popularity, they were not sufficiently remunerative to sustain performers. Alex de Haas has pointed out that comedians, in order to support themselves and their families, used to tour the fairs, the exhibitions, and the annual local festivities in the provinces. ${ }^{66}$

According most likely to Barbarossa, the pseudonym for H. C. Schröder, the editor-in-chief and entertainment critic of the daily De Telegraaf, this practice was pioneered by the Ensemble Solser en Hesse, ${ }^{67}$ the company that Lion Solser had established in 1897 with Piet Hesse and their wives, the soubrettes Adriënne Solser-Willemsens and Anna Hesse-Slauderof. ${ }^{68}$ Adriënne Solser must have been one of the many that had followed in their footsteps by 1915. Nevertheless, her career chronology shows a remarkable frequency of returns to the Casino Soesman between 1904 and 1909, the year in which she was on the bill twice within a period of three months. ${ }^{69}$ Contemporary advertisements in newspapers also confirm Haas' observation that prolongations were extremely rare. ${ }^{70} \mathrm{~A}$ standard booking lasted two weeks, after which even the most popular comedian had to yield her or his place to a new attraction and wait half a year or longer before being booked again in the same theater or even the same city. This system obviously guaranteed the highly regarded diversity of the variété programs and brought about the ongoing circulation of the large contingent of performers. 


\section{New Entertainment Genres and Blurry Boundaries}

Within the programs in the first-class variété-theaters, new entertainment genres were introduced from the moment they emerged. This applies to cabaret, revue, one-act plays, volksstukken (folk plays), and cinema. Up until the war, Dutch variété took advantage of the new by incorporating the most attractive and the best of what staged entertainment had to offer; most of the variété artistes went along with the changing demand. Some of these artistes reshaped their repertoire and style in line with the new genres, as did Louis Davids and Louisette. Others joined in the variété and appeared with individual acts in revues, in cabaret programs, or, after 1912, in between film screenings, a practice put into effect by Louise Fleuron and Adriënne Solser, to name but a few. One of the effects was an increasing diversification within the profession of male and female comic actors. Typical of the 1910s, the various genres of entertainment existed alongside one another, their boundaries relatively blurry, and actresses and actors switched back and forth among them.

Dutch cabaret entered on the variété stage right after the turn of the century. Two models were followed: the German Überbrettl style, which embraced the incorporation of short sketches into an overall intimate program of songs and verses and which was performed on a stage; and the French Chat noir mode, which displayed textual and political sophistication in performances by individuals carried out amidst the audience. Representatives of the two schools - such as Oscar, Baron von Fielitz and Ernst Von Wolzogen and their troupes from Germany, and Yvette Guilbert and Aristide Bruant from Francewere featured on Dutch stages by $1895,{ }^{71}$ but it took a few years before their followers in the Netherlands followed suit.

Among the cabaret's differences from the variété, the greatest emphasis was placed upon its intimate atmosphere and its proclivity for textual refinement and subtlety; thus it was called intieme kunst (intimate art) or kleinkunst (cabaret). Seminal adjectives used to indicate its qualities were "fijn" (delicate), ${ }^{72}$ and "zuiver" (pure). ${ }^{73}$ The most prominent among the early exponents of Dutch cabaret were Koos Speenhoff and Césarine Speenhoff-Prinz, who established their company "Het Kleine Tooneel" in 1909 after their separation from that other pivotal, but in this context rarely acknowledged, figure of Nap de la Mar and his company "Het Vrije Tooneel”, which existed from 1907 until 1915 and rose again from 1918 to 1923. During the 1910s, they were joined by Jean Louis Pisuisse and his company "Intieme Kunst" and several others. ${ }^{74}$

The French model was adopted instead by individual Dutch comedians, most notably by men such as Eduard Jacobs. ${ }^{75}$ According to the novelist, songwriter, and essayist Jeanne Reyneke van Stuwe, cabaret performers introduced restraint, candidness, eloquence, and social satire into the entertainers' deliv- 
ery and their songs; the texts, called "levensliederen" in Dutch language, spoke in the concise and true manner of life: "The cabaret song is the street song purified, the folk song shortened and empowered. The cabaret song is the street song, the folk song turned into art". ${ }^{76}$ The delivery was entertaining, but also provoked thought. ${ }^{77}$ Reyneke van Stuwe mentioned a few women, in addition to the majority of men, including Anna Klaassen and Antoinette Sohns, who, in the style of Yvette Guilbert, presented drames condensés in which they enacted what they were singing about. In her effort to clear the ground for a defense of cabaret as an art, Reyneke van Stuwe sharply contrasted cabaret to variété, suggesting that the latter was inferior and remained indecent. My research, however, supports a different conclusion. The decency and sophistication which she, and many historians in her wake, claimed to have been the rule in cabaret performances, already prevailed in Dutch variété during the 1910s, if only for the reason that the two genres over the course of the twenty years in question were 40 part and parcel of one another: not only in the reception by the contemporary press, but also as presented on the stages and as practiced by the performers.

In an unsuccessful attempt to distinguish between cabaret and variété, the variété critic of De Kunst was led to assert in 1913, that there was simply a difference in excellence, not in essence. ${ }^{78}$ Three years later, the Theatergids stated that cabaret was a mix of one-act plays, monologues, chansons, and some music. ${ }^{79}$ The most noticeable and characteristic difference from a genuine variété program might have been the ever fewer number of acrobats, illusionists, trained animals, clowns, and conjurers, but by the mid-1910s, such acts were not only absent from cabaret programs but were likewise vanishing from the variété stage itself. In the latter, solo singers, dance, mime, and one act-plays, in other words, acts that required refined talents, were featured instead. ${ }^{80}$

Many advertisements reveal that, until the mid-1910s, variété acts were programmed in combination with intiem toneel in the Netherlands and that someone like Jacobs would also appear in revues. ${ }^{81}$ The Speenhoffs, the De la Mars and the Jacobs represented major attractions for the renowned variététheaters of Rotterdam and Amsterdam.

In order to further underpin my thesis that such mixed programming constituted a trend, I will elaborate on some programs that included Adriënne Solser. In 1909, she appeared as a karakter soubrette at Casino Variété Soesman on a bill with the most successful sketch performed by Het Vrije Tooneel, “Z'n Edelachtbare” (His Honor), featuring Nap de la Mar, his wife Sien de la Mar-Klopper, and Koos and Césarine Speenhoff, who, in addition, performed in other acts on the program. The program further included a German conjurer, "a comical female juggler and quick-change artiste" and "new pictures from the Casino Bioscope". ${ }^{82}$ The satirical sketch "Z'n Edelachtbare” was written by Tony Schmitz, a writer of verses and comic sketches for the variété. It 
ridiculed the mayor of a town in the southern Catholic province of Brabant who presumably had interrupted a previous performance by Speenhoff and De la Mar on account of the indecent language used in it. ${ }^{83}$ Another example dates from 1911, when Adriënne Solser as a "Hollandsche soubrette" had a slot in the variété program that traditionally accompanied the annual International Wrestling Match at the Casino Variété, between a one-act play "Loulou", a trained-dog routine, and a comic pantomime. ${ }^{84}$ In 1914, we find Solser performing at the Panopticum Theater in Amsterdam in a program with songs by the "popular poet-singer Eduard Jacobs", a duet by The Niblets, in which the man sang the soprano and the woman the baritone part; a number with trained pigeons, a female dancer, and a sketch, "At Home", by Les Niards. ${ }^{85}$

One-act plays or sketches-short pieces that did not require a change of decor-were considered a feature of the much-discussed effort for respectability and for the improvement of that would be enhanced by the rise of cabaret. In a condensed historiography of the genre, Martin Liket, a playwright and critic of the Theatergids, traced the variéte's international origins back to French musichall, German cabaret, and American vaudeville, and pointed out that variété often concerned famous plays delivered in a condensed form..$^{86}$ The sketch "Loulou" seems to be an instance of this practice since it was probably adapted from the scandal-provoking plays "Erdgeist" (1895) and "Die Büchse der Pandora" (1904) by one of the founders of the Munich Überbrettl, Frank Wedekind. ${ }^{87}$ In his article, Liket contended that this trend had been brought to the Netherlands by the sketches of Nap de la Mar and the duo Solser en Hesse. Apart from these performers, Liket ascertained in 1918 that "Holland has not yet been very productive in this dramatic genre", ${ }^{88}$ but he added that Nap de la Mar was about to venture into it again. During the 1910s, De la Mar worked not only as an actor and comedian but also as a producer of sketches, operettas, and, as I shall emphasize further on, volksstukken. His involvement in these popular theater genres was part of De la Mar's on-going contribution to Dutch popular theater in the $1910{ }^{89}$

A second sign that boundaries between genres were rather blurry before the war was that actresses and actors from the "serious" theater, cabaret, and variété did not stick to "their" own genres and stages but switched readily from one to another. In the context of a passionate plea for regarding variété performers as artists, De Kunst noticed this phenomenon as early as $1910 .{ }^{90}$ This trend continued during the 1910 s, as may be illustrated by the career of the actress, director, and novelist Caroline van Dommelen (1874-1957).

In addition to recurrent engagements with the Koninklijke Vereeniging het Nederlandsch Tooneel, the major theater company of the Netherlands with which Louis Bouwmeester and Theo Mann-Bouwmeester were also affiliated, and with other companies offering "high" theater such as those of Verkade and Heyermans, Caro van Dommelen appeared in cabaret programs 


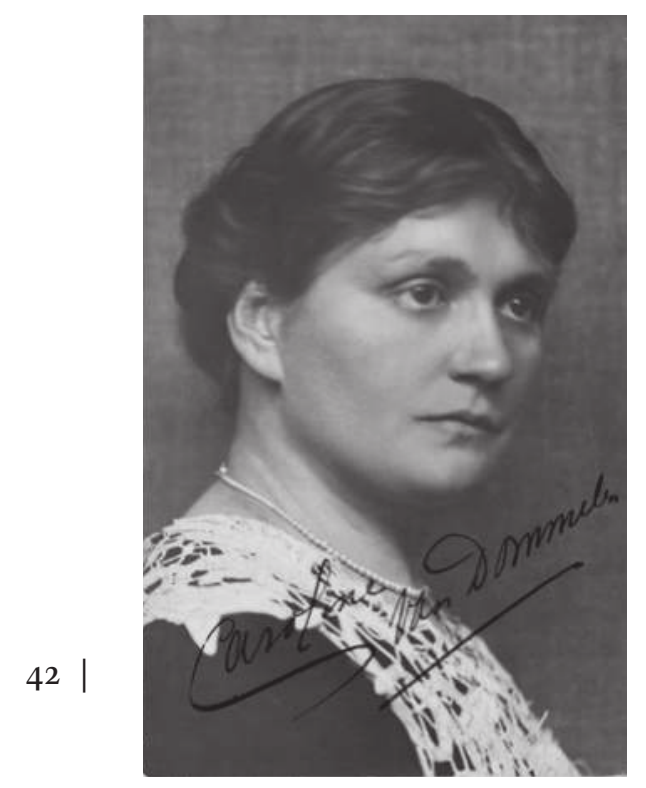

Fig. I.6: Caroline van Dommelen. Undated publicity portrait by anonymous photographer.

with the Speenhoff couple ${ }^{91}$ and Jean Louis Pisuisse. She likewise performed as a conférencière, that is to say, an entertainer who tied the various elements of a cabaret program together, in places like the Amsterdam variété-theater Panopticum.

At the outbreak of the war, popular theater stages had trouble in filling and sufficiently varying their programs, for they had traditionally been dependent upon a supply of foreign acts, performers, and films. The supply was blocked due to the mobilization abroad and the limitations placed upon international traffic; thus, several Dutch actors and especially actresses felt motivated to give the lighter theater genres a try. Another reason for Van Dommelen to seek an expansion of her possibilities may have been the fact that even before the war "high" theater was drastically losing its appeal: sometimes the booming cabaret was held responsible for this, sometimes the increasing popularity of cinema. In 1913, making a strong case against the idea that cinema was at fault, De Kunst urged the theater world to reflect upon its own lack of quality, its insignificant repertoire, the engagement of incompetent players and the endless re-staging of outdated plays. ${ }^{92}$ If such a swipe came at all close to being an accurate depiction of the state of things in the theater, one can understand that a versatile actress like Caroline van Dommelen would have wanted to seek more exciting areas of employment. In doing so, she carried on a tradition of versatility among Dutch actors, which was indeed stimulated by wartime conditions but was not created by them. Like several of her colleagues from the- 
ater and operetta, she had, for instance, already ventured into working for the cinema in the early 1910s. ${ }^{93}$ Caroline van Dommelen not only starred in but also wrote and directed films for Film-Fabriek F. A. Nöggerath, ${ }^{94}$ the film production company owned by the director of the Flora variété-theater in Amsterdam. The art and cinema historian Ansje van Beusekom has pointed out that the connection between the Flora and the film production of this actress was a material, and financial, manifestation of the interrelationship between the revue and filmmaking in the Netherlands during those years. ${ }^{95}$ When viewed from the perspective of the actors involved, the scope of such interrelationships can be broadened to include popular theater and film. As for Caroline van Dommelen, after having starred in six films, three of which she directed or co-directed, she gave up her commitment to cinema in 1912, because, in her own words, "it is such a nerve-wracking métier that you can't keep combining it with stage acting. It's the one or the other!" ${ }^{6}$

The new entertainment genres of revue and film, finally, were virtually simultaneously introduced in the Dutch variété. The format of the revue was copied from Paris, where, towards the end of the nineteenth century, every self-respecting music-hall would stage a revue at the end of the year. The French revues were structured around a loose thematic thread and were characterized by a satirical treatment of cultural, topical, and local matters; only after the turn of the century did they become increasingly spectacular. While I shall elaborate further on the Parisian revue when I consider Musidora, let it here suffice to say that the first Dutch revues, as written and staged by August Reyding beginning in 1889, followed the Parisian models in the satirical treatment of political and topical issues, according to the historian of the Dutch revue Dries Krijn. ${ }^{97}$ Reyding's revues dealt primarily with typical Amsterdam tribulations, making a crucial contribution to the cultivation of Amsterdam folk types in Dutch variété and on the Dutch popular stage-a tradition of central importance to Adriënne Solser's stage persona.

Reyding also introduced the use of specially made film clips, DE LEVENDE GEÏLLUSTREERDE REUZEN-BRIEFKAARTEN (The Illustrated Giant Living Postcards), as integral inserts in his revue of 1899, "De Nieuwe Prikkel" (The New Prickle), ${ }^{98}$ and thus initiated the close relation between Dutch revue and early cinema. ${ }^{99}$ In her illuminating article, Beusekom delineates the reciprocal, multifaceted, and changing bonds between revue and film in the Netherlands. She marks out a trail leading from the omnivorous revue, which swallowed up more and more of variété attractions, including film, to the Dutch cinema of the 1920s, which brought forth a genre of its own, which, for its part, absorbed a variety of the revue's constituent elements. Most pertinent to Solser's stage career is what Beusekom writes about the changing relations between revue and variété. The absorptive tendency she ascribes to the revue may just as prop- 
erly be attributed to the variété, which generously accommodated new popular stage genres and helped them to find a public. Dutch variété was indeed overshadowed, yet not by the revue alone, but also by volksstukken, cabaret, and cinema: during the war, it lost its overarching function, and by 1917, variété acts had been relegated to the margins of cinema programs, revues, and cabaret.

While blurry boundaries and the co-existence of entertainment genres were the rule, the contours of an increasing distinction between the genres began to shine through during the early 1910s. One of the signs for this was the construction of new sites for the presentation of specific genres: the 19111912 season was marked by the opening of numerous cinemas in the major cities of entertainment, ${ }^{100}$ and this was followed by the establishment of myriad cabarets. My investigation of the advertisements in local newspapers reveals that five cabarets opened during the spring of 1913 in Rotterdam alone. Dutch variété performers were to be found everywhere, in cinemas as well as in caba44 rets. Cato Culp, for instance, added luster to the screening of TOTENTANZ (The Dance of the Dead) with Asta Nielsen at the Thalia-Bioscooptheater in August 1912, and Adriënne Solser was on the bill of the Cabaret Metropole for the entire month of February 1914. ${ }^{101}$ Another significant locale, opened in March 1913, was the "Rozen-Theater" in Amsterdam. ${ }^{102}$ Situated in the district of the Jordaan, in less than a year, this cinema-variété theater developed into a home for sketches, plays, revues, operettas, and variété acts related to the genre of comedy named after the neighborhood: the "Jordaan-genre".

Between 1904 and 1914, Adriënne Solser, unlike many of her colleagues, did not often switch between genres, but stuck to the one she had initially chosen, that is to say, she appeared on stage predominantly as a soubrette doing solo acts. The number of female singers and actors performing solo or in duos had significantly increased by 1910. As most of the pioneering ones were still active, new voices and talents needed to distinguish themselves from them and from one another. The distinction between chiefly vocal performance on the one hand and performance that centered on comic acting was still pertinent, but within each mode, a further differentiation became vital. Throughout the years, the term soubrette was still used by female performers, yet other terms were coming into fashion at the same time. Such a multiplicity of labels points to a growing diversification in the field, not only among male comedians, but also and especially among female performers.

The singers among the soubrettes often used the labels couplet-zangeres (singer of verses), as did Betsy van der Heym; ${ }^{103}$ operette-zangeres (operetta singer), as did Annie Backer; and liederen-zangeres (singer of German Lieder), as did Anna Klaasen and Julia Culp. ${ }^{104}$ The reviews of their performances evoked the delicate and attentive atmosphere of cabaret more than the lighthearted and exuberant spirit of variété: 
Mrs. Klaasen has a very good repertoire, varied and merry, and her delivery has the exquisite cachet that turns each song into a little genre-piece. Anna Klaasen does not merely sing her songs, she enacts them; every facetious verse she sings becomes a comic act, every pensive song, a miniature drama. ${ }^{105}$

The further success of the revue after the turn of the century, now in the form of a reisrevue, a traveling revue for a national audience, fostered a new type of female entertainer, the commère, a counterpart of the conférencière in cabaret. The separate acts and sketches of a revue were traditionally linked together by the compère and the commère, male and female entertainers who in a spirited and improvised dialogue guided the audience through the evening with introductions to the upcoming performers and with references to the thematic thread. Celebrated commères were, for instance, Rika Davids (1886-1943), active in revues starring her brother Louis and the former soubrette Mimi Boesnach (1899-1982), who became the leading lady of the Bouwmeester revue. ${ }^{106}$ Adriënne Solser never performed in the role of the commère, although she might well have proven to be a good one, according to the chief editor of De Kunst and leading critic Nathan Heyman Wolf. In a 1916 article, in which he criticized popular stage managements for complaining about the warrelated lack of first-class performers for variété and cabaret programs, Wolf argued and demonstrated that he, without much preparation, could compile at least six highly varied and excellent programs featuring Dutch actors alone. In one of these, Adriënne Solser was cast as the commère, an honor she shared in Wolf's proposal with Caroline van Dommelen, and with Piet Köhler as a compère. ${ }^{107}$

According to the reviews, Adriënne Solser's performances were imparted with an infectiousness similar to those of Louise Fleuron and Heintje Davids. ${ }^{108}$ Later on in their careers, Fleuron and Solser came to share an equal fame in their performances of the type of Komische Alte: "the old spinster who on account of her romantic or other whims becomes the laughingstock of assorted stage adventures" ${ }^{109}$ Fleuron performed this role in operettas, Solser, as we shall see, in cinema, albeit not as an old spinster but as a not so young married woman. Adriënne Solser took on comical, if not farcical, acts already during the 1910s. Critics used to remark upon the jocularity of her performance and its success with the public. ${ }^{110}$ How she achieved her successes was made clear in this comment on one of her early performances in Amsterdam, in which she played a peasant woman from the province of Zeeland:

As a chanteuse à diction she can compete with the best. Her creations are unaffected, without histrionic overemphasis, and, wherever in the world 
she might perform, everyone will understand her enchanting resonant laugh, her decently farcical action and diction. ${ }^{111}$

In the advertisements for Solser throughout the 1910s, the entire range of tags for the soubrettes of variété and cabaret appears: "Voordracht Soubrette"(1908), "Karakter Soubrette" (1909), "Hollandsche Soubrette" (1911), "Humoriste" (1912), "Neerlands Eerste Soubrette" (1912), "Neêrlands Eerste Cabaret-artiste" (1913), "Hollandsche Voordrachtskunstenares" (1914), "Humoristische Conférencière" (1916), and "Karakter-humoriste" (1919). ${ }^{112}$ According to Klöters, the second term in such labels indicated the métier while the first expressed the means used; ${ }^{113}$ the combination of "character" with "soubrette" or "humoriste," for instance, signified that the act was centered around a character from whose point of view the jokes and stories were presented. Thus, if "Hollandsche" (Dutch) was the adjective, the emphasis would be on the intelligibility of 46 | the acts, and the epithet "Neerlands Eerste" (the Netherlands' First), which was also used by, again, Louise Fleuron, rather signified ranking than sequence. The terms voordrachtskunstenares and conférencière originated, as we have seen, from the sophisticated cabaret while humoriste was the updated expression for the komiek or couplet-zanger or -zangeres from the variété. Wolf, in his proposal for good cabaret programs during the war, labeled Solser a "humoristische conférencière", a qualification that expressed and summarized her humorous, acting, and improvisational talents. What is interesting about the ensemble of labels, indeed, is that they suggest that a much greater variety of verses and subjects was presented than the reviews would otherwise indicate. This impression is confirmed by the "couplettenboeken" (notebooks with verses) of Solser's preserved at the EYE Filmmuseum, the contents of which offer insight into what was covered by the recurrent phrase "Mooi nieuw repertoire" (Fine new repertoire), with which the comic actress' appearances invariably were announced in the contemporary advertisements.

\section{Entracte: Solser's Repertoire and Stage Persona}

Adriënne Solser's preserved notebooks contain approximately fifty different verses and rhyming monologues, but their status within the whole of her stage repertoire remains uncertain. Considering that the collection does not contain anything from before 1904, and in view of the long duration of her stage career, her repertoire must have been more extensive than that. Given the fact that her earliest work is missing, it may also have in fact been more varied than it now seems to be. On occasion, in advertisements and reviews titles of acts are mentioned that do not match any of the texts preserved, as 


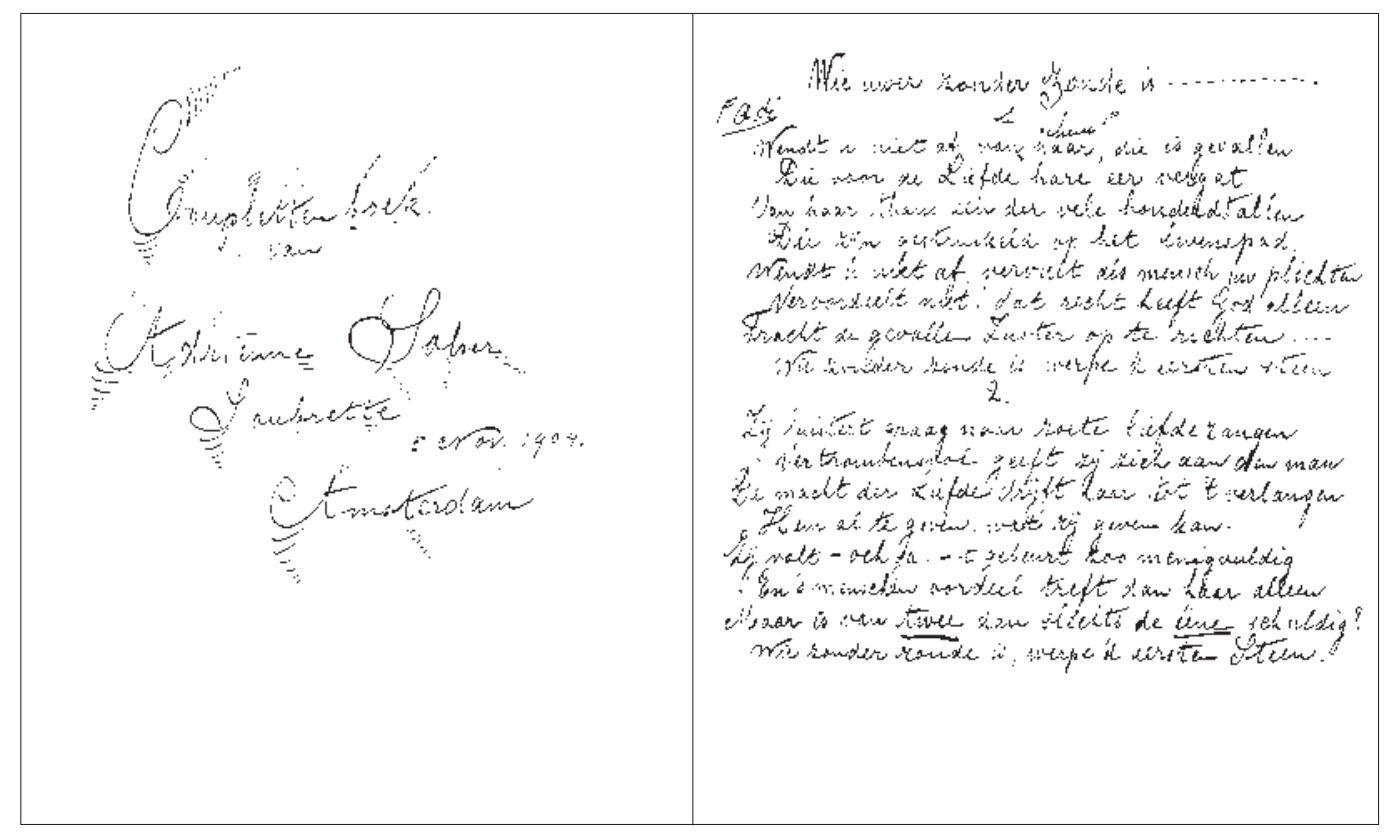

Fig. I.7: First pages of one of Solser's handwritten notebooks.

for instance the 1914 karakterschets (character sketch) "Ka als suffragette" (Ka as suffragette), also known as "De suffragette uit de Jordaan" (The suffragette from the Jordaan), ${ }^{114}$ or the sketch of the female fish-monger in Ter Hall's revue "1918". ${ }^{115}$ The question of the extent to which the preserved collection is representative of Solser's repertoire, can nevertheless be answered, though with due caution, by linking particular verses of hers to the rare reviews in which her performances are discussed with specificity sufficient to enable us to recognize the verse or act that was delivered. What then becomes clear is that the collection indeed contains several of her most popular acts. From the scanty dates in the notebooks it can also be established that from around 1914 onwards the character of the Jordaan woman began to figure prominently, which is a matter with which I shall deal presently. Last but not least, there is the question of who wrote the texts. Only in two or three cases are the verses followed by a person's name, but then without giving any indication of its significance. In a sole instance I have been able to retrieve an author by cross-referencing published articles, but that was because the writer himself referred to the particular verse. Even after the enactment of the law on copyright in 1912, it was not common practice in variété publicity or reviews for the author's names to be specified. In the Netherlands, the practice was that many performers either bought verses or commissioned writers to draft them. 
Whether Adriënne Solser did herself write any of the verses in her repertoire, remains therefore another unanswerable question.

Nevertheless, the collection as preserved discloses certain aspects of Adriënne Solser's performances, because they gave shape to her stage persona in terms of both the topics raised and the views conveyed. Once soubrettes and comedians belonged to the top of the field, they were advertised not by their acts, but by their names, their particular skills or specializations, and by such vague indications as "fine new repertoire". This practice implies that their public knew what to expect, that there was a continuity to their performances not only as regards comic or vocal talent but also in terms of stage persona. While bearing in mind Alex de Haas' warning not to take the texts simply at face value, I shall therefore scrutinize the verses in order to discern particular traits of Adriënne Solser's stage persona.

Most of the verses contain a simple but well-constructed plot, with a neat 48 ending that allows for either a mild moralization or a surprise twist by way of conclusion. Their rhythm, however, lends them a light tone. Rhyme is carefully insisted upon and the refrains are catchy, which was typical of the variété. Some verses are mere nonsense poetry, playing with and punning on the sounds of words. An example is "Ik wou" (I wish), which ends with the wish: "I wish I were a string-bean, I would never have to go alone, for I would always be fetched". ${ }^{116}$

The verses breathe the edifying atmosphere that variété and other performing arts were then expected to uphold. The female protagonists repeatedly emphasize their decency and the texts contain nothing risqué or vulgar. Nonetheless, as we have seen, the Anna Judic song that Solser performed at the Vic in the early 1890s, and which is not contained in the notebooks, is suggestive of a degree of impishness. Some verses in the notebooks, moreover, deal with women's lust and libido in a strikingly candid manner as, for instance, one that goes under the title "Vrijen" (Making love), which features a peasant girl singing the praises of her fiancé's amorous attentions:

Have you, young girls, so sweet,

Not yet a lover taken?

Then I'll tell a secret for you to repeat:

Do visit us in the country,

Sturdy farmers' boys we've got

Strong-looking, what more do you want?

And they'll show you soon

They make love better than a gentleman. ${ }^{117}$ 
While this verse was part of Adriënne Solser's pre-war repertoire, later on in her career, she used to deliver another, both more daring and more complex verse on the subject: "Jammer dat niemand het ziet" (Pity, no one shall see it). It is included in a notebook dated October 4, 1935, ${ }^{118}$ when Adriënne Solser had already reached the age of sixty. Moreover, for around two decades, she had been known to be a voluptuous woman, a feature that she did not hesitate to poke fun at during her performances. The first-person narrator of the verse informs the audience of her longing for a man:

But once homewards I've made my way,

And have removed my clothes of the day,

In the mirr'r I look

And nearly faint with desire

Then inside I feel so wondrous,

So lonely, sep'rate, curious,

And indeed I could scream with sorrow -

Pity, no one shall see it. ${ }^{119}$

In the next strophe she specifies that she is quivering with lust, to contend in the refrain:

After the stroke of midnight's hour, when

All alone my form I admire, then

I do not find it that unattractive

Pity, no one shall see it. ${ }^{120}$

With Solser's age and physique in one's mind's eye, it is difficult to imagine that she could have delivered this verse without at least a dose of irony vis-à-vis her body. Be that as it may, the vantage-point here is that of the first-person female narrator, and her looking at herself does seem to add something sensual to the irony.

The verses contain few references to topical matters or to politics, which accords with a remark made by Solser in a letter she wrote in the 1930 s to the board of film censors and in which she stated: "I myself do not care for politics." ${ }^{121}$ The war, patriotism, or new laws concerning alcohol use and morals come up in her verses, but they usually do not constitute the main topic; rather, they function as prompts for commenting upon situations or upon the experiences of individuals affected by them. An exception was made for the issue of women's suffrage, which in any case had already become one of the most popular butts of Dutch variété, all the more so since, in 1908, Chrétienni and Louisette had commissioned Rido to write an entire-and highly acclaimed- 
revue with Louisette in the role of a leading women's liberation activist. ${ }^{122}$ Unfortunately, the verse "Ka als suffragette", as was noted above, has not been preserved, and on the basis of the surviving repertoire it is impossible to say what twists and turns it might have included. This notwithstanding, the repertoire contains one verse, "Verschillende meeningen over Algemeen Kiesrecht" ${ }^{123}$ (Various opinions on Universal Suffrage), which could only have been written after Dutch women obtained suffrage in 1920 and probably dates from around the moment when they first went to the polls in May $1921 .{ }^{124}$ It lists various responses to the new possibility of suffrage and it features a good number of the characters peopling Solser's verses. There are working-class women, who either hope that "women turn the Lower Chamber/Into the finest room in the house", ${ }^{125}$ or are burdened with work to the extent that they cannot even think of making a choice; there are two old spinsters, one of whom will vote for a woman to avenge herself upon men, none of whom ever wanted her, while 50 | the other will indeed vote for one "even if only for the illusion/that I actually can choose a man"; ${ }^{126}$ and then there is the prostitute who does not care one way or the other. Men are displeased with the new situation. The verse ends with a sensible woman, who summons other women to take up the responsibility they now share with men in this century of woman. The argument made has little substance, and the text is not very witty; however, since topical matters were of only minor concern in Solser's repertoire, it is worth noting that in this question she made an exception and had her stage persona rejoice in women finally obtaining the right to vote.

One of her copywriters, Uiltje (literally: owlet) - a pseudonym used by two journalists at De Telegraaf for signing their satirical output, David Orobio de Castro and G. Blok ${ }^{127}$-once noted that Adriënne Solser did not like to take sides. He had written for her a verse satirizing housemaids from the perspective of their mistresses. Solser was indeed willing to take it on in her repertoire, Uiltje recalled, but only under the condition that he write a companion verse, in which the mistresses were indicted from the maids' point of view, "for, in her view, one-sidedness was completely out of the question." ${ }^{128}$ Whether this was Solser's sincere motivation, or whether she just made Uiltje believe it was, remains uncertain. It is proper, however, to raise this question in the two contexts of Uiltje's observation and of Solser's repertoire. The writer regretted having met with Solser's request because he-quite boastfully-feared having contributed to the maids'-as he would have it, ridiculous-demands for higher salaries. In retrospect, he felt the need to distance himself from a viewpoint he had promoted but did not himself support. Solser's repertoire contains far more verses sympathizing with working-class people than with the well-to-do, and when the latter are represented, the purpose is to emphasize differences of class. ${ }^{129}$ My impression, therefore, is that Solser did not so 
much refuse to take sides, as she preferred not to take only the side chosen by the author, that is to say, the side of the mistresses.

Instead of politics and topical matters, the verses usually deal with poor people's lives, differences between men and women, and with women's experiences. The verses about poor people are often mildly moralistic, calling for empathy with those who are quickly condemned, or exposing the hypocrisy of those of a higher social rank. A touching example of the first is the rhyming monologue "De dief" ${ }_{130}$ (The thief), about a poor man who is about to burgle a rich man's house on St. Nicholas Eve ${ }^{131}$ in order to buy some food and gifts for his daughter. In the house, he encounters a girl of his own child's age, who believes him to be St. Nicholas returning to bring her even more presents than she had already received. Upon learning the thief's true intentions, the girl hands him her new doll to give to her "little sister". Her generosity and solidarity generate remorse in the man, who vows that he will never again attempt to get money in a dishonest way.

Hypocrisy is tackled in a subtle way in another monologue, "De Sina's appelschil" (The orange peel). It unmasks the manner in which people tend to strike at those lower than they in the social hierarchy merely in order to make themselves feel better. A "fine man", a baron, nearly slips on an orange peel; he blames his wife; she blames the old maid, who blames the servant, and he the kitchen maid. Having no one below herself in the house, the latter, in her turn, leaves to blame the woman at the greengrocer's, who talks back to the girl instead of continuing the downward spiral. I like this monologue for three reasons in particular. First, its Lisa-and-the-bucket-structure is as effective as it is deceiving, in that it seems to be but a harmless verse, only at the end revealing its built-in irony. Secondly, it introduces the folk woman, who talks big but is good at heart, and who refuses to let herself be bullied by someone who is or merely pretends to be higher in the social hierarchy. Finally, this folk woman is astute and does not fear to break the mechanism in which the girl is caught. These are the basic and sympathetic characteristics of the character of "Bet" whom Adriënne Solser would soon create and embody on-stage and on-screen. Now, the dating of this text is as problematic as it is pertinent. It appears in a notebook before the only verse provided with a date, namely, April 1914. If the sequence of verses is a chronological one, then this vegetable vendor may be understood as being a seminal draft of the persona of Bet. Here, the monologue would suggest that the persona was a conception of Solser's from 1914 or before, which, unfortunately, is all there is to be known about its early manifestations.

Another verse dealing with hypocrisy, in this case among the clergy, is one of the best of the entire collection. This verse, written in French, poses as a young girl's confession that she has been seeing a young man. It consists of 
twelve stanzas with four lines each, suggesting an exchange of questions and answers between the girl, named Brigitte, and her priest. Brigitte's confession comes in brief lines and is in each case followed by the priest encouraging her to reveal more:
If you please, go on
My darling Brigitte
Whatever next did happen
I implore you to tell. ${ }^{132}$

What is so great about this verse is that the repetitive rhythm co-operates in creating the content, in that it contributes to suggesting the prurient curiosity of the priest, which is eventually exposed in all clarity in the final stanza, when Brigitte reveals what it was that she showed to her date: "My photographic por-

52 | trait, Mr. Priest," whereupon the priest answered, in, as I surmise, immense disappointment:

In the end, you're a bother

Brigitte, I now leave you

One does not trouble one's Father

With so small a sin. ${ }^{133}$

In addition to the ingénue, the chanteuse, the prostitute, the maid, and the mistress, Solser's repertoire featured female professionals typical of the 1910s, such as the points-woman for the railroads, and the policewoman. The pointswoman is not only made fun of, but also presented as a widowed mother and a responsible and dutiful worker, who explains to the audience what her job entails. ${ }^{134}$ The policewoman apparently was a rather new phenomenon, which is conveyed by means of puns and wise-cracks. For instance, it is suggested that a feminine form of the Dutch word "agent" did not yet exist, but the proper one, "agente," had been carefully omitted from those used in the text: "Agenteres, Agenterin, Agenteuse, Agentrice". ${ }^{135}$ Potentially very funny is the self-mockery concerning Solser's own girth, which she turns into the policewoman's advantage by declaring that "this is the first policeman they cannot take for a ride, so we may be sure that this first Agenteuse was deemed enough of a heavyweight when they chose her." ${ }^{136}$ The policewoman's job allows for commentary on social wrongs, and here there thus return, among others, the woman abandoned by her husband as well as the unemployed man who has to steal his food. The woman is advised to leave her man and the man without a job will not be arrested, as far as the policewoman is concerned.

Although Solser created for herself a stage persona that was not a feminist 
or a suffragette in the political sense of the word, this persona did maintain straightforward views about the wrongs of men vis-à-vis women. Men who mislead and cheat on women form a recurrent issue in the collection, and the stage persona often assures her audience that she defends the decency that men threaten. It is highly unlikely, within the context of the performance, that a passage such as the following would have come to mean something other than what it seems to say:

Though he call you his darling beauty

Do not trust him, beware, he lies [...]

His greatest pleasure

Is spoiling your ingenuousness. ${ }^{137}$

This particular verse counteracts its initial accusation by consoling men in the last stanza:

For, oh, the earth

Without men wasn't worth

And, do believe me, I can

Not live without a sweet man. ${ }^{138}$

Other verses do not do so, as for instance the one in which men are depicted as foxes:

If the woman is sly

A fox is the man likewise

His tricks are always well-planned out

If there's something to catch. ${ }^{139}$

The harshest descriptions of men's evil attitudes towards women are to be found in the various songs about soubrettes and prostitutes. One soubrette, for instance, describes her conflicting feelings: on stage she has to pretend to be happy and merry, while in her heart she is devastated because her husband cheated on her and then abandoned her and her child, whereupon the baby died of grief. ${ }^{140}$ The song, from a notebook with texts dating from 1907 to 1918 , echoes the discussion about the splits between the on- and off-stage lives of soubrettes that was pervasive during the 1910s; or, in another song; a woman became a prostitute and an alcoholic after she had been left by her lover: "I sacrificed my honor on the altar of love, all for the one who thereupon left me." ${ }^{141}$ As did the verse about the thief, this song calls for empathy with an outcast. 
On the other hand, some verses do also criticize women's attitude towards men. For instance, a song with the seemingly unambiguous title "De mannen begrijpen ons niet”" ${ }^{142}$ (Men don't understand us) ridicules women's complaints about men's incomprehension; it is even conceivable that, if presented in a certain manner, it might have turned into a parody of women feigning too much naiveté about their own behavior. Some verses in Solser's repertoire indeed presented women as being as inscrutable and selfish as men are tyrannical:

The women are no more unswerving

This I quite frankly say

Love sometimes is too demanding

And then it soon blows away. ${ }^{143}$

54 | The context of this stanza is the ironic question why all women prefer different types of men, while what they want from them is always the very same thing. Within Solser's preserved repertoire, however, verses criticizing men are in the majority. One even opens with a comment on her male colleagues: "if one listens to comedians, they praise the men; women are ridiculed, we don't get angry" ${ }^{144}$ But, as irony would have it, these lines stem from the verse that unmasks women's self-indulgence, to which I have already referred.

Prostitutes and chanteuses are represented as the poorest devils among women, for the older they get, the more they will be rejected by both men and society. Alcohol is often the only friend they have left. Such are the women's fates depicted in "De bloem der terrassen" ${ }^{145}$ (The flower of the sidewalk cafés), "De chanteuse", 146 "De trap der dronkenschap" 147 (The ladder of drunkenness), and "De nachtvlinder" ${ }^{48}$ (The night-owl). None of these verses has a reproving tone, in fact they sound rather compassionate:

Do allay her great pain

Don't treat her with disdain

They've too known it who now laughter feign:

Do have pity, please. ${ }^{149}$

In a way, these texts sustain the sleazy image of the profession, which they even exacerbate in support of their aim to ask for pity for these victims of circumstance. At first sight, it seems strange that even a thriving professional in the field such as Solser would include in her repertoire such cliché-ridden images of her profession, when they diverged so obviously from her personal experience and practice; this, in contrast with Louise Fleuron, for instance, who sang at least one song presenting a more realistic picture of the conditions of 
her work..$^{150}$ The practice of employing copy-writers, and these mostly men, ${ }^{151}$ may constitute one explanation for the divergence of image and experience displayed in verses delivered by Solser, but, given that we do not know the full range of the spectrum from which she could make her selections, these conditions cannot be further determined. The key to the question, however, seems to be offered by one of the professional requirements pointed out earlier, so aptly summarized by Louisette's portraitist: the soubrette's art "needs a certain quick and buoyant jollity [...] which excludes all subjectivity." ${ }^{152}$ This elimination of subjectivity, and thus of a direct appeal by the actress to the spectator's possible empathy with herself, corresponds to one of the essential conditions for creating laughter, as defined by Henri Bergson in his study of the comical: "laughter is incompatible with emotion. Depict some fault, however trifling, in such a way as to arouse sympathy, fear, or pity; the mischief is done, it is impossible for us to laugh." ${ }^{153}$ Adriënne Solser and her colleagues in variété must have perfectly understood this point, and it is for this reason that the texts she delivered can be read as expressions of personal experiences or views of neither the performers nor the authors. Rather, they reflect prevailing yet select opinions and discussions of the time.

All in all, Adriënne Solser's stage persona came close to a common woman, who was clever enough not to let herself be fooled by life, class, men, or language. At times she was archaic, but, most often, she shows her acquaintance with modern life. She displays a strong commitment to the social fates of women and outcasts. Neither topical matters nor politics were her subject, yet they could serve as a welcome background for dealing with the way people's lives were affected by social circumstances. One, still detectable, aspect of Solser's comedy was that she played on her hefty physique, a comic device which she further developed and utilized in the character for which she subsequently became known.

\section{THE YEARS OF CHARACTER COMEDY, 1914-1920}

After 1914, Adriënne Solser earned more and more acclaim —-from both critics and audiences - as a karakter-humoriste (satirical singer in character), most notably when she played the role of the Amsterdam (or sometimes Rotterdam) folk woman. In 1915, for instance, she appeared in a small "Jordaan-revue" by Rido at the Rozen-Theater, in which she had two parts: a poor woman mourning her son's death in the war, and a middle-class spouse. All of it was delivered "in strict Jordaan dialect" by "Adriënne Solser-the petty bourgeois missus with a thundering voice, who shakes the audience's ears when she sings to her husband: 'Give me a kiss'”. ${ }^{154}$ Solser's assignment to the theater, 
which, in the meantime had become known as the foremost outlet for the Jordaan genre, was renewed for the first two weeks of October 1915, in a variété program including a farce written by Tony Schmitz. ${ }^{155}$ The folk woman impersonated by Solser tended to become a woman selling vegetables or fish at the market, as was the case in a revue mounted by Ter Hall with Louise Fleuron as the commère. ${ }^{156}$

\section{Adriënne Solser as the Amsterdam Folk Woman}

By 1918, Solser had come chiefly to personify the woman from the Amsterdam working-class quarter the Jordaan, a part of the city famous for the humor, good-heartedness, idiosyncrasy, and candor of its inhabitants. Two of the earliest references to such a creation of Solser's that I have been able to retrieve

56 | from the newspapers date from January and February 1914, when she was announced with her new karakterschets "Ka als suffragette" (also entitled "De suffragette uit de Jordaan") in the Rozen-Theater in Amsterdam and in the Cabaret Metropole in Rotterdam, respectively. ${ }^{157}$ One year later, Solser had fixed the female character's first name and occupation, establishing the persona she would feature throughout her further career: "Great popular success for Adriënne Solser in her [...] creation 'Big Bet from the vegetable market'” De Kunst noted; $;^{15}$ and the daily Haagsche Courant identified "Bolle Bet uit de Willemsstraat (te Amsterdam)" (Big Bet from the Willemsstreet in Amsterdam) as being "a very nice creation". ${ }^{159}$ From then on, the market woman from the Jordaan named Bet (or, less frequently, Ka or Kee) became Solser's most prominent stage persona, regardless of whether she was embellished with the soubriquet "bolle" (big), "tante" (aunt), or "de koningin van de Jordaan" (the queen of the Jordaan). By 1919, then, Solser was generally known as "the popular character comedienne, known for her hilarious delivery of folk types from Amsterdam and Rotterdam". ${ }^{160}$ This is rather interesting considering that, after the rise of the salonkomiek and the humoriste, such sustained preference for character comedy had gone out of fashion among male and female variété performers. ${ }^{161}$ None of Adriënne Solser's female colleagues is known to have cultivated such a clear-cut comic persona during the 1920s. Revue and cabaret, moreover, stimulated versatility. Contrary to these trends, Adriënne Solser would make character comedy into a trademark during the rest of her career.

Adriënne Solser's preserved notebooks contain several texts with the Bet character as protagonist, including the above-mentioned verse "Bolle Bet uit de Willemsstraat". Like the monologue "Bolle Bet gaat aan "t tooneel" (Big Bet goes on stage) in the same notebook, which dates from the mid-1910s, and the 1918 dialogue "Bet en Hein aan "t tooneel" (Bet and Hein on stage), the 
verse features the Jordaan character trying her luck on the popular stage. The refrain of the verse offers an introduction of the character to her audience:

Here you have Big Bettie,

Known all throughout the town,

She likes things when they're funny,

There she enjoys renown;

Around here she's the heartiest,

Not to mention the bulkiest,

Greeted wherever she may trot:

Big Bettie from the Willemsstraat. ${ }^{162}$

The "plot" informs us that she used to be a green-grocer, but hopes to earn more money in the variété, and, because she is still new to the stage, she invites the audience to help her by singing along with the refrain. The prose text "Bolle Bet gaat aan 't tooneel" is a satirical account of Bet's stage career. The "story" is that she aspired to join the comic theater, which, like the operetta, was more esteemed than the variété, but none of the extant companies wanted her, despite her alleged talents. She asserts that she actually felt what she enacted, and that she made others feel it too: she once knocked her stage partner down, sending him to the hospital. When confronting each genre, Adriënne Solser's own peculiarities were used: one company did not want her because of her big mouth, another because of her lack of dramatic training, and, for the revue, her legs were too plump. That is why, in the end, she announced that she was establishing her own company: "What I offer is not a parade of legs, no 'asem' in exile, but real genuine spine-tingling folk plays." ${ }^{163}$ Thus, the Bet persona made fun of Solser's profession, career, ambitions, and physique all at once.

In the 1918 dialogue, Bet is a cleaning woman who is married to Hein, an electrician. The entire conversation deals with their aspirations to go on-stage and display their versatile talents. The traits of this presentation of Bet are even more specifically traceable to Adriënne Solser personally. For instance, she originated from a family of actors, enjoyed hardly any education, and was high-spirited. I am aware that I am getting into a tricky subject by pointing out such similarities, when I myself argued earlier that Solser's verses and her own experience and attitude were not correlative. And yet I am not arguing that the Bet persona should be identified with the actress who created her, or the other way around. My point is that, in the Bet texts, some of Solser's oddities were indeed inserted into her stage persona. This raises two questions: who wrote the texts, and what were the conditions and effects of these insertions? My answer to the first question may well be debatable, but it seems plausible to 
claim that Adriënne Solser had input in these prose texts. The second question requires a more extended treatment. One of the conditions for playing on her own oddities was her fame and the stage persona she had thus far developed. As I have noted above, the Bet persona was a common woman clever enough not to be fooled. In the Bet texts, then, it turns out that this common woman has ambitions for the stage. The insertion of Solser's own oddities into the texts must have had a comical purpose as well as effect: they were a droll device to be added to the actress' mockery of her own physique. Her career and talents as a variété performer were employed for creating fun. On top of that, the Bet persona was confined to a specific form of entertainment. At one point in the conversation between Bet and Hein, Bet demonstrates her talent to singing "operaam" (literally, an open window), but as a composite it sounds like "opera". From the surviving text, it remains unclear whether Solser indeed was capable of singing opera, or whether she just delivered a

58 persiflage; either way, Hein does not care for such singing, he finds it too highflown. In response to his disapproval, Bet asks, "Well, what do you want then? It was pure art, wasn't it?" and he answers: "That's why it's no good. The audience doesn't want art. People want to laugh." 164 This observation about the audiences' preferences during the 1910s was in line with Solser's own experience on the popular stage. The dialogue, moreover, refers to a divide within the realm of popular entertainment, which had manifested itself by 1918 in clearer definitions of genres. Quite in contrast to the pre-war period, with its mixed programming and blurry boundaries, by the end of the war, a performer either made art or induced people to laugh. With her Bet persona, Adriënne Solser explicitly chose the latter.

\section{Stage History of Amsterdam Folk Characters}

When Adriënne Solser picked up the Amsterdam folk woman as her chief stage persona around the mid-teens, the character already had a history on the popular stage. It belonged to what, in retrospect, would be labeled the "Jordaan-genre" or "Jordaankomedie" (Jordaan-comedy): a specific type of Dutch popular theater and cinema that was as well-liked by the public as it was an increasing cause of controversy in the eyes of critics and historians from the mid-1910s until the 1930 .

The contemporary term volksstukken, folk or people's plays, had acquired two meanings in Dutch theater history: it referred to the folk dramas by Herman Heyermans, on the one hand, and to the Amsterdam comic plays by Herman Bouber, on the other. Although Bouber's comic plays are sometimes discussed in theater history, they are typically marginalized. ${ }^{165}$ Literary history, 
moreover, has canonized only Heyermans' dramas, thereby relegating Bouber's plays to the margins of popular culture and as failing to meet the standards of literature. ${ }^{166}$ In consequence, a history of the Amsterdam volksstukken as they emerged and attained the height of popularity during the 1910s, is now due to be written.

Herman Heyermans was a socialist playwright and critic who wrote popular plays at the turn of the century for the legitimate stage. His 1900 fisherman's drama "Op hoop van zegen” (The Good Hope) ran for years; it had two hundred performances by May 1903 and five hundred by January 1915, and in its status as a genuine volksstuk, it has been adapted to cinema four times between 1918 and 1986. The role of the tragic mother, Kniertje, who loses all her sons in a shipwreck, was repeatedly played by the leading Heyermans actress Esther de Boer-van Rijk, ${ }^{167}$ on-stage as well as in two film adaptations. While highly esteemed for their naturalistic style and their dramatic and literary qualities, Heyermans' plays about the social wrongs and the misery of the poor also met much critique from viewers, not only from anti-socialists, ${ }^{168}$ but also from those who argued for a less idealistic and a more light-hearted and cheerful representation of Dutch people. An astute articulation of this quest for a more merry approach can be found in a review of the aforementioned comic operetta " $n$ Amsterdamsche Hartjesdag” by Johan Kelly, in which Adriënne Solser played one of the Jordaan women roaming the streets the night before the annual fair. The critic compared the production to the work of seventeenth-century Dutch poets, ${ }^{169}$ on the one hand, and to contemporary realist plays — read: Heyermans' works—on the other:

Kelly succeeds in being true without bringing too much reality on stage. [...] What makes Kelly far removed from the realists of our times and renders him more akin to the seventeenth-century playwrights, is that he still notices people laughing in real life, that according to him not all faces are sour and not all eyes gloomy, that people open their mouths for other things than defending or disputing theories. ${ }^{170}$

The aspect of cheerfulness missing from Heyermans' social dramas, found representation in the Jordaan-komedies, which were basically a mixture of social drama and comic scenes set in the Amsterdam neighborhood of the Jordaan or peopled with archetypical characters from the district. The chief examples of this specific genre were the volksstukken of the couple Herman and Aaf Bouber, who, from 1915 onwards, wrote and staged the core stock of Jordaan-komedies still known to this day. But before elaborating upon those plays and their relation to Adriënne Solser's work, it is necessary first to discuss the vivid and genre-crossing tradition of staging light volksstukken and 
Amsterdam characters that was established during the interval between Heyermans and the Bouber couple: between 1900 and 1915, that is. In so doing, the characteristics of the genre will be illuminated and the meanings of the prefix volks- (folk) will be explored.

The Jordaan was and is a quarter in the centre of Amsterdam, which was, at the time, a working-class district characterized by the low social standard and the poor living conditions of at least half of its population. ${ }^{171}$ It was also a rebellious neighborhood, whose history included various revolts, such as the potato-riot of 1919, and strikes against the reduction of relief subsidies and the rise of rents during the 1920s and 1930s. Bert Hogenkamp has pointed out that such social and political activism, however, was neither a topic nor a perspective included in the fictional genre in which the Jordaan featured, be it in plays or in films. ${ }^{172}$ Rather, this genre focused on the idiosyncrasy and the humor of the neighborhood folk and on their putative loyalty and verbal asser-

60 | tiveness. The residents, "Jordanezen", were notorious for their idioms-a combination of local flavor and a sociolect of their own-and for their colorful wise-cracks. ${ }^{173}$ The Jordaan genre was peopled with outspoken characters like Bet, Hein, Kee, Janus, Ka, Mie, and Dries, who were embellished with traits like candidness, chumminess, and insouciance. In the words of the influential critic Barbarossa, these figures were a "blend of benevolence, decorum, and good-for-nothing", ${ }^{174}$ which helped them master whatever problems might arise.

Because it was set in the neighborhood and it gently parodied typical Jordaan folks, the operetta " $n$ Amsterdamsche Hartjesdag" may be considered as an early sample of the Jordaan genre. Moreover, as in the plays of the Bouber couple, music took on an important role in it. In addition to such intertextual kinship, extra-textual interrelations may be detected when the sites of the theatrical presentation and, consequently, the make-up of the audience are considered. The operetta was staged at the Frascati-Schouwburg run by Gustave Prot and son, known as "the theater of laughs", ${ }^{175}$ which had established a tradition of offering plays about and for Amsterdam people as an alternative to their usual bill of French boulevard comedies and operettas. The comical operettas known as "the Prot genre" were famous for their lush staging-Gustave Prot Sr. was originally a set-designer-and for their fine cast: comedians and soubrettes hired by Prot were considered to have taken a step up in the stage hierarchy. Newspaper reports of the Solsers on Prot's stage, for instance, bear witness to this idea.

The Frascati-Schouwburg was one of the playhouses in the Plantage neighbourhood of Amsterdam, where the Schouwburg Stoel en Spree, later known as the Plantage-Schouwburg, and the Artis-Schouwburg, later renamed the Hollandsche Schouwburg, were located as well. Before the turn of the cen- 
tury, these playhouses were known for programming light and racy comedies, comic operettas, and sensational melodramas, called "draken" (literally: dragons) in the Dutch vernacular. They used to draw large crowds of common people, both from the neighboring Jewish quarter and from the Jordaan district. Around 1900, these playhouses turned into nurseries for volksstukken, a function they upheld for decades to come. In particular, at the turn of the century, the Schouwburg Stoel en Spree began hosting plays about Amsterdam and its people, a trend followed during the 1910s by the Hollandsche Schouwburg. Central to this development was Marius Spree (1876-1929), a playwright, leading actor, and one of the directors of the Schouwburg Stoel en Spree. Throughout his life and career, Spree showed himself an enduring personality in the writing, performing, and staging of Dutch volksstukken, plays that were were performed in both Amsterdam and Rotterdam as well as taking these cities as their setting. ${ }^{176}$ Together with Frits Stoel, Spree undertook the exploitation of the Amsterdam theater in 1895, and, in 1901, it was noted that a significant change had taken place at the Plantage-Schouwburg. ${ }^{177}$ Instead of sensational melodramas, more and more "slices of reality" ${ }^{178}$ were staged, to enormous applause. ${ }^{179}$ Spree had adapted several short stories written by Justus van Maurik, a famous chronicler of day and night-life in Amsterdam, for the popular stage. One of these stories was "Teun de Nachtwacht" (Teun, the Night-watchman),

a sad story [...], although the folly and the comical behavior of the neighbors make people roar with laughter. [...] The audience took such pleasure in the scenes, cheering and laughing so loudly during the performance that the actors could no longer be heard. People were laughing their heads off. ${ }^{80}$

The lively involvement of the audience was not only a phenomenon typical of the Plantage neighborhood, but would accompany the genre as long as it remained popular. A significant element employed by Spree was the use of the broad Amsterdam tongue. Last but not least, the plays were highly appreciated for their elevating and heartening intent. ${ }^{181}$ Such slightly moralizing tendencies and the happy endings became two of the characteristics of folk comedies. Spree's plays "Jan Smees", "Mottige Janus" (Pock-Marked Janus), and "Rooie Sien", are still among those considered as epitomizing the genre. The sobriquet of the female protagonist Kee in "Jan Smees" was "Koningin van de Jordaan" (Queen of the Jordaan), ${ }^{182}$ a phrase that Adriënne Solser borrowed in the early 1920 s for the title of her first film in the BET series.

Dries Krijn has pointed out another, nearly simultaneous emergence of Jordaan characters, beginning with August Reyding's 1897 revue "Luilekker- 
land" (Land of milk and honey). ${ }^{183}$ Krijn depicts the character, Pietje Puck, as a womanizer, a loafer and a sponger, whereas his wife's only characterizing feature is her nickname, Zwarte Kardoes (Black Puss). Likewise, Klöters avows that the cult of the Jordaan-komedie was initiated by this revue. ${ }^{184}$ According to Krijn, however, Pietje Puck and Zwarte Kardoes were preceded by the Amsterdam couple Thomasvaer and Pieternel, who were the characters of a comic opera which, by that time, had invariably been performed after the traditional Amsterdam New Year's Day staging of one of the classics of the Dutch theater, Vondel's "Geysbrecht van Aemstel" for more than a century. ${ }^{185}$ The roles of Thomasvaer and Pieternel commented upon the events of the year gone by from a local perspective. In short, local characters gained popularity almost simultaneously in a variety of theatrical genres around 1900 . The writings by Justus van Maurik and J. Werumeus Bunink upon which Marius Spree based his plays, further fuelled the interest in Amsterdam and its people and legiti-

62 mated it from the side of popular literature, a function to be taken over in the course of the 1910 s by the novels of Israel Querido. It was most notably this author's four-part Jordaan cycle, published between 1912 and $1925,{ }^{186}$ that showed the life of the people, their folk humor and their local tongue, to be fit for literary treatment; while other writers proved that all of this could appeal highly to audiences and critics when dramatized for the popular stage.

Marius Spree was one of the actors instrumental to the rise of the Jordaan genre who also wrote the plays that constituted the genre. ${ }^{187}$ Most of the players in the field, however, preferred to separate the labor of writing from acting and directing. Lion Solser used to plot the basic idea for the Jordaan sketches of the Ensemble Solser en Hesse, besides doing the stage direction and starring in them, but he commissioned others to author and draw up the pieces. ${ }^{188}$ One of his authors was Tony Schmitz (1879-1920), the highly prolific composer of verses for, among many others, Louise Fleuron and Nap de la Mar. ${ }^{189}$ Through his four sketches written for the Ensemble Solser en Hesse, Schmitz contributed significantly to the early popularity of the Jordaan genre as did Rido, who authored the first Solser en Hesse sketch in 1910 and subsequently wrote many revues about Amsterdam and the Jordaan, in one of which Adriënne Solser performed. ${ }^{190}$ Last but not least, there were, of course, Herman Bouber and his wife Aaf Bouber-ten Hoope. ${ }^{191}$ Their "Mooie Neel" (Pretty Nell), "Bleeke Bet", "Oranje Hein" (Orange Hein), "Ronde Ka” (Round Ka), and "De Jantjes" (The Jack-tars), became as synonymous with the genre as Spree's title-characters were.

The writing of Jordaan-komedies required precision because the plays and characters staged before and during the 1910 s were primarily aimed at-and most often reached - the audience they portrayed and parodied, and it was precisely the people of the Jordaan who composed the critical public that was 
known never to laugh out of politeness. ${ }^{192}$ As in the review of Spree's "Teun de Nachtwacht", contemporary press reports remark upon the public's response as an indication whether or not this delicate endeavor had been successfully delivered. Jan Grootveld, the actor who played Pietje Puck in Reyding's revue, had personally experienced the warm embrace of the Jordaan folks, who had invited him to their neighborhood and had lionized him during an entire afternoon in order to pay tribute to the character he had created. ${ }^{193}$ When Bouber's "Bleeke Bet" was staged at the Hollandsche Schouwburg in 1918, critics once more noted the engaged and cheerful response of the public from the Jordaan. ${ }^{194} \mathrm{~A}$ rather sarcastic but no less telling account of the popularity of the genre with the people of the Jordaan was provided by a columnist who was unable to attend the 1915 performance of a revue by Rido in the RozenTheater, which was situated right in the middle of the district, frequented by many of the locals, and a centre for the genre since the outbreak of the war. The house - with one thousand seats—was fully booked three days in advance! And the critic sighed:

The future of authors and theater managers lies in the Jordaan, I tell you. Adam in Exile? A Midsummer Night's Dream?

Outdone. An era gone by.

"Cauliflower Hein" and "Shrimp Bet."

That's the future!

Hail the Jordaan! Hail the Jordaan! ${ }^{195}$

This column was one of the few manifestations of the growing irritation in the theater press with the popularity of the Jordaan genre, which was mainly expressed in the shape of neglect and omission. In its sarcastic account of the impossibility of attending these popular shows, however, this particular comment illuminates one important factor in that irritation: the critic felt excluded from the party. In this case, it was a physical exclusion, but the experience probably fed into an alienation from the genre to which professional critics were increasingly susceptible. This alienation was a result of the direct and collective appeal of the Jordaan plays to the audience to whom they were addressed. In contrast to Heyermans' dramas, these volksstukken were not just about the common people, but they belonged to them and to their folk culture.

In his reminiscences of those times, Rido pointed out that the Ensemble Solser en Hesse was the direct forerunner of the Jordaan genre of which Herman and Aaf Bouber were to become the main historical representatives. ${ }^{196} \mathrm{By}$ emphasizing this, Rido laid claim to having been a co-initiator of the genre, as he was the one whom Lion Solser had commissioned to author the ensemble's first Jordaan sketch. The format of Solser en Hesse's sketches was indeed 
new, constituting an expansion of their earlier karakterschetsen, little sketches built around prototypes. ${ }^{197}$ According to the necrologies of Lion Solser, who died by his own hand on August 3, 1915, Solser en Hesse were instrumental to the introduction of one-act plays to the Dutch variété. By 1910, their karakterschetsen had evolved into longer farcical sketches. In contrast to what Spree had done and to what Bouber was going to do, that is to say, to create social drama with comic scenes and side characters, Solser en Hesse focused chiefly on gags and gimmicks, on begetting laughter, while incidentally including some dramatic moments. Just as Spree had done, however, they made use of Amsterdam slang on stage. They also inserted sing-a-longs and dance numbers into the show, which enabled the audience to engage in collective and active participation. In this latter regard, they were following the model established by Jan Grootveld as Pietje Puck, whose refrain and dance had been the hit numbers of the revue "Luilekkerland". ${ }^{198}$ Such was the genre of Jordaan 64 sketches as exemplified by the Ensemble Solser en Hesse.

Lion Solser and Piet Hesse (1872-1936) had both been employed at the Plantage-Schouwburg before they began as a verse-singing itinerant duo working the provincial festivities in $1897 .{ }^{199}$ After having married the Prot soubrettes Adriënne Willemsens and Anna Slauderof, they established Ensemble Solser en Hesse around 1900, with the four of them as the main actors. Lion Solser was the artistic and Piet Hesse the commercial director of the troupe. Occasionally, another Solser brother, Louis, would join in as an extra, while Adriënne stood in for Lion only during the last months before his death. ${ }^{200}$

During the first decade of the twentieth century, the Ensemble Solser en Hesse belonged to the most sought-after attractions of the Flora and the Circus Carré in Amsterdam, and the Casino Variété in Rotterdam, while they also continued to tour the country and occasionally returned to play at the Plantage theater district. ${ }^{201}$ The success of their 1909 parody of one of the classics of Dutch theater, Joost van den Vondel's "Adam in ballingschap", encouraged them to hire a theater for September 1910 and to create a kermisstuk, a piece for the fair. Even though the fairs had been suspended, the traditional month of the fair-August for Rotterdam, September for Amsterdam, and May for The Hague-was still celebrated with playhouses that offered unpretentious entertainment. ${ }^{202}$ Unpretentiousness was not a pejorative notion but rather accepted as a valid classification for vermaakskunst (the art of entertainment) and self-confidently employed by the makers of the farces and revues presented. Before and during the war, the audiences and the popular theater press alike considered it an achievement if performers succeeded in entertaining them throughout the performance and even more so if the shows were jocose, like those of the Ensemble Solser en Hesse. ${ }^{203}$

Each September from 1910 to 1915 , a new Jordaan farce was produced 
by the Ensemble Solser en Hesse, with which they scored triumph upon triumph. The efficacious ideas and storylines were devised by Lion Solser, who also did the stage direction of the sketches and often took on the female lead. Whereas Piet Hesse had been born and raised in Amsterdam, Solser acquired the accent and the spirit of the Jordaan by doing extensive research at markets and cafés, where he went in search of typical costumes, expressions, and bits of behavior.

This is how the Amsterdam volksstukken and the characters in them as played by Solser and Hesse became precise and apt imitations of reality, and equivalent to some of Justus van Maurik's stories. In their acting, they have emphasized the sensitive, the human, and the altruistic qualities of ordinary people, and the jollity with which they wrap them up. Lion Solser's creations evinced his sympathy for common people, and the pleasure he took in their conduct. Through his acting, he became one of them while their conduct became art. ${ }^{204}$

Their first sketch in the genre, "Heb je "t kind al gezien?" (Have you seen the baby yet?), was set in the proto-street of the Jordaan district: the Willemsstraat. It pictured the excitement of the people, most notably of Ka the fishmonger, upon learning that the royal parade for the baby Princess Juliana intended to pay a call to their street: "L. Solser is a gem of an Amsterdam fishmonger, with all the humor that used to belong to the genre", ${ }^{205}$ Rössing wrote admiringly. In addition to the location, the female type, the idioms, and the jollity, two other elements characteristic of the "genre Solser en Hesse" were introduced: song and dance intermezzos and a heartfelt moment; "mindful of the tears and the laughter, a moving song by a good woman in distress, in the face of which the people from the Jordaan instantly put their hands in their pockets", ${ }^{206}$ Rido remembered.

But Lion Solser's best-known "creation" was Mie, another fishmonger, who appeared in the sketch "Weet je 't al van Schellevis-Mie?" (Have you heard the news of Haddock Mie?) from 1914-1915. This sketch was so notable that the columnist of De Theatergids declared it the hit of the theater season. His impressionistic description of Solser's role is priceless, its irony notwithstanding:

Haddock Mie, presented by Lion Solser with all the charm and goodness of heart and looseness of legs that is hers. Watch her hips swaying, Lion Solser! Watch her tango, Lion Solser! Watch her pat-a-cake, Lion Solser, and watch her scrape the scales from her fish, Lion Solser! Watch her in her poshest fashionable dress and her brightest white smock, Lion Solser! 


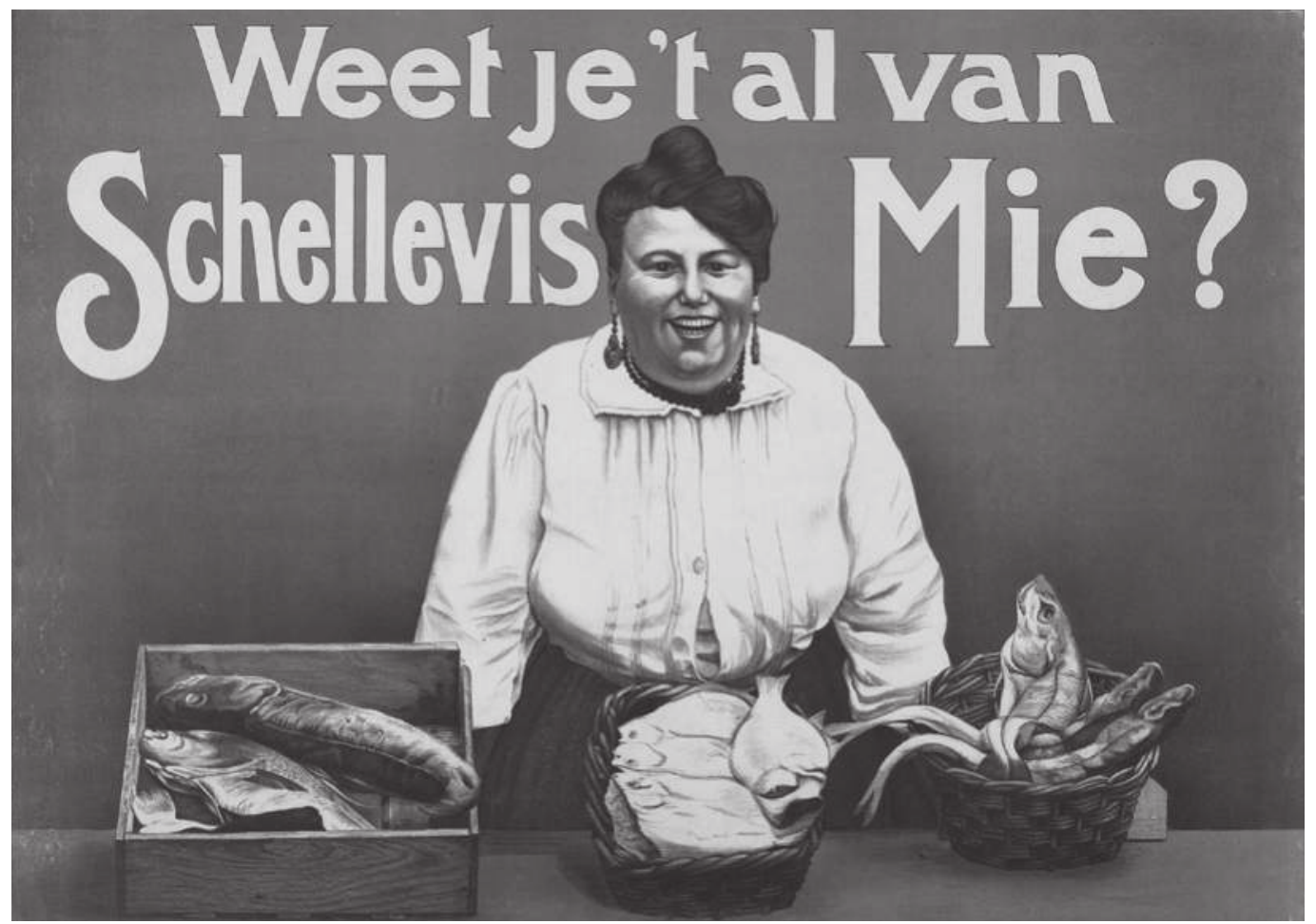

Fig. I.8: Poster for Lion Solser's most well-known and last role, 1915 .

And then tell me if she isn't an asset to the guild of women fishmongers, Lion Solser! Hear her voice, hear her tongue! [...]

Well, Lion Solser deserves the honorary membership in the Free Society of Women Fishmongers based on Dutch Reformed principles, "The Obstinate Buoy." ${ }^{207}$

"Schellevisch-Mie" was staged 100 times, even though the performance was repeatedly cancelled due to Lion Solser's worsening neurasthenia. After his death, Anna Hesse-Slauderof took on the title part and even selected the sketch for the celebration of her thirtieth stage-anniversary. ${ }^{208}$ The Ensemble Solser en Hesse continued to perform, although they stopped producing new Jordaan sketches. It had become impossible to imagine Dutch popular theater of the 1910 s without the genre they had created and epitomized. With their one-act plays and sketches, Solser and Hesse had substantially contributed to the hype that had come to surround comic Jordaan characters by the mid-teens. They likewise had had a pivotal role in the migration and transformation of the genre from the provincial variété and urban cabaret to the Amsterdam playhouses specializing in Jordaan plays. Moreover they had 
highlighted a comic female character-albeit in drag-, but the character was apparently womanly enough to be played by women later on.

Herman Bouber, himself a semi-professional actor, disliked the sensational melodramas in which his wife Aaf played at the Plantage Schouwburg, because they were set in a milieu and presented in a language alien to the public. ${ }^{209}$ According to Rido, Bouber had observed in the performances of the Ensemble Solser en Hesse how much the audience appreciated the use of its familiar tongue and idioms, a connection documented in contemporary reviews. ${ }^{210}$ It seems likely that the plays staged by Marius Spree at the PlantageSchouwburg up until 1912 had been another source of inspiration for Bouber. ${ }^{211}$ For, while Solser's main aim had been to make people laugh, Bouber sought a balance between dramatic and comic elements that was much more akin to the one found in Spree's plays. Another similarity between these two was their choice of titles, which consisted of a typical Jordaan nickname. Bouber's first Jordaan comedy, “Mooie Neel: De Trots van de Jordaan” (Pretty Nell: The Pride of the Jordaan), premiered at the Rozen-Theater in August 1916. ${ }^{212}$

Fig. I.9: Caricature of Lion Solser in the role of Haddock-Mie. Cover page Theatergids, 31 January 1915 .

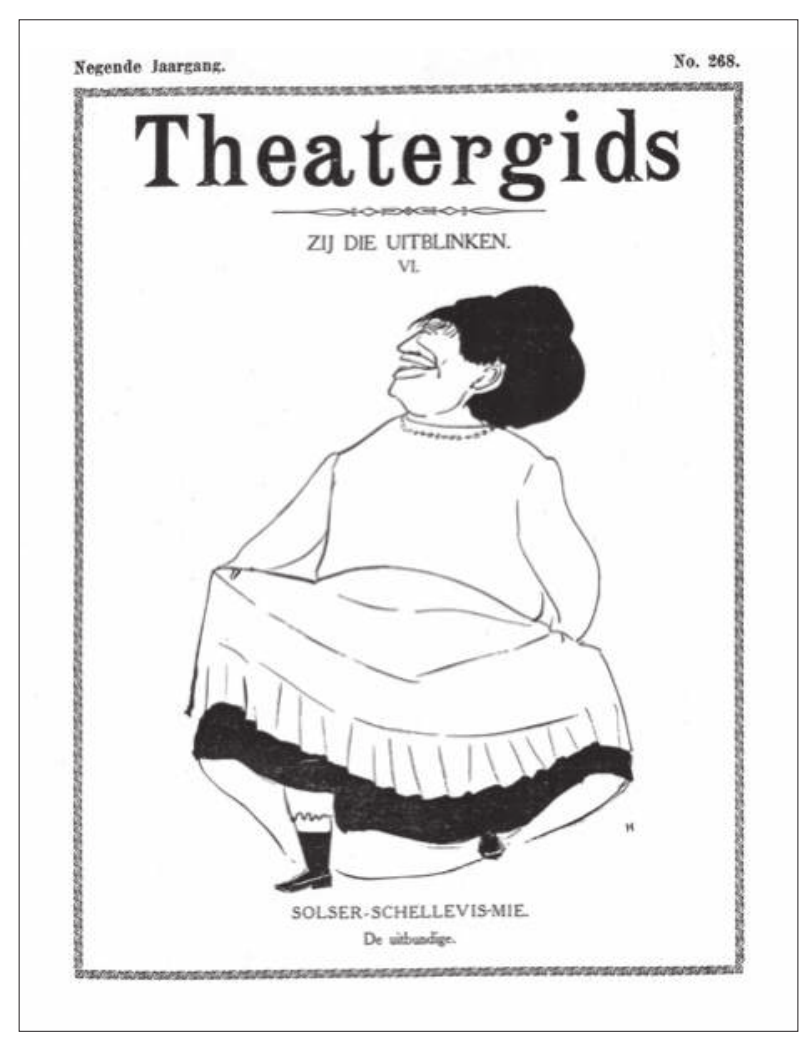


With at least as much success as the Ensemble Solser en Hesse had, Bouber filled the void after Lion Solser's death had interrupted the stream of new Jordaan sketches. Thus in 1918 there followed "Bleeke Bet" and "Linke Louwtje" (Wily Little Louw), and, in 1919, "Oranje Hein”, "Manussie van Alles" (Jackof-all-trades), and "De Jantjes", after which the flow tapered off for awhile. ${ }^{213}$ It picked up again, but at a slower pace, with "Blonde Ka" (Blond Ka) in 1923, "De Jantjes II" somewhat later in the decade, and "Zeemansvrouwen" (Seaman's Wives) in 1928.

To create and sustain his successes, Bouber surrounded himself with actors and collaborators who had gained experience with the genre and with the popular stage: first and foremost, Nap de la Mar, who undertook the stage direction of "Bleeke Bet" and "Linke Louwtje". Rido articulated Bouber's enthusiasm with his stage director: "Nap walks the actors through all parts, just from memory, without the text. And the author was amazed watching 68 Nap make much more of the characters than what he had seen in them." ${ }^{214}$ As actors, Bouber assured himself of the collaboration of Jan Buderman, Louis van Dommelen, Piet Köhler, and Aaf Bouber, to name only those I have previously mentioned. ${ }^{215}$ Crucial to their success was also the long-term collaboration with Louis Davids and Margie Morris, who wrote and composed, respectively, the sing-a-longs that eventually turned into staple offerings. Furthermore, there was Piet Hesse, who, along with his ensemble, took several of the comedies on tour through the provinces. And, last but not least, the pieces were either premiered at the Rozen-Theater and prolonged at the Hollandsche Schouwburg, or the reverse.

Rido called "Bleeke Bet" one of the merriest Jordaan comedies ever written by Bouber and simultaneously identified it as the prototype for Bouber's later plays. ${ }^{216}$ In retrospect, however, it is hard to tell what it was precisely that made these plays so merry. Their plots, to be sure, seem more dramatic than farcical. "Bleeke Bet" tells a story about Bet, who manages a green-grocery while longing to own a tavern, and about her attractive daughter Jans, who has given her heart to the sturdy but good-natured Ko. The usurer landlord van Zanten would like Jans to marry his simpleton son, and promises to give Bet her bar if she manages to change her daughter's mind. Bet is also involved in his shady smuggling operation. This is the set-up for a series of machinations and intrigues carried out by a range of local characters, before the happy ending is reached and the conflict between selfishness and young people's right to happiness is overcome. The conflict is loosely connected to class differences but is basically defined as a moral one-there are good people and there are bad people in either class - and the community represented is both split and narrow. The only reference to an outside world is to the sea: Ko signs up as a sailor for a year, is reported to have been killed in a shipwreck, but then 
returns safely; thus, although bad is done yet eventually forgiven within the residents' world, the outside world may portend risk and danger, even though things turn out better than feared. ${ }^{217}$

Since the mirth is not located in the plot nor in the kind of gags that constituted the Ensemble Solser en Hesse's trademark, it must have inhered in the spirit of the play, its use of the local idiom, its incorporation of dance and music numbers, as well as in the characterizations of local types. To capture this spirit, Wolf's wildly enthusiastic account may be of help:

This is the most genuine and sincere folk humor, the purest kind of Amsterdam popular wit one can think of! This is the Amsterdam folk in its droll routine, for better or worse, true to life's ups and downs! ${ }^{218}$

Unfortunately, all silent film versions adapted from the plays are missing, except for some clips from DE JANTJES (1922). The surviving ZEEMANSVROUWEN (1930) was originally exhibited as a silent film, but restored in 2003 by the Nederlands Filmmuseum as a sound film with a reconstructed dialogue and new music. ${ }^{219}$ The surviving sound adaptations of DE JANTJES (1934) and, most notably, of BLEEKE BET (1934), in contrast, do not seem to capture the merry spirit of the plays. ${ }^{220}$ BLEEKE BET was reported to differ from both the play and its silent adaptation, unfortunately without a further clarification of how. ${ }^{221}$ Rido judged it as a poor film and suggested that this was one of the reasons for the bad name the plays had acquired in theater history. ${ }^{222}$ One of the problems the film poses for present-day spectators is its unbalanced rhythm, with the actors breaking into song and bringing the action to a halt, whereas it was precisely the hit songs that ought to have been among the film's greatest assets, as they had been among the play's. Another issue is how to get immersed in the humor displayed in the characters. Rather than merry, in my eyes, they seem to be heartless and pathetic-Bet, played by Aaf Bouber, as well as Goocheme Sally (Smart Sally), played by Louis Davids in the silent film and by Sylvain Poons in the sound film-particularly so. The film contains some intentionally comic scenes; for instance, a scene in which an angry Jans throws the presents she was given by her beau out the window, or another in which Bet does the same with the dishes. But these scenes in no way clarify, let alone recreate, the overall high-spirited effect the story and its characters seem to have had on their theater audience at the time. They do prove, however, that the comical is both historical and local in nature, a product of its time and its place.

Nevertheless, various descriptions disclose that one of the main differences between the sketches by Solser en Hesse and the volksstukken by Bouber is the construction of the plot. With the former, a simple premise occasions a series of jocose but familiar scenes; a small inheritance, for instance, trig- 
gers a night out. As such, they are farces with an episodic structure. Bouber, by contrast, weaves a fabric of relations around typical characters based on a dramatic conflict, often a love theme, and accordingly employs a more (melo) dramatic structure. In this respect, his plays are closer to Spree's than to Solser's. Another difference is that Bouber's plots do not revolve around one central, dominant female Jordaan character: in "Bleeke Bet" the Bet character is a supporting role. Moreover, this Bet was a far cry from the good-humored, carefree, and candid character created for the stage by Lion Solser. It is my impression, therefore, that Adriënne Solser's Bet persona came much closer to her brother's creations than to Bouber's female Jordaan characters.

After 1915, Jordaan comedy became all the rage, even beyond the works of Bouber, Nap de la Mar, Spree, Rido, and Adriënne Solser. The Jordaan duo "Mie en Ko" ${ }^{223}$ continued cross-dressing in the variété tradition that had been made popular by the Ensemble Solser en Hesse. In the popular theater con70 | text, the Frascati-Schouwburg staged a Jordaan adaptation of a Flemish volksklucht (people's farce) in 1917, "Kee van de Lindengracht naar Parijs" (Kee of the Lindengracht goes to Paris), which proved to be, according to Wolf,

a play so full of life and so full of jokes that, although not always of the most refined sort, they bubble over with humor as in a farce by Bredero or Langendijk. [...] Kee is played in a truly Kee-esque manner. ${ }^{224}$

The female Jordaan character's name, by then, had become a trademark in its own right.

Volksstukken had become generic, as the literary critic Martin Liket proclaimed in 1918; however, he also criticized them for being nothing other than a revival of the archaic melodrama and reproached the authors for the lack of acuteness. None of these "volksdichters" (folk poets), according to Liket, had known how "to arouse the national spirit of our country, [...] to more candidly address our countrymen, to get a little deeper into the heart of the nation, [...] or to flog the languor of our people with the whip of his mighty word." ${ }^{25}$ Liket called for a witty and acute style, instead of the slightly moralistic but generally indiscriminate tone characteristic of the genre. This acuteness, moreover, should be widened from a local group of people-namely, the people of the Jordaan-to include the Dutch population as a whole. Liket's ideal seems to be based upon a slippage in the meaning of the prefix volks- in the two terms volksstukken and volksdichter. Seen from the perspective of genre and of the ways in which genres are used by those who create them and by those whom they address, the prefix has divergent meanings. The volksstukken drew upon keen observation and addressed the audience in an immediate, collective manner. As such, volksstukken belong to the realm of folk culture, in the 
Bakhtinian sense in which a culture derives from and belongs to the people. ${ }^{226}$ On the other hand, the term volksdichter implies a reflection upon and the condensation of material gained from observation and, by consequence, a different mode of address, which can also be inferred from Jeanne Reyneke van Stuwe's delineation of Speenhoff's craft:

Speenhoff's verses are the reflection of the Dutch people's "mood," and we admire him and are proud of our national bard who is not merely "entertaining" but can also in his austere clarity strike the most touching notes. ${ }^{227}$

The volksdichter reflects and condenses a shared spirit for the people, and, as Liket suggested, holds up a mirror to the population he sings about. As a poet, he belongs to the realm of cabaret and literature, to the arts, which address people not collectively, but as individuals. The prefix, in this case, signifies a mood or spirit prevalent but latent in the people's culture. Thus, Liket's slippage between the two meanings of volks- can be read as a sign that a gap was emerging between people's plays and popular art. Unpretentiousness was still an esteemed quality and linked to humor and genuineness, but art was now located elsewhere. 



\section{Adriënne Solser and the Dutch Silent Cinema}

\section{INTERACTION ON-STAGE AND ON-SCREEN 1896-1930}

Mixed programs in the Dutch Variété and Cinemas

When Belgian agent Camille Cerf introduced the novelty invented by the Lumière Brothers as "De Cinematograaf" (The Cinematograph) to the Netherlands on March 12, 1896, ${ }^{1}$ Adriënne Solser was not present; she was not even in Europe. She was living halfway around the world, in Pretoria, South Africa, with her children then-husband. ${ }^{2}$ Prior to her return by 1900 , so-called "levende photographie" (living photography) had become the permanent closing act of variété programs, but the initial curiosity for it was waning. ${ }^{3}$ Two years later, however, the brief dip in popularity of cinema had been overcome. A greater assortment of genres, such as comedies and trick films, more spectacular actualities and the addition of recorded or live music to the exhibition, had revived the public's interest. ${ }^{4}$ In this manner, film programs were subordinated to the rules of variété, which required, as we have seen, variety first and foremost, awe-inspiring displays of technical and artistic skill, and a capacity to entertain. Within the scope of variété programs, films used to be announced not individually but in packages, with the filmnummer (the film act) bearing labels such as "The Royal Bioscope" (at the Flora), "The American Bio-tableaux" (at the Carré), "Nieuwe Bioscope Tafereelen" (at the Casino Variété), or "Royal Circus Bioscope" (at the Circus Variété). Such labeling was still common in 1909 and the Flora even continued with this labeling until 1914. ${ }^{5}$ Thus, the habit of screening films as a variété act in popular stage programs persisted alongside the practice of exhibiting films alone, which had arisen in the meantime and became increasingly prevalent. Between 1903 and 1907 , full-length film programs had been hosted by mobile film exhibi- 
tors at fairs and festivities and had subsequently found shelter in permanent cinemas. However, the cinemas that opened in the few years after 1907 were initially unsuccessful. ${ }^{6}$ They offered continuous film screenings and allowed audiences to enter at any time, ${ }^{7}$ which presumably made the staging of live acts undesirable. They also established the habit of advertising films individually and, a little later, of identifying them with their given or translated title and an indication of their genre, such as "komisch" (comic) or "natuuropname" (a nature view). While the exhibition of films was struggling around 1910, the variété was enjoying enormous popularity. As I argued in the previous section, its attractiveness as a form of mass entertainment was largely based upon variété's overarching function of introducing and housing new popular stage genres and upon the continuous improvement and refinement of those genres in which Dutch comic performers won important positions. Adriënne Solser, indeed, frequently delivered her acts and verses in programs that included a 74 film act. ${ }^{8}$ Thus, considering the prevalence of film programming within Dutch variété, it is clear that the variété has had a more longstanding influence upon the acceptance of cinema in the Netherlands than has often been acknowledged. ${ }^{9}$ The variété also left its mark on how film was perceived during the 1910s: not merely as an autonomous form of art or entertainment, ${ }^{10}$ but also as an inextricable ingredient of popular stage culture.

In contrast to most of the permanent cinemas, which programmed film exclusively, the Amsterdam Bioscope-Theater, managed and programmed by Flora co-manager Franz Anton Nöggerath Jr., offered a mix of live acts and film screenings from its opening in $1907 .{ }^{11}$ According to Wolf, the cinema was a "familietheater" (family theater) and one of the places frequented by "the better and best public". ${ }^{12}$ Half of the program there comprised short plays by, for instance, Speenhoff's and Nap de la Mar's "Het Vrije Tooneel", ${ }^{13}$ as well as performances by renowned soubrettes such as Louise Fleuron and Cato Culp. Thus, the co-exhibition of staged and screened items initiated within the variété was transferred to places meant for the screening of films. At the Bioscope-Theater, such mixed programming remained the rule after the 191112 season, during which the Netherlands witnessed an unprecedented boom in new cinemas. ${ }^{14}$ Up until that season, the film program was announced under the label "The Royal Bioscope", that is to say, in a style inspired by the variété, in which individual films were not identified. Exceptions were made for Nöggerath's own film productions, including the coverage of the festive visit of the baby Princess Juliana to Amsterdam or the air show at Heerenveen, in May and August 1910, respectively. ${ }^{15}$ The Bioscope-Theater was nonetheless already considered to be primarily a venue for film by $1910 .{ }^{16}$ By March 1911, Nöggerath had begun to adopt the practice devised by the mobile and the permanent cinema exhibitors of featuring individual films in advertisements, of 
which DE BLANKE SLAVIN (Danish original title: DEN HVIDE SLAVEHANDEL, (White Slavery) Alfred Lind, Fotorama 1910) is the earliest example. ${ }^{17}$ It was also the first individual film to be discussed in the Dutch papers. ${ }^{18}$ Up until the mid-teens, however, advertisements rendered the names of the live acts in a larger and more eye-catching font than those of the film titles, as, for instance, the one that announced Louise Fleuron as "Neêrlands Eerste Soubrette" (the Netherlands' first soubrette) paired with the feature film DE TERUGKOMST VAN DEN DOODGEWAANDE (The Return of the Man Presumed Dead). ${ }^{19}$ Such typography may be read as an indication that, before the war, live acts were expected to attract larger audiences than films.

By 1916, the balance in the Bioscope-Theater's program had shifted towards including more film screenings than live acts, but comic performers and soubrettes were consistently featured as late as 1922. During the war years, the typography for advertising live acts and film titles changed accordingly; by 1918, advertisements switched from an equally sized to a larger font for the film titles. ${ }^{20}$ Yet, even then, the film critic of Theatergids asked rhetorically whether the full house was due to the films offered or to the appearance of the live performer: "Was it perhaps Jules Boesnach who drew the crowd?" ${ }^{21}$ Not that the films shown at the Bioscope-Theater were minor or boring, quite the contrary: their visual quality and the acting were considered to be outstanding. ${ }^{22}$ The formula of mixed programming thus remained appreciated by audiences and critics alike well after the cinema had gained the right to exist independently of the popular stage.

In its programming and advertising practices, the Bioscope-Theater epitomized continuous trends in Dutch film exhibition. These practices illustrate that, during its heyday, the Dutch variété contributed significantly to the appeal for audiences to watch films. This highlights the substantial and longstanding contribution made by comic performers to attract audiences to see films, not only at this particular Amsterdam Bioscope-Theater, but, as will become apparent, in a substantial number of other cinemas and theaters as well.

In 1910, the Bioscope-Theater was criticized for programming "too much sensational stuff", ${ }^{23}$ but, as advertisements at the time did not yet specify the title of the films, we know only that Nöggerath distributed the productions of French companies such as Gaumont and Éclair, the American Biograph and Vitagraph, the German Messter, and the Italian Cines, Ambrosio, and Itala. ${ }^{24}$ It thus concerned the usual genres of early international cinema: comic subjects, travelogues, historical and religious drama, early westerns, and so forth. It seems that the reproach was taken seriously-or that it came at the right moment-for, a decade later, the cinema's programming was, in retrospect, judged to have been "groundbreaking and trend-setting". ${ }^{25}$ Nöggerath was 
said to have introduced new genres and stars to the Netherlands and to have spread them throughout the country thanks to his distribution company. Naturally, he had also shown the output of his production company, such as, for instance, DE BANNELINGEN (The Exiles, Film-Fabriek F. A. Nöggerath 1911) by and with Caroline van Dommelen and Flora house director Léon Boedels, as well as, after 1913, productions by the company's successor, the FilmfabriekHollandia, such as the comedy TOFFE JONGENS ONDER DE MOBILISATIE (Fine Lads during the Mobilization, Filmfabriek-Hollandia 1914) by Caroline's brother, Jan van Dommelen. ${ }^{26}$ Releases of foreign productions during the early 1910 s included the Danish white-slave film with Asta Nielsen mentioned earlier, ADRIENNE LECOUVREUR (Éclipse 1913) with Sarah Bernhardt, ${ }^{27}$ Italian spectacle films like QUO VADIS? (Cines 1913), as well as the "film-mimodrama" HISTOIRE D'UN PIERROT (Story of a Pierrot, Celio 1914), and further diva films with Francesca Bertini. ${ }^{28}$ In 1916 and 1917, the cinema had box office hits with 76 (compilations of) American serials with Francis Ford and Grace Cunard, PEG VAN DEN CIRCUS (The Adventures of Peg O' the Ring, Universal, 1916) and HET GeHEIMZINNIGE MASKeR (The Purple Mask, Universal, 1916). ${ }^{29}$ This short list, however select it may appear, illustrates that Nöggerath's Bioscope-Theater, in combination with his distribution company, was one of the prominent players in the field of importing film to the Netherlands and making it attractive to large and mixed audiences. ${ }^{30}$ Nöggerath achieved this goal with a twofold strategy in which he diverged, in part, from his colleagues. In his capacity as a film distributor, he did what the others were doing and jumped on the bandwagon of featuring emerging genres and film stars; yet, as an exhibitor, he combined film screenings with live acts by well-loved comedians from the Dutch popular stage. As someone committed to both the cinema and the variété, he obviously did not believe in competition between the two, but foresaw that cinema exhibition could benefit from the support of acts by variété entertainers.

By 1912, other cinemas were copying the principle of mixing staged and screened programs. The Rotterdam Thalia-Bioscoop-Theater, run by the future cinema tycoon Abraham Tuschinski, regularly set out to feature specialiteiten (attractions) with a hoofdfilm, (a feature film), or a schlager, (a hit film). ${ }^{31}$ From then on, the practice of combining stage and screen exhibition spread further and further, for instance, to the Rotterdam cinemas Apollotheater, Imperial, Bioscope Américain, and Olympia. ${ }^{32}$ In Amsterdam, the Alberts Frères picked up the concept with their "Bioscopisch Cabaret Artistique", a 1912 program at the Grand Théâtre featuring a fiction film (with lecturing), a newsreel, and, after the intermission: "Adriënne Solser, Soubrette." ${ }^{3}$ The choice of the latter was, according to De Kunst, a lucky debut, not for her, but for Alberts Frères' mixed programming. The periodical reviewed Solser's performance at length while mentioning the films only as an afterthought. ${ }^{34}$ During the following 
Fig. I.10: Advertisement Rozen-Theater, Theatergids, 10 January 1914, 4.

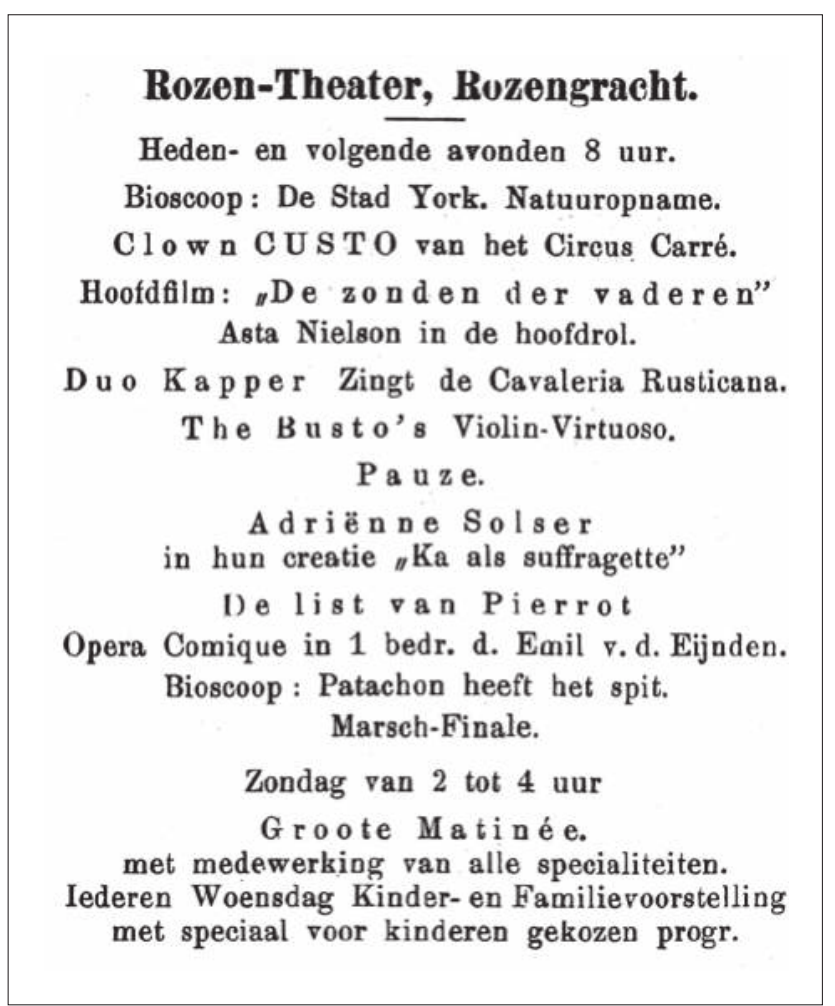

year, Amsterdam also offered a great deal of combined screen and stage programming. In contrast with Rotterdam, however, such mixed programs less frequently occurred in cinemas than in novel "cinema-variété" theaters, which were especially fit for combinations of variété and film, such as the RozenTheater, the Panopticum Theater, the Prinsen-Theater, and the Tip-TopTheater. ${ }^{35}$ The programming in these Amsterdam locales, in fact, united two trends: the tendency at the Edison Bioscope and other neighborhood cinemas to include more live acts in their film programs,,$^{36}$ on the one hand, and the trend at popular playhouses and specialiteitentheaters like the Apollo Theater, the Rembrandt Theater, the Vereeniging (also known as the Beurs-bioscoop) and Bellevue, ${ }^{37}$ to include more films in their stage programs. The Apollo Theater had long been one such specialiteitentheater, where Adriënne Solser too used to perform and where she did a character act as a peasant woman, in March 1910. ${ }^{38}$ The Rozen-Theater, in contrast, had opened in March 1913 as a "Cinema Variété Theater" 39 and used to advertise films in as specified a manner as it did its stage acts, utilizing typefaces of equal size for both. In January 1914, for instance, it announced the following program: 


\author{
Bioscope: York City. Nature view \\ Clown Custo of Circus Carré \\ Feature film: "The sins of the fathers" starring Asta Nielsen \\ Duo Kapper sings the Cavaleria Rusticana \\ The Busto's Violin Virtuoso \\ Intermission \\ Adriënne Solser in their [sic] creation "Ka the suffragette" \\ Pierrot's ruse. One-act comic opera by Emil van der Eijnden \\ Bioscope: Patachon's lumbago \\ March finale. ${ }^{40}$
}

Such parity in the advertisement of films and live acts was to be found only in the publicity of such "Cinema Variété" theaters, and then only around 1914 and 1915. Otherwise, cinemas mainly offered film programs and used to spec78 ify the film titles, the genres, and the stars, and, when appropriate, the name of the accompanying performer, yet not any further variété acts or sketches that may have been included in the program. Popular playhouses that chiefly offered live-staged entertainment, furthermore, did specify the stage acts, but summarized the films in a one-liner, thereby upholding the custom inaugurated by the variété: "And more superb films". Thus read, for instance, the line that announced the film program complementing a staged parody of "Carmen", featuring Adriënne Solser and Louis Contran, in the Beurs-Bioscoop in $1913 .^{41}$ The reviews reflected the contemporary hierarchy of cinema and variété. De Theatergids, which, its name not withstanding, closely followed developments in cinema and variété exhibition, ran an enthusiastic two-column review of the parody and the verses by the two comedians on its cover page, with only brief remarks about the two films, an Italian one about the traffic in children and an unspecified comic film. ${ }^{42}$ This was in line with the general attitude of the paper when discussing cinema before the war: it focused on the entire program and the experience of an evening out, including the extent to which the individual acts, whether screened or staged, contributed to the overall impression. ${ }^{43}$ In this instance, the impression had been dominated by the staged parody, not by the additional films.

After 1912, individual films and specific cinematic qualities were focused on more and more in advertising and reviews, ${ }^{44}$ and continuous film exhibition in cinemas expanded further. Despite these developments towards cinema as an autonomous form of entertainment, the practice of combined screen and stage exhibition was not readily abandoned in the Netherlands. On the contrary, it was maintained alongside the exhibition of films alone and even received an extra boost from the outbreak of the war in August 1914. As was said before, the supply of films, at least initially, became less secure, and 
the international exchange of variété artists was blocked. This situation yielded increasing chances for employment for both old and new generations of Dutch comic performers, who were in high demand in popular theaters, cabarets, and cinemas. ${ }^{45}$ In the fall of 1915 , in Rotterdam alone, live performances by Jules and Bertha Boesnach, Albert Bol, Louis Contran, Duo Paulus, Louise Fleuron, Jeanne Horsten, Lucien, Kees Pruis, Sophie Smith, and Adriënne Solser complemented the film programs. ${ }^{46}$ As the first war years were also the years during which the long feature film became the standard, and concepts such as the main program and the side program arose, ${ }^{47}$ advertisements evinced a tendency to promote the titles of films more prominently than before and the announcements of variété acts were gradually reduced to one-liners such as "Nieuwe specialiteiten" (New attractions). $4^{8}$ This trend persisted in subsequent years: in 1916, the Tivoli Bioscope showed a film called NEDRA along with first-rate variété acts, and Tuschinski's Thalia Theater-Cinema Royal featured the Dutch films LA RENZONI and MAJOOR FRANS (Major Frans) along with "an extensive program with live performers" ${ }^{49}$ Thus, in the course of the war years, the specialiteiten in cinemas were relegated to the position that films had once occupied in variété programs: present and indispensable, but no longer specified. Excepted from this rule were the still highly popular Dutch comic performers, as shown in the instance of the Bioscope-Theater's programming and advertising. In June 1917, Adriënne Solser was announced as a soubrette on stage following a screening of a HOMUNCULUs installment in Tuschinski's Nieuw Olympia Theater, with her name and the film's title set in more or less the same large typeface in the advertisement. ${ }^{50}$ In 1918 , however, the advertisements still featured the live entertainers' acts by name, but less prominently than they did the films just as in the case of the BioscopeTheater. ${ }^{11}$ During the early 1920 , finally, the artiste's act began to be perceived as in competition with film screenings. ${ }^{22}$ The advice was to keep the act short-only ten minutes-so that it would not lure audiences back into the variété and could instead function as a welcome relief from the eye-strain that the viewing of films was assumed to cause.

The changing relations between variété and film programming paralleled those between variété and the emerging genres in popular theater of revue, cabaret, and sketches: when the variété lost its overarching function, these emerging genres were transformed into autonomous genres of entertainment. The only ones who held their permanently exceptional position within the very dynamic field of popular entertainment during the 1910 s were Dutch comic performers. They followed exactly the path taken by cinema: from ambulant and temporary venues through the variété to permanent cinemas; and, having outlasted the variété, they continued to contribute to the popularity of those genres, including cinema. As they remained capable of attracting 
large followings, it is neither surprising nor archaic that the programming of live acts alongside the film screenings in neighbourhood cinemas and in provincial cinemas in the Netherlands continued until the advent of the sound film. ${ }^{53}$ Thus, the contribution of the soubrettes and the comedians to teaching "their" audiences to accept and enjoy cinema as a new and attractive form of popular entertainment, was not only enduring but also widespread.

The live performances in mixed stage and screen programs, whether in variété-theaters, popular theaters, or cinemas, did not interact with film screenings, and Adriënne Solser's acts were no exception in this regard. Of the pre-1920 verses in Solser's notebooks, none refers to cinema. In the "Bioscopisch Cabaret Artistique" Solser reportedly involved the lecturer Willy Mullens in her act, but the reviewer did not recount how she did, as he wanted to avoid disclosing the point of her gag. ${ }^{54}$ Neither did he mention if the lecturing itself constituted a topic in Solser's performance. He called it a nice little opening $80 \mid$ scene prefacing her act entitled "Een Verjaardagsvisite" (A Birthday Party)". ${ }^{55}$ In it, Solser as performer tells the audience that she arrived late on stage because she had been attending a birthday party where people had been doing acts. As elsewhere in her repertoire, Solser employs her own stage experiences as a comic device, rather than satirizing films, film screenings, or exhibition practices. Thus, remarkably enough, both Solser's repertoire notebooks, as preserved, and the list of her stage appearances up until 1920 furnish not the slightest sign of anticipating the turn to cinema her career would take after 1921. Adriënne Solser's involvement in film production did not spring primarily from the intent of disentangling cinema from popular staged entertainment. For her, the boundaries between the two remained blurred, and, by accompanying her films with live appearances, she insisted on keeping it that way. Regarded thus, her perception of cinema was closer to that of Dutch audiences and exhibitors attuned to mixed programming, than to that of the producers and filmmakers of the times who aspired to create an autonomous Dutch cinema.

\section{Staging Films: Lecturing}

An additional element linking film exhibition to staged events was the pervasive tradition of lecturing. In the Netherlands, it was developed during the heyday of the reisbioscopen by the ambulant cinema exhibitors out of concern with the film program as a whole. Lecturing proved to be a more flexible and entertaining accompaniment to films than what the variétés then used to offer, and it also went beyond the translation of foreign subtitles: its basic function was to frame the program and to assure the comprehension of the 
relatively loose narratives. ${ }^{56}$ Initiated by Alberts Frères, the trade name of the Mullens brothers Willy and Bernard (who was also known as Albert), the practice was widely imitated by other travelling film exhibitors, and, after 1907, it was transferred to the permanent cinemas. ${ }^{57}$ Although lecturing is known to have survived throughout the silent era, its function changed in the course of the 1910s. By 1913, a debate had arisen about the lecturer's indispensability or redundance, which stimulated Wolf to articulate the qualities of the craftsmen that were unanimously considered to be invaluable. The critic adorned the lecturers with the talents requisite for stage entertainers: "A good lecturer takes you in right away, such that you are engaged in the events from the very start." ${ }^{8}$ For the lecturer's activity, Wolf preferred the term "vertolken" (interpreting) over "expliceren" (lecturing; literally: explaining), and his favourite was Willy Mullens, whom he also called Mr. Alberts:

Mr. Alberts interprets his films sparingly, clearly, accurately, in good

Dutch, with a pleasant voice, and he is witty as well [...] He experiences the film and acts along. [...] He adds nothing and he omits nothing. ${ }^{59}$

Another good example, in his opinion, was Henri de Jong of the Bioscope-Theater, who used to reenact the actors' actions and emotions, and to speak their dialogue. "And in many films the dramatization of the action has a very strong effect on the audience." ${ }^{60}$ At the Edison-Bioscope, a former stage comedian, Charles Braakensiek, perfected this dramatizing style: "Through intonation and delivery, Braakensiek adds individuality to every part." ${ }^{61}$ Thus, the lecturer was capable of intensifying and deepening the film experience. Wolf also distinguished between lecturing for drama and for comedy, and thought the latter to be even more difficult, for with comedy, the lecturer's function was to provide variety, which, "by means of a simple, witty word, by short witty phrasing, even a single remark, stimulates a greater degree of attention". ${ }^{62}$ The accompaniment of comic films required optimal variety, restraint, improvisational talent, and ingenuity, in addition to a sense of timing. As we have seen, such craft requirements applied equally to soubrettes and comedians. For that reason, it is quite astonishing that hardly anyone from the large contingent of Dutch comic performers ventured into this profession. Reasons for this may be merely circumstantial in nature: the comedians were finding sufficient employment; they probably earned more money and enjoyed a higher status by performing in the variété than they would have as lecturers; and, most likely, they felt that an attachment to a fixed locale conflicted with the sense of independence concomitant to their profession. Considering the requirements for lecturing, however, it is unsurprising that Adriënne Solser indeed undertook the accompaniment of her films with personal appearances. Her variété expe- 
rience and career made her a natural for the job. Nonetheless, it was quite exceptional that she - as a woman — did so. ${ }^{63}$ It was also unique that she, as the on-screen protagonist, performed as the films' lecturer. Solser's simultaneous screen and stage appearances, then, may be considered another sign that she understood film as a constitutive element in popular staged entertainment: not only did she have the films screened, she staged them as well.

The advent of longer feature films, with their implied narrators and interiorised narratives, and the emergence of more self-contained acting styles, like those deployed by Asta Nielsen and the Italian divas, rendered the lecturer a redundant figure and often even an annoying one: between 1913 and 1917, the lecturer ceased to mediate between the screen and the audience and began to compete with the on-screen actions and emotions. ${ }^{64}$ As would be the case with live performers a few years later, the lecturer was no longer understood as contributing to the entire program but as distracting from and disturbing the

82 individual film experience. Only few knew how to unify film and lecturing:

the task of the actor [who was previously a lecturer] became more and more that of an author as well, in order to convey in the vernacular the situations indicated in the descriptive titles and to bring the characters to life for the audience. ${ }^{65}$

In first-class cinemas, therefore, the lecturer was gradually replaced by live music. Nevertheless, the lecturer continued to be accepted and appreciated in neighborhood and folk cinemas, which otherwise showed the same films as the so-called "elite" cinemas but just a few weeks later ${ }^{66}$ as well as the genre of comedy. In 1918, the lecturer for comic films was compared to the contemporary cabaret-artist: "Both are entrusted with keeping up the audience's spirit and, moreover, with making sure it does not evaporate or fade." ${ }^{67}$ It was stated explicitly that the lecturer deserved "the honorary title of 'voordrachts-kunstenaar' who is able to get deep into the heart of the people's soul with an apt adage or a witty remark." ${ }^{68}$ The lecturer for comedies was expected to be volks in both senses of the word: he constituted a native element in a predominantly imported film program, ${ }^{69}$ he was of the people, and simultaneously knew how to condense and articulate certain collective experiences for the people. By 1924, Amsterdam had only two lecturers left: at the neighborhood cinemas the Edison Bioscoop and the Apollo Theater. ${ }^{70}$ In the latter, Herman Vas-Diaz entertained the patrons with a combination of acting and speech:

Night after night he suffers anew with the shattered ingénue, experiences the sharp remorse of the criminal, and revenges the slur upon the family's honor. He is the stand-in for the entire cast, and he does not 
play his part by heart, but from the heart. Inspired by that prompter's box, he adds a shine to the silent shadows on the wall and outclasses the intertitles with his brilliant eloquence..$^{71}$

When Adriënne Solser took up a similar combination of acting and animated the story by a live accompaniment to the farcical films in which she starred during the 1920s, she therewith carried on and highlighted a tradition in Dutch cinema exhibition that continued to find recognition in the context of popular cinema.

Viewed from a perspective centered on films and on film production, the history of the lecturer in the Netherlands and his confinement to neighborhood cinemas and comic genres is one of the stories of the cinema outgrowing its old context of fairs and staged popular entertainment and instead developing into something independent of all accompaniment, which constituted an ideal it had been approaching since the mid-teens and that it fully reached once sound film was introduced. From such a classical point of view, however, Adriënne Solser's career in Dutch cinema-neither the films she made, nor the success she achieved with them-cannot be accounted for, because then it all seems anachronistic, or at best anomalous. If, however, the vantage-point of film exhibition and programming is factored in, then the history of on-stage accompaniment of films, comprising comic performers and lecturers alike, makes the co-existence of two forms of cinema in the Netherlands during the 1910 an 1920 s apparent, namely film as an element of the popular stage and film as a self-contained form of entertainment or art. It is precisely this ongoing co-existence of popular cinema and popular theater that conditioned Adriënne Solser's career as an actress, as a filmmaker, and as someone who accompanied her own screenings with live performances.

\section{Dutch Comic Film Production until 1920}

In contrast with what was written in the contemporary press during the early 1920s, comic film production existed in the Netherlands long before Alex Benno and Adriënne Solser began to make farces in the 1920s. Comic film production in the Netherlands included early shorts, inserts in revues, and experiments in mixing film and theater. During the heyday of the ambulant cinema, comic shorts were produced that indeed highlight the interrelatedness of Dutch popular stage and silent cinema. Geoffrey Donaldson's research and publications during the 1980 os in the Dutch film monthly Skrien have resulted in his invaluable yet saddening-for most of these films are "missing", as he put it so evocatively-filmography of Dutch silent fiction film. His research 
reveals that, up until 1910, Alberts Frères were the most prolific among Dutch film producers and that their production aimed predominantly at amusing the audience..$^{72}$ As ambulant film exhibitors, they shot short comic sketches about local topics, offering audiences the pleasure not only of laughter, but also of recognizing the familiar. The films' titles usually bore an indication of the scene of the action, like EEN INTERESSANT KOFFIEPRAATJE TUSSCHEN VERSCHILLENDE CELEBRITEITEN VAN ROERMOND (An Interesting Coffee-Table Gossip Between Various Roermond Celebrities, Alberts Frères 1904) or DE MÉSAVENTURE VAN EEN FRANSCH HEERTJE ZONDER PANTALON AAN HET STRAND TE ZANDVOORT (The Misadventure of a French Dandy Without Trousers on the Beach at Zandvoort, Alberts Frères 1905). ${ }^{73}$ This was certainly not a characteristic of Alberts Frères' films alone, but also of those by other ambulant cinema exhibitors of the time. As was the case with the Jordaan genre in the variété and the popular theater, local specificity apparently formed a favor-

84 ite component of Dutch conceptions of what was comic in a film. Some of the film titles were even in the regional dialect; in this case, that of the southern province of Limburg: E FIEN HIERKE VAAN "MESTREECH VEUROET" (A Fine Gentleman of the Club "Mestreech Veuroet", Alberts Frères 1907). ${ }^{74}$ Just as with the Jordaan sketches and plays, this type of film may be considered as instances of addressing local audiences in their sense of collectivity, something that will subsequently appear as a recurrent aspect of Dutch comic film and theater production.

A further important early impulse to Dutch filmmaking came from the world of the variété, in which ideas from abroad were quickly imported and copied and in which money was available for experimentation. ${ }^{75}$ Because variété aimed at amusing people and making them laugh, it often included comic film production. Frits van Haarlem Jr. of Circus Carré and, as mentioned earlier, Franz Anton Nöggerath Sr. and Jr. of the Flora, were active in filmmaking. They produced and screened not only actualities or local views, but comic items as well, most notably as inserts in revues or in interaction with variété acts. Van Haarlem produced an actuality insert in the revue "Amsterdam Bovenal" (Amsterdam Above All) of 1903, and both actualities and fiction in "Koning 'Kziezoowat in Amsterdam" (King Iseesowhat in Amsterdam) with Louis and Rika Davids in 1906. ${ }^{76}$ Likewise, at the Circus Carré, Louisette and Chrétienni tried their hand at it in their 1910 acts "Van Boerin tot Artist" (From Peasant Girl to Artiste) and "Kees en Trijn" (Kees and Trijn), using a self-made comic chase film as an introduction to their live act. In the following six years, Louisette and Chrétienni travelled with the act to Germany, England, and the USA, ${ }^{77}$ and the interaction between what happened on-stage and on-screen was received as a novelty in each country. "[T]hose people from Amsterdam introduce a variety number that is entirely new to English audiences," ${ }^{78}$ wrote 


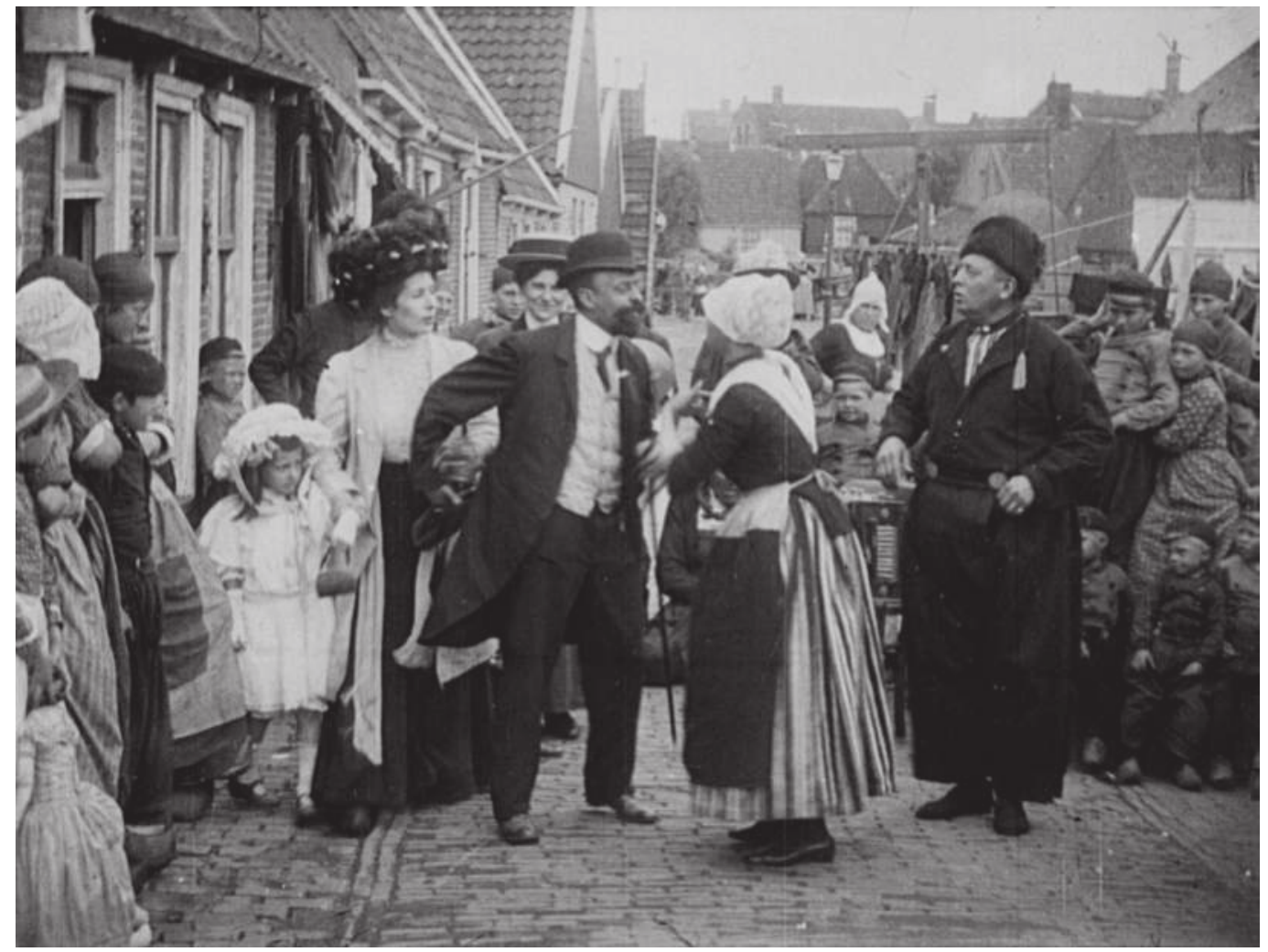

Fig. I.11: Chrétienni and Louisette in VAN BOERIN TOT ARTIESTE.

a British paper, and in New York the act was acclaimed as "something entirely away of what America has seen". ${ }^{79}$ The film parts have been preserved at the EYE Filmmuseum, and reviews describe the further stage act.

The film introduces Kees and Trijn from the traditional fishing village of Volendam. Much to Kees' dismay, Trijn is convinced that she has the talent to become a variété artiste. While doing a local dance in the streets, she is, indeed, "discovered" by a showman. Kees tries to hold her back from leaving the village, but in vain: using every means of transport that crosses her path, Trijn rushes to the city and goes abroad, entering a particular theater in each place. Kees, who is hot on her heels, has trouble gaining admittance but eventually manages. Each time, the shots of the entrance of the theater match the place where the actors were performing. Kees' and Trijn's stormy arrivals in the room were staged live. Once on stage, Chrétienni used to impersonate various conductors, while Louisette was "doing a Spanish, French or Italian soubret [sic]" and earning "vociferous plaudits" ${ }^{\circ 0}$ for the dances she performed.

The filmed parts allowed for the inclusion of cinematic devices common to 
early comedies and other shorts, such as the chase, the use of modern means of transportation, and a slapstick-like scene for Chretienni to outwit the personnel who were trying to prevent him from entering the theater. Another stylistic, and quite intriguing, device was provided by takes that included actual observers of the scenes being shot. In such takes, bystanders do not just watch the action but are staring straight into the camera, as if curious about what is taking place behind it or beyond the shooting. On the one hand, the device produces an impression of contingency and actuality of the shootings, and, on the other, it links the awestruck audience watching the screen to the awestruck people on the screen. Spectators in the room are connected to spectators in front of the camera, thus establishing a sense of commonality. The same device was-willingly or not—employed by Adriënne Solser in her films, had much the same effect. Additionally, Louisette and Chrétienni were among those of Solser's predecessors who used film to expand their stage acts. ${ }^{81}$

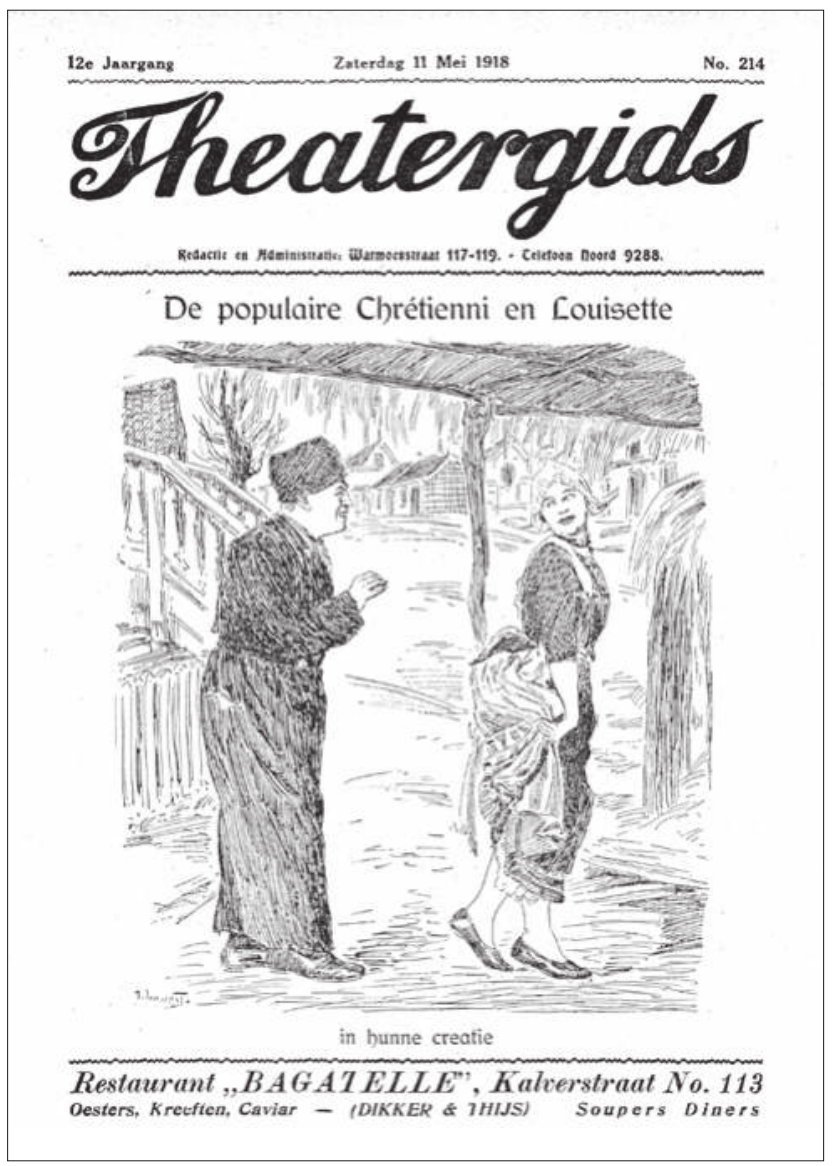

Fig. I.12: Caricature on the cover of Theatergids, 11 May 1918. 
In addition to such formal aspects, Louisette and Chrétienni's act was also related to Solser's work thematically. First, there is the woman who aspires to work in the variété and who insists that she has the talents to do so. Second, this is used for motivating the farce. In contrast to Bet, however, Trijn does not engage in long debates and competitions with her selfish lover, but just goes for it, metaphorically and literally. As such, she impersonates the enterprising young woman of the time, whereas Bet seems to belong to the earlier generation of women who were wise enough not to be fooled by men, yet incapable of escaping from them and of setting their own rules. Third, both acts dealt with relations between men and women, although one in a more lighthearted manner than the other. While their problems with men seem to be generally similar, they do diverge significantly in their responses to them, most notably in relation to the contemporary issue of the women's liberation movement. Earlier, and in a much more explicit fashion than Solser, Louisette and Chrétienni had taken up the theme of the "vrije vrouwen beweging" (free women's movement) in their 1908 farce "Amsterdam in de Blommetjes" (Amsterdam flowering). ${ }^{82}$ Written by Rido, this farce parodied women's pursuit of participation in the municipality council of the capital, but, as far as can be gathered from the surviving song texts, ${ }^{83}$ it did so in a remarkably mild way. The mise-en-scène by Frits van Haarlem included women from the room booing Chrétienni's disparaging songs about women, while cheering Louisette's counter-actions and proposals for solving the city's problems, thus soliciting support among the audience for the case made by the "free women". ${ }^{84}$ The reviews, moreover, underscore the impression that, despite the parodic intent, the women's endeavor was not completely ridiculed; that is to say, it was saved by the charming Louisette who led it.

Franz Anton Nöggerath Sr. and Jr. experimented with producing films of their own within the variété context much more consistently and extensively than Frits van Haarlem. ${ }^{85}$ Shortly after the elder Nöggerath had founded a distribution office in 1897, he embarked upon the shooting and production of films that were screened in the Flora programs as parts of the "The Royal Bioscope" act. After the premature death of Nöggerath Sr. in 1908, the business was productively carried on by his son, who had enjoyed an education as a cameraman and garnered further experience in the film business during his eleven-year stay in England. ${ }^{86}$ In a brochure published to mark the opening of his new studio, ${ }^{87}$ Nöggerath Jr. pointed out that his father had already shot a number of comic films on the rooftop of the Flora building, including DE MUIS (The Mouse) and HET SKAATSPEL (The Game of Skat), both dated to 1899 by Donaldson, by 1902, when a fire destroyed the Flora building and all their previously made films, ${ }^{88}$ The first starred a mechanical mouse stirring up a women's meeting, while the second was a filmed act by the German comedian 
Dietrich Ulps. Between 1909 and 1913, when production was resumed, more than twenty films were produced by the Film-Fabriek F. A. Nöggerath, half of which were drama, ${ }^{89}$ the other half comic shorts.

The real take-off of comic film production at Nöggerath's, however, seems to have occurred in 1911, with an insert in the revue "Amsterdam op hol!" (Amsterdam Stampede!) ${ }^{90}$ with the life and soul of the Flora revues, Isidore Zwaaf. ${ }^{91}$ The author of the revue, Rido, may have been aware of Chrétienni and Louisette's act "Kees en Trijn", but he later recalled that he got the idea for it from a chase film from the "Royal Bioscope" program in which a crowd pursued someone through the city who had all sorts of crazy adventures. ${ }^{92}$ Whatever his model may have been, Rido copied the device, with, in his own words, the following result:

The revue opened with everyone upset because the leading man, Isidore Zwaaf, had not yet arrived. At a loss, stage director Boedels made a phone call to Zwaaf at home. Next, a film clip showed Zwaaf taking a nap on his sofa. Drowsily he picked up the phone. He appeared to believe that the revue was to be staged only the following evening. In haste he got dressed and dashed out the door. While underway, all sorts of accidents happened. He ran into a ladder, was chased by a ferocious dog, and got raised up by a draw-bridge. In his desperation he "accidentally" stole a car, and was pursued by its owner, the police, and a growing crowd. (...) Eventually, he dashed into the Amstelstraat, where, at the entrance of the Flora, he was anxiously awaited by the manager, the stage director, and some ticket-takers. With the film finished and the film screen vanishing, Zwaaf in person and out of breath came running into the theater, encouraged by the entire troupe. He dashed into the auditorium right through the audience and rushed onto the stage, where he was welcomed by loud cheering, a cheering in which the audience readily partook night after night. ${ }^{93}$

As in Chrétienni and Louisette's combined film and stage act, the comic chase film and the following live arrival expanded the range of ways in which the variété and revue actors used to grab the audience from the very beginning. An additional important effect was that the "fake" presence of the on-screen character, followed by the live presence of the character on stage, was experienced as funny in its own right: "the combination of appearance and reality is most droll", ${ }^{94}$ a reviewer noted about Zwaaf's act.

Confronting the actors on screen with their live presence was already a familiar comic device since the 1909 Bioscope-Theater premier of a combined stage and screen play called " $999+1$ ", another Nöggerath production from a 
script by Rido. ${ }^{95}$ Donaldson concluded from the reviews that the film inserts were an integral part of the play and that the stage characters commented on the behavior of the characters in the film inserts. ${ }^{96}$ Although it cannot be established whether Adriënne Solser also commented on the characters of her films during the screenings, it is tempting to imagine that she did; even if not, she exploited the recurrent comic device of a simultaneous on-screen and on-stage presence further. Despite its recurrence, however, each time that the device was deployed, it was embraced as a novelty. In 1914, it was even given a name, as if what was at stake were a new genre, "filmspel" - a film-play-and was reported to have been created by the French comedian Max Linder. ${ }^{97}$

In addition to his experiments with theater, film, and revue inserts, ${ }^{98} \mathrm{Nög}$ gerath produced some comic shorts with Zwaaf, with the comic operetta duo Kelly and Lageman, and initiated a series with the comedian and future star of the Ter Hall and Bouwmeester revues, Johan Buziau. ${ }^{99}$ With these 1912 productions, some of which were also released in other European countries, Nöggerath seems to have aimed at following another practice common abroad, namely, making use of the fame and appeal of popular stage comedians to draw large audiences to see comic film productions. After he resumed film production in 1913, however, this strategy was applied only incidentally by film producers during the rest of the decade. One farce with variété-artisten was made in 1917, Willy Mullens directed a comic short with Buziau and Roosje Köhler-van Gelder in 1918, and Maurits Binger and Louis Davids made a fulllength comedy featuring Davids, Margie Morris, and Lola Cornero in 1919. ${ }^{100}$ Comic film production in the Netherlands, more so than dramatic film production, which enjoyed a temporary upturn during the war, remained an incidental affair throughout the decade. This is all the more astonishing given the comic potential present at the time on Dutch popular stages and considering the enormous popularity of Dutch comic actors and folk plays. It is even more strange in view of the early and ample employment records in dramatic film of stage actors such as the Bouwmeesters, the Van Dommelens, and the Chrispijn family, who had led the way from stage to screen for actors. Already in 1912, Louis Bouwmeester had defended such a career move against its opponents by stating: "A stage performance is ephemeral, a performance in cinema lasts forever." ${ }^{101}$ And, finally, the minimal amount of comic film production is curious in light of the relatively prolific production of films during the war, most notably by the Filmfabriek-Hollandia. ${ }^{102}$ The filmmakers attached to this studio, however, preferred to make films that did not "express much optimism", suggesting that the Netherlands "is a gloomy place where evil, usually in the form of a compelling emotion or forbidden passion, is ruthlessly punished", as Peter Delpeut aptly summarized Dutch drama production of the time in his introduction to Donaldson's filmography. ${ }^{103}$ Although Delpeut 
insisted that this is the predominant impression given off by the material that has been preserved, Donaldson's research into missing films does not really alter the general picture vis-à-vis comic film. He listed only five further comic productions, of which the three MIJNTJE EN TRIJNTJE (Mijntje and Trijntje) shorts of 1913 and DE VERWISSELING ONDER HET BED (The Mistake under the Bed) of 1914 were made by Louis H. Chrispijn Sr., and "de gelegenheidskomedie" (topical comedy) TOFFE JONGENS ONDER DE MOBILISATIE (1914) ${ }^{104}$ was directed by Jan van Dommelen. None of the featured actors were known from the popular stage.

\section{Reviewing Interaction Between Stage and Screen}

Through the course of the decade, cinema, just like cabaret, the volksstukken, 90 | and the revue, had abandoned the umbrella of variété and firmly established itself as an autonomous mode of entertainment by offering a range of largely imported material. Initially, imports were chiefly European, but, after the middle of the war, American-made films became much more prominent. In this respect, cinema assumed the function of offering non-Dutch entertainment that had previously been fulfilled by variété. Simultaneously, it developed into a volkskunst, in the sense that it was an art for the people but not of them. This was the formulation of Max van Wesel, who, in 1924, articulated his main thoughts in almost the same phrases as those employed by Reyneke van Stuwe with regard to cabaret and by Liket concerning his ideal volksstukken:
film is a new, genuine work of art [...] There is an intense exchange between art and the people, with the creative artist as the medium who, after all, is himself a child of the time, and who is deeply rooted in the animated life of the people. [...] Film offers us a pure projection of reality. ${ }^{105}$

Thus, by the early twenties, in Dutch conceptualisations of developments in popular entertainment, cinema had travelled the same route as had cabaret. As performing arts, they were connected by the increasing prominence of the mediating function of the artist who had created the text that was delivered, in other words, the artist "behind" the art, not the artiste who performed it. Moreover, cabaret had become, and cinema was still developing into, a form of entertainment in its own right. As did many of his contemporaries, Max van Wesel too believed that film art should free itself from the influence of theater and literature and develop its own potentialities in order to reach full maturity. ${ }^{106}$ Even if this were still a mere prospect, cinema had undeniably left the 
realm of the art of the people and entered the sphere of an art for the people by 1920. One of the factors involved in this process was the conception of what Dutch cinema could or should be. During the war, a rather pretentious film production had been established by the film directors Binger and Frenkel that aimed at making Dutch artistic films for an international market. However prolific it may have been for a few years, it did not achieve continuity. The reasons for these developments adduced by historians include the increase of production costs together with the lack of capital in the Netherlands for film production, ${ }^{107}$ as well as the initial neglect of, and the subsequent apathetic response to, the worldwide shifts that had taken place during the war on all levels of film production and especially of distribution. ${ }^{108}$ My analysis of the conceptions of cinema as an art for the people versus a popular and staged entertainment of the people, and the way in which such divergent conceptions contributed to cinema's popularity in the Netherlands, allows me to point out a further reason for the decline of Dutch film production. Filmmakers failed to make use of the amply available and well-liked comic talent of those who wrote for and peopled the popular stage, for the latter was considered to be too Dutch, too much of the people, and too unpretentious. So one may say that Dutch film production of the 1910s was not only a victim of the dearth of investments and professionalism, but also of the widening gap between the popular stage and the performing arts. It failed to understand how it could become popular with its own compatriots.

Dutch cinema and the popular stage were aliens by the end of the decade. I have argued, however, that this is far less true if the vantage-points of programming and exhibition are factored in and the interaction between staged entertainment and filmmaking is taken into account. In the sphere of programming and exhibition, cinema remained part of Dutch popular culture. Although no longer a necessity, the Dutch element in film exhibition represented by the lecturer was maintained within particular contexts, especially those of popular cinema. The same holds for the practice of mixing live acts and screenings in cinema programs: while no longer indispensable, Dutch comic performers continued to appear in cinemas and to draw a considerable portion of the audience. A significant impulse for filmmaking, and most notably for the making of comic films, had come from variété programmers. Within the variété, films appeared as parts of live acts and as inserts in revues; in other words, as an ingredient and a means to expand stage acts. As long as live acts and revues remained popular, long into the 1920s, film never entirely lost this function, despite its otherwise established autonomy. It is through these sites that the lines of a tradition of Dutch comic filmmaking can be retraced, which provides an appropriate historical context for the films that Adriënne Solser made and the manner in which she presented them. 


\section{DUTCH COMIC FILM DURING THE 1920 S}

During the 1920s, comic film at last became a vital part of Dutch film production. This was largely due to two producers-directors: Alex Benno and Adriënne Solser. In total, the two of them were responsible for ten percent of the 100 feature films made in the Netherlands during the decade. Incidentally, two former Hollandia directors, Maurits Binger and Theo Frenkel Sr., had made comedies as well in both Benno and Solser were often involved, as distributor and actress, respectively.

\section{Adriënne Solser as an On- and Off-screen Film Performer}

The first screen appearance of Adriënne Solser was in a two-act film made in

92 | 1921 by Alex Benno. The short marks the beginning of a four-year collaboration between Benno as a film director and Solser as a farce film actress. They had known each other for a long time: when Benno celebrated his jubilee as an impresario in 1909, Solser was among the artist friends who contributed to the festive evening. ${ }^{109}$ Aside from that, they were the same age (forty-eight in 1921), both descendants of a showman's family touring the fairs, and were both Jewish. They had professionally matured in the variété and their careers had been modified by the dynamics in the entertainment field taking place over the preceding three decades. At this point, they set out together for a new future in the cinema and what really connected them was a shared wish to revive Dutch film production in a more popular direction than had yet been attempted. In contrast to Binger and his associates, who made visually stylish films based upon renowned literary works and theater plays, Benno and Solser embraced Dutch popular culture wholeheartedly and aimed at producing pure entertainment. For Benno, one goal was to generate substantially more capital than Binger had been capable of: "If it was not an achievement in terms of art, it surely was financially." ${ }^{110}$ As for Solser, she expanded her art of entertaining into the new medium, but, as always, she continued to serve the audience, which had sustained her fame and acclaim. Even in a rather disparaging review of one of her films, the critic admitted scornfully: "Adriënne Solser has quite a bit of comical talent and makes the audience, her audience, laugh." ${ }_{111}$ From the perspective of Dutch film production, such an overt choice for the commercial and the popular was unconventional in those years. From the perspective of a soubrette who drew audiences to film screenings, however, Solser's step onto the silver screen made perfect sense: it merged her popularity with that of the cinema, to the advantage of both. 
Fig. I.13: Alex Benno. Anonymous photographer.

According to the contemporary press, ${ }^{112}$ it took Benno eight hours to complete his first joint effort with Solser, DE DROOM VAN HADT-JE-ME-MAAR (The Dream of "If-You-Only-Had-Me"). Most notably, the short testifies to the popular stage background of both the director and the actress. With it, Alex Benno commented upon a topical issue: in April 1921, the notorious Amsterdam tramp Hadt-Je-Me-Maar had been nominated as a candidate to the municipal council by a group protesting the recently introduced election law, and, much to the authorities' dismay, he obtained enough votes to be entitled to a seat. ${ }^{113}$ Arrested once again for drunkenness and vagrancy, he was never able to assume his office. This true story stirred Benno to his DREAM, which was released in cinemas that very month. Hence, the little comedy dealt with a local and topical event, just as comic films or acts in the cabaret or the revue might have done.

Hadt-Je-Me-Maar (played by himself) dreams that he tours the city before taking up his duties at the Municipal Council. Once installed, he is warmly cheered by a group of female admirers headed by his landlady, played by Adriënne Solser. The eight-minute clip preserved at the EYE Filmmuseum shows Solser as a street version of the type of the Komische Alte, a hefty, boisterous, grey-haired woman. The contemporary press claimed her performance an adroit one: "Mrs. Adriënne Solser aptly portrayed the keeper of the hotel where Hadt-je-me-maar would lodge."114 Her part included applauding, encourag- 
ing the hero, and displaying a contagious delight. According to the critic, the comic effect was heightened by intertitles in idioms of the Jordaan. Thus, the setting, character, and language of Adriënne Solser's first film appearance were completely in tune with her variété and revue character acts built around the Bet persona.

In an informative publication about this often neglected filmmaker, Marcel Westhoff has stated that Alex Benno, the pseudonym of Benjamin Bonefang (1872 or 1873-1952), had reached a decisive moment in his career by the time he made this film. ${ }^{115}$ For over two decades, he had proven himself a highly versatile background figure in the Dutch variété and film business. He had authored popular literature and plays; appeared as a character comedian and wrestler in the variété; and acted as a mobile cinema exhibitor, camera assistant, ${ }^{116}$ impresario, and film lecturer before joining the Filmfabriek-Hollandia soon after its foundation in 1912. For seven years, he remained with 94 Hollandia, the most professional studio in the Netherlands, as a property man and production assistant. Westhoff, rather temptingly, argues that Benno may have been involved in script-writing and directing as well, particularly of the rare comic shorts that diverged from the studio's usual output. ${ }^{117}$ Donaldson's meticulous research indeed permits this possibility in one particular instance, but he ascribes the other comic shorts mentioned in Westhoff's essay to Louis Chrispijn Sr. ${ }^{118}$ When the Hollandia studio ran into severe financial and organisational difficulties, Alex Benno initially planned once again to seek employment as an impresario in the exhibition branches of the variété and the cinema. ${ }^{119}$ His career, however, took an additional turn: Benno became not only a major distributor, but also an energetic producer and director of fulllength farcical film in the Netherlands.

Although Benno's career as a filmmaker was by no means limited to his collaboration with Solser, the foundations for their further itineraries in cinema were laid jointly. Between 1921 and 1924, Benno directed and produced four films for three different companies that he either owned or in which he was involved: DE DROOM VAN HADT-JE-ME-MAAR (1921) for his own company Satiriek Film Cie., KEE EN JANUS NAAR BERLIJN (Kee and Janus Go to Berlin 1922) and the screen adaptation of Bouber's BLEEKE BET (1923) for his Actueel Film, and KEE EN JANUS NAAR PARIJS (1923) for the Dutch Film Co., which he, together with David Sluizer, established on the ashes of the Filmfabriek-Hollandia. ${ }^{120}$ Meanwhile, with Fred Penley, Benno also distributed two more adaptations of popular stage plays for Actueel Film: Bouber's DE JANTJES, for which Benno and Penley had bought the rights and commissioned Maurits Binger and B. E. Doxat-Pratt to direct for the Filmfabriek-Hollandia; and Marius Spree's MotTige JANus (1922), directed by Binger and the final Hollandia production. ${ }^{121}$ Actueel Film was both a production and a distribu- 
tion company, and was able to retain the distribution rights to these and the remaining Hollandia films after the bankruptcy of the firm in $1923 .{ }^{122}$ Among the films mentioned thus far, Solser was involved in all but BLEEKE BET and MotTige JANUS. Benno was the first in the Dutch film industry to undertake and to capitalize on screen adaptations of the immensely popular volksstukken, and he dared to cast in the films many of the popular stage actors who had played the roles in the theater productions. In doing so, he counted on the qualities and the talents that constituted Dutch popular theater. Throughout his career, he returned to volksstukken again and again. ${ }^{123}$ When he was asked how this choice had come about, he referred to his first feature-length film with Adriënne Solser, KEE EN JANUS NAAR BERLIJN: "It was quite a success. Because of this film I confined myself exclusively to the making of folk plays." ${ }^{124}$ Before that, he had already had a profitable experience in distribution with DE JANTJES.

As I noted above, the first adaptation of DE JANTJES to cinema had been commissioned by Benno and Penley from Binger and Doxat-Pratt, who had all collaborated at the Filmfabriek-Hollandia. In an attempt to go international after the war, Binger and his associates had made a number of so-called "Anglo-Hollandia" productions, chiefly with British actors, adapted from British stories, and under British direction, which were judged to be quite boring by the Dutch press. ${ }^{125}$ When Benno announced his plans to have DE JANTJES adapted to the screen, the initiative received an enthusiastic welcome for presenting a "real Dutch film". ${ }^{126}$ Concerning the final result, however, the newspapers-with one notable exception-were sparse with praise, whereas the film papers, driven to keep morale high in support of the Dutch film industry, stressed that the mise-en-scène and the camera and production values were excellent and that the film lived up to the original atmosphere and qualities of the stage play. ${ }^{127}$ The kinship to the stage performance was attributed in part to the appearances in the cinema adaptation of several of the stage actors, including Beppie de Vries as Blonde Greet and Louis Davids as one of the Jack-Tars. ${ }^{128}$ Adriënne Solser played a supporting role: she would never be forgotten, if the periodical Cinema en Theater may be believed, for her part of Na Druppel, the female half of a duo of Amsterdam street singers. ${ }^{129}$ A further merit pointed out in the reviews was the "musical illustration" with classic tunes from the play written by Davids and Morris. Neither the press reviews nor Donaldson specify whether Adriënne Solser or any of the other actors was personally involved in the live accompaniment at cinemas. Nevertheless, the sing-a-longs created "an interaction between the film actors on the screen and their audience certainly no less direct than the one in the theater". ${ }^{130}$ Thus, both the cast and the accompaniment cued the audiences to the staged performances and this significantly contributed to the film's success. 
The film itself is largely missing; only a few short fragments have survived in which Solser appears in one dramatic and two comic scenes. The fragment of the dramatic scene is too short to reveal very much about Solser's part, but it does suggest that Na Druppel's looks very much resembled those of Hadt-JeMe-Maar's landlady. ${ }^{131}$ The scene is set in a pub and deals with the effects of the rumor that Dolle Dries' fiancée Blonde Greet has been unfaithful to him: Dries gets into a fight and is taken to jail. According to the plot summary in Donaldson, it was Na Druppel and her husband De Mop who were involved in spreading the false rumor. ${ }^{132}$ Just as in Bouber's "Bleeke Bet", then, neither the older nor the younger female characters seem to be particularly friendly. The old woman acts rather nastily and the younger one naïvely. In my earlier discussion of Bouber's plays I pointed out how such traits were understood to constitute the characters' highly esteemed truthfulness to life. However, neither nastiness nor naïveté accorded with the Bet persona Adriënne Solser had 96 developed, nor with the film appearances she already may have had in mind and would later create for herself.

The surviving comic fragments from DE JANTJES indicate more about Adriënne Solser as an actress. One of them shows her to have been a first-rate scene-stealer, outplaying every other actor within the frame. Deprived of voice and text, Solser's strategy for dominating the screen was entirely physical: by ample gesticulation and a quite surprising array of jumps and other movements, she utilized both her soubrette skills and her physical massiveness. She simply filled the screen with a centre-stage presence, recalling the stage entertainer who must pique her audience's attention immediately and sustain it throughout the act-all by herself. Although it cannot be ascertained whether Solser's act belonged to the original stage play or was added on in the screen adaptation, ${ }^{133}$ this particular scene relates to the once-common practice of filming variété acts. With regard to Solser as a film actress, the clip strongly raises the suspicion that she was easy to work with only for a producer or a director who would let her have her way.

To a certain extent, the occurrence of such a scene also lends support to Ansje van Beusekom's argument concerning the assimilative capacity of cinema, which, in the sound era, would incorporate the Dutch variété and revue. ${ }^{134}$ As I have contended, however, soubrette acts, revue, popular plays, and cinema coexisted throughout the 1920s. The reviews and plot descriptions of DE JANTJES, for the most part, echo those of the original play, which had been structured around a dramatic and non-topical plot. The use of singa-longs belonged among the features of the theater genre. In this sense, the silent version of the film seems to have held a position different from that of the sound adaptation: while taking over early traditions of comic filmmaking, such as the filming of variété acts, it was related less closely to the con- 
ventions of the revue than to those established by Herman Bouber's popular plays.

Quite in contrast to Bouber's plays and their cinematic adaptations, Benno's subsequent films, KEE EN JANUS NAAR BERLIJN and KEE EN JANUS NAAR PARIJS, were centered on the female character of Kee Mol, "the true Jordaan woman from the Willemsstraat", ${ }^{135}$ and her husband Janus, played by Kees Pruis in the Berlin film and by Piet Köhler in the Paris sequel, both stars from the popular stage. ${ }^{136}$ The two films were written and directed by Alex Benno and featured Adriënne Solser as the leading actress. Benno recalled in 1926 how the idea had come up after he had met two genuine Jordaan inhabitants on a Rhine boat and observed their inappropriate manners yet uninhibited enjoyment. ${ }^{137}$

In the Berlin film, Kee and Janus win a little money in the local lottery, which, because of the German currency crisis of 1921 and 1922, allows them to travel to Berlin and spend extravagantly. They behave like quirky provincials whose conduct in the wider world leads to silly and adventurous situations, a motif likewise employed in the Paris sequel. In the latter, Kee and Janus visit the city of light for their honeymoon after having celebrated their marriage at home. With these simple storylines, Benno and Solser revived for the screen the formula launched on stage by Solser en Hesse, who used to spin out a thin thread of silly and exuberant situations featuring a Jordaan couple, with the female half as the focal point. This was not the only characteristic they took from Solser en Hesse's stage farces. The currency question, for instance, brings to mind the motif of the sketch "Ga j'mee de erfenis delen van Oome Hein?," in which an inheritance from an uncle prompted a tour of Amsterdam nightlife. Kee and Janus do indeed visit a cabaret in Berlin and the Moulin Rouge in Paris, and each of the films contains a scene with a Jordaan dance as well. In addition, the treatment of topics very much resembles the way the verses Adriënne Solser had earlier delivered: they were not the point of the film, but formed a pretext for the couple's adventures. The condition of recognition for creating a sense of commonality between what was shown on screen and the audience, which was pivotal in the Jordaan genre, was likewise fulfilled this time around. Dutch audiences were said to be familiar with Berlin and thus the site where the action of the film took place. ${ }^{138}$

The Paris sequel was partially situated in the Jordaan. ${ }^{139}$ More importantly, sing-a-longs, often delivered live by Adriënne Solser herself, added to the establishment of a sense of commonality during the screening. The KEE EN JANUSfilms seem to have differed in one notable respect from the old variété acts and plays in the Jordaan genre: they lacked dramatic moments, the notorious tear that ought to come along with laughter. Both the critics and the audiences, however, recognized the genre with its comic situations and its folk humor. ${ }^{140}$ 


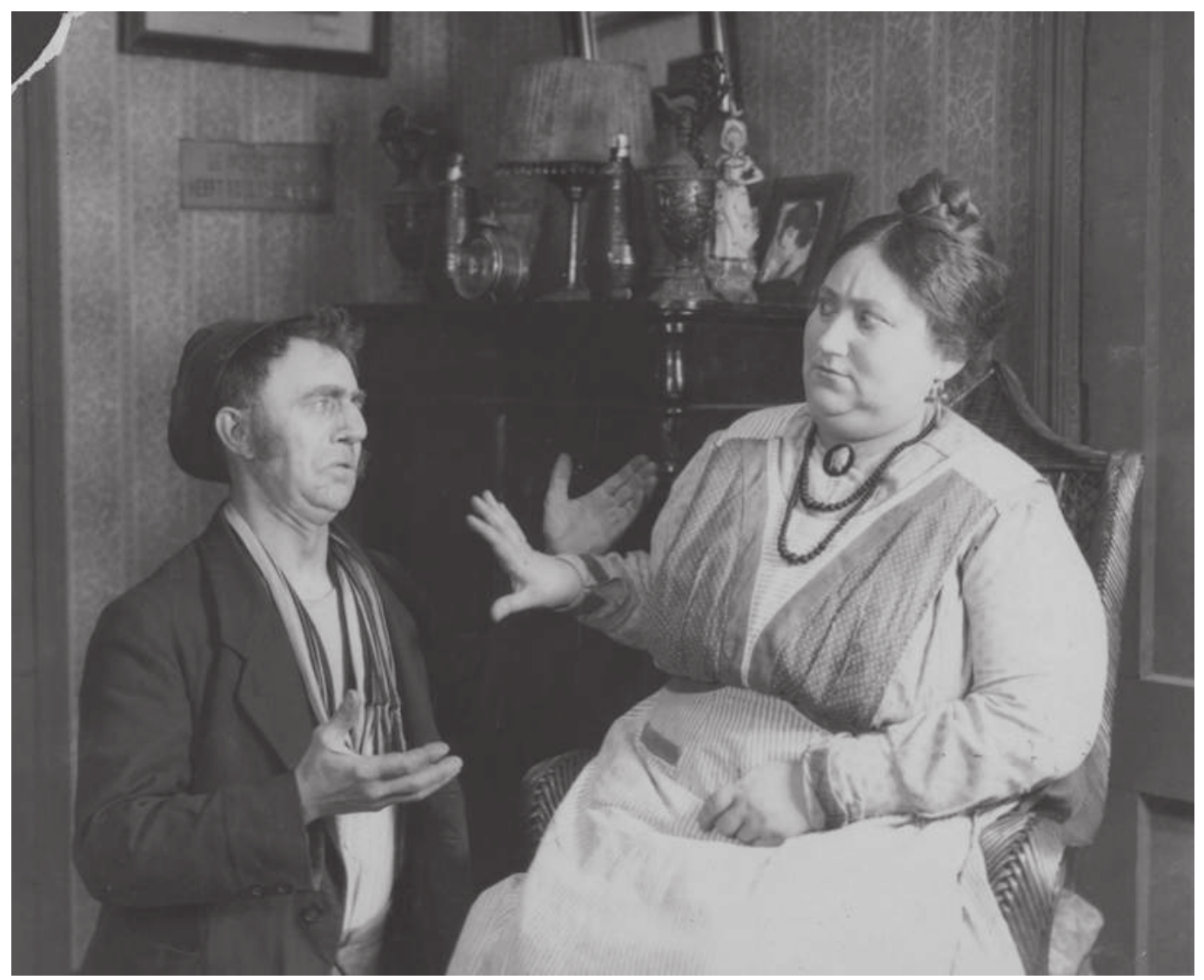

Fig. I.14: Adriënne Solser and probably Piet Köhler in unidentified film.

Given that the scenarist and director already knew his leading actress well, it is not inconceivable that Benno had Solser in mind while writing the scenario for KEE EN JANUS NAAR BERLIJN. Within four weeks' time he had contracted her and her co-star Kees Pruis. ${ }^{141}$ If not in advance, then certainly during the shooting of both the first KEE EN JANUS-film and its sequel, Benno must have counted on the scene-stealing talents and farcical demeanor of Adriënne Solser. As both films are missing, no print-related reading can be produced of the contributions of the two leading comedians to the farce. The EYE Filmmuseum does, however, hold one still featuring Piet Köhler and Adriënne Solser that may tell its own story. ${ }^{142}$ It displays a buxom female figure dominating the picture-occupying more than half of the frame-frowning at her husband and gesturing to him to keep his distance; it also shows the torso of a relatively slender man kneeling at her feet, holding his hand as if begging her pardon and pleading his own innocence. The accent of the picture is on the physical 
contrast between the two, and the action reveals how their relationship is balanced: it is not he but she who wears the pants here.

Stills from KEE EN JANUS NAAR PARIJS were published in Cinema en Theater, a magazine for the film-going public. ${ }^{143}$ In them, Janus' face seems rounder and he wears glasses, which lends him more substance and authority than the schlemiel had in the other photograph, but still he is the helpless party, standing most often behind the much larger and more imposing Kee. Together, they convey the impression of a bouncy couple, feasting, dancing, quibbling, and, later, comforting one another. Each of the six stills represents a key moment in their cinematic life and collectively demonstrate that, whatever may happen, Kee is at the center of the excitement, full of movement. She dances, sings, argues, or falls from her bed, and the physical performance is matched by a corresponding mien with emotions and sensations ranging from skepticism to delight and from reservation to plain annoyance or pain. The three stills of the Berlin film published in Kunst en Amusement in no way contradict this impression: even though Janus is taller than Kee here, she is her own person and he stands by his woman. ${ }^{144}$

All in all, these stills picture Kee as a temperamental but good-natured person, a kind of excessive child, incapable of doing any harm, in return for which she will not accept that any wrongs are done to her or her peers. Plot summaries, moreover, testify to Kee's dominance and Janus' adoration of her: "And if she did not like something, Janus did not disagree." ${ }^{145}$ Such a personality is fundamentally commensurate with the Bet persona prior to 1920 (and afterwards as well) as it appears in the prose texts contained in Adriënne Solser's notebooks. ${ }^{146}$

Benno and Solser's creation of Kee overlaps with Solser's Bet persona to such an extent that it seems not too far-fetched to assume that Benno had indeed let Solser have her way during the shooting of the films and accordingly consented to the actress' significant input into the shaping of her character for the screen adaptation. This notion of Solser's constitutive involvement in the film may be further substantiated if the live accompaniment to the filmsanother aspect in which Adriënne Solser was prominently featured-is considered. Most reviews commended Solser's performances in both of the KEE EN JANUS-films, and her live appearances were said to have heightened the merriment. ${ }^{147}$ One rave review emphasized the quality of the intertitles in relation to the live delivery:

The intertitles, finally, perfectly match the film's humor and appear to have been written by an able hand, for time and again, and in part because of Adriënne Solser's catchy lecturing, they generate inexorable roaring laughter in the room. ${ }^{148}$ 


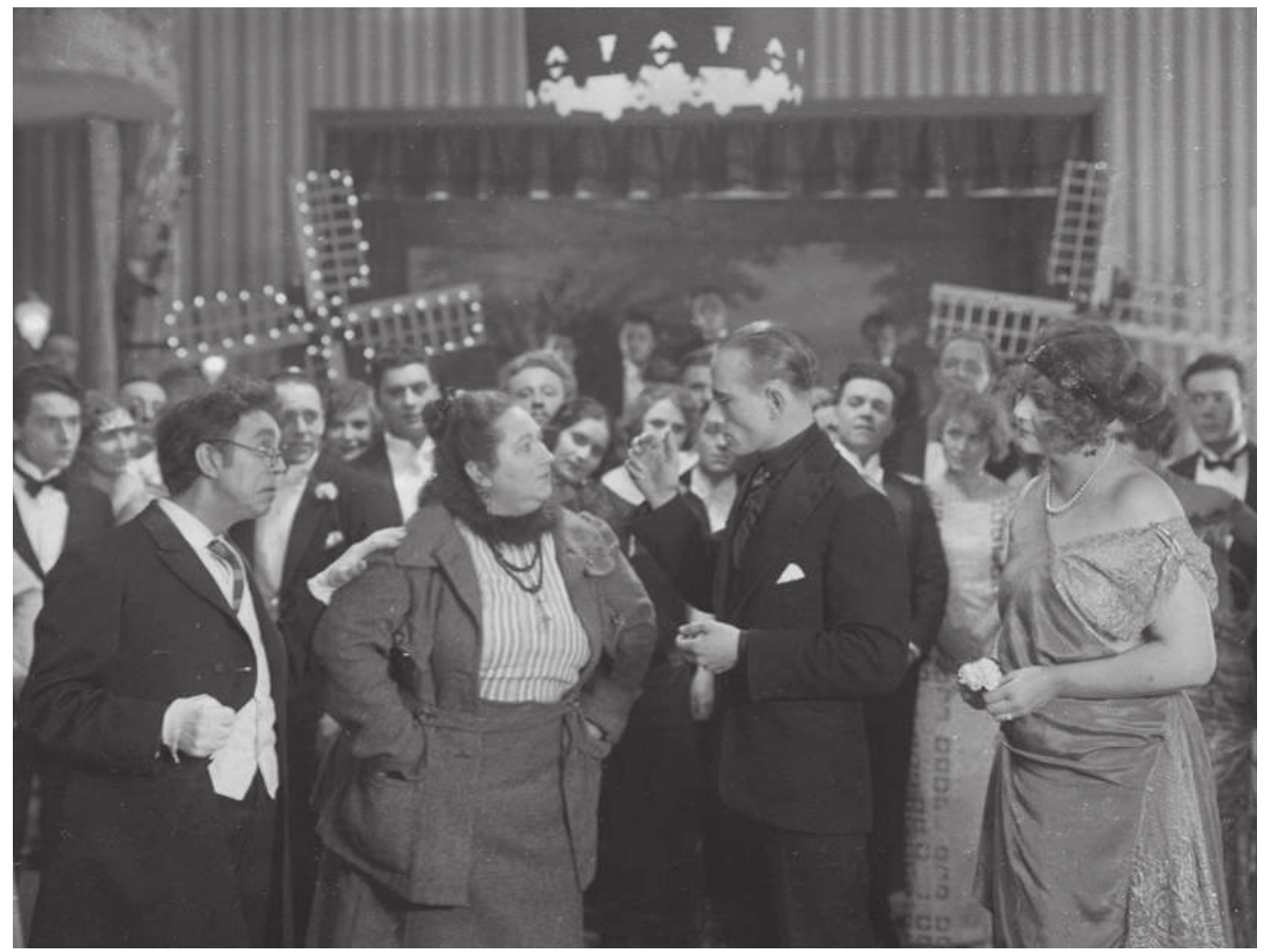

Fig. I.15: Kee and Janus in the Moulin Rouge. Still from KEE EN JANUS NAAR PARIJS.

A review linking the titles to the lecturing hints at Solser's involvement. This is suggested even more strongly when considered in light of the criticism that was aimed at Benno for his drama MOOI JUULTJE VAN VOLENDAM (Beautiful Julie of Volendam) a year later. This criticism concerned the intertitles in particular, which were deemed too numerous, too lengthy, and often redundant: "Benno, who drafted the scenario (and therefore the titles as well), is no writer and no man of letters." ${ }^{149}$ Although this last remark is innacurate-Benno had published writings around the turn of the century-, and although Benno was readily credited for writing the scenarios of the KEE EN JANUS-films, the contrast between these two critics' judgments is so evident that it is highly unlikely that he alone was responsible for writing the titles. Accordingly, I believe that Adriënne Solser not only had her way with the role of Kee, but also with the titles and the lecturing.

The narrative structure of the KEE EN JANUS-films comprises a series of loosely connected silly adventures meant to provoke a good laugh. The struc- 


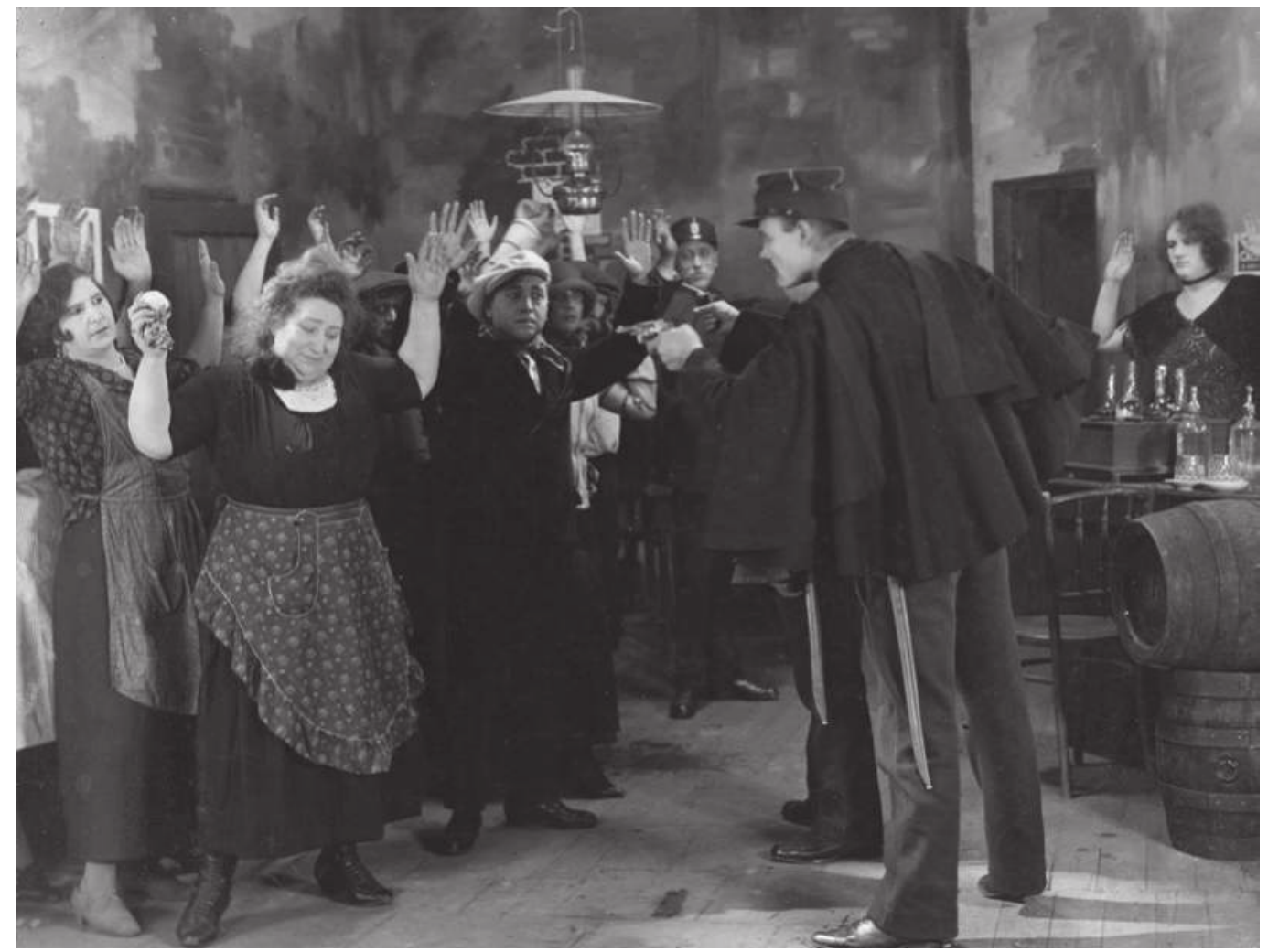

Fig. I.16: Kee caught in a hold-up in an underworld joint in Paris. Still from KEE EN JANUS NAAR PARIJS.

ture recalls a revue or an episode film and the accounts of the contents, which typically consisted mainly of lists of sites and situations; thus, one reviewer summarized KEE EN JANUS NAAR BERLIJN accordingly:

The scene at the border, on the bus on Unter den Linden, with the openair photographer in front of the Siegessäule, in the posh restaurant, Janus gone off with a Berlin girl and Kee pursuing and catching them, the bedroom scenes in which the guests are woken up by the bellowed Jordaan songs, after which they are thrown out by the Berlin police, oh, I would have to list everything in this snappy film revue, a wonderful depiction of the adventures every Dutch visitor has gone through to a greater or lesser extent, whether while shopping in the department store Wertheim or having trouble at the border! ${ }^{150}$

And another remarked about KEE EN JANUS NAAR PARIJS: 
And who would not want to savor the lovely tours of the City of Lights, the shots taken from the Eiffel Tower, the adventures at night, the visit to the underworld joint, the interior of the Moulin Rouge, in sum, all the sensations Kee and Janus have experienced and all those wonderful pictures of Paris the film offers? ${ }^{151}$

More ironic comments suggested that the audience was invited to laugh not with but at the protagonists. ${ }^{152}$

In short, both the positive and the negative reviews testify to the fact that the narratives were structured in an episodic mode and that the spectator's identification was not actively sought. By virtue of the latter cinematic choice, these films fulfilled one of the fundamental Bergson's conditions for calling forth laughter: excluding subjectivity on the side of the actress and precluding empathy on the side of the spectator. It is necessary to keep this in mind with 102 regard to Adriënne Solser's live accompaniment. Such a sequential structure has no-or, at best, a very weak-implied narrator with whom the lecturer, whose function it was to keep up the spirits of the audience, would have to compete. Unfortunately, the reviews do not disclose how Adriënne Solser discharged her assignment. Secondly, Solser appeared live on stage as a character who had stepped down from the screen, doubling, speaking, and most likely singing her own and her co-actors' parts. Thus, she must have functioned like the actor-lecturer, who, in the case of comic films, used to magnify the farcical side of the characters. As I pointed out earlier, an actor's simultaneous stage and screen presence was already experienced as something comical in its own right. During this time, most reviews, including the negative ones, confirm that Solser's live presence added substantially to the merriment. As far as Solser herself was concerned, however, it seems that she could not manage without language and voice in order to render her cinematic Kee or Bet persona maximally silly, so she managed to merge physical farce with humor created with the means of language. After the KEE EN JANUS-films, the combination of a film-screening and Solser's in-person appearance became one of the trademarks of the films featuring and made by Adriënne Solser.

The two KEE EN JANUS-films proved themselves to be "kasmagneten", (box-office magnets): commercial successes for Alex Benno and popular successes for Adriënne Solser. With their respective six- and nine-week runs at the Amsterdam Passage-Bioscoop and the many other cities to which the prints were sent, ${ }^{153}$ the films did much better than had previous Dutch film productions, including DE JANTJES, which had run for five weeks in Amsterdam. ${ }^{154}$ This was all the more amazing ${ }^{155}$ for, in 1922 , when the first KEE EN JANUS-film was released, a profound malaise in film-going hit the Netherlands, which Kunst en Amusement attributed mainly to economic reasons, ${ }^{156}$ but which, 
suggests Beusekom, was also due to the lack of quality and variation in the supply of films. ${ }^{157}$ It is also surprising because, just as had DE JANTJES, the two films received a mixed reception in the press, ranging from rave reviews in the trade press and the supportive publication of pictures and summaries in popular film magazines, to either disparaging criticism or sheer neglect in the newspapers. This notwithstanding, both films generated a massive turn-out, for which the popularity of the comedians featured and of the genre of the Jordaan farce were most likely particularly responsible.

Insofar as the response in the press was positive, this coverage was heavily colored by the hope for a new future for Dutch film production after the debacle of the Filmfabriek-Hollandia and its British co-productions. Such hopes seemed to be fulfilled when Benno, together with David Sluizer, established a new studio - the Dutch Film Co., which was most probably financed by his earnings from the distribution of DE JANTJES, BLEEKE BET, and KEE EN JANUS NAAR BERLIJN-in 1923 on the old premises of the Hollandia. Consequently, the announcement of the Paris sequel as the first production to be undertaken by the Dutch Film Co. was warmly welcomed as a clever choice. Under the headline "Hollands Filmindustrie Herleeft!" (Holland's film industry revitalizes!), both Nieuw Weekblad voor de Cinematografie and Cinema en Theater praised the courage, ambitions, and confidence in national production of Benno and his associates. With a part of the film press, the concentration on a popular Dutch subject matter and, in particular, the employment of popular Dutch actors was met with warm approval..${ }^{15^{8}} \mathrm{~A}$ critic with an almost visionary eye praised the collaboration between Solser and Köhler: "Their acting together was so droll, that their creation ensured them an overnight popularity on the silver screen." 159 The winning combination would later be put into action in two more films from the Dutch Film Co.. As for this film, their contribution prompted the critic to judge it for what it offered and for what it sought to offer, no more and certainly no less than that: no ambitions of art or new directions for art films, but "excellent entertainment art which lets people forget their worries for a few hours". ${ }^{160}$ The results of the collaboration between Adriënne Solser and Alex Benno, therefore, included a reassessment of the pre-war art of entertaining and of its transfer from the popular stage to the cinema. Both the audiences and a committed press acknowledged the achievement.

Despite the popular and commercial success of the films, Alex Benno felt the urge to defend his choice for the genre, not only against the expanded ambitions for Dutch film production, but against his own aspirations as well. His argument was that such films were in demand, whereas other genres were not. ${ }^{161}$ Moreover, he ascribed the pooh-poohing his productions encountered to the fact that this particular genre was not suitable for selling to the international market. ${ }^{162}$ Voices less supportive of his attempts to create a 
solid financial basis for Dutch filmmaking could be heard as well in the daily press and its crushing reviews of the KEE EN JANUS-films. Main points of criticism included the pointlessness of the story, the caricatural treatment of the subject matter, and the acting, which was considered cinematically inept. ${ }^{163}$ Further resistance to Benno's initiative-and perhaps jealousy of his achievement?-may be tracked in the contemporary debates about the direction Dutch film production ought to take. Even the Dutch Film Co.'s office manager, in a polemical attempt to defend the firm's policy of making films regardless of the actors' lack of cinematographic experience, of the scarce financial resources, and of the lack of export possibilities, called the genre constituted by DE JANTJES, MOTTIGE JANUS, and KEE EN JANUS NAAR BERLIJN a dilettantish one. ${ }^{164}$ Most remarks, however, were more indirect, as, for instance, this plea for high-grade humor instead of

so-called farces that are just chains of pointless "comic situations." [...] Humor has to be simple. Based upon the human. For this reason, true humor is international. ${ }^{165}$

The expression of such general and exemplary views must be understood in the larger context of the concerns in those years with the future of the Dutch film industry. Such concerns also make explicable the reluctance to surrender to the looming prospect of an industry for domestic consumption alone.

In January 1924, the Dutch Film Co. announced that it had abandoned the "Jordanerie" and that it was deliberating about making something in the genre of the American farce, though with Dutch artistes. ${ }^{166}$ In March 1924, Alex Benno left the company, due to the pressure of work and a possible disagreement with the studio manager David Sluizer, according to Westhoff. ${ }^{167}$ It is unclear to what extent the disagreement and the abandonment of the Jordaan-farces are related, but it is likely that they were. The function of artistic director was taken over by a son of Theo Mann-Bouwmeester, Theo Frenkel Sr., who had directed films since 1908, both in the Netherlands and abroad, before he joined the Dutch Film Co. in $1924 .{ }^{168} \mathrm{He}$ directed AMSTERDAM BIJ NACHT (1924), a popular drama with comic moments based upon Herman Bouber's play "Blonde Ka". The advertisements for it included the significant sentence: "This film does need NO LECTURING, it shows you that also in our country good films can be made," ${ }^{169}$ which would seem to indicate the disagreement between the director and the producer. Adriënne Solser and Piet Köhler were cast again as an Amsterdam couple, but this time in supporting roles embodying the comic moments in the drama. One published still from the film shows them in a situation where Köhler dances with another woman and Solser furiously claims him back. ${ }^{170}$ As with Benno's films, AMSTERDAM 
BIJ NACHT won great acclaim for including so many familiar faces from the popular stage. ${ }^{171}$

One review remarked that the Amsterdam couple of cloth merchants, played by Solser and Köhler, was not from the Jordaan, but Jewish. ${ }^{172}$ Along with the part of the ice-cream vendor Sally in BLEEKE BET, they belong to the rare representations of Jews in the Dutch silent cinema. ${ }^{173}$ Hetty Berg, the curator of an exhibition about Jews in Amsterdam entertainment before the Second World War, observed a striking discrepancy between the considerable on-stage presence of Jewish entertainers and actors, and their performances, which hardly ever contained anything Jewish. ${ }^{174}$ My survey of texts delivered by Adriënne Solser leads to a similar conclusion: in none of them was Jewishness a topic. Such a discrepancy is even more pertinent vis-à-vis popular films and farces, because they carried on a tradition of plays and performances that addressed both the Jordaan people and the Jewish audiences frequenting the Jordaan and Plantage neighborhood theaters. As for Adriënne Solser, her role in AMSTERDAM BIJ NACHT remained the only part in which she played a Jewish character, but since this film too is missing, nothing can be said about the manner in which she did so.

Solser was recast with Köhler in Frenkel's next film, the circus-drama CIRQUE HOLLANDAIS (The Dutch Circus 1924), in which the duo played the bandleader and his wife, a cook and cashier. ${ }^{175}$ Like its predecessor, the new film by Frenkel was praised for the way it conveyed a typical Dutch atmosphere and for the eminent cast, including Louis Bouwmeester (at more than eighty years of age!) in a double role, Esther de Boer-van Rijk, Aaf Bouber, and Adriënne Solser as "a fat and cuddly mom". ${ }^{176}$ Although a small part, it was noticed: "As I already suspected but now think I know for certain, Adriënne Solser has true comic talent." ${ }^{177}$ The preserved fragments from the film feature her too briefly to permit an assessment of this observation.

\section{A Difficult Choice}

For over two years, Adriënne Solser had been increasingly present on Dutch screens in several films that were highly popular with audiences. Together with Alex Benno, she had developed a formula that suited the screen adaptation of her stage persona and allowed her to continue her art of entertaining. This formula included, in the tradition of the Ensemble Solser en Hesse, a temperamental yet good-hearted female protagonist who connected the loosely structured scenes of an episodic or revue-like farce; the direction's and the male co-star's probable acceptance of her scene-stealing acting style; and the opportunity for her, as a soubrette, to dominate not only the screen but, with 
her live appearances, the screenings as well. A further element in the formula was serialization. The remarkable turn-out for the KEE EN JANUS-screenings, moreover, must have convinced her that there were still audiences waiting to see and hear Adriënne Solser. Otherwise, the type of the Komische Alte or the Bet persona would have relegated her to playing the comic supporting roles of rather pathetic or even nasty characters in screen adaptations of Bouber's and other Dutch volksstukken that were more dramatic than comic. While both Benno and Frenkel preferred to carry on with the latter, no other self-respecting Dutch film-maker could have been expected to be willing to venture into the genre of the Jordaan farce, which was increasingly despised by the press and the industry yet suited to Adriënne Solser's talents and experience. The year 1924, then, must have confronted the actress, at age fifty-one, with a difficult choice: either leave both screen and stage at a glorious moment in her career, or proceed on her own. While announcing her decision for the first 106 option, she in fact pursued the latter.

\section{ADRIËNNE SOLSER'S PRODUCTION COMPANY 1924-1928}

The year 1924 culminated for Adriënne Solser in the commemoration of her-actual or merely alleged ${ }^{178}$ - fortieth anniversary on stage, which she celebrated with her first film production: BET, DE KONINGIN VAN DE JORDAAN (Bet, the Queen of the Jordaan). The very fact that Solser celebrated this jubilee with a film - and not, say, with an evening of live acts by artiste friends just as in 1919-illustrates that she used the film screen as an additional venue for her soubrette acts. ${ }^{179}$ In combining the screenings of her films with personal appearances, Solser also carryied on the "staging" of film as this practice had taken shape in the lecturing at popular cinemas in the Netherlands. By virtue of such a practice and conception, Adriënne Solser did indeed rigorously turn away from the leading aspirations for an-albeit at the time illusory-autonomous Dutch film production. Those aspirations represented an amalgam of nostalgic memories of what Dutch film production at least had promised to become during the 1910 s and of technical and aesthetic ideals derived from American, German, Russian, and French cinema of the late 1910 and early 1920s. Critical discourses on cinema, moreover, had not developed the means by which to grasp the popularity with Dutch audiences of cinema-going in general and of watching Dutch film comedies in particular. ${ }^{180}$ Neither would they develop anytime soon; by the mid-1920s, a new and more intellectual generation of critics began writing about film, who particularly despised everything that was popular and $\operatorname{comic}^{181}$ and who would gradually come to lead the Dutch debates on film as an autonomous work of art. ${ }^{182}$ The excep- 
tionally profitable Dutch fiction films of the 1920s, consisting of the screen adaptations of popular plays and of Benno and Solser's films with their original scenarios, neither aspired to uphold nor fulfilled such ideals. In terms of genre, acting, aesthetics, and production values, their films were a far cry from those envisioned by these critics, yet they did too well with Dutch audiences to be neglected entirely. They were unpretentious, volks in the pre-war sense of being anchored in popular culture, and they were farces. At their heart were the performers, rather than a writer or film-maker who creates art. By the early 1920s, however, not only the discourses about film, but the discourses about the performing arts likewise exchanged qualities such as those of Benno and Solser's work for a new set of standards of wit and sophistication expressed in refined language and in a spiritual approach towards the performance. Critics who discussed the 1920 s film farces in an obliging manner, were basically bereft of valid contemporary standards and typically drew on concepts used for reviewing the popular stage of the 1910s. The gap in Dutch cinema between the ambitions and the resulting product, then, matched a discursive and conceptual vacuum and it is with these two voids in mind that the contradictory responses to Adriënne Solser's film production ought to be read.

BET, DE KONINGIN VAN DE JORDAAN was advertised as a jubilee and farewell at once: "The final film of our dear Dutch film star Adriënne Solser, who herewith celebrates her fortieth anniversary and quits theater and film for good." ${ }^{183}$ If this announcement can be believed, it would imply that Solser, at least initially, had no further ambitions than to make this one film and thus was uninterested in filmmaking per se. This would partly clarify her abstinence from involvement in ambitious Dutch filmmaking and her maintenance a stage-related conception of cinema against the major trends in filmmaking and exhibition. Solser may have harbored the idea of establishing a film company of her own for some time; the path to initiating one had been outlined if not actively prepared when her son André Boesnach was trained in Paris as a projectionist and assistant director. ${ }^{184}$ It may be that Solser wanted to provide her son with a good start by getting involved in this jubilee film, so that the company could then go on without her. ${ }^{185}$ Nevertheless, her intent to retire seems not to have been very steadfast: half a year after the first film had proven itself a box office hit, the production of a sequel was announced. ${ }^{186}$ And after a second sequel, released in February 1927, Solser seemed to have made up her mind: she announced that she would refrain from live accompaniment of her films, but not from filming. ${ }^{187}$ From the rare reviews of her next film, it cannot be determined whether she did indeed abstain from accompanying her films in person. Four years after the first run of her last film, however, she again took up the practice during a tour through the provinces. ${ }^{188} \mathrm{~A}$ final, yet for all of these reasons not improbable possibility, is that the announcement 


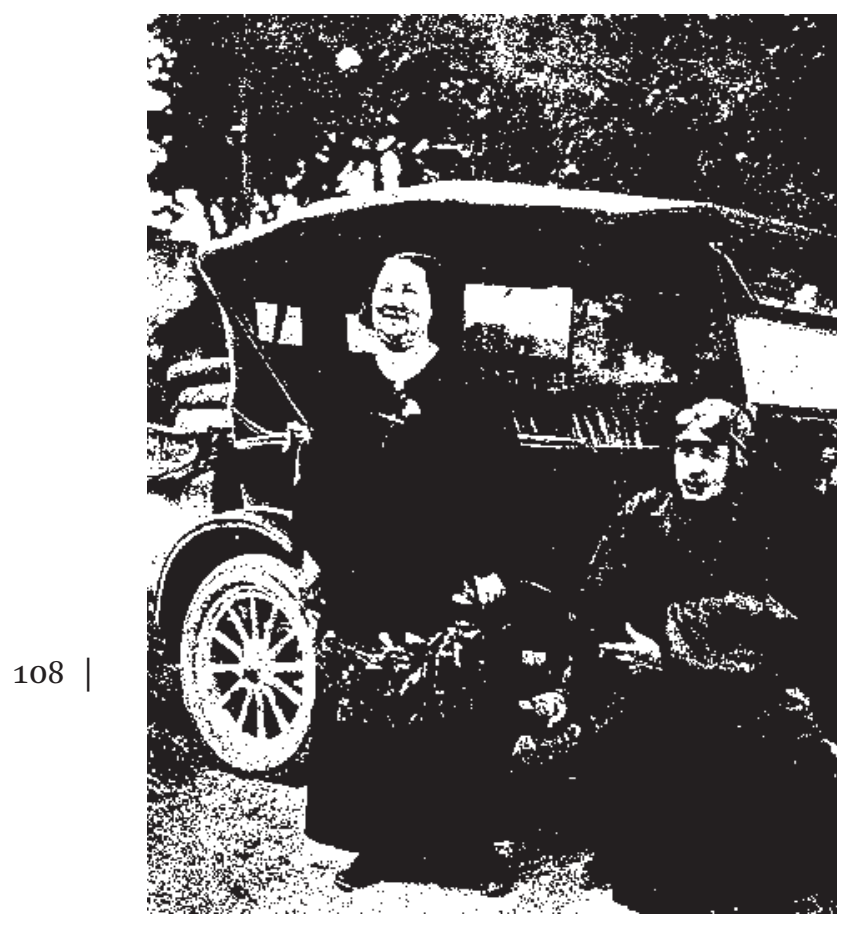

Fig. I.17: Solser and her son André Boesnach. Still from BET TREKT DE 100.000.

of the retirement, just as of the jubilee, was merely made for publicity's sake. Be this as it may, in September 1924, the Hollandia-Belgica Film Mij. "Eureka" was incorporated, with André Boesnach and a former collaborator of Alex Benno, Jules Suikerman, as the directors, ${ }^{189}$ in order to produce the "groote Hollandsche jubileum-film: BET, DE KONINGIN VAN DE JORDAAN" (the big Dutch jubilee film) featuring Adriënne Solser and directed by her. ${ }^{190}$

The Hollando-Belgica Film Mij. "Eureka" was set up as a combined film production and distribution office. ${ }^{191}$ In this way, it followed the lucrative example set by Benno's Actueel Film. The company was first located at Amsterdam, but soon transferred to Schoten, near Haarlem, the town where the Filmfabriek-Hollandia and the Dutch Film Co. had been situated. After having produced the second film, the office moved to larger premises in Rotterdam in January 1926 and announced that it had secured several films for distribution. ${ }^{192}$ In subsequent advertisements, however, only the films with Solser were offered, although in the records of a legal proceeding regarding the inventory of the Eureka studio, various prints of non-Eureka films were listed. ${ }^{193}$ After completion of its third film, Eureka rented an additional building at Schiedam, a town near Rotterdam, and fixed up a film studio. ${ }^{194}$ Here the fourth, and last, Eureka film was produced. 
Much as had happened with the Dutch Film Co., the new company was warmly welcomed by the trade press and accorded best wishes for a productive future. ${ }^{195}$ Remarks on the courage and energy of the Eureka people were to be repeated over and over again in the corporate press. It was most especially as a business enterprise that Eureka initially obtained the confidence of the film world, not only thanks to Adriënne Solser's reputation as a crowd-pleaser, but also because, aside from Frenkel and Benno, few film producers still managed to find funding for new initiatives by 1924, which Boesnach and Solser were in fact able to do. The difficulties of the general funding situation only worsened in the following years, to such an extent that the entire Dutch film harvest of the year 1927 consisted of no more than one feature length film, the Eureka production BET ZIT IN DE PENARIE (Bet in an Awful Fix). ${ }^{196}$

The scarce circumstantial documentation reveals how some of the productions were financed. Solser's debut was funded (or possibly co-funded) by a hotel owner from Vlissingen, A. W. Smits, who claimed ownership of the film in a couple of advertisements. ${ }^{197}$ His name, or more precisely the trading company formed by his heirs after his death in January 1925 , reappeared on the occasion of the third Eureka production. ${ }^{198}$ The contract between the Smits heirs and Boesnach and Solser states that the Smits heirs invested NFL 20,000 in the third Eureka film, BET ZIT IN DE PENARIE, for which they acquired ownership of the film until the full amount had been repaid; from the moment of completion of the film, Boesnach received $10 \%$ of the gross income in order to cover the exploitation costs; after clearing the debts, the ownership of the film was divided equally in thirds among the Smits heirs, Boesnach, and Solser; and Solser committed herself to accompany the film in person with lecturing. ${ }^{199}$ These selected points may clarify the specific issues I shall now address. For buying extra equipment for the studio at Schiedam, Boesnach made a deal with the financing company Hadima (Haagsche Disconto Maatschappij) in which he sold the studio's fixtures and fittings to them but was then allowed to keep them on loan. ${ }^{200}$ Included among the stock listed was two-thirds of a negative of BET, DE KONINGIN VAN DE JORDAAN. Considering, then, that Smits had invested money in this film as well, it is safe to assume that the conditions for the funding of Solser's first film were similar to those for her third. Over BET ZIT IN DE PENARIE, in contrast, Boesnach and the Smits heirs fell out sometime between August 1927 and March 1928, because Boesnach resumed further exhibition of the film despite the fact that he still owed almost three-quarters of the sum to the investors and that the film, at least according to the Smits heirs, was still in demand. ${ }^{201}$ One can think of two possible motivations for the decision: either the film did not do well enough to justify continuing its display, or Boesnach planned to concentrate entirely on the opening of the studio in September 1927 and on the new production, BET 
NAAR DE OLYMPIADE, which he intended to direct and for which he wrote the scenario.

There is no documentation of any investments that Adriënne Solser might personally have made, nor of the financing of the second and fourth Eureka films: BET TREKT DE 100.000 (Bet Wins 100,000) and BET NAAR DE OLYMPIADE, respectively. Schiedam newspapers suggested that Hadima was involved in the funding of the latter, but this was denied in court in 1927. Additional funds may perhaps have come from some Dutch trading firms, such as the grocery chain Simon de Wit in Eureka's first production, and the coffee brand Van Nelle in its last; however, although their names and logotypes figure prominently in the films, it remains uncertain how substantial their contributions may have been. As no further investors seem to have been involved, the conclusion stands that Adriënne Solser poured a considerable amount of own money into her films.

110 Apart from Boesnach and Solser, the crew and cast of the Eureka films, for the most part, changed with each production. An experienced cameraman, however, was hired for each. Of these, the first was Pierre Hulsman (18941941), who was credited with the co-direction of both the initial Bet-film and its sequel. Hulsman began his career at the Filmfabriek-Hollandia as an assistant cameraman. Later, he became a manager of laboratories. ${ }^{202}$ The cameraman of the second Bet-film was Henk Alsem, who was better known from war reports shot for his company Hispano Film. ${ }^{203}$ The two subsequent Eureka productions were photographed by a cameraman about whom contemporary press mentioned only that he came from France, Fernand Gauthier. ${ }^{204}$ The director's credit of the third production went to André Boesnach, who was also scheduled to shoot the following film. Circumstances rendered this impossible, however, so Theo Frenkel Sr., with whom Solser had worked previously, was hired in his place.

The writers of the screenplays for the films alternated as well. Solser's jubilee film was written by Alfred Harvey, who had formerly played a supporting role in Frenkel Sr.'s CIRQUE HOLLANDAIS, and who, according to Donaldson, was Adriënne Solser's friend at the time. ${ }^{205}$ The second and fourth Bet-films were written by Boesnach, while the scenario credit for the third went to Eugène Beeckman, a Belgian composer of operettas and operas who had collaborated during the 1910 s with Tony Schmitz ${ }^{206}$ and Nap de la Mar. ${ }^{207} \mathrm{He}$ also had drafted numerous cabaret songs, for, among others, Kees Pruis - the comedian who played Janus in the first of the Kee en Janus films-as well as some of the songs delivered live by Solser at the screening of her film. Beeckman was also featured on the screen as the man whom Bet fancied and eventually married. His wife, Nap de la Mar's sister Josefien, had a double role in Solser's last production. Additional co-stars of Solser's included Henk Liver- 
more, who was said to have won the hearts of spectators because of his special facial expressions $\mathrm{s}^{208}$ in the second Eureka production, as well as the popular stage comedians Jan Nooy and Alex de Meester, in the first and fourth of films, respectively. Jan Nooy had acted with and led various popular theater companies, had played at the Plantage Schouwburg, and had performed in revues by Rido. ${ }^{209}$ His wife, Beppie Nooy-Blaaser, played Bet's friend from the market in Solser's first film, and reappeared in her last. Alex de Meester was a comedian famous especially from revues by Rido and Ter Hall. Before appearing in a supporting role in the third Bet-film and co-starring in the fourth, he gathered film experience in CIRQUE HOLLANDAIS and Benno's DE ARTIESTENREVUE. ${ }^{210}$ Further popular stage comedians to be cast in Solser's films were Rinus de Wilde, with whom Solser had formed a duo in 1918, and the Spanish comedian Pitouto, the stage-name of Pedro Elviro. Thus, just as Benno, Boesnach and Solser too relied on the potential of some of the comic actors from the Dutch popular stage.

One more collaborator of Solser and Boesnach's needs to be mentioned, for she had been the studio's factotum, but later grew into a respected film

Fig. I.18: Margot Laurentius-Jonas, Riki de Meester, Eugène Beeckman, and Adrënne Solser. Still from BET ZIT IN DE PENARIE.

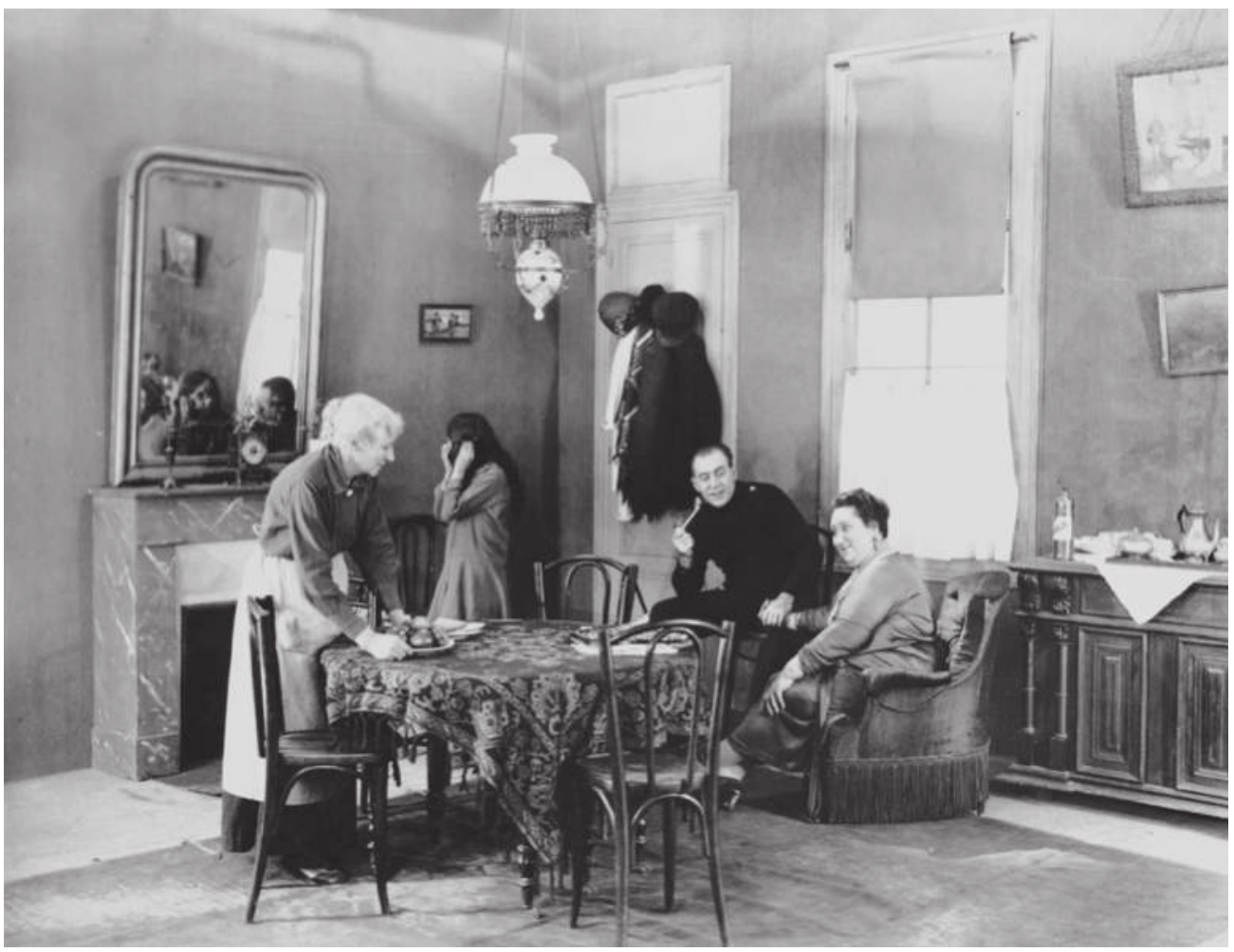




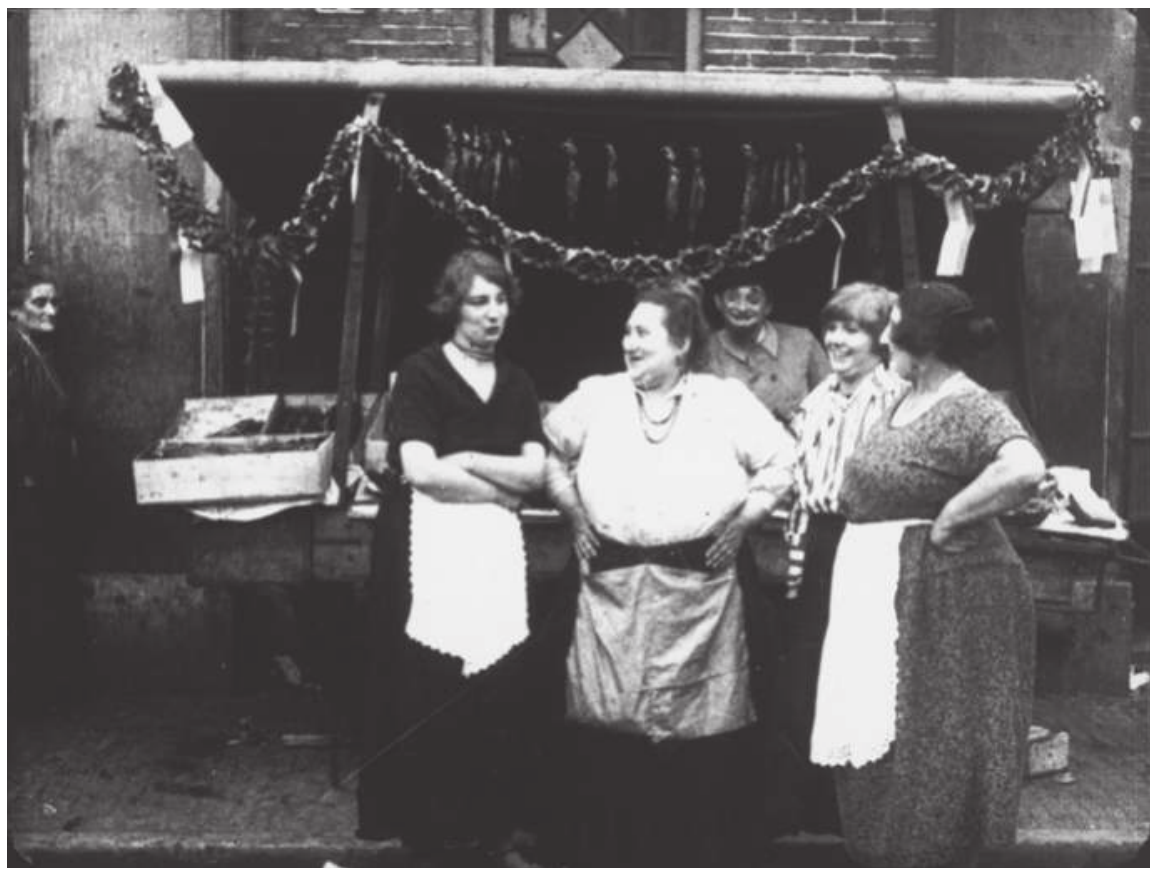

Fig. I.19: At the market, with Beppy Nooy-Blaaser and, in the background, Jan Nooy. Still from BET, DE KONINGIN VAN DE JORDAAN.

editor: Lien d'Oliveyra (1912-1995), Boesnach's half-sister and Solser's daughter from her third marriage. ${ }^{211}$ One of the local Schiedam newspapers paid tribute to her indispensable presence:

A curious little creature is Lientje, the studio's young factotum who, her young age notwithstanding, speaks fluent French with the Gallic cinematographer; Lientje, who welcomes the guests with casual charm, who for a change acts as an extra, who makes coffee and tea, who also tinkers with the bulbs if they fail to work, who stands ready by the lens with her inevitable little slate with the white chalk figures of the upcoming scene, and who in the midst of all of this leaps on her bicycle, dirty as she is, in her overalls if need be-there is no time to bathe and change-to run an errand. That is the only moment someone in the studio calls in vain: Lientje! Lientje! ${ }^{212}$

Eureka recommended its films to exhibitors in the trade press by glaring advertisements in a style that had been copied from the variété and that remained 
more popular during the 1920 s than many who advocated the communication of serious information about films to the public would have liked. ${ }^{213}$ This was yet another aspect in which Boesnach and Solser imitated Alex Benno's style of marketing. If attention was drawn to the KEE EN JANUS-films by means of slogans such as "For the audience an attraction and for cinema managers a box-office magnet!" ${ }^{214}$ and "Formerly, many were too late to book it. Act more quickly now and let the audience laugh!" ${ }^{15}$ the Bet-films were advertised with recommendations such as "Now you can do business again!! This will be a box-office magnet!!" ${ }^{16}$ and "What does a film with Adriënne Solser entail? Money for the managers-Success for the artiste-Pleasure for the audience." ${ }^{217}$ Moreover, both Actueel Film and Eureka marketed their films as "sensational" by providing listings of the shooting locations, and conveyed a defense against the accusation of not living up to the aspirations harbored by the film world. A crucial difference, however, was that Benno was more tactical than Solser and Boesnach. Whereas Benno contended:

It is easy to make a high-budget film with grand architecture, mass scenes, and the best directors in the world, but it is definitely an art to manufacture with modest means a film that is an attraction for the audience and a box-office magnet for cinema-managers! ${ }^{218}$

Eureka tried a provocative track: "This superb film opus promises a complete revival of the dwindling industry! Grand in set-up and acting!," ${ }^{19}$ or "The biggest hit ever produced by the Dutch film industry!" ${ }^{220}$ and "The best Dutch film both in terms of acting and of cinematography!" ${ }^{221}$ The main disparity was not the degree of the bluff, but the approach taken in the defense: Benno confronted illusory ambitions, while Boesnach and Solser challenged the Dutch film industry by positioning themselves out in front of its present and past. ${ }^{222}$ They once even struck a direct blow at the trade: "Despite malicious gossip, our film is achieving [...] increasing success." ${ }^{223}$ It was not the loud advertisements per se but the bragging and pomposity they exhibited that caused irritation, and such resentments were made public by the accounts of two conflicts in which Solser and Boesnach had gotten involved and that were spelled out by the trade paper Nieuw Weekblad voor de Cinematografie.

The first conflict was brought about by a boycott imposed by the Dutch film trade organization, the Nederlandse Bioscoopbond (NBB). After Eureka had leased the film BET TREKT DE 100.000 in January 1925 to the boycotted Scala Theater in Haarlem, the company was fined a considerable sum. Boesnach's appeal was discussed in the general meeting, and reported in Nieuw Weekblad voor de Cinematografie. ${ }^{224}$ For my purposes, it is not the conflict per se that is interesting, but the impression that the article gives about how the Eureka 
staff was actually judged by the trade. Initially, it was Boesnach's more than Solser's conduct in business dealings that was attacked. However, he proved his case and was found to be not guilty of violating the rules. From the moment that this became apparent in the meeting, some members began to discuss Solser's lecturing, which she, it was suggested, could have decided to abstain from once she knew about the boycott, but she was also cleared of the charge in the end. Both the accusations and the coverage illustrate that Solser and Boesnach were viewed as outsiders to and perhaps even as intruders in the Dutch film world, whose rules they had yet to be taught.

The second conflict arose from speeches and statements delivered by Boesnach on the occasion of the opening of the Eureka Studio at Schiedam, and not only was it covered in full detail in Nieuw Weekblad voor de Cinematografie, but it was also largely created by the paper in the first place. Quite contrary to custom, a critical account of the opening was published, pointing 114 out the significant absence of representatives from the Dutch film world and the annoying self-glorification evinced both by Boesnach's speech and by a pamphlet distributed during the event. ${ }^{225}$ The bone of contention was the sheer disregard of previous Dutch filmmaking initiatives and the presentation of Eureka as being the first Dutch film company and the savior of the future. The account thus confirmed the outsider position of the Eureka people on two levels: materially, by the absence of Solser's former and future collaborators in the cinema, ${ }^{226}$ and discursively, by Boesnach's failure to situate the company in its historical and national context. Boesnach's subsequent letters to the editor prompted the articulation of criticisms that had been thus far held back.

Having announced that it would be proceeding with the production of seven BET sequels, Eureka was criticized for the quality of the work: "How does the management envision improving film production in our country? Surely not only by adding seven new films to the BET-series?" 227 With each of the two further episodes in the dispute, the tone became more vicious. It was stated that the studio was poorly furnished, that the direction, the acting, and the scenarios of the BET films were inferior, and that the whole enterprise was dilettantish. How little was left of the paper's usual gently accommodating attitude towards new enterprises, as the reporter-anonymous as usual-himself admitted, ${ }^{228}$ and how wide had the gap become between Dutch film production as envisioned and as actually realized at the time!

The controversy was further fuelled by the publications of the influential French film journalist Charles Le Fraper, who had attended the studio's opening and had taken Boesnach's account for granted. Indeed, he reported to the French film periodicals and newspapers that the Netherlands too was finally joining the club of film-producing countries. ${ }^{229}$ Apparently still consid- 
ering getting involved in the distribution of French films, Boesnach had also informed Le Fraper that French product was barely reaching the Dutch cinemas. According to Nieuw Weekblad voor de Cinematografie, this was yet another misrepresentation in desperate need of correction, especially because it affected Dutch-French trade relationships and the image of the Netherlands abroad. ${ }^{230}$ Boesnach's argument was refuted by a Dutch distributor, Wolff, who had listed the French films actually released in the Netherlands in 1926 and 1927; to everyone's surprise, eighty percent of the total French film production was represented. ${ }^{231}$ According to the periodical, however, every error published by Le Fraper was solely Boesnach's fault and not, say, the responsibility of an experienced journalist who should have done research of his own. Although I do not mean to contest the trade paper's denunciation of Boesnach's pomposity, the frenzy and persistence with which it voiced its disapproval, in five (!) installments of two to three pages each, does give rise to speculation. The paper's active role in the conflict suggests that it was settling some old or concealed scores, rather than registering a change of attitude visà-vis Boesnach prompted by some unwise statements from him. On the other hand, the paper seemed sincerely to have believed in Eureka and to have lost faith in its prospects after the opening of the studio.

While all of this indicates that Boesnach was deemed to be conceited, it left Adriënne Solser's reputation largely untouched. The only disapproval that was voiced concerned her plans to establish an acting school and to discover stars, ${ }^{232}$ because "one [ought] to know quite a bit more about film acting than she does in order to be entitled to grant someone the certificate of film artiste?" ${ }^{233}$ It remains uncertain if this relative reticence resulted from the paper's respect for Solser's skills, age, and womanhood, or whether the case was precisely the opposite, that is to say, it was a gender bias that rendered her as a woman not accountable. In the course of the two discussions, however, the point of "Solser and the cinema" was given sharp expression: "An Adriënne Solser film is only any good when she lectures. Without her there is no film." 234 Thus, even from an antagonistic point of view, the inextricable interrelatedness of cinema and live action in Adriënne Solser's conception of film remained unchallenged.

Eureka had run into trouble with its backers by September 1927, when the studio at Schiedam was opened, as well as with the trade press. However, nobody could have foreseen how wry the title of their latest film, BET ZIT IN DE PENARIE, would turn out to be. Because, Solser and Boesnach, undaunted, undertook a further installment in the BET series. Then trouble turned into drama: almost exactly half a year after the opening of the studio, on March 20, 1928, André Boesnach, at age thirty-two, passed away from influenza. ${ }^{235}$ It was not only a personal drama for Adriënne Solser, who thereby lost a child- 
her favorite son and close collaborator-but also a drama for her business: ultimately she had to give up the studio and lost at least two of her films. ${ }^{236}$ Directly after the funeral, Solser took on the management of the company and completed the film in production under the direction of Theo Frenkel, Sr. By July 1928, BET NAAR DE OLYMPIADE had reached the cinemas. ${ }^{237}$ In September 1928, however, Solser contacted Hadima to ask it to sell the studio's inventory to a third party, because she was no longer capable of covering the costs of rent, electricity, personnel, and insurance for which she was liable. This move caused a clash with the Smits heirs, who still held a claim on Eureka by their funding of BET ZIT IN DE PENARIE. As it turned out, while Boesnach had been negotiating with the investors, he had offered the inventory of the studio as collateral to both the Smits heirs (in February 1927) and to Hadima (in August 1927). In this conflict, Adriënne Solser took the side of the Smits heirs, but they lost their case. ${ }^{238}$ Prints of BET, DE KONINGIN VAN DE JORDAAN and of BET 116 | TREKT DE 100.000, along with the apparel and furnishings of the studio, were sold by Hadima to E. IJdo and Johan Köhler. ${ }^{239}$

\section{Solser's Live Act and the Bet-character}

Even more so than had the KEE EN JANUS-films, the BET films met a mixed response in the press. The trade paper Kunst en Amusement did not review the BET films, whereas on the occasion of the KEE EN JANUS-films they had featured Adriënne Solser - in her Kee costume-even in a portrait on the cover. ${ }^{240}$ In contrast to this, Weekblad Cinema en Theater devoted to each of the BEт films a page with a summary and several stills, and Nieuw Weekblad voor de Cinematografie published synopses, brief notes about the shootings, and positive reviews of two of the four BET films. In addition, a portrait of Adriënne Solser graced the cover of Nieuw Weekblad voor de Cinematografie on the occasion of the release of the second BET film. ${ }^{241}$ The paper's gently accommodating attitude reads like sheer support and understanding of the distinctiveness of Solser's films. The self-confident Eureka slogans emphasized that the BET films aimed primarily at entertaining people: "No profound studious art, but superficial entertainment, yet making everyone laugh their heads off." ${ }^{242}$ Just as when Solser and Hesse introduced their sketches, and Benno his films, with assertive statements to their entertaining qualities, now too part of the film press gratefully adopted those statements as guidelines for the articulation of their appreciation. Even though, by the mid-1920s, the attribute of unpretentiousness served as an excuse rather than as a quality that was still valid, the term figured prominently in the reviews once again. For instance, an initially not very positive article on the first BET film took a sympathetic turn after having avowed: 
In her "opening speech" Mrs. Solser states that she herself directed the film, "so if I did not do it right, please do overlook it a little." When that's asked so nicely! [...] And when, furthermore, the film is completely without pretensions! ${ }^{243}$

The review went on to assert that the film depicted priceless adventures and contained many surprising and comic moments, which were maximized by Solser's live performance on stage, delivered in "Jordaan argot and peppered with splendid swearing that left nothing to be desired." ${ }^{244}$ At the celebration of the fiftieth screening of the film at The Hague in March 1925, it was stated that Adriënne Solser, in the tradition of her illustrious brothers, had acquired a distinct position in the worlds of theater and film. Moreover, she was honored for creating a genre of her own: "Over the past years you have concentrated more on film and proven yourself to be a natural-born Komische Alte. Your creation of this part is outstanding." ${ }^{245}$ It was Adriënne Solser who indeed had transferred the type of the Komische Alte, certainly in the Netherlands, from stage to screen: first with Benno's films, then with her own. One of the most eloquent formulations of a favorable view of Solser's work from the perspective of its unpretentiousness appeared in, of all papers, Nieuw Weekblad voor de Cinematografie:

Adriënne Solser does not pretend to create a work of art. [...] When she makes a film, she asks herself how to entertain the audience [...]. Thus it is that she herself re-enacts the entire film. [...] The comic performer Adriënne Solser wants to make people laugh [...]. Therefore, this film has to be looked at from a completely different perspective than any other film. People come to see Adriënne Solser, and perhaps even more to hear her. ${ }^{246}$

The instruction that one ought to approach Solser's films from an entirely different angle than other films is of crucial importance, and, in the opinion of the author cited, it was prompted by the actress' paramount on-screen performance and her live appearances at the screenings. This alternative approach and its accompanying language, constructed to describe the appeal of farce in cinema, compelled recourse in concepts that constituted the critical discourses about staged entertainment. From such a perspective, Solser's main skills were her stage presence, her capacity to grasp immediately and to hold the audience's attention, and her ability to keep people laughing throughout: "She cracks a new joke every minute and time and again it shows how close her interaction with the audience is. [...] Solser's comic potency does not wane for a second." ${ }^{247}$ Another critic concluded that it was largely thanks to her performance that the film became such a hit. ${ }^{248}$ 


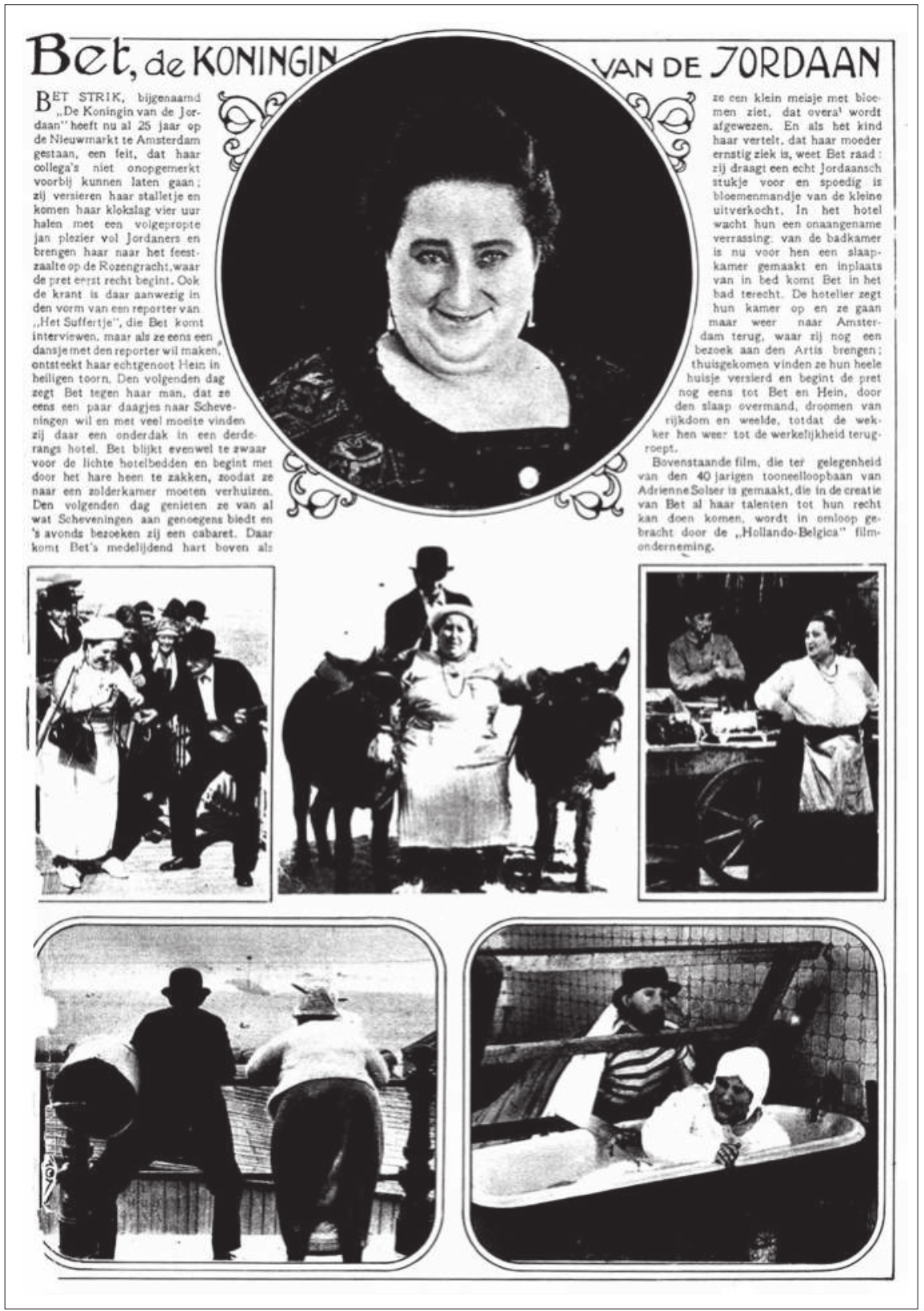

Fig. I.20: Review and stills of BET, DE KONINGIN VAN DE JORDAAN in Weekblad Cinema en Theater, n.d., nr. 44, 1924, n.p. 
Solser toured the Dutch provinces with BET, DE KONINGIN VAN DE JORDAAN and BET NAAR DE OLYMPIADE once more between October 1932 and May 1934, and her scrapbook of reviews in local papers has been preserved. During those years, sound film was becoming a standard in the Netherlands, so Solser's performances with her silent films increasingly became a curiosity. It was precisely this situation that prompted reporters to articulate what was so special about the event, and thus the reviews contain invaluable descriptions of what Solser actually did while on stage during the screening.

First of all, she introduced the film by pointing out that she spoke in the Jordaan dialect, which was invariably acknowledged as a comic device in its own right. ${ }^{249}$ Secondly, she did not mince her words, which no true woman from the Jordaan would do. Furthermore, just as the older actor-lecturers had done, she enlivened the emotions expressed on screen:

the famous Jordaan star performs live on stage next to the screen and sings and sways and talks and sneers and swears with crass guttural sounds with every movement of her impressive shadow. ${ }^{250}$

Although this was not explicitly stated, the comic effect of the simultaneous live and screen appearance did resonate: "It is indeed quite nice to see the protagonist from the silver screen suddenly standing there in the flesh." ${ }^{251}$ Elsewhere, a link with sound film was drawn: "At times she hollers so tremendously that the film becomes more than a "talkie." ${ }^{252}$ Such an association of the Bet-films with sound film was neither new nor rare, ${ }^{253}$ because it had already been expressed in 1928:

The Bet-films in fact were primitive precursors of the so-called "talking pictures." No, they were even more than that, because a talking picture will not be interrupted in order that the audience may have an encore of the funniest or most touching song, which Mrs. Solser was always happy to give. ${ }^{254}$

This same writer reported that the performance created a certain intimacy among the public in the auditorium. Another contended that the live act created an impression such that it was as though one experienced the whole story personally. ${ }^{255}$ Thus Solser's live act added a contact with the spectators that the films alone did not establish. In addition to the physical presence and vocal locution described, her tools included singing the merry songs in which the jollity of the people of the Jordaan was celebrated in the diegesis, and that engendered a feeling of shared pleasure in the auditorium. The words of some of the songs were shown in intertitles on screen, so that people could 
sing along with them as in a karaoke setting avant la lettre. On the other hand, Solser also inserted sensitive remarks and touching songs, most notably into scenes that contained a thoughtful message. Thus she brought into play the combination of a laugh and a tear characteristic of the popular stage, a familiar medium.

On top of this, Solser continuously cracked jokes, for which the films, as the editing of the preserved prints testifies, indeed offered enough time. They contain several conversation scenes between the actors, which obviously only lasted long because they were meant to be dubbed live and filled out with some wise-cracking. We actually can observe the actors, and most notably Solser herself, speaking, although such a scene is not always followed by a title with dialogue, as for instance the one in BET, DE KONINGIN VAN DE JORDAAN in which Bet dances so energetically with the reporter who has just interviewed her that she falls to the floor, hurting herself so that she cannot stand up again 120 without assistance. Hein, who witnesses this with increasing jealousy, consoles her in the end, but not without lamenting. The print does not contain any titles in this scene, but it was in a reconstruction of Solser's live act when plausible words were added to it, something to the effect of "Please don't do that ever again."

Another instance is found in a scene in Bet and Hein's bakery in BET NAAR DE OLYMPIADE, in which she tests the contents of a bottle that he has tried to convince her is milk. From the gluttonous appetite and the disbelief registered on her face and the envy and anxiety on his, it is obvious that the bottle does not, in fact, contain milk, but this is not articulated in titles while she is emptying the bottle. The extant prints reveal that there was space for additional commentary or dialogue and that various scenes actually required it. They indeed offer quite a few comic moments, but not so many as to lend support to the contemporary reports of the audience's continuous laughter. The latter confirm that the incessantly flowing laughter was the result of Solser's live performance. In the screenings of one of the lost films, moreover, Solser was reported to have inserted a sketch that she performed live with another actor, the former film lecturer Charles Braakensiek. ${ }^{256}$ Therefore, I would like to suggest that the film prints be treated like the songs and verses from the variété that have been handed down on paper, which, as I pointed out, should not be read to the letter but be taken as guidelines for a scintillating performance. As film prints, they fully represent neither the dynamics nor the laughter-provoking qualities of the show and thus they do not suffice to document Adriënne Solser's art of entertainment.

To a certain extent, this was acknowledged by Peter Delpeut, a former curator at the EYE Filmmuseum. Only after having witnessed a reconstruction of the live accompaniment, conducted by the Dutch jazz singer Jet Pit, did Del- 
peut understand how Solser's films, which he found to be "unbearable if not unwatchable" when shown unaccompanied, "could once (and still can) work for a receptive audience." ${ }^{257}$ By taking into account that the films were never meant to be screened alone, Delpeut, unlike his predecessors' attempts to assess Solser's films, situated her films in the tradition of showing films with appropriate accompaniment, whether live music or opera fragments or popular sing-a-longs. In line with my analysis, Delpeut noticed that the sing-a-longs with the adaptations of volksstukken must have created a "communal enjoyment" and "an element of the Dutch national character". ${ }^{25}$ However, Delpeut returned to the notion of film as art in his conclusion, stating that Solser's "Bet films also reveal that all artistic standards in camera work, direction and acting were gladly sacrificed to this end", ${ }^{259}$ the goal of creating a feeling of commonality in the audience. To judge Solser's films in light of an ideal of film as an autonomous work of art does not do her films justice. Within the framework of Solser's practice and ambitions, film was neither autonomous nor an art; unlike the accompaniment of the pianist or the lecturer, her live act was neither subordinate to the film nor could it be substituted. The contemporary reports suggest that the screened and staged acts were tied together in a balanced interaction. Solser's cinema was plain entertainment based upon an interactive relationship between the stage and the screen, and, as such, her films were an inextricable ingredient in popular stage culture. This popular stage culture, certainly in the Netherlands, had included film and most notably comic or farcical cinema for quite a long time. However, this does not mean that Solser's cinema ought to be situated outside or on the margins of the film culture that existed then. On the contrary, her films belonged to a culture of producing, programming, and watching film within the context of the popular theater, that persisted longer than Dutch film histories have thus far considered.

Because Adriënne Solser transferred the character she had developed on-stage to the silver screen, I shall discuss the BET films, to begin with, by exploring that farcical female character and Solser's manner of acting it. As I mentioned earlier, prints of the first Eureka production, BET, DE KONINGIN VAN DE JORDAAN (1924), and of the final one, BET NAAR DE OLYMPIADE (1928), which will hereafter be cited as BET I and BET IV, have been preserved, thus allowing for a text-related re-assessment. In accordance with Solser's conception of cinema as popular staged entertainment, however, I shall, as far as possible, include her live accompaniment in the analysis. Despite my focus on popular theater influences, moreover, I shall, as far as relevant, also explore the formats and devices originating from popular cinema of the time, to which Solser's films referred. In this way, I hope to review them from an affirmative perspective, that is to say without measuring them against standards that they did not aim to meet. 
The Bet film character was a continuation of the persona Solser had developed on-stage and then, in collaboration with Benno, adapted to the screen in the character of Kee. As such she belonged both to the stage and to the cinema. She was the streetwise female bully with a heart of gold, but while she was just as full of zest and as silly as Kee was, Bet was both more fearless and more sociable. Each of the films contains scenes of parties and festive occasions that testify to Bet's exuberance. They are set in the Jordaan or in a cabaret and feature Bet as the cheerleader or as a performer. Bet dances about energetically, arms in the air, her voice raised above everyone else's. In her state of excitement, she may fall flat on the floor (as in BET I) or step on her dancing partner's toes (as in BET IV) and then seem foolishly miserable, but her bad mood never lasts.

Bet is fearless in two respects: in her curiosity and boldness concerning the unknown, and in her opposition to injustice. Bet is sheer bossiness and 122 does not shun conflict with either men or authorities. These character traits constitute a narrative basis for generating situations that are often farcical and sometimes touching. The inclusion of moving scenes in a film farce is one

Fig. I.21: Still from BET NAAR DE OLYMPIADE.

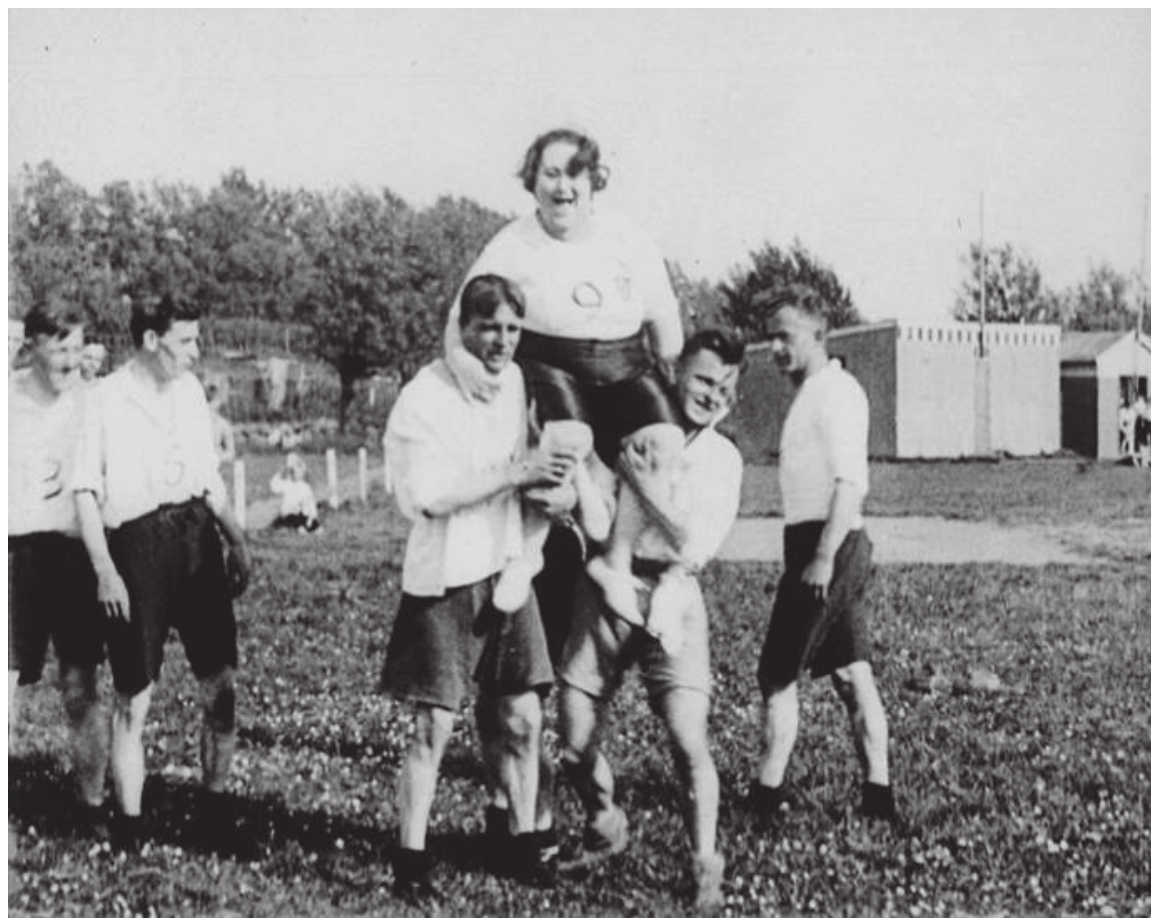


way in which Adriënne Solser carried on the tradition created by the Ensemble Solser en Hesse on stage. In a heartfelt scene in BET I, we see Bet scolding and kicking out the landlord who dares to bother a poor sick mother because she has not been able to pay the rent recently. In BET IV, she cries out against the evil of unattended crosswalks and helps save a child from being overrun by a train. She also pays a visit to a dying old man, a former soldier in the colonies now forgotten by the nation. While this touching insert may be controversial to post-colonial minds, it fed into a nationalism purportedly avowed by Jordaan people. Such scenes center arround the injustice and neglect of the needs of the poor and feeble, and sustaining the image of solidarity and candor of the Jordaan folk. In the Bet films, such sociable tendencies are attributed to Jordaan women in particular.

However, given that the Bet films are farces, Bet's fearlessness must of course generate mainly farcical situations. Examples are indeed abundant. At the Amsterdam zoo in BET I, for instance, she feeds the baboons with peanuts, but she comes so close to them that one baboon gets to her and grabs her hat: the farcical stems from her scuffle with the ape and her broken-heartedness about the loss of her hat. In BET IV, which tells of Bet's dream of finding acceptance as the official representative of the Jordaan at the Olympic Games in Amsterdam, her bravery and pugnacity propel the entire farce. She goes on her own to The Hague (where she has never been before!), neutralizes the pedantry of some sham (and self-righteous) authorities, and outstrips her male competitors with a little help from her husband. When the committee's president refuses to allow her to participate in the Games, she just pulls him over his desk and strips off his trousers. While this scene may be considered vulgar and a literal instance of tits-and-ass comedy, it works better when seen from the point-of-view of the fearless woman at the heart of the farce. The action as such may be too awkward to be funny, but it is fun to see Bet having her way.

The fearless woman motif evokes a cinematic genre highly popular during the 1910 s and early 1920 s, that is to say, the genre for which Ben Singer has coined the term "the serial-queen melodrama", serials with intrepid women as their protagonists. ${ }^{260}$ Such serials were thrilling adventure stories and their format was governed by strict rules. In the United States, where the format had been developed during the early 1910 s, they came in numerous instalments each of about half an hour and were either structured as continuous stories in which each episode ended with a cliffhanger, or as self-contained chapters linked together by the reappearance of the same characters. (In the latter case they were not called serials but series.) When they reached Europe during the war, when feature-length films had become the standard, they were usually exhibited as compilations of two or three original instalments.

Although series and serials were not a comic genre and although their 
format in the strict sense was not adopted in Solser's films, it is nevertheless possible to trace certain affinities. First of all, the series' titles often included the given name of their heroine. Titles such as BET ZIT IN DE PENARIE and BET NAAR DE OLYMPIADE are reminiscent of PEG VAN HET CIRCUS (PEG O' THE RING) Or DE AVONTUREN VAN ELAINE (THE EXPLOITS OF ELAINE). Secondly, apart from Bet, other characters reappeared in them, most notably her husband Hein. Thirdly, although they always used Bet's name in the films' titles, Boesnach and Solser presented the Bet films as a series, one might say as full-length chapters. At the time when the Eureka Studio was opened, they had planned to produce seven more of them, each with Bet's name in the title, some even with the alliteration that was a requisite of the format, such as "Bet in de bakkerij" (Bet in the Bakery) and "Bet de moderne behangster" (Bet the Modern Paperhanger) ${ }^{261}$ Moreover, BET ZIT IN DE PENARIE was itself intended to be exhibited in two instalments, as the advertise124 | ment announced it as "fortnightly series-film". ${ }^{262}$ This advertisement lends support to my assumption that the idea of making series, if not serials in the strict sense of the word, was indeed in the minds of Solser and Boesnach. It was also reported that, for France, where the film was released under the title LE MOULIN À VENT (The Wind-Mill), a four-week series was planned, "while

Fig. I.22: Still from BET ZIT IN DE PENARIE.

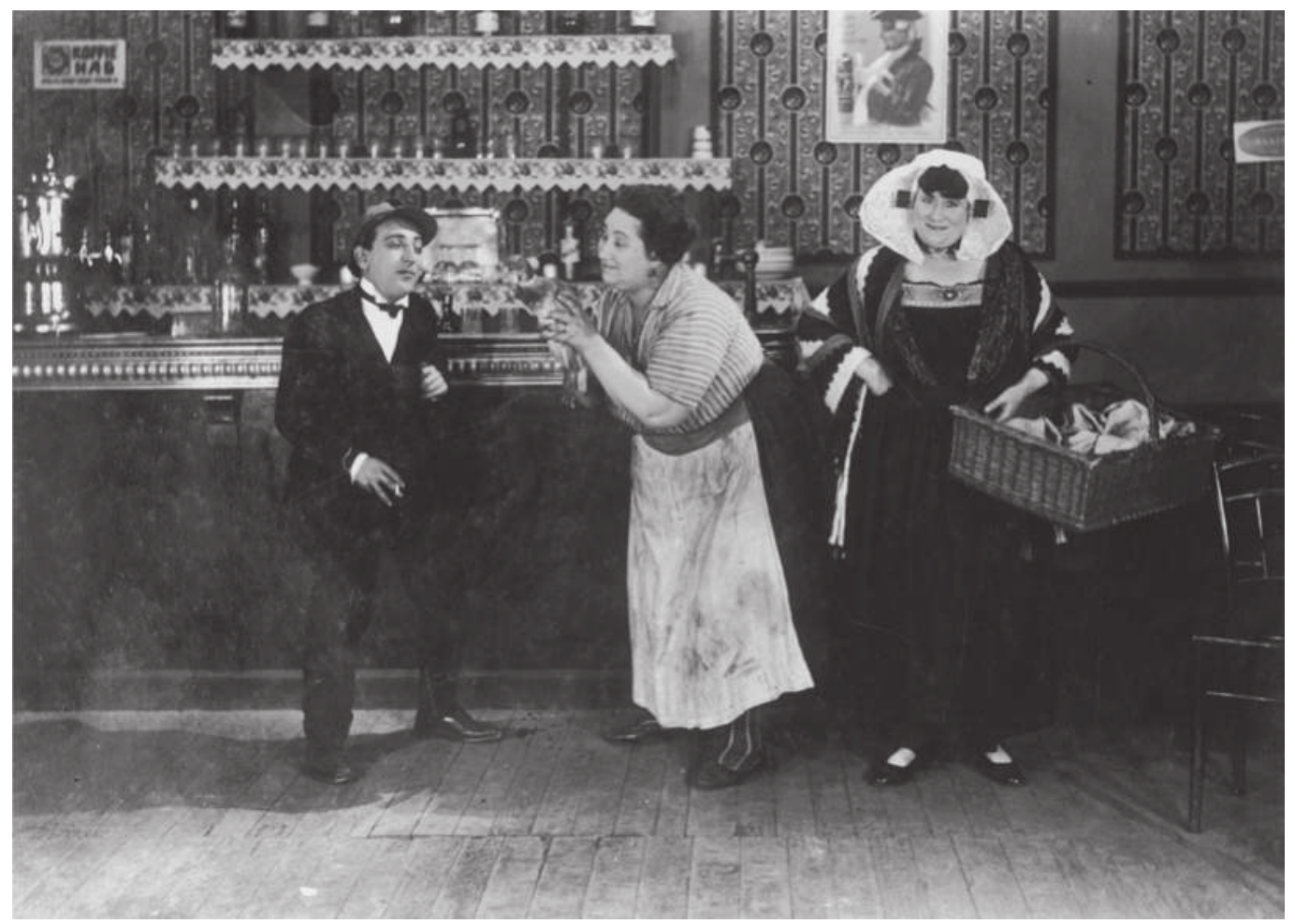


experience shows that in our own country more than two weeks is not to be recommended". ${ }^{263}$

Moreover, some of the films include specific serial-queen melodrama motifs. One of these is the insert of potentially dangerous situations in exotic sites, from which the heroine has to save herself. This was, for instance, the case in BET TREKT DE 100.000, in which Bet goes to Algeria and faces all sorts of dangers out of sheer curiosity. The preparation for the Olympic Games also creates risky situations in unknown sites, firstly because Bet is not an athlete yet enters the realm of sports, and secondly because she would comp with men. BET IV in fact incorporates even further motifs from such serials. One of them is the topic of a woman doing what men usually do. In order to show how strong she is, Bet lifts her much taller dancing partner up in the air with just one arm. Another motif is that, as a consequence of Bet's courage and strength, she saves Hein repeatedly, from falling over a rail along the canals, from falling from the streetcar, or-and this is the climax-from drowning in an indoor swimming pool. All of this, however, is presented in a nonsensical mode and Bet partly cheats her way into becoming a winner. Therefore, one possible subtext may be the film's mockery of the serial-queen melodrama, which would make it an example of a "fearless woman farce".

Vital to the construction of Bet's character is her relationship with Hein. Compared with the Bet and Hein created by Solser and De Wilde for the stage, the two have matured. Rather than aspirations, they now have a past, as in BET I, in which the protagonist celebrates her twenty-fifth anniversary as a market vendor. In BET IV, Hein is eager to see Bet swimming, because, he says, "Misschien word ik dan weer verliefd op je" (Maybe then I'll fall in love with you again). They are presented as a longstanding couple, who have stuck together despite their oddities. Such main comic roles for older women were rare in Dutch cinema. The couple is childless, which allows both characters, particularly at their age, to be more adventurous than if they had parental responsibilities to fulfill. This notwithstanding, their consistent characters contrast with one another. Bet knows better in all matters, controls the money, and takes initiative. She treats Hein either as a servant bound to follow her whims (as in BET I) or as a naughty child to be watched constantly in order to keep him from mischief (as in BET IV). In either case, she leaves no doubt about who is to be considered the "better half" of the couple. Or, as one critic put it:

Hein [...] is the man-who-gets-the-thrashing, generously administered during the myriad droll complications and domestic quarrels from which Bet invariably emerges triumphant, ${ }^{264}$

and another moaned: 


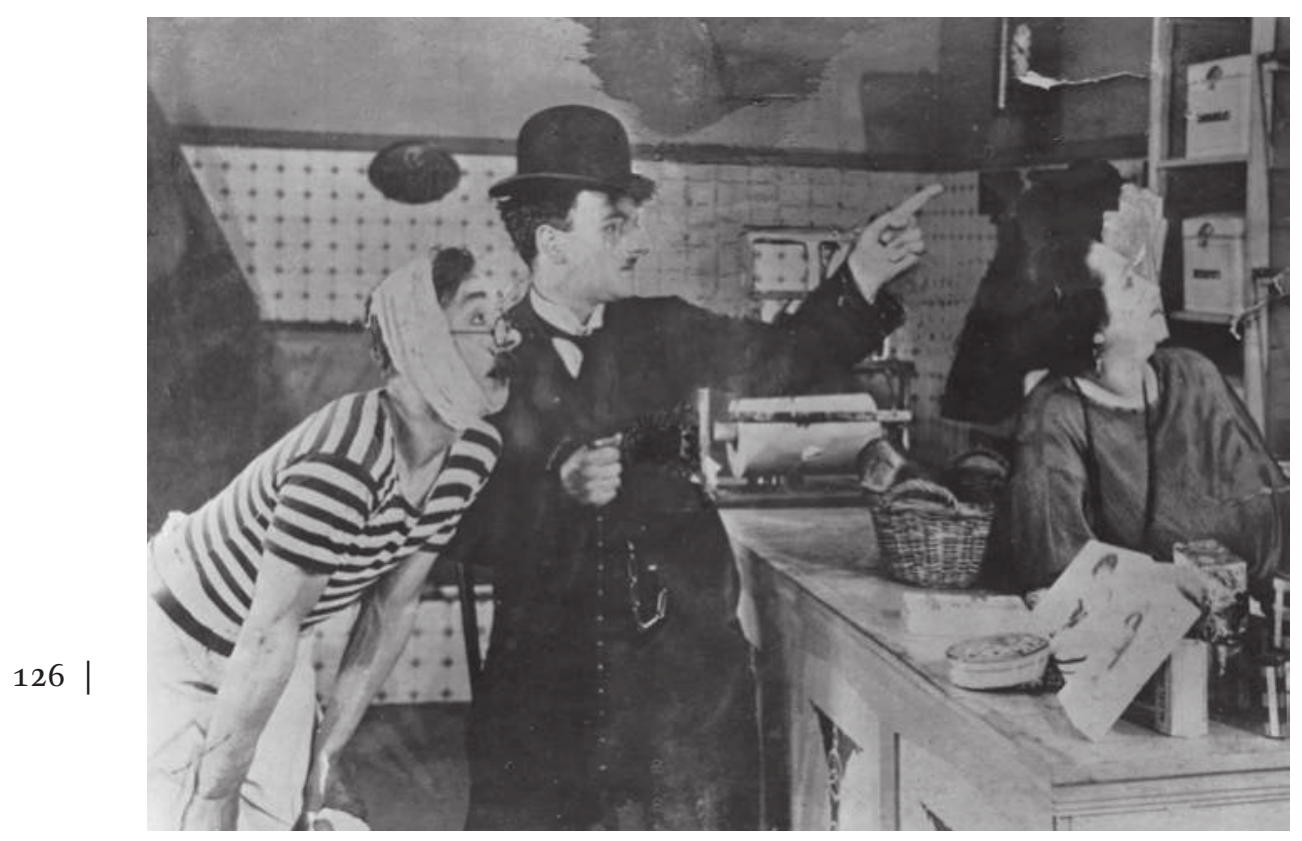

Fig. I.23: Bet and Hein in their bakery, being cheated by a Chaplin imitator. Still from BET NAAR DE OLYMPIADE.

Whoever has never seen in action a female "wearing the pants," as the saying goes, ought to go and watch Bet in this film [...] then one will immediately understand what "henpecked" means. ${ }^{265}$

Nevertheless, there are subtle differences between the two Heins, which have an effect on the respective Bets. The first Bet is not above occasionally heightening the effect of Hein's clumsiness, even if this works to her own detriment in the end. For instance, when as first-time visitors to the bath resort of Scheveningen they descend onto a terrace and enjoy some ice-cream, Hein asks for a larger spoon than the one he was given. The background to the joke is the KEE EN JANUS-motif of the Jordaan people not knowing how to behave out in the wider world, which has been abridged, in BET I, to the question of their table-manners. While everyone at the terrace laughs at the odd couple, Bet lends hilarity a hand by throwing the ice-cream at Hein's face and then demonstratively licking her fingers. By this act, obviously intended to render Hein ridiculous in the eyes of the onlookers, she becomes no less ludicrous than he is. In such scenes, of which there are a number in BET I, her bossiness 
is ridiculed ostentatiously, not least by Solser's own performance and direction. Thus, we are invited to laugh at them, not with them.

For his part, in BET IV, Hein does take things with less docility and balks at heeding his wife's faultfinding. For instance, at a certain point he falls into his dough vat (they are owners of a bakery) and then goes to take a bath. In the meantime, Bet chats in the living room with an elegant woman friend. Seemingly dressed in no more than a loincloth, Hein enters the room and parodies a graceful dance, exposing his skinny frame. Of course, Bet scolds him and tries to safeguard her visitor from the indecent and unattractive sight, but Hein just takes his time before sauntering into the alcove. As the women are leaving, his naughty face peeps through the curtains. Here, and generally throughout the entire film, a farce is created but without jibing at the characters, not even at Bet's bossiness. As a viewer, one oscillates between laughing at them and laughing with them.

To my mind, the differences between the two Heins are not so much a feature of the narrative itself as they are an effect of the different screen images and acting styles of Jan Nooy and Alex de Meester, respectively, a difference which rebounds upon those of Adriënne Solser and alters them. Solser plays a stout and mobile Bet in both films, while Hein is bony and oafish. Bet displays her authority by slapping the first Hein's fingers and kicking the second in the rear, while otherwise shoving and dragging him as she pleases. However, while in principle they played the same role, the actors opposite Solser varied in their performance. As a consequence of their different acting styles, the substance of their roles changed. Jan Nooy not only played a dry stick, but was one in his acting as well. He seemed paralyzed in his role, as if he lacked the farcical and physical tools needed to counteract Solser's thrashings about. This may well have been due to a weak director incapable of curbing Solser enough to allow her co-star to come into his own. Neither Solser nor Hulsman had directing experience.

In contrast to Nooy, Alex de Meester used his body and face as if they were elastic, which enabled him to compete with Solser in both performance and presence. His half-naked dancing act testifies to this and can be just as scene-stealing as some of Solser's acts, while poking fun at them at the same time. Moreover, he does things like push Bet through a doorframe with his buttock, or appear with a huge bandage around his head because his jaw is aching, or throw a cream pie at an imposter. In other words, he has at his disposal physical tools as extraverted as Solser's. It is quite likely that the experienced director of this film, Theo Frenkel Sr., who knew Solser well, having directed her in two of his films, supported De Meester's decision to employ these physical tools in full. In place of Nooy's duffer, De Meester created a lively henpecked husband. 
The emphasis on Bet's proportions in the films is remarkable. There are manifold situations in which her figure is satirized: she gets stuck in a revolving door, requires a couple of donkeys in order to take a ride on the beach, and crashes through the frame of a hotel bed and cannot extricate herself from it on her own. Or, gesturing about her heftiness, she asks the sailors if the boat will hold her. Nevertheless, her largeness is never a problem for her: it merely generates hilarious situations or lends her weight, metaphorically speaking. The jealousy scene in BET I, moreover, suggests that it may also be attractive, something that is more fully exploited in BET IV. Her surname in the latter film is "Mager" (Lean), and the locals prod her to take part in the Olympic Games by calling her "Slanke Lelie" (Slim Lily). Compared to her first film, Bet indeed seems to have lost weight, but only just enough to show off her body - and Solser's mobility, still astonishing for someone at age fifty-five-in the various sports outfits that are indispensable when preparing for 128 the Games. She appears in a wrestling costume, black tights under a white pair of shorts, which highlights her bulky torso; in a sailor suit that makes her look young and boyish; and, of course, in a bathing suit, a kind of dark short dress with a belt, which in fact becomes her well. However, the contrast with the other women present at the pool is immense and after they have helped her undress, her appearance calls forth hearty laughter from the bathing beauties all the same. After the men have been sent away from the dressing room, Bet has no problem heightening the mirth of the women by spinning around a few times with her pants around her ankles and by dancing in front of a distorting mirror, which only renders her bigger; the women continue on laughing the entire time. The scene is interesting for several reasons. It is one of the extended scenes without intertitles, and therefore presumably offered ample room for additional jokes in Solser's live act. Furthermore, it communicates to audiences that it is permissible to laugh at Bet's girth and as such transfers to the screen the irony on the issue exhibited in Solser's earlier variété performances. With the women epitomizing laughter and in view of Bet's indulging in the fun after the men have exited, it also conveys that women in particular are better able to take Bet's - and, by virtue of the scene with the mirror, their own-weight lightly. Simultaneously, however, the scene shows Bet to be fat but not unattractive. Thus it lends support to an aspect of her character evoked in two earlier scenes in which she flirted openly with a sandwich-man and chatted with a local officer, who was visibly flattered by her attentions. When she finally descends the steps to the pool while taking off her bathing robe, she looks almost elegant and definitely victorious.

The foregrounding of the costumes and the focus on Bet's and the other women's bodies in BET IV brings to mind the genre of the revue. The film contains many more aspects and scenes in which the revue format is invoked. 
First of all, it picked up a topical issue, as the Olympic Games were indeed held in Amsterdam in 1928 and women were admitted to take part in them for the first time, although only in athletics. Furthermore, it contained a persiflage on one of the most influential critics of the genre, Barbarossa, himself an occasional revue-writer, an insider's joke characteristic of the revue format. It also employed the typical revue device of the running gag: the three members of the jury that had to evaluate Bet's activities were shown with booze in hand each time they appeared. The women at the swimming pool, undressing themselves and showing off their bathing suits, recalled the scantily-clad girls who were a staple embellishment of the revue. In addition, Bet's appearances in a choice of outfits, including tight suits and cross-dressing, are reminiscent of the revue device of laying emphasis upon the variation of costumes. And, last but not least, behind the pool there is a white staircase decorated with palm trees, which refers to the obligatory staircase from which the star of the revue used to descend. The mise-en-scène hinted at the finale of a revue, with the countless girls escorting Bet on her descent and waving their arms, suggestive of the attendant glitter and glamour. But, because of the farcical turn given to all of it and because of the satiric approach to Bet's proportions, it does not merely represent an adoption of revue devices, but also actively mocks the genre. Thus the film can be read not only as a "fearless woman farce", but also as an "attractive woman farce".

As long as Adriënne Solser did not have to play the buffoon, her acting was relatively natural and restrained. As previously pointed out, already in 1910 she was known for acting without histrionic frills. As a comic actress, moreover, she was not intent on expressing emotions but on displaying sensations. When conveying pain, her mien was that of a child weeping, not of an adult suffering. In addition, she had her live performance, in which she could add verbal jokes and explanations. Most of her comedy on-screen was created with tools different from mien or gesture, that is to say, with her body; hence the slapping, the kicking, the pushing and pulling, the jumping, the dancing, and the falling. Hence also the exposure of her figure, and the emphasis placed upon it. In this sense she had effectively adopted a slapstick style of acting, which had migrated from the popular stage to the comic screen. It went awry in only two kind of scenes: in physical clashes with things or people, in which she tended to fidget and to move too wildly, especially her arms, and in scenes with her at the center of the excitement and jollity, in which she tended to overdo practically her entire performance.

Solser's relation to the camera was, from a cinematic perspective, not developed or reflective. The camera, and the editing in its wake, was meant to register her and the other actors' performances. As tools, camera and editing were not used to construct cinematic spectators, but were instead employed to 
address people as groups of onlookers watching the antics of the characters. In this way, audiences were addressed as they had been in popular theater, a manner that they obviously loved. Again, the manner in which Solser's live act interfered with such a communication remains a subject of speculation. If it indeed was as though one experienced the whole story personally by virtue of her presence, as the reviewer whom I cited wrote, then her act must have made up for a point of view that would otherwise have been missing. This, however, seems implausible on two counts: first, it opposes Bergson's thesis of the necessity of abstaining from subjectivity on the actor's side and from sympathy on the spectator's if laughter is to be produced, something which, I have argued, Solser and her colleagues understood very well; and second, it stands in contradiction to the manner in which the Jordaan genre functioned, which addressed audiences precisely in their commonality and disregarded the individual. In the best case, then, Solser's accompaniment offered a point of view 130 that allowed the audiences to oscillate between laughing with and laughing at the comic heroine and hero.

Just as in the films made for Louisette and Chrétienni's variété act "Van Boerin tot Artist", the onlookers on the scene in front of the camera were included in the frame and, in their turn, gazed at the camera and into the lens. Most notably in BET I, such images recur so often that they cannot be considered accidental. In one of the first instances, the device is linked to Bet's self-mockery vis-à-vis her physique. Here, she tries to climb onto a cart full of party guests setting out to ride through Amsterdam, but fails a few times. Friends trying to pull her inside the cart end up falling off it instead. A dozen pairs of men, who have been watching her vain struggle, finally manage to push her backside up. Women and men from the crowd, laughing at the situation, continue to do so while looking into the camera. In the last shot of the scene, the laughing crowd even cuts off the camera's view of the cart. The film contains at least six further scenes in which onlookers, who gather due to some ludicrous situation in which Bet has found herself, gaze at the camera. As in "Van Boerin tot Artist", here too there is produced an effect of contingency and actuality of the shooting, as well as commonality between the audiences on the screen and those who are watching it. In this way, Adriënne Solser and her co-director Pierre Hulsman drew on devices from early film, which had migrated to the mixed theater and film acts in Dutch variété and that returned to the cinema with BET I.

One of the preserved prints of BET I opens with an impressionist sequence of life at and around a market. These images originate from a source other than Eureka and bear the trademark V.V.V.O. Journaal. They show fish, fruit, flowers, and other merchandise, alternating with shots of people selling and buying, eating and smoking, and so forth. The sequence suggests that one is 
about to see a documentary rather than a farce. Together with the crowd watching the action, these documentary-like images are one of the few instances in which the film plainly refers to cinema.

BET IV contains more cinematic references. It has animated images - a moon winks at the audience and watches over the city while Bet dreams of participating in the Olympics-, double prints, and dissolves that render the impression of crowds visiting Amsterdam for the Games. We see trains enter the station and busy streets. In one shot, a mirror is used to produce an effect of rushing traffic. It shows the crowds pouring out of the central station, and the mirrored image of a streetcar passing by. The film also offers a Charlie Chaplin imitation. ${ }^{266}$

By pointing out such imagery, as well as by making the connection to the serials, I draw attention to the fact that the BET films are not entirely devoid of references to film culture, even though their interrelatedness with the popular stage is far more eye-catching and significant. These images offer a construction of the Jordaan and its people that diverges from that provided by the adaptations of Bouber's plays. In Solser's films, the Jordaan is not depicted as a self-contained village, in the eyes of which the wider world is a dangerous place, but rather as an idiosyncratic part of a larger whole, that is to say, the city of Amsterdam and-by virtue of Bet's trips to Scheveningen and The Hague-the country of the Netherlands.

\section{Solser's Career in the Cinema}

With Adriënne Solser's films, the film historian who has abandoned the idea that the only films worthy of scrutiny are those that are works of art, may be confronted, as I have hoped to demonstrate, with new vistas of a world otherwise largely obscured, that is to say, the world of Dutch variété and popular theater of the 1910 s and 1920s. To a certain extent, Solser's films document that world straight from the source, most notably because they had no pretension of being film art. The acts of a soubrette were recorded by and through them and, thus, insofar as prints have been preserved, saved from an everlasting transience. A second merit is that Solser's oeuvre did not seem to fit into the usual categories, accordingly forcing me to look beyond the narrow world of Dutch film production of those years. Her films have guided me to the practices of mixed stage and film production and especially exhibition. These practices were longstanding and widespread and the role of soubrettes and their male colleagues in making film-watching outside and inside the cinemas acceptable to large audiences was pivotal. My survey of Dutch comic film production brought to light the striking gap between the comic acting poten- 
tial present on the stage and the aspirations of Dutch filmmakers of the 1910s, who did not care for comedy or farce.

Such were the concepts upon which Adriënne Solser drew when she began collaborating with Alex Benno and Theo Frenkel, Sr. as producers and directors and upon which she continued to draw in her own film productions. She made use of her fame and appeal to large audiences to the benefit of the Dutch comic film. Hers was the art of entertaining and in order to achieve the continuous laughter for which she aimed, she used her comic potential on screen, but invariably combined it with live performance. Thus, she established not only her own film production at a time when funding was hard to find in the Netherlands, but also her own practice of exhibiting films. She exploited the comic device of simultaneous screen and stage presence. She carried into the 1920 s concepts and practices which seemed anachronistic, but which in fact, by her handling of them, would prove to be and remain highly popular with

132 audiences well into the 1930s.

\section{EPILOGUE}

After the events at Schiedam, Adriënne Solser initially gave both theater and film the cold shoulder. She moved to The Hague where she opened a guest house for actors and artists in 1929, Pension Liena, named after Engelina, one of her own given names and her mother's and her daughter Lien's as well. By 1931, she went on tour with her films again, accompanying BET, DE KONINGIN VAN DE JORDAAN live, to be followed by BET NAAR DE OLYMPIADE between October 1932 and May 1934. On February 18, 1933, Adriënne Solser turned sixty. In 1934, she reappeared on the screen in the sound comedy HET MEISJE MET DEN BLAUWEN HOED (The Girl with the Blue Hat), directed by exiled filmmaker Rudolf Meinert, in which she once again played an Amsterdam greengrocer. Solser's notebooks contain a verse inspired by this role that she delivered as an entr'acte in a cinema program at the Beurs Theater in Groningen in May 1935. According to the review, Solser's name was still well-known and her act was a big hit. ${ }^{267}$ That same year she played a supporting role in two more films, both directed by Haro von Peski, SuIKERFREule (Sugar Lady) and HET LEVEN IS NIET ZO KWAAD (Life isn't That Bad). These parts were so insignificant that they were barely even noticed. Meanwhile, she continued performing on-stage, as revealed by her notebooks. ${ }^{268}$ In one of them, Bet claims that she had given up on film:

They've filmed Auntie Bet in a great number of cities, Those films I've lectured on and amplified nationwide, 
But then I thought: no, Bet, film offers you no inner peace, Now it's time that you return with due speed to the stage. ${ }^{269}$

Note the switch from the third to the first person in the first two lines, and thus the distinction between the two, which is nonetheless abandoned in the following one. Finally, another notebook, dated October 1935, testified to the revival of several old Bet verses on stage, including "Bolle Bet uit de Willemsstraat" and "Tante Bet de Garnalenpelster".

Nothing can be retrieved concerning how Adriënne Solser lived after 1935, except that she played another supporting role in the 1943 film by Gerard Rutten, IK FLUIT IN DE HOOP DAT JIJ ZULT KOMEN (I whistle and hope that you'll be coming). That same year, on February 17, both the newspapers $D e$ Telegraaf and Algemeen Dagblad announced that she would turn seventy the next day. The brief notices contain nothing new, but testify to the fact that she was still sufficiently remembered - as a Jew during the Second World War-to have her birthday acknowledge. Nine months later, the contents of the notices were repeated, but with a different introduction:

At around seventy years of age, the former variété and film artiste Adriënne Solser from Amsterdam has passed away in the Doetinchem general hospital. Adriënne Solser had traveled to Doetinchem several months ago. In the bustle at the station she was pushed while exiting the train; she broke her thighbone and had to be hospitalized for eight weeks. She was due to return to Amsterdam shortly. However, during a last treatment she fell ill and a little later died unexpectedly. ${ }^{270}$ 


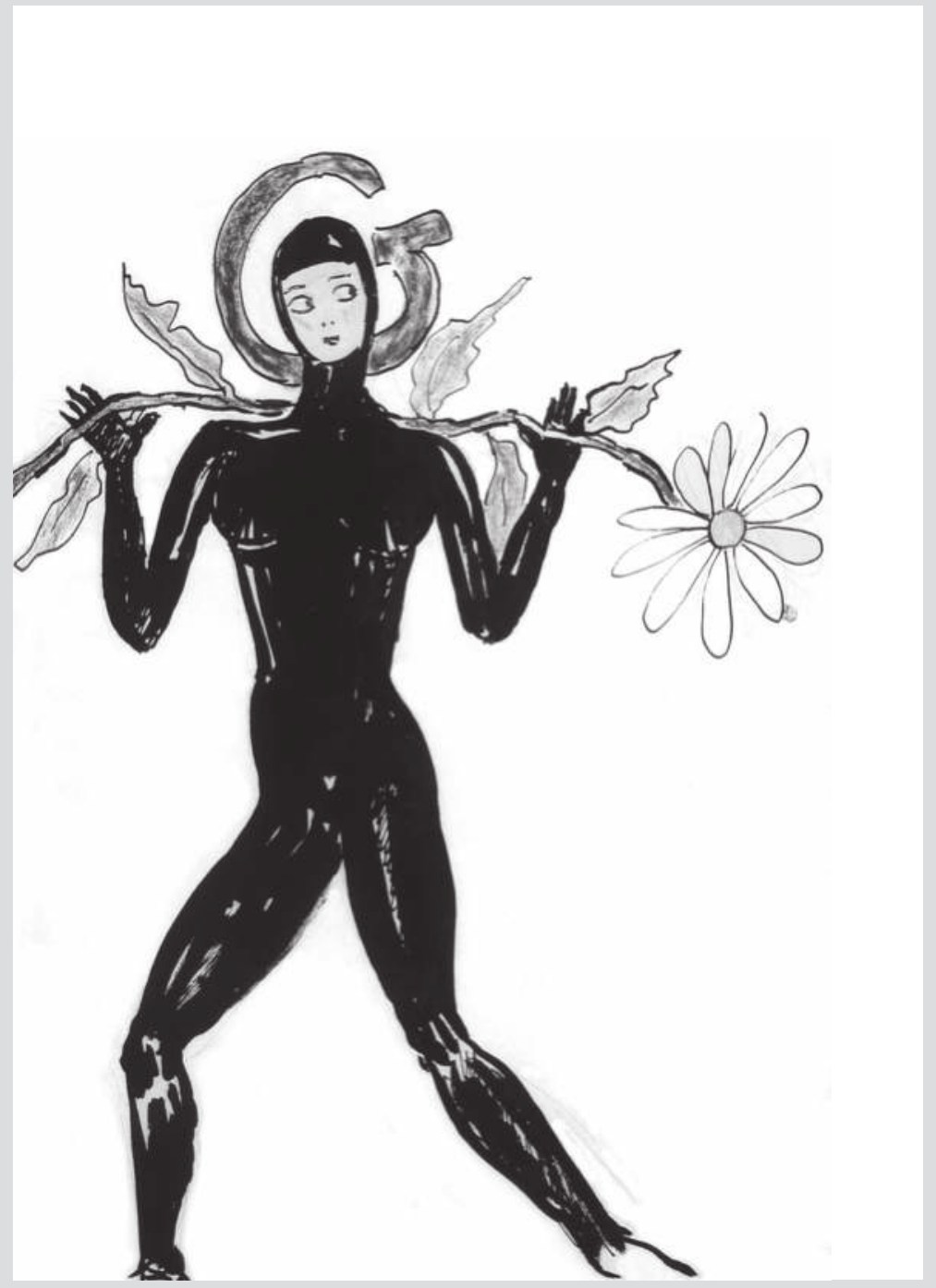

Irma Vep. Drawing by Musidora in a undated letter to Louis Gaumont, Bibliothèque du Film, Cinémathèque française. Courtesy C. Marot. 
PART II

MUSIDORA

FRANCE 


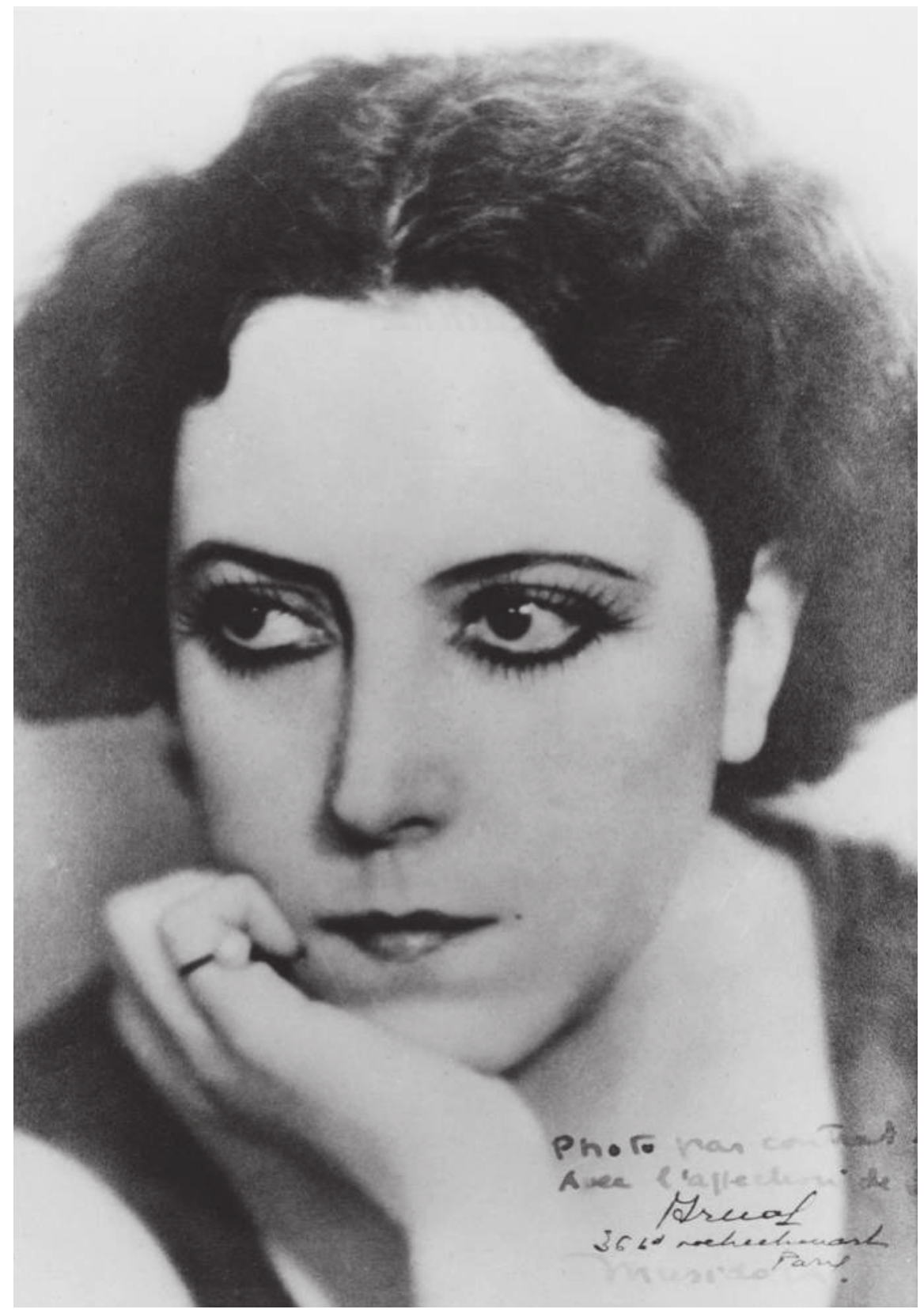

Fig. II.1: Publicity portrait by Photo Irnof. 


\section{Musidora on the French Popular Stage}

Musidora was born Jeanne Roques in $1889,{ }^{1}$ the year in which schooling for children of both sexes became compulsory in France. This was also ten years after reforms in education had been carried out to the effect that women could receive a trainings as, for instance, teachers. ${ }^{2}$ Musidora recollected that one of her career aspirations was to become a schoolteacher in the province, ${ }^{3}$ and she indeed studied for the teaching license after high school graduation. ${ }^{4} \mathrm{Her}$ father, Jacques Roques, apart from being a composer of tunes and operettas for the popular stage, was also a teacher of music. It is a sign of the times that his daughter actually had the opportunity to follow in his footsteps. Those times, the era between 1871 and 1914, are known as the Belle Époque between the establishment of the Third Republic and the outbreak of the Great War. This particular epoch in the history of France enjoyed relative political stability and progressive economic, social and cultural dynamics. The final two decades of the nineteenth century in particular witnessed the stabilization of the democratization process, which sanctioned, among other things, the institution of human and worker's rights and the advent of state schools and general education, ${ }^{5}$ which also incited the struggle for women's rights and suffrage. ${ }^{6}$ Musidora's mother, Marie Porchez, was an outright exponent of this socially engaged and culturally advanced body of thought. Under the pseudonym Marie Clémence, she co-edited a journal entitled Le Vengeur with the motto 'Sociologie, Féminisme, Art' in 1897. ${ }^{7}$ Although a professional painter herself, she abstained from a promising career in model drawing for the sake of her marriage and her husband's work, ${ }^{8}$ and, given her active propagation of women's rights, she must have wished for her daughter to have freedom of choice. Musidora did indeed claim that freedom once it became necessary: 
when she married a family doctor in 1927 , she informed the press that he promised a condition sine qua non to their union that she could continue to work as an actress and an artist. ${ }^{9}$ When referring to her date of birth, Musidora herself used to point to other highlights of the year, namely two events directly bearing on turn-of-the-century popular culture: "the same year as the Eiffel Tower and Charlot". ${ }^{10}$ The Eiffel Tower was emblematic of the World Fair of 1889 and stood for the democratization of entertainment marking the era, the country, and the city of Paris. ${ }^{11}$ Charlot was the French pet name for the tramp persona developed by Charlie Chaplin-also considered by the French to be one of the most eminent comic actors of silent cinema-, whose career, like Musidora's, would include popular stage acting, screen acting, and producing and directing films in which he starred.

The Roques family belonged to a circle of friends with a broad interest in topical, literary, artistic and philosophical matter, the latter of which was 138 | Jacques Roques' favorite subject, and about which he published a book: L'idéal social in $1895 .{ }^{12}$ The poet Albert Mérat was a family friend, who at the time, worked as a librarian and read to little Jeanne poetry by Baudelaire, Théophile Gautier, and the Parnassians, a nineteenth century group of poets revolting against romantic lyricism and political commitment and upholding the principle of l'art pour l'art (art for art's sake) in prosody. ${ }^{13}$ In reticent remarks about her upbringing, Musidora omitted what eventually withheld her from becoming a teacher; instead, she emphasized that she pursued the artistic talents with which she was gifted in addition to her intellect. Her father had taught her to sing and her mother had taught her to draw, but somehow this dark-haired, ravishing beauty had been bitten by the bug for the stage, la Foi, in French. ${ }^{14}$ Musidora's published self-presentations do not contain concrete references to actresses she may have considered her models; they do, however, give one hint at a theatrical genre that she might have envisaged to make her own: at school, she directed a theater-circus. ${ }^{15}$ If combined with her allusions to the World Fair and to comic film, then it seems safe to conclude that she did not aspire to the legitimate stage at the Comédie Française or the Opéra, but fancied more popular types of theater, which, as will become apparent, offered an increasing number of professional possibilities for talented, smart, and ambitious young women after the turn of the century. Even though-or perhaps because- - her father was involved in stagecraft as a composer of popular music, the Roques sent their only child to an art school. Class may have been involved in this decision: until the 190os, female performers in popular entertainment often came from the lower class and went on stage as early as their teenage years, often forgoing schooling. In addition to art school, Jeanne Roques took a course in diction at the Conservatoire de la Chanson with the Montmartre cabaret artist and fin diseur Mévisto Ainé before making her stage 
debut at age 21, in $1910 .{ }^{16}$ Apart from that, she learned the acting metier, like most of her colleagues, the hard way. ${ }^{17}$ Raised in an artistic, semi-intellectual, leftist, and feminist milieu common for Paris in the Belle Époque, Jeanne Roques made her educational choices accordingly and the literary and artistic education left its marks on her entire career as Musidora.

An obvious trace of Jeanne Roques' literariness was the stage name she selected. Musidora's namesake was a character from a 1838 novella by Théophile Gautier, Fortunio, an adventure and crime story that features a courtesan who falls for a dandy. ${ }^{18}$ The actress asserted that she adopted the name merely for its euphony and pointed out that the character in the novella has "very fair hair, not at all like me". ${ }^{19}$ Nevertheless, the character of the aventurière (adventuress) prefigured, as Belgian novelist and film historian Johan Daisne noted in his eulogy of the actress, the parts in Feuillade's crime series that Musidora played before the camera in the 1910s, and, as I will argue, in several of her self-produced films as well. ${ }^{20}$

All the same, a French teenager at the beginning of the twentieth century had less fatalistic female models at hand, in fiction as well as in real life. Among the most widely read stories of the era were the Claudine-novels, of which a series of four were published between 1900 and 1907. The first three were written under the name of Willy, and the fourth by name of the actual author, Colette. Along with her schoolmates, Musidora read the first novel, Claudine à l'école, while preparing for her finals, probably in $1906 .{ }^{21}$ She vividly remembered how they revelled in the novelty of style and characters:

The young language, so new, the characters so vivid, so close to us, made all of us deliriously enthused. [...] Claudine represented the "talent" made to fit our marvellous youth. ${ }^{22}$

In her compelling biography, Secrets of the flesh. A life of Colette, Judith Thurman argues that Colette "invented the modern teenager" with Claudine. ${ }^{23}$ The guiding question in Colette's writing was, according to her biographer: "how, around 1900, could you possibly become an individual -yourself- and a woman?" ${ }^{4}$ Analyzing Claudine à l'école from a feminist point of view, Thurman reads it against the disconcerting options ambitious young women faced in turn-of-the-century Paris. They had access to education and new professions-teaching, writing, medicine, law, journalism-yet, in private, they were still expected to be submissive and virtuous and were legally subjected to their husband's control by way of the Napoleonic code, which regulated marriage. This living contradiction was enhanced by the cultural hedonism that pervaded public and private life. ${ }^{25}$ Women felt, and actually were, invited to partake in this world of pleasures and to discover their own rights to it, both 
as consumers and as professionals earning a living in it. Reading the Claudine character against this backdrop, Thurman concludes that the character of Claudine offered one of the first critical views of these contradictory demands: "Claudine at school is a novel about hypocrisy from the point of view of [...] a young girl who has not yet lost her candor [...]." ${ }^{26}$

The self-acclaimed author of the Claudine novels, Colette's husband Henri Gautier-Villars, who used the name Willy as his nom de plume, maintained correspondence with Jeanne Roques' schoolmates, one of which introduced her to him. ${ }^{27}$ Thurman confirms that, because of the character's popularity, Willy was besieged by young women. "No, mister Willy, Claudine is me" ${ }^{28}$ had been the sentence with which Polaire, the vedette of the Eldorado, who aspired to the boulevard theater, convinced Willy to give her the role in the stage adaptation of two of the novels in 1902. According to Colette, Polaire reinvented Claudine for the stage:

What Polaire made of Claudine is unforgettable. She understood everything about nuance, finesse, undertone, and translated it wonderfully. Mocking all probability, she dressed her sixteen year old character as if designed by Poulbot [that is to say comic and touching at once]: stockings, a black children's smock which the heroine in the second act exchanged for a frothing white dress, equally inexplicable. But the audience raved about everything Polaire did. ${ }^{29}$

Due to this play, which had an initial run of 123 representations and numerous reprises, and, thanks to Polaire's interpretation of the role, was widely imitated in music-hall and revues, Claudine became the most popular fictional character of the beginning of the twentieth century. ${ }^{30}$ Thanks to the play, moreover, the book became a best-seller. ${ }^{31}$

If the picture of Polaire as Claudine that Colette included in Mes Apprentissages ${ }^{32}$ is compared with the photograph of Jeanne Roques in Cazals' Musidora. La dixième muse, 33 teenaged Musidora looks like one of the girls who used to mimic the character in the way Polaire had shaped her for the stage. The comparison also suggests that she, at age seventeen, had been bitten by the theater bug already and coveted playing the part. ${ }^{34}$ That is to say, if the photograph was not taken in the early 1910s, when Musidora, as her French biographers suggest, performed the character. ${ }^{35}$ Be that as it may, Musidora claimed that her primary interest in meeting Willy concerned not him, but Colette. To express her admiration, she wrote her a letter and included a drawing of "a naked and embellished Claudine", ${ }^{36}$ after which she pressured Willy to talk her idol into a reply: 
by telling him how taken, enchanted, and dazzled I was by his wife, whom he in my view seemed to leave alone too much. I made him rather fierce reproaches and added that Colette was very pretty. ${ }^{37}$

It is difficult to determine precisely when this happened. Musidora herself, in her radio lectures, mentioned various years, most notably 1906 and 1908..$^{8}$ Colette and Willy lived separately beginning in 1906, which speaks for the earlier date, because it is highly unlikely that Musidora was ignorant of the separation, even though the couple was not yet officially divorced. Colette replied to Musidora's letter in December 1908, which marked the beginning of an affectionate correspondence and a lifelong fondness. ${ }^{39}$ According to Thurman, they first met in person in 1910, after Musidora had written "an ecstatic review" of a lecture by Colette.$^{40}$ Despite the sixteen year age gap, Musidora and Colette, professionally and as women, shared friends and significant parts of their lives and work. ${ }^{41}$

In addition to providing the not-yet Musidora with a fictional character with which to identify, Colette may have served as a role model for her as well, which will become apparent in this careerography, in more than one regard. In her reminiscences of Colette, Musidora recounted their collaboration on films, to which I shall return in due course. She furthermore highlighted her close friendship with the woman she came to embrace as her "adopting mother", "teacher of the heart", and "godmother." ${ }^{22}$ Musidora's reverence may likewise have concerned Colette as a popular stage actress. As of 1906, the unrecognized female writer struggling to establish her name and her independence, earned a living by acting in pantomimes and sketches. For six years, Colette performed in music-hall and the boulevard theater, often teaming up with the mimes Christine Kerf and George Wague, who taught her the métier. ${ }^{43}$ Some of the pieces in which she appeared received mixed responses or stirred up controversy, but her performances met with the highest acclaim in the reviews that I encountered. The leading Parisian daily for the performing arts, Comoedia, wrote about the pantomime "La chatte amoureuse" (The Cat in Love) as a gem of humor, imagination, and lightness. ${ }^{44}$ Louis Delluc, who, in 1912, wrote about music-hall but not yet about film, used almost exactly the same words. ${ }^{45}$ Musidora, who appeared in a supporting role in the same program as Colette in 1912, recounted that she acted as a kind of groupie at the time: "As soon as Colette forgot an accessory, a ribbon, some make-up, a comb, I ran to her dressing room to bring what she needed, only too happy to be chosen." ${ }^{46}$ The anecdote gives rise to the idea that the example set by Colette the actress may have encouraged Musidora to venture into stagecraft as well. This becomes even more likely when accounting for Thurman's feminist interpretation of Colette's performing activities: the revolt she acted out 
by refusing "decent" professions for women and by breaking away from her position as a ghostwriter for her husband, the courage she exhibited in taking up acting as a profession, and the independence she displayed in making her own money. "The music-hall," writes Colette, "[...] made me [...] a tough and honest little businesswoman. It's a profession which the least gifted of women learns quickly, when her freedom and life depend on it." ${ }^{47}$ Just like the author of these lines, Musidora was a multi-talented woman and earning her freedom with the artistic talents with which she was endowed apparently appealed to her much more than any other career options for women at the beginning of the twentieth century.

\section{Musidora's Early Acting Career}

142 | Musidora mentioned her part as La Môme Liquette (The shirt chick) in the popular drama "La Loupiote" (The kid) as her stage debut..$^{8}$ Her biographers, Francis Lacassin and Patrick Cazals, mention a vaudeville play (a specific French kind of farce) in which she performed a few months earlier, but for which she had not yet used her stage name. ${ }^{99}$ If they are right, which is difficult to confirm since the theater in question did not advertise its cast lists in the leading papers, Musidora's stage debut took place on July 15, 1910..$^{\circ}$ If Musidora herself was right, it took place on September 11, 1910, in the Théâtre Montparnasse, a neighborhood theater that passed its programs on to its two annexes, Théâtre de Grenelle and Théâtre des Gobelins..$^{51}$ In "La Loupiote" she played a supporting part, for which, however, she devoted much efforts to get right:

I played [...] the role of a girl of easy virtue. I had never left my family. I had always lived decently and was not sure what to think of the behavior of the "girls." So, in deepest secret I went up to Montmartre. I began talking to the "girls" and the "pimps," told them about my adventure and asked for advice. The "gang" took things very seriously. They gave me lessons. They taught me how to find the right tone, and the first night all my little bunch was present. The "tough guys" gave the loudest applause..$^{2}$

This account suggests that Musidora used to shape her parts by basing them on social realities and lifelike types known to the public for which she performed. It is worth pointing this out, because from early on and throughout her career on-stage and in cinema, Musidora adopted this discourse in her acting and the theatrical and cinematic genres in which she chose to act. As I will demonstrate in several more instances, the references to social realities 
and lifelike types were elements of a discourse that connected the truly popular forms of stage, literature, and cinema of the times. Such references implied a specific relationship between actress and audience, a shared awareness of the efforts involved to include and to appeal to the people's experiences and knowledge. How Musidora shaped this relationship through her acting, her stage parts, and her screen characters, is the guiding question of my study of her career and oeuvre.

In the first years of her stage career Musidora, played supporting parts in popular plays, such as the policier (detective play) "Nick Carter" $(1910)^{53}$, the vaudeville plays "Le Matricule 607" (Soldier Number 607) (1912)54 and "Un coup de téléphone" (A Telephone Call) (1913), ${ }^{55}$ and the féerie or pièce à grand spectacle (fairy play or spectacle play) "L'Insaisissable Stanley Collins" (The Elusive Stanley Collins) (1913). ${ }^{6}$ Such minor roles usually concerned miniature parodies of which the actress had to make the most to be noticed. Musidora did, to such an extent that more than one reviewer noticed her brief appearance as the Egyptian vendor Soliman in "L'Insaisissable Stanley Collins":

And Miss Musidora was loudly applauded in a very short role of the little Egyptian, in which she wittily evoked the young vendors of peanuts and carpets, you know...: "Take it, meester... Ees good... Take it, Madam... Not spensive at all... fifty francs... Listen... Madam...forty... Okay, twenty francs... Look, Madam, all fine, all wool... Ten francs, yo want?... No?... Come on, two francs, ok?... Here you are, Madam..." ${ }^{57}$

Delluc was also impressed by her performance, so much so that he reminded readers of it still in 1918:

And you have not forgotten the Egyptian boy [...] which she enacted with such apt graphic grace at the Châtelet [...]. There was high esteem for the delicate eurythmics for which her dance and facial expression could have put her in the top of Parisian artistes..$^{8}$

\section{French Popular Stage Genres}

The French popular stage and its genres were woven into the era's social texture, much more so than high literature or the legitimate stage. ${ }^{59}$ Each of the genres were related to the social realities in which their audiences lived. The crime melodramas of the mid-eighteenth century recycled the assassinations that haunted the city at the time ${ }^{60}$ a method which, as we will see, in the mid- 
1910s, was adopted by filmmaker Louis Feuillade for the crime series featuring Musidora. Farce, vaudeville in French language ${ }^{61}$, and comedy of manners dealt with the social hypocrisy that marked the second Empire: officially, order and progress were proclaimed, but, privately, the bourgeoisie sought (sexual) pleasures and wealth. ${ }^{62}$ Further on, I will elaborate on how Feuillade also adapted this genre to cinema, and which parts Musidora played in those adaptations. Féerie ${ }^{63}$, or fairy plays, and spectacle catered to the curiosity of people for the far away and the exotic, incited by the inventions of railways, photography, and other technical novelties that allowed them to travel or to have access to images from elsewhere. As a producer and (co-)director of films made and set in Spain, Musidora would contribute to the satisfaction of such curiosity in cinema as well.

These popular stage genres required a dramaturgy and ways of acting that aimed to provoke sensations in and responses from their audiences, wheth144 | er compassion, laughter, awe, fright, or anger, and which theater historian Michel Corvin categorizes under the header "a dramaturgy of effect". ${ }^{64}$ The intention was not to offer acute criticism or theatrical realism, which were rather the ambitions of the cabaret and the legitimate stage, instead, the popular stage sought to divert, to amuse, and to thrill. Insights in the dramaturgic and thespian means with which such pleasures were created can be derived from reviews of the plays in which Musidora performed.

In Comoedia, the acting in "L'Insaissable Stanley Collins" was discussed in due detail. ${ }^{65}$ The prototype of the heroic reporter was represented with the actor's usual zest, exuberance, and ease. The type of rich business man was composed as a most pleasant caricature: the actor dwelled in exaggeration and, by presenting his character through a magnifying glass, created a lovely pastiche of his stubborn silliness and vanity. The various smaller roles by the star actor De Max were also highlighted: "One senses, [...] the intense pleasure which the grand actor tries to bring to his performance, he is playing, in the true sense of the word." ${ }^{66}$ Finally, the actresses were complimented on their performances: one exaggerated the melodramatic aspect of her part as necessary to the performance, the other one was charming in her ingeniousness and bravery. Musidora, in her brief appearance as Soliman, was said to have displayed an apt confidence and a talent for imitation.

The reviews disclose a knowledgeable appraisal of the theatrical genres that made up the Parisian popular stage at the beginning of the twentieth century. Moreover, the success of such plays - "L'Insaisissable Stanley Collins" ran uninterrupted for three months - suggests that audiences knew as much as critics did as to what to expect and how to relish it. A generous acceptance of the generic rules was pivotal to enjoyment. For the pièce à grand spectacle, such rules included a focus on spectacular detail and on the actors' ingenu- 
ity to handle the insignificance of the plot and the absence of psychology. Although rooted in social realities, the characters were clichéd, so that audiences quickly knew who they were meant to be ${ }^{67}$ This is how I understand why Musidora points out her efforts to get the type right: it had to be true to life as well as clear-cut. But, precisely because of the generalized makeup of the characters, actors and actresses had to add something special, such as zest, exuberance, exaggeration, confidence, and, in the best case, playfulness. Such additions constituted the warp and woof of comic stage acting. Similar discursive conditions held for other popular stage genres of the time, and, as I will detail in due course, most notably for the Parisian revues in which Musidora performed during the 1910 s. $^{68}$

\section{MUSIDORA IN MUSIC-HALL AND THE PARISIAN REVUE, 1912-1914}

Musidora's stage appearance at the Châtelet had, in fact, been a brief stint between her affiliations with two of the most illustrious café-concerts and music-halls of Paris. From April 1912 through May 1913, she had been a member of "the sparkling troupe of the Ba-ta-clan". ${ }^{69}$ Afterwards, from February through June 1914, she performed at the Folies-Bergère. At both places, she predominantly acted in revues, but, at the Ba-ta-clan, also in the previously mentioned vaudeville play that ran for nearly two months, from August 30 through October $20,1912 .^{70}$ This two-act play was on the bill with two more program items: the pantomime with Colette, "L'Oiseau de nuit" and a tour de chant..$^{11}$ In the nineteenth century café-concert, the tour de chant signified a series of songs and verses delivered by one female or male performer, the vedette of the evening, and was the highlight of the program. In early twentieth century music-hall, however, it functioned as an introduction for the actors of the plays that made up the core of the program..$^{72}$ It served as a teaser for the performance qualities the audience could expect but was rarely included in the reviews. This time it was, and the articles disclose that Musidora did not partake in the tour de chant during the first month of the play's run, but that she did from September $30 .{ }^{73}$ This may be considered as an upgrade of Musidora's status within the program, especially at the Ba-ta-clan, which was known for engaging only noted performers. ${ }^{74}$

In the Belle Epoque, café-concert and music-hall represented and cultivated

the people's rights to refined entertainment. In the nineteenth century caféconcert, admission was free; in fin-de-siècle and early twentieth century musichall, prices were kept low or varied; and program information was circulated as widely as possible for both. According to histories of French music-hall, Paris and its suburbs counted over 150 music-halls and related stages by $1890 .{ }^{75}$ 
Jean-Jacques Meusy, in his comprehensive study of the advent of cinema in the French capital, Paris Palaces ou les temps des cinémas (1894-1918), gives the official figures for 1905: 46 music-halls and playhouses, and 46 concerts and café-concerts. ${ }^{76}$ In 1914, the musicologist and editor of a studious periodical about the performing arts, Louis Laloy, observed: "Paris is nowadays more than ever the city of pleasure." 77 The myriad assortment of halls and houses drew socially distinct patronages, to be sure, but, in their entirety, they ubiquitously accommodated all stratifications of the population: young and old, women and men, workers and aristocrats, provincials and visitors from abroad, common families and artists, and intellectuals and bohemians. ${ }^{78}$ Laloy, in defence of the frivolous popular stage against his haughty colleages' objections, specified that the attitudes that connected these divergent groups were honesty and the search for a sincere opinion. ${ }^{79}$ At the beginning of the twentieth century, then, café-concert and music-hall constituted a dynamic, 146 | progressive, and prosperous entertainment industry and therefore offered employment to a broad assembly of entertainers and entrepreneurs, to women as well as to men. Most pertinent to my discussion of Musidora's career, and evident from music-hall histories as well as from the contemporary press, is that those who produced, wrote, and performed in this field were genuinely respected and honestly adored for the quality of the entertainment they provided to their pleasure- and sincerity-seeking audiences.

In the French language, the terms café-concert and music-hall signify two formulas of popular stage programming, yet could additionally refer to the establishments where such programs were offered (in which cases I shall not italicize the words). Historical studies of the venues and their offerings usually bracket the terms together, as, for instance, does the elaborate and encyclopedic history of Parisian establishments and their programs Music-hall et Café-Concert, researched by Philippe Chauveau and co-edited by André Sallée. According to Chauveau, the term café-concert was still in use only by force of habit by the eve of war. ${ }^{80}$ This concerned the venues, while the program formula had become so unusual already by 1912 that it made a headline in Comoedia: "Fursy offers a genuine café-concert evening!" ${ }^{81} \mathrm{~A}$ similar equation in the use of terms occurred about a decade later: the stages that, in the 1920s, were called music-halls, predominantly offered revues..$^{82}$ Musidora, then, when performing at the Ba-ta-clan and the Folies-Bergère successively, switched from a caféconcert to a music-hall in terms of place and stature, as the Folies-Bergère was one of the most prestigious music-halls in town, yet not in terms of program formula: in the early 1910 s, both places offered music-hall programs, and, to add to the confusion, mainly revues.

As program formulas, café-concert, music-hall and revue were at once closely related, historically successive, temporarily co-existent, and generical- 
ly distinct. Each formula evolved from its predecessor, adopting and adjusting conventions and elements, co-existed for awhile with and only gradually eclipsed its antecedent. ${ }^{83}$ Classic music-hall histories tend primarily to discuss the formulas along their related and successive lines, highlighting the differences between the nineteenth-century café-concert and the spectacular and showy revues of the 1920 s. From such a perspective, the music-hall and revue of the 1910 s are barely considered ${ }^{84}$, and the type of Parisian revue in which Musidora acted is largely obscured. Although already labelled revue à grand spectacle (spectacular revue), this Parisian revue ought not to be equated with the showy revues of the interbellum. An examination of contemporary sources allows for a reassessment of Musidora's performances in music-hall and revue within their specific, historical, and local contexts.

Contemporary critics witnessed how music-hall and revue gained momentum in Paris in the early 1910s. Most notably, Louis Laloy and Curnonsky astutely articulated and reflected upon the shifts as they observed them, and their articles provide a contemporary meta-discourse on the rules, functions, and reception of various forms of popular entertainment. ${ }^{85}$ Curnonsky wrote already for the weekly Paris qui chante, when he and his colleagues in Comoedia in 1910 and in Le Théatre in 1912 began to cover the opening nights of revues with large and detailed reviews. Laloy established his profound column on music-hall, revue and related performing arts in the periodical Revue Musicale S.I.M. in February 1913. The cited article on the program offered by Henri Fursy, the former owner and vedette of the cabaret La Boîte à Fursy and the director of the café-concert the Scala from 1910 to 1913 , listed the components of a café-concert program: a succession of French fantaisistes (all-round entertainers) and singers, who offered twentysix numéros (solo acts) overall, in addition to a tour de chant, and a comic sketch to close things off. It was a miscellaneous program format, that prioritized song and solo acts yet included an ensemble performance at the end, which could be a sketch or a small revue. Laloy furthermore pointed out the modesty of the stage and the sets, and asserted that Fursy "proudly rejects the foreign intrusion" ${ }^{86}$ This was not because he could not afford it, Laloy added, but because Fursy saw to it that the spirit would triumph over flashy but cheap luxury. According to contemporary critics, then, café-concert, in the first place, catered to the mind and fed into French pride and spirits. Music-hall before the 1910 adopted the miscellaneous program format, and added to the entertainers, singers, and sketches numéros visuels: deft acts, dance, animal acts, cinema, ballet, and pantomime ${ }^{87}$ Such virtuoso and spectacular acts primarily addressed the eyes, which, according to Laloy, understood the international language of pleasure. ${ }^{88}$ Music-hall programs hence inherited from café-concert the appeal to the mind and the enhance- 
ment of national pride, while addressing the eyes and international appeal were the new elements they provided.

Whereas in 1909 virtually every Parisian café-concert and music-hall offered such miscellaneous attractions, the format soon gave way to more unified programming. By 1913, animal and deft acts were suppressed in favor of more sketches, more operettas and, first and foremost, more revues. ${ }^{89}$ While the café-concert program was loosely structured by variety and alternation, that of music-hall or revue was unified, either internally through a narrative, as in sketches and operettas, or externally through a thematic thread, as in the revue. ${ }^{90}$ Music-halls holding on to the formula of presenting miscellaneous attractions, such as the Alhambra, received special praise and encouragement. ${ }^{11}$ During the war years, the staging of narratively or thematically unified performances further expanded. ${ }^{92}$ By the early 1920s, only three of the prominent music-halls of Paris regularly offered programs of single acts, including 148 the Olympia and the Alhambra. ${ }^{93}$ In the latter, Musidora was reported to have sung and danced in a one act fantaisie "La Barrière" (The Barrier) in September 1920.94 Throughout the 1910s, however, she continued to perform in revues: between August 1915 and the end of 1919 in (at least) eleven revues in almost as many different music-halls, cabarets, and theaters. Before further elaborating on the revue, a closer look at another aspect of pre-war music-hall pertinent to Musidora's career is necessary: that of the performance.

\section{Of Vedettes and "their" Genres}

The loose programming of the café-concert generated certain conventions, some of which survived in music-hall while others were abandoned during the early 1910s. First and foremost, it created vedettes, French singers and entertainers who, with their solo performances, became the darlings of audiences and press and who constituted the indispensable top of the bill. ${ }^{95}$ One of the pioneering female crowd-pullers was Thérésa, who, between 1863 and 1893, was the star of the Alcazar, the Ambassadeurs, and the Eldorado. ${ }^{6}$ She was of working class descent and therefore close to her audience, with whose worries, tastes, and aspirations she was only too familiar. Her songs and verses reputedly represented life as it was experienced in the city, at the market, or at the fair, for example. ${ }^{97}$ In her act as a chanteuse comique (a performer making fun of daily life), she mocked the conventionality of the Second Empire. As a nineteenth century woman, moreover, she found in stagecraft an opportunity to earn a living and, as legend has it, much more than that..$^{8}$ In doing so, Thérésa paved the way to economic self-support as well as to stature and fame for countless female colleagues and successors in the field. And she also con- 
tributed to setting the standard of sincerity in enacting true-to-life types and in mocking social realities, which, apparent in both Musidora's and Colette's acting, continued to prevail in early twentieth-century music-hall.

Another convention created at the café-concert and closely related to the vedettes, was the recurrence of established stage personas, easily recognizable characters that mirrored the social horizon of a generally poorly educated audience, called genres in the jargon. Thérésa and her colleagues, Paulus, Dranem, Polin, Jeanne Bloch, Mayol, and Polaire, created the genres of the chanteuse comique, the gambilleur (a flexible dancer), the scieur or comique idiot (a clownish comic presenting nonsense songs and verses), the comique troupier or tourlourou (the trooper or coarse comic), the comique or chanteuse colosse (the huge female comic), the fantaisiste de charme (the gentleman humorist), and the gommeuse épileptique (a wriggling womanly singer of racy songs), in that order. ${ }^{99}$ Each of these stage characters was molded in a special repertoire and act, and complemented with a silhouette manufactured with makeup, garments, and accessories. ${ }^{100}$ Together they offered a range of social caricatures additional to those in the théatre du boulevard. Audiences came not so much to hear, but to watch the performers sing ${ }^{101}$ and used to express their acclaim or disdain loudly. The songs and verses delivered, moreover, often were new words to well-known tunes, so that those who had heard and read the lyrics once could readily sing along with them. ${ }^{102}$ Paris qui chante in the early 1910 s still speaks of "chanson créée par..." (song created by), and what follows is not the name of the author of the text, but the name of the performer who (first) presented it on stage, regardless of whether he or she had written it.

The example of Polaire illustrates how the genres made the women performers feel exposed. Remembered by her friend Colette, Polaire was cited to have repeatedly complained about her pre-1900 male audiences: "I can hear what they think, it is ugly, it is awful [...]" ${ }^{103}$ Colette herself recalled feeling distressed while watching Polaire in her tour de chant, while other café-concert visitors laughed at the actress' nervous agility that they considered to be a constitutive element of the genre of the gommeuse épileptique as she herself had created it:

Aside from the brownish black of her eyelids, the lacquer of her fantastic long eyelashes, the purplish red on her lips, she did not use makeup other than her own intermittent radiance, a touch of a tear in her unbounded eyes, a big and sorrowful smile, all those pathetic truths which belied her diabolic, curved eyebrows, her annoying goat ankle, the jumps of a snake-waist, and which proclaimed luminously, humidly, tenderly, persuasively, that Polaire's soul had chosen the wrong body. Such an error irrevocably comes with symptoms considered comic, such 
as nervous spasms, a jumping from one foot on the other, as if the soil had burned the agile soles of Polaire. ${ }^{104}$

In other words, the audience did not laugh with Polaire, but at her. ${ }^{105}$

The female performer credited with taming the audience and teaching them to listen and to pay attention is the legendary diseuse Yvette Guilbert. ${ }^{106}$ As she recounts in her memoirs, Guilbert refused the prevailing performance practices and stubbornly refrained from agile gesticulation, formulaic makeup, and archetypical accessories, while insisting upon restrained expression, natural makeup and slim dresses of plain, often green, cloth. Instead of enacting a type, she aspired to

compile an exhibition of sung humorous caricatures of all indecencies, all excesses and all vices of my contemporaries and just make them laugh about themselves (because no one will cry about it.) ${ }^{107}$

To that aim, she searched for more subtle and poetic texts than the common, to her mind, poor and moronic ones. She introduced a yet unknown writer, Léon Xanroff, and further developed a sharp sense for what intonation and acting could do to enliven a text and to create humor. In this way, she paved the way for talented and sensitive female singers and actors to insist on perspicacity in their texts and subtleties in their performance, two qualities that marked early twentieth-century music-hall and revue, and, according to Laloy, were highly appreciated by the perceptive Parisian public. ${ }^{108}$

Thanks to Guilbert and others who edified the café-concert, early twentieth-century music-hall offered performers an ambiance in which to develop a broad range of talents and skills. By the time Musidora entered the trade, the chief requirements were intelligence and versatility. Polaire and other vedettes of the café-concert shaped and adapted to the requirement of adaptability and fine-tuning through stints in boulevard theater. ${ }^{109}$ As we have seen, Musidora herself made her debut in popular plays before switching to music-hall and revue. The exchange between established and emerging types of popular theater contributed to the rise of the status of performers. According to Laloy, music-hall actors were even more capable than comedians, singers, and dancers who were unable to alternate between the various theatrical forms. ${ }^{110}$ In Comoedia and Le Théâtre, moreover, music-hall actors' performances were discussed no less respectfully and knowledgeably than those of the boulevard and the legitimate theater. For the early twentieth-century generation of actresses, including middle-class women like Colette and Musidora, such rise of status of the profession must have added to the appeal of working on the stage. In line with the demand for versatility of performers and with the 
Fig. II.2: Picture postcard Polaire, c. 1900.

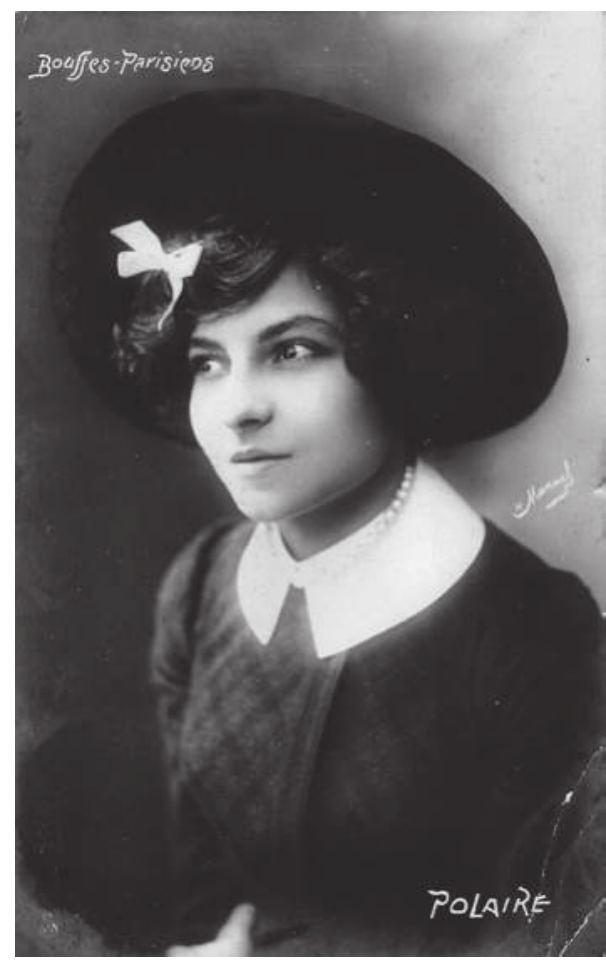

increasing prominence of programs with a narrative or thematic thread in prewar music-hall, neither of the two opted for performing solo.

\section{Musidora in the Parisian Revue}

For over two years, at the Ba-ta-clan and the Folies-Bergère, Musidora predominantly performed in revues. At the Ba-ta-clan, from April 6 until June 30, 1912, she was cast in “Ça grise!” (It's Intoxicating!); from August 30, 1912 until March 16, 1913, in "La Revue de Ba-ta-clan" (The Revue of the Ba-ta-clan); ${ }^{111}$ and from March 23 until June 1, 1913, in "Bien... Marie!” (Well done... Marie!). At the Folies-Bergère, she appeared in "La Revue de l'Amour" (The Revue of Love) from February 8 until the end of March 1914, and in "La Revue Galante" (The Racy Revue) from April 4 until June 30, 1914. Musidora's ranking among the performers can be derived from the layout and typographic details of the program leaflets: at both music-halls, she belonged to the middle rank, second from the top of the bill. ${ }^{112}$ The vedettes of these revues-and of the respective halls-were Colette, Dutard and Fina Montjoie, Nuibo and Geneviève 


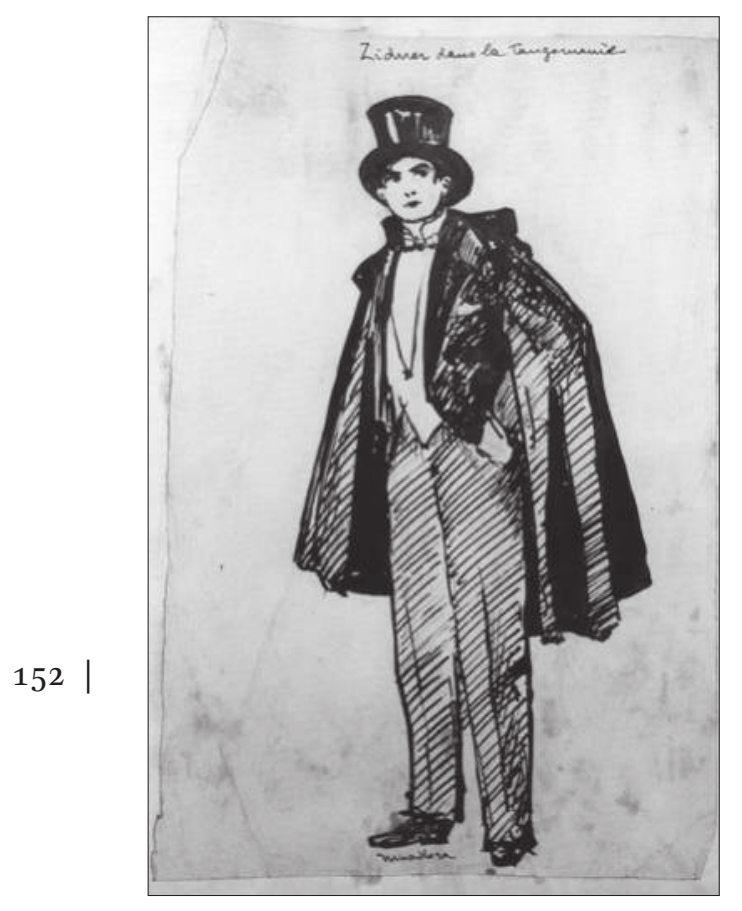

Fig. II.3: Drawing of Paul Zidner by Musidora.

Williams, Dutard, Maud D'Orby, and Simone Kotbrune at the Ba-ta-clan; and Raimu, Nina Myral, Marcelle Yrven, Mado Minty, and Paul Zidner at the FoliesBergère.

While each of the others belonged to the top performers of music-hall of the early 1910s, their names and achievements are not commemorated as such in histories of the trade. If commemorated, it is for other aspects of their careers, for instance, because of their involvement in cinema-as in the case of Raimu, and Musidora, for that matter-or their notoriety as writers, as in the case of Colette. ${ }^{113}$ For one thing, their omission may be indicative of the transience of their reputations themselves, as the 1922 collection Nos Vedettes included only two of the names listed above: Nina Myral and Raimu, even though the composer of the collection, Joë Bridge, had been a pre-war musichall songwriter and reviewer. ${ }^{114}$ This omission may also point to the aforementioned blind spot in music-hall and revue histories for the specificity of this particular staged entertainment in the 1910 .

In each revue, Musidora performed in more than one tableau (the separate sketches or acts of which a revue was composed), and, in each case, in another part. At the Ba-ta-clan, she was on the program in four acting appearances in the first revue, in addition to three performances as a singer; she had 
two performances in the second and three in the third. At the Folies-Bergère, she played three parts in each revue. The number of acts listed above is the absolute minimum, because the programs also contained intermezzos and an apotheosis without further specification of the performers, and sometimes the reviews mention parts or acts not listed in the programs, or the other way around. Nonetheless, both programs and reviews shed light on details of the parts and acts in which Musidora was involved.

The program booklet of "Ça grise" discloses that Musidora sang three songs. ${ }^{115}$ One of the songs was part of a rather racy love duet between a guard and his girlfriend:

\author{
Believe me, my only wish is \\ to give you much pleasure \\ Give me your mouth, give me your eyes \\ Give me your feet, give me your hair \\ Give me even your naked self \\ With every hair underneath!116
}

The other songs dealt with topical issues: one criticized the habit newspapers had of shortening reviews of revues, the next depicted the nuisance of dog-dirt on Parisian stoops. Doing such songs, apparently, was not Musidora's core type of performance, yet as far as the programs disclose this information, she did so occasionally: in another revue at the Ba-ta-clan in 1913, in a revue at the Scala in 1916, and in the music-hall program of the Alhambra in 1920. In a 1919 review, she was nonetheless praised for singing well. ${ }^{117}$

Musidora was noticed for her talent for imitation in her first revue at the Ba-ta-clan: "and next, a completely saucy girl! Musidora, who was, as it seems, the revelation of the evening, and who imitates Spinelly, Mistinguett and Lavallière to the effect of mistaking her for them!" ${ }^{118}$ This was in the fifteenth tableau, in a sketch about a couple of youngsters who visit the spring revue and-ironically-cheer for vedettes from other music-halls and theaters. ${ }^{119}$ Such jocose comments on the trade and its conventions were ubiquitous in music-hall and revue. According to the program booklet, the sketch depicted the rush in the streets caused by the crowds on their way to the Ba-ta-clan. In Musidora's second revue, she earned praise for her creation of the character: "Miss Musidora gave a very apt enactment of the young handsome lad, whose eye is not yet open enough to appreciate the [...] feminine joys of life." ${ }^{120}$ The occasion was a cross-dressing part in the 28th tableau, entitled "La Caserne d'Eugénie" (The Barracks of [Empress] Eugénie).

At the Folies-Bergère, Musidora acted in more complex parts. In a tableau of "La Revue de l'Amour" entitled "Les gommeuses moderns" (The modern 
gommeuses), she played the wife of the dancer of the Ballets Russes, Nijinski, both of whom were victims of what Curnonsky called the superstition of eugenics, a topical issue of the time. ${ }^{121}$ In Le Théâtre, the critic seized his chance for a eulogy of the actress:

In the first place the two scenes interpreted [...] with a charming finesse and lightness by Mr. Paul Clerc and Miss Musidora [...] Miss Musidora has a very good diction and shows qualities of an excellent actress: evidently, she is very intelligent and she must adore her métier; I believe that she will find her true employment in very modern ingénues or in cross-dressing roles - and that she will soon be back to the stage. ${ }^{122}$

In this tableau, Musidora was judged as acting with a subtlety and lightness worthy of the boulevard theater, while, in another, the critic considers her

154 | "adorable and intelligently mischievous in the role of the little hubby". ${ }^{123}$ The second revue in which she appeared at the Folies-Bergère enabled her to demonstrate her talents for parody in three consecutive tableaux commenting on the "tango-mania" seizing Paris. Curnonskywas impressed again: "Miss Musidora has given a charming grace and roguishness to the role of the female tango-maniac." 124

The narrative of the last of the three tableaux called "Le Rêve du Tango" (The Dream of the Tango) included a pretext scene for an undressing act, after the couple has returned home tired from a day of tangoing. The scene inspired the reviewer to remarking-between brackets indeed-"(Musidora differs pleasantly from so many other pretty women who have nothing to wear; she has almost nothing to take off!)". ${ }^{125}$ The description and remark support the impression that Musidora had embraced the so-called tradition académique, the "corporal tradition" of the tableau de prétexte, in which the narrative merely served as a pretext for exposing women's bodies. ${ }^{126}$ By 1912, this "tradition" made up an indispensable ingredient of Parisian music-hall and, as I will point out hereafter, Musidora's mentrix Colette had adopted it before Musidora. The tradition académique accounted for a great deal of Musidora's foxy reputation established by her later admirers, the Surrealists, and her French biographers in their wake. The close look at Musidora's stage appearances that I have offered and upon which I will continue to elaborate, shows that her parts and her acting were not restricted to merely exhibiting her body and that contemporary criticism was less blinded by her "sculptured body"127 or her "shapely legs" 128 than her future fans would be. Nonetheless, she was involved in this eye-pleasing convention and, for that reason, an elaboration of its history and Musidora's handling it is required here.

The tradition of exhibiting women's bodies had a history of its own, to 
which the poet-singer and Ba-ta-clan director Gaston Habrekorn was a key figure, but not the only player. It had been initiated in 1894 at the Divan Japonais, by its director at the time, Maxime Lisbonne. ${ }^{129}$ By that time, the Divan Japonais was a café between a boîte à chahut and a boîte à chanson, that is to say, between a café-concert frequented by students and a cabaret, because of its relatively small size and the intellectual and socialite clientele that had been attracted by Yvette Guilbert a few years earlier. After Guilbert's departure "dans Paris" 130 in 1892, the place was badly in need of a new crowd-puller. To that end, Lisbonne staged a sketch, which just displayed the suggestive title "Le Coucher d'Yvette" (Yvette goes to bed) and was announced as a pantomime en 1 acte (one act pantomime). The legend fails to clarify if the inclusion of Guilbert's first name in the title was mocking the diseuse's desertion of the place. The pantomime was a half an hour act that presented a woman slowly undressing - to her underwear and no further, to be sure-, but the tone was set and the success was phenomenal. Not only did the actress, Blanche Cavelli, with her act leave "dans Paris", but music-halls like the Folies-Bergère and the Olympia quickly included similar acts in their programs, which could be recognized from suggestive titles such as "Le bain de la Maid" (The Maid Takes a Bath), "Suzanne et la Grande Chaleur" (Suzanne and the Heatwave), "Lianne chez le Médecin" (Lianne at the Doctor's), and "La Puce" (The Flea). ${ }^{131}$ The subsequent director of the Divan Japonais, Habrekorn, likewise capitalized on the craze by writing chansons sensuelles (sensual songs) and complementing them with poses sensuelles (sensual poses), which were, according to Chauveau, "illustrated by those ladies dressed entirely in a tight bodysuit". ${ }^{132}$ During his management of the Ba-ta-clan, from 1905 through 1910, Habrekorn continued "professing the cult of the tight bodysuit", as Curnonsky captioned the practice, ${ }^{133}$ most notably through the insertion of tableaux vivants in the annual revue. By the 1910s, such scenes were accepted as mere pretexts for exposing women's bodies as a spectacle. With the tight black bodysuit that Musidora wore in her part as the female cat-burglar Irma Vep in LES VAMPIRES, she adopted and ironically adapted the culte du maillot to the silent cinema.

The tableau de prétexte became a standard ingredient of revues, as also in "La Revue de Ba-ta-clan". ${ }^{134}$ By the time of this revue, in which Musidora acted, the management was in the hands of Bénédicte Rasimi, one of the female managing directors of the Parisian café-concerts and music-halls. ${ }^{135}$ Originally a costume designer, she took great pains in the decoration of the revues she mounted: the scenery and the outfits were invariably rewarded the highest praise. Her speciality was the refined work with colors. ${ }^{1{ }^{16}}$ She was considered no more prudish than her male colleagues, yet approached the required sensuality with noted tact and taste. In Laloy's view, the generosity of beautiful women towards admiring onlookers was characteristic of the genre, 


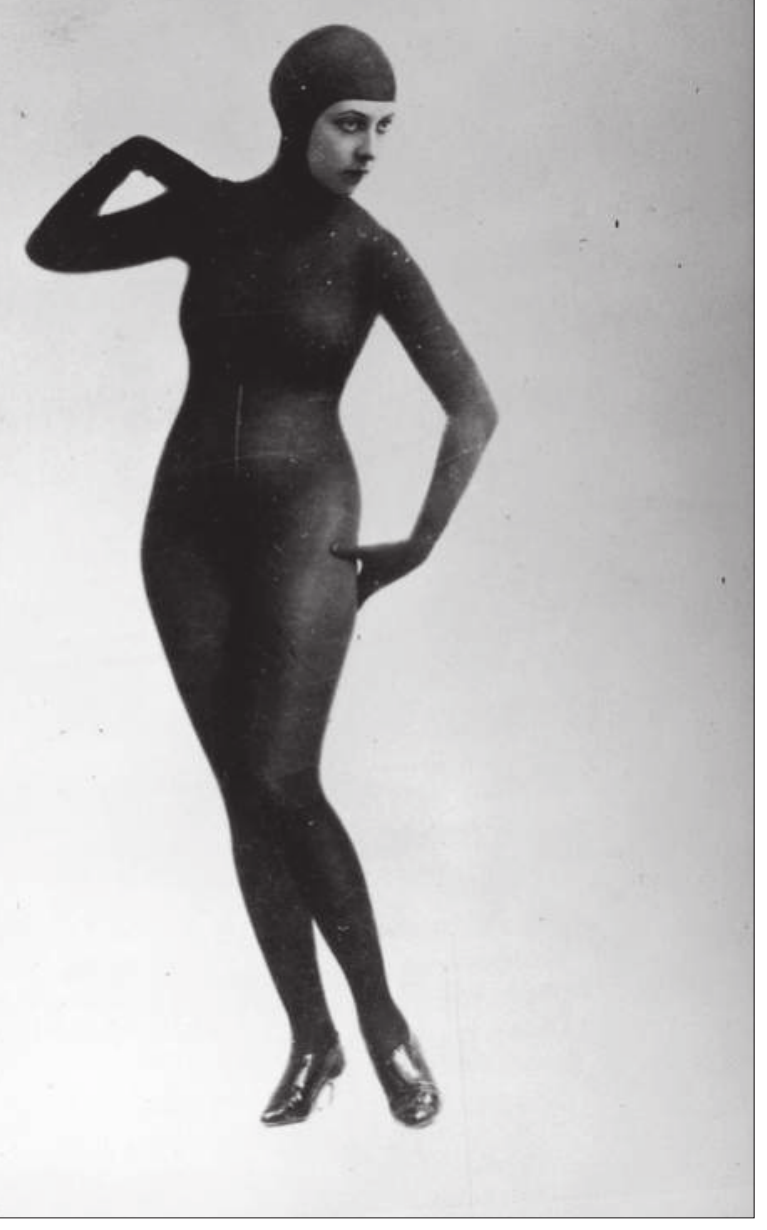

Fig. II.4: Musidora in her black body suit ironically adapting the culte du maillot from music-hall to the silent cinema. LES VAMPIRES, a film by Louis Feuillade.

Gaumont Production 1915.

which prompted him to ask rhetorically: "Do people believe that such a spectacle corrupts the morals? On the contrary, it refines and purifies them. Which woman would not desire a lover educated at this school?" 137 Ten years later, the surrealist writer Louis Aragon, invoking the state of mind of his generation in the first year of the war, directly linked the Irma Vep film figure in her maillot noir to music-hall:

That magic [of the serials], that attraction [of the bandits], merged with the charm of a great sexual revelation. The theaters were closed or barely open. The Moulin Rouge had just burned. In that fire, which could have been a disaster for the sensuality of thousands of youngsters, what was left to shape and mark the desires of an emerging nation? It was the task of Musidora's black bodysuit to prepare family fathers and rebels to 
France. This magnificent beast of the night hence became our Venus and our goddess of Reason. ${ }^{138}$

An interesting aspect of both men's phrasing is that they acknowledged that men needed guidance in how to behave towards women and their new ways of posing. In the pleasure these men derived from what they were offered, Laloy dissected even sadistic traits:

What they need are all those swinging arms, all those legs simultaneously lifted, all those cheeks pink from the same make up, all those breasts well dished up in identical bodices like fresh fruits in baskets. The summit of their bliss are the costumes which somehow injure or violate the female body, in this way suggesting to these one hour pashas the flattering idea that the desirable slaves are at their mercy. Hence those costumes that reveal what they should hide, and so many brutally sheath dresses under the pretext of swallows, asparagus, chestnut blossoms and plums. What do our middle classes dream of? The music-hall they frequent provides the answer. ${ }^{139}$

The conception of music-hall as a dream machine tailored to the desires of men seems to prefigure feminist film criticism of the seventies, which exposed narrative cinema as a dream machine tailored to masculine sadism and voyeurism. ${ }^{140}$ Laloy, however, did not intend to criticize-quite the contrary-; he assumed that the temporary fullfilment of the dream would console the "one-hour pashas" with their fates at home, where they "would contemplate with less revulsion the long skirts with which their wives hide their forever dormant charms". ${ }^{141}$ The on-stage "desirable slaves at their mercy", meanwhile, had their own reasons to adopt the tradition académique.

Years before Musidora did so, Colette contributed her mite to the exhibition of women's bodies on the popular stage. With her appearances, she went much further than the veiled eroticism to which music-hall audiences had become accustomed by the first decade of the new century. In 1907, two pantomimes in which she acted caused sensation: "Rêve d'Égypte" (Dream of Egypt), which provoked the "scandal of the Moulin Rouge", ${ }^{142}$ and "La Chair" (The Flesh), which was first staged at the Apollo theatre, and subsequentlywith much success - was taken on tour through the French provinces, Belgium, and Switzerland for four years. ${ }^{143}$ The scandal in question concerned the involvement in the play of Colette's lesbian lover Missy (the nickname of Sophie-Mathilde-Adèle-Denise de Morny, Marquise de Belboeuf, here cast as "Yssim") and the Moulin Rouge's abuse of the latter's aristocratic descent for publicity reasons, rather than the raciness of Colette's part: 
[She played] a beautiful Egyptian mummy, and "Yssim" the archaeologist who discovers her. The mummy comes back to life in a jewelled bra, slowly and seductively unwinds her transparent wrappings, and at the climax of the dance, passionately embraces the archaeologist. ${ }^{144}$

If the pantomime had been part of a revue, it would have made up for a perfect tableau de prétexte, with the difference that Colette was not wearing a bodysuit underneath her bra and wrappings. Neither did she in "La Chair", ${ }^{145}$ which Thurman describes as

the original bodice-ripper. It takes place in a smuggler's hut on the Austro-Hungarian border. Wague plays the smuggler; Colette his mistress, Yulka; and Christine Kerf (in drag), Yulka's lover. The smuggler discovers them, and in a paroxysm of fury, tears Yulka's shift from shoulder to 158 thigh. At the sight of the naked breast (the left one), he prostrates himself at Yulka's feet. ${ }^{146}$

Thurman further notes that "[i]n 1906 acting professionally was virtually synonymous with prostitution [...] and for a middle-class woman [...] the class treason was almost worse than the imputed moral turpitude." ${ }^{147}$ If this was indeed the case, Colette did not care one bit; as Thurman concludes, she instead seized her chance to publicly defy sexual and moral hypocrisy. This may have made her, I would add, a model for middle-class women like Musidora not to shy away from the tradition académique and its ally, the culte $d u$ maillot, and to play with it for their own purposes. This is what Musidora did when she wore the tight bodysuit in her part of Irma Vep in Feuillade's film LES VAMPIRES. She continued to play with it for her own purposes time and again, on-stage as well as on-screen. ${ }^{148}$ Certainly, her shapely body was far from unnoticed in the black bodysuit, but, as a pleasure for the eyes, it was embedded in a discourse of appraisal of Musidora's qualities and versatility as a performer. First and foremost, she was seen as a popular comic stage actress, and an intelligent and multifaceted one at that. This was possible because of the perspective of knowledgeable appraisal with which not only popular plays were approached, but, most notably, the popular stage genre, which gained momentum in the pre-war years: the Parisian revue à grand spectacle.

As a program formula, the pre-war revue à grand spectacle aimed at, and succeeded in, diverting the mind as well as pleasing the eyes. Contemporary critics explained how it achieved this balance: "As an intermediary between comedy and féerie, drawing from both, it has inevitable rules, from which it almost cannot escape, and it constitutes, moreover, an instrument for edu- 
Fig. II.5: George Wague and Colette as mimes. Picture postcard c. 1907.

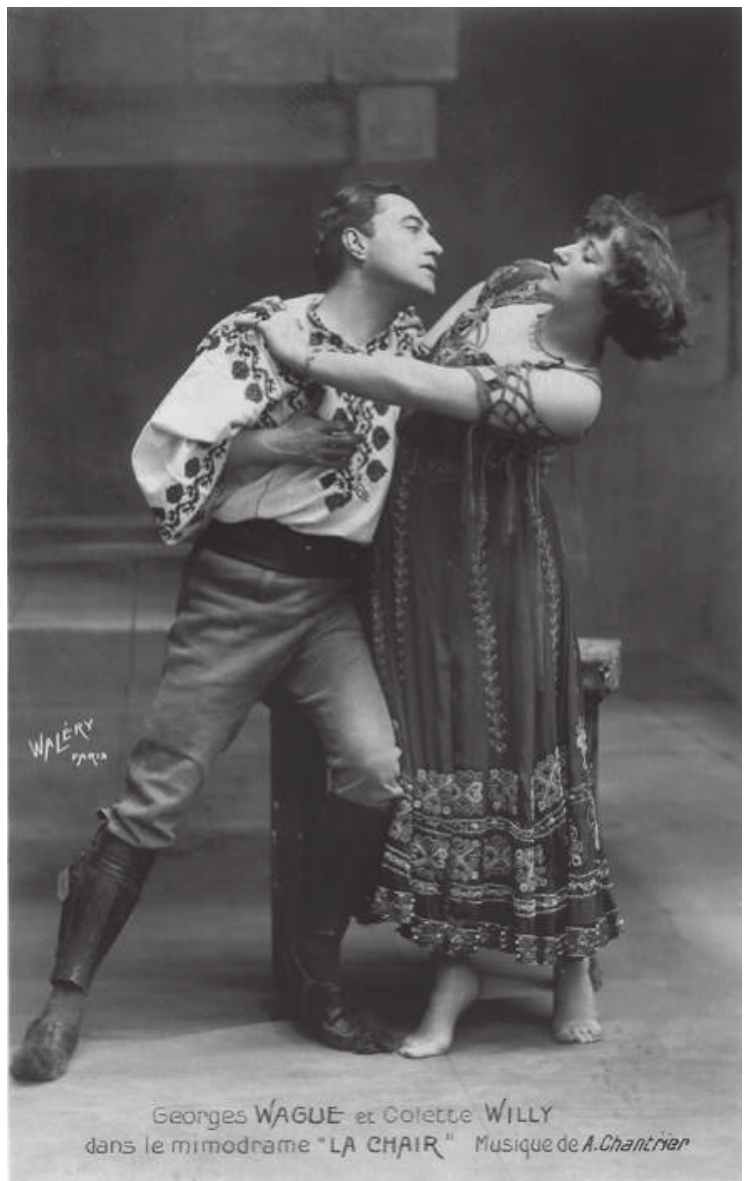

cation." ${ }^{149}$ The educational effect not only concerned men's manners with women and sexuality, but also cultural and political matter:

The revue provides answers to everything the public is curious for. Not only does it inform it about the latest scientific discoveries and keeps it posted on political predictions, but it condenses in a pleasant way, for its own use, the works of art which it only knows from hearsay and the discussions of aesthetics of which the papers have transmitted the echo. [...] All of it simplified, no doubt, but therewith made accessible for apprentice or rebellious minds; after the copy they can appreciate the original; and this propaganda through the image is more favorable for the works than many an argument or eulogy. ${ }^{150}$ 
Social excesses and arrogance were countered with what was considered French taste:

The revue [...] merely indicates the excesses of vice, ambition and foolishness; it claims to draw from common sense; it addresses that honest, unbiased public that always has provided the most exact assesment of French taste; it is the harmless revenge of that taste on charlatans of whatever origin... ${ }^{151}$

Above all, Laloy asserted: "Finally, the revue is cheerful. Earnest on occasion, it soon regains its smile without bitterness. [...] this type of joking is too humorous to be able to offend." ${ }^{152}$

Instances of Musidora's sketches that deal with topical issues include: the one on the youngsters falling in love at an early age and the one on the, surpris160 | ingly timeless, question of dog-dirt in "Ça grise!" at the Ba-ta-clan. The theme of this revue was Parisian street life and the current topic was security. ${ }^{153} \mathrm{Of}$ the Ba-ta-clan revue "Bien, Marie!...", the thematic thread consisted of women's issues, ranging from a female firefighter (played by Musidora) to a traditional siren, from feminism to Little Red Riding Hood, from lace underwear to virginity. Musidora also sang a text satirizing male domination and praising feminist achievements:

Under the male rule, men rather beastly

Always blocked up all the positions [...]

The women were allowed to only make kids [...]

The feminist rule is far less unfair

We now have the power to choose [...]

And to embrace everything which gives us pleasure. ${ }^{154}$

Comoedia listed further references to current topics, among which a sketch on the trial against a gang of criminals called the bandits of Pegomas, and some on issues related to the Balkan War. The review pointed out a patriotic tableau as well. ${ }^{155}$

The works of art for which Laloy thought the audience curious included music and literature as well as plays and revues. "Ça grise!" contained a historical tableau on Lucretia Borgia, with Musidora cross-dressed as Livarot; "La Revue de Ba-ta-clan" included a series of tableaux representing the oeuvre of the recently deceased composer Jules Massenet (1842-1912); and in "Bien, Marie!..." five paintings by Albert Guillaume were reconstituted, which at once served as tableaux de prétextes. ${ }^{156}$ Among the plays were: "Les Éclaireuses" (The Guides) by Maurice Donnay, which was satirized as the avant-garde of 
the "feminine" movement; the André de Lorde drama "Au telephone" (At the Telephone); and "L'Homme qui assassina" (The Man who Murdered) by Pierre Frondaie. In the tableau "Le théâtre des frissons" (The Theater of Frisson), Musidora performed opposite of the vedette of the revue, Charles Dutard, and she earned praise for her remarkable qualities as a comic actress. ${ }^{157}$ The revues mocked were those of the Olympia and the Folies-Bergère, the latter because of offering a virgin as one of its highlights. ${ }^{158}$ That this, given the $t a b^{-}$ leau de prétexte and its history at the Ba-ta-clan, seems a case of the pot calling the kettle black, probably added to the fun.

One of the current topics addressed in "La Revue de l'Amour" at the FoliesBergère and in a tableau with Musidora, was the aforementioned discussion on eugenetics and the wife of Nijinski. Other examples included the upcoming elections, new taxes, and the demolition of one of Paris' old districts, the Island of Saint-Louis. ${ }^{159}$ In this tableau, Musidora was said to have played "as a born actress the role of the socialite who spends her life at tea-tangos". Further hot issues were modern dance and, most notably, the tango, which returned in the Folies-Bergère's consecutive revue, "La Revue Galante”. In this revue, one of the tableaux on the tango was a Pathé film featuring Musidora, which I will discuss shortly. In "La Revue Galante", the work of the philosopher Henri Bergson was subject to Tramel's comic treatment. This revue also contained a potentially didactic sketch illustrating and parodying how three different contemporary dramatists, Gabriele D’Annunzio, Henri Bernstein, and Georges Feydeau, would each handle a crime story in which the criminal was caught in the act.

The creation of the cheerfulness was, in the first place, the work of the revuistes (revue authors), often duos who wrote and designed the scenes, parts, dialogues, and song texts for the revues of the early 1910s. Reviewers pointed out their contributions and merits conscientiously:

They have reached, this time, the pinnacle of perfection: their revue exclusively consists of cheerful scenes, which are linked together in an ingenious manner, endlessly varied and versatile [...] in a highly appealing artistic tone [...]. Their grand comic sense develops freely. [...] Their text is succinct, perspicuous, quick, often saucy, sometimes sassy, never coarse; their verses are "easy," and nicely dashed off; their "timbres" are very well chosen. ${ }^{160}$

The Ba-ta-clan and its authors Celval and Charley paid much attention to textual wit and therefore were reported to have magnified the revue as a jointly spectacular and literary genre. ${ }^{161}$ The revues of the Folies-Bergère, in contrast, were considered to lean towards cabaret and the boulevard theater. ${ }^{162}$ Cur- 
nonsky specified the revuistes' skill in "La Revue Galante": "She is sumptuous, voluptuous, luxurious-sometimes lascivious... But above all, the authors have managed with a rare ability, to translate the latest events into spectacle." ${ }^{163}$ Everything presented at the Folies-Bergère had to be a pretext for spectacle, for parades, for ballets and for apotheoses. ${ }^{164}$

Of the revues of the Folies-Bergère, no texts or verses have been preserved, and may even not have been issued, as the Folies-Bergère had no café-concert history and was a music-hall where people did not come to hear but to watch the performance (and each other). As with the spectacular plays, the interest was in the details of the mise-en-scène. ${ }^{165}$ While at the Ba-ta-clan the cheerfulness rather leaned on witty scenes and texts, at the Folies-Bergère, it was enacted and translated into spectacle. One of the forms the translation into spectacle could take, was film.

162

\section{Revue and Film}

Musidora's undressing act as the tango maniac, which I have re-assessed as an example of a current topic satirized and the tradition académique, was followed by a film, LA VILLE DE MADAME TANGO (The City of Madame Tango). The program booklet of the revue discloses that it concerned a Pathé production probably solely exhibited within the revue for which it was made. ${ }^{166}$ Curnonsky applauded it for its resourcefulness. ${ }^{167}$ The framework of appraisal for the film drew from concepts pertaining to the reception of the revue à grand spectacle such as making visible and understanding some of the vices of contemporary life and the degree of ingenuity involved in their enactment. Curnonsky also distinguished between what was acted live on-stage and what was shown onscreen:

But barely in bed, the tango mania grips them again... they start to reel again and everything reels around them; the cupboard, the bed, the bedside table, the chairs... an unreleased film by the Pathé Company shows them being surrounded by all tenants, who vie with one another in tangoing... Next, they appear in the street, where everything starts reeling, the houses, the cars, the sidewalk... They flee from the tango... The train starts reeling; they land at a far away beach... exhausted, they fall down by the ocean blue. But the tango pursues them in their dream. Even the seagulls dance around them [...]. It all is played by Zidner, Musidora, the Fassio Troupe and the lithe and gracious Miss Myosa with a baffling panache. ${ }^{168}$ 
While the seagulls were impersonated by actors, the reeling houses, sidewalks, and train must have been presented by means of trick-film. The tool of animated objects brings to mind a 1911 Pathé film, ROSALIE ET SES MEubles FIDÈLES (Rosalie and Her Loyal Furniture), directed by Roméo Bosetti and featuring the former chanteuse comique Sarah Duhamel. ${ }^{169} \mathrm{~A}$ print of this enchanting, one-reel comic trick film-one of the ROSALIE-series-is preserved at the EYE Filmmuseum. The buxom but bouncy Rosalie is unable to pay the rent of her tenement and her landlord has her furniture publicly auctioned. Sadly walking down the street, she sees her furniture sitting on the sidewalk to be carried to a new place and kisses and waves goodbye to the pieces. They, in response, start moving by themselves: the table, the cupboard, the mirror, and chairs loyally follow their former owner, all the way through the streets, up the stairs, and back home. Their pliant and smooth movements were created by stop-motion, a cinematic device in use since Georges Méliès had first employed it around 1896-1897. ${ }^{170}$ This tried and tested tool most likely did the trick for the tango performing objects in LA VILLE DE MADAME TANGO as well. But, as film further enhanced the visualisation and the translation into spectacle of a social phenomenon, Curnonsky declared it the kind of tableau for the Folies-Bergère. ${ }^{171}$

Acting was another condition sine qua non for the cheerfulness created in the revue. Reviewers used to discuss each of the actors' contributions to the buffoonery. With regard to Musidora, then, I have already pointed out her proficiency in imitation, parody, and creation of types. Many parts offered by the revue were caricatures of contemporary or historical figures, literary characters, or social archetypes, and Musidora did a variety of them. The figures, obviously, had names-Mme Du Barry or Livarot, Mme Nijinski or Mme Lui (the French nickname for American film actor Harold Lloyd)-and so did some of the characters and archetypes: Musidora played parts of a certain Caroline, a Maurice, and a Mimi. The Virginie she did in "La Revue Galante" at the Folies-Bergère was taken from a popular novel, Paul et Virginie, by Henri Bernardin de Saint-Pierre. ${ }^{172}$ Today, it is difficult to ascertain to whom or to what other names referred, but, for insiders such as reviewers and contemporary spectators, the intertextual references must have provided part of the pleasure, not only in terms of information, but also in terms of recognition. Some social archetypes are still clear as they are indicated with an appellation: La Pompière (neologism for the female firefighter) or La Tangomaniaque (idem for the female tango-maniac), for example. Playing such caricatures demanded getting the type right, which required, also according to contemporary critics, observation and precision. Musidora's literary education and penchant for reading must have served her well in this regard. In the second place, the type had to be made funny, and, therefore, those extras were necessary, which 
made up what I have earlier called the warp and woof of comic acting. The extras credited to Musidora that have come up so far, were confidence, finesse, and lightness. In her role of Virginie, Curnonsky accredited her artlessness:

we attend the idyll of Paul and Virginie - an idyll well modernized and interpreted with an exquisite charm by Zidner, Paul seductive and juvenile, and by the intelligent and cultured Musidora, who has been capable of lending Virginie a mischievous artlessness and divine legs. Of this sweet part, Miss Musidora was capable of making a highly original creation that has brought her the most deserved success. ${ }^{173}$

Confidence, finesse, lightness and artlessness are terms pointing towards an aptitude in performing, towards the mastery of the métier. According to Laloy, as we have seen, such mastery entailed the creation of fine-tuned perfor164 mances based upon keen observation and a flair for satire. The assessments of Musidora's revue performances attest to the fact that she had both. In her performances, she was furthermore deemed "spirituelle" (witty), "à la fantaisie si personelle" (with her so personal fancy), "malicieuse et vive" (roguish and quick), or "gavroche" (streetwise). As adjectives, these terms indicate a knowledgeable appraisal of not only generic rules but also of acting style, an awareness of the thespian means with which the precision and the comic were created and that was shared by audience and actress. They imply that Musidora, on stage, acted and play-acted at once. And, as I will contend, it is this acting/play-acting, that Musidora carried over to the cinema.

Few pictures of Musidora have survived from the early years, in which she passed from discovery in the eve in 1912 to star of tomorrow in $1914 .{ }^{174}$ One of them, as Soliman in "L'Insaisissable Stanley Collins", shows her on the stage. ${ }^{175}$ The stage photos published with the reviews of plays or revues à grand spectacle invariably emphasized the richness of the scenery and costumes. The picture from the play makes the actors seem figurines in a pompous exotic set and renders Musidora unrecognizable. The publicity stills from the revues published in the papers usually show, in addition to the luscious scenery, large troupes of actors and actresses making up a tableau, a ballet, or an apotheosis. None of the published set photos of the revues in which Musidora acted at the Ba-ta-clan and the Folies-Bergère featured her, perhaps because she mostly played in tableaux with a smaller cast. On the other hand, the vedettes of the revues featured in the newspapers with studio portraits or drawn caricatures, but Musidora, as star of tomorrow and ranked secondary on the bill, was not yet qualified for such treatment. The studio portraits, moreover, reveal little about acting talents. Two such portraits of Musidora were nonetheless printed inside the program leaflet of the revues at the Ba- 
Fig. II.6: Musidora in the picture postcard series «Nos artistes dans leur loges» issued by Comoedia.

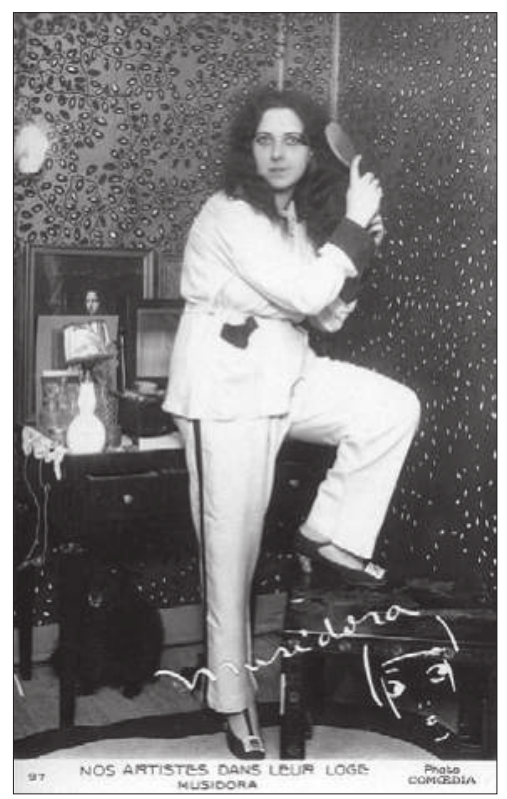

ta-clan. ${ }^{176}$ One shows a round-eyed and dark-haired Musidora with bared shoulders and a fine necklace, with a serious expression on her face but across whose lips plays an ironic smile. The other one renders her younger and more innocent, but no less ravishing. Her thick, black, curly hair reveals the presence of Southern-European blood in her veins: her paternal grandmother was of Spanish descent. Some further pictures of the time did evoke the cliché of the scarcely dressed music-hall actress. ${ }^{177}$ One included in Lacassin's study of Musidora's career shows her with bare legs and bare shoulders and dressed in a frivolous ballet costume; another shows her, presumably in her dressing room at the Folies-Bergère, again with bare arms and legs, and dressed in just a bra and shorts. ${ }^{178}$ On Flickr, moreover, a very rare picture postcard can be found, showing Musidora decently dressed in a kind of pajamas, but with very elegant shoes, while brushing her hair, standing with her back to the dressing table, and with one foot on a stool. ${ }^{179}$ From underneath the dressing table, a small black dog watches the photographer. It was originally issued by Comoedia in a series of picture postcards, "Nos artistes dans leur loge" (Our artistes in their dressing room), but carries no date. In the lower right corner, Musidora's signature was printed as well as a small self-caricature as Irma Vep; this dates the picture to post-1916. The most appealing and interesting pictures of Musidora of the pre-war years show her cross-dressed: tailored men's suits render her proud, handsome, and playful, a demeanor on which she capitalizes, as will become apparent, most notably in her self-produced films. 


\section{Musidora's Writings and Caricatures}

During her early years on the Parisian popular stage and parallel to her acting, Musidora also established herself as a writer. A 1913 mention of her literary work:

No doubt that Musidora, who combines her fine acting with most delicate literary qualities, soon will produce for us a biography of Musi-cat, following the example of Colette Willy who glorified "Toby-dog". ${ }^{180}$

As of early 1913, Musidora had published novellas in the "magazine gay", Fantasio, a weekly established in 1905, named after an 1834 comedy in prose by Alfred de Musset and filled with tongue-in-cheek reports of popular stage performances and short stories by authors like Willy; the poet and drama author 166 | Maurice Magre; and the revuiste, singer, and later cabaret owner Jean Bastia; both dramatists with whom Musidora would work on stage during and after the war. ${ }^{181}$ In Fantasio, she published regularly until December 1916, and at least one of her stories concerned the popular stage. ${ }^{182}$ Also in this sense, then, Musidora followed an example set by Colette, who, in her books La Vagabonde (1910) (The Vagabond) and L'Envers du music-hall (1913) (published in English as Music-hall Side-Lights), had manifested herself an astute observer of the backstage hardships and distressing lives of the slave performers in provincial music-hall by contrasting them with the pleasures they provided to their audiences. ${ }^{183}$ Varying on the perspective from which to tell the story, Musidora chose a soldier on leave from the front visiting an expensive and pretentious, yet small café-concert that offered a very poor program. A fictitious tale, it is nonetheless interesting for the reasons that Musidora broached to explain the poor quality of the acts beyond their evident mediocrity, predictability, and lack of style. The musicians, for instance, continued their conversations while playing and the chanteuse was so indifferent to everything that nobody would even notice her. In this short story, Musidora says that, to make a performance worthwhile and to make a performer noticeable, it is necessary to reckon with the magic of the stage, to respect the audience, and to perform with zest and zeal. While it remains guesswork if these criteria influenced her own performance practice, they do resonate, as I will illustrate further on, in her fictional and factual writings on acting for the camera.

Musidora employed another one of her talents for rendering her views on the stage-craft in which she was worked: by drawing croquis (caricatures) of her colleagues and publishing them in Comoedia. I have inserted a few of these in this text, not only to prove that Musidora had "definitely various strings to her art" ${ }^{184}$ but also because, as miniature glimpses of a bygone popular culture, 
Fig. II.7: Caricature by Musidora celebrating the success of the revue of the Ba-ta-clan. Comoedia, 4 May 1912, 4 .

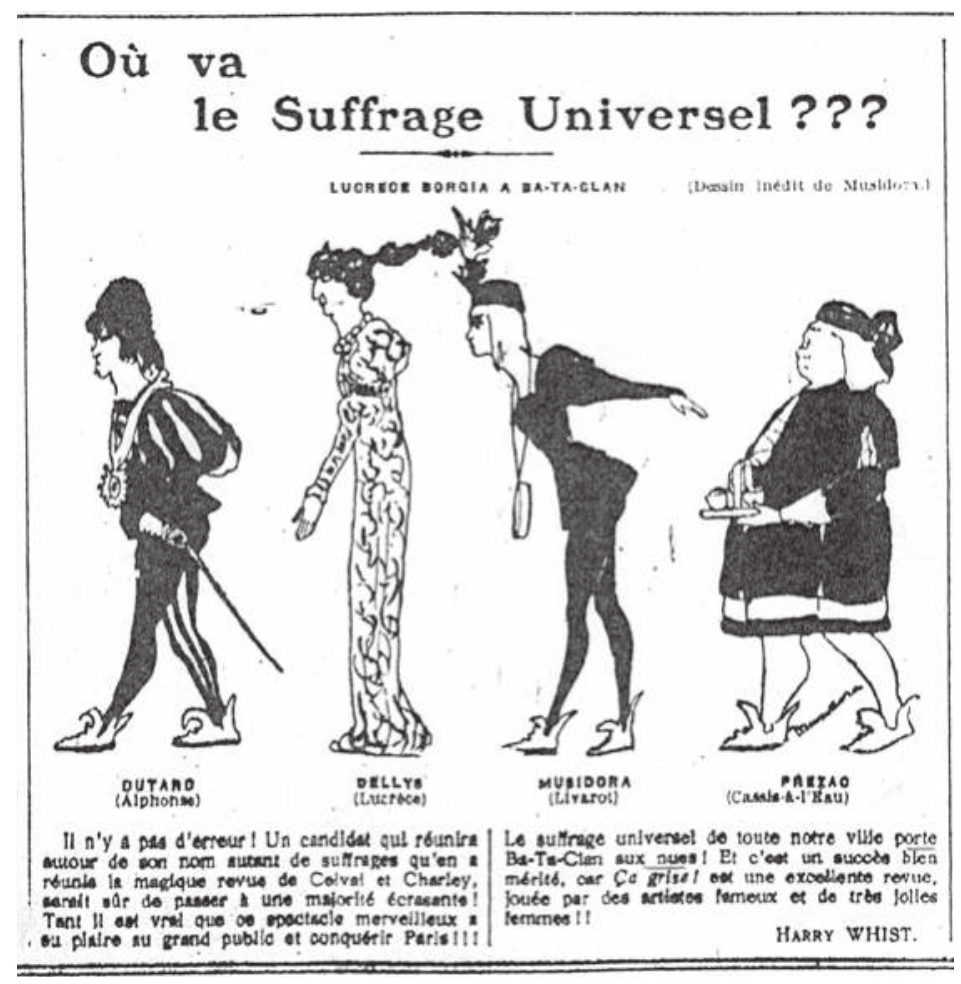

they attest to the lightheartedness that seems to have pervaded every facet of pre-war music-hall and Parisian revue.

\section{Conditions of Musidora's Stage Career by 1914}

With her multiple talents, Musidora had chosen a profession and popular stage genres that enabled her to exert her versatility, her acting skills, and her knowledge of literature and art. Most notably, the pre-war Parisian revue à grand spectacle, with its wit, its textual perspicacity, and its groundedness in contemporary social, cultural, and political reality had become her professional habitat as a stage actress. As a popular stage genre gaining momentum in the early 1910s, and savored by a wide range of social groups, including artists and intellectuals, the Parisian revue ensured Musidora extensive exposure and prominent praise in the contemporary press. Although she, in the wake of her self-chosen godmother and mentrix Colette, embraced the tradition académique and occasionally adopted the culte du maillot, Musidora's reputation as a performer was not confined at all to the cliché of the scarcely dressed woman. Instead, she was esteemed as a multi-faceted comic actress. As with the pièce à grand spectacle, people took pleasure in the acting, and in 
the spectacular details of mise-en-scène, sets, and costumes. French musichall had also set the artistes free from the relatively constrictive genres of solo performance of the old café-concert and enabled them to invite the audience to amuse themselves with them, instead of at their expense. The communication with the audience was conditioned by a knowledgeable appraisal of generic conventions and acting styles, a shared awareness of how the wit and merriment were created. This forged a double acting, a simultaneous acting and play-acting, that Musidora also mastered, and that she, as I will demonstrate in my discussion of her work with Louis Feuillade, transferred to the cinema. 


\section{Musidora and the French Silent Cinema}

MUSIDORA AS AN ACTRESS AT GAUMONT 1914-1916

In the spring of $1914,{ }^{1}$ Musidora was offered another option for expanding her already versatile talents as an actress:

I have acted in vaudeville plays...

And a man came to fetch me for acting in a drama...

Another one, who had seen me in the drama, carried me away to the revue...

The one who had seen me in the revue, wrote to me:

"The cinema is an art, come and act in films." ${ }_{2}$

The man who saw her in the revue and who solicited her collaboration was Louis Feuillade, leading film director of the second largest film company in France at the time, Gaumont.

Musidora's nearly three year affiliation ${ }^{3}$ with Gaumont is most strongly marked by her acting in films directed by Louis Feuillade, although, in 1915, she also worked with other Gaumont directors such as Gaston Ravel, Léonce Perret, and Jacques Feyder. Louis Feuillade (1873-1925) was not only the leading film director at the company, but, since 1907, was its artistic supervisor as well. That year, he succeeded his mentrix Alice Guy-Blaché, who left for the United States after having occupied the position of leading filmmaker and supervisor of the Gaumont production for the previous ten years. ${ }^{4}$ By 1914, Feuillade was one of the most prolific, versatile, and established of French filmmakers. Because of company policy, his name was still unknown to the public, but his films usually did very well at the box-office. ${ }^{5}$ He made his films within the disciplined rhythm maintained at the Gaumont studios and 
Fig. II.8: Louis Feuillade.

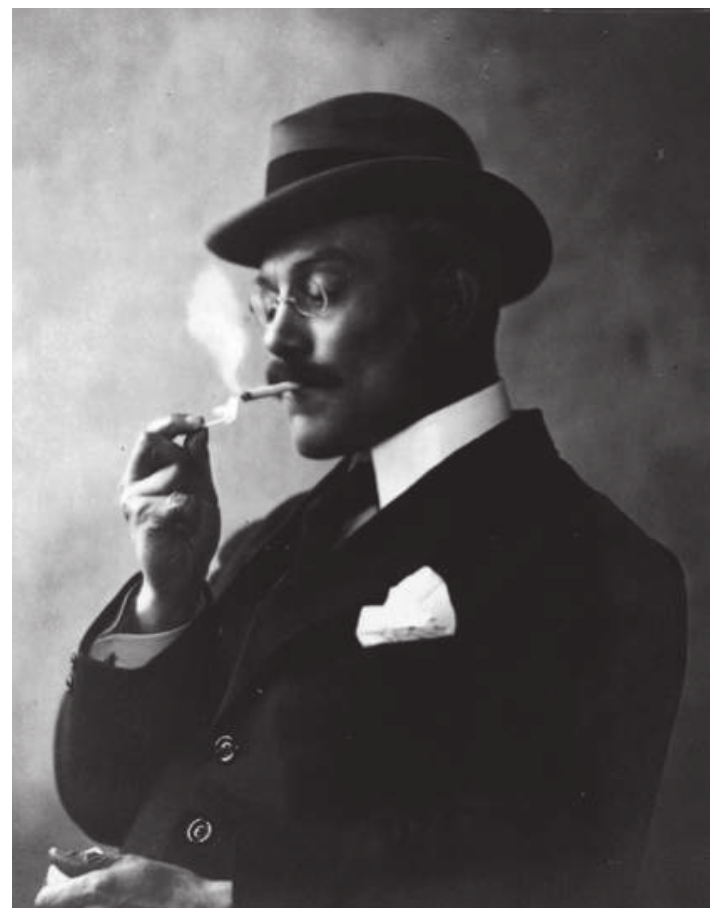

amounted during the pre-war years to an average of one or two films per week. ${ }^{6}$ They included the entire array of popular film genres at the time, including historical and contemporary dramas, crime series, and, above all, a variety of comic subjects. The high production rate and the hybrid nature of Feuillade's work were significantly sustained by the fact that he was able to work with a large but select troupe of actors and actresses, that he had gathered around him throughout the years. Some of them were employed for their versatility, like Renée Carl and Yvette Andreyor, others for a specific quality they brought to films, as was the case with René Navarre, Marcel Levesque, Musidora, and the child actors Bébé and Bout de Zan. But all of them were enticed to relatively restrained acting drawing from their "genius", as Feuillade preferred to call his actors' distinctive presence and ingenuity. ${ }^{7}$ His joyous nature and fertile imagination in combination with his longstanding experience and his feeling for what the public wanted to see created a highly productive work environment of shared respect and of pleasure and playfulness. Casts and crews at Gaumont felt that they were special and that they were making something special. ${ }^{8}$ This climate was cultivated for two reasons: it helped bear the financial and disciplinary restraints imposed by the boss, Léon Gaumont, whom Feuillade secretly but tellingly nicknamed "le barbelé" (the barb wire), and 
it helped sustain the competition with Gaumont's primary rivals Pathé and, after 1916, American cinema. ${ }^{9}$

Feuillade took great pride in writing original scripts and deviating from them while shooting, although he also made use of theatrical and literary sources by 1914. He was a well-read man with a great knowledge of painting. and had a vivid interest in the popular stage. All of this was unknown to Musidora when Feuillade solicited her collaboration, and she claims that her first response to him had been negative: "Film? You are kidding me. I am no acrobat!"10 But Feuillade managed to change her ignorant attitude, after which the spirited, literate, versatile, and doubtlessly ambitious rising star quickly recognized in him a soul mate:

His volubility, his manners, I liked everything in this man who got through his work in an animated, intelligent and comprehensive move. [...] Behind his pince-nez, one saw a thousant scripts dancing, passing by, being spun out, one more poignant than the other... His great intelligence, his adaptability made him a true friend to me right away. ${ }^{11}$

Feuillade, in turn, was particularly charmed by Musidora's extraordinariness, as speaks from this, to my knowledge, only retrievable statement from him about the actress:

your pretty oval little face is one of those to which my memory attaches itself with the greatest pleasure; first, because you are not ordinary and second because you have always approached me with an attitude filial and respectful at once, which is a peculiarity of spoilt children. ${ }^{12}$

During her Gaumont time, Musidora participated in at least 31 films made by Feuillade. In addition to the two famous episode films, LES VAMPIRES and JUDEX, which consisted of ten and twelve episodes respectively, but which I tally here as one film each, she appeared in a historical drama, a contemporary drama, some patriotic films, and a series of comic subjects. My discussion of them along generic lines allows me to point out the extent to which these films exemplify the close ties of Feuillade's cinema with the popular stage culture of the times. Because Feuillade not only recruited acting talent from musichall and boulevard theater, but also took inspiration from the stage's tried and trusted generic formulas and subject matter. In contrast to contemporary and later assessments that consider this aspect of his work a drawback or a defiance of cinematic specificity, some of which will be discussed in due course, I argue that Feuillade's self-confident drawing from the popular stage constituted a significant element of his understanding of cinema as a popular art. 
This is particularly pertinent to the two genres in which Feuillade used to cast Musidora, comic and episode films, but equally relevant to the two dramas in which Feuillade first tested his new asset.

The chronology of titles in which Musidora appears and some surviving anecdotes suggest that Feuillade's initial idea of how to employ Musidora's talent was in dramas. Musidora's first screen appearances in Gaumont films were in a historical drama and a contemporary drama in which she played supporting parts. ${ }^{13}$ Musidora's own recollections include that Feuillade had asked her to play the Virgin Mary in a biblical film and that she declined the offer because it was planned to be shot in Palestine, whereas she had no intentions to quit the revue at the Folies-Bergère, which was bound to run until June 3oth. ${ }^{14}$ Feuillade's colleague and friend, Henri Fescourt, who accompanied the filmmaker to watch Musidora perform on stage, recalled that they were searching for "beautiful women, colorful figures, archetypes"15 to act in their

172 films. They were primarily impressed by Musidora's dance act, which, probably, was included in the third tableau, "Paul et Virginie à Paris": ${ }^{16}$

We saw, supported by a quite handsome partner, a young woman flexible like the stalk of a plant, with slim and long legs, with a pure bust exposed by a bright bodysuit, skipping like an antelope in front of a mesmerized public. The body, as soon as having lightly touched the floor, relaxed, swung up again, fell back, turned around on its axis in the air with a nervous grace. This play of graphic rhythms unfolded in a harsh lighting that gave it an at once crisp, somewhat savage and strangely sensual note. ${ }^{17}$

If Fescourt understood the crisp note as an effect of the lighting, Musidora's reminiscences foreground a combination of sensual presence and mode of acting:

I played a Virginie that [the novelist] Bernardin de Saint-Pierre definitely had not conceived of. Three leaves embroidered on tulle covered my breasts and fifteen blades of grass arranged like a large comet hid my navel. A noble expression of purity and ingenuousness sat on my face. This ingenuousness caused me to be summoned to the Gaumont studio. ${ }^{18}$

Feuillade himself, according to Fescourt, pointed out the features of Musidora's face that specifically qualified her for working in front of the camera: "The face is very good at close distance. The eyes will be marvellous in projection." 19 The expression of ingenuousness, Musidora's eye-catching presence, and her striking eyes, apparently, initially enticed Feuillade to try her in the dramatic genre. 


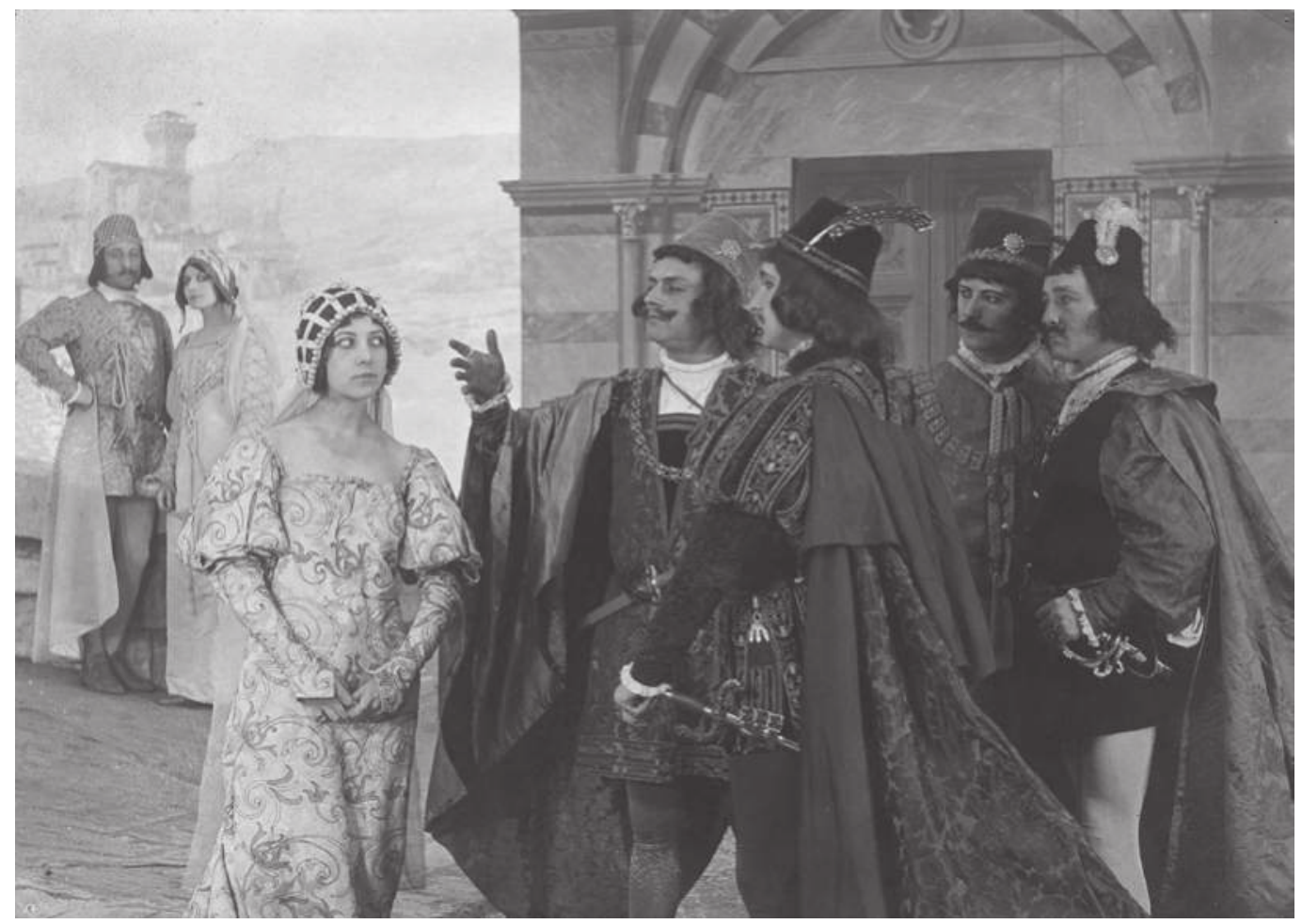

Fig. II.9: Set photo SEVERO TORELLI, a film by Louis Feuillade. Gaumont production 1914.

\section{Feuillade’s Dramas and Comic Films with Musidora}

Musidora's first appearance on the screen of the Gaumont-Palace, the cinema where Gaumont's and Feuillade's films usually premiered, was on June 5,1914 , in the historical drama SEVERO TORELLI. ${ }^{20}$ It was a film in the series "Grands Films Artistiques", a collective name for Gaumont films that made up the main feature of the program, but which were not exclusively directed by Feuillade. ${ }^{21}$ With its 1208 meters, SEVERO TORELLI was one of the longest films Feuillade had made so far, and, with its lush costuming and richly embellished sets, was also one of the more costly ones. Half of the announcement of the film in Comoedia went into raptures about how varied and well-taken care of the sets were, and Musidora also recalled it for this aspect:

First there is my debut film at Gaumont: SEVERO TORELLI, with a leaning tower of Pisa made of painted card board, with a street made out of pebbles on the floor, with a fake bridge and costumes from La Reine

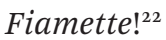


Musidora's sniggering reflection six years after date notwithstanding, the surviving print of the film demonstrates that those painted backdrops were no less than stunning: ${ }^{23}$ the tower of Pisa was drawn in graphic detail and the water underneath the fake bridge really seemed to sparkle. The film also contains an impressive trick scene in which white-clad and carefully choreographed specters stagger the spectator as much as they do the main characters. According to Richard Abel, the spectacle of sets and costumes constituted one of the main attractions of the genre of the historical film. ${ }^{24}$ This aspect of the critical appreciation brought to the genre, then, paralleled the enthusiasm about the sets and costuming in popular stage genres such as fairy plays and revues à grand spectacle.

The Comoedia-announcement acclaimed the film not only for this ornamental aspect, but also for its dramatic power and its compelling emotions:

174 The hesitations, the disgust, the remorse... Dona Pia's disgrace, her outraged pride and her final gesture, the revolt of the people of Pisa, make up the most tragic plot which one can imagine. ${ }^{25}$

Dona Pia was the mother of the protagonist of the story, Severo Torelli, and was played by Renée Carl. She was the star of the film and her role and name were not only singled out in the announcement, but also in the opening shots of the film. The drama is set in fifteenth-century Italy and weaves political and emotional motifs into a fatal plot centering on men. The political motifs include the son's duty to carry out his father's unfinished task of overthrowing Florence's governor, Barnabo Spinola, who tyrannizes Pisa. The emotional motifs include Severo's discovery that Torelli is not his genuine father, but is, in fact, Spinola, who once claimed the handsome Dona Pia in exchange for Torelli's life. With her, according to Fescourt, "intense and tragic physiognomy" and "so controlled and expressive acting style", ${ }^{26}$ Renée Carl invigorates an otherwise aloof drama with emotions relatable for spectators. Feuillade, who, since Carl's entry at Gaumont in January 1907 , cast her in virtually every film he made, ${ }^{27}$ granted her various lengthy shots and scenes that allowed her to exploit her solid demeanor and glowing eyes to the maximum effect. At one point, at least, she directly addresses spectators by looking into the camera. The function of this gaze is to intensify the emotion-the mother's determination to stand by her son, regardless of his choice-and communicate this to spectators. If it is true, as Fescourt contends, that Renée Carl was among the first actresses in France to understand the secret of acting in silent cinema, ${ }^{28}$ and if it is also true, as the Gaumont and Feuillade actress Yvette Andreyor has reported, that Renée Carl was gentle, fair, and benevolent towards debutantes, ${ }^{29}$ Musidora may have picked up 
some valuable tricks of the trade from her experienced forerunner as Feuillade's favorite actress.

In SEVERO TORELLI, Musidora played the relatively modest part of Portia, the mistress of Barnabo Spinola who is secretly and vainly in love with Severo Torelli. She appears several times veiled and indiscernible, but is prominently visible in three scenes: two lighthearted and cheerful, the third perturbed and dramatic. In the cheerful scenes, which were set at a store and in a street, she talks Spinola out of liquidating one of his contestants who was an ally of Severo's. A little later, she runs into Severo and his friends. The friends thank her with admiration for her courage, but Severo, to her great sorrow, hardly notices her and behaves perfunctorily. In these scenes, Musidora's acting style comes across as breezy, agile, and artless. In the scene with Spinola, she inserts an actor's strategy that she carries on in many of her subsequent screen roles: moving her eyes to solicit complicity from the spectators. If she, in the process, looks into the camera, it is to the effect of communicating to the public her thoughts on what is going on within the diegesis. As Fescourt observes, "she brought out the features of her characters through the way she gazed, listened, contemplated..." ${ }^{\circ 0}$ Traces of this method are already present in this screen role. The dramatic scene emphasizes, above all, her remarkable beauty. In it, a veiled Portia approaches Severo to profess her love for him. Torn between curiosity and a sense of fatalism, he takes away the veil and discovers who the mysterious woman is. The shot exhibits Musidora's gorgeous neck and décolleté. Rejected by Severo, Portia soon falls into distress. She collapses, stretches out her arms, and, once more, the camera renders her unearthily handsome. Whereas in dramatic scenes Musidora's way of acting resembles Carl's, it differs in cheerful scenes. Musidora brings to the fore her character's sentiments with natural ease. The roles that Feuillade conceives for her, from the beginning and throughout her affiliation with Gaumont, enables her to fully exploit her eye-catching presence as well as her artless way of acting.

As we have seen, Musidora demonstrated such artlessness already in her stage performances, and, in this respect, her acting in cinema can be understood as a continuation of her way of acting developed for the popular stage. This suggestion turns out less far-fetched than it seems at first sight if additional connections to practices borrowed from the popular stage are taken into account. Succeeding a highly successful stage play, SEVERO TORELLI constituted the first adaptation to the screen of the epic poem with the same title written by François Coppée. ${ }^{31}$ As the staging was explicitly mentioned in the publicity, one may assume that it contributed considerably to the popularization of the literary text, similar to the staging of Colette's Claudine-plays. Furthermore, a luxuriously produced 63-page booklet was handed out to the public, a sort of story in pictures, with various stills, a cast list, a detailed 
plot outline, and many dialogues on rhyme, probably taken from the literary source..$^{32}$ This practice brings to mind the often equally posh printing matter that accompanied programs and revues in café-concert and music-hall. In sum, SEVERO TORELLI was not only connected to the popular stage in some of its representational strategies, such as the spectacular sets and costumes and the ways of acting, but also in the conceptual framework of its public presentation. Similar representational strategies and a similar framework of presentation apply to Musidora's next film directed by Feuillade, LE CALVAIRE (The Agony).

Two weeks after SEVERO TORELLI, the programs of the Gaumont-Palace and the Tivoli Cinema offered a second film with Musidora, the mundane drama LE CALVAIRE, another "Grand film artistique" with Renée Carl en vedette in the role of a tragic mother of a son in trouble. In this 859 meter film, ${ }^{33}$ Musidora played the part of a music-hall actress who, unknowingly, was the source of the trouble, and this offered her a more extensive appearance than in her 176 | preceding Gaumont film. She not only played the character, but, in a direct reference to the stage, also wore the headdress designed by Poiret, which she had worn in the "La Revue Galante" at the Folies-Bergère. ${ }^{34}$ It was common practice at Gaumont for actors to bring their own wardrobe when cast in contemporary parts. ${ }^{35}$ The gown that she wore in this part, however, made her less proud:

My head covered with pearls, my feet in shoes of satin and with tapering heels, which made it difficult to keep my balance, half hidden under a veil of silky cotton, in the Greek way, of a somewhat silly kind, such was the way how I had to consolidate my position on the silver screen. ${ }^{36}$

The reference to the popular stage was emphasized even further in the publicity for LE CALVAIRE, in which Musidora's name was singled out by the caption "des Folies-Bergère", where she indeed continued to perform while the film was shot. Her status as a music-hall actress was considered to give the film extra esteem. No print of it is known to survive, but there are advertisements with six stills, of which three include Musidora, and there is, just like in the case of the previous film, a twenty-three-page publicity booklet that contains five additional stills featuring Musidora. ${ }^{37}$ The photographs invoke a connection between the part and Musidora's work on-stage, although the film itself seems not to have lived up to that expectation. According to the summaries and outlines, the story does not contain any scenes with the actress on-stage or otherwise at work. Hence, the references to Musidora's stage fame were arbitrary with respect to content, and thus only served publicity aims. For this contemporary drama, then, the suggestion of truthfulness was a positive point, and the association with music-hall an additional asset. 
Musidora with the headdress by Poiret, which she wore in "La Revue Galante" and in LE CALVAIRE. Photo Waléry.

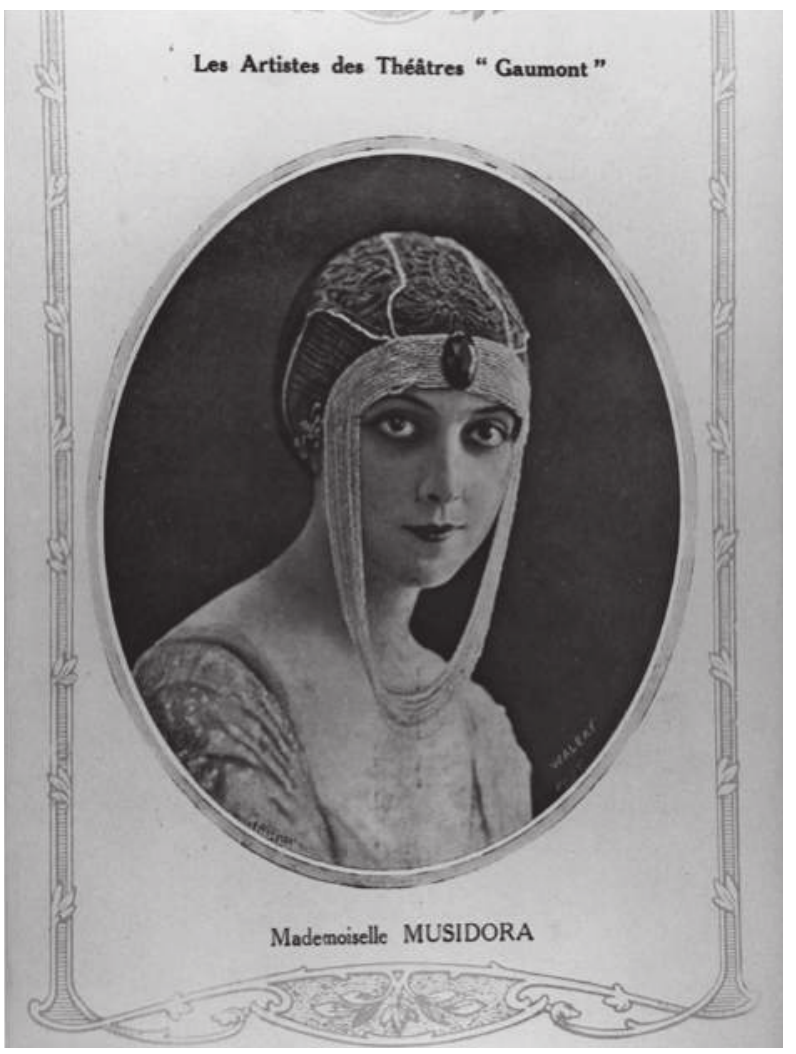

LE CALVAIRE nonetheless seems to have offered Musidora two major scenes that unleash the drama. In both, her character goes through an escalating quarrel with her jealous lover, who is the good-for-nothing son who runs into trouble and is spoiled by his mother. The first scene is set in her dressing room at the music-hall, the second, in his car and at her apartment, successively. In her dressing room, she wears her music-hall outfit, and the pictures show her upset yet resolute. In the scene at her apartment, she wears a somewhat homely outfit, and is pictured once talking her lover round and once with an expression of shock, because he, in his drunken rage, has smashed a carafe on the table. The summary discloses that she eventually throws him out. In the drama that unfolds, the actress is murdered, her lover becomes a chief suspect, and his mother has to face the dilemma of standing by her son or letting him down. The actress' murder causes her disappearance from the diegesis, which continues to focus on the agony of the mother. Despite the fact that no moving images of the film are available, the stills indicate a similar correspondence between role and acting style as pointed out previously: Musi- 
dora seems to have acted with ease and ingenuousness, giving her character an energetic and dynamic quality.

Neither of the two films has been discussed in extant studies of Feuillade's work, but Lacassin mentions them in his booklet on Musidora as examples of how Feuillade, from the beginning, employed her "qualités plastiques", a phrase that remains ambiguous as to whether it refers to her visual attractiveness, her pliability, or both. ${ }^{38}$ In the above, I have tried to complicate this view on the collaboration between filmmaker and actress through emphasizing her mode of acting. As she had done on stage, Musidora showed confidence in the creation of types, held up artlessness in her way of expressing sentiments and thoughts, which she moreover communicated to spectators through moving her eyes. In addition to the historical and contemporary drama mentioned, Feuillade and some of his colleagues later utilized Musidora's qualities in another dramatic genre, the patriotic drama that emerged from the war. Feuil178 lade cast Musidora in three patriotic films, Léonce Perret in two, and some nine were directed by Gaston Ravel after scenarios by Nora Januxi. ${ }^{39}$ Of this lot, only Ravel's L'AUTRE VICTOIRE (The Other Victory) is known to survive, although in an incomplete print. ${ }^{40}$ The extant fragments of the film do nonetheless corroborate the above observations about Musidora's screen presence.

I have pointed out that SEVERO TORELLI and LE CALVAIRE were released as "Grands Films Artistiques". As Richard Abel has shown, this caption refers to Gaumont's answer to a direction in French film production, which, in 1909, had been initiated by Pathé's satellite firms Film d'Art and its immediate successor, the Société Cinématographique des Auteurs et Gens de Lettres (hereafter, the SCAGL)..$^{41}$ In response to the 1908-1909 crisis in cinema attendance, both the Film D'Art and the SCAGL had promoted the active involvement of dramatists, writers, and stage actors in filmmaking to liberate cinema from its current status as a music-hall attraction and to attract more sophisticated audiences to the newly established cinemas. In their unremitting competition with Pathé, Gaumont and Feuillade meanwhile disputed the tactics of drawing from the stage and printed sources by internally and publicly cultivating a preference for original scripts and for actors they themselves had molded for working in front of a camera. ${ }^{42}$ In trade paper advertisements, they claimed a set of aesthetic principles and artistic intentions that guided their pre-war production, such as Feuillade's series of the "Films Esthétiques" in 1910 and his "Scènes de La Vie Telle Qu'elle Est" in 1911. As a referential model for the first series, the art of painting was specified: "because its address is to our eyes". ${ }^{43}$ For the second, truthfulness was invoked as a guideline: "These scenes want to be and are slices of life." ${ }^{44}$ In such advertized statements, the stage and literature were referred to as cultural forms from which film turned: "We do not believe that the cinema is condemned to remain exclusively tributary of 
the theater and to restrict itself to adaptations." ${ }^{45}$ In another, it was asserted that their plan was "to divert the French cinema from the influence of Rocambole in order to raise it toward a higher destiny". ${ }^{6}$

In light of such declarations of intent, the multi-layered connections to the stage of films like SEVERO TORELLI and LE CALVAIRE seems at odds with the profile Feuillade and Gaumont constructed for their film production. But even if they did not profess so in public, I would argue that these films, and several others, testify to the fact that they, much like their rivals, did turn to the stage and to literature for subject matter and inspiration. For instance, one year before SEVERO TORELLI, Feuillade filmed the serial novel written by Pierre Souvestre and Marcel Allain, FANTÔMAS, and, as is generally known, with considerable success. When it comes to stage actors working before the camera, moreover, Musidora was not the first or the last candidate. Fernand Hermann, the actor who played the lead in both SEVERO TORELLI and LE CALVAIRE, to name but one of her peers, had a twelve year career on the popular stage. ${ }^{47}$ The key to what Gaumont and Feuillade adopted and adapted from stage and from literature, however, was not the legitimate theater or high literature. The keyword was that they looked for what appealed to a large public: that is to say, they looked for popular culture.

According to Fescourt, Feuillade's motto for his own films and for the supervision of Gaumont's film production was: "A film has to sell. Let us look for what it needs to please the public." ${ }^{48}$ Fescourt called Feuillade a virtuoso in this regard, whose flair for pleasing crowds came close to divination. In Gaumont's advertized statements for Feuillade's films, which were arguably drafted by the director himself, a former journalist, the crowd was invariably invoked as the final judge. This was already the case in 1911, when the announcement of the "Scènes de la Vie Telle qu'elle est" read that the public would tell them if the effort had been successful, ${ }^{49}$ and still held for 1922 , when Feuillade, in the presentation of his ninth serial LE FILS DU FLIBUSTIER (The Son of the Buccaneer), directly addressed the public in such terms: "oh public, sovereign judge of our films and master of our destinies." ${ }^{\circ 0}$ In the 1916 statement to announce JUDEX, Feuillade gave his vision of his films' spectators:

What is JUDEX? [...] A film... which we have wished to be popular in the largest and the most wholesome sense of the word, a family spectacle inciting the most noble sentiments in which we have made every effort to please Children and Adults, thanks to a plot with the most diverse and unforeseen intricacies. ${ }^{51}$

In this description resonates the broadness of the music-hall and popular stage public, the public of the pre-eminent entertainment industry of the 
time, which before and during the war, determined what was to become popular. As much as Feuillade and Gaumont professed aesthetic innovation and artistic aspirations, the films had to sell and to appeal to a broad public. Seen from this perspective, Feuillade's adoption and adaption of popular stage talent and subject matter to the screen becomes less contradictory. The idea of a genuinely popular art was indebted to the conceptual framework of pre-war music-hall and revue, which was the paramount divertissement for the eye and the mind. For Feuillade and his contemporaries, this was a matter of fact, but today, this conceptual context needs reconstruction. And, indeed, were "the address to the eye" and the "exposure of slices of life", as Feuillade phrased them, not also two of the primary aims of the revue, as I argue in my discussion of them? Was the Folies-Bergère not the select site for him and Fescourt to find beautiful women, colorful figures, and archetypes? Had music-hall and revue not also had the intermediary function of distributing and popularizing 180 | knowledge of art and literature? And did the claim of a naturalistic or realistic aesthetic, as Abel has argued, not mask the melodramatic origins of Feuillade's fiction and the close interconnection that existed between melodrama, realism, and sensationalism in late nineteenth-century French stage drama and fiction $?^{5^{2}}$

By consequence of the negation of popular literature and theater as sources of inspiration, the further ramifications of the interconnections between Feuillade's cinema and French popular culture of the mid-teens have long remained obscured. ${ }^{53}$ However, looking at Feuillade's films from the perspective of how they drew from the stage, provides a context for understanding how they could attain popularity. And, most interestingly, Feuillade appears to have copied the strategies of the Film d'Art and the SCAGL much more extensively than he and Gaumont were willing to admit. These strategies include the involvement in film of popular stage actors and actresses like Musidora and a brief discussion of them may illuminate my point.

The Film d'Art took its actors from high theater and adapted literary classics, but, because of the varying success of its films, this strategy was considered controversial by 1914. One of its achievements, however, was that it revived the genre and elevated the status of the historical film. ${ }^{54}$ As SEVERO TORELLI illustrates, this was also the case beyond the Film d'Art's own productions. In addition to that, the Film d'Art initiated the promotional strategy of drawing the spectator's attention specifically to the actors, along with their theatrical associations: "Le Bargy, de la Comédie Française" as the poster for their film L'ASSASSINAT DU DUC DU GUISE (The Assassination of the Duc du Guise, 1908) read. ${ }^{55}$ We have seen already that Feuillade used such phrasing to advertise Musidora in the publicity for LE CALVAIRE. Even more than the Film d'Art, however, it was the SCAGL, a company headed by the feuilleton 
writer and boulevard playwright Pierre Decourcelle, which productively drew from France's literary patrimony, to the wide circulation of which the popular stage adaptations had been instrumental. But, as Jean-Jacques Meusy has contended, even more so than the renown of the authors and script-writers, it was the fame of the actors that attracted audiences to the SCAGL films. ${ }^{56}$ The SCAGL actors did not come primarily from the Comédie Française, as those of the Film d'Art, but from the popular stage and music-hall, as, for instance, the boulevard theater actress Polaire, the dancer from the Odéon and the Olympia Stacia de Napierkowska, the comic actor from the Variétés Prince, and the music-hall vedette, Mistinguett. These popular actresses, as Abel points out, began to display the latest fashions in playing seductive figures, sometimes associated with the theater. ${ }^{57}$ Musidora's part in LE CALVAIRE exemplifies this trend as well. Feuillade, at about the same time as he secured the collaboration of Musidora and Hermann, further engaged the comic actor and Musidora's future partner in comedy Marcel Levesque, "du Palais Royal”, a vaudeville theater. Of the SCAGL actresses, Polaire and Mistinguett, in 1914, can be seen as forerunners of Musidora, both in terms of their careers and the type of roles they chose.

Previously, I described how Polaire's status shifted from, during the 189os, gommeuse épileptique and vedette of the café-concert, to one of the leading ladies of the boulevard theater in the 1900 s through her interpretation of Colette's Claudine. Polaire, whose real name was Emilie-Marie BouchardZouzé, ${ }^{8}$ was of Algerian descend, and, according to Jacques-Charles, her muscular body resembled that of a little Arab. ${ }^{59}$ Her special feature was her "taille de guêpe" (wasp waist, 40 centimetres all around, according to legend), which, as Colette observed, was emphasized by her exceptionally high and wide chest. Both on- and off-stage, moreover, Polaire cultivated an exotic intonation in her French. ${ }^{60}$ This combination of androgyny and color deviated from the beauty standards for Parisian women in the Belle Époque, which required a curvaceous body and pale skin. The success of the role of Claudine subjugated Polaire to being typecast again: "For a long time people wished to see in Polaire only the irresponsible and depraved little brat, with her nude calves, her short curly hair, and the black apron." She countered the problem in 1910 through proceeding to music-hall, where she, according to Curnonsky, could demonstrate her versatility and mastery of the métier. At the Olympia, "she was in turn playful, mischievous, creative, sad and cynical." ${ }^{61}$ By the end of the decade, Polaire had secured the second position in the top five of female music-hall stars in France, right after Mistinguett. ${ }^{62}$

Polaire and Musidora shared more than a fascination for the figure of Claudine and a close friendship with Colette. The popular stage enabled each of them to demonstrate the mastery of her métier and the versatility of her tal- 
ent. Yet, Polaire too was "fetched" by the cinema, that is to say, by the SCAGL, just a few years before Musidora. One of Polaire's SCAGL films, of which a print exists, LA TOURNÉE DES GRANDS DUCS (Going Out On a Spree, 1910), was directed by the stage actor and author of revues, comic plays, and operettas, Yves Mirande. ${ }^{63}$ It is a mischievous ten-minute sketch about what the French called apaches (tough guys) and what Abel characterizes as the "most publicised deviant 'other' supposedly threatening French bourgeois social order" of the era, first, in the daily newspapers and, as of 1904, in film. ${ }^{64}$

The story is set in two places, a restaurant and an underground joint, and Polaire plays the female protagonist of the gang. ${ }^{65}$ Polaire adopts a provocative air and moves around with her arms characteristically akimbo to emphasize both the character's vulgarity and her own legendary waifish waist. ${ }^{66}$ In addition, her character, which was not given a name in the film, engages in the apache dance, a rough skip in which the male partner slings and flings the 182 woman around the floor. ${ }^{67}$ Polaire's part precedes Musidora's roles of the midteens in Feuillade's serials LES VAMPIRES and JUDEX, and Musidora stylized her screen presence following this model.

The Apache Dance, which is also featured in LES VAMPIRES, was created for the music-hall stage in 1907, at the Moulin Rouge, by the fantaisiste (all-round entertainer) Mistinguett and the chanteur anglais Max Dearly, in their famous act "La valse chaloupée" (The Apache Dance). ${ }^{68}$ After performing for ten years at the Eldorado in the genre of the gommeuse épileptique created by Polaire, Mistinguett's position rose to that of demi-vedette at the Moulin Rouge. In the course of the 1910s, she acquired vedette-status in her partnership-professional and in private - with Maurice Chevalier, which began in 1911 in a revue at the Folies-Bergère and ended in 1920, when La Miss was unwilling to share with her partner her top-of-the-bill position as meneuse de la revue (leading lady of the revue) at the Casino de Paris. ${ }^{69}$ By then, Mistinguett had already reached the first place in the top five female vedettes of the French revue, and entered a subsequent, two-decade period of unparalleled stardom, as a sign of which may count the inclusion of her pet name "Miss" in the titles of revues, a prestige hardly any other music-hall star of the time ever attained. Examples include: "Celle à Miss!" at the Ba-ta-clan in 1917; "La Revue de Mistinguett" at the Moulin Rouge in 1925; and "Paris Miss" at the Casino de Paris in 1929. ${ }^{70}$ Already a crowd favorite by the early 1910s, Mistinguett was, like Polaire, lured to the cinema by the SCAGL, with the result that, between 1909 and 1917, she was featured in numerous films. ${ }^{71}$ Several of these appear to have parallels with films in which Feuillade cast Musidora and at least one of them seems to have drawn from Musidora's work. A brief discussion of some of the films may illuminate such parallels.

Just like Musidora in LE CALVAIRE, Mistinguett, in at least two contempo- 
rary dramas, was cast as "herself", that is to say, as a famous popular stage actress. In one of these, L'ÉPOUVANTE (The Trepidation, 1911), which was directed by Georges Monca and based on a script by Decourcelle, she played an actress returning to her apartment after the show to find a jewel thief in her bedroom. Abel depicts it as an utterly suspenseful and exciting action film that narrates how the actress handles the situation and manages to retrieve her jewels. ${ }^{72}$ The film print, preserved at the EYE Filmmuseum, shows that she handles it by saving the thief from a perilous position in which he finds himself while escaping from the police. Grateful that she saved his life, he returns the stolen jewels to her.

Emmanuelle Toulet has pointed out that one of the differences between the Film d'Art and the SCAGL was that the latter not only adapted stage dramas, but also comic subject matter such as the immensely popular vaudeville plays by Labiche and Sardou. ${ }^{73}$ In her first years with the SCAGL, Mistinguett indeed played various comic roles, as, for instance, in LA RUSE DE MISS PLUMCAKE (Miss Plumcake's Trick, Georges Monca 1911), in which she parodies and lampoons Parisian men's idolatry with American women. LA FIANCÉE RÉCALCITRANTE (A Will of her Own, 1909) and LA DOCTORESSE (The Female Doctor, Georges Monca, 1910) are likewise comic subjects. In this latter film, a parody about a woman's choice between love and career, Mistinguett was seconded by a colleague of hers from the popular stage, Charles Petitdemange, who used the stage name Prince, and, in the cinema of the 1910s, was known as Rigadin, as, for instance, in LES TIMIDITÉS DE RIGADIN (A Shy Youth). ${ }^{74}$ According to Richard Abel, the Rigadin figure drew from the tradition of vaudeville plays and light stage comedies and often parodied serious bourgeois drama and its principal subject of love. ${ }^{75}$ In his retelling of the film, Abel does not exactly specify Mistinguett's acting, but her role seems farcical. It also implies a great deal of narrative agency, as she plays the animator of the situations that constitute the fun and render Prince as the (anti-) hero of the farce. Light stage comedy as a conceptual source of inspiration for filmmaking as well as the utilization of stage actors' comic talents for the screen, appears to be highly pertinent to Musidora's collaboration with Feuillade, because, in the first month of her affiliation with Gaumont, Feuillade tested Musidora not only in the two dramas discussed, but also in the comic genre, and he would cast her time and again in his ciné-vaudevilles (vaudeville films). These comic films constitute a substantial part of Musidora's career at Gaumont, but have thus far received little attention among historians and scholars interested in Musidora's roles and films. My discussion of the ciné-vaudevilles may equally provide insights in the extent to which this segment of Feuillade's oeuvre drew inspiration from the popular stage.

Feuillade began making ciné-vaudevilles before the war and prolonged the 
genre during the war years. Initially, they were launched as a series, under the motto "La Vie drôle" (The funny life), which premiered on December 12, 1913 and carried on with a frequency of one film per month until its last release on June 26, 1914. This seventh and final film in the series was also the first one with Musidora in the cast. After that, the motto of "La Vie drôle" was abandoned, but the generic indication of ciné-vaudeville, which had been coined by Gaumont and Feuillade and remained exclusive to them, was, as the advertisements document, subsequently applied to almost all of the vaudeville films featuring Marcel Levesque. ${ }^{76}$ Levesque was the comic actor who, as of the fourth ciné-vaudeville released on February 6, 1914, invariably played one of the films' main characters until he quit Gaumont in December 1917. ${ }^{77}$ In the course of these four years, Feuillade made at least 26 films in the genre, in fifteen of which Musidora played a supporting part. ${ }^{78}$

Only one of the ciné-vaudevilles with Musidora in the cast is known to 184 Survive, namely, LAGOURDETTE GENTLEMAN CAMBRIOLEUR (Lagourdette, Gentleman Burglar). ${ }^{79}$ It was first released in December 1916 and parodied the reception of the notorious crime series LES VAMPIRES (1915-1916). In addition to this print, there is an almost three-minute fragment extant, LE RÉVEIL DE L'ARTISTE (The Awakening of the Actor), from a comedy released in January 1917 as a benefit film for the war orphans and a joint effort of French film companies, C'EST POUR LES ORPHELINS (It's for the Orphans), ${ }^{80}$ which I include in this discussion as it features both Musidora and Levesque in comic roles. Otherwise, only contemporary paratextual material-synopses, advertisements, reviews and stills - is available for the study of Musidora's vaudeville films at Gaumont. The actress never mentioned these films in accounts of her career. ${ }^{81}$ Marcel Levesque, in contrast, paid ample attention to them in his reminiscences and described them as a core section of his oeuvre with Feuillade, who built them to a large extent, albeit not exclusively, around his comic talent. While the lack of surviving prints admittedly limits the scope of my discussion, I shall nonetheless attempt to explore their significance in the context of Feuillade's comic oeuvre and Musidora's career. To that aim, I shall draw from a range of primary and secondary sources, including an article written by Laurent Le Forestier, which argues against Francis Lacassin's assessment of the ciné-vaudevilles as "articles de pêche", unambitious quickies made to keep the business going and to allow Feuillade to go off fishing in the afternoons. ${ }^{82}$ In the process, I will also render homage to Marcel Levesque, whose contribution to the ciné-vaudevilles deserves more attention than film historians have hitherto granted it.

Unlike previous series in which Feuillade announced a new aesthetic or genre, the ciné-vaudevilles did not come with a public address proclaiming the filmmaker's considerations and intentions. According to Marcel Levesque, 


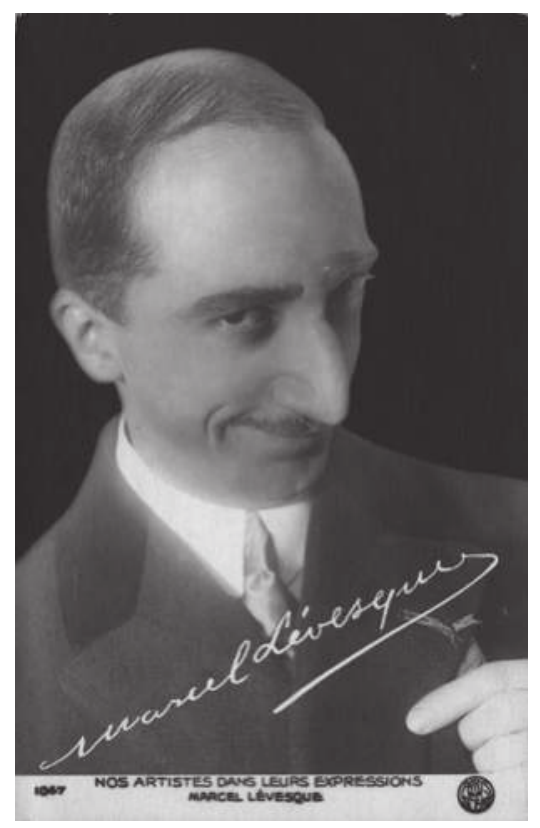

Fig. II.11: Marcel Levesque. Picture postcard.

they came about beside Feuillade's core productions, such as the grand films artistiques and the series and serials, on which the filmmaker worked from Monday through Thursday mornings, but it usually took a similar time spanThursday through Saturday afternoons - to manufacture one ciné-vaudeville. ${ }^{83}$ They hence can hardly be considered a by-product of the firm's more prestigious output, as Laurent Le Forestier has also pointed out. According to this historian, comic subjects were an important source of income and, by 1913, began making up the majority of Gaumont production, in fact a bit more than half of it. ${ }^{84}$ Within that category, a division was maintained between so-called "scènes comiques" and "comédies", which, according to Le Forestier, in the final analysis can only be distinguished by the degree of ambition they exemplify. Feuillade, until 1913, availed himself primarily of "scènes comiques" with the child actors Bébé and Bout de Zan; these less ambitious productions allowed him a greater freedom to live out his naughty and facetious imagination. ${ }^{85} \mathrm{He}$ simultaneously assigned the production of further comic one-reelers to his colleague Jean Durand, who created the series of CALINo, zigoto, and ONÉSIME. ${ }^{86}$ According to Richard Abel, the Gaumont comic one-reelers had their repetition of gags and their slapstick-like, physical comedy that "put their actors through pratfalls, pummelling and pursuits" ${ }^{87}$ in common with series by other firms, but simultaneously deviated from other series in that they were "especially adept at turning this kind of comic film into social commentary" ${ }^{88}$ According to Le Forestier, Feuillade's series with Bébé and most 
notably Bout de Zan showed a high interest in character, in situations, and in the linearity of the story. For Feuillade, human behavior was more important than physical effects. This made his "scènes comiques", more than those of others, closer to the works of popular theater, which otherwise found their cinematic equivalent in what were called "comédies". ${ }^{89}$

BÉBÉ APACHE provides an early example of the nature of Feuillade's "scènes comiques". ${ }^{\circ}$ In the film, made and released in 1910, the children Bébé (Clément Mary) and Fonfon (Alphonsine Mary) imitate the attitudes and gestures of gangsters, including the famous apache-dance. Feuillade's interest in character, situations, and narrative linearity shows in the children's performances as much as in the plot. Notwithstanding the fact that the children perfectly imitate the criminals as stylized for the stage, they remain child performers in that they regularly communicate to each other and to the audience their fun with disguising as and outwitting the gangsters. In such instances, they seem 186 | to forget their parts, burst into laughter, glance at the camera, and make visible the effort to get back into their roles. The ten-minute film conveys a clear and neat little narrative, in which all loose ends are tied. Even the medals the children are awarded for their daring and smart act are made of chocolate.

The Bébé series was succeeded by a series of short comedies featuring Bout de Zan as played by René Poyen, in one of which Musidora is said to have been cast. This film, BOUT DE ZAN ET L'ESPION (Bout de Zan and the Spy) was set to be released in early $1915,{ }^{91}$ but was forbidden by the censors, because, as one critic assumed, the title alone was already offensive..$^{92}$ Only from its initial title, BOUT DE ZAN ET LE BOCHE (Bout de Zan and the Kraut) could one read that the spy was a German;93 the term of abuse indicated that it concerned a sly and evil character. The surviving synopsis discloses yet another smartly constructed little plot, with Bout de Zan now in the pivotal role of preventing his prospective stepfather-a naval officer and inventor of a new torpedo-from divulging his secret to the enemy. The summary mentions only one part for a woman, which Lacassin ascribes to Suzanne Le Bret, who took over the role of playing Bout de Zan's mother in the series after Renée Carl left Gaumont after the outbreak of the war. It therefore remains uncertain what part Musidora had in this film or if she appeared in it at all. ${ }^{94}$

Apart from some incidental samples by Feuillade, the making of what was called "comedies" at Gaumont up to 1913 was predominantly the business of Léonce Perret, whose series LÉONCE was intended to compete with the relatively refined comedy of manners in the RIGADIN- and MAX-series by Pathé. ${ }^{95}$ Léonce Perret shared with Prince a career history in popular theater: both had worked with Antoine at the Odéon and acted several years at the famous boulevard theater the Variétés before entering cinema around $1907 .{ }^{96}$ According to Abel, Perret's Léonce was a more solid, assured bourgeois type than 
Prince's Don Juan, yet, in contrast to the latter's conventionality, very modern in his habits. ${ }^{97}$ The relatively modern attitude in Perret's characters was, at least in part, an effect of the involvement of Suzanne Grandais, who co-starred in most of his LÉONCE-films of 1912 and 1913 and who enacted the type of the modern ingénue in the series.

Within this context of Gaumont comic film production of 1913, Feuillade's ciné-vaudevilles can be understood as having pushed the genre towards lengthier and more sophisticated comedies. As Le Forestier has pointed out, with their seven to eight hundred meters, the ciné-vaudevilles may have been shorter than the average Grand Film Artistique Gaumont, but, at the same time, they were significantly longer, and hence arguably more prestigious, than any of the scènes comiques and comédies made thus far, even the LÉONCE -series, which ran an average length of thirteen minutes or 230 meters. It seems, moreover, that the generic indication coined for them in the publicity, set them apart from the usual comic subject. As Abel has noted, the overt reference to vaudeville plays was a new way to capitalize on the popularity of such plays and also to lure their audiences into the cinemas. ${ }^{98}$ In a remark concluding his jottings on one of the ciné-vaudevilles, Feuillade identifies the intended audience as the intellectual elite: "Completely silly but played by genre actors, [it] may make the intellectual elite smile." 99 The popular stage audience, as we have seen in the previous section of this careerography, was accustomed to being addressed in their knowledge of generic rules, which made the move of adapting stage vaudeville to ciné-vaudeville and the inclusion of the reference to the popular stage genre in its generic title even more pertinent. The continued use of the genre-label throughout the years, then, suggests that the films benefitted from the reference to such a well-established popular stage genre and that it became a trademark adding to their prestige. Contemporary reviews confirm the working of both the trademark and the knowledge about the genre:

LA PEINE DU TALION (The Punishment of Revenge) is a vaudeville played by Marcel Levesque from the Palais Royal, that is to say that the script stands in the tradition dear to Labiche, Gondinet and other entertaining authors of drama. [...] The imbroglios of this well directed vaudeville will amuse even the most morose audiences. ${ }^{100}$

As was common in reviews of the stage genre, special attention was drawn to the acting: "Granted, the idea is not very novel, but how it has been interpreted makes out its entertaining charm."

One more parallel between the popular stage and the screen needs elaboration in order to understand the status of the ciné-vaudevilles and the 
knowledgeable appraisal they met at the time. The parallels in their reception stretched beyond the individual films and performances, beyond the specific genre references, as well as beyond the contributions of actresses and actors, which I have outlined so far. This additional parallel concerns the formats in which stage and screen programs were offered throughout much of the 1910 s. Both kinds of programs showed more similarities than histories of cinema and of music-hall, which discuss the relationship between screen and stage as a competitive struggle for autonomy and survival, tend to acknowledge. To be sure, I am not disputing that a competitive relation existed as well, that cinema was still struggling to gain legitimacy and to become independent from the popular stage within which it had matured, and that the popular stage, which had so wholeheartedly embraced the novelty of cinema, now found itself battling for the sustenance of its position of the pre-eminent amusement of the time. What I am suggesting, and shall exemplify, is that simultaneously with 188 and alongside this competitive relation, another connection can be detected as well: a coexistence and integration of stage and screen acts within both program formats and that this coexistence and integration was more continuous and regular than a perspective of competition allows for. It is precisely Musidora's travelling from stage and screen and vice versa, which has led me to pay attention to this non-competitive and mutually constitutive relation between the two modes of entertainment before the war and throughout the 1910 .

\section{Coexistence Cinema and Stage Performance}

By 1914, the non-competitive coexistence of cinema and stage performance had taken various shapes. Films were included in music-hall and popular stage programs. This most notably applied to two genres, "actualités" and trick films, of old genres for which the popular stage, with its visualization of marvels and prominence of spectacle, provided a conceptual habitat. Musidora's performance in the filmed insert of the revue at the Folies-Bergère, LA VILLE DE MADAME TANGO, constitutes an example, as well as the Éclair films preceding the revue. The correlation in the perception of cinema and of music-hall was pointed out by Curnonsky, who, in 1914, grumbled:

Our big music-halls satisfy this almost unanimous taste for spectacle, which lures the crowds to the cinema, to boxing and soccer championships, to racing circuits and aerodromes,--hence, anywhere where it suffices to watch. ${ }^{102}$ 
After 1909, the trick film genre declined in terms of production, and, because the tricks were largely known to the public, they were given a comic dimension. ${ }^{103}$ The comic was, as we have seen in the previous section, as much as the spectacular, one of the pillars of the Parisian popular stage and therefore it may not come as a surprise that the comic trick film was able to survive within music-hall and revue programs.

As Jean-Jacques Meusy asserts in his study of how cinema procured its position among the "spectacles traditionnels" (traditional performances), such fusion of staged and screened scenes was so ubiquitous in Paris on the eve of the war that some foresaw in it the settlement of the rivalry between stage and screen. ${ }^{104}$ It was an exhibition practice in the non-comic as well as in the comic genre. An early instance of a non-comic fusion of staged and screened scenes was the filmed BALLET DU FEU (Ballet of the Fire) at the Châtelet in 1896, which was projected within the play "La Biche au Bois" (The Doe of the Forest) and in the shooting of which Feuillade's predecessor and mentrix at Gaumont, Alice Guy, had probably been involved. ${ }^{105}$ Filmed scenes included in staged plays allowed for flashbacks; for the representations of dreams, memories, obsessions; and other deviations from the narrative flow. ${ }^{106}$ The tangoing objects in the revue at the Folies-Bergère constitute an instance of how revues also used to expand their illusionary space through the use of film. Henri Fescourt remembered a similar tableau in a revue he watched at the Folies-Bergère in 1913 or 1914:

Right and left on a screen hiding stage props, filmed landscapes were projected, which were shot in travelling and unfolded from the back of the stage towards the audience. At the centre of the set, the back of an American railway carriage was reconstituted as realistic scenery. On the platform, "live" characters walked up and down, shouted and played, while on the front stage, that is to say centre stage, an actor, seen from behind, called them, ran on the spot and seemingly pursued the train. It seemed to be moving, because at either side of it telegraph posts, wisps of smoke, meadows, forests and rivers passed towards the spectators. ${ }^{107}$

Most commonly, however, the mix of screen and live appearance was a feature of acts by entertainers and comic actors in café-concert and music-hall. By 1913, it was often applied by comic actors who had ventured into cinema. In a 1904 revue at the Folies-Bergère, the fantaisiste Fragson let his live appearance be preceded by the screening of a film of a wild automobile race through Paris; similarly, the film comedian Max Linder's live sketch, in 1913, was preceded by a film showing his arrival in a balloon at the Alhambra music-hall roof top, after which he descended to the stage sliding down a long rope. ${ }^{108}$ According 
to Paul Adrian, who has written about the interaction between music-hall and cinema in the history of music-hall and revue, such "integrated acts" in which the film served as a prologue to the live appearance of an artist, occurred in revues until 1948. ${ }^{109}$ As already pointed out in Part I of this book, Linder even gave his mix of screen and stage appearances a distinct name- "Kinéma-MaxSketch"- and held on to the formula even beyond his already extensive film production.

The coexistence of stage and screen performances not only took shape in stage performances, but also in cinema programs. By 1913, in the middle of the second boom of cinema construction in Paris, only a minority of permanent or temporary cinemas offered film exclusively, or continuous screenings foregoing live acts. ${ }^{110}$ Most of them inserted live acts in the film program, much like the film act had been inserted in the music-hall program. A primary, and in the context of Musidora's oeuvre with Feuillade, most pertinent example, were the

190 | Gaumont cinemas, such as the Gaumont-Palace and the Tivoli-Cinema. The Gaumont-Palace, with its 3,400 seats, was the largest cinema in the world at its opening in 1911, and it remained one of the most prestigious film temples of Paris throughout the decade. ${ }^{111}$ In addition to film screenings, the program offered "Attractions sensationelles" (sensational attractions) ${ }^{112}$ or "Attractions inédites et variées" (new and varied attractions), ${ }^{113}$ usually clowns, acrobats or other virtuoso acts. An undated program flyer reprinted in a booklet issued on the occasion of Gaumont's centennial featured the screening of Feuillade's comedy BOUT DE ZAN VOLE UN ÉLÉPHANT (Bout de Zan Steals an Elephant, 1913) followed by "Les 4 Daltons, Strong-Acrobats [sic] et Équilibristes", ${ }^{114}$ and the 1914/1915 Gaumont program flyer for the ciné-vaudeville with Musidora, LE COUP DU FAKIR (The Feat of the Fakir), announced as the live act "Le Trio Charley Meteor (Trapèze)." ${ }^{115}$ Likewise, the June 1916 program featuring "Le grand film mystérieux: LES VAMPIRES: L'HOMME DES POISONS" (The great mystery film: Les Vampires: The Man Of The Poisons) was preceded by the "Attraction: Le Trio Monika, jongleurs fantaisistes", and even the March 1917 program, with the seventh episode of Feuillade's JUDEx, still included a performance by "Alphonso Silvano (Sensationnel Equilibriste)", ${ }^{116}$ implying that the practice of inserting live acts in the film programs was sustained throughout the war. This programming practice was not only common at Gaumont cinemas, but elsewhere too, as, for instance, at Lutetia-Wagram, the Rex, and the Alhambra. ${ }^{117}$

Emmanuelle Toulet has argued, that the insertion of virtuoso acts may be read as a sign of a continuous relationship between music-hall and cinematographic spectacle. She also contends that such acts constituted an element of luxury in the cinemas and not, as is often assumed in film histories, a distracting relic of the cinema's music-hall heritage. ${ }^{118}$ Toulet's assessment can 
be further underscored by the findings of my examination of French musichall, which concludes that the deft acts were highly appreciated and constitutive elements of the programs and that they contributed to the prestige of the house when brought in from abroad. Deft acts, moreover, graciously survived the shifts from café-concert to music-hall and revue as they primarily catered to the eye and hence kept up the revue's ambition to speak the "international language of pleasure". The foreign names of the acrobats programmed at the Gaumont-Palace suggest that the virtuoso acts may have had a similar significance within film programs, which otherwise offered merely French film productions. A further circumstance supporting the idea of continuity between music-hall and cinematographic spectacle can be read from a side remark in the Gaumont centennial booklet: "In the back of the theater, small tables with lamp-shaded lights permitted customers to eat and drink while watching the film, a common practice at café-concert halls." ${ }^{119}$ Finally, just like an evening at the music-hall, the cinema program at the Gaumont-Palace started at 8.ooPM and lasted the entire evening. And, much like revues, which typically consisted of two acts, the cinema program was divided into two parts. All of these circumstances, the roominess of the theater, the presentation of live acts, the occasion for eating and drinking, as well as the resemblance of how the program was structured, shaped the experience of cinema-going after the model of attending popular stage performances.

A final yet significant parallel between film programs and music-hall programs was the significance attributed to variety and genre differentiation. Richard Abel points out how film producers from early on used the concept of genre as a strategy to offer subject variation within "cinema of attraction" programs at music-halls and the like. ${ }^{120}$ In the previous section, I explored the importance of the notion of genre in the context of the French popular stage, as it offered audiences the assurance of what to expect as well as the pleasure of recognition. For the marketing of their novelty, then, film producers, who at the time mostly simultaneously worked as exhibitors of their films, adopted a tried and trusted strategy in the very stage context in which they entered. By consequence of the repetitiveness inherent in the emphasis on genre and the familiar, variety was required, and the film program obviously met this requirement within its own niche of a numéro visuel as well. Not only were early and short film programs constructed upon the premises of variety and genre emphasis, but long evening film programs such as those offered by Gaumont during the 1910 as well.

The coexistence of live and screened performances, the circumstances reminiscent of music-hall, and the sustained prominence in the perception of film of concepts like genre, variety, and spectacle imply that in France, the primary, and, for over two decades, foremost, film-watching experience 
was strongly marked by the expectations for pleasure and entertainment as shaped by the popular stage. From such a perspective, Feuillade's creation of the genre of ciné-vaudevilles becomes less of an anomaly.

\section{Ciné-vaudeville and Stage Vaudeville}

In the mid-nineteenth century, French vaudeville came to be a distinctive genre from the more pensive comedy of manners. Theater historian J.P. Thomasseau offers a concise overview of the development and features of the genre. ${ }^{121}$ From 1815 to 1850 , the genre was dominated by the playwright Eugène Scribe; from 1850, by Eugène Labiche; and from 1892 through the 1910s, by Georges Feydeau. These three authors successively developed the structure and characteristics of this genre of comic plays, which was considered utterly French

192 because of its thematic focus on romantic relationships and its linguistic focus on dialogue and word-play. It drew from and mocked contemporary social realities, and-more particularly-the bourgeoisie that sought pleasure and wealth. Vaudeville plays had in common the unexpected and explosive encounters, the combination of incompatible situations, and the confrontations of characters who did not yet know one other. The characters themselves were defined by neither a past, nor a psychology nor an awareness of their inner drives. Instead, they were solely guided by their actions and by their reactions to those of the other characters. Such compulsive logic notwithstanding, the nonsensical chain of events always ended in the heavens of happiness.

The philosopher Henri Bergson assigned to vaudeville plays, and most notably those by Labiche, a pivotal role in his theory of laughter, Le Rire, Essai sur la signification du comique. ${ }^{122}$ Central to his study of vaudeville plays and comic acting was the notion of "raideur mécanique" (mechanical rigidity), that ought to be internalized in both the narrative and the character. ${ }^{123}$ Bergson argued that the comic was generated by "the mechanical in the living". ${ }^{124}$ The endeavor of the writer of the plays, the vaudevilliste, was to make such rigidity transparent, to reveal to the public the strings that made the puppets dance. This, however, had to be handled discreetly, so that the exterior appearance of probability was maintained. ${ }^{125}$ The endeavor of the comic actor was to present such rigidity as an automatism, but without taking away the spectator's impression of watching a living being. ${ }^{126}$ The more precisely the two impressions of a mechanism at work and being human overlap, the more comical it is. For that reason, repetition and imitation generate laughter automatically, according to Bergson, as they draw attention to the mechanical in a person and in life. Bodily obstinacy, when the attention is drawn to the physique of a person instead of to his inner state, has the same effect. ${ }^{127}$ 
Vaudeville plays not only presented comic characters, but also employed a specific set of plot devices. The plots were constructed upon the basis of "situations", sets of circumstances that generated an internal logic of events. ${ }^{128}$ The procedure to make such situations comical were repetition, inversion, and, what Bergson calls "interférence des series", the interference of two altogether independent series of events that can be interpreted in two entirely different meanings at the same time. ${ }^{129}$ Repetition of situations may include the coincidental meeting between two people. ${ }^{130} \mathrm{~A}$ ubiquitous application of the device of repetition is between masters and servants, in which the servants repeat in another tone and a philistine style what the masters have done previously. ${ }^{131}$ The situational application of inversion could be found in the inversion of roles and situations that turned against the one who created them. It was the logic of the prosecutor being prosecuted, the deceiver deceived, or, to add a phrasing related to both comic theater and cinema, "l'arroseur arrosé" (the waterer watered). ${ }^{132}$ One application of the interaction of series in vaudeville was the "quiproquo" or the mistaken identity: the interpretation that the actor offers as opposed to the meaning that spectators attribute to that identity. ${ }^{133}$

Feuillade's ciné-vaudevilles were, by no means, adaptations of the two- and three-act plays written by Labiche and Feydeau and staged in theaters like the Palais Royal and at café-concerts like the Ba-ta-clan to close off the music-hall program. Le Forestier calls Feuillade's films "pastiches" in the sense that the filmmaker freely borrowed the principles of the genre, while keeping in mind that he made films instead of staging plays. ${ }^{134}$ The lead actor of the cinévaudevilles, Marcel Levesque, proclaimed himself an adherent of Bergson's theory of laughter, which makes it probable that Feuillade was familiar with the theory as well. ${ }^{135}$

The primary sources, from the Bibliothèque Nationale de France, Département des Arts du Spectacle in the "Dossier Gaumont scénarios", allow for a more detailed generic assessment of the ciné-vaudevilles featuring Levesque and Musidora. This file includes synopses of most of the ciné-vaudevilles under scrutiny here, as they were deposited for copyright reasons in the "Dépot légal". The texts raise a set of questions with regard to Feuillade's working method on the ciné-vaudevilles, some of which seem to speak against the widely held assumption of Feuillade's penchant for improvisations on the plots.

Although none of the synopses are signed with an author's name, there is little reason to doubt that Feuillade had drafted them himself. The synopses have been jotted down in a graphic writing style, obviously by someone who was used to "think" film. They often denoted precise shots: "head of Blairot", ${ }^{136}$ or dialogue lines like "My Birdie, aren't you hiding something?" ${ }^{137}$ A question prompted by these documents and by the lack of surviving prints is to what extent the plots of the finished films paralleled those in the summaries. It can- 
not be answered from a comparison of the surviving print of LAGOURDETTE GENTLEMAN CAMBRIOLEUR with its synopsis, because this summary appears to be one of the few missing from the collection in the Bibliothèque Nationale de France. However, these texts were drafted not only for copyright deposit, but literally identical drafts appeared in special sections reserved for such summaries in film periodicals like Le Film and Le Courrier Cinématographique as well as in program flyers of the Gaumont Palace. This practice suggests large similarities between films and summaries, which justifies two, albeit divergent, assumptions about Feuillade's working method with regard to the cinévaudevilles: either he closely followed the plots as once drafted (which would conflict with the assumption of improvisation on the plots during shooting as also held by Le Forestier) ${ }^{138}$ or he drafted the texts after completion of the production. A comment in Le Courrier Cinématographique, which had begun to add to the synopses brief remarks on the films' qualities, contradicts the latter 194 | possiblility. One comment on the ciné-vaudeville, DÉBROUILLE -TOI! (Fend for yourself!), suggests an ending deviant from the one in the synopsis. ${ }^{139}$ How- $^{-}$ ever, because the deviation seems noteworthy, it may have been an exception rather than the rule.

Another possibility may have been that Feuillade largely drafted the plots, but left their endings open for improvisation. This practice would be suggested by another type of document, of which I have found only one in the archives with respect to the ciné-vaudevilles, preparatory notes in Feuillade's handwriting, for LE COUP DU FAKIR. ${ }^{140}$ Set against the film's synopsis, the notes offer information on Feuillade's process of thinking and working procedure, and the importance he assigned to the contribution of the actors. In the notes, the main characters do not yet have plot names, but are denoted with the names of the actors: "Mr. and Mrs. Lévesque are visiting Mrs. Renot, in order to take her daughter Musi to a garden party at the home of admiral Facalamer." ${ }^{141}$ In the synopsis, the Levesque couple has turned into a Mr. and Mrs. Blairot, "tante Renot" into aunt Sidonie, Musidora's pet name "Musi" into Suzette, and the admiral into Captain Rascasse. ${ }^{142}$ Moreover, in his synopsis, Feuillade speaks to Lévesque's character in a direct mode, warning him: "That will cost you dearly..." ${ }^{143}$ The author-director's organization of the plot suggests that he allowed for, and counted on, a substantial contribution of the actors he had in mind, a practice to which, as will become apparent further on, both Levesque and Musidora's recollections attest. Second, after two introductory sentences, the notes are not further drafted as a narration, but turn more and more into sketchy indications of scenes of encounters and events, which were left to be developed later on: "Poitel and his father will be asking the hand of the girl; is accepted" and "crazy dance, little handle". ${ }^{144}$ Parallel to the increase of sketchiness, the handwriting itself shows signs of hurry. Nonetheless, the 
major imbroglios correspond with those recorded in the synopsis deposited for copyright purposes. Third, the jottings end with several lines crossed out. If set against the synopsis, this correction appears to have concerned the ending. The notes are closed off with the remark that I have cited previously to point out the audience that Feuillade envisioned for his ciné-vaudevilles: "played by genre actors, [it] may make the intellectual elite smile..." ${ }^{145}$ I repeat it because, in the context of the present discussion of Feuillade's working method, it is illuminating for another reason. It discloses that, for the intellectual elite that the ciné-vaudevilles targeted, the involvement of stage actors skilled in the genre was crucial.

Among the principles of stage vaudeville employed by Feuillade, were, as Le Forestier has noted, the two- and the three-act structure. ${ }^{146}$ Levesque remembered that this structure was abandoned after the third film in the series, which, in his opinion, transformed the stage vaudeville entirely into cinematic vaudeville. ${ }^{147}$ After the seventh and final film of the "La Vie drôle"series, upon which Le Forestier largely based his analysis, the indication "en 3 actes" indeed no longer appeared in advertisements. Unfortunately, Levesque did not specify how Feuillade further transformed the theatrical vaudeville into the cinematic vaudeville. Le Forestier, for his part, precisely focuses on this topic in terms of theatrical and cinematic aesthetics in the first place and in terms of techniques and organisation in the second. That is to say, he has analyzed how Feuillade solved the problems of space and time posed by some of the stage conventions, such as the recurring appearance of the vaudeville door and the limited variation of locations and sites. ${ }^{148}$ Le Forestier's examination of the solutions and innovations that Feuillade developed to solve such problems with cinematic devices such as shot-shot relationships and editing is illuminating, but not my primary concern here. Instead of examining the differences between the theatrical and cinematic genres, I explore the continuities between the two. Those were the "details" that, in my opinion, spectators, and the press, as will become apparent, used to appreciate in Feuillade's ciné-vaudevilles. This appreciation drew from the experience of watching stage vaudeville, and it equally applied to the actors' performances in the films. The continuities between stage vaudeville and Feuillade's ciné-vaudevilles, then, can be located in the employment of typical plot devices and physical comedy, in raising particular themes, and in the actors' performance styles, both Levesque's and Musidora's.

Feuillade's ciné-vaudevilles featuring Levesque and Musidora made ample use of the devices of repetition, inversion, and intersecting series of interpretations. ${ }^{149}$ As the synopsis of TU N'ÉPOUSERAS JAMAIS UN AVOCAT (You'll never marry a lawyer) discloses, the second act of the film was entirely built around the repetition of the doorbell ringing, and, by consequence, the unexpected 
meeting, time and again of different people. The narrative function of these meetings is to obstruct the lawyer's desire to be alone with his girlfriend. Another ciné-vaudeville built around a running gag was DÉBROUILLE -TOI!. The title refers to the repetitive advice an uncle gave to his nephew, who prefers leisure over working and who repeatedly proposes an occupation that his uncle loaths. The complication is that both uncle and nephew court the same girl, and that the nephew's occupations interfere with the uncle's dream of winning the girl for himself. The story ends with an inversion: the nephew marries the girl, so that he fends for himself in a way contrary to what the uncle would have expected. Repetition and inversion are also the structuring devices of LE COLLIER DE PERLES (The Pearl Necklace), in which a married couple falls victim to their mutual suspicion. She is too curious, he repeatedly lies to her, and, with the pearl necklace from the title as the catalyst, each of them ends up as a "deceiver deceived". The "deceiver deceived" motif is applied in 196 | LES FOURBERIES DE PINGOUIN (Penguin's Rogueries) as well. Here, it serves to give a husband who is having an affair, a dose of his own medicine. Likewise, Feuillade applies the device of the "quiproquo" or mistaken identity, as, for instance, in LE SOSIE (The look-alike), of which the very title points to the device. In L'ESCAPADE DE FILOCHE (Filoche's escapade), finally, it is a jealous husband who, initially mistaken for a bachelor himself, mistakes the identity of his brother-in-law, whom he has never met before, for his wife's lover. In these plots, the mistaking produces series of hilarious situations in which misunderstandings and divergent interpretations tumble over one another. If anything, the adroit use of such devices highlights Feuillade's outstanding propensity for plot construction and comic character composition.

This attention to narrative and character notwithstanding, Feuillade also created comic effects by drawing attention to the physical, whether or not in combination with the devices of repetition or inversion. TU N'ÉPOUSERAS JAMAIS UN AVOCAT presents a judge who repeatedly falls asleep and otherwise roams the streets to molest women. Both narrative motifs serve to ridicule the authority that he exercises over the lawyer and his daughter and eventually invert the relation between the men. In L'ESCAPADE DE FILOCHE, the entire first act is constructed around Gustave Filoche's hunt for his second shoe, in the process of which he gets stuck with his nose between pickets in the fence. Levesque's large nose was the comic actor's trademark.

Faithful to the rules of the theatrical genre, Feuillade's ciné-vaudevilles invariably resulted in a happy ending. In the construction of the plots, Feuillade capitalized on his capability to weave ludicrous situations and antic intricacies and to resolve neatly the intrigue. Simultaneously, he kept up the appearance of plausibility. Feuillade's vaudeville films do not drive at the absurd (as Feydeau's plays) or at destructiveness (as the comic series), but 
Fig. II.12: Caricature of Marcel Levesque highlighting his nose, by Don, Cinéa, 9 September 1921, 18.

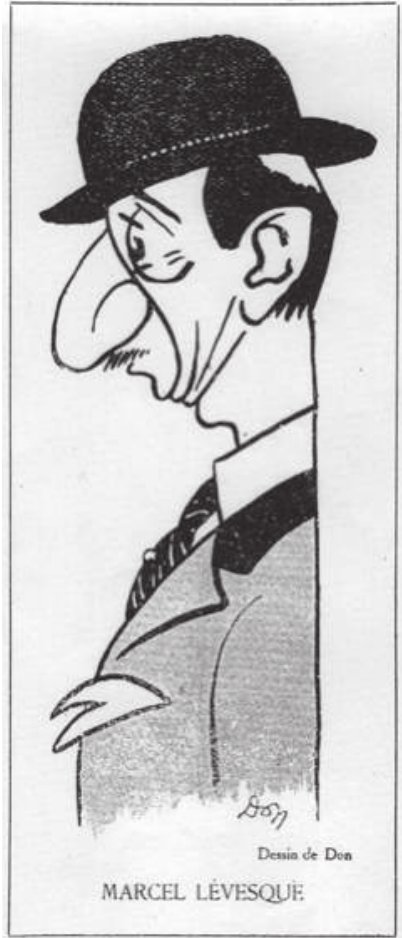

their logic seems natural. ${ }^{150}$ Henri Fescourt remembers Feuillade's "sens de la gouaillerie" (sense for mocking) based upon "beaucoup d'observation" (much observation) and his simultaneous abstention from illogicality and absurdity in the plots. ${ }^{151}$ At a thematic level, the rule of the happy ending had consequences for how the principal topic of the ciné-vaudevilles was managed. Like their Pathé counterparts, the RIGADIN- and the MAX-series, Feuillade's cinévaudevilles made fun of romantic relationships between men and women. As in the stage genre, moreover, many of the characters were involved in premarital or extra-marital relationships, ${ }^{152}$ making men's penchant for flirtation with and courting women a staple motif of the plots. But whatever the imbroglios, the misunderstandings or the misbehavior the heroes engaged in, so do the synopses disclose, the obligatory happy ending ensures that lovers get each other, husbands and wives forgive each other, and that rivalry, jealousy, and unfaithfulness is settled and forgotten. By consequence, men's flirtation and courting may have earned them an incidental cuff on the ears, but, in the final analysis, it was tolerated; whether the object of the men's infatuation was married or engaged or not, whether she was responsive or not, and whether the wives or girlfriends were present or not. Men's insatiable desire for women 
was presented as an inevitable fact of life and often provided the drive for the male characters' unusual behavior. Just like Bout de Zan's naughty actions usually turned out guileless, enamored men's behavior usually turned out inculpable. In this regard, Feuillade's ciné-vaudevilles were neither judgmental nor moralistic, and hence met with the expectation of audiences to have a good time rather than to endure a sermon.

Other aspects of social behavior were criticized, though mildly. If the plots commented on generational conflicts within families, they usually sided with the youngsters. In TU N'ÉPOUSERAS JAMAIS UN AVOCAT, the alleged authority of the father figure was ridiculed in three regards: the individual, the institutional, and the paternal. He is the judge with the two tics that I mentioned earlier. His repeated narcoleptic episodes and molestations of women in the streets ridicules him as an individual. As a judge, moreover, his sleepiness prevents him from hearing the lawyer's plea, while he calls the lawyer a liar 198 nonetheless. As a father, he refuses his daughter's hand to the lawyer because he considers him a liar. The judge's misjudgment and his dirty old man behavior eventually undermines his paternal authority too. Dirty old man's conduct was perhaps one of the few forms of men's behavior that was rendered unacceptable in Feuillade's ciné-vaudevilles.

In the treatment of behavior or attitudes ascribed to men or women separately, one general line can be discerned in the summaries of the cinévaudevilles. Jealousy and obsessiveness are never spared Feuillade's mocking, whatever the gender of the character. Examples include "that wonderful friend Blairot" in LE COUP DU FAKIR, who is jealous of the lover of his illegitimate flame, and Madame Pingouin in LES FOURBERIES DE PINGOUIN, the synopsis of which gives her obsessiveness as the reason for her husband's escape in the very first line: "Mrs. Penguin adores her husband, but her affection grows tyrannical, to the extent that Penguin more and more attempts to liberate himself from it." ${ }^{153}$ Nonetheless, in both plots, the men, prior to the happy ending, receive "a resounding slap in the face" 154 from their wives for their misconduct. The role of guardians of decorum was more often reserved for the female than for the male characters. SI vous NE M'AIMEZ PAS (If You Don't Love Me) even makes men's selfishness its explicit theme:

Angèle is wise to men's mentality; she silences Turlupin, who is in no way ready to die for her, and reveals the viciousness of Seraphin, whom Turlupin throws out, affirming to (his sister and Seraphin's fiancée) Simone that she better remain an old spinster with the man of honor he is than marry such a pain-in-the-neck. ${ }^{155}$ 
LE COLLIER DE PERLES, in turn, ridicules women's curiosity:

There is in the world no woman nosier than the wife of Mr. Jéricot. Her instinctive jealousy and curiosity, which are prodded by the talk of two of her pals who repeat at every occasion: "one has to watch out with men", prompt her to meticulously search the pockets of her husband and examine the contents of his desk with an accuracy worthy of better employ. ${ }^{156}$

However, because such commentary on family and gender relations occurred within the context of vaudeville in cinema, the purpose was to entertain people, not to affront them or teach them a lesson. In sum, Feuillade's jocose view of people and their behaviors targeted men and women, young and old, authoritarian and romantic. Although his sympathy was rather with the youngsters and the rebellious, it was often, but not always, with the women too. Most interestingly, in order to get the types right, that is to say, credible and comic at once, and to appeal simultaneously to the intellectual audience envisioned for the ciné-vaudevilles, the filmmaker sought the collaboration of professional comic actors from the popular stage.

Casting comic stage actors in the ciné-vaudevilles was against the principles professed by Feuillade and Gaumont, but not against the actual practices of the firm. Apart from Perret's involvement and the specific collaboration of the music-hall comedians “Les Pouics” in Durand's scènes comiques, the firm's adage was to work with actors and actresses unaffected by stage acting, so that experienced filmmakers and colleagues could coach the newcomers to act in front of the camera. To a certain extent, Renée Carl and Suzanne Grandais exemplified this practice. ${ }^{157}$ For the ciné-vaudevilles, Feuillade hired Madeleine Guitty from the Palais Royal and added her colleagues Charles Lamy and Marcel Levesque to the troupe. ${ }^{158}$ If seen from this perspective, the inclusion of the music-hall actress Musidora in Feuillade's cast was not singular. All of them exemplify the continuity between stage and screen that existed throughout the 1910s, but the actor whom Feuillade made indispensable to his concept of ciné-vaudeville, was Marcel Levesque.

Marcel Levesque (1877-1962) made his stage debut in 1896, played for five years at the Athénée of Paul Deval, for four years at the Odéon of Antoine and proceeded in 1909 to the Palais Royal, one of the pre-eminent vaudeville stages of Paris, which offered plays by Labiche, Sardou and Feydeau. ${ }^{159}$ About this part of Levesque's career, a raving Louis Delluc recalled:

He perfectly played poetic comedies [...] [he was] unaffected, sensitive and touching. [...] But Marcel Levesque has turned away from the plumes, the rhymes and the silk capes to venture into the vaudeville 
genre. He has created a type, a tone, a genre, and the Palais Royal owes to him evenings of amazing cheerfulness. ${ }^{160}$

In 1913, the actor was asked by Perret, whom he knew from the Athénée, to act in two of his LÉONCE-films. ${ }^{161}$ Levesque remembered that he found his first screen appearances a great deception, although he did not explain why. Nevertheless, Feuillade noticed his finesse and invited him to collaborate with him. ${ }^{162}$ In Gaumont advertisements, Levesque was furthermore publicized with the epithet "du Palais Royal" ${ }^{163}$ Although he loved working for the screen, and, after the years with Feuillade, he returned to it periodically, stage acting remained his primary occupation throughout his career. ${ }^{164}$

By the time Musidora was added to the troupe that played the ciné-vaudevilles, Levesque's involvement was a staple part of their formula. As of the forth film in the series of "La Vie drôle", sOMNAMBuLEs (Sleepwalkers), which 200 | premiered on February 6, 1914, he played the male protagonist of the subsequent ciné-vaudevilles, of which there are more than twenty, and his comic presence was constitutive of the genre. In the advertisements, his name was always prominently mentioned and, in later years, portraits and stills featuring him were included in these advertisements as well. By May 1916, when his fame was rising because of his role of Mazzamette in the crime-series LES VAMPIRES, the Gaumont advertisements bestowed him with the epithet "L'inimitable comique du Palais Royal" (The inimitable comic actor from the Palais Royal), which, as of August 1916, was replaced with "L'irrésistible Marcel Lévesque" (The irresistible Marcel Levesque). ${ }^{165}$ Levesque's face was provided with traits readily perceived as comical: his large nose, big eyes, and almost bold head automatically drew attention to the obstinacy of his body. In his performances, some critics reprimanded him for doing too much ${ }^{166}$ or for acting with too much zeal. ${ }^{167}$ LE RÉVEIL DE L'ARTISTE indeed contains scenes in which Levesque flails about wildly, simultaneously putting on his jacket and dashing off, not standing still for a moment, tumbling over people and objects, and barging through the scenes. These shots full of movement significantly speed up the film.

The opening and closing scenes, in contrast, testify to the actor's finesse and subtlety. I have rarely seen someone sleep in such a farcical manner. One arm above his head, the other on top of the sheet, he acts the breathing of the deep sleeper, while his mien connotes blissful dreams. Once awake, he reads the invitation to come to the studio with a deadpan expression, thus inciting the spectator's curiosity. In the closing scene, in which he listens to the instructions of the director, he wipes his forehead and neck with a handkerchief, signalling the sweat it has cost him to arrive at the studio, and makes a droopy face. Once he learns about his role, his look turns disappointed, 
because the story has Bout de Zan outwitting and catching him. Then Bout de Zan tells the director that he is making a "navet", a trashy piece of art, and Levesque boasts: "so I am not the only one who says so!" Levesque rendered these varied expressions plainly and without exaggeration.

Levesque's excellence in combination with his experience in film acting made him, during and right after the war, one of the pre-eminent comic actors of French cinema. This was not just suggested in Gaumont's publicity, but also articulated in reviews of the ciné-vaudevilles:

When I say that the amusing film SI vOUS NE M'AIMEZ PAS (530 metres) is being acted by the high-spirited Musidora and the excellent artiste Marcel Lévesque, I'll find myself spared from telling you its imbroglios, because everyone knows how entertaining the imagination of these two actors is whilst they always keep up a correct and tasteful tone. ${ }^{168}$

His facial expressions and his comic movements and gestures were praised. ${ }^{169}$ Delluc, by then a prominent film critic, lauded Levesque in 1919 as "the most visual, the most cinematic of our actors". ${ }^{170}$ Delluc's colleague Albert Bonneau, re-evaluating comic film production in France and lamenting the virtual disappearance of the genre by 1923 , asserted:

His irresistibly comic silhouette, his most preposterous gestures immediately spotlighted him. [...] During the period of 1915-1917, one can certainly affirm that he grew into a favorite of the masses together with Pearl White and Musidora. ${ }^{171}$

A most graphic and comprehensive description of Levesque's comic performance appeared in the paper Le Crapouillot, in their rubric "Les rois de l'écran" (The kings of the screen):

A nose. The nose of Levesque, if it had been shorter, the entire aspect of its owner would have changed: so much is obvious... but the entire aspect of the world of cinema as well. [...] At once grotesque and human, that is how the talent of the artiste appears. It is a double and paradoxical impression, which only he, or almost only he, is capable of creating. An agile marionette, which seems to be moved, in fits and starts, by strings: and suddenly the mechanical movements stop; the immovable marionette turns human; the fixed gaze softens; and see how from the eyes role two tears - two tears that came from a heart. ${ }^{172}$ 
From nose to heart, from comic appearance to expression of feelings, from marionette to human being; these delineations of Levesque's comedy echo Bergson's views. Levesque knew how to bring the obstinacy of the body in conjunction with the flexibility of the soul, and how to play out the mechanical in the alive. As a comic actor, he made visual the physical and mental strings, which let the character move and to which it was attached, and simultaneously remained convincing as a living being. It was a balancing act, which, according to contemporary critics, Marcel Levesque performed in a way that few others in French silent cinema were capable of.

Different from the MAX-, RIGADIN-, and even the LÉONCE-comedies, in which the plots centered around one male character and his female co-star, Feuillade's ciné-vaudevilles were usually based upon a relatively even distribution of more than two protagonists. Although Levesque constituted the films' principal asset in the publicity, most plots as handed down include 202 roles as focal as his, in the first place for Musidora, but also for the Gaumont vedettes Édouard Mathé, Suzanne Le Bret, and Lise Laurent. The stories were often composed around two befriended or rivalling couples, in addition to a young woman with whom one of the male characters would flirt, or some more distant brother or friend who added to the imbroglios. The average was four to six characters in well-matched positions, at least two of which were male and one was Levesque's role. They used to be complemented with a couple of supporting parts. In two films - LE SOSIE (1915) and SI VOUS NE M'AIMEZ PAS (1916) - such supporting parts were played by Levesque. From such a combination of characters emerged the premise required for the story to take its inevitable run to more complications and the happy ending. By consequence, the ciné-vaudevilles offered Levesque quite a choice of roles, instead of one recurring character. He played an honest lawyer courting the dysfunctional judge's daughter, as in TU N'ÉPOUSERAS JAMAIS UN AVOCAT (1914), or a goodfor-nothing nephew who courts the same woman as his uncle in DÉBROUILLETOI! (1917). In other ciné-vaudevilles, he impersonates a painter, or a writer, who (mis)takes artistic license for the license to be unfaithful to his girlfriend. Although flirting, courting women, and unfaithfulness were staple motifs of the ciné-vaudevilles and the principal drive of their male protagonists, Levesque also played dedicated husbands, as in HOTEL DE LA GARE (1914) and LE COLLIER DE PERLES (1915). Feuillade hence did not pin Levesque down to one recurring type, but offered him an assortment of characters with miscellaneous traits to exploit comically.

By consequence of this choice of characters played by Levesque, Musidora's roles in the ciné-vaudevilles varied accordingly. Of two of the sixteen vaudeville films in which she acted, her role is unknown, and in four of them, it seems of minor importance. In the remaining ten films, her parts were as var- 


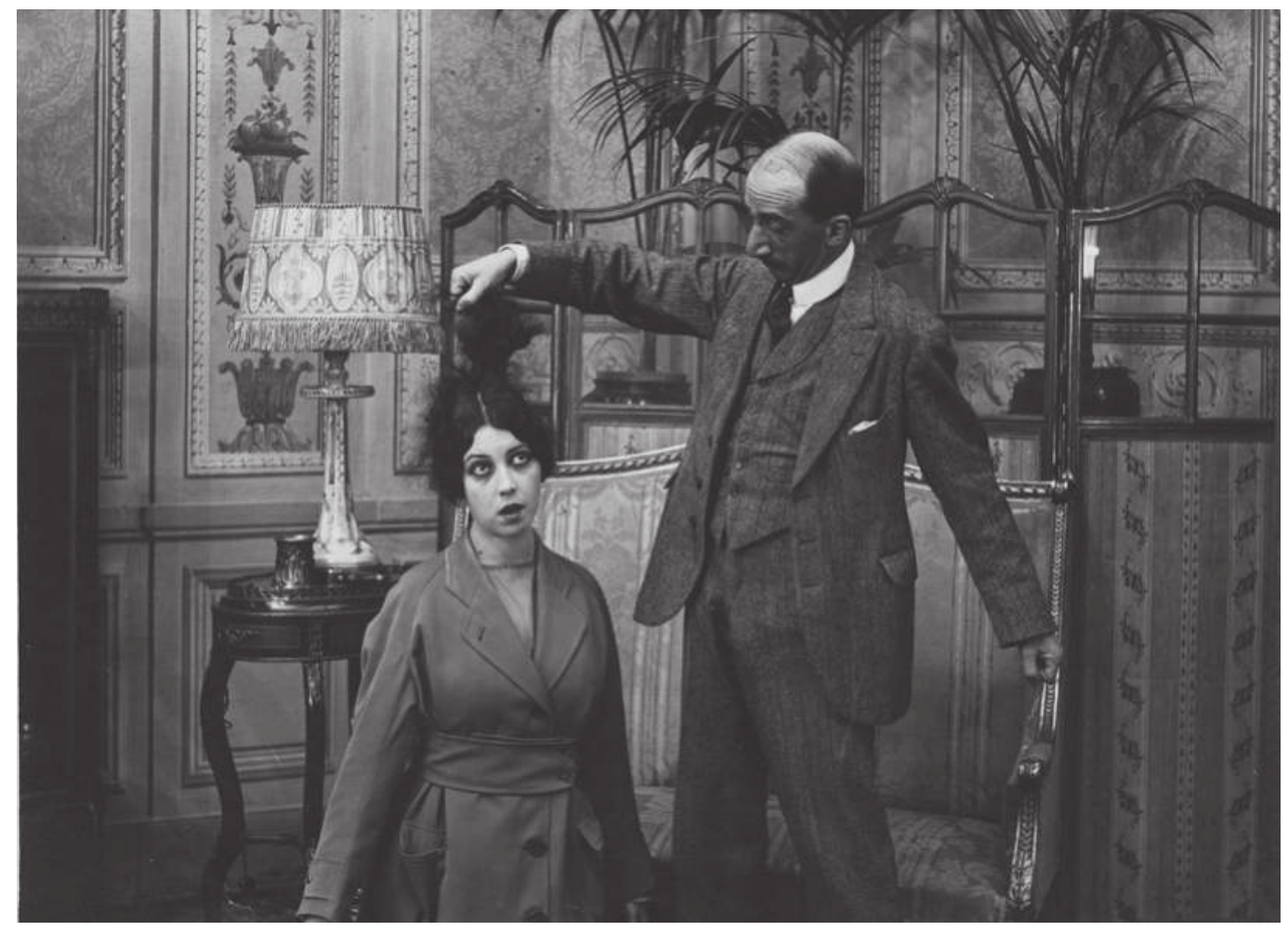

Fig. II.13: Musidora and Marcel Levesque in LA PEINE DU TALION, a ciné-vaudeville by Louis Feuillade. Gaumont production 1915.

ied as Levesque's. For instance, Musidora could play someone's nubile daughter or niece, as in TU N'ÉPOUSERAS JAMAIS UN AVOCAT or LES FIANÇAILLES D'AGÉNOR; a solidly married wife, as in LE COLLIER DE PERLES; an artist's muse or model, as in the films with the painter and the writer; or, in a parodying reference to her role as the female cat-burglar in LES VAMPIRES, an adventurous woman as in LAGOURDETTE GENTLEMAN CAMBRIOLEUR. Feuillade wrote roles for Musidora ranging from the modern ingénues Estelle Tapir and Amélie Bigoudette to the music-hall actress Aliette, from the cranky wife Madame Jéricot, to the loyal friend exposing men's selfish mentality Simone Turlupin, from the painter's model Rose Laroze to the mistress Miss Friquette. More than Musidora herself ever acknowledged, then, Feuillade in his comic films made use of her versatility and, more specifically, of her resourcefulness as a comic actress. On the basis of the synopses, then, it seems safe to emphasize that the significance of the ciné-vaudevilles within Musidora's career is that they highlight her as a comic film actress.

One tip of the veil of Musidora as a comic actress can be lifted by examining the fragment from the benefit film, LE RÉVEIL DE L'ARTISTE, and Musidora's performance as the maid of the artiste and his family. In the opening 
scene, her character applies the vaudeville device of imitation, and, as pointed out previously, the device becomes extra comical if the servant imitates the master. I have described the pose of Levesque sleeping, which is striking and evocative in its own comedy. The maid imitates his pose and, in doing so, highlights and parodies it. The parody emanates from the fact that Musidora did not faithfully copy the pose, but added to her movements an affected flavor and to her expression a smirk. At this point, the otherwise bored look in her eyes turns sardonic, while, a little later, it changes into that of a goody-goody. As no one else but the sleeping Levesque is present in the room at that moment, the addressee of her imitation act is the camera. Her play-acting, however, exceeds mischievousness within the diegesis. It calls to mind the suspicion that she was not a proper maid, but merely disguised as one. This was yet another level of comedy, above the imitation and the parody, and was evoked by her glances and gestures. She could put it into effect because disguise or mistaken iden204 tity was, as is well known, a central narrative device used by Feuillade in his crime series LES VAMPIRES and JUDEX. At the time of the release of LE RÉVEIL DE L'ARTISTE, LES VAMPIRES had closed off its successful first run in Parisian cinemas, while JUDEX opened on the very same day as the benefit film did. ${ }^{173}$ In both series, Musidora played a criminal heroine - the cat-burglar Irma Vep in LES VAMPIRES and the malicious Diana Monti in JUDEX - who disguised herself as, for instance, a telephone operator or a private teacher to execute her exploits. One of Irma Vep's disguises in the third installment of LES VAMPIRES, had been that of, precisely, a maid, and, like in LE RÉVEIL DE L'ARTISTE, she wore the standard maid's garb and had an utterly goody-goody mien. In the series, spectators knew that she was impersonating this Irma Vep disguise. What Feuillade and Musidora suggested in the opening scene of LE RÉVEIL DE L'ARTISTE, then, was that spectators were not watching the actress in merely the role of a maid mocking her master's artistic sensibility, but that they were offered yet another appearance of the scheming Irma Vep, much in the same way as in her role as Diana Monti. No matter that the remaining minutes of the short comedy did not follow up on this expectation, but, instead, turned to spoof the vanity of film actors, including the maid's/Musidora's. The point of the play-acting, then, was that Musidora communicated to audiences not merely the mischievousness of her part within the diegesis, but that she added another dimension. What in drama could be read as contemplation, in Musidora's comic acting was linked to her screen presence beyond the diegesis: it became intertextual.

Three of Feuillade's ciné-vaudevilles, among which is the surviving LAGOURDETTE GENTLEMAN CAMBRIOLEUR, likewise refer to the popular series. In the two missing films, the references are comprised in Levesque's roles, yet in the surviving one, it is in Musidora's again. In LES FOURBERIES DE PINGUIN, the 
allusion concerns Levesque's own role as Mazzamette in LES VAMPIRES. Penguin seeks escape from his over-possessive wife and opportunistically utilizes his resemblance to the character from the series as a means to approach the married woman whom he, in established vaudeville tradition, fancies. In other words, the reference functions as a narrative motif to help the vaudeville hero achieve his questionable goal. The film was released on June 23,1916 , one week before the tenth and final episode of LES VAMPIRES reached cinemas. ${ }^{174}$ Both LAGOURDETTE GENTLEMAN CAMBRIOLEUR and MON ONCLE (My Uncle), in contrast, were released some six months after the closing episodes of the series LES VAMPIRES and the serial JUDEX, respectively. With these two cinévaudevilles, one may say that Feuillade and his actors not only kept alive the memory of the series and serial, but also seized their chances to comment on the reception of these crime series. Most notably, LES VAMPIRES had provoked a debate about cinema as "l'école du crime" (the school of crime). The term was a favorite of moralists advocating a more wholesome cinema than the romantic and adventurous representation of criminal exploits, because it was feared that youngsters took inspiration from and imitate the heroes. ${ }^{175}$ Partly in response to this debate, the heroic protagonist of JUDEX was no longer a criminal, but a romantic gallant and the righter of wrongs. ${ }^{176} \mathrm{In}$ the ciné-vaudeville MON ONCLE, then, Feuillade himself spoofed the idolatry of the righteous character he had created:

Next he cries out, while taking a rigorous decision... (Because that old fogey of a Tourteau only looks at things through the eyes of Judex and only swears by him, it is Judex in person who will ask him for the hand of his foster daughter...) How so?... it was simple... Baptistin, sitting astride on the shoulders of the banker Favraux and wrapped in the wide black cape of Judex, will once more knock on the door of the inhospitable house, which, by miracle, will open up in front of him.... What uncle Baptistin Pouflaquet did not manage to obtain for his cousin the day before, Judex, the great righter of wrongs, obtains for his protégé immediately. ${ }^{177}$

If MON ONCLE enabled Levesque as Baptistin to pose as Judex, but with a wink, LAGOURDETTE GENTLEMAN CAMBRIOLEUR granted Musidora the part of the gang leader, and with a vengeance. In LES VAMPIRES, she had been several successive grand vampires' girlfriend, but, in the ciné-vaudeville, she spurs her new admirer, Lagourdette, into burglary in order to earn her adoration. And, after the necessary vaudeville twists and turns had offered this admirer a chance to outwit her, they allow her to regain command. This notwithstanding the obligatory happy ending, which eventually required that both of them admit their tricks, forgive each other, and commit to one another romanti- 
cally. In this ciné-vaudeville, Feuillade and Musidora play along with a reading: of LES VAMPIRES in which Irma Vep was the "Grand Vampire", rather than the successive leaders of the gang.

The targets proper of Feuillade's spoofing and vaudevilliste craftsmanship, however, were the moralist reception and its institutional guardians, the police, who, in fact, had tried to ban parts of LES VAMPIREs. ${ }^{178}$ The cinévaudeville introduced Musidora's (nameless) character while reading in the novelization of LES VAMPIRES, and shows her raving about the protagonists and mesmerized by their alleged ubiquity. In the first place, then, Feuillade seemed to reclaim his story from the social and moral realm and to resituate it in the realm of fiction and fantasy. In addition, he indeed let Musidora enact a youngster inspired by and imitating the fictional models' exploits against which the moralists warned. To further complicate things, Feuillade set against the scheming female character a no less scheming Lagourdette, who 206 pays and instructs his servants to have themselves robbed of the jewels he first provided them with and, in this manner, solves the dilemma in which he was caught. This vaudeville twist transfers the adventurous woman's acclaimed wickedness to a rather guileless and playful sphere. A successive twist, moreover, turns it into astuteness. Because, whereas the servants put on their imposture convincingly, Lagourdette goes about his task so clumsily, that his heart's desire sees through his game. In reaction, she copies his trick and instructs the servants to pretend to be outraged by the burglary so that Lagourdette is then arrested by the police. At the police station, finally, all of them confess to their set-ups, which leaves one single party as the ultimate fools: the police. The contemporary press noticed Feuillade's joking with consent and teased whomever they expected not to be able to appreciate it, as in this case of the editor-in-chief of the newspaper L'Oeuvre, Gustave Féry:

But good gracious, watch carefully for Féry! I bet that he will cry out, [...] "There she is, the school of crime. There she is!" In any case, we have had a jolly good time with the unexpected twists and turns that poor Lagourdette was put through, who, for the beautiful eyes of a coquette, "appears a loser from a challenge of which Chimène is the award" and who conquers her nonetheless, his Chimène. Anyway, I do not believe that his method of burglary will seriously harm our children's morals! ${ }^{179}$

LAGOURDETTE GENTLEMAN CAMBRIOLEUR was Feuillade's twentieth cinévaudeville and advertised as Gaumont's Christmas comedy of December 1916. ${ }^{180}$ The ads for it were as large and as classily designed as those for Gaumont's prestigious dramas; they often measured an entire page of a periodical and included several stills, two of which showed Musidora and Levesque 
and one the actors playing the servants. As was now typical, Marcel Levesque "du Palais Royal” was listed as the film's main attraction. More exceptionally, Musidora's name was listed too. ${ }^{181}$ Her inclusion signals the acumen of Gaumont's publicity policy, which capitalized on the rise of Musidora's fame both in cinema and on-stage. In cinema, this rise had been prompted by her performances in the ciné-vaudevilles and in LES VAMPIRES as well as by her articles on the making of the series, to which I will return later in that context. Onstage, she had reached the top of the bill for the first time in September 1916, in a revue at the cabaret La Pie qui Chante. ${ }^{182}$ Advertizing her name along with Levesque's could only increase the high expectations created by the slogan that accompanied LAGOURDETTE GENTLEMAN CAMBRIOLEUR: "Thirty-five minutes of FRANK MERRIMENT!" ${ }^{183}$

In the press, the response to the film was solely positive. ${ }^{184}$ All reviews took for granted that this ciné-vaudeville went even further than ridiculing the objections of moralists and the police and that it likewise could be read as a veiled commercial for the novelzation of the series. The publication disclosed to the public Feuillade's name as the author of the film series and the co-author, with George Meirs, of the novelization. From the perspective of a veiled commercial, this becomes a salient detail. In the ciné-vaudeville, Feuillade made the adventurous woman not only read the story and rave about it, but also made her ostensibly display its cover page to the camera. If the novelization had not been as much a Gaumont and Feuillade production as was the film, one could nearly speak of witty product placement-of the novel and its author alike. By the same token, Feuillade seems to have claimed his credits as the author and director of the ciné-vaudeville LAGOURDETTE GENTLEMAN CAMBRIOLEUR and for the entire series with Levesque and/or Musidora.

This ciné-vaudeville of Feuillade provides a good example of the matching of the male and the female protagonists. This not only applies to the fact that each follows a distinct obsession, but also to their trading of narrative agency. In the scenes of Lagourdette's visit to his heart's desire, she is the narrative agent: she is reading, she appears disturbed by the interruption of the visit and bored with her visitor's stories and amorous attention, and tells him to demonstrate his heroism. In the following scenes at Lagourdette's home, he is the narrative agent: he ponders how to pull himself out of the situation, shows the details of his plan to his servants, instructs the couple and provides them with the necessary attributes, and appears highly contented with the prospect of his solution to the problem. In the next scenes, which take place at a public place, the foyer of a music-hall, he is the agent at first, but she takes over halfway through. In these scenes, he greets her chivalrously, escorts her into and out of the hall, and steals the watch chain from his servant, albeit with his help. Musidora observes this with a puzzled look. These scenes are followed 
by an intermission in which the servant misbehaves, after which Lagourdette mimes to his heart's desire that he will continue burgling and does so by stealing his female servant's necklace. The servant reacts affirmatively, which is followed by a shot of Musidora with an expression of disbelief: what the heck is going on here? From this moment on, the narrative agency is again hers: she makes clear that she understands, confronts the servants and, sneers. She also reveals that she has stolen Lagourdette's address book without him noticing. (At this point in the surviving print, a scene is probably missing that was mentioned in one of the reviews and was said to have included Musidora paying and instructing the servants. $)^{185}$ The part at the music-hall concludes with reactions and events following from her action, with, as I recounted above, the servants acting outraged and the police arresting Lagourdette. At the police station, the servants carry on with their new roles, Musidora scolds Lagourdette for his clumsiness and Lagourdette is interrogated by the super208 intendent. Eventually, he takes over again and reveals the set-up and his motivation - "I did it for her"- to the fooled police. The final scene of the film is for the servants, back home in Lagourdette's kitchen, where they share with one other their fun with the imposture, yet also their preference to remain their ordinary selves.

Feuillade used the scenes with the servants to insert a great deal of physical comedy in this ciné-vaudeville, that is to say if the definition of physical comedy is expanded beyond Levesque's application of it to scenes of chase, crisis and chaos. The understanding of physical comedy which I would adopt, does not only derive from the deftness of the numéro visuel, but also from the physical and visual tools utilized by comic stage performers. The tools may have included exalted movement, gestures, grimaces, and attributes such as typifying dress, makeup, and characteristic objects. In LAGOURDETTE GENTLEMAN CAMBRIOLEUR, the servants were played by actors whose appearances and acting styles brought to mind such stage comedy. The makeup, physiognomy, and gestures of the female servant-played by Léontine, as the curator Mariann Lewinsky has identified her, a comic Gaumont actress whose real name is unknown-in particular tended towards burlesque and caricature. The male servant was played by Paul Montel, an actor not known from cinema and not belonging to Feuillade's stable: Lacassin's filmography only lists him in the cast of one prior ciné-vaudeville, sI VOUS NE M'AIMEZ PAS, and in none of Feuillade's further films. ${ }^{186}$ Stills with both actor and actress were included in the advertisements, a detail that suggests a high degree of popularity. With their acting styles, they add a flavor of comic stage acting and its attention to the physical as a means of expression to this ciné-vaudeville.

In Feuillade's pastiche of the vaudeville genre, the role of the servants is not to simply ridicule upper class people's behavior, but to comment on it as 
well. The commentary finds expression in gestures and movement. The male servant, for instance, repeatedly taps his forehead in response to Lagourdette's proposal, in a mode of direct address to the camera and out of sight of his master. In the same direct address mode, the servants present themselves dressed up, partly contented, partly ill at ease; curtsying in particular needs more practice. In the scenes set at the music-hall, their imposture is convincing, whereas Lagourdette does the opposite and hams up his role. His hamming is presented physically as well, through gesturing that he searches the jacket of his victim and only accomplishes the theft of the servant's watch after the latter has guided his hand to the right spot. The male servant, on the other hand, forgets about his imposture when ordering a drink: he uses the barstool as a table and puts his feet on another bar stool while getting terribly drunk. Back home in the kitchen, then, the servants become their joyous selves again, making jokes, miming their contentment with each other as well as their freshly acquired skill in curtsying, and enjoying the servants' privilege to lick the ladle.

Musidora almost entirely refrains from physical comedy in this cinévaudeville. ${ }^{187}$ She applies it only in one instance, when she, alone again after Levesque has left, gets up from her chair and imitates his dance around the room and, through facial expression and by looking straight into the camera, communicates to spectators her vivid interest in Lagourdette's promised burglary. In most of the film, her acting method is to exaggerate things only slightly. If she is compelled with her reading, her physiognomy expresses that she is very compelled. If she is captivated by the story of LES VAMPIRES, she moves her eyes emphatically around to indicate that they could be present in the room. If she is bored by her admirer's visit, she raises her eyes to heaven and sighs a few times to communicate extreme boredom. And if she is talking about the novel she's reading, she talks animatedly and with great ardor. Most significantly, she plays this while seated in an armchair, a position that seriously reduces the possibility for physical comedy. Her main means of expression, hence, are her face and eyes and what makes it comical is her measured exaggeration. In her comic acting, then, Musidora maintained a degree of truthfulness in the creation of types, and ingenuousness and lightness in the way of expressing thoughts and intentions as in her dramatic roles. Feuillade exploited her mastery of such comic acting in two close shots of her face that appear later in the film, in the first of which, she expresses her astonishment about Lagourdette's method of burgling and, in the second, her disdain for it. While the first shot is dominated by her huge eyes, which she opens as widely as possible, the second is focuses on her lips, which she presses together while curling up the corners of her mouth. The point is that she, precisely through the subtlety of her comic exaggeration, not only communicates with the char- 
acters within the diegesis, but also appealed to her audience to engage with her gibing. Whereas play-acting proper, as Levesque did in the direct address mode, solicits the spectator's complicity with the comic character's point of view within the diegesis, Musidora's comic acting solicits from the audience a complicity beyond her role. She communicates, and from this surviving print still communicates to me today, her pleasure in the act of comic acting.

\section{Feuillade's Serials with Musidora}

Returned from three months of war service in July 1915, Louis Feuillade returned to Gaumont and set out to further develop the genre of crime films that he had undertaken with FANTÔMAs before the war. Alongside his continuous production of ciné-vaudevilles and dramas-which, due to the war, pri210 marily dealt with patriotic themes - he wrote and directed two episode films featuring Musidora and Levesque within less than two years: LES VAMPIRES, in ten installments, was released in 1915-1916, and JUDEx, in twelve installments was released in $1917 .{ }^{188}$

These two crime series belong to the most widely discussed productions from Feuillade's and Musidora's cinematic oeuvres, since the 1940 from film historical perspectives and, since the mid-1990s, also from a critical feminist approach. Both strands of research testify to the fascination with the Irma Vep-figure that Musidora plays in LES VAMPIRES. This figure, however, had already acquired an afterlife during the 1910 s and 1920s. A brief survey of the reappearances of the Irma Vep-figure in the French theater and literature may illustrate how it, historiographically seen, became an icon of Feuillade's cinema and of Musidora's contribution to the French silent cinema. It will also disclose who has had a hand in the icon's afterlife.

In chronological order, one of the first to create an afterlife for the Irma Vep-figure was Musidora herself, who, as a stage actress, appeared in the black tight bodysuit that was made into the trademark of the figure and the series right through Gaumont's publicity. Musidora performed in the suit in sketches in revues from 1916 onward ${ }^{189}$ and, throughout her lifetime, invoked her Irma Vep role time and again in fictional and non-fictional accounts of her experiences. The relationship of the actress with the figure, I have argued on the basis of these recurrences, ran from ambivalence to the eventual acceptance of its capability to survive film history. ${ }^{190}$ While in the 1910 s playing with the figure in her theatrical and published work, because it offered her both narrative and artistic agency as well as a continuity of fame, she simultaneously emphasized that she, Musidora, was not Irma Vep, even not a bit like her. ${ }^{191}$ In later years, she no longer rejected the conflation because it had preserved 
her from the film historic oblivion she might have been subjected to otherwise. It may be illustrative in this respect, that the Commission des Recherches Historiques, installed by Henri Langlois at the Cinémathèque française in order to establish an oral history of French silent cinema as remembered by professional eye-witnesses, indeed included sessions on LES VAMPIRES and Louis Feuillade, but none on Musidora's own film production. ${ }^{192}$ This was the case notwithstanding the fact that Musidora herself had the responsibility to gather her former colleagues in these sessions and to make typescripts of the audiotapes recorded there.

A further contribution to the afterlife of Irma Vep, as is widely known, was made by the Surrealists in the mid-twenties, who ardently payed tribute to the figure in their writings and plays. The Surrealists became instrumental in the commemoration of the Irma Vep-figure in film histories because they provided two discursive conditions: they articulated their perception of the figure as tailored to teenage boys' erotic and rebellious fantasies and, in their roles of film critics and members of a recognized art school, they created an entry for it in cultural history. This detour from cinema in the afterlife of Irma Vep paved the way for film historians such as René Jeanne and Charles Ford and the former Surrealist Georges Sadoul to include Irma Vep in the film historic standard works they published at the end of the 1940s. At the same time, Musidora's research at the Cinemathèque française, from which these film historians obtained much information on the silent era, drew their attention to Musidora's career as a film producer and a director in the silent cinema. This line was continued in the publications by Feuillade's and Musidora's former colleague Henri Fescourt (1959), Feuillade's as well as Musidora's first biographer Francis Lacassin (1970), and Musidora's second biographer Patrick Cazals (1978). A first English language reassessment of Feuillade's serials was written by the American film critic and historian Richard Roud (1980).

In his study of Musidora's film career, Lacassin designates the Irma Vepfigure baffling and cruel, or disturbing-the classic femme fatale. He also points out that she could become the only true star of the series because of the war circumstances, which forced Feuillade to regularly replace his male actors and hence have the Grand Vampire eliminated at one point or another. ${ }^{193}$ As for Cazals, he could not choose whether the Irma Vep-figure comes closer to a goddess or a demon, but he openly refrains from further elaborating on it out of fear of spoiling its perennial charm. ${ }^{194}$ The scenes in which Irma Vep appears in her black silken bodysuit are, in this biographer's view, among the most erotic ones in the first quarter century of cinema. Richard Roud has emphasized that the presence of Irma Vep indicates that the battle between good and evil that underlies the series is not only political or social, but sexual as well. ${ }^{195} \mathrm{He}$ also underlines the narrative twist that Irma Vep is not killed by 
the police or the journalist, but by the latter's wife, in which he sees an indication that it does not matter at all that the bandits were captured in the end: the audience is well aware that this is just a kind of self-censorship to get the series past the police.

From a feminist viewpoint, Monica Dall'Asta has analyzed the figure of Irma Vep as an allegory, a personification of ambiguity. Looking in particular at the iconographic qualities of the silkenness and the blackness of Irma Vep's famous bodysuit, she detects how the suit reveals the feminine shape of the body and simultaneously covers the suggested nudity like a pair of stockings. It creates a tension between utter closeness and utter distance. Also, because the suit is at once identical with and different from the black suits worn by the male members of the gang, according to Dall'Asta, a new feminity is presented that is both androgynous and mobile like a cat. ${ }^{196}$ Vicky Callahan sees in the Irma Vep figure a designation of criminality as 212 female in which the source of anxiety (criminality) is linked to sexual difference. ${ }^{197}$ She also argues that the suit functions both to reveal and to conceal the female body, but in a more abstract sense: as the site of the female body as difference. ${ }^{198}$ Much like Roud, Callahan questions the death of Irma Vep; in fact the figure escapes from death and in later series by Feuillade "she 'returns' to the scene of the crime" through references and reminders-even if Musidora, after JUDEx, was no longer cast in the films themselves. This is how the figure, according to Callahan, in one film after another, increasingly becomes the personification of crime and evil. ${ }^{199}$ On the other hand, the ever-changing relationships of Irma Vep and of Diana Monti in JUDEX mock the monogamous heterosexual couple, Callahan notes. ${ }^{200}$ According to Eva Warth, finally, Musidora in her black suit constitutes "a site in which the body is shown and experienced differently" than in modern day cinema, which is one of the specific pleasures and fascinations that early cinema offers viewers today. Its emptiness of meaning opens a space for a sensual, affective perception and experience. ${ }^{201}$

In sum, these film historic and feminist accounts treat the figure of Irma Vep in the black bodysuit as an embodiment of eroticism, evil, criminality, sexual difference, ambiguity, mobility, and silent film-experience. It seems as if a good many concepts of concern to the viewer can be projected onto the black bodysuit, attesting to Warth's observation of its emptiness of meaning. However, as I have pointed out in my article on the afterlife of Irma Vep, the figure appears in this suit only in some eight minutes of screening time from the over six hour-long series! ${ }^{202}$ In all other scenes, she is dressed in contemporary fashion or in a costume that suits her disguise, and in JUDEX, she does not wear the suit at all, but instead appears at one point in a much less suggestive bathing suit. This raises the question if the contemporary reception of 
LES VAMPIRES was dominated by the figure in the suit as it came to be in film historic and feminist memory.

In the discussions referred to, moreover, both LES VAMPIRES and JUDEX are primarily treated as crime series; their dark and mysterious sides wholly catch attention. The large portions of comedy and wit they also offer, are either overlooked, relegated to marginal significance, or, as indicated most emphatically in Roud, connected to the rebellious minds of anarchist criminals of the times. I wish to highlight that these comic and witty elements had important functions in the reception of the series and the female figures. For this aim, I will explore the cinematic and non-cinematic devices from which these elements were drawn, reconstructing the contemporary cultural framework within which the series and the roles of Irma Vep and Diana Monti were conceived and received in the process.

For inserting comic elements in LES VAMPIRES, Feuillade borrowed from $19^{\text {th }}$ century stage melodrama, ciné-vaudeville and the pre-war Parisian revue. To guarantee the success of this inclusion, the filmmaker called upon the vaudeville actor Marcel Levesque, the child actor Bout-de-Zan, and, as I will suggest, Musidora in her capacity as a witty and comic revue actress.

Like the melodramas that had attracted the crowds to the "Boulevard du Crime" in the 19th century, Feuillade capitalized on the fascination with criminals, but also adapted its treatment to the spirit of the times. In the early 1910s, anarchist criminal gangs like the notorious Bande à Bonnot mesmerized large crowds of people as much as they scared them. ${ }^{203}$ An important influence on this public fascination had been the contemporary press and the actuality film, which represented the offenders not as downright criminals, but as "tragic bandits", who exposed the authorities' and the police's ineffectiveness to catch them and thereby heroically defied the institutions maintaining law and order. ${ }^{204}$ In LES VAMPIRES, it is indeed a journalist who chases the bandits, rather than the police who are largely incompetent or too late to accomplish much. With this in mind, it becomes understandable that the exploits of LES VAMPIRES were also seen as defying authorities and the police, which led to the police's temporary ban of the fifth episode of the series, as is well-known thanks to Musidora's mention of it. Like the Bande à Bonnot, moreover, who primarily robbed banks, the Vampires burgle and steal from the wealthy. But, in order to escape from the grimness with which criminality was doomed in real life, Feuillade had recourse to a formal device brought up by Marcel Levesque, one of the principal actors of LES VAMPIRES and JUDEX. Levesque explained that, after Feuillade had proposed the role to him, that is to say a comic part in a drame noir, he was initially puzzled by the combination, but: 
Being a man from the stage, I eventually decided that, after all, a comic character was an element of relief, that should benefit the atmosphere of the dark drama through contrasting it. The theater gives many an example of this function, from the old melodramas of the boulevard du crime to the modern ones at the Ambigu. ${ }^{205}$

Richard Abel has observed that, with the integration of comedy into another genre, Feuillade and Levesque initiated a trend that would persist well into the 1920 s and that became the way in which French comedy survived beyond the decline of the comic shorts during the war. ${ }^{206}$ Feuillade's strategy, indeed, went beyond inserting Levesque's comic presence and contrasting it with the noir side of the drama: he incorporated a whole range of elements from the comic generic environment that he had designed for the actor, the ciné-vaudevilles. The fact that the comic character was embedded in his cultural habitat, 214 I'd like to argue, has had an important impact on the reception of the series as a whole.

One of the ciné-vaudeville elements was the word-punning with names. Mazzamette, the name of Levesque's character, brought to mind the joyous and good-natured mentality of the south of France, of which Feuillade himself reputedly was the very incarnation. ${ }^{207}$ In the fourth part of the series, Mazzamette poses as a wine merchant selling Muscat de Lunel, a dessert wine from Feuillade's hometown and a reference to his descent, which was a winegrowing family. Although such biographical information about Feuillade was unknown to the contemporary public, the references served to contribute to the joyous tone. Whereas further "good" characters in LES VAMPIRES were given common names, those of the gang leaders were bestowed with imaginative associations. The name of the gang itself is already jocose, because its members are no blood sucking vampires, but burglars and jewel thieves. Among them, there is a baron "des Mortesaigues" (of the acute deaths), a "Vénénos" (vénéneux = poisonous), and a "Satanas." The most exquisite word-pun was reserved for Irma Vep, whose name was an anagram of the word vampire. With a trick film device- of letters on a poster ${ }^{208}$ changing their position back and forth between Irma Vep and Vampire-the anagram play was visualized in the third episode of the series, and in the eighth, it reappears as a communication tool applied by the criminals. As soon as the imprisoned Irma Vep has recognized Satanas in his disguise of a prison priest, she knows that she has to make an anagram of the message in order to decipher it. Through "Le cryptogramme rouge" (The red cryptogram), which is the title of the third episode and the name given to a notebook containing coded indications for the vampires' schemes, the word-play also acquires a narrative function. As soon as the journalist chasing the Vampires, Philippe Guérande, has secured the 
notebook, he treats its contents as a puzzle, providing him with information on where to look for the bandits. One of the effects of this punning on names and words was that the element of play was emphasized in the criminals and their exploits.

Another element taken from the ciné-vaudevilles-and from the comic genre in general-was physical and visual comedy, of which a great deal was inserted in LES VAMPIRES. Many of the criminals' actions were cinematically represented as gags, involving trickery and virtuosity to make the impossible seem possible. In the fifth episode, for instance, Guérande was kidnapped by means of a hook, which suddenly clutched his neck when he was leaning out of the window to search the street for suspects and pulled him outside and down to the street. The sequence consists of an interior shot, tinted light brown on the video copy of the American print, ${ }^{209}$ of Mathé leaning out of the window of his office; an exterior, tinted blue to mark the difference, of him further leaning out of the window and getting caught with the hook; and another exterior down on the street, in which Irma Vep and her helpers pull Guérande down and stuff him into a clothes hamper on a car. What has been visibly pulled down and popped into the basket was a doll. The mise-en-scène, together with the use of the doll and the swiftness of the action, gives the entire sequence a slapstick flavor, addressing spectators' sense for pranks rather than fuelling their alleged admiration for the gangsters. The series contains many more instances of characters hiding in baskets and trunks, a motif that Feuillade made use of in his ciné-vaudevilles ${ }^{210}$ and that, from early on in French cinema, was ubiquitous in comic shorts. According to Musidora's recollections, Feuillade deliberately made the bandits simulate virtually impossible actions:

He did all of this to his full amusement, like a little boy who would say: "I am going to make an electric and silent cannon; they won't take that seriously, will they?" And he did it in jest. ${ }^{211}$

Physical comedy was also what Levesque's participation brought to LES VAMPIRES. Oscar-Cloud Mazzamette was a friend and acolyte of Philippe Guérande, who appears in every episode of the series. His somewhat silly and goofy actions had much better results than viewers might expect. This motif brings to mind the BOUT DE ZAN-series, in which naughtiness usually turns out to be much more clever than could be foreseen. In the third episode of LES VAMPIRES, the device of repetition is used: Mazzamette whizzes down the chimney and tumbles into the room just like Philippe had done before him, but, in addition to that, he carries something important with him; the poisoned pen that he has stolen from the Vampires. In the fourth episode, Mazzamette poses as the wine merchant at Irma Vep's home, but only to let in Philippe without 
her noticing - a case of mistaken identity. In the fifth episode, Mazzamette is unable to sleep, and, while droopily watering the plants on the windowsill, he notices two suspects entering a door across the street. He takes a look, plots a way to copy the key, enters the building, and eventually sets Philippe free from captivity by the Vampires. Once more, Levesque's character is rendered less goofy than it first seemed, and, more significantly even, as one of the few in the series who is repeatedly able to outsmart the bad guys. Often, he directly acts towards the camera as if he were telling spectators to take precise notice of his perceptiveness and smart solutions. ${ }^{212}$ The significance of Levesque's role in LES VAMPIRES, then, is to suggest that smartness is inherent to unruly and comic characters rather than to the outright vicious ones.

The association with the Bout de Zan character was made manifest in the eighth episode of LES VAMPIRES and most notably in two sequences that provide excellent illustrations of both Bout de Zan's and Levesque's physical act216 ing. The acting devices include disguise and drawing attention to the physical, as well as direct address to the camera. Bout de Zan appears in these scenes as Mazzamette's son Eustache and constitutes a redoubling of the presence of comic actors in the series. The son, moreover, takes after his father, as he has been dismissed from school because of his unruliness and the practical jokes he performs on his teachers. In the presence of the concierge, who has escorted the boy home, Mazzamette pretends to be annoyed with the situation and angry with his son, and initially keeps up that attitude when alone with the boy. While Mazzamette sees the concierge out, Eustache communicates directly to the spectator how pleased he is to have fooled school and his dad. Shortly thereafter, Mazzamette lets go of his pretended sternness, acts towards the camera too, and presents his son to the spectator with a forgiving expression and gestures as if to say, "look at him, isn't he adorable." Next, the father informs his son to his latest plan: to dress up as tramps find out the address where Satanas, the then Grand Vampire, is staying. Disguise here serves as a comic device in itself already, most notably in Eustache, who has transferred his familiar tramp outfit from the BOUT DE ZAN-series to LES VAMPIRES. Just as in those scènes comiques, disobedience is rewarded with the success of outsmarting the bad guy(s).

The scenes with Levesque often have a vaudeville flavor. Many are set at Mazzamette's or Guérande's apartment, invoking the homeliness typical of the genre as well as contrasting with the exterior environments and public spaces where the Vampires usually operate. Philippe Guérande is not quite a vaudeville type because he has a mother and a fiancée and does not allow himself to be distracted from his work or his love by any circumstance. Towards Mazzamette, he has a corrective role, telling his friend how to behave and how to pay attention to more serious things than he usually does. Mazzamette, in 
turn, slips more and more into his vaudeville character in the course of the episodes. He becomes wealthy in the sixth episode, after which he makes a habit of having a ball and flirting with women in episode seven, and definitely falls in love and "gets his Chimène" in episode ten. The two final scenes of LES VAMPIRES, moreover, were not reserved for the very last Vampire to be killed, Irma Vep, but offered the happy ending to the ciné-vaudeville running through the series: that is to say, they present Mazzamette proposing to Augustine-a widow and the maid of the newlyweds Philippe and Jane-and Philippe giving his blessing to the marriage after Mazzamette has assured his friend that he will mend his ways. The closing shot shows the couples kissing.

A fourth and final element in which Feuillade may have been inspired by his ciné-vaudevilles, is the complexity of plot construction combined with clear resolutions of the intrigue. LES VAMPIRES is one extensive testimony of Feuillade's pleasure in weaving ludicrous situations and antic intricacies, while he simultaneously-and carefully-maintained the appearance of probability.

Fig. II.14: Irma Vep tied up by Guérande but cautions her colleague through honking the horn. Film still from LES VAMPIRES IX, L'HOMME DES POISSONS, a film by Louis Feuillade. Gaumont production 1915/16.

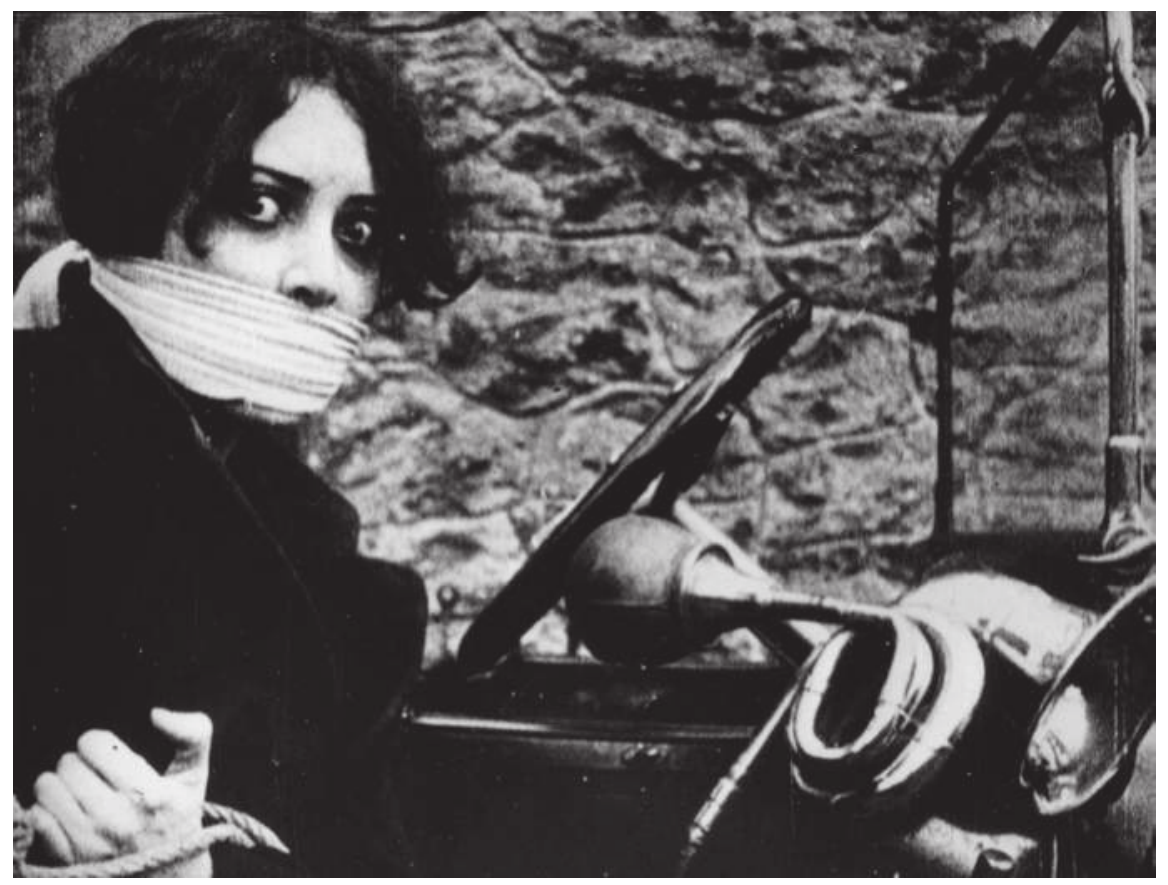


The intrigue, moreover, is merely based upon action and reaction, and quite in the tradition of the popular theater, not on psychological character motivation. Feuillade applied such principles not only to the comic scenes, but to the "noir" parts of the episodes as well, rendering the narrative set-ups wondrous and the intricacies compelling, while, through his on-location shooting, maintaining plausibility and closeness to that with which the public was familiar. One of the rare scenes of interaction between Mazzamette and Irma Vep, in the nineth episode, provides a good example of this. Irma Vep lies on the pavement after having been overthrown and tied up by Guérande. Mazzamette approaches driving a car and the two men lift their captive into the vehicle with the expectation that Venenos will come to her rescue so that they can catch him too, but Irma Vep manages to caution her colleague by honking the horn three times by banging on it with her head. Together, they manage to escape in the car. Such vaudevillesque elements in LES VAMPIRES cause specta218 tors to follow the intricacies and the characters not with anxiety or shivery, but with a smile.

If Levesque's presence in LES VAMPIRES is embedded in an array of comic and vaudevillesque narrative and visual devices, Musidora's appearance as Irma Vep is borrowed from music-hall and revue conventions. As has often been noticed, the scheming Irma Vep preferably popped up in one or another disguise, be it a maid or a telephone operator, a sailor or a viscount. However, it usually goes unnoticed that, first, the disguises concerned recognizable types as in a fairy play or a revue, and that, second, they often played along with well-known Parisian music-hall conventions such as female cross-dressing and the tradition académique. In her sailors' suit, Musidora's cross-dressing turns out gamine, in the elegant suit of the viscount, it becomes androgynous, while in both she is breathtakingly seductive. This becomes all the more salient if the prohibition of cross-dressing in France is taken into account, which, after 1909, allowed women to wear trousers only for biking and horseriding, or, indeed, on the stage - but not in public or in daily life.

Musidora acted the various types so true to life that spectators had trouble recognizing her: "My character, Irma Vep, [...] changed from episode to episode, to the extent that even the public itself did not recognize me immediately." ${ }^{213}$ The degree of pride ringing through this assertion brings to mind the truthfulness and ingenuousness that marked her acting on the stage. To help spectators solve the puzzle that this acting style brought to LES VAMPIRES, then, music-hall sign language was utilized: Musidora had Irma Vep place her arms akimbo - a gesture which, as I have pointed out, signified the apache woman ever since it was introduced to the popular stage by Mistinguett and transferred to the screen by Polaire. 


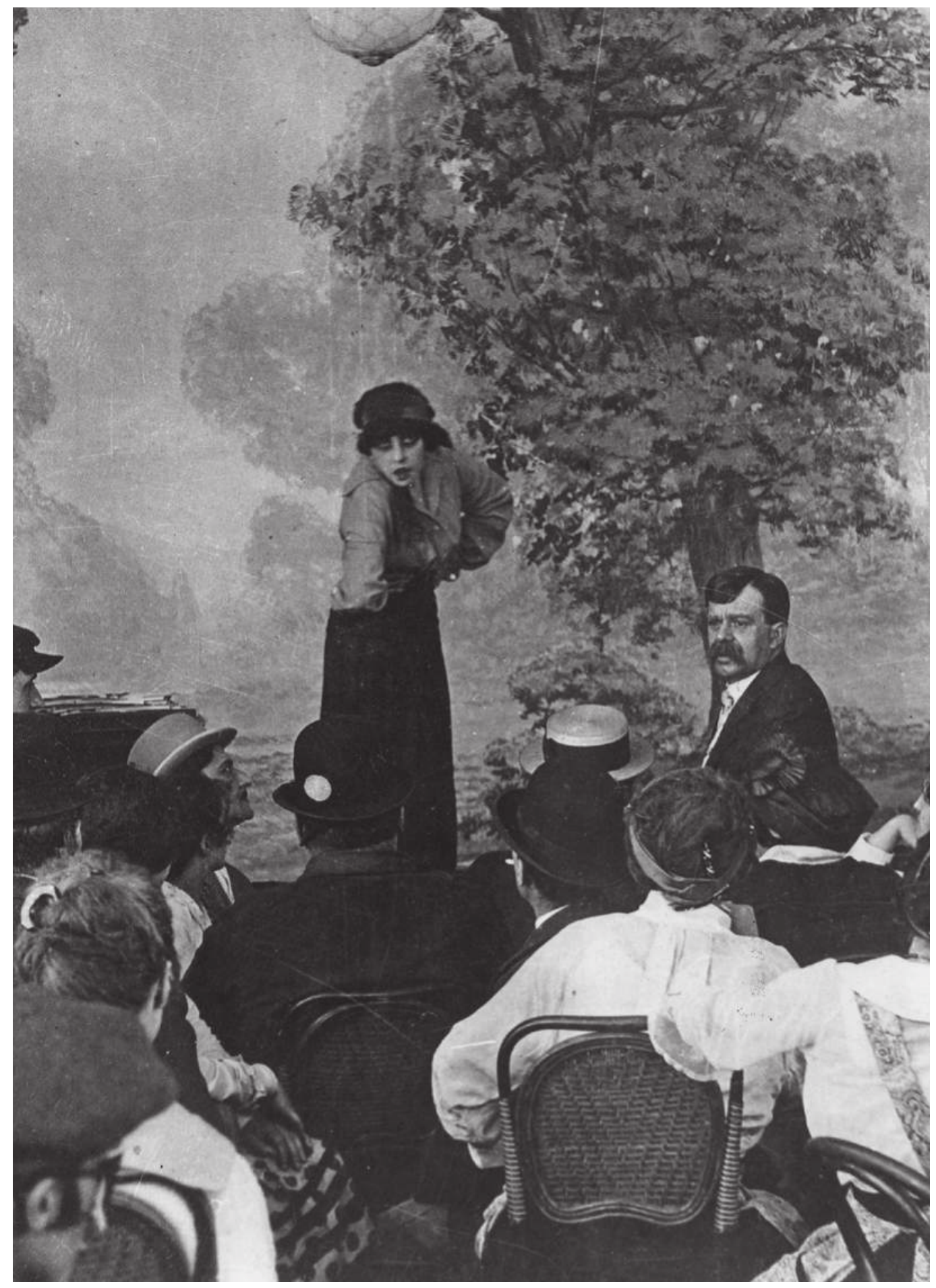

Fig. II.15: Irma Vep incognito and with her arms akimbo in the cabaret. Film still from LES VAMPIRES III, LE CRYPTOGRAMME ROUGE, a film by Louis Feuillade, Gaumont production, 1915. 
Scenes at a cabaret, where the Vampires meet, further back up the apache association. In the tenth episode, the Vampires even perform the Apache dance. But the most shrewd reference to the revue, which continued to be Musidora's professional terrain parallel to the cinema, was the famous black bodysuit that she wore in two of her appearances as Irma Vep "herself", that is to say while burgling. This suit was-and in none of the discussions of the suit and the figure referred to above was this noticed-an adaptation to the screen of the culte du maillot and the tradition académique, the witty tradition established in French music-hall and revue to display women's bodies' shapeliness wrapped in a tight skin color suit. Musidora herself has pointed out what about the suit was new to the screen:

In the stunning VAMPIRES, I introduced the most discrete luxury. The black tight bodysuit had been worn before me by Josette Andriot, but it had been made of decent cotton. The micromesh silk of my suit would for a long time set astir the youth of $1916 .{ }^{214}$

The micromesh quality of the cloth made possible the tightness of the suit and was reminiscent of the luxury for which the revue was famous. The quote is taken from a letter that Musidora wrote to Georges Sadoul at the end of the 1940s and that the film historian included in his Histoire générale du cinéma. It was, as I have noted, the time in which Musidora herself participated in film historical research through the oral history project of the Cinémathèque française. Therefore, it ought to be noticed that Musidora, for the sake of film history, recorded that she had introduced the lavishness of the silken suit. One possible interpretation of her phrasing would be that she was enabled to do so through the mere fact that she had played the part; however, her way of putting it may likewise imply that Musidora had had her say in the choice of the suit. This is what she suggests twice in fictionalized recollections of her acting for LES VAMPIRES and once in the interview for Radio Suisse Romande.

In the fictionalized accounts, she reconstructed her dialogues with Feuillade. In one, the young girl playing "la belle Irma" confided to the director: "You see, what I have been after is the excessive delicacy of the mesh of silk, so that the skin plays through the transparency, I so much wanted it to be quite adorable!" ${ }^{215}$ In the other, Feuillade said to her: "I agree with all of your innovations. Your delicate bodysuit of transparent silk... the bodysuit of the female vampire, you did well in demanding that it was made of silk." ${ }^{216}$ These fictional dialogue lines could be considered mere products of artistic license, if it had not been that Musidora had claimed her "demanding" the silken material in a non-fictional context. For the Swiss radio in 1947, Musidora answered the 
interviewer's question as to whether the maillot noir had been invented for other reasons than to impress the boys:

I believe that the reasons were foremost aesthetical, because I had demanded that it was made of silk as I found that the transparency of the silk on the skin and on the body - I had a well-shaped body at the timemade it possible to truly offer the audience a small sculpture [...], something at once quite wondrous and highly chaste and very eye-catching too. [...] Half man, half woman, one can not quite be certain what it is. ${ }^{217}$

Given the information that, for contemporary films, actors were supposed to provide their own wardrobes, Musidora may have even been in charge of supplying the suit. ${ }^{218}$ She may have kept it to herself throughout her lifetime, using it for stage appearances and reportedly still possessing it in 1957, when she gave an interview a few months before her death. ${ }^{219}$ Regardless of whether she or Feuillade, or both of them in consent, introduced the silken stretch suit to the screen, its effect was to invoke the connotation of the luxury, the sexual

Fig. II.16: Musidora posing in the silken black body suit at her home, photo Louis Silvestre, 1915 .

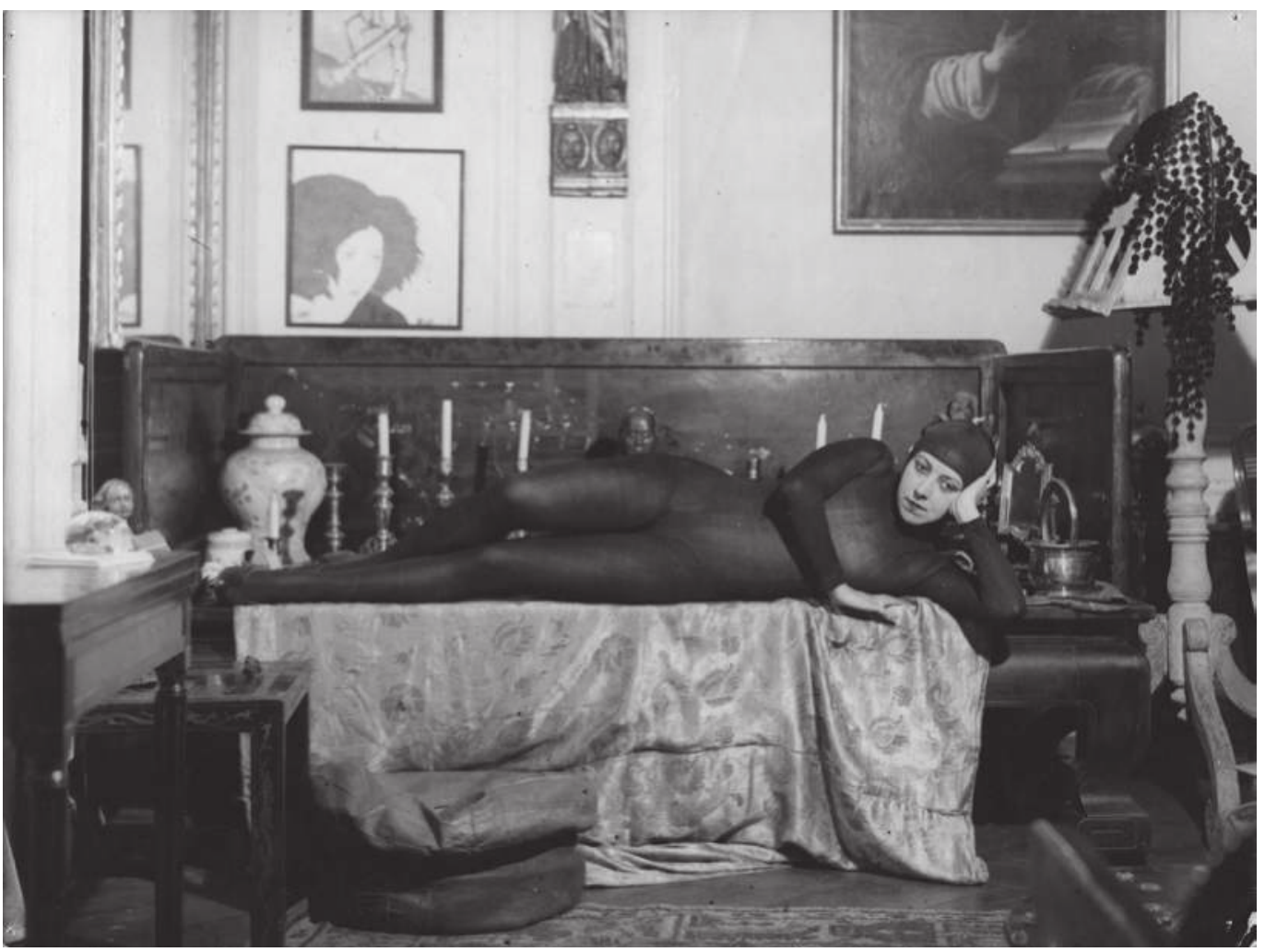


ambiguity, and the frivolous eroticism that French audiences in the mid-teens were acquainted with from French music-hall and revue. As documented earlier on in this careerography, the contemporary viewers indeed associated the suit and the Irma Vep-figure with music-hall culture.

The connection to popular stage culture not only emerges from contemporary reception or historical knowledge. The reference has been inserted into the grain of the text of the series as well. As a matter of fact, the black tight bodysuit was not only worn by Musidora in LES VAMPIRES, but also-in an earlier episode-by Stacia de Napierkowska, the dancer known from the Châtelet and the Folies-Bergère. ${ }^{220}$ In the second episode, Napierkowska's character of the dancer Marfa Koutiloff - a hint at the Ballet Russes in which she used to excel-is killed by a poisonous ring, given to her by the Grand Vampire, because rumor had it that she was Philippe Guérande's girlfriend. Feuillade narrativized her brief and tragic appearance as a dance act that she performed 222 on a theater stage. On the popular stage, dance was, after the tableaux vivants, the foremost act for women in which the exposure of the female body could be enveloped in artistic virtuosity. ${ }^{221}$ Napierkowska's scenes provide us with a fine example of this combination. On the one hand, we watch a professional ballet dancer at work, on the other, her body shapes are well exposed to the camera. Just as in Musidora's scene, the use of the light adds to the exposition of breasts and belly, which is further highlighted through a close shot of the camera. The narrativization of the scene as a dance performance, however, frames the exposition of the female body as an element of art and training. The potential sleekness of the suit on Napierkowska is undermined by a few additional accessories - large ears on her cap and a cape like the wings of a bat-, which Musidora, later on in her screen appearance, would omit. The ears ridicule the costume, whereas the cape animalizes it, placing the character in the tradition of literary and filmed batmen such as Zigomar and Fantômas. ${ }^{222}$

Josette Andriot, whom Musidora mentioned to have worn the black bodysuit before her, had done so in two films by Victorin-Hippolyte Jasset: the last of his three ZIGOMAR-films and the spy film PROTÉA, both made in 1913. A closer look at these appearances has become possible thanks to the rediscovery of a PROTÉA print long considered to be lost. ${ }^{223}$ A comparison of the scenes in which Andriot wears the suit with those in which Musidora wears hers, moreover, highlights how the mise-en-scène and the camerawork capitalized on the qualities of the silk on the body.

In ZIGOMAR, PEAU D’ANGUILLE (Zigomar Eelskin) Andriot plays Rosaria, the accomplice of the bandit Zigomar. She wears the high-necked black suit in about half of the 45-minute film and always in scenes in which the emphasis is on her undauntedness, her physical control, and her mobility, and her equalization to the master bandit. When she climbs up a wall or jumps from 


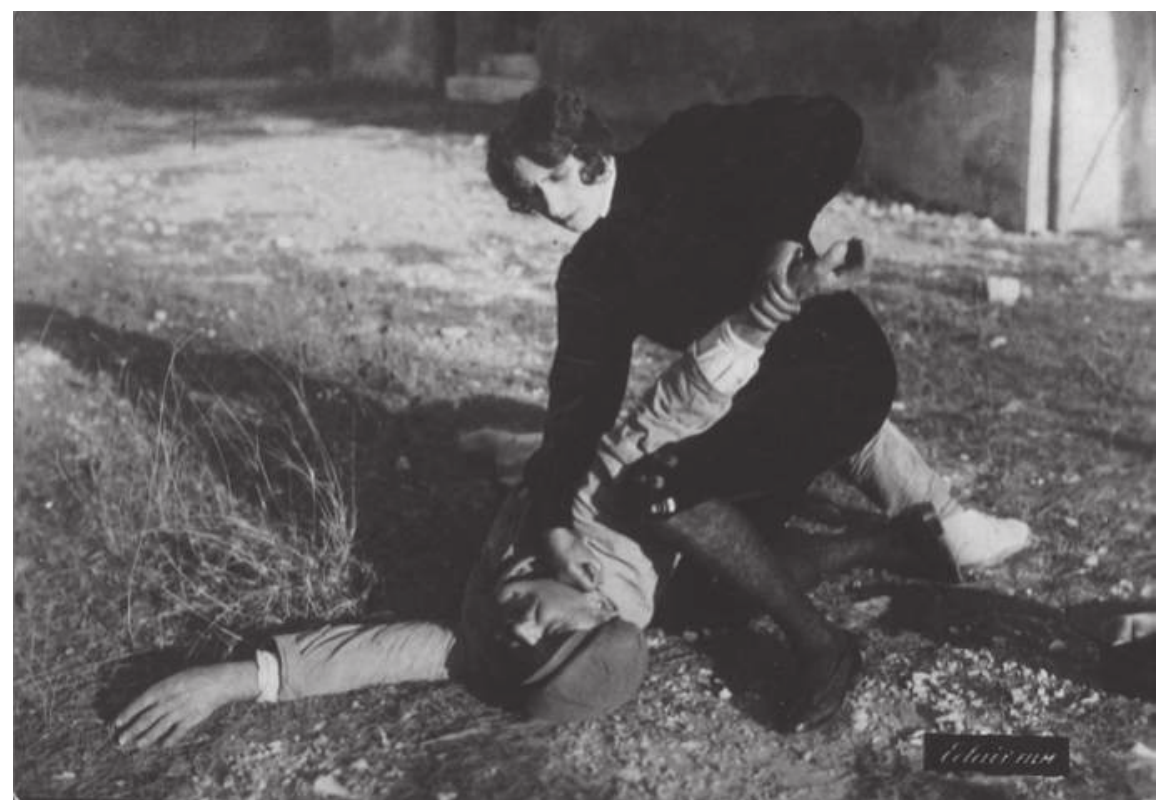

Fig. II.17: Josette Andriot in PROTÉA wearing the black body suit at work. Set photo.

balcony to balcony, the shape of her buttocks is pronouncedly visible, but with the connotation of muscular strength rather than erotic attraction. Towards the end of the film, there is a scene in which she and Zigomar are caught in a floaded cellar and in which their suits turn wet and stick to their bodies. Still, hers does not look sexy, even when she is pulled backwards up to the floor. A very brief frontal shot of her body in the wet suit indeed shows the shape of her breasts, but, again, not in a suggestive manner. In the following shot, she stands next to Zigomar and the suit is, quite significantly, dry again: it rather serves to conceal than to reveal sexual difference.

This is also the case in PROTÉA, a French detective story with a female master spy as its protagonist. ${ }^{24}$ Although Protéa does appear in the suit in much less screen time than Rosaria, rendering it relatively extraordinary, the camera and the mise-en-scène present it as a working suit: the outfit worn by burglars for protection, as the model and the blackness of the costume conceals them in the dark. The first shot of Protéa in her black suit shows her putting on a black cap, an action that distracts from the suit and how it looks on her. The camera frames her waist-up, and this shot is followed by a closer shot of her head and cap, which draws attention to her large eyes. In the subsequent shot, she opens a door and sticks her head through, an action that, again, draws 
attention to her head rather than to her body. The surviving print of the film does not contain a shot with Protéa's entire body in the suit. In the following sequence, we see her at work wearing the suit, but from a distance and against a dark background. There is no exposition of body or suit that brings to mind the culte du maillot or the sculptural quality that Musidora attributed to it.

If we compare this to how Feuillade and his cinematographer Georges Guérin $^{25}$ introduced Musidora in the black suit in the fifth episode of their series, the differences in approach and effect become obvious. Like Protéa, Irma Vep is shown at work, but not obscured by the dark and the distance, so that the sculptural and female shapes of her body are highlighted right away. Both the sleekness of her suit and her elegant movements, moreover, are set against those of her fellow burglars who all wear blouse-like shirts as tops above their black tights. In the sixth episode, moreover, the silhouette of the female body in the suit is framed as a spectacle by means of the light224 ing and mise-en-scène. Within the diegesis, these scenes present Irma Vep searching a hotel room, after which she gets caught by the leader of a rival gang, Moreno. After he has dragged her into his room, Moreno eyes his catch from top to toe. The camera duplicates his gaze without overlapping with it, revealing the duplicity of the male gaze. A little later, we see Irma Vep vainly struggling against Moreno's grip and the chloroform that he uses to numb her, her body lying in an armchair. In these images, the skin and the nipples clearly shine through the suit-most notably in big screen projection and to an extent that some onlookers believed to have seen everything it covered. ${ }^{226}$ Musidora has suggested that the effect of transparency of the cloth was intensified by the use of the light. In her play, "Le prince des ténèbres" (The Prince of the Darkness), she claims that Feuillade told her: "We will play with the light on the silk of your translucent bodysuit and you, you will play this for me like a great actress." ${ }^{227}$ But even in case Musidora just invented the dialogue after having had a chance to see a surviving print of LES VAMPIRES in $1947,{ }^{228}$ the images illustrate that the mise-en-scène, lighting, and framing charged Irma Vep's appearance with an eroticism that seems absent from Protéa's. The same holds for the cross-dressing scenes, which occur in both series as well. Whereas Jasset renders Protéa wearing an army uniform purely as a narrative function in the spy plot, Musidora, Feuillade, and Guérin portray Irma Vep's cross-dressing as a model illustration of bisexual seductiveness.

Irma Vep was not only much more seductive and mysterious than her predecessor, but also unabashedly evil. Protéa is a female genius spy, about whom the title cards quite tellingly declare "Mais il fallait beaucoup plus pour décourager Protéa" and "Il fallait beaucoup pour s'emparer de Protéa" (It takes much more to discourage Protéa and it takes a lot to seize Protéa). What Abel concludes on the basis of synopses and reviews, can now be confirmed 
from the print. ${ }^{22}$ The character was a French older sister of the American serial queens Helen and Elaine, whose intrepidity mesmerized cinema audiences overseas from November or December 1914 and constituted the breakthrough in France of American serial queen melodramas in $1915 .{ }^{230}$ The Protéa played by Josette Andriot was as intrepid and athletic as the Elaine played by Pearl White. She performed her tasks, moreover, in order to protect the interests of the government that hired her. In other words, her exploits sprang from righteousness and loyalty to her commissioner, however ambiguous his motives may have been. Elaine's, Helen's, or Pauline's motives sprang from their daredevil ways of coping with dangerous situations, but they also appealed to the spectators' sympathy and sense of justice.

Irma Vep, in contrast, was the female criminal impersonated, and, instead of a serial queen copy-cat, she constituted an ingenious alternative to their forthrightness. Her scheming and burgling was driven by mere evil. Her image was conceived in contrast to the one of Elaine Dodge and probably Protéa too: although dark-haired like Protéa, Irma Vep was malicious and alluring. The alluring aspect of her image drew, as I have argued above, from music-hall iconography in conjunction with shrewd mise-en-scène, framing, and lighting. In other words, it brought a Parisian flavor to the darkness of the drama, which was enhanced with the insertion of (ciné-)vaudeville devices that embedded it in a sphere of comedy and playfulness. The point of the cinematic style of LES VAMPIRES, its fantastic realism, its comic aspects, as well as its foreclosing character identification, was that it discouraged spectators to take the matter and the Irma Vep character too seriously, and instead let themselves be enchanted by the series' game of mischievousness. Musidora, once asked if, among her fan mail, she had also received letters of protestation for embodying a female icon of evil, affirmed this playful view on the character of Irma Vep:

No! Never, never; I have not received any letter of protest. I believe that between the public and me a certain understanding existed. They figured that she murders, but she does so to amuse us. Because, after all, one laughed and realized, no, she has not murdered for the killing, but she has murdered to entertain us-not to frighten us. ${ }^{231}$

LES VAMPIRES, still today, makes spectators smile rather than shiver and it is the insertion of comedy and Parisian allure that makes it differ substantially both from its French predecessor and its American counterparts.

The contemporary reception of the series, nonetheless, oscillated between appreciation and disapproval. Disapproval was often fuelled by moralists' and authorities' worries about the social impact of the representation of crime in the series. Moralists feared that the films would work like a school of crime, 
because they did not only display, in detail, the preparations for a variety of criminal acts, but also rendered the bandits extremely romantic and attractive. ${ }^{232}$ Some critics also worried about the larger demoralizing effects of the ubiquity of phantasmagorical tricks in the series, through which crime was represented as an enterprise of conjuring conducted by the villains. ${ }^{233}$ Authorities such as the police, moreover, protested the ridicule of their competences. ${ }^{234}$ Generally, such objections did not apply to Musidora's part in the series, except for one comment attesting to the provocative allure of her performance:

It is almost unbelievable that Musidora, who all the same has such beautiful eyes, would nourish such evil plans as carried out by L'HOMME DES POISSONS. It is obvious that the crime films, by living themselves up through the presence of beautiful women, will delay their death-struggle and will ensure for themselves a death in beauty. ${ }^{235}$

Beyond moralist considerations, disapproval was fed by concerns of film critics worrying about the quality and future of cinema in general and in France in particular. Guillaume Danvers in Ciné-Journal, for instance, blamed most crime series, including LES VAMPIRES, for playing too many tricks on feasibility:

Remember that our working class people, the habitual cinema goers, in matters of electricity, mechanics and so forth, are judges of a rare competence whom one should not try to fool. The cinema, which by way of photography should faithfully reproduce facts and events, ought not to accommodate tricks: it should leave that to the theater which has shown itself a master in presenting works of art made from cardboard. The cinema ought to be sincere; that is its invincible force, that is its appeal throughout the world. ${ }^{236}$

Danvers belonged among the critics who argued that the cinema ought to turn away from the theater, which made him reject the entire genre of crime films. Another critic, who wrote under the pseudonym, Le Voyeur in Hebdo-Film, grumbled about every instance of improbability that struck him. ${ }^{237}$ At times, he also pointed out editing problems, when shots or narrative sequences ran too long, in his taste. ${ }^{238}$ Nonetheless, the pseudonymous critic appears to have intended his criticism constructively, as he accepted the genre and consequently enveloped his comments in assertions of how interesting the films were in terms of cinematic craftsmanship. ${ }^{239} \mathrm{He}$ admired the complexity of the narration, ${ }^{240}$ complimented the acting in general terms, and once, even called Levesque better than Chaplin. ${ }^{241}$ Le Voyeur also compared LES VAMPIRES to 
LES MYSTÈRES DE NEW YORK: "Well, it is every bit as good as the MYSTÈRES and it is quite better in terms of camera and acting. [..] it is French cinema, and much better than many another." ${ }^{242}$

The competition between the French and the American series went beyond aesthetics and most notably concerned aspects of marketing strategy and production policy. LES MYSTÈRES premiered in France on December 3, 1915 in 156 cinemas throughout the country and was bound to offer a weekly installment for three and a half months. ${ }^{243}$ The American serial was completed by the time it reached France, whereas the production of LES VAMPIRES went on during its run in the cinemas. ${ }^{244}$ In addition to that, episodes of the latter were released much more irregularly and with longer intervals, roughly once a month. Most importantly, LES MYSTÈRES was accompanied by a publicity strategy novel for France, that is to say, the publication of its novelization in one of the major newspapers paralleled the weekly release of the fourteen subsequent episodes of the film. Although, as I have pointed out, French cinema- and theater-goers were accustomed to synopses of performed plays and exhibited films, the regular and long-standing publication in a newspaper with millions of readers was of a different order. It nonetheless prompted Gaumont and Feuillade to issue a publication of LES VAMPIRES as well, which was available to critics by mid-April 1916 and was written jointly and signed by Feuillade and the crime novelist George Meirs. ${ }^{245}$ Lacassin has reproached the novelization for giving the characters an internal life and for its far too wordy style compared to the poignant images. ${ }^{246}$ Contemporary critics, however, applauded the initiative and sang the praises of the fantasy necessary for devising such plots. ${ }^{247}$

By May and June 1916, when these considerations were published, French cinema was in a precarious position due to the war. The pride of being the foremost film producing country in the world gave way to concerns about the imminent loss of that position, most notably vis-à-vis the American expansion to the European market, of which the large-scale launch of LES MYSTĖRES DE NEW YORK and other serials was one of the signals. This concern about the future of French cinema resonates in the constructive criticism conveyed in such reviews as those of Le Voyeur, and even more so in the enthusiasm about the popularity of LES VAMPIRES with audiences in the provinces and abroad. Reviewers invariably stated that it was excellent French cinema, as if the public's enthusiasm, which they always mentioned, and the increasing distance, in terms of both time and space, helped to turn goodwill into outright appreciation of the series' cinematic qualities. ${ }^{248}$

If relatively few reviews of LES VAMPIRES appeared in print in 1915 and 1916, the reason was not just the initial distaste for the genre. Most obviously, Ciné-Journal kept silent editorially on LES VAMPIRES, despite the fact that it ran the entire series of ten advertisements. However, Ciné-Journal, only by excep- 
tion, reviewed individual films during this period and rather published overviews of trends and debates, such as the ones by Danvers' cited above. Quite a few other film periodicals had suspended publication because of the war and only some had begun reappearing by June 1916, when the tenth episode of LES VAMPIRES premiered in Parisian cinemas. Le Courrier Cinématographique, for instance, resurfaced only in December 1916, and Filma did so in February 1917. The war stop of the quotidian for the performing arts, Comoedia, which from, March 1913 onwards, ran a daily column "Cinématographes" edited by J.-L. Croze, even lasted until September $1919 .{ }^{249}$ It is hard to tell, therefore, if the reviews and background articles that were published in Le Cinéma et l'Écho du Cinéma réunis and Hebdo-Film, in fact do represent the full scope of the debate provoked by LES VAMPIRES and the genre of crime series. Nonetheless, they seem to justify two conclusions: first, objections hardly ever concerned Musidora's role in the series, which underpins my argument that the recep228 tion of the Irma Vep figure went along the lines of expectations of popular stage performance, that is to say, expectations to be amused and seduced by, rather than to be shocked or provoked to imitate her or her gang; second, the moral and cinematic objections that were initially brought forward melted away with the growing popularity of the series with the public, both in France and abroad, and gave way to hope for the survival of French popular cinema.

One contemporary voice mixing in the debates incited by LES VAMPIRES and LES MYSTÈRES DE NEW YORK deserves extra consideration here: the voice of Musidora, who recounted her experiences in film production in a selection of periodicals. Her first intervention on the issue appeared in the "magazine gay" Fantasio, for which she wrote short stories. Her fictionalized report "Les dangers du cinema" spells out the danger of cinema for actresses doing their own stunts. In the story, she emphasized the truthfulness of the images of LES VAMPIRES, and simultaneously aligns herself with the intrepidity and athletic skills so widely admired in the American serial queens and, most notably, Pearl White. ${ }^{250}$ The single page story contains the following dialogue between her and her friends after the shooting of a scene of LES VAMPIRES, for which she had to lie flat underneath a moving train:

- I have been under a moving train "for the sake of cinema"! I am greeted with a general burst of laughter. I protest:

- Now you see! I risk to hurt myself in order to amuse the public, and my best friends do not believe me: it is disgusting!

René, who just returned from the front, covered with medals, wounds and glory, says with a sceptic smile:

- You must have been under a train made of cardboard, with wheels turning on the spot; a trick of the kind they perform at the Châtelet. 
- $\quad$ But no [...]! I repeat to you, to all of you, I have been under a real train, at Brunoy! ${ }^{251}$

The most interesting aspect of this dialogue is the contrast between the filming on location and the spectacular yet fake backdrops for which the Châtelet theater was known. Musidora, here, engaged in the very debate that Danvers had invoked: that cinema ought to distinguish itself from theater through truthfulness. Her argument, however, was that it did already: no cardboard sets were used.

Once the actress in the story has convinced her friends of the truth of her anecdote, they talk about the danger she has been in, after which she details how she experienced the event, what she saw, how the train sounded and felt, and so forth. This latter part of the text, written in a style at once realistic and evocative, was apparently considered so pertinent that it was reproduced in several further papers and periodicals, from the film paper Le Cinéma et l'Écho du cinéma réunis to the daily Paris Midi. ${ }^{252}$ Its significance was, as Musidora pointed out in another text, that it denied what everyone thought, namely "that the scene contained trick effects". ${ }^{253}$ In a second story, Musidora expanded the topic of courage involved in acting for the camera to a variety of efforts and crafts indispensable to filmmaking. Those involved in the shooting of a film were now set against an ignorant snob and his equally ignorant flirt, who think that making films is nothing but fake and easy to do. Their visit to the studio teaches them otherwise. The story enables Musidora to depict, in vivid style and graphic detail, some of the ins and outs of the work, not only of actors and director, but of extras, cameramen, and props men too. Again, the story deals with risks taken for the sake of cinema and the references to LES VAMPIRES are thinly veiled: instead of a Grand Vampire, there is a Grand Von Pyr with his accomplice Irma and, without his name being spelled out, there is "one of our great comic actors with the famous nose." ${ }^{254}$ The described scene from the crime film in-the-making was one of the more spectacular ones of the series, in which Satanas blows up a cabaret with a cannon shot from his hotel room window. In the scene showing the effects of the blow, we see a chandelier falling down from the ceiling, a profusion of panic among the guests and a cloud of dust, suggesting chaos and damage. The point of Musidora's story was that the explosion was closely reproduced on-set:

Everyone actually seemed to be having a good time. Launched by a dexterous hand, the bomb explodes right in the middle of the cabaret, a bang resounds, a horrible and harrowing bang. The walls topple over, the chandeliers come down, a young extra faints for fear. A black velvet soot slowly comes down. ${ }^{255}$ 
In her recollections published in the early 1940s, Musidora recounted how she and Fernand Herrman, who played her lover Moreno, were actually hurt in the blow: her arm was dislocated and Herrman's cheek bled from being hit by a falling piece of scenery. ${ }^{256}$ The personal risks that Musidora-and other actors - took for the sake of cinema was a recurring topic throughout her writings on film. The necessity for stressing the "truthfulness" of actions and locations in Feuillade's work and, as we will see, in her own work as well, then, sprang from the debate in which the quality and future of cinema was related to the plausibility of what was shown and to the extent to which it distinguished itself from theater and its way of make-believe.

The detailed depiction of the work in front of the camera in Musidora's story reveals a second concern. Her description of the considerations of the cinematographer suggests a clear sensibility for how images were produced in the cinema:

The cinematographer, who supervises the shape of the shadows and the patches of light, orders the carts [with the lamps, A.F.] to be moved, so that the head of our grand Von Pyr does not produce two or three shadows on the wall of painted cloth which are fused, blurry and of unequal intensity. Instead, one, very neat cut-out dramatises this tableau of the crime film. ${ }^{257}$

Given the hindsight that Musidora, within three years from this date, made her debut as a filmmaker herself and that she also talked about how images were created in that context, it does not seem unreasonable to read in this story of hers an announcement of her ambitions in that direction. Musidora's main point, however, was that she knew very well what she was doing as an actress, even though she enveloped the description of her specific way of acting in an observation made by the snob:

The snob has come to see the grand film, in which the young girl triumphs whose round eyes follow him in their somewhat peculiar manner of slowly looking from right to left, while fixing for a moment their iris towards the spectator. ${ }^{258}$

This is an accurate and adroit characterization of Musidora's way of acting with her eyes in LES VAMPIRES, which she applied throughout, only varying the duration of the glance towards the observer. The sidelong glance-both in its literal and in its metaphorical sense-was ubiquitous in the series as Irma Vep's trademark. In its indirect address, her glance implied an acknowledgement of the spectator's presence. Three effects can be ascribed to it, one 
diegetic and two extra-diegetic. ${ }^{259}$ Within the diegesis, it intensified the sense of mystery and scheming to be associated with the presence of the Vampires and of Irma Vep in particular. In the fourth episode of LES VAMPIRES, for instance, we see her eavesdropping behind a wall, while moving her eyes from side to side and making them skim over the camera, representing her high interest in what she hears. Beyond the diegesis, her eye movement may have addressed spectators in two ways: as she describes in her story, and as has been contended throughout history, it often mesmerized people and enticed them to become enamored, both with Irma Vep and Musidora; as Musidora has pointed out in her interview for Swiss radio, moreover, it also invited spectators to complicity, not with her evil scheming within the diegesis, but with her playing a game for their amusement. In 1920, she articulated her enchantment with the role thus:

I will spare you the titles which I have forgotten among, by the way, all of my Gaumont films. I will make an exception for LES VAMPIRES, which has been for me an unalloyed pleasure. The idea to be a bad woman and to assassinate in each episode the innocent victim, had countless charms for me. ${ }^{260}$

What is special to Musidora's acting, then, is that she, in LES VAMPIRES, much like in the ciné-vaudeville parody of it, LAGOURDETTE GENTLEMAN CAMBRIOLEUR, communicates to spectators this pleasure in the act of acting. That, in my view, is one of the qualities that makes the series and Musidora's contribution to it fascinating still today: she invites and enables me to share in that pleasure through giving a knowing wink and making people smile. Musidora's way of representing the femme fatale or bad woman, then, transcends the weighty and fraught connotations usually associated with these terms: her knowing winks flavors her candid acting with playfulness and wit.

In the role of Diana Monti in JUDEx, Musidora was given yet another chance to play an evil character and, in each episode, harm the innocent victim. It is very possible to see in Diana Monti a recurrence of Irma Vep, as Callahan more emphatically has done than anyone before her. ${ }^{261}$ Still, there are some significant differences as well. Even more seductive and wicked than Irma Vep, Diana Monti is far less mysterious. There are several scenes in which she explicitly instigates her accomplice to killing or kidnapping, suggesting that she rules the roost, but the bandits have no heroic connotation of rebellion against moralists or authorities. The men are, rather, victims of the spell of this wicked female character in which attractiveness completely overlaps selfish villainy. Diana Monti's motive is to become rich through blackmail. Her seductiveness does not exceed the narrative; its aim is to subdue her lovers. In 
this role, Musidora wears the most exquisite dress and is often filmed in a way that renders her, like in other Feuillade films, breathtakingly beautiful, but this is also motivated from within the diegesis. A good example is the scene in the fifth episode in which she schemes with Morales while lying stretched out in all her glory on an polar bear rug, with her elbows resting on the ferocious head with its gaping jaws. Seductiveness and ferociousness captured in one image.

As one can observe, the mysterious and romantic figure in JUDEx is not one of the bandits, but the male hero. He constantly uses disguise in order to perform his tasks of avenging his father and of protecting or rescuing the woman he is secretly courting, Jacqueline (Yvette Andreyor). So Feuillade made this Judex (René Cresté) the radiant star of the series rather than Diana Monti. His story of avenging and courting is at the heart of the narrative, while Diana's and her accomplices' crimes seem only marginal, even more so against the 232 backdrop of the crimes committed by the banker Favraux, who has driven several people into ruin and misery. In Diana's disguises, moreover, she is easy to recognize throughout, even in her cross-dressing scenes in the tenth and eleventh episodes. More importantly, her leadership is repeatedly questioned, because either her partners in crime refuse to follow her orders or her wicked plans fail. In such a context, Diana Monti's main crime is seduction: not only of her accomplices, but even the banker, the "good" son of one of his victims, and the detective are not safe from her.

I agree with Callahan that this reduction of Diana Monti to a classic femme fatale is largely due to the melodramatic dichotomy of the bad Diana versus the good woman, Jacqueline. ${ }^{262}$ But I also think that there are other factors involved. Again, this can be closer analyzed if references to the popular stage and Musidora's way of acting are taken into account.

The scene that parallels the one with Irma Vep in the black suit appears in the fifth episode and is set in an abandoned mill, where Diana and her partner in crime Morales keep the chloroformed and kidnapped Jacqueline hostage. Morales refuses Diana's order to kill Jacqueline, Diana threatens to stab him, and Morales manages to overthrow her. They are caught in the act by one of the victims of the banker Favraux, the former owner of the mill, Kerjean, who has returned to the place to commemorate his wife, who died of grief over her husband's misfortune. Diana Monti escapes and hides behind a door, listening to the dialogue that develops. Morales reveals to Kerjean that he is, in fact, is his son and that Diana Monti has seduced him into crime. Morales convinces his father, Kerjean, that he wishes to return to honesty. We see Diana behind the door make a fist and scold him. Next, and this is the moment in the series that I consider to parallel the one between Irma Vep and Moreno, Diana starts to take off her clothes piece by piece, until she wears only a bathing suit. 


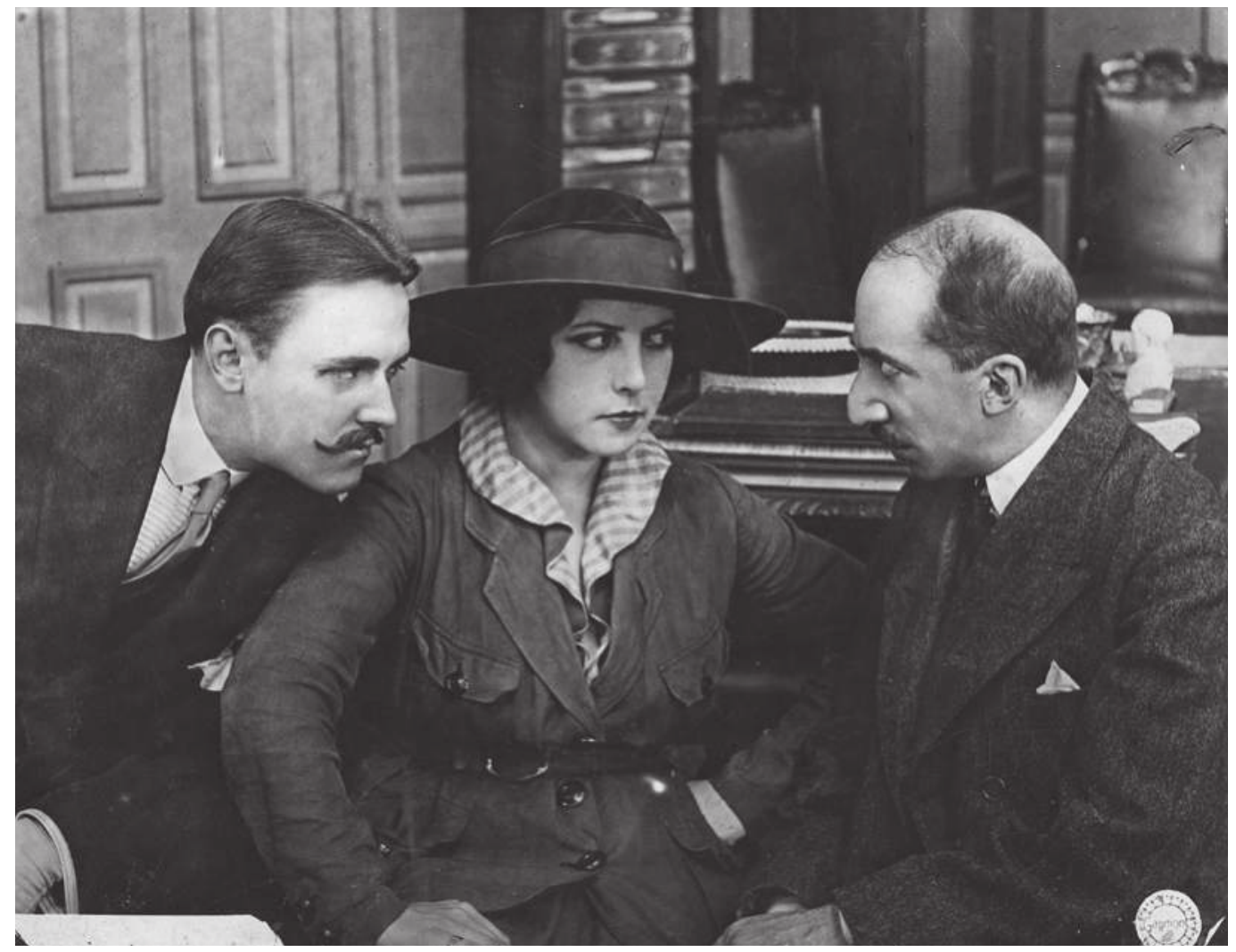

Fig. II.18: Diana Monti's main crime is seduction: even the detective is not safe from her. Still from JUDEX, a film by Louis Feuillade, Gaumont production 1917.

Although this is a reference to the tradition académique, it is not one to the culte du maillot, and it is not as refined and shrewd as the black bodysuit. It is more vulgar, and simultaneously more athletic. It is more vulgar, because, before Diana descends through a hole into the water underneath the mill, we are shown her naked legs and allowed a peek between her breasts; it is more athletic because the bathing suit looks as if it is made of cotton (!), and rather conveys sports than luxury or eroticism. The sporty connotation is affirmed by Diana's next action: she dives into the water and swims away. The association with sports is reaffirmed in a scene in the final episode, in which Daisy Torp, a dancer from the Nouveau Cirque, swims in the cold sea, ascends the ship where Diana and Morales are keeping Judex hostage, and frees Judex. Later, Daisy is shown climbing in the stays of the ship's mast. While the reference to the popular stage is present in the character of Daisy, the emphasis is on her training, not the art of dancing. ${ }^{263}$ The vulgarity, on the other hand, is further buttressed in the final scene of Diana Monti in the series, which shows 
her corpse being washed ashore. Lying on her back, with her head bent backwards, the skirt washed up by the sea to the effect that her knee stockings, bare upper legs, and even a glimpse of her black panties become visible-a more disgracing and lifeless image is hard to imagine.

Another reference to the popular stage are the vaudevillesque scenes with Levesque that have been inserted in the melodrama, much like in LES VAMPIRES, although there are three episodes in JUDEX without his comic presence. In these episodes, other characters take over the comic function, as in the third episode with Le Môme Réglisse (Bout-de-Zan), or in the fourth episode with the pack of dogs belonging to Judex. The comic character, Cocantin, moreover, acts as the detective, who, from the beginning, casts doubt on his capabilities in investigation. These doubts are additionally raised because initially he is hired by the malicious banker who wants him to find out who is the mysterious Judex threatening him. Neither is Cocantin suspicious of Diana, 234 who believes that he is Judex, and hence flirts with him each time they meet. There is only one aspect in which Cocantin has a constructive function, which is that he unconditionally believes that Judex is right in accusing Favraux of bringing others to ruin. But unlike Mazzamette's goofy actions, Cocantin's hardly ever lead to solving a problem or saving a victim. This becomes fully apparent in the scenes in which Daisy dives into the sea while Cocantin stays behind on the beach helplessly running up and down the shore because he cannot swim. Not the detective, but his date defeats the villains.

In his statement announcing the series, Feuillade assured the public, most likely in response to the conflicting reception of his previous series, that JUDEX was a popular and wholesome family spectacle as well as a spectacle of emotions, joy and art that wished to offer a truthful story, full of adventure, love, laughter, and tears. ${ }^{264}$ Accounting for the imagination from which the story sprang, he placed himself confidently in the tradition of the French popular literature of Alexandre Dumas. All of this was cheered in the contemporary press, which confirmed that the series was not a vindication of crime from which candidate burglars would learn new methods. ${ }^{265}$ Rather, it was considered a heroic-comic series, in which the dramatic was gripping and the comic was always poignant. Levesque's role was received as a satire on the usual detective and a Parisian, witty satire at that. ${ }^{266}$

Musidora's role engendered a range of comments. One was the familiar projection of eroticism, most notably on her scene in the bathing suit, which met with both admiration ${ }^{267}$ and disapproval. ${ }^{268}$ Another response pointed to a degree of pleasantry in the figure of Diana Monti: "Miss Musidora, who has to flee in great haste, plunges into the river in such a marvelous way, that one forgets the blackness of her soul for the moment." ${ }^{269}$ A final remark linked her dramatic and comic acting: 
Fig. II.19: Diana Monti in her bathing suit. Still from JUDEx, a film by Louis Feuillade, Gaumont production 1917.

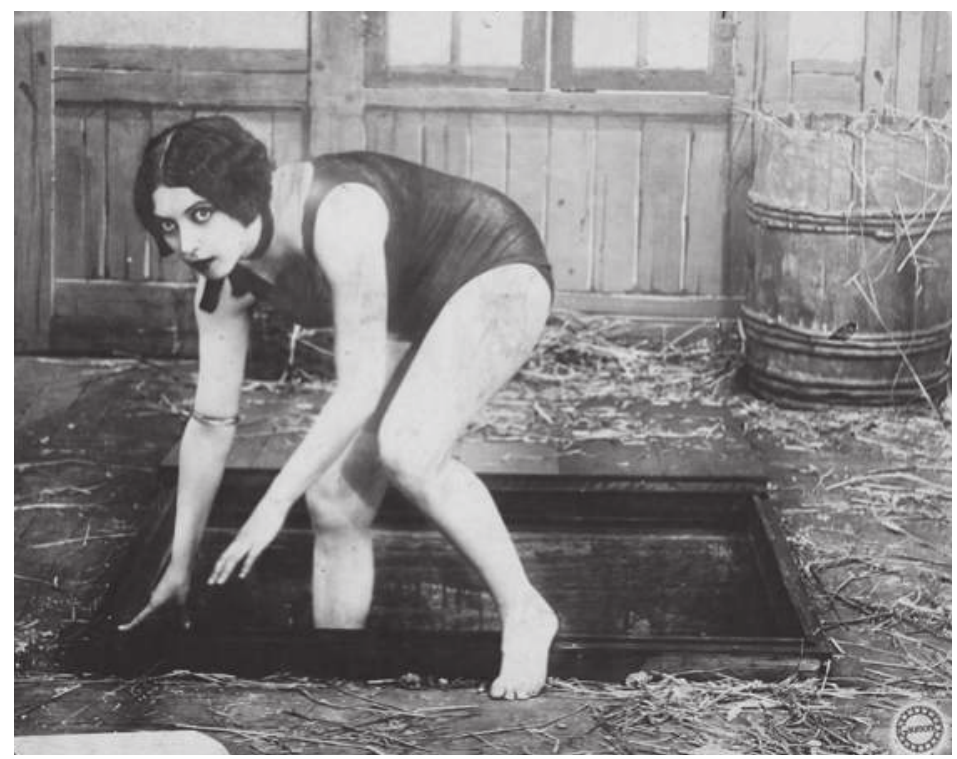

and the adventuress ready for every crime, is Miss Musidora who, after having made herself a deserved name as a comic performer, adds to her glances that we have known to be so smiling, dramatic flashes which are all the more frightening because they come as a surprise. ${ }^{270}$

In other words, in the contemporary reception, Diana Monti was not taken seriously in her villainy. It was obvious to (most) spectators that she committed her crimes to entertain them, not to scare them. To my knowledge, Musidora herself has written only one brief line about the figure of Diana Monti: "JUDEX, whom I have chased with my intense dislike, has earned me the reputation of bad girl.," ${ }^{271}$ It is an acknowledgement of the success of the series, which was much bigger than that of LES VAMPIRES and which consolidated her status as a French film vedette. Her acting continued the style that she had developed in her role of Irma Vep, including, right from the first shot of JUDEx onward, her sidelong glance and her arms akimbo. What she added were two instances of downright play-acting. In the opening episode of the series, she applies this comic acting device in a scene with the malicious banker, Favraux, and, in the sixth episode, in a scene with the detective, Cocantin. In both cases, Diana Monti ostensibly pretends to seduce the man opposite her, while, to the audience, displaying her disgust with the banker and her contempt with the detective. Also in these cases, the play-acting undercuts the seriousness of her seductiveness and instead presents it with a knowing wink to the spectator while simultaneously communicating her pleasure in the act of comic acting. 


\section{MUSIDORA AS AN ACTRESS 1916-1918}

Already during Musidora's affiliation with Gaumont, which seems to have ended in the late summer or early fall of 1917, announcements appeared in the trade papers of projects with other firms and filmmakers, among which the production company of the filmmaker André Hugon, who proudly lined up Musidora's engagement with Mistinguett and Marie-Louise Derval, fellow music-hall vedettes who had established a career in film as well. ${ }^{272}$ Musidora indeed took leading roles in three dramas directed by Hugon: CHACALS (Jackals, released in April 1917), JOHANNÈs, FILS DE JOHANNÈs, (John, Son of John, released in June 1918), and MAMZELLE CHIFFON (Miss Chiffon, released in March 1919). CHACALS was welcomed as the first of a series promising a happy collaboration between Musidora and Hugon; the film was deemed powerful, earning a ranking as "Bien, Presque Très Bien" (good, almost very 236 good). ${ }^{273}$ More mixed were the responses to the following two productions, which earned just an "Assez Bien" (passable). ${ }^{274}$ Musidora, however, was said to have shown that she definitely had the stature to handle dramatic leading roles. ${ }^{275}$ In CHACALS and JOHANNÈS, FILS DE JOHANNÈs she played similar parts as a treacherous seductress triggering the misery and death of more than one man, but both plots are, as the titles indicate, really about the fates of the men seduced and betrayed. In MAMZELLE CHIFFON, which received severe criticism for its lack of drama and its implausible plot, she played an unwed and poor teenage mother, who nonetheless finds happiness and a rich man. The potential agency in the role was traded for coincidence. ${ }^{276}$ As far as the reviews and plot summaries disclose, the three films seem rather depraved of profundity, which prompted Le Film to advise directors to cast Musidora in psychological comedies instead of in adventurous and melodramatic plots. ${ }^{277}$ The actress occasionally mentioned the titles of her production with Hugon, but never published anything substantial about them. I read this as an indication that Hugon had been barely able to fulfill Musidora's ambitions in playing dramatic leading roles.

Much more positive, in contrast, was the response to Musidora's collaboration with Colette, which occurred parallel to Musidora's affiliation with Hugon, for providing subject matter and plots. In 1916 and 1918, Musidora was involved in three films drawing from Colette's work: MINNE, after the novel L'Ingénue libertine (The Libertine Ingénue); LA VAGABONDE (The Vagabond), after the novel with the same title; and LA FLAMME CACHÉE (The Hidden Flame), after an original scenario written by Colette for Musidora. ${ }^{278}$ No prints of these films are known to be extant, and, of MINNE, it is even doubtful if it was ever actually made or finished. ${ }^{279}$ In these films too, Musidora played the leading roles, while, according to Lacassin, she also contributed to the 
Fig. II.20: Musidora playing yet another treacherous seductress in JOHANNÈs, FILS DE JOHANNÈS (André Hugon 1918).

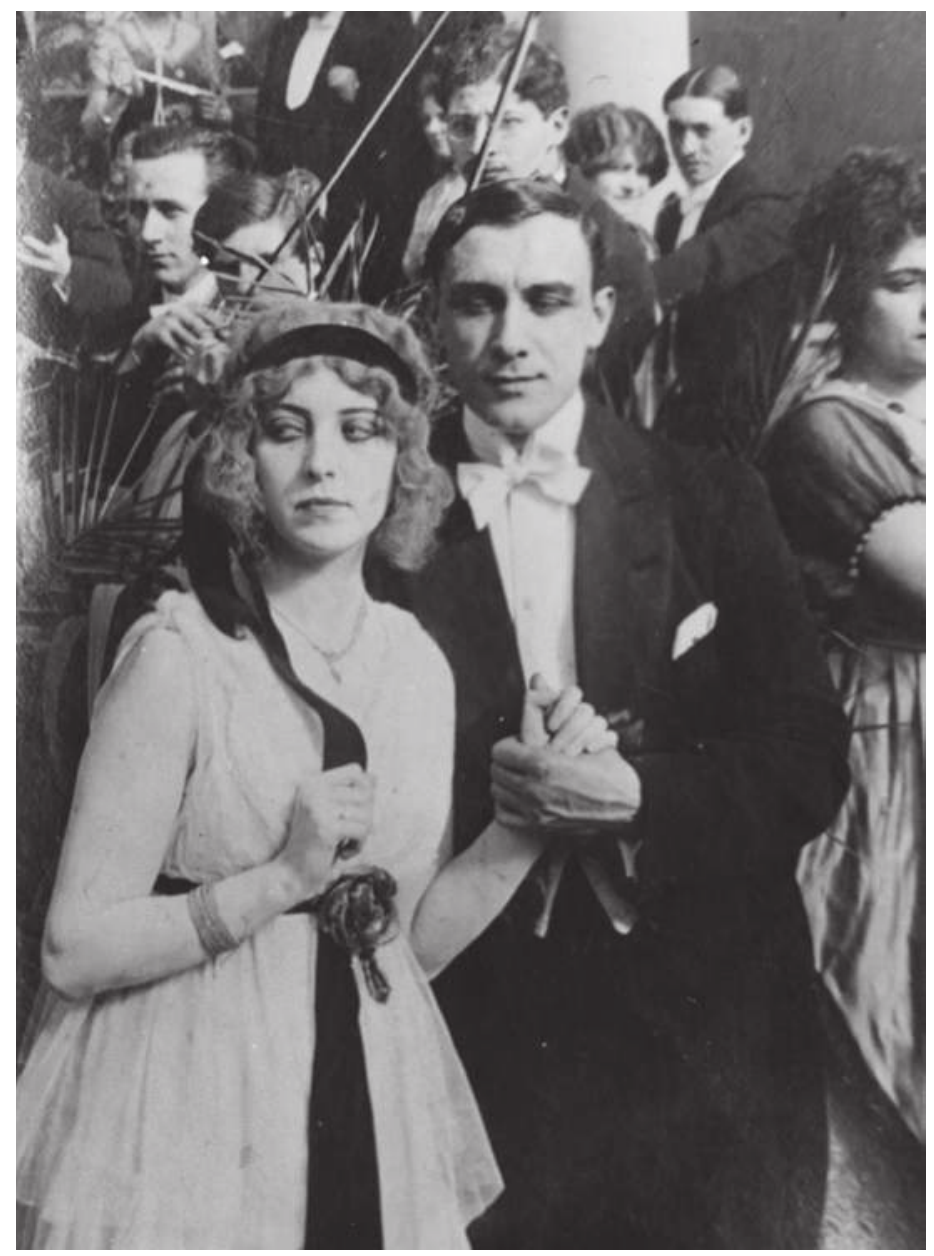

"adaptation" [shooting script] OF LA VAGABONDE (directed by Eugenio Perego) as well as to the direction of MINNE ("adaptation" by Jacques de Baroncelli) and LA FLAMME CACHÉE (co-directed by Roger Lion). ${ }^{280}$ For the latter claims, I have found no support in the contemporary press, advertisements, reviews, or articles from Musidora's own pen published at the time. ${ }^{281}$ If Musidora actually contributed to the scripts and the direction, then, she did not go public with the fact-or, more precisely, not yet, because she would do so with the film she wrote, produced, and directed in 1919 and was released three weeks after LA FLAMME CACHÉE in the spring of 1920, VICENTA. ${ }^{282}$ Handled by the same distributor, Union-Éclair, these two films were advertised together, whereby Musidora was listed as the director of VICENTA but not of LA FLAMME CACHÉE. ${ }^{283}$ The latter film was solely announced as an "unpublished dramatic plot by Colette", ${ }^{284}$ perhaps out of reverence for the well-known writer turned scenarist. One of the few other French women filmmakers making her debut in 
those years was Germaine Dulac, and right from her first film released in 1917, she insisted on claiming production, scenario, and direction credits. ${ }^{285} \mathrm{As}$ is widely known, Dulac further underpinned her position as a filmmaker with theoretical texts. ${ }^{286}$ The analogy with Musidora fails insofar as Dulac had been a journalist before venturing into film direction, not an actress; neither did she act in her own productions. It may nonetheless be concluded, that, until 1919, acting meant more to Musidora than anything else she did in film. Even after having proclaimed the direction of VICENTA, Musidora presented herself first and foremost as an actress. Echoing Colette's title "A Short Manual for the Aspiring Scenario Writer" published in 1918 in Filma, Musidora wrote for the same periodical two years later her "Petit cours à l'usage de ceux qui voudraient devenir vedette de cinema" (Little manual for the Aspiring Vedette of Cinema), ${ }^{287}$ the topic of which I shall discuss in due course. Here, I refer to it to point out that Musidora in her 1916-1918 films and writings most productively 238 sought the collaboration of the noted novelist and essayist on music-hall and cinema, Colette, and that she therewith affiliated herself with the invigorating views on cinema advocated by her friend that were adopted and debated by the new generation of French film critics and filmmakers. This is the reason why Colette's experience and thought figures again in this portion of Musidora's careerography.

Colette's first known article on cinema appeared in the newspaper Le Matin on March 19, 1914, and, from May to July 1917, she wrote for Le Film. ${ }^{288}$ In her reviews and comments, she argued against vaudeville plot constructions, grotesque imbroglios, improper studio settings, cheap and inaccurate costumes, and dramatic overacting, of which she saw too much to her taste, especially in French and Italian films. Although she, to my mind, paints a bit of a caricature of French cinema of the time, her observations abound with knowing wit and genuine enthusiasm for new forms of cinematic representation. The position she spoke from was that of the guileless but perceptive spectator, who brings to mind the sincere but acute public of pre-war music-hall and revue described by Laloy and Curnonsky. Colette demanded from cinema "spectacle, marvels, incontestable miracles" ${ }^{289}$ In the third year of the war, which had deprived music-hall and revue of its main assets, she asked: "What is left for the public? Where can it bath itself in decorative illusion, adventure and romance, high life, society, inexhaustible splendor? At the cinema." ${ }^{290}$ In Colette's view, American films, and a few French ones, promised new and enthralling forms of cinematic representation, of which her successor at Le Film, the former music-hall critic Louis Delluc, became one of the most prominent spokesmen, and, which, in film history and theory, is known under the tag of photogénie. ${ }^{291}$

In the fall of 1917, Colette published her impressions on the shooting of LA VAGABONDE, the film based on her 1910 novel that starred Musidora and 
was directed by Eugenio Perego for Film d'Arte Italiana (Pathé Italy). The title of the article, "L'Envers du Cinéma" (The Seamy Side of the Cinema), brings to mind Colette's 1913 collection of sketches L'Envers du Music-Hall, therewith promising another keen and compassionate observation of performance and performers on the film set. Her astute bystander's view, moreover, obviously drew from her experience as an actress. In the article on the shooting of LA VAGABONDE, Colette discusses Musidora's relation to the camera in photogenic terms:

There is nothing whiter than her white, powdered face, unless it is her naked arms, her bare neck, the white of her eyes. Every time I look at her eyes my memory whispers to me the phrase of Charles-Louis-Philippe: "She had eyes of great expanse..." Black, her hair; black her eyelashes; her dark mouth is open over her white teeth-she is already just like her cinematic image, and the professionals of Italy and France will compliment her to you in a manner that permits of no reply: "Anything more photogenic than her you couldn't find!" ${ }^{292}$

As with music-hall actors, Colette notices the features brought to the image by the actress' disposition, but, beyond them, depicts the skills and command required to achieve the quality of photogénie in film. It was not enough to apply whitening powder and blackening lipstick, she argues. The necessary skills included adaptability to the most austere circumstances on outdoor locations and a stoic tolerance of the heat under the glass-top studio, supplemented with astute reflection and utter concentration:

They film. They film "fillers", "transitions" [...] which, placed like ingenious sutures between the important scenes, will give the audience the illusion of truth, of real life, of ubiquity... Attentive to the director's instructions, the beautiful black-and-white young woman sways into the magnificent light at 3 P.M. "You come in here, you go out there, in between you stop a moment and listen uneasily to see if your husband's following you." She listens, reflects, poses this Sibylline question: "How much?" "Six feet, maybe seven..." A hermetic dialogue, in which the initiated can understand that this "transition" must be acted at a pace that will allow it to be captured on at most seven feet of film. ${ }^{293}$

After the director had called it a day, the vedette was given an additional task:

“Basta per oggi! È finito! È finito!” Nevertheless, as the adolescent cries of joy of the released resound, the director detains the photogenic young 
woman, who is listening to the program for tomorrow: "Tomorrow, little one, we're filming at Nemi and the car leaves at 8 A.M. Bring the costume for the flight, the dress for the garden, the evening dress with the coat, all the accessories. Don't forget anything, all right? Nemi isn't just around the corner...." She listens in hopeless submission, nods "yes, yes" and recites in a low voice the litany of her baggage: "The pink dress, the grey stockings, the doeskin slippers, the black tulle robe, the violet coat, the white gloves, the diadem, the kimono, the furred mules, the blue suit..." And as if until this minute, by an effort of will, she had been in command of nature, she suddenly begins to sweat freely and goes off toward her dressing room reciting her psalms: "The violet coat, the blue suit (etc.)..." 294

If I quote Colette's text at length, it is not simply for the intensity of her 240 account, but also to underscore her insistence on the actress' command of her pro-filmic appearance and performance. Rather than about acting in terms of expression, she writes about presence before the camera based on adaptability, concentration, and insight. The issue of the right attire, moreover, was one of Colette's favorite topics and, for her, a sign of the "luxury, magnificence, fantasy" spent on the mise-en-scène. This focus complies with the assumption undergirding the conception of photogénie, as Richard Abel has summarized it, that the "real" was a prerequisite of film representation and signification. ${ }^{295}$ "But it also assumed", Abel cautions, "that the 'real' was transformed by the camera/screen, which, without eliminating that realness, changed it into something radically new." According to Colette' observation, then, the actress prepared for that transformation in that she already resembled her cinematic image, which Musidora accomplished in every regard.

\section{Musidora Speaking about Acting in LA VAGABONDE}

Musidora, in a self-presentation in Le Film, detailed her acting work from her own experience:

And all the same, how difficult it is to really comprehend that complex art. To know how to "think" even only a little slop. To have "fifteen metres" of fear and "twenty metres" of tears; to withdraw into oneself to the point of no longer seeing the cranking machine, nor the cruel light which burns the pupils and yellows the cornea; to truly merge into a painted backdrop if you are summoned to "act as if you are leaning, the wall moves, please bend over without disappearing from the field [of 
vision of the camera]..." How difficult it is to barely use make-up, on the cheeks, the lips and the eyes, to discern which hairdo will be fine, the dress that will not become too outdated. And how much one has to train one's memory for the thousand details of one's outfit that will return in the course of a film. ${ }^{296}$

More specifically on LA VAGABONDE, she contended:

I have attempted to render my whole heart, my whole thought in my face, very much like the Roman sun did cast transparent, even translucent shadows all over the white canopy under the glass roof. ${ }^{297}$

What Musidora is saying here, it seems to me, is how "being already like her cinematic image" was achieved. Louis Delluc corroborated Colette's impressions after having seen the film:

LA VAGABONDE gives us Musidora back; Miss Musidora has been popular since JUDEX. But she was sincere before that and had a very interesting visual grace, which had been noticed at the Cigale, at the Châtelet and elsewhere. Since, she has appeared little on the stage. Too bad for the stage. But she has filmed a lot. Nonetheless, this is the first time that I see her on screen in a proper role. Let us hope that this will just be the first of a nice series. And that this artiste with the beautiful face, with the remarkable immobility, with the exquisite spirit, will not be condemned to cat burglars and other phenomena of the popular cinema. She deserves better than that. Much better. ${ }^{298}$

Also according to Delluc, then, an actor was good when she or he was sincere, herself in beauty and spirit, and, as Colette had measured Hayakawa, "immobile" in front of the camera. What counted was her character, her taste, and her intelligence, in short, her personality. When Musidora articulated her own conception of photogénie for actors in her "Petit Cours...", she defined it along the same lines:

To have a face that is "photogenic", a word created on behalf of the screen, means a face that comes across well on a picture. It may be round, bony, unpleasant or friendly, as the role requires; but it has to surpass ordinariness, or to be that ordinary that it comprises an entire race, an entire people, an entire personality. ${ }^{299}$ 
Among the types beyond ordinariness, she listed stars also figuring in Colette's and Delluc's pantheon: Sessue Hayakawa, William Hart as Rio Jim and Charlie Chaplin, describing them as "those we had not imagined and who have 'invented' and imposed themselves only through their personality." ${ }^{00}$ The ordinary or prototypical kind of star, on the other hand, was epitomized by Douglas Fairbanks and Pearl White:

Pearl White epitomizes the beautiful American girl. [...] all youngsters who imagine an American adventure heroine, imagine her with Pearl's face. Therefore ordinariness by absence of personality, but perfection and complete reunion of all perfections. The perfect being loses its personality because it is the ideal of an entire world. ${ }^{301}$

Like Colette and Delluc, Musidora considered the stars' silhouettes, as she 242 called them in café-concert idiom, to be created from features the actors possessed already. Drawing from their acting experience, moreover, both Colette and Musidora pointed out that such features required handling in front of the camera. The vedette achieved photogénie through gearing her or his personal appearance to being photographed by, what Musidora called the "docile camera", and what Abel has denoted as "the impassive camera's eye", even though it was entitled to discover "the new within the already given." ${ }^{02}$ The person conditioning the photogenic, in Colette's and Musidora's views, was the featured actress or actor, not the cameraman or the director. "I considered the cinematographer an instrument just like the camera and the tripod," Musidora would claim in retrospect. ${ }^{303}$ This importance accredited to the actor may be at the heart of Musidora's aloofness in publicly claiming the co-writing of the scenario or co-direction of the films in which she acted, in these as well as in subsequent years.

Musidora obviously consented and was pleased that influential critics like Colette and Delluc depicted her work in terms of photogénie, as it probably gave her parts and films an allure of promise and progress in comparison to her anterior oeuvre. As I will illustrate in my discussions of the films she subsequently produced, co-directed, and starred in, she also adopted some of the criteria relating to mise-en-scène as advanced by Colette and shared by the post-war generation of filmmakers. This notwithstanding, it would be a misrepresentation to frame Musidora as fully adept of the "school" of photogénie, as there are also signs that she retreated from its requirements. A closer look at how she did, may further illuminate her views on and aspirations with screen acting and filmmaking.

A sign that Musidora indeed questioned photogénie is a photograph published in Delluc's newly established film periodical Cinéa in July 1921, which, 


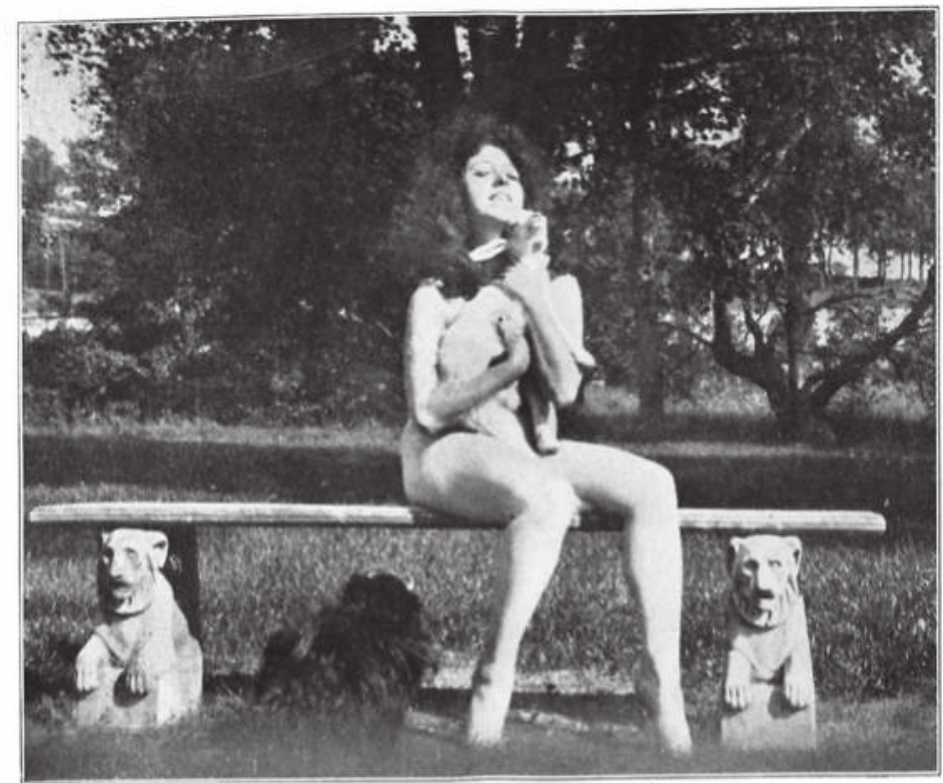

X faut être "Thotogémique des hieds a la tite.

A pres c,a il est permis d'avovi du talent.

$$
\text { Musidora }
$$


in its timing and placement, may be read as the conclusion of and full stop behind Musidora's public statements on the topic. ${ }^{304}$ Whereas her articles had been frank, pensive, and supportive, this photograph and its caption in her handwriting was bold, witty, and subversive. It shows Musidora seated on a stone bench in a park. She is naked, the picture is taken from a slightly low and left angle and displays her bare legs and arms from the side, while she covers her belly, breasts, and neck with a a lamb she holds in her arms. Her chin is just above the lamb's head, her head leans back, her eyelids are almost closed, yet she glances down into the lens through her eyelashes. A small black dog low in the frame stands with its back to the camera looking at her with the lamb in her arms; two stone lions that form the legs of the bench, face the camera. The handwritten caption reads in English translation: "It is imperative to be 'photogenic' from top to toe. After that, it is permitted to have talent. Musidora." 305

244 The photograph undercuts the weightiness of the appraisal implied in photogénie in a number of ways. Through Musidora's nudity, it visually links photogénie to the tradition académique, and thereby suggests that there is little new under the sun (also literally: the picture was taken in the sun). As she posed in the nude, (she put her feet in a pose that displayed her toes spread out), the picture even seems to say that photogénie is stripping the actress more bare than the culte du maillot did. The dog in the lower frame looks up at her as if to caution: take care!, ${ }^{306}$ and the solid stony lions enhance the protectiveness of the animals with their guarding poses. Musidora looks down at the camera through her eyelashes, and thereby acknowledges its presence. She covers her body's feminine signs with the emblem of virtuousness (the lamb) and thus suggests the camera's gaze to be impertinent. The knowing smile on her lips indicates that she does not take impertinent gazes for granted. Perhaps it also says that she has experienced the camera to be far less docile than she used to believe, and that what its gaze discovered in Iwas less new than expected. Musidora's handwritten text, finally, can be read as an ironic overstatement exposing the effacement of talent inherent in the overexposure of beauty and personality in the concept of photogénie. In other words, Musidora wittily and subtly told Delluc and company that she wished to distance herself from the concept as it was applied to her acting and rather to judge her for her talents and skills than for her femininity and looks.

Musidora also subtly countered Delluc's assessments of Feuillade's serials as facile and her roles in them as improper to her caliber. Delluc's remarks in this regard were part of his crusade against the still prolific and successful Gaumont filmmaker, whom he blamed for wasting his and his actors' talents on "serialised abominations" ${ }^{307}$ Or, rather, as Delluc specified two years later, his crusade against the genre of serial films, which he admitted not to under- 
stand at all and considered formulaic products and insults against the art of film he sought. ${ }^{308}$ Delluc was, as I have pointed out, by far not the only critic who deplored the serial vogue on artistic grounds. Musidora countered the critique on serials indirectly but consistently in her texts, through obstinately mentioning LES VAMPIRES and JUDEX for having given her pleasure and fame, while additionally expressing her esteem for Feuillade, as with these lines concluding her notes on LA VAGABONDE:

Before finishing, I'd like to thank Mr. Feuillade, whose tremendous fantasy has created LES VAMPIRES. It was so much fun working with him, that I cannot forget the man to whom I owe, a bit, what I am. Musidora. ${ }^{309}$

On another occasion, she hinted at her understanding of differences in the reception of the series by different audiences: "And I will always be grateful to Mr. Feuillade for having entrusted to me an Irma Vep who has made me famous in the world of the 'suburban street urchins' and even beyond." ${ }^{10}$ In a 1921 interview, she called Feuillade "my great friend [...], because thanks to him I could leave (Gaumont) without being troubled by all my crimes." ${ }^{111}$ In other words, thanks to Feuillade's fantasy, Irma Vep's and Diana Monti's criminal acts were not to be taken seriously. Also, in later years, Musidora would not forget to pay tribute to the filmmaker. Against the background of the repeated calls upon Feuillade to turn to something more elevated than crime series, Musidora's recurrent tributes can be read as not only expressions of gratitude and loyalty to the filmmaker who had offered her the status of a film star, but also as subtle acts of revolt against the denigration of the genre.

\section{MUSIDORA WRITING, DIRECTING, ACTING AND PRODUCING FILMS 1919-1924}

In December 1919, Filma casually stated in its section "On dit que..." (Rumor has it that...): "Musidora has founded a production company of which she will be at once the author, the director and the star actress." ${ }^{12}$ It is the only reference to the establishment of Film Musidora, or Les Films Musidora, as the company would be indicated in advertisements, that I have come across in the film periodicals that I have scrutinized. ${ }^{313}$ Musidora herself, apparently, had not made public the establishment of her own film production company, although it must have been incorporated several months earlier, before the shooting of VICENTA, which, according to Lacassin, had taken place in August and September of 1919. ${ }^{314}$ As noted above, however, Musidora claimed the scenario and direction credits for the film in the publicity and the distributor, Union-Éclair, advertized it accordingly. 
Comoedia Illustré published in February 1920 a personal statement from Musidora on her concerns with the scenario and the film. The term photogénie does not occur in it, not even with regard to the beauty of the scenery surrounding the location, an attractive chateau "dusty with legend" that was situated in the Basque Pyrenees, where the story was largely set and the film was shot. ${ }^{315}$ Musidora nonetheless mentioned a masquerade party, for which she had obtained eighteenth-century Venetian costumes and white masks. While the on-location shooting, the choice of extant settings and the attention to details of costume and luxury in the mise-en-scène invoked ideals of photogenic cinema, these ideals do not resonate in Musidora's discussion of the acting, the story, or the female protagonist.

In the article, Musidora does not talk about her own acting, but articulates 246 | praise for her co-actors: Jean Guitry for creating a multifaceted character that is "at once prodigious, oblique and friendly" and Ginette Chrysias for acting her American character "with so much truth that, when she says 'oui' on the screen, you'll be convinced that she said 'yes'." ${ }^{116}$ If Musidora-the-director expected a degree of "truth" from her actors, she emphasized that this was achieved in the acting: "Guitry has some very specific gestures that delight me and that will make an entire personality." ${ }^{17}$ In other words, she emphasized the work the actors' had to do, instead of its effacement before the camera.

In one of the rare reviews of VICENTA in French film periodicals, Musidora was reproached for having sacrificed her own acting to her direction:

I am surprised to notice, that Musidora, in the role that she has constructed for herself, only modestly has employed herself. Musidora the director does not favor Musidora the artiste. More than that, she sacrifices herself. I would reproach her, for instance, for not bringing out the photogenic qualities of the pretty woman she is. ${ }^{318}$

The evaluation is interesting, because if Musidora indeed sacrificed her photogenic qualities, she may have been prompted to it by something other than modesty. That is to say, perhaps she had been searching for alternatives for the disregard for her acting talents that the concept of photogénie seemed to entail for her, as my interpretation reads of the picture discussed above (which, moreover, was published between the release of VICENTA and Musidora's next production). Colette, in a letter to Musidora after having watched her in Hugon's JOHANNÈs, FILS DE JOHANNÈs, intimated already that capturing prettiness and using talent were not the same thing: 
You have a range of incomparable faces, in close-up, those in the circus in particular. Your features are beautiful, your expressions are subtle and focussed. One cannot do better. The film itself, in which you are very good (even though no one has considered to infer from you and from the character you enact only a quarter of the necessary effect), has a ridiculous ending, entre nous. [...] You are also very pretty in the little episode of the "sergeant" with the billet. That's about all I can say. But it seems to me-which may be pure pride on my part-while knowing you as I do and well aware of the assets of your face and your gesture, it seems to me that, just through simple advices, through fully unselfish observations, I would contribute, when the occasion arises, to a maximum effect which no one so far has inferred from you... ${ }^{319}$

Rather than modesty, the search for this maximum effect, even if it failed, may have been Musidora's very motivation in abstaining from highlighting her prettiness in VICENTA.

VICENTA told a romantic adventure story with a female protagonist. Although Musidora called her heroine courageous, she also depicted her as a contradictory character:

Vicenta is kind of a heroine. She loves only pleasure. She prefers the modern civilisation of our grand Paris over the healthy security of the Basque country. [...] But the day on which our way of understanding life will crush her heart, she will ask her Basque Country the simple act of devotion, namely revenge. ${ }^{320}$

According to the brief plot summary offered by Lacassin, the heroine asks the lover from her youth in Basque Country to kill the prince who, in the dangerous Paris, has seduced her but has rejected her for a rich American woman. ${ }^{321}$ No print of the film is known to survive, and I have not come across a more elaborate synopsis of the story, so it is difficult to know how the character dealt with the dilemmas with which Musidora-the-scenarist confronted her. The lack of print and documentation is all the more regrettable, because the contradictions involved sound quite intriguing: modern (urban) mores versus traditional (provincial) protection, (masculine) opportunism versus selfsacrifice, a woman's thirst for pleasure versus her call for revenge once that pleasure turns against her. In addition, the film was made after one of the few original scenarios by Musidora and the character of Vicenta was less obviously modelled on herself than the protagonist of the other original scenario she filmed, LA TERRE DES TAUREAUX (The Land of the Bulls), which I shall discuss later. Nonetheless, story and characters seem to have mattered to Musidora. 


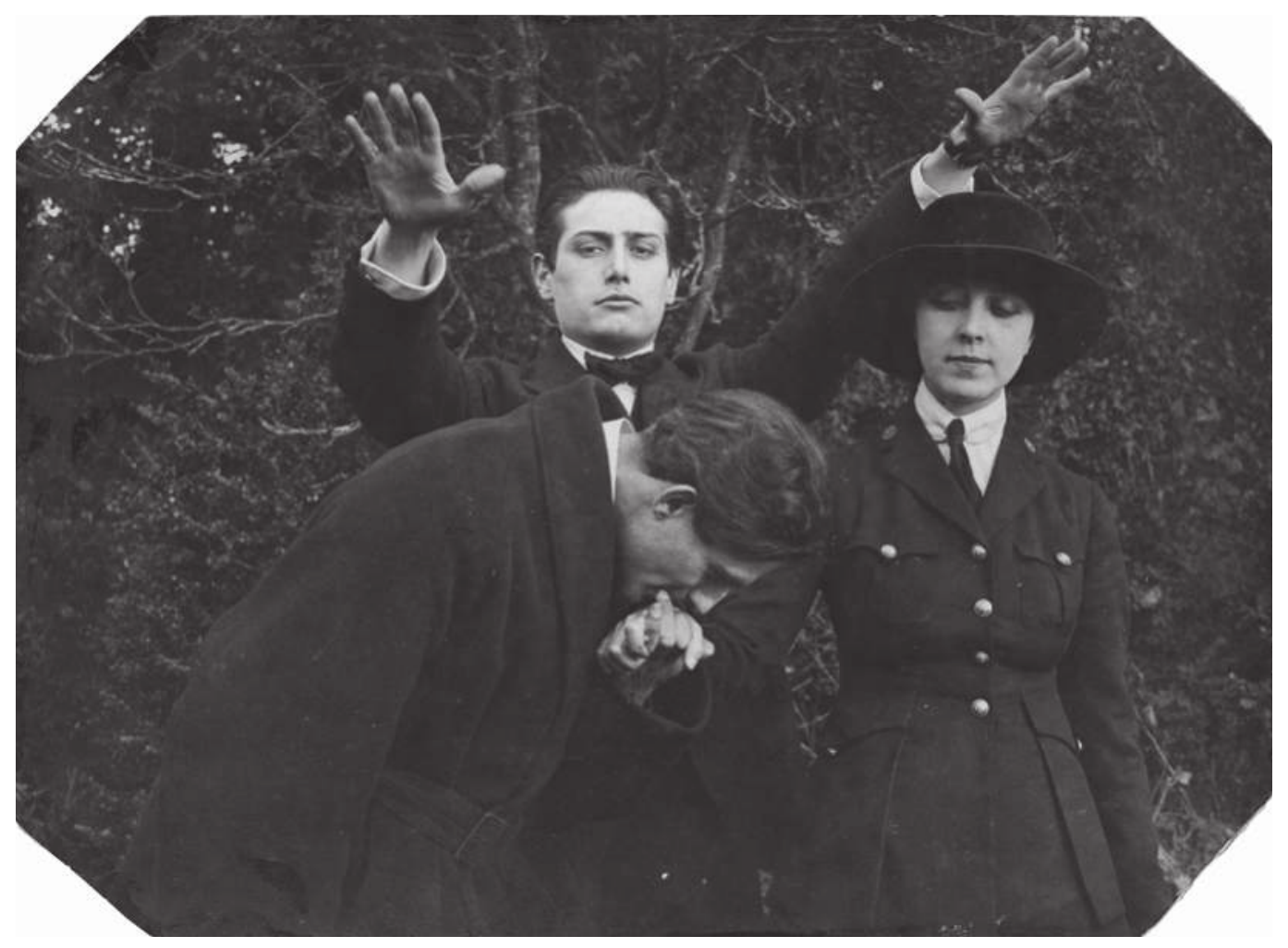

Fig. II.22: Musidora with Lagrenée and Younel in LA FLAMME CACHÉE. Still.

In Le Film, Musidora depicted Vicenta as one of her "méchante femme" (bad women) figures, in which she included the Feuillade serials as well as LA FLAMME CACHÉE:

For that reason, Colette has written LA FLAMME CACHÉE, in which I do not have the most pleasant attitude. For that reason, in my next film VICENTA I exploit a poor man in love and committed to the point of selfabnegation, in order to dispose of the man who failed to keep his word..$^{322}$

The question is to what extent the contradictory nature of the character of Vicenta can be reduced to “badness”. Irma Vep's scheming and killing indeed emanates from sheer viciousness, but even if Annie Morin, the protagonist of LA FLAMME CACHÉE, seems to act out of cool calculation, she seems driven by an understandable self-righteousness. ${ }^{323}$ Musidora's protagonist seems to have been provided with an emotional justification for her mean actions: her broken heart. The fact that, as Lacassin has noted, in the contemporary press the badness of character was not subjected to moral judgment, may also 
point to such a motivation. That is to say, as far as the film was reviewed at all. ${ }^{324}$ If, as Musidora suggested, her protagonist had something in common with Colette's, it seems non-conformist self-righteousness rather than plain viciousness.

On the basis of the scarce documentation on VICENTA, it is my assumption that Musidora as a producer-director aspired to integrate some of the ideals of photogenic cinema, most notably, those of mise-en-scène, and the role of the camera, with a popular story and its subject matter of adventure and romance, and a non-conformist female protagonist. However tentative this conclusion may be, it can be further substantiated with what Musidora said about and did in her next film, POUR DON CARLOS (For Don Carlos). ${ }^{325}$

\section{POUR DON CARLOS (1921)}

In the spring of 1919, during the preparations for shooting VICENTA, Musidora secured from the best-selling writer Pierre Benoit the film rights of the novel he was currently writing. ${ }^{326}$ She was well aware that Benoit's award-winning novel published that year, L'Atlantide, was being adapted to the screen by one of her former directors at Gaumont, Jacques Feyder, although the film's phenomenal and exceptional box-office success were yet to come. ${ }^{327}$ Benoit was writing his third "roman d'amour et d'aventures géographiques" (romance and geographical adventure novel), Pour Don Carlos. ${ }^{328}$ The genre, setting, and heroine of the novel were so similar to those of the scenario that Musidora had previously fashioned for herself, that it seemed to have been written for her. One similarity concerns the geographical setting, the Basque Pyrenees region; another, the protagonist of the adventurous woman, or, in Musidora's "bad woman" characterization:

And I definitely promise you that Allégria will kill at least one person and will let suffer quite a few others. [...] With a keen eye, I will continue scheming atrocious plots, in which I determine the hour of the rendezvous, the method of attacking, the kind of death and... of course I will reserve for myself the right to escape. ${ }^{329}$

Like Colette's Annie Morin and Musidora's own Vicenta, Benoit's Allégria was rather non-conformist than plainly vicious. A fantasy figure all the same, her scheming and killing was justified by a historical cause: the 1873-1876 guerrilla in favor of the claimant to the Spanish throne, Carlos de Bourbon-Molina. The fictional character of Allégria Detchart was a Carlist commander, whose non-conformist actions were motivated by the struggle against the French and 
Spanish armies, and by love. The contemporary press classified the character as a "peculiar type" $33^{30}$ and a heroine with "a quite passionate temperament and $[. .$.$] not the model of all virtues." { }^{331}$ Despite the ambivalence resonating in these assessments, Allégria was considered a gripping character because of her devotion and her peculiarity.

Reviewers critical of Benoit's writing blamed the novel for historical inaccuracies and improbabilities in character constructions. This criticism is reminiscent of the improbabilities and machinations for which Feuillade's serials were reproached. Thirty years later, the Belgian poet, novelist, and literary and film scholar, Johan Daisne, drew attention to the generic connection between the work of Benoit and that of Feuillade. In his eulogy on JUDEx, Daisne put Feuillade's serial on one line with Benoit's novels and pointed out that their adventure plots offered a realist diegetic universe, yet appealed to fantasy in terms of events and characters. ${ }^{332}$ To render plausible the improbabilities in 250 | the plots, Daisne argued, writers of adventure stories had to be masters of narration and of imagination. It seems to me that Musidora recognized that quality in Benoit's work as she had done in Feuillade's serials.

Critics favorable of Benoit's book praised it for its truthfulness in particular:

That task [of bringing Don Carlos back to the throne], which has been treated by the novel with high impartiality and which was inspired by the cult of truthfulness, at times reaches a powerful lyricism, the magnificent result of a thorough study, of documentation and historical discovery. The works of Pierre Benoit possess, in addition to various other merits, that of documentary sincerity, which is a prelude for literary sincerity, and both are illuminated by the eternal truth which revives and enlightens the pure conscience of the novelist. ${ }^{333}$

From what Musidora has told about the shooting of POUR DON CARLOS, it seems that she and Benoit fully agreed on the indispensability of truthfulness of the images and plausibility of the diegetic universe. As an extra guarantee, Benoit insisted on the involvement of someone familiar with the Carlist movement and the Basque Country, for which he appointed the same person who had provided him with the necessary documentation for the story, Don Carlos' own son, Jaime de Bourbon, also known as de Lasuen, who, for the film's credits, took on the nom de plume Jacques Lasseyne. ${ }^{334}$ Proudly, Musidora declared:

POUR DON CARLOS will be a bit like L'ARLÉSIENNE (The Woman from Arles), Don Carlos will not be visible on screen, or barely, but there will 
be the splendid and unknown Carlist country, the wild Jaizkibel. That entire, essentially peasant war in the middle of the huge mountains and the small farms, with the most docile, the most sincere and the most poignant extras; extras who are still unaware of the cinema, and who pass by in an "exodus" from the village with the same donkey as in 1875. A touching old woman, aided by a kid, had prepared her cart on her own. She remembers the war so well. Nothing was missing, not the old Basque chest, not the cat in the cage, not the donkey, not the peppers and the onions hidden in the folded mattresses. ${ }^{335}$

It is significant that Musidora invokes as her model not L'ATLANTIDE, but L'ARLÉSIENNE, a film made by theater and film director André Antoine, who was known for having introduced amateur actors and naturalist aesthetics to the stage. Between 1915 and 1921, Antoine directed eight films ${ }^{336}$ in which he translated to film his ideas on how to create realism, thereby emphasizing the differences between the techniques involved in the two modes of representation. ${ }^{337}$ He shared with the champions of photogénie the pursuit of a selfevident and self-effacing style of cinematic representation, but had different views on how to achieve it. Not all of Antoine's ideas, but some of them seem to have inspired Musidora's approach to the direction and shooting of POUR DON CARLOS.

For instance, Antoine not only advocated the use of extant locations for sets, but also the inclusion of local inhabitants for small roles. ${ }^{33^{8}}$ This principle resonates in Musidora's inclusion of locals as extras. Also, Antoine insisted on the employment of stage actors for the main parts, among whom, in L'ARLÉSIENNE, a nude dancer from the Casino de Paris, Marthe Fabris. ${ }^{339}$ Musidora likewise assigned stage actors to the cast of POUR DON CARLOS, including Lucien Guitry and Abel Tarride. Following Antoine's admonishment to employ multiple camera sets in order to film actors and occurrences in their aspects unawares, Musidora also hired two cinematographers, Frank Daniau-Johnston and Crouan. ${ }^{340}$

One of the main differences between Delluc and Antoine concerned the importance of subject matter. ${ }^{341}$ Antoine did not prefer original scenarios, but, in seven out of his eight films, chose nineteenth-century realist or naturalist fiction, such as, for L'ARLÉSIENNE, the novel by Alphonse Daudet, which, like Benoit's, mixed naturalism with fantasy. ${ }^{342}$ This choice earned him the reprimand from Delluc that the plots were too convoluted and too romantic compared with the pictorial quality he brought to his films. ${ }^{343}$ However, such stories, according to Abel's paraphrasing of Antoine, "would allow the narrative cinema to represent life 'as it really was,' to hold up a window or mirror for the spectator." ${ }^{344}$ The idea to represent "life as it really was" echoes Benoit's 
"historical" approach and Musidora's care for the accurracy and authenticity of extras and props. The idea of opening a window for the spectator, moreover, reverberates in a rhetorical question with which Musidora concludes her account of how she shot POUR DON CARLOS: "Nonetheless, is it not an advantage, for each country, to inform the entire world of the marvels of its architecture and its landscapes?" 345 This question additionally invokes the final rapport that links Musidora's films to Antoine's views: the role of regions and landscapes. Like POUR DON CARLOS, L'ARLÉSIENNE was set in one of the southern regions of France, the Camargue. ${ }^{346}$ POUR DON CARLOS is also akin to L'ARLÉSIENNE in the way in which the camera approaches the landscapes, although Antoine's film much more graphically and extensively depicts daily life in a rural area. With a few exceptions, action and dialogue take place in the open air and the film abounds with scenic shots and scenes with domestic animals such as sheep, goats, horses, bulls, and chicken. These shots add to the

252 fatalism of the romance a flavor of inevitability: it has always been like this and will always be like this. In Musidora's film, the landscape, animals, and locals are likewise framed, lighted, and graphically organized in such a way that they convey atmosphere: "The dead horses, the pools of blood, the blue flies will contribute their own bits of emotion and will be playing along with the groups of houses in fire and with all the great actors." ${ }^{347}$ Although it is difficult to say from the documentation available if these effects were the work of Musidora herself, her cameramen Frank Daniau-Johnston and Crouan, or even Jacques Lasseyne, they seem nonetheless to have met with her directorial aspirations with this film.

If this was the conceptual background chosen by Musidora, Delluc's opinion on POUR DON CARLOS does not come as a surprise:

Pierre Benoit's novel accumulates so many themes, characters and dramatic or adventurous themes, that the director, in order not to let anything escape, first had to construct a film of exaggerated proportions. Intelligent revisions have lightened and improved this profuse film and made it more common and accessible. Not everything in it is convincing. But some passages are of a remarkable photogénie. The feeling of the camera for the landscape is particularly striking. Which is rarer than you may think. Musidora has been able to adapt to her qualities an eminent role that the novelist, doubtlessly on purpose, had left somewhat vague. She expresses in it a sense of simplicity, which we appreciate, and her death, which is modest and balanced, is a beautiful page on which we can hear the sigh of the sea. ${ }^{348}$ 
Because of the conceit in Delluc's tone, one wonders if he himself had been involved in the "intelligent revisions" that had simplified the film's plot and shortened the print with one-fifth of its, probably, original 2400 metres. ${ }^{349}$ At any rate, André de Reusse of Hebdo-Film also considered the new cut an improvement.

For this book, I viewed on the editing table a print of POUR DON CARLOS that was missing 551 of the 2000 meters of which were most likely released. ${ }^{30}$ It lacked opening credits, several titles, and, probably, some shots explaining transitions in space and time between sequences and occasionally shots within them. I have also read an undated typescript of a synopsis with a selection of intertitle texts translated into German, of which, however, it is not clear if it summarizes the initial cut or the shortened one. ${ }^{351} \mathrm{~A}$ comparison of print and synopsis fosters the assumption that the print is missing entire scenes as well, while the order of sequences at times seems to have been mixed or broken. Scenes missing are, for instance, those in which De Preneste avows his enamored feelings for Allégria and his wavering between her and his fiancée to which both the synopsis and some of the reviews refer; the print only contains scenes with De Preneste doubting his fitness for the job and scenes with Allégria trying to control and conceal her desire for him. Also, the synopsis suggests a structuring of the plot in a prologue and eight parts, but, in the print, this structure has not been lived up to or was eradicated at one time or another. According to Musidora, moreover, the opening image of the film, a painting, was accompanied by intertitles representing five stanzas of a song written by Benoit and recounting the history of Allégria Detchart's commitment to the Carlist cause. ${ }^{352}$ These titles were missing from the print, but their placement in the film's opening explains how it was possible to cut that story from the scene in which Allégria tells her history to someone else in the diegesis. In this scene, we see them sit and talk, and Allégria's conclusion is that she has told everything, that her father was a Carlist and that she grew up among the soldiers. In my viewing experience, the state of the print hampered narrative intelligibility, but it seems safe to blame the problem on the lost meters, because none of the reviews published in 1921 criticized the film for that reason; quite the contrary: notes of disapproval expressed concern that it was still a little too long: ${ }^{353}$ But because, as I have argued, story and character mattered to Musidora, I will offer a concise, yet inevitably tentative, plot summary of POUR DON CARLOS.

Allégria Detchart is a commander in the Carlist guerrilla against the army of the Spanish government. The year is 1876, and the Carlists control part of northern Spain. Their struggle is supported by the inhabitants of the area, who adore Allégria as much as her comrades do. This is all unknown to Olivier de Préneste, a young duke from Biarritz, who is about to marry Lucille 

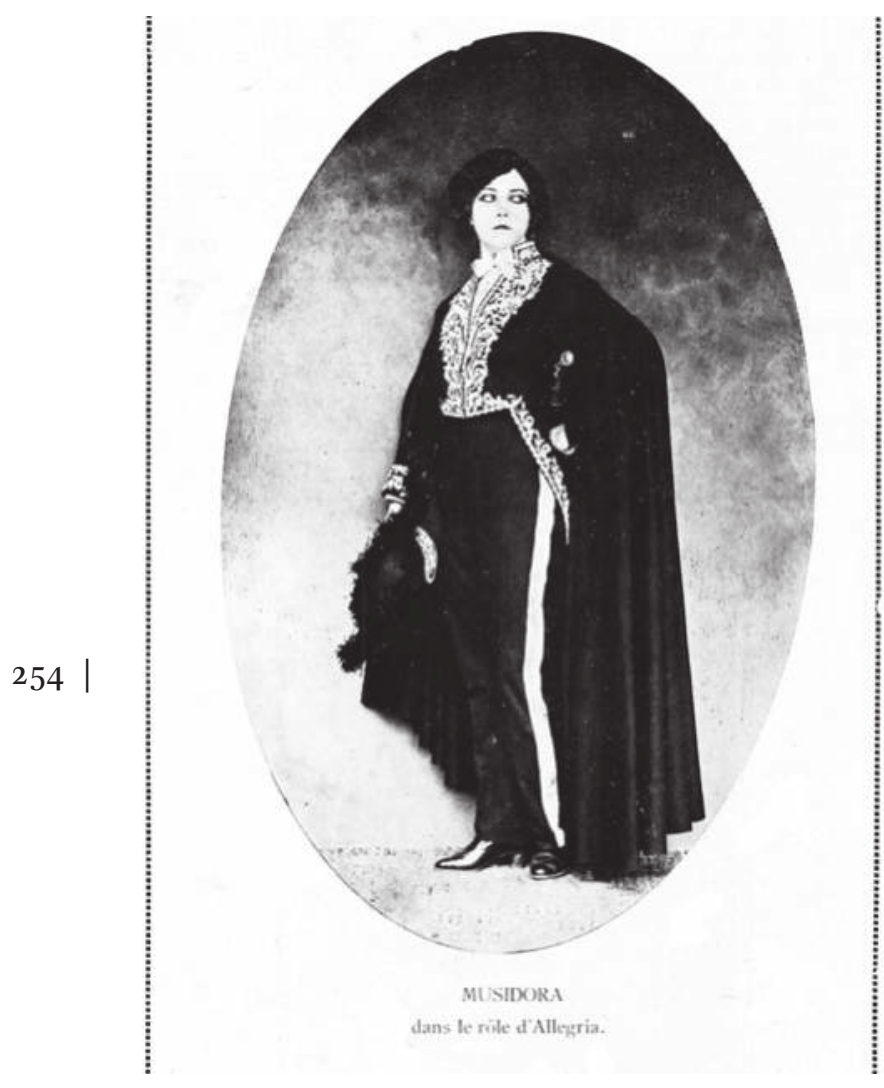

Fig. II.23: Musidora as the Carlist guerilla commander Allégria in POUR DON CARLOS. Cinéa, 16 December 1921, 7.

de Mercoeur and accept the vacant post of sub-prefect in the Basque town of Villeléon. After his arrival, strange things happen until he finds out that his position has been seized by someone else. This person appears to be Allégria Detchart, who, from their first encounter onwards, shows Olivier that he is in her power and who pushes him to join the Carlists. To achieve this, she first convinces Olivier that he will be unable to cope with his task of fighting the Carlists because of the support they enjoy from the locals, and, second, she befriends and wins over Lucille. Olivier, however, not only gives in, but also begins to fall in love with Allégria. Allégria has the same feelings for him, but she hides them for the sake of Lucille.

Then the situation changes. The Carlists begin to lose ground against the Spanish army and the people flee from the town. Several of the Carlists are killed in the battles, and Olivier and the faithful Magnoac are arrested by the royalist French, delivered to the Spanish army, and await their execution. Allégria, who used to visit the battlefields in the company of Lucille, orders 
the young woman to leave and find a safer place. Incognito, Allégria crosses the Spanish border in search for Olivier and Magnoac. At the police station, she is recognized, but nonetheless follows up on her plan to free Olivier. She blackmails an officer and seduces and kills the general after having secured his signature for the release of Olivier.

Allégria and Olivier have fled to a mountaintop and hear the shot with which Magnoac is executed. Exhausted and wounded, they arrive at the house of the old shepherd and loyal, Carlist Pedro, where he and his granddaughter, Conchita, were visited by Don Carlos just two days before. When they learn that there is a price on the fugitives' heads, Allégria orders Pedro to help Olivier escape to Biarritz, where Lucille waits for him. Allégria herself hides in an old pirate castle near the shore and is taken care of by Conchita, but Conchita is followed by a traitor who informs the police. When the police turn up at Allégria's hide-out, Conchita manages to escape, and Allégria shoots the traitor. The police kill Allégria and, while Olivier and Lucille are reunited in Biarritz and trustfully wait for news from Spain, Pedro and Conchita quietly bury Allégria on a ridge by the sea.

Musidora herself repeated one point on which her adaptation deviated from Benoit's novel, the ending, which she had changed with the writer's consent. In the book, Olivier was not reunited with Lucille in Biarritz, nor did Allégria die in Spain, but the women sailed off in a boat to a new destiny:

Olivier de Préneste watching his fiancée Lucille de Mercoeur depart in a close embrace with Allégria Detchart... I have preferred to let Allégria die for the cause of Don Carlos, which in my opinion was more simple, easier to understand. ${ }^{354}$

In the interview for Radio Suisse Romande, Musidora called the ending she had chosen "less Parisian". ${ }^{355}$ The expression implies that the two women embracing would have had a socialite and romantic, probably even libertine connotation, also given the narrative motif that they, in the book as in the film, were in love with one and the same man. I find Musidora's reasoning somewhat peculiar, especially given the fantasy character and the popularity of Benoit's work, and given the fact that a subtext of romantically afflicted women's bonding was a recurrent plot device in the author's novels..$^{356}$ Neither Daisne nor Thévénot clarify what Musidora had meant exactly. (And in case they did ask her, her answer remains off-the-record.) Contemporary reviews, moreover, do not include objections against the novel's ending. One of the reviews of the film, however, hints at what may have been a more plausible reason for the change: 
The melancholic, bitter ending which is one of the best parts of the book, disappears to be replaced by an ordinary and melodramatic conclusion, of which the final tableau - the burying - reminds one, too much, of the ultimate scenes of L'ATLANTIDE. ${ }^{357}$

The comparison lends support to the assumption that Musidora wanted a death scene for herself, as Marie-Louise Iribe had performed, to the highest acclaim, in L'ATLANTIDE. In a letter to Benoit, Musidora graphically recounted how she had created, acted, and directed her interment:

It was a grave like any other, ordinary, simple and moving! A wooden cross. A spade, a rifle, wild flowers. That was all. The shepherd put me down in the cold earth. All of us were moved. I heard the sound of the waves and held my breath. As soon as the cameras had been adjusted, 256 I inhaled a big breath of air while the old shepherd, trembling, began to throw his heaps of ground on me. The ground was heavy, and cold on my imprisoned legs, on my entire stiffened body, of which only the head protruded. And this time, the cameras had to move closer, because I had wanted my face to be covered as my body, so that the impression of getting buried would be genuine. I took another deep breath, and searched for total immobility. And I gave myself the sign: "Action...". The first scoop of ground fell on my chin and cheeks... The second covered my eyes. The third left only the tip of my nose free. The ultimate, heavy and definitive one had forever hidden my face. It was about time! All of this had lasted barely twenty-five seconds, but I suffocated; my mouth ate crunching earth, my ears were stuffed with mud, I kept my eyelashes closed out of fear to fill my eyes with scratching grains of sand. And it was with the word "Damn!..." that I regained my friends, the air, the sun, warmth and life. .35

Simplicity, immobility and truthfulness were the keywords of Musidora's approach, and they resonate in the appraisal from critics that she earned for the death and burial scenes:

her death, which she has brought on to herself when defending herself against the soldiers charged with capturing her; her immediate and unceremonious burial by a Carlist shepherd luckily are more interesting than the rest. Mrs. Musidora has acted the final scene very well—which is difficult. 359 
Boisyvan, in L'Intransigeant, was likewise impressed: “This death has provided us with a moment of dramatic expression which makes Musidora into a very grand artiste. It only lasts for a few metres, but it is unforgettable." ${ }^{600}$ In a letter to her friend, Colette voiced her approval as well:

In the film, you are utterly remarkable. The final part, which is yours, is truly faultless, irreproachable where you are concerned. Austerity, expression, you have it all in there. The part with you in amazon attire is excellent, nothing equals a faithful reconstitution of costume. [...] and did you hear the spontaneity with which your death was applauded? The fading of your eye, the immediate collapse, it matches Hayakawa. ${ }^{361}$

Colette could not have expressed her opinion in more flattering terms. For all the attention the death and burial scenes were given, then, my assumption reads that Musidora was eager to demonstrate that she could infer the maximum effect from her dramatic acting and that this ending served that aim better than Benoit's.

For my discussion of the part of Allégria, and how Musidora shaped and acted the character, I shall select four sequences with a different appearance of the character in each. In the first, she is cross-dressed as the sub-prefect while overpowering De Préneste. In the second, she is in Amazon attire and inspecting the battlefields in the company of Lucille. In the third sequence, we see her in tatters seducing an anti-Carlist general; and, in the fourth, she is, in rustic dress, being shot and buried. I will probe each sequence to the extent to which it lends substance to my observation that Musidora, even if she adopted the requirements of photogenic acting for the burial scene, also gave the character of Allégria an ambiguity and created a complicity with viewers that referred to the act of acting.

The opening sequences of the surviving print present the character of Olivier de Préneste and his perception of diegetic events. The point made in the scenes is that he finds himself in a new situation and that strange things happen: he cannot trust his perception. The trustworthiness of his perception is further put to doubt in his first encounter with Allégria. This doubt concerns two aspects: the sex and the power of the person in front of him. In order to feed that doubt, Musidora renders the dress and demeanor of Allégria incongruous. She is cross-dressed in a pair of trousers and a classy frock with a front richly embroidered in Spanish style, silver on black, but her hairdo and makeup are more ambiguous in terms of gender. She is introduced by a title card "Un étrange sous-prefect" (A strange sub-prefect) that had no relation to a diegetic character, but belonged to an implied narrator who spoke to viewers, yet with a wink. De Préneste's response-he believes that he sees "une amu- 
sante mystification" (an amusing make-believe)—pulls her appearance into a sphere of staging, as if it concerned an act of costuming and play-acting, but her facial expression and gestures counter the play-acting invoked by the costume. While clarifying to De Préneste that he is at her mercy, Allégria's facial expression remains stern and unmoved, her posture straight and authoritative, and she holds her arms crossed in front of her chest. At the moment that he begins to understand and to succumb to her will, she slams the desk with her hand. This is not play-acting, but a clear-cut display of power.

The location is the sub-prefect's office. Allégria stands behind and beside a wooden desk and De Préneste sits opposite her. Another character present in the room is Maypur, a local and a Carlist, who has let in De Préneste, but, instead of welcoming him as his new superior, has neglected him and locked him up in the reception room. Maypur (dressed in striped trousers and with a kerchief on the head, which, given the attention to details of costume, was 258 probably Basque clothing) stands in a corner, watching the interaction, and, after a while, demonstrates his loyalty to Allégria by firing at a bust representing the Spanish authorities. The grit falls on her frock, and she dusts it down with a superior gesture. In the entire sequence, then, Musidora's costume communicates that Allégria acting, but Musidora's acting conveys that she is in character. The implicit reference to popular stage cross-dressing extends the incongruousness between appearance and performance beyond Olivier's perception in the diegesis. While the ambiguity is solved within the diegesis, it lingers on in the perception of viewers.

Allégria's amazon appearances suggest an ambiguity as well, but of a different sort. By the time that we see her in this attire, we know that she has made friends with Lucille, Olivier's sweetheart, and that Lucille is unconditionally devoted to the Carlist cause. ${ }^{362}$ But the Carlist guerrilla is waning and the loyal locals are fleeing. In Lucille's company, Allégria watches the exodus of the locals with contentment and a sense of triumph, as if she considers it her achievement, instead of showing empathy with the people. Both women ride horses, and Allégria wears an austere black amazon costume: tight jacket with stitched loops over a long skirt and a Carlist, or Basque, beret. Both women, moreover, think of Olivier, who is on the battlefield vainly attempting to defend of the positions of the Carlists together with the faithful Magnoac. This is shown in lengthy combat shots edited parallel to the exodus scene. Having reached the battlefield, the women learn from Maypur that there are casualties among the warriors. Maypur admonishes the women to take care and holds Lucille back, but Allégria makes her way to the lines in search of Olivier. In stark contrast to the helpless Lucille, Allégria behaves tough and bossy, one hand on her hip, head straight up, not afraid of anyone, whether low- or highranked. But she does not find Olivier, for whom she searches. 
In a narratively somewhat bizarre scene, Allégria is knocked out by one of the men on the battlefield. ${ }^{363}$ After Allégria has regained her composure, she summons Lucille to leave, because, as she tells her, her role is over. In these sequences, the character of Allégria wavers between, on the one hand, friendliness and indomitability, and, on the other, unscrupulous superiority over others, including Lucille and the locals. The contrast with the credulous and docile Lucille further bolsters Allégria's unscrupulousness. Musidora acts this ambiguity and contrast without batting an eyelid, that is to say, playing both aspects as if completely self-evident and integral to each other. Instead of being solved within the diegesis, this ambiguity in Allégria's character is to a certain extent sustained in consecutive scenes.

Allégria's appearances in rags occur in a new situation. The Carlist battle is practically lost. Both De Préneste and Magnoac are held prisoner by the Spanish police, but Allégria does not know where exactly. She is disguised as a beggar and-dressed in rags and with tousled, fuzzy hair-, roams the countryside searching for them. In a village, the women put her to work because they do not like beggars. After a while, they nonetheless help her to get to the police station, where she is unmasked by a commander straightaway. Wideeyed underneath her bushy hair, she looks contrite; she straightens up, looks at the commander, and asks how his son is doing. He answers that he does not know; she tells him that he is in the Carlists' hands and shows him his son's army badge for evidence that she is not bluffing. The commander sighs and asks her what she wants. She replies that she wants to see the general to set free the French hostages. He tells her, "impossible”, because the French will be executed at four o'clock the next morning. In the medium close-up of Allégria's face in response to this announcement, Musidora employs three different facial expressions. First, she tilts her head and looks aside in fright and fear; next, with her head still slightly to the side, her eyes roll towards the commander and her lips curl in a knowing smile, connoting Allégria's scheming; then, looking straight ahead with a winning and sly glance, Allégria informs the man that his refusal will not do any good to his son. Cut to the commander, sighing again. Cut back to Allégria, same position and framing as before, but now looking to the side in Musidora's trademark sidelong glance. Within the diegesis, it signifies that Allégria has been only pretending contriteness, while all the time scheming and thinking of what to do next.

In the following scene, Allégria obtains from the general the ticket to Olivier's freedom. The price for it, however, she offers point-blank and on her own accord. In exchange for his signature, she offers him her body. She lets the man know through baring one shoulder. In rags and with bushy hair, Musidora makes Allégria look gorgeously seductive and savage; she does not act provocatively or vulgarly, but she is inviting and beguiling. In my opinion, 
this has a twofold function: one within and one beyond the diegesis. Within the diegesis, it motivates her desirability for the general, who cannot resist the offer. Beyond, it seems to evince that Musidora does not rely on the photogenic qualities of her body and face: narratively, as unsympathetic as possible, and dressed and made up as unbecoming as possible, she employs her acting skills to appear beautiful, even in rags, and beguiling without becoming tasteless.

Although Allégria is in the asking position within the diegesis, she is in charge throughout the scene. She communicates her command over the situation with her eyes, through looking to the side, while pretending willingness to the general. It is as if Allégria keeps reminding viewers that she is not doing things simply because she is vicious, but because she has a purpose and a scheme. Nonetheless, she plays the game she has initiated. When the moment arrives, she moves backwards towards the bed, while the general faces and follows her. Her facial expression is seductive, his is excited and leer260 ing. She holds his hand and pulls him as if on a string in a harmoniously choreographed movement. While she lays on her back in the cushions, he turns away to undress. At that moment, she scrunches her face, she moves her hand to her forehead, signifying potential worry to the viewers. With one shoulder bared she continues to exhibit her beauty. Then follows a medium close-up of the leering face of the general approaching her again and a medium close-up of her with an expression between hope and fear, with wide eyes conveying willingness and anguish at the same time. The synopsis contains a caption, "Holophernes", an intertextual reference to the biblical story of Judith and Holofernes, which reads that Judith seduces the enemy general and kills him to save the city of Bethulia. Reviewers, too, mentioned the story and other viewers familiar with it probably understood right away why Allégria was wavering between hope and fear and how the encounter with the general would end. ${ }^{64}$ Musidora's way of acting the scene seems to indirectly address that knowledge among spectators.

From this sequence, the print cuts to a title card reading "Ceux qui veillent" (Those waking), which is followed by a shot of De Préneste and fellow prisoners in a dungeon. Another title card reads "Ceux qui dorment" (Those sleeping) and is followed by, a shot of a dozing guard, and one of Allégria on the desk of the general with her head on her arms. She awakes with a jolt and says “Mon Dieu, j'ai dormi” (My God, I've slept). She seems alone in the room, so she tells herself, or us, or both, what she has been doing. Next, she looks around, takes the note of the general, rings the hand-bell, and, only then, we get to see a shot disclosing what has happened: a long shot shows the bed with the canopy closed and a limp hand protruding from it, dangling above a pool of blood. Like Judith, Allégria has killed the enemy general. The sequence earned praise in contemporary press for its intensity: 


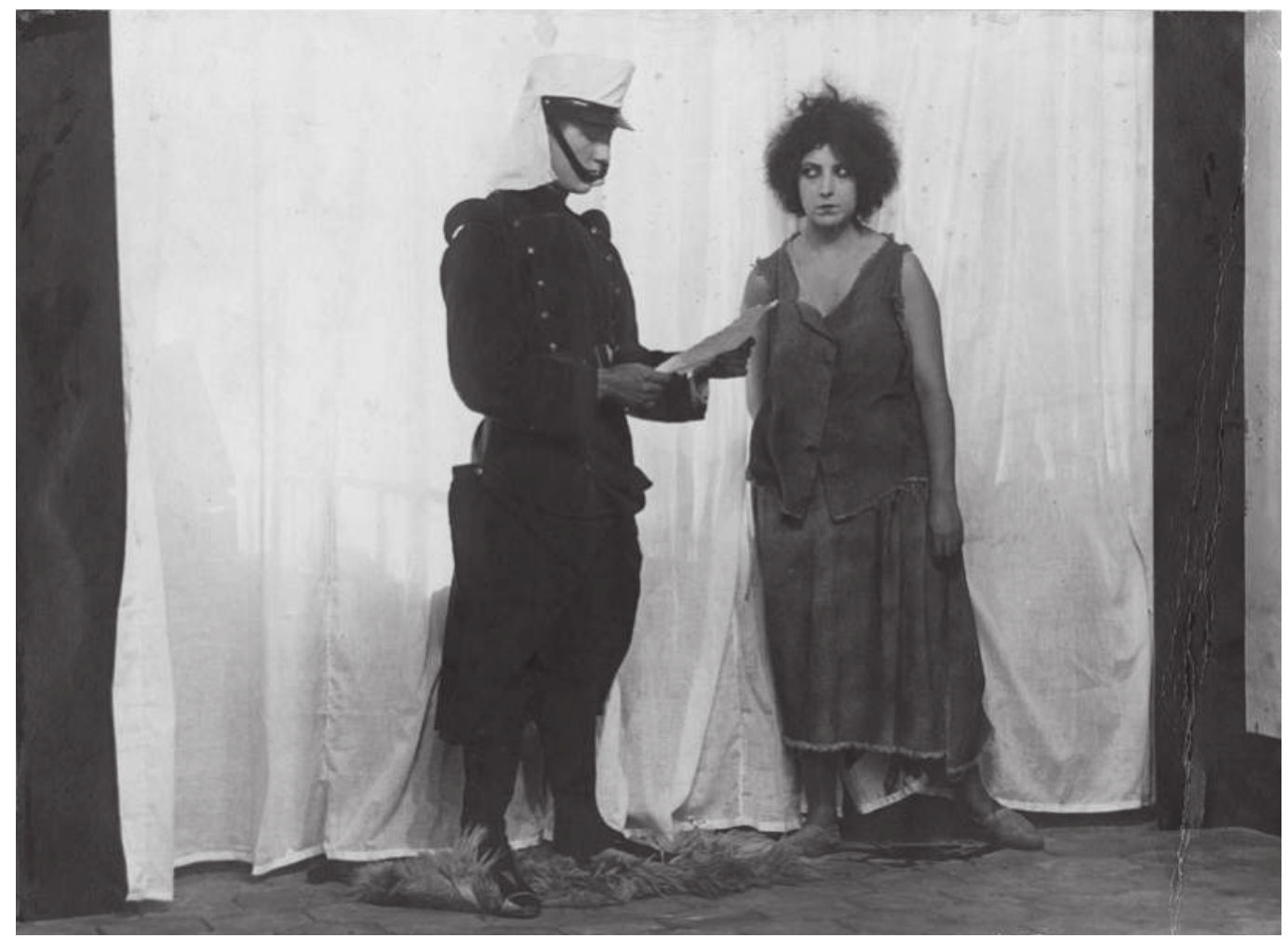

Fig. II.24: Allégria arrested by police in POUR DON CARLOS. Still.

we understand that from the moment that the piece of paper is in her possession, the other will not live much longer. And the drama unfolds in a flash. It is one of the most moving scenes of the film. Simple, dense, bold, the effect is perfectly achieved by the very austerity of the means and the acting. ${ }^{365}$

In the death and burial scenes, Allégria is gunned down in front of a brick wall, which allows Musidora to drop down slowly, her legs crossed, arms wide, and with an expression of agony on her face. Leaning against the wall, she remains seated so that the camera views her frontally. As Colette and others have observed, she acts fully photogenic in this scene: with austerity, expression, and intensity. Within the diegesis, her death comes suddenly, although, in the preceding scenes, she is often shown alone in a deeply melancholic mood. This mood, however, seems to stem from the renouncement of her love for Olivier and her unfulfilled wish to reunite him with Lucille. This is most notably suggested by the parallel editing with scenes set in Biarritz, of Olivier and Lucille hoping for news from her. Allégria has indeed written them a fare- 
well letter and the moment that it is handed over to them is the very moment that she is shot. After that, the policemen approach her dead body, push it a little to see if she has indeed died, and prop it on its side. The policemen handle her body like an object, and Musidora acts truthfully limp. After a cutback to Biarritz, with Lucille and Olivier enjoying one another's company, we see Pedro and Conchita digging the grave, putting the body in it, and filling it with flowers and dirt. The close shot showing the face being covered with earth, unfortunately, is missing from the surviving print. The final shot, a high angle extreme long shot, shows Pedro and Conchita as tiny figures kneeling beside the freshly dug grave on top of a cliff by the sea that splashes far below them.

These scenes match and translate into images conveying the change Allégria has undergone and the turn the story has taken. From an ambiguous, at once passionate and unscrupulous character that schemes for a cause, to a mundane woman in love that schemes and kills for loyalty and love. If 262 | this change "normalizes" her initial non-conformity, it also leaves her emptyhanded and lonesome. The closing scenes accentuate precisely the loneliness and ordinariness and therewith render her a woman that is a victim of love. On the other hand, these images do replace the perspective with which the film opens and the novel ends, that is to say, that of the male protagonist. They replace it with the perspective of the female character, whatever one may think of her.

To round off this discussion of Musidora's acting in POUR DON CARLOS, I shall quote two contemporary and contrary assessments of it. A favorable one reads:

But the pivotal role, Allégria's, if I may say so, the pillar of everything, is played by Musidora, who has moulded it into a truly personal and poignant creation. Very elaborated, detailed till the bottom of her soul, her character has been shaped with the mastery, the authority which the public likes. Musidora is a versatile artiste who no role can deter. To every one of them, she contributes her talent and her artistic conception, and the role of Allégria is definitely one of those in which she can give free rein to her artistic temperament. ${ }^{366}$

A more critical note highlights the acting:

She knows how to be poignant, tragic even; she will be more still when she has become entirely self-confident, she will be able to abandon herself and adapt to the movement of the drama, and no longer create the impression that she is watching herself play. ${ }^{367}$ 
Rather than lack of self-confidence, I would argue, the issue seems to have been Musidora's artistic conception of the role of Allégria and the change she undergoes. As I have illustrated with my discussion of the four appearances, Musidora's acting initially involved references to the act of acting and an indirect address to spectators, as in her comic and adventure roles. In the subsequent dramatic scenes, she omitted the references to acting and complied with the effacing of the act of acting required by photogenic acting. That was, it seems to me, what the critic expected her to do throughout, and therewith bid farewell to her adventurous roles of the 1910s, both in terms of character and of acting style.

\section{SOLEIL ET OMBRE (1922)}

With her next feature film, SOLEIL ET OMBRE (Sun and Shadow), Musidora continued on the chosen path. ${ }^{368}$ The story's setting in Andalusia called for shooting on location and on extant sites. It fit in with what Abel has categorized as "Spanish films", a French film genre that enjoyed a brief vogue in the early 1920 s and in which Abel included POUR DON CARLOS. ${ }^{369}$ Other than Musidora herself in dual roles, only one other professional actor was cast in the film, Paul Vermoyal. Locals play themselves as extras, and the Cordoban bull breeder and rejoneador (torero on horseback) Antonio Cañero plays the character of Janara. ${ }^{370}$ The degree of authenticity of most notably the bullfighting scenes may be attested to by the fact that this and Musidora's subsequent film featuring Cañero are now considered historical documents about Spain's first rejoneador, which allow historians of bullfighting to discern his style and skill. ${ }^{371}$ Directed and shot by the same crew as POUR DON CARLOS, moreover, SOLEIL ET OMBRE has a similar graphic quality in the images of objects and sites that conveys atmosphere and moods. The film's black and white exteriors are highly pictographic and make the most of the harsh contrasts between sun and shadow as well as of the local architectural features and landscape. Objects speak for themselves; for instance, the Spanish scarf that the Andalusian girl, Juana, wears or throws away, or the fan that she holds above her eyes to shield them from the sun, which underscores the dark expression in her face. A shadow of Juana on the wall behind her pictures her indecision. A shot showing her face behind traditional Andalusian gratings, with her most beautiful makeup but also holding the gratings with her hands while looking down the street, is an evocative representation of her sentiments of being rejected and caged by her love. ${ }^{372}$

The plot was based upon a novella, L'Espagnole, by the popular novelist Maria Star. ${ }^{373}$ It tells an intensely bitter story of love in vain of an Andalusian 


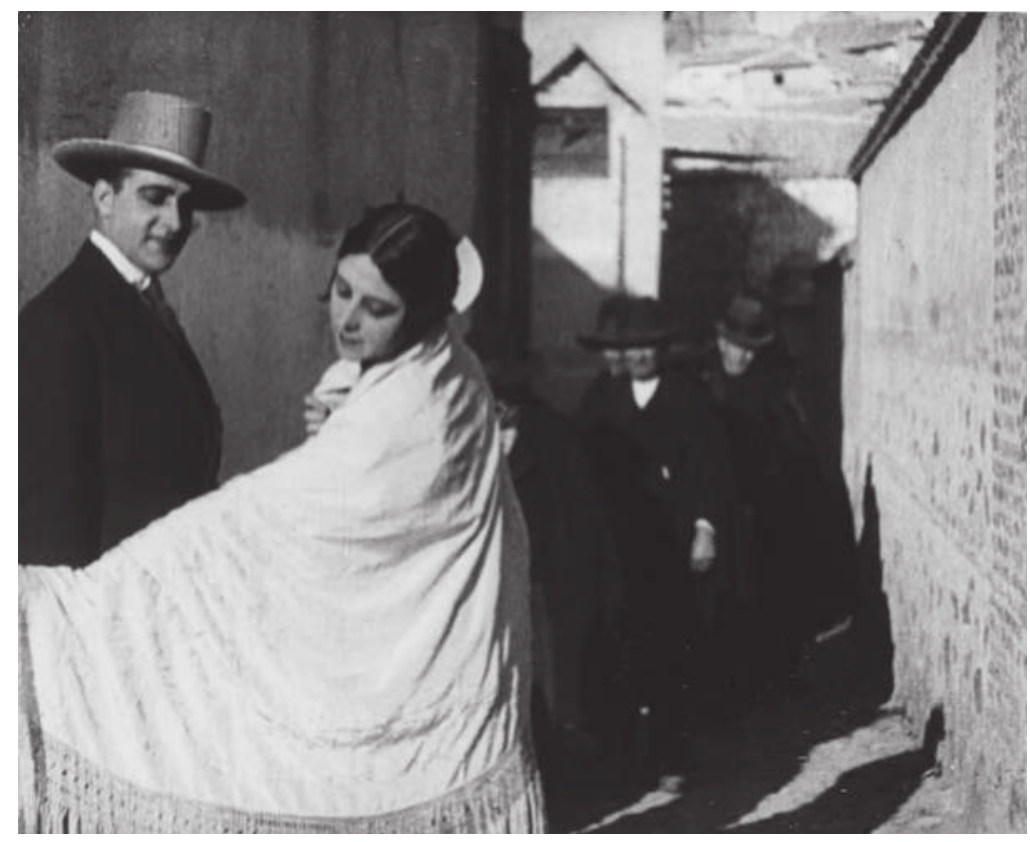

Fig. II.25: Juana admiring the scarf Janara has given to her in SOLEIL ET OMBRE. Still.

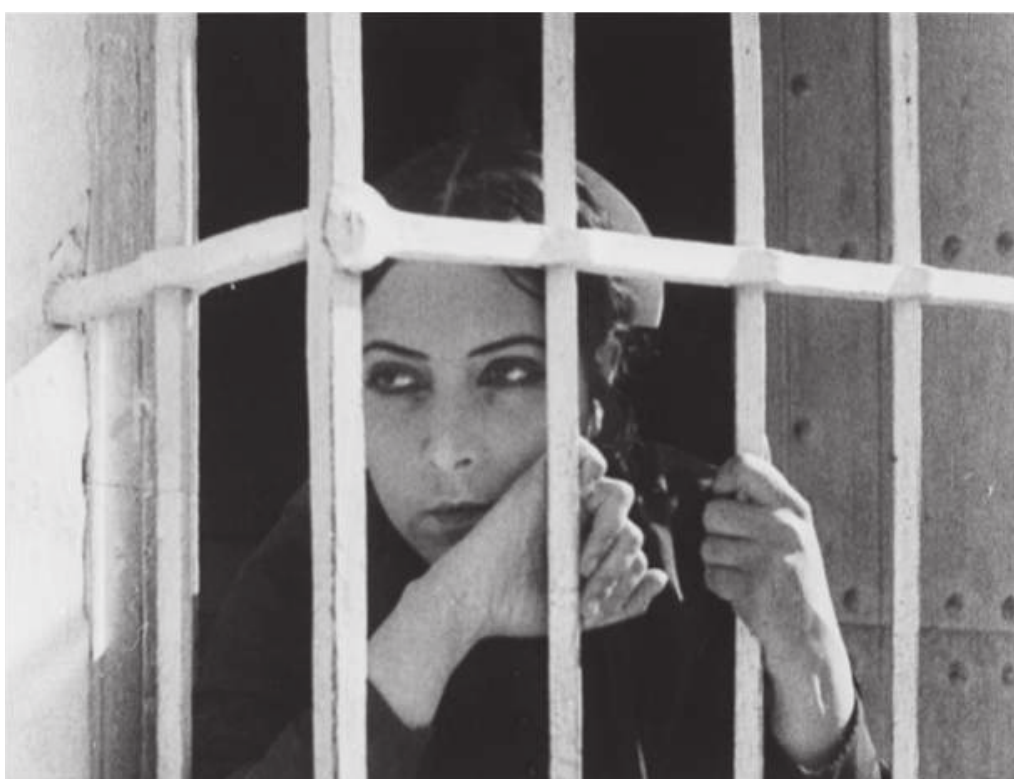

Fig. II.26: Juana feeling rejected and caged by her love. SOLEIL ET OMBRE. Still. 
waitress engaged to a bullfighter, who abandons her for a rich blonde from abroad. Musidora cast herself in both women's parts, therewith implicitely referring to the act of acting. In the role of the Andalusian Juana, Musidora enacts with concentration and sincerity her initial bliss and the pangs of jealousy, grief, lethargy, and other shifts of mood. There are several moments in which she looks into the camera, but these glances remain diegetic: they communicate Juana's emotions to spectators. The nameless blonde, in contrast, was molded by Musidora into an insensitive and conceited figure, which is how the Andalusian girl may have perceived her, but which also makes the disparity between the two characters rather static. While consistently telling the story from the perspective of Juana, the film's tone is inescapably fatalistic: death is announced from the beginning and, in the end, the bull kills the torero and the Andalusian girl kills the foreign blonde. Likewise, her friend and protector, the hunchback antiquarian, renounces his love for her. There is one scene towards the end in which he, with his cape and hat-reminiscent of Judex, but, otherwise, is the opposite of a young and handsome hero-, who will get the girl he loves. Nonetheless, he saves Juana by taking her to the nuns. The ambivalence in this resolution, however, does not rupture the conformity that follows from the pervading fatalism. Within Musidora's professed preference for unruly heroines, this seems the odd one out. Or should we conclude that Juana killing her rival was a pardonable revenge act and that she simply gets away with it? The seven-page program booklet, with a summary of the plot and two stills on every page, tells the story as dryly as the film does, but motivates it by stating that it takes place "in a land very bitter, very rough, where everything has a special value, every action an unknown effect." ${ }^{374}$ It might well be that Lacassin's interpretation that SOLEIL ET OMBRE demonstrates "the simplicity of cruelty" comes closest to the film's point. ${ }^{375}$ It certainly explains the gloomy fates of the characters.

The simplicity of cruelty would also explain the fashion in which the practice of bullfighting is depicted in SOLEIL ET OMBRE. While the torero shows off his supremacy by planting one weapon after the other in the bull, the pain, rage, and exhaustion of the animal are being displayed as well. Interesting is the subtle parallel drawn in the editing (by Nini Bonnefoy) between Juana and the animal, which seems to mirror the girl's sentiments. This analogy is reversed in a shot (also to be found on YouTube) ${ }^{376}$ in which Musidora approaches the camera with such a menacing expression on her face that Juana seems to be mimic the tortured bull. During the bullfight the blonde is unusually sensitive, looking away because she can't bear to watch the brutal spectacle. She nonetheless applauds the torero, who has promised his life and that of the bull to her by tossing his cape to her before the fight, which he previously, as is shown in a flashback, had done to Juana. Being publicly thrusted aside in this way, 


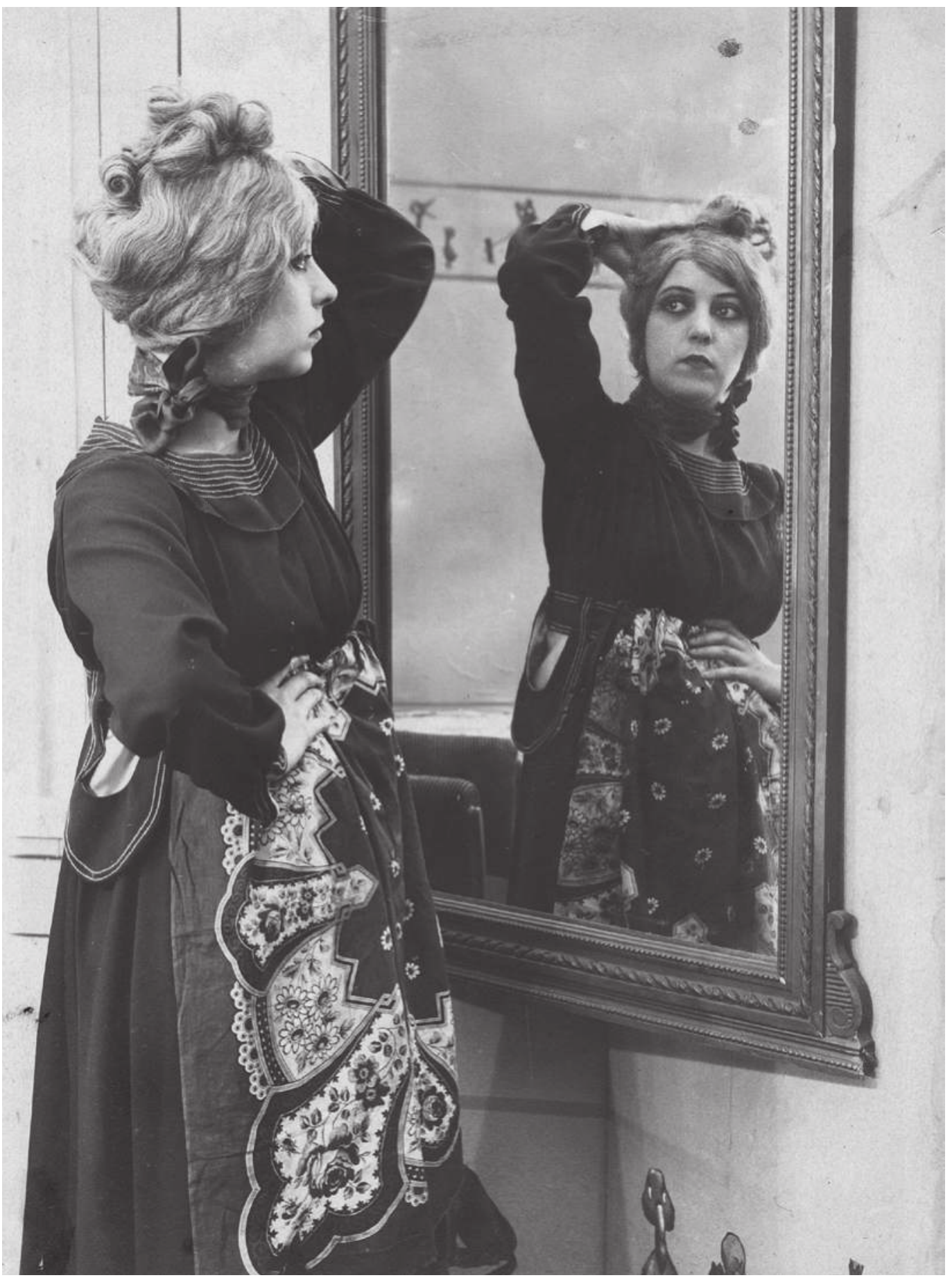

Fig. II.27: Musidora as the foreign blonde in SOLEIL ET OMBRE. Set photo. 
Juana observes the torero's actions in the ring grimly and with a tense face, but refrains from applauding. Later on in the film, there is a scene at the bull farm, in which Juana desparately tries to draw the torero's attention by challenging a bull with her scarf. Janara succeeds in chasing the animal away from her, but, after she has been run over and is lying on the soil, he does not recognize her or show any consideration for her well-being. He simply returns to the blonde, as indifferent to Juana as to a bull after it has died. At the end of the film, in a scene set in the deserted bull ring, Juana once more acts like a torero by killing her rival with the poisoned lances used to weaken the bull. This is not to say that I read her acting as a torero as an act of transgressing gender boundaries, because Juana kills a woman instead of a bull. Her vengeful murder conforms to the rules of cruelty. Seen this way, the film seems to make the point that love or passion inevitably leads to suffering and death.

In 1924, after having made a second film in which both Cañero and bullfighting are prominently present, Musidora publicly explained her fascination with the controversial type of spectacle: "I have been a 'torera' out of love." 377 Her love concerned, as she explained, the man and, more importantly, the danger and the risk to die involved in the "art" of bullfighting. She had learned to view bullfighting as a heroic and courageous fight against death and as a glorification of life..$^{378}$ Although this sounds like an awkwardly romantic view on the cruel tradition, it does shed light on another point of SOLEIL ET OMBRE: the film may have been a study of the connection between love and death.

The connection between love and death must have fascinated Musidora extraordinarily, because it was likewise at the heart of her novel Paroxysmes. De l'Amour à la Mort (Paroxysms. From Love to Death), which was published twelve years after the film was made. ${ }^{379}$ The novel has several striking parallels with the film, such as the consistent female perspective, the romance with the famous torero, the rich woman from abroad for whom the torero leaves the protagonist, the cruelties committed in the name of love, and the immeasurable heartache of the woman who is abandoned by the man whom she had hoped would be hers. These parallels or repeated motifs may point to two distinct possibilities: one would be that Musidora took the motifs from Maria Star's novella and her own film as a framework to further elaborate on and contemplate the topic, or, if the novel indeed was as autobiographical as it presents itself in tone and references, ${ }^{380}$ the novella and the film may have addressed Musidora's curiosity for what might await her if she would really fall in love with an Andalusian man. Curiosly, because the film scenario was obviously written before 1922 , while the romance with the torero seems to have taken place during a few months in 1924 before it ended with Cañero leaving Musidora for a Russian princess. ${ }^{381}$ It may therefore be illuminating to take a look at the differences between Musidora's film and the novel. 


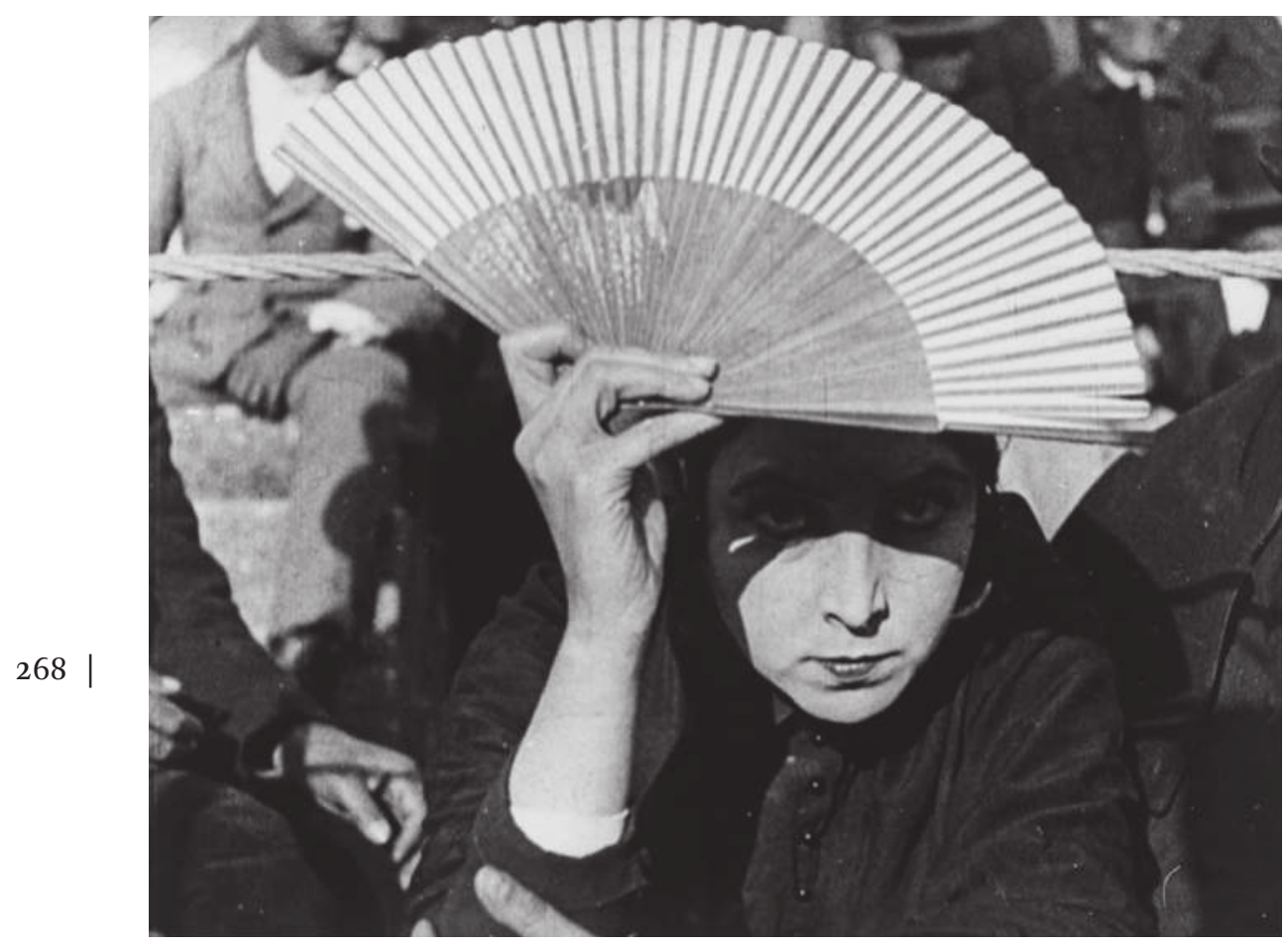

Fig. II.28: Juana observing the torero's actions in the ring in SOLEIL ET OMBRE. Still.

The novel extensively deals with the woman's mental struggle not to surrender to the fatalism inherent in her love, not to become a man's slave and pine for him, as well as to regain the zest for life and love without him. In fact, it depicts love between woman and man as an inherently sadomasochistic relationship, literally in these words: "I have met the man of my life, the man I have chosen as a master. He quite liked me as his concubine for a few months, but he refused me as a wife and rejected me as a slave." ${ }^{82}$ In the novel, the loving woman finds an escape from the rules of cruelty, which she notices everywhere around her in Andalusia. Whether or not this matched Musidora's experiences in her affair with Cañero is less significant here than that the novel allowed such an escape while the film did not. First, the protagonist of the novel is not the local girl, but a celebrated Parisian dancer, Flora, who, for the first time in her life, loves with her heart. In other words, the central perspective has been shifted from the Andalusian girl in the film to the foreign woman in the novel. The first part of the novel recounts how she leaves behind her Parisian lovers for whom she merely feels lust or tenderness, not love, and how she discovers 
in Spain that making love and loving passionately are different experiences. In the middle of the novel, her struggle with her emotions and her observations of the rules of cruelty is depicted. This is when the local girl appears, and, observing how the torero treats this girl, the Parisian dancer infers the slavemaster relationship that awaits her as well. In addition, the cruelties committed in the name of love are now explicitely depicted as specific to Andalusian culture and traditions. Still, in this part, the foreign woman feels ready to accept the rules of cruelty, but her willingness is roughly marred by the man's rejection of her love and his disappearance. He enters into a relationship with a third woman, another woman from abroad who is, unlike Flora, rich. For a while, Flora stays in Spain performing on-stage while wallowing in heartache to such an extent that she would rather be dead. In the third and final part of the novel, Flora returns to France to bid farewell to her dying mother and to recover from her heartsick depression. In other words, the character of Flora in the novel is much more multilayered than the character of Juana in the film. In addition, the perspective of the outsider character of the Parisian dancer allows for observation and contemplation of Andalusian culture and women's lives, which, in the film, occur as well, but never acquire the complexity and depth that they reach in the novel. Third, and this may be the most important difference, not jealousy is the drive of the narrative, but heart-searching and thinking about the impossibility of this love. In contrast to the film, the novel suggests that women are able to fight death and to glorify life in ways far less cruel than Andalusian men would demand of them. Nonetheless, looking at the film through the lens of the novel illuminates dimensions of the character of Juana that, in the film, remain under the surface.

Despite its conveyed conformance to the rules of cruelty, SOLEIL ET OMBRE can then be seen as a tale about the clash between traditional and cosmopolitan morals as they affect women's love relationships, which is a recurring theme in the stories that Musidora chose and which she explored from various perspectives. The fact that Musidora played both characters herself, moreover, has fascinated other scholars as well. Whereas the French critic Jacques Durand conjectures that Musidora would have reserved the dual role for herself out of passion and unwillingness to share Cañero with another woman, even on the screen, ${ }^{383}$ feminist scholars such as Vicki Callahan and María Camí-Vela offer more than biographical readings. Callahan proposes that "Musidora might not be gesturing toward any one definitive commentary on her public/private persona but rather might be demonstrating the multiple possibilities that could exist within any particular identity." ${ }^{84}$ Callahan relates the aspect of performance in the dual role to the performance of the bullfighter, which Musidora, in the opening titlecard in her subsequent film, characterized "the Art of Gesture". In Callahan's analysis, the gesture stands for the 
excess of possibilities, as do the performance and the image. ${ }^{385}$ Camí-Vela expands this argument with a detailed analysis of a surviving Spanish print of SOLEIL ET OMBRE. ${ }^{386}$ Departing from the various roles that Musidora performs in and around the film-local/foreign woman, director/actress-Camí-Vela explores the conflicting positions that mark the narrative. Through the, in her words, nearly ethnographic shots of the rural village and its inhabitants, a confrontation with modernity is suggested in the arrival of the foreign blonde, a femme fatale, who is eyed in astonishment and curiosity by the locals. Via the differences in belief - Juana is religious, the foreign blonde is agnostic - she points out the virgin/whore dichotomy that divides the two characters. In this redoubling or dissociation, Camí-Vela goes on to argue, following Callahan, that the dual role defies the fixedness of an identity, while there are also several moments in which the Spanish girl virtually transforms into the foreign woman and vice versa. Such transformations go hand-in-hand with a change 270 of the gaze. While the first regularly looks into the camera and therewith acquires subjectivity, the second is always the object of the gaze. This is how Musidora the director, in Camí-Vela's analysis, both exposed and subverted the objectification and erotization of the body of Musidora the filmstar in fiction and in life. Camí-Vela's point is that SOLEIL ET OMBRE refuses to resolve these conflicting possibilities and instead proposes an "I" that accommodates ambiguity and contradiction. I do consent that Musidora was interested in and studied conflicting possibilities for herself and for other women, but, in my opinion, she does not expose them in this film but depicts them within conventional boundaries and clichés.

Thus, remains the question, addressed by neither Callahan nor CamíVela, ${ }^{387}$ as to why Musidora once again did not claim the direction nor the codirection for this film in French publicity, not even in the publicity booklet mentioned above, even though she was credited for the co-direction in the opening credits of the surviving French print. The publicity booklet and the contemporary press attributed the director's credit solely to Jacques Lasseyne, whose only fame consisted of the fact that he had also co-directed Musidora's preceding film. I cannot but conclude that acting still mattered more to Musidora than directing, which may have been her professional reason to cast herself in dual roles. She might have wished to display her versatility and adaptability as an actress. My comparison of the film and the novel points to her thematic interest in these roles, and why, as a producer, she chose the story for her film: Musidora wanted to investigate the rules of cruelty to which a woman in love with a man of Andalusian culture might be subjected. But were these choices understood in the contemporary reception of the film? The few reviews of the film that I have traced attest to the mixed response that SOLEIL ET OMBRE met in France. Cinéa and Ciné-Journal raved about the film's visual 
accomplishedness and narrative clarity, and praised Musidora's acting in her dual role for being varied and moving. ${ }^{388} \mathrm{Hebdo}$-Film, in contrast, reproached the direction for lacking rhythm and Musidora for having taken on the role of the foreign woman. In addition, the French were said not to like the inequality, the slaughter involved in Spanish bullfighting, and that it did not suffice to state in a title that one does or does not love the cruel tradition. ${ }^{89}$ Perhaps this revulsion explains the silence about the film in other periodicals and papers, but it definitely did not discourage Musidora from venturing into a new, yet entirely different project on the same topic.

\section{LA TERRE DES TAUREAUX (1924)}

Musidora made LA TERRE DES TAUREAUX after an original scenario that she wrote. She produced and directed it and played its female protagonist opposite Cañero. It differs from Musidora's previous productions in several ways. First, it is a satire, not a drama, and second, it was not intended to be presented as a film, but the film parts were meant to be screened along with and between live performances by Musidora and Cañero. It likewise differs in Musidora's selfpresentation: she was not only present on-stage and on-screen as an actress, but also cast herself in the role of filmmaker and signed, as Vicki Callahan has justly pointed out, the production with her name and signature on the titlecards that opened and closed the film. ${ }^{390}$

The satirized issues concern everything that hitherto had seemed dear to Musidora: her star image in the cinema and on-stage, filmmaking, adventurous women's roles, bullfighting, and romantic love. For these reasons, and because of the self-irony that pervades both the filmed and the live parts of the performance, I would like to consider LA TERRE DES TAUREAUX a selfreflective rather than an autobiographical production, even though Musidora, in the opening title of the film, suggests that autobiography played a role in her conception of the project. It obviously does, but indirectly. Rather than a story about Musidora's personal or love life, it is a humorous statement about popularity in the silent cinema and a clever, sincere, and playful reflection on a film world and a film press that did not take sufficient notice of her aspirations as a filmmaker and primarily wished to see her in dramatic parts and in closely defined acting styles. What I admire most in LA TERRE DES TAUREAUX is that it does not exhibit bitterness at all, but instead comes accross as an at once reflective and ironic self-portrait of Musidora as a professional silent film actress and director.

The two Musidora-scholars that so far have discussed LA TERRE DES TAUREAUX, treat it in ways that different from one another. Lacassin, basing his 
assessment on a scenario, describes it as a film and stage show, of which the filmed parts are a far cry from the norms of commercial cinema because they were made with very limited financial resources and without the support of a professional cast and crew. ${ }^{391}$ He distinguishes three elements in the production: documentary parts about bullfighting, a satirical part about the world of spectacle, and a part that he assesses as an autobiographical reverie about Musidora's romance with Cañero. A reverie because the scenario that Lacassin read ended with the torero proposing marriage, and Musidora, on stage, singing songs about the marriage, while, in reality, Cañero had left her by the time she presented the film in Spain. Vicki Callahan does not consider the staged parts or the satirical and comic aspects, but focuses, in the filmed parts, on the recurrence of the bullfighter's motif, the ways in which Musidora presented herself as a filmmaker, and the significance of performance. The kinship between bullfighting and film acting that Callahan derives from Musi-

272 | dora's characterization of bullfighting as "the Art of Gesture" indeed provides a more professional and cinematic explanation for the star's fascination with this "sport" than her infatuation with a torero would do because it calls attention to the performative aspects that the actress and the torero share. Drawing a line from Musidora's choice of a pseudonym, via her alignment with Colette, the mythic status of the Irma Vep figure and Musidora's playful treatment of it in her writings and stage appearances down to LA TERRE DES TAUREAUX, Callahan discerns an ongoing project of establishing, what she calls, "zones of indeterminacy". ${ }^{392}$ While I fully agree with Callahan that "Musidora was someone extremely attentive both to her public persona and her ability to contstruct the narrative(s) that surrounded this persona," 393 I would be more hesitant to attribute to her that she "might be pointing to the inability to limit or define identity itself". ${ }^{394}$ This hesitance follows from an alternative reading of the question in the opening title card that is central to Callahan's argument. The question reads in French: "Pourquoi la vie ne vaudrait-elle pas un roman?", which Callahan translates as "Why isn't life as good as a novel?" and interprets this as if Musidora would not have accepted a life or an identity as a married woman without a novel or a performance. ${ }^{395}$ While this may be true for the real life Musidora-as it would be for any actress, director, and writer of her stature-I would like to question if this is what she intended to say here. My translation of the question would read "Why should life not be worth a novel?", emphasizing the phrase's rhetorical bearing as well as the suggestion that life is often considered not to be worth a novel. The next lines of the intertitle state that "this is an adventure story about the real Spain" and that "it has been made in the middle of constant danger", referring to the local reality and bullfighting as much as to Musidora's practice of performing the stuntwork of her adventurous roles, which placed her too in constant danger, as she repeat- 
ed tirelessly in public statements. ${ }^{396}$ In other words, in my reading, Musidora does not contrast life and novel, but points out - as in most of her projectsthe lifelike caliber of the story that spectators are presented. She additionally stated that it was the "love for sports, journalism and autobiography"-all three non-fiction-that enabled her to present LA TERRE DES TAUREAUX. That these statements were not entirely devoid of irony becomes apparent from the surviving film print only after the initial factual part about bull raising and bullfighting has ended and the tone shifts to comedy and satire. My impression, therefore, is that Musidora's concern with this particular project were the historical experiences, images, and performances that shaped and continued to shape her career on- and off-screen. The moderate production conditions and, most notably, the absence of the pressure to please the French film press may have worked as a catalyst to choose a style and a tone more close to her work on the stage than to film production. This perspective becomes more pertinent when the production's live acts are taken into account.

The knowledge that the production was intended as a mix of live performance and film screenings can be verified from Musidora's handwritten scenario dated 1922 and preserved at the BiFi. After the title, the text specifies: "scenario drafted by Musidora for a grand tour, in part film, in part stage." 397 Unfortunately, the scenario does not clarify which scenes were intended for live performance and which for the filmed sequences, except for two scenes, to which I shall return. Also, scenes and title cards in the scenario that are missing from the print do not always match or fit in the scenes present in it. From the material at hand, then, it is difficult to reconstruct with certainty the presentation as it may have been performed. Nonetheless, from the two live acts described in the scenario, it can be inferred that they enhanced the selfreflective and ironic tone of the presentation.

The surviving film print contains a mix of factual, comic, and romantic adventure sequences. The factual sequences present the cult of bull raising and bullfighting in Andalusia, with the bulls and Cañero as the protagonists; the comic sequences deal with star images on-stage and in the cinema, with Musidora as the protagonist; and the romantic adventure sequences, with both Musidora and Cañero as the protagonists, comment on male and female heroism and romance. The point is that all of this is subjected to ironic reflection, and that an important tool for this reflection are references to Musidora's public persona and preceding roles and films. Musidora applies here the intertextual form and satiric tone of French music-hall to the personal mode that she had maintained in her writings and blends them into a self-ironic portrait of a celebrated actress and an underexposed film director.

The scenario contains a scene, quite early in the narrative that is absent from the print and in which Musidora tells an interviewer from a film maga- 
zine that her next film will be exclusively about bulls. ${ }^{398}$ In other words, she introduces herself not as a fictional character, but as Musidora the filmmaker. The print contains various title cards that narrate the story as a first person account and, in them, she presents herself as a filmmaker as well: "I was in Spain to search for an actor for a film about the art of bullfighting." The titles can be read as the filmmaker's narration because, in the shot after the cited title, we see her in a Spanish town, getting out of a car and acting as if looking for something. ${ }^{399} \mathrm{~A}$ second reason, of course, was that it was publicly known that Musidora had already made one film in Spain with a torero as the leading man. In the subsequent shots, she is shown attending a bullfight, enjoying the show, applauding the torero, and deciding that she has found the protagonist for her film: "After the bullfight, I congratulated Antonio Cañero and offered him to become one of the grand stars of the screen.... by shooting a film with me." If this intertitle did not already mock her status of film director, the next 274 | title did so in no uncertain terms: "I left with a refusal."

As a film about bulls and bullfighting, LA TERRE DES TAUREAUX seems, at certain points, an ironic reworking of SOLEIL ET OMBRE. Whereas the "constant danger" the bulls pose is stated and described in the intertitles, it is absent from the images or the actions. At times, the danger is even almost ridiculed, for instance in the scene in which the bullfighter "exercises" fighting with a young bull and the animal's flippant jumping and running acquires a jolly touch. Likewise, the parallel in the drama between suffering fiancée and fighting bull as victims of the torero is revisited in the epilogue, in which Musidora merrily stands in for a bull (holding a chair with horns tied to it) and comments in an intertitle that this is the only way in which a woman should carry horns - that is to say, for fake.

The most hilarious scenes are those in which Musidora pretends to be a would-be film star. In them, she ridicules both Cañero's and her own vanity as stars in their respective fields. First, she has Cañero act upon his vanity and has him place an advertisement in the newspaper, in which he offers money to a film star or a rising star to make a film on bulls. But, instead of simply accepting, the star decides to beat the torero at his own game. To that aim, she disguises as a most ugly and clumsy would-be film actress. (That he fails to recognize her may be read as a reference to her roles in the Feuillade serials). Her imposture leads to a series of downright slapstick scenes, in which she acts as ill-mannered, ungracious, and unattractive as possible. Musidora's visible pleasure in playing the "ugly girl", as the character is called in the title cards, may be read as accentuating the act of acting and as an ironic reference to her legendary photogenic star image. The slapstick scenes follow Cañero's scheming of how to get rid of her and culminate in a scene in which he hopes that she will be knocked out by "une vache brave" (a cow of the breed of the 


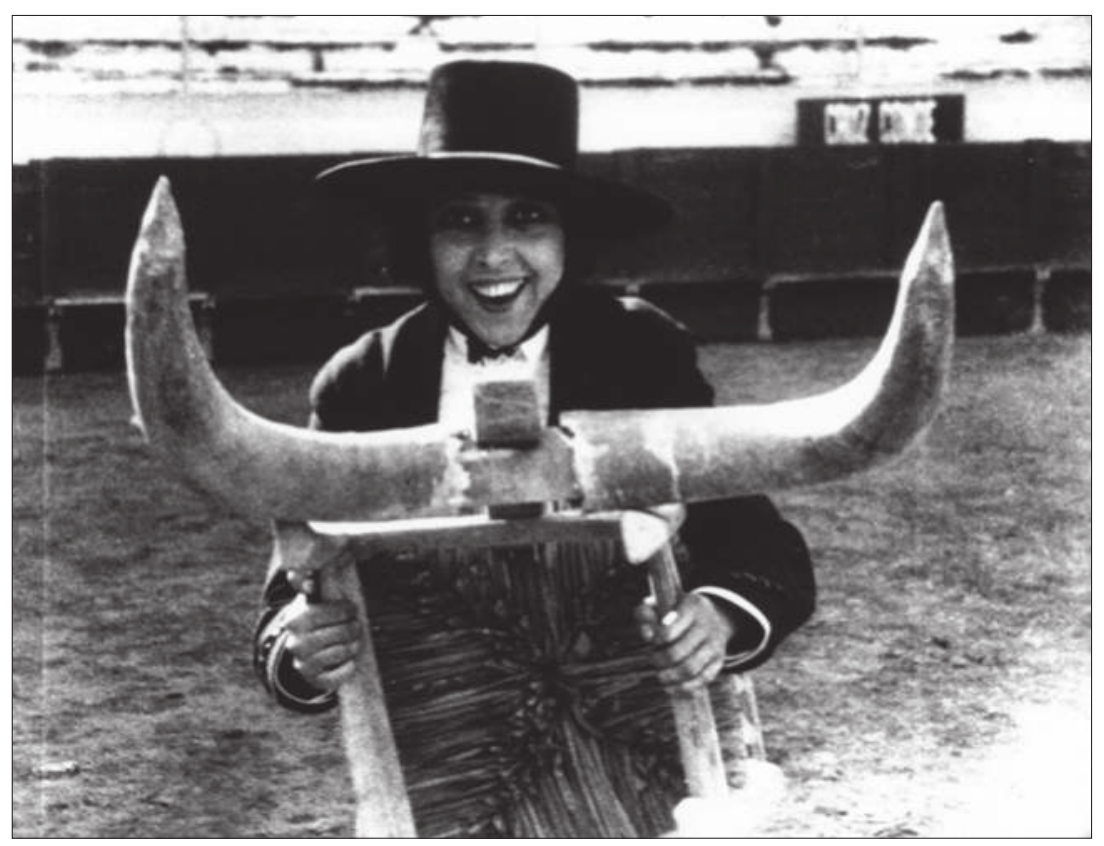

Fig. II.29: Musidora merrily standing in for a bull in LA TERRE DES TAUREAUX. Still.

fighting bull, called "toro bravo"). Not she, however, but he gets tossed on the cow's horns, after which she saves him by pulling the cow's tail. With this "act of bravery", as it is characterized in the subsequent title card, Musidora ridicules female film heroism as well as the courage of the bullfighter whom she saves. The scene furthermore looks like an inversion of the scene in SOLEIL ET OMBRE in which the Andalusian girl was run down by a cow and the torero did not pay any attention to her well-being.

After this scene, the film star's metamorphosis from ugly girl into her beautiful and beguiling self takes place. The fact that Musidora visibly enacts the metamorphosis can be read as another accentuation of the act of acting. Her combing her hair in the act seems a reference to a picture postcard in the Comoedia-series- "Our artists in their dressing room"-,which likewise shows her with a hairbrush in her hand..$^{400}$ Of course, the torero wants her to stay after the transformation, but now she is the one to refuse. The reasons she tells him are professional: that he did not want to be in her film and that she has been summoned back to the theater to play. In the scenario, she even says to him: "I belong first to the public, to my art, to my contracts." Right after the title card with his question "You refuse to follow me?" a medium close shot shows her pondering and glancing sidelong at the camera. From this glance, which we know from her roles as Irma Vep and Diana Monti, it is obvious that the answer will be no. After these scenes, she turns into the adventurous hero- 
ine of an action plot, in which she travels from the land of bulls to the stage in the city. But this heroine is subjected to irony from the start, for which the narrative device of competition between female and male heroism has been applied and reversed.

Cañero tells her that she can go, but takes his horse back and announces that he will catch up with her easily. She starts out cross-dressed, but soon changes into a woman's dress. This action is motivated by the fact that the hero will be looking for a woman in Andalusian men's costume. The irony derives from a contrast in the range and speed of the means of transportation used by heroine and hero. While she starts out on foot, then buys a donkey, exchanges it for a horse and jumps on a train, he starts out on horseback with a group of helpers, but gradually loses tempo, the horse, a bicycle, and his men, who are unable to find the cross-dressed woman. Nonetheless, they meet again in Musidora's dressing room in the theater in the city. In the surviving print, the 276 | hero arrives first in the city by eventually taking a plane, as a deus ex machina concluding the mockery of his heroism. In the scenario, however, the heroine is the one who takes a plane and arrives first, which would fit the accumulative

Fig. II.30: Ironic citation of LES VAMPIRES:

Musidora riding the front of the train in LA TERRE DES TAUREAUX. Still.

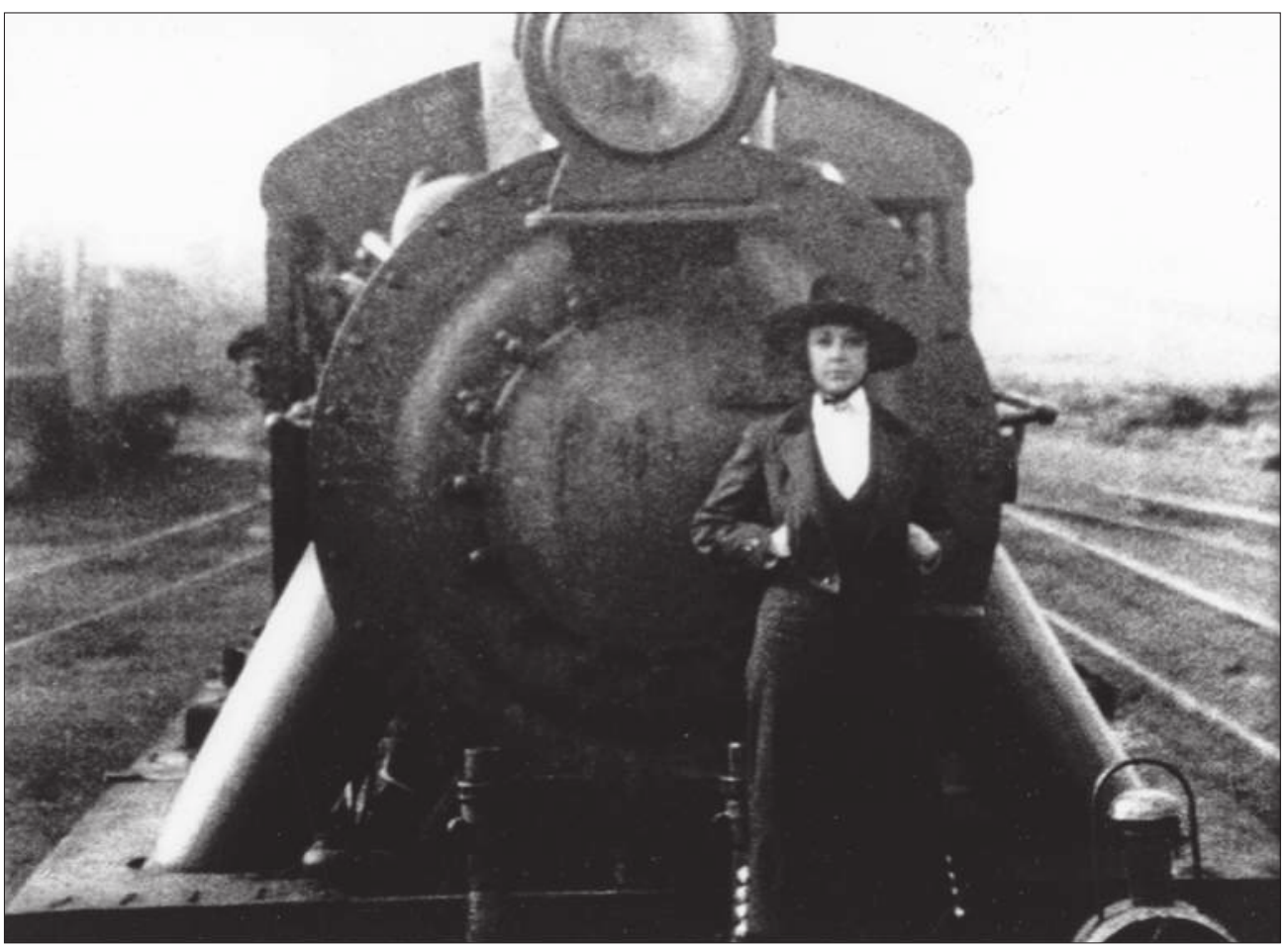


series of faster means of transportation that she used. The scene with the train cites the scene in LES VAMPIRES in which she lay flat on the rails underneath the riding wagons: now she climbs onto the locomotive and rides its front end straight towards the camera.

The scenario suggests two live acts inserted at this point in the presentation. These live acts allow Musidora to thank her devoted stage public and to mock the film press. The first act goes as follows: at the theater, the director and the public wait for Musidora, who is late for the performance. The director fears that she will not come at all. The public continues to wait patiently, and a woman makes a favorable remark on her live performances: "I like to hear the sound of her voice. The screen and the stage are very different things." Eventually Musidora arrives, offers the public her excuses, and recounts her adventures.

In the second live act, she receives an interviewer from the film press in her dressing room. He begins talking to her while she changes behind a folding screen. He does not ask any questions, but continues talking, while her head behind the folding screen nods yes and no. Eventually, he says goodbye with the line: "My article along these lines will appear tomorrow. It is a revelation for our readers. It is utterly interesting." In short: while her devoted stage public waited to hear her stories and views, the film press was only interested in its own.

Seen from a perspective of ambition and choice, Musidora used the freedom from commercial or artistic filmmaking for witty references to her fame as a film actress and to her failure to gain recognition as a film director. She additionally used it to pay tribute to her popular stage audience that she, it seems, experienced as more faithful than her film audience. Most importantly, she seems to have taken distance with this project from the ambitions in filmmaking and acting as were expected from her. Much like with the photograph with which she commented on photogénie, she looked at these ambitions with irony and humor, and, between the lines, criticized them for curtailing her versatility. This reading of LA TERRE DES TAUREAUX is prompted once the comic scenes and combination of screen and stage performance are taken into account. In my opinion, the production illuminates why Musidora, for many years, refrained from filmmaking, why she acted in a supporting part in only one more film in 1926, but continued acting on the popular stage as she had done throughout her career in the silent cinema. 


\section{EPILOGUE}

Musidora produced and directed another short film in 1950, LA MAGIQUE IMAGE, which is not known to survive today. According to L'Écran français, it is a tribute to Louis Feuillade and the myth of Irma Vep: "At the sight of feminine beauty, the 'Magic Image', the young boys wake up and are overwhelmed by the desire to touch the elusive woman." ${ }^{401}$ At the time, Musidora was working for the Cinémathèque française in an oral history project and collecting the testimonies from her colleagues from the silent cinema for the Commission des Recherches Historiques. In 1926, she was elected "Reine du Cinéma" (Queen of Cinema). In 1927, she married a friend from her youth, her mother's local doctor, Clément Marot (not to be confused with the poet with the same name). She did also act on-stage after the marriage, but, after the birth of her son in 1931, less so than she had before. Instead, she turned to sculpting and 278 writing. She published two novels, the previously discussed Paroxysmes. De l'Amour à la mort, and the serialized Arlequin et Arabella, ${ }^{402}$ as well as a collection of poems and a children's book, in addition to the essays and lectures on Colette, Pierre Louÿs, and on the shooting of LES VAMPIRES cited in this careerography. Musidora died on December 10, 1957. 



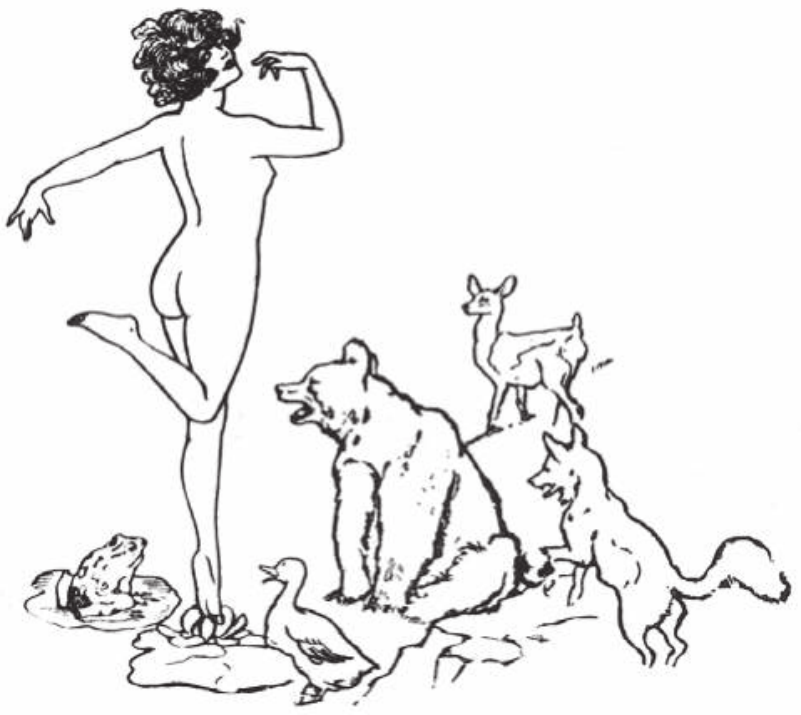

Fragment from an advertisement for BACK TO GOD'S COUNTRY emphasizing Nell Shipman's nude scene, Boise State University (see page 354). 


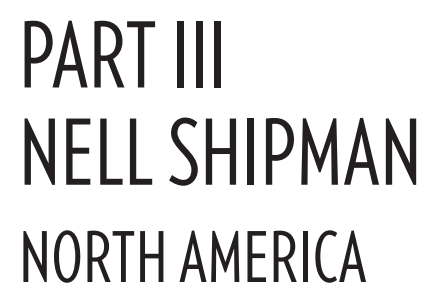




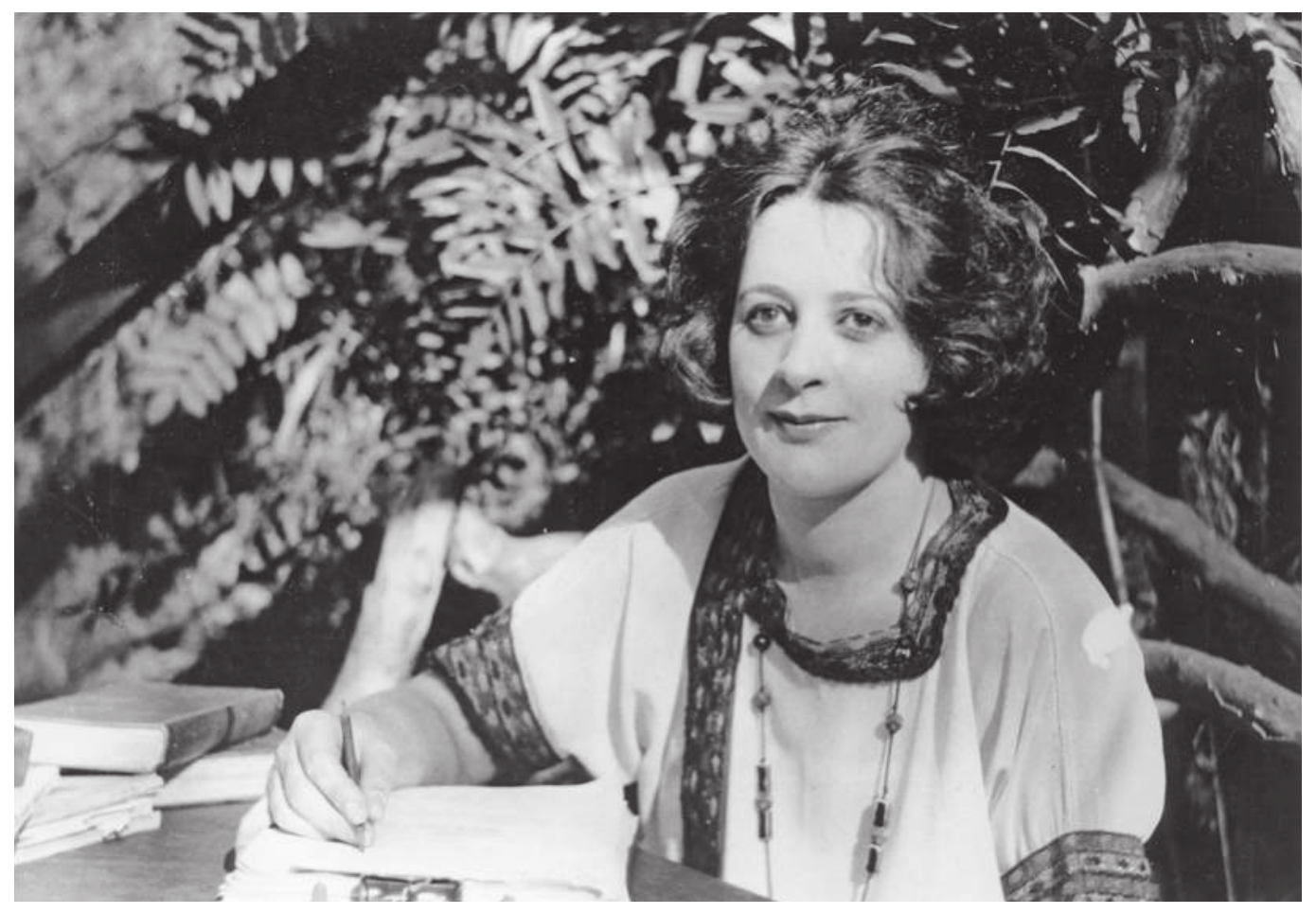

Fig. III.1: Nell Shipman writing at home. 


\section{Nell Shipman on the American Popular Stage}

NELL SHIPMAN'S STAGE CAREER 1907-1911

In July 1909, Nell Shipman, then known by her maiden name Helen Barham, was a member of a stock company that had gone to Alaska with its owner, the theatrical manager and playwright Charles A. Taylor. On the way back to Seattle, Taylor wrote a role especially for her, the role of Alaska Lou in the play "The Girl from Alaska", a circumstance that was even mentioned in a Seattle newspaper. ${ }^{1}$ In her memoirs, the actress recounts how both the Alaska tour and the play brought on an epiphany for her:

Charlie went on with his play about the Girl from Alaska. She, as the cold days and colder nights passed slowly and the old sternwheeler bucked new ice and old current, realized that she was indeed "from Alaska." [...] [I]ts impressions, its images, were chiseling themselves forever into her consciousness - grooving putty which would harden into marble. [...] On my last night in Fairbanks, I saw the Lights for the first time as I ran under the shimmering, jewelled curtains of the Northern sky with a malamute at my side. The running of the race is lonely. [...] But to run with a great dog through an Arctic night under cloud-ribbons of color that bind the animal's and the human's hair alike-illumine their flying feet, catch their twin breaths in a net of beauty—-means one understands and loves God's Country!²

The associations on which this recollection is built are significant for a number of reasons. For one thing, they illustrate Shipman's inclination to identify personally with the stage and screen persona, "Queen of the Dog Sleds," as some dubbed her, or the "Girl from God's Country", the sobriquet in cinema publicity that she cherished throughout her life. Or, again in her own words: "I 


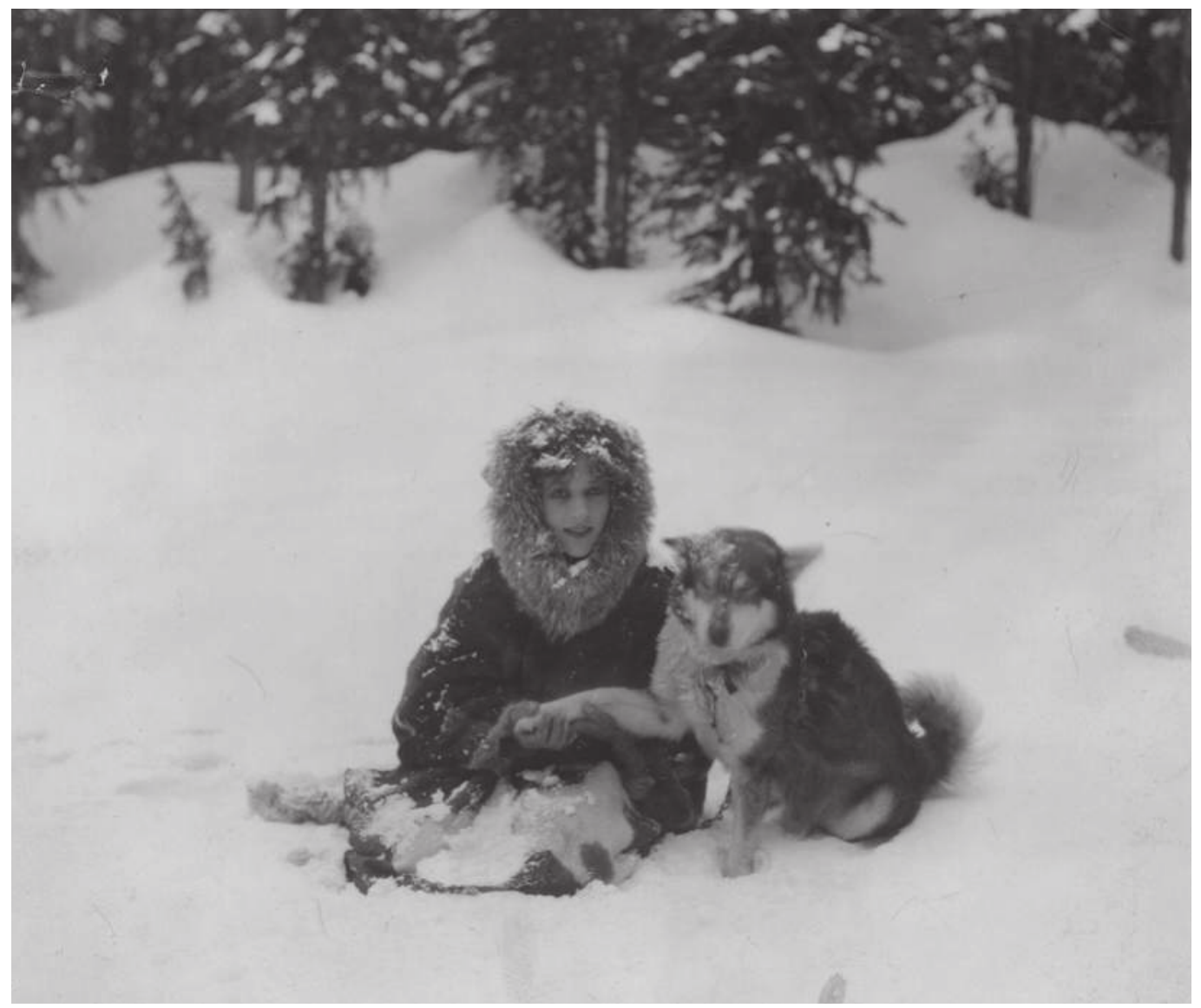

Fig. III.2: Nell Shipman in character, here with her Alaskan Malamute Tex.

think I was experiencing a home-coming of the soul. [...] [I]nside, I trod in soft moccasins and my braid curved over breasts beginning to bud." 3 This correlation between her personal disposition and her favorite character in fictional works in-print and on-screen had a momentous impact on both her career and her private life. The "home-coming of the soul" was associated with "the vast country which, in the months nibbling at my seventeenth birthday, was to determine my actions over many a birthday to follow. Alaska!"4 An important focus of my assessment of Nell Shipman's career will be how, precisely, the association of her personality with her stage and screen persona guided her professional actions and choices.

Shipman's affinity with "The Girl from Alaska” is redolent of a particular, historically, and culturally specific conception of realism that motivated much of her oeuvre. This notion of realism was shared by and informed the two genres of popular culture that, in the title of the play, seem to merge much as they 
would do in her publicity sobriquet: the stage genre of sensational melodrama (The Girl from...) and the literary genre of Northwest drama (...Alaska or God's Country). This conceptual nexus informs my discussions of the works of Nell Shipman's career: the parts she played on-stage and on-screen, her literary work and scenario writing, and, eventually, the films she would produce and direct.

Nell Shipman was born Helen Foster Barham, in Victoria, British Columbia, on October 25, 1892, but, during her teenage years, she was based near and in Seattle, Washington, where the Foster Barham family had moved around the turn of the century. ${ }^{5}$ Helen Barham's parents and elder brother Maurice were not inclined towards cultural activities, but she nonetheless took dancing and acting lessons at the Egan Dramatic and Operatic School in $1906 .{ }^{6}$ Seattle, with its port and railroad connections, was known as the Gateway to the Klondike at the time and was a booming and progressive city with an exemplary cultural life. ${ }^{7}$ Until the mid-1910s, the stage was the preeminent form of popular entertainment in town, even though films were also shown in vaudeville and opera houses and, after 1906, at the storefront theaters known as nickelodeons. ${ }^{8}$ As for popular theater, touring companies presented musical comedy and traditional melodrama at various venues, and vaudeville was provided by the expanding Pantages Circuit. A teenage girl "bitten by the Bug", ${ }^{9}$ then, had a choice of possibilities for trying out her thespian aspirations. In musical comedy and melodrama, she could attempt a series of stock characters, such as ingénues, soubrettes, leading ladies, and the parts that were, in Shipman's words, “known as 'Sads', the misunderstood gals who came home to the farmhouse, babe in arms, and caught ruddy hell for their fun". ${ }^{10}$ Vaudeville offered chances to perform in dance and musical acts and to act in sketches or playlets. In about four years' time, Helen Barham gathered experience in nearly the whole range of roles. ${ }^{11}$

In October 1907, the month in which she turned fifteen, Shipman played the soubrette part of Mame, a Poor Girl, in the musical comedy "At Yale", a performance for which she received notice in the New York Dramatic Mirror. ${ }^{12}$ Written by the prolific melodrama playwright Owen Davis and staged by the popular stage-and later silent film - actor Paul Gilmore, this "college play" had previously toured the North- and Midwestern states, with Shipman as the ingénue. ${ }^{13}$ For its consecutive run in the Northeast, the cast was largely replaced, but Helen Barham was recast as the soubrette. "Miss Barham, as Mame, acted well the character she played," noted The Washington Herald in its review of the successful play. ${ }^{14}$

From the fall of 1908 until early 1910, Barham/Shipman was affiliated with three stock companies: the National Stock Company of Dave Williams, the Taylor Stock Company of Charles A. Taylor, and the Sutton Players of "Uncle" 
Dick Sutton. Taylor and Sutton belonged to the most important permanent stock companies in the United States in 1907. In one of Shipman's unpublished recollections, "Fade In", she fondly remembers Taylor as "the C.A.T. of blood and thunder melodrama" and as "[t]he fine old King of Ten-Twenty-Thirt[y]." ${ }^{15}$ Ben Singer, who researched this so-called "ten-twenty-thirty", "blood and thunder", "barn-storming", or "cheap" melodrama for his book Melodrama and Modernity, distinguishes this type of stage melodrama from the family or domestic drama and refers to it as "sensational melodrama", or "the melodrama of spectacular diegetic realism." ${ }^{16}$ By 1907, this popularprice theater was big business and had expanded into every American city. It was an industry thriving on a generic product, not on big-name actors, literary playwrights, or prestigious titles. Considered "unsophisticated, nationalistic, anti-intellectual and highly visual" in theater histories, sensational melodrama catered to the working class. ${ }^{17}$ Companies toured with a repertory of plays 286 | that were staged alternately during the one to five days' sojourns in a city or town. In the summer of 1907, the New York Dramatic Mirror signaled an important trend away from touring towards permanent stock companies. ${ }^{18}$ For a melodrama actress like Helen Barham, this had the advantage that she could find work closer to home and stay longer in one place than with the traveling roadshows. On the other hand, this shift was an announcement of the demise of stage melodrama in the United States, which would, as Singer has related, take off in the spring of 1908 in New York and affect other parts of the country within three years. ${ }^{19}$

With the National Stock Company, Helen Barham performed in Lewiston, Idaho in October and November 1908 in at least two melodramas: "An Arkansas Romance" and "What Women Will Do". In the first of these, she had the role of the ingénue: "Miss Barham is a most pleasing and artistic ingénue, and her handling of the rather difficult character of Madge, the daughter of an outlaw, was highly acceptable." ${ }^{20}$ In the second, "a comedy full of action and with good dramatic situations," she was said to have acted her most delightful part to perfection. ${ }^{21}$ In her memoirs, Shipman does not mention these titles, only that she "studied one part while [she] rehearsed another and played a third. In Lewiston, Idaho, we changed bills twice weekly." 22

With the Taylor Stock company, Helen Barham went on tour again, playing the female lead of Mercedes, another daughter of an outlaw, in "Yosemite", written by Charles A. Taylor. In July 1909, this frontier melodrama set in California was performed in Juneau and Skagway, Alaska, ${ }^{23}$ as well as in Dawson City, in the Yukon territory of Canada, where the actress impressed the reviewer with her beauty and emotional acting. ${ }^{24}$ It was assumed that she was barely eighteen years of age; in reality, she was only sixteen. In November 1909, we find her in Portland, Oregon, in the role of Alaska Lou in Taylor's play “The Girl 
from Alaska”. In this adultery drama, the Alaskan girl is the ingénue brought home by the husband. Portland's correspondent for the New York Dramatic Mirror did not bother to mention Helen Barham's performance. ${ }^{25}$ The play was alternately programmed with Taylor's older success melodrama "Queen of the Highway", of which Shipman remembered that she had to ride "a horse to the footlights, rearing it so it pawed the air over the orchestra pit". ${ }^{26}$ The Alaska and Yukon tours, however, suffered from poor attendance, as did the company's winter stint in Oregon. In her memoirs, Shipman points out the changes that were occurring in the composition of the public, as the Alaskan audience no longer consisted of the "glamor-whores" escorted by gold diggers, but of "[t]he wives of respectable store-keepers and mine-operators". ${ }^{27}$ Implying that the latter expected something more cultivated, she calls Taylor Stock "second rate" and contrasts it with troupes featuring more well-known actors in competition with which Taylor Stock was bound to be outclassed. By the end of 1909, the Taylor show had closed and, in early January 1910, Helen Barham left for Salt Lake City to join the Sutton Players as their leading lady. ${ }^{28}$

The roles in which Barham appeared at the Grand Theatre in Salt Lake City between mid-January and mid-March 1910 earned her the highest praise so far in her acting career. On the occasion of her performance in "The Night Before Christmas", the New York Dramatic Mirror reported that "Helen Barham, the new leading woman, made friends at once. She is graceful and dressy, and has a good voice." ${ }^{29}$ When she played a French adventuress in the society melodrama "In A Woman's Power", the local press pointed her out as "the striking character of the drama. Miss Barham is emotional and the character of Laura gave her powers full sweep." ${ }^{30}$ About her role as a poor girl who falls in love with a Russian prince in "For Her Sake", another local paper commented: "Helen Barham has done nothing better since her appearance in this city than as Olga, a child of the people." ${ }^{1}$

Unfortunately for the leading lady of the Sutton Players, however, the demise of stage melodrama began to acquire nationwide proportions, and Dick Sutton announced that, from March 19, 1910, no more melodramas would be staged at the Grand. Through acting in such repertory and stock, however, Helen Barham had advanced from ingénue and soubrette parts to playing the leads. She remembered to have "had fun and a diversity of parts". ${ }^{32}$

While recounting the fun, Shipman listed, remarkably succinctly if related to Singer's analysis, typical features of sensational melodrama. In addition to the stock parts and repertory plays, she mentioned the musical and comical breaks between each of the four acts, the painted backdrops, the presence of live animals like pigeons and horses on the stage, and the interaction between actors and audiences. For Singer, these are precisely the elements that contributed to the distinctive pleasures of sensational melodrama, constitutive of a realism 
that he calls "an apperceptive aesthetic of media-awareness, a fascination with what technique and artifice can do", which, moreover, "operated alongside an aesthetic of absorptive realism." ${ }^{33}$ As I will argue further on, both modes of realism can be discerned in Shipman's writings and in her cinematic work.

Helen Barham's career in cheap melodrama thus exemplifies both the heyday and downfall of the trade. The distinctive pleasures it offered were overshadowed by its routine character and its commercialism and were outdone by more innovative and newer amusements such as vaudeville and the nickelodeons. ${ }^{34}$ The nickelodeons, moreover, offered film programs for a nickel, a much lower price than a seat cost in the "ten-twenty-thirty". The change was most graphically illustrated by the fact that, by the spring of 1910 , literally all New York City venues that had once offered live melodrama were showing films, while stage "melodrama with all its people ha[d] become little more than a memory." 35

288 Elsewhere, the transformation took shape more gradually. The number of companies touring the United States diminished "from an all-time high of 420 companies in 1904 to 337 in 1908, 236 in 1910, 95 in 1915, and a mere 25 in 1918." ${ }^{6}$ Seattle's first—and, as it turned out, temporary-stock and vaudeville theater was converted into an exclusive motion picture venue in 1911, while the stage remained the city's preeminent form of popular entertainment, its nickelodeons notwithstanding. ${ }^{37}$ Against this backdrop, it is likely that Helen Barham considered the moving pictures not yet as an alternative for the branch of staged entertainment in which she was making her way, even though she was noticing the signs of its downfall. Although "very broke and very disheartened" ${ }^{8}$ when her affiliation with the Sutton Players came to an end, she opted to take her chances in other, and more distinguished, types of live popular entertainment. She turned to vaudeville, despite an earlier failed attempt to enter this branch of the trade. ${ }^{39}$

By the end of the first decade of the century, American vaudeville prospered. As with the late nineteenth-century transformations of staged entertainment in Europe, such as the shifts from the café-concert to music-hall in France, and from the tingel-tangel to variété in the Netherlands, in the United States, variety and burlesque shows had been "uplifted" to vaudeville and were providing decent and popular entertainment for large audiences throughout the country. Vaudeville's advance is epitomized by the career of another Seattle-based showman, Alexander or Alec Pantages, who opened his first theater in the city in 1902 and had come to own and manage vaudeville venues up and down the Pacific coast by 1909, from Los Angeles to Vancouver, a theater chain known as the Pantages Circuit. At the peak of his success in the middle of the twenties, his chain consisted of more than 70 vaudeville houses located throughout the United States and Canada. ${ }^{40}$ 
In 1909, Shipman secured a part in a seventeen minute long sketch booked for the mid-February program and advertized in a Seattle paper under the headline "Unequalled Vaudeville": "Dave Williams \& Co, present the comedy playlet 'According to the Code"”, with Verne Layton as Lafe Lukins, Dave Williams as Sam Malone, and Helen Barham as Mary Leach. ${ }^{41}$ That it concerned the Pantages Theatre can be confirmed from an announcement and advertizement in The Seattle Star of February 13, 1909. Pantages offered medium-time vaudeville. As a manager, he was known for his exceptionally sensitive understanding of what his audiences in the somewhat smaller cities wanted, as well as for supervizing the programming of his theaters in person. His bills included film screenings, which, on the 1909 bill, were listed (without further detail) under the caption "Pantagescope. New Motion Pictures" and were given the closing spot, which followed right after the headliner. It was typically reserved for "acts that were so boring or downright annoying that they might encourage patrons to leave before the next show [began]"..$^{2}$ That people left, accords with Shipman's recollections: "Alec Pantages used them to empty his vaudeville theater and accommodate the next file of customers." 43 But she liked to watch the films, remembering a Pathé trick film in particular, but not its title.

Helen Barham spent six weeks performing in the Dave Williams sketch in the Pantages Circuit, after which she tried, along with her friend Lillian Mullally, to repeat this relatively comfortable experience with a show of her own comprized of several numbers. ${ }^{44}$ Pantages let them test it in Everett, Washington, but the local manager "canned the Act" after its first performance because the audience did not appreciate it. ${ }^{45}$ Barham and Mullally adjusted it for a show in Snohomish, Washington, and then headed to Vancouver, where both actresses found small parts in an operetta, "Bohemian Girl"-Helen Barham as a chorus-girl, one of the lowest ranking roles she had yet had. When Maurice Barham came to meet them in Vancouver, the girls were so broke and hungry that he shipped his sister home to Seattle right away. "My eighteenth birthday was due in October. I was a tremendous and resounding failure in my chosen profession, apparently doomed to eternal stranding and near starvation." ${ }^{46}$

\section{Entracte: Some Reflections on the Memoirs as a Source}

The attentive reader will have noticed a problem in the chronology, for which I have thus far followed Shipman's memoirs. The Pantages engagement took place in February and March 1909, that is to say in between and not after Helen Barham's affiliations with the Taylor Company, and, most notably, also before her trip to Alaska with the latter and before her engagement with the 
Sutton Players in Salt Lake City. Now, two explanations are possible for Shipman's rearrangement of her experiences. The first is that her memory simply failed her. In letters to her fan-pals at the time she was writing the memoirs, she admitted to having trouble recalling dates:

All this in the memoir book-which it really is and NOT a fillum history. It will not be liked by all ye ardent and factual COLLECTORS. It happens to be backgrounded by the movie era but it is most terribly a personal narration and spares no horses. This may be against it for publication. The facts, ma'am, just the facts! [...] Are you getting, or wanting the credit sheet [...]? It lists most of it, including books and magazine articles. But doesn't give dates. Maybe I'm past the dating stage! ${ }^{47}$

The Nell Shipman Archive at Boise State University Library holds two different 290 | typescripts of her curriculum vitae, both drafted by herself. Only one of these, entitled "Nell Shipman-dossier", is provided with dates; she may have composed it in response to such requests. ${ }^{48}$ It lists her engagements in the same order: Pantages after Taylor.

Possibly in an effort to compensate for the admitted weakness of her memory, Shipman took great pains to get things right. Her correspondence documents that she inquired at libraries and archives to check the dates pertinent to her career and that she consulted the collectors with whom she was in touch. She had lost several of her scrapbooks and only one of them survived the vicissitudes of her life. ${ }^{49}$ It chiefly contains clippings from her Florida years from 1926 to 1932, and has a jotting on the cover in her handwriting: "Original Vitagraph + First National Lost". Her main memory aids, then, were two autobiographical texts published years before, "This Little Bear Went Hollywood" and "The Movie That Couldn't Be Screened," both of which deal with her film work. ${ }^{50}$ Her stage career, by contrast, was the subject of some of the fictionalized autobiographical manuscripts that she herself stored, among which was the unpublished first part of her 1931 autobiographical novel, Abandoned Trails. ${ }^{{ }^{1}}$ Given the mnemonic difficulties with which she was faced, it is impressive how much of what she presents of occurrences, places, and names turns out to be correct when checked, or at least plausible.

A second explanation for her having recounted her stock and vaudeville experiences in this order may pertain to her desire to structure the narrative. After all, by the time she wrote her memoirs, she was first and foremost an experienced writer. She had been writing throughout her life, in a variety of genres, including novels, a children's book, autobiographical fiction and nonfiction, scenarios, and letters. The basic structure chosen for recounting this stage period of her career is one of the alternation of relative successes and 
plain flops, with overall advancement evident primarily in the status of the roles she had played: from ingénues to soubrettes and then to leads. Another sign of the progress made can be seen in the stature of the staged amusements with which she was successively affiliated, that is to say, from repertory melodrama to vaudeville. Admitting that she had returned to Taylor's and Suttons languishing stock companies would have spoiled the narrative preparation for what Shipman presents as the climax of the episode, to which I shall turn shortly. This retrospective arrangement, then, could also figure as an instance of artistic license taken by the author.

The issue of artistic license likewise comes to mind in connection with Shipman's dwelling time and, again, upon her lack of talent for "her chosen profession". Basically, she constructs the image of herself as a hopeless misfit, both as an actress and in her ability to make a living. At best, she was having fun or had been just a pretty face, but having a talent for acting? Not in the least. Given that we are dealing with a former film star narrating her pre-cinematic past, the tone in which she speaks of it cannot simply be assessed as being what she herself called "an unpompous, stuffyless way of doing the damned thing." ${ }^{2}$ Rather than merely the opposite of affected pomp, the tone is often plainly degrading, and, in light of the contemporary reviews, quite unjustly so.

Three factors may have impelled this self-denigration. One is a staple element of women's autobiographical narrations as remarked upon in literary studies: women tend to represent their accomplishments as resulting from mere luck or from the efforts, insights, and generosity of mentors and friends. ${ }^{53}$ Shipman's memoirs seem to be a case in point: luck plays an important role, as do the efforts of others "to make a better actress of [her]" 54 and to offer her opportunities, as she credits her mentors Taylor and Pantages with having done. The serial alternation of successes and flops, moreover, yields the impression that each part she managed to secure was owed to a surprising turn of fate: whatever had previously occurred scarcely exercised any effect on what happened next. Instead of a talent or ambition for acting, then, it is Shipman's stamina, which motivates her actions and choices. It becomes clear that such stamina constituted an important trait of her favorite screen parts as well.

A second factor in the belittlement of her efforts may have been the historical moment during which she wrote the memoirs. Her correspondence reveals that Shipman began planning to write them in September 1966, when she mentioned the project to a literary agent. ${ }^{55}$ But apparently it took a while before she could really "settle down to the task", as she remarked to a film collector in March 1968, a date also mentioned by her son Barry Shipman in his "Afterword" to the memoirs. ${ }^{56}$ She had completed the first book of what was meant to be a series by February 1969. ${ }^{57}$ Throughout the 1960 , her cor- 
respondence with film buffs and historians pestering her for information on her career on-stage and in cinema had made her aware of a resurgent interest in the silent era and its legends. The 1967 publication of the reminiscences of her Idaho carpenter and set-dresser, Lloyd Peters, moreover, convinced her that there was not only a demand for facts and figures among film historians, but also a niche for personal accounts of individual experiences in the silent cinema. In her correspondence, she defends her own manuscript accordingly: "It is a self-portrait, a first hand account of one woman's doings in a strange and unique world only now coming into common interest. ${ }^{8}$ Furthermore, she refused to "add yet another Now It Can Be Told to the list" 59 or another "Little Me-usually with an 'As Told To' format." ${ }^{60}$ She obviously knew of the gossiping and ghostwriting practices in the composition of the autobiographies of the era and aspired instead to a more personal perspective and tone. The main problem Shipman faced in the 1960 s was that she, in contrast to such "as told 292 | to" memoirs, was writing against film-historical oblivion. ${ }^{61}$ Until then, official film history had virtually ignored her presence and work in the American silent cinema. So how could she boast of her talent and merits without sounding merely pretentious and pathetic? In my opinion, Shipman chose understatement as one of her rhetorical strategies.

A third rationale to disparage Helen Barham's talents and accomplishments may have been that Shipman was writing as a film actress about her past as a stage actress. Most pertinent to her experience had been that the cinema required styles of acting that differed from those common on the stage. In her memoirs, she devoted several pages to the issue in order to convince the reader that she was aware of the differences:

My first scene for Mr. Sturgeon [at Vitagraph] was a single take. I knew that the Director behind the spindly tripod was sweating it out. He hated stage actors and I was one. He said they were given too flourishing entrances and exits, exaggerated take-ums, emphasized registration of emotions which for the camera were best expressed by a lifted eyebrow. At the Lodge dinner table, if his fritter-minded leading lady would listen, Rollin held forth on the evil of stagy mannerisms, [...]. Rollin said, and this annoyed me because I was certain that in all my stage-acting days I never did it, the Ham indulged in a ducking of his knees like a quasicurtsy before making his exit toward the off-scene menace. ${ }^{62}$

Here, between the lines, Shipman makes the point that her acting capabilities, to the extent that she possessed them, were suited much more to the screen than to the popular stage. In this sense, her dismissive attitude reflects an opinion widely held by film people in the 1910s and 1920s-the tribe to 
which she once belonged and amidst which she now reclaimed her historical position. Significant in this regard is her anecdote about Mary Fuller, whom she knew from the play "At Yale", and whom she met again some years later at a Universal party, after Fuller had become one of the most popular serial stars of the early 1910s. Fuller advised Shipman not to allude to her stock theater past ${ }^{63}$ which suggests that the alternative choice would have been for Shipman to leave her stage career out of the memoirs altogether. But she decided otherwise. She stated that her "personal narration" required that various strands make up its leitmotif:

a magic mantle, a covering into which was woven the warp and woof of dreams, a garment of many broken threads which botch its dimly discernible pattern. Many broken threads going, seemingly, nowhere; but some running straight, so that their ends are traceable to their beginnings—-result" clearly linked to "causal event." ${ }^{64}$

Some of these straight threads-as I argue, expanding upon Shipman's own views - sprang precisely from her experiences on the popular stage. They include the resolve to pursue an acting career against all odds and the familiarity with the modes of realism operative in melodrama set in the Northwest.

\section{The Climax of the Stage Period}

If Barham/Shipman felt like "a tremendous and resounding failure" in 1910, she did not act upon it. Instead, she applied to the "posh" stock company of George Baker from Portland, Oregon in October and landed the leading part of Necia in Rex Beach's Northwest drama "The Barrier". A 1916 advertisement with photos of Nell Shipman in various leads "in plays and photo-dramas", records that she starred in "The Barrier" for two seasons. ${ }^{65}$ In her memoirs, she writes that the show closed as she "began to swell" from pregnancy, about a year after her application. ${ }^{66}$ This appears not to have been exactly the case; the show went on in September 1916, but with Eleanor Haber instead of Helen Barham in the role of Necia. ${ }^{67}$

The American Amusement Company, as the troupe and crew responsible for the staging of "The Barrier" was named, performed in Idaho, Oregon, Utah, and Washington State from January until September 1911. Helen Barham had been especially engaged, along with other western players, for this transcontinental tour that followed after a highly successful first season in the eastern states. The reviews attest to the fact that "Necia [was] getting good notices" ${ }^{68}$ or, rather, that Shipman even in this case was using under- 
statement as a rhetorical strategy. The theater critic from Ogden, Utah, was impressed:

Miss Helen Barham, as Necia, the "halfbreed," was fascinating in a very difficult part. It is a decided rest to see an actress so capable of merging her own personality in that of the character she is playing, and just a word should be said of Miss Barham's voice: it is wonderfully resonant and readily responds to every emotion, doting a great deal to quickly win the sympathy of the audience for the unfortunate Necia. ${ }^{69}$

It is striking, in my opinion, that the critic noticed the actress' identification with the role. Its significance for her career, apart from its having been the high point with which she concluded her work on the stage, was quite precisely pronounced in the self-portrait "Me", as published in the magazine $P$ Po- $^{-}$ 294 | toplay in February 1919:

Finally, I was given "Necia” in Rex Beach's play “The Barrier.” My first part in pictures was "The Woman” in GOD's COUNTRY AND THE WOMAN, a part very similar to "Necia." ${ }^{70}$

This autobiographical text was likewise a narrative building towards a climactic ending, but the heart of the matter is the connection that Shipman makes between the role of Necia in the play and The Woman's part in the film. Already at the time, and not only in retrospect, it appeared to be of pivotal importance for her oeuvre. Several more roles that she chose or wrote for herself later on, and quite a few protagonists of her stories, are literary and cinematic sisters of the Necia of Beach's play. The kinship between the two parts as alerted to by Shipman also draws one's attention to their common generic setting: the literary, theatrical, and soon-to-be cinematic genre of Northwest drama. ${ }^{71}$ The 1908 novel, 1910 play, and 1917 film THE BARRIER, all produced by Rex Beach himself, epitomize the migration of this genre through different branches of American popular culture of the early twentieth century.

Northwest drama consisted of stories set in the Pacific Northwest or Arctic North of the United States or Canada, which were circulated as dime novels or serialized novels or short stories in pulp magazines and in other late nineteenth and early twentieth century commercial vehicles for popular fiction. Quite a few fiction authors and playwrights picked up this genre at one point or another, but literary scholars consider Jack London to be its most masterful exponent. ${ }^{72}$ While Shipman proudly remembered having been compared as an author to Jack London in the $1930 \mathrm{~s},{ }^{73}$ she played Londonesque heroines on neither stage nor screen. However, Northwest drama is equally relevant to the 
extensive oeuvres of Rex Beach and, most notably, James Oliver Curwood, and their work was no less popular with readers and film-goers of the 1910s than London's. ${ }^{74}$

Rex Beach's writing career spanned forty years, in which he published numerous articles, short stories, and more than 30 novels. ${ }^{75}$ Fourteen of the latter were filmed, in addition to the sixteen original scenarios he had written since $1910 .{ }^{76}$ The Barrier was a best-selling novel in 1908, and, aside from being staged, it was also made into a film three times, first in 1917, independently produced by Beach himself. ${ }^{77}$ Shipman was not cast in this film, since she was affiliated with Vitagraph at the time, where, among other films, she starred in the Northwest dramas GOD'S COUNTRY AND THE WOMAN (1915) and BAREE, SON OF KAZAN (1918), each based upon the eponymous story by James Oliver Curwood. ${ }^{78}$

One of the charms of Northwest stories was that they were supposed to be based upon experiences and observations made by the author in person. Rex Beach, for instance, allegedly traveled the Yukon for five years, struck no gold in the literal sense, yet discovered a symbolic gold mine when he began to write adventure stories set in the wilderness of Alaska. ${ }^{79}$ James Oliver Curwood, a native of Michigan like Beach, reputedly spent much of his time hunting in and trekking the Canadian Northwoods, where most of his animal stories were set. The writing, moreover, turned him from an ardent hunter into a fervent conservationist in the mid-1910s. ${ }^{80}$ Allusions to first-hand accounts, a convention adopted from Western writing in general, apparently helped to authenticate the atmosphere and events set forth in Northwest stories. ${ }^{81}$ Shipman's association of herself with the part of Alaska Lou and her handed-down identification with the one of Necia, then, may be connected to this same tradition of authenticating fictional matter.

Northwest drama indeed shares other general characteristics with the Western. One commonality derives from the melodramatic propensities of frontier, gold rush, and adventure plots, inciting actions and conflicts in outdoor settings, and within an episodic narrative structure. Secondly, their plot devices encompass misjudgments, frame-ups, fights, perils, and narrow escapes that invoke discrepancies between "wilderness" and "civilization". Both types of stories likewise share the moralities of melodrama, with its sharply-edged portrayals of good guys and bad guys, in which the villain is "either an ugly gunslinger or a suave, polished hypocrite". ${ }^{82}$ But, with a closer look at Northwest drama, quite a few differences become apparent as well. As a corpus of stories taking shape in relation to a particular geographical region, it presents characters, kinds of events, and historical references that are rather specific. An examination of such elements in the novel, The Barrier, may serve as an preliminary attempt to sort out some of these..$^{83}$ 


\section{The Barrier as Northwest Drama}

The site of the action is a traders' post on the Yukon river named Flambeau. The central figure in the community is the trader Old Man Gale, also known as John Gaylord, who lives with Alluna and their three children, Necia, Molly, and John. The old man is wise, softhearted, and respected by everyone. Alluna is a Native American woman and is treated by him at once as a squaw and as a peer; in return, she obeys him as her master, yet with sincere loyalty to him. Molly and John look as if they were their children, but Necia does not. She is a very beautiful seventeen-year-old girl with a sun-tanned but comparatively fair complexion. Another figure in the community is 'Poleon Doret, a handsome and kindhearted French Canadian trapper, who, from the moment when he arrived four years earlier, has developed a deep affection for Necia. Into this company enters Meade Burrell, a descendant of Kentucky slave-holders and 296 a member of a military family, who has been sent to Flambeau to keep law and order. Of the stock character of the villain, the novel actually presents two: Runnion and Stark. The latter's evil schemes to win Necia furnish the plot with a succession of sensational events.

The novel offers an action and a romantic plot-line, which is typical for Northwest drama. The action plot makes use of two motifs: the search for gold and adventurers haunted by their pasts. The romance unfolds between Necia Gaylord and Meade Burrell. Their love is mutual, however hard each may try to resist or deny it. The motive for their reluctance centers on Necia's ethnic origin. To her and everyone else's knowledge, she is the child of Gale and Alluna, that is to say, a "half-breed", as children of a Native American woman and a white man were called at the time. ${ }^{84}$ For Lieutenant Burrell, marrying a nonwhite woman is out of the question. Meade fears that he would be cast out by his family and lose his job; Necia fears that he will only take her as a squaw or as a mistress. Such considerations give rise to remarkably realistic discussions about the obstacles for their love. In the end, Old Man Gale informs Burrell about the secret from his past and about Necia's "real", and entirely white, descent, revealing to him that Meridy Bennett is the name that corresponds with her identity.

Two social issues are addressed, both concerning women's social status. One is, as we have seen, the low status of a "half-breed" girl, the other is domestic violence of husband against wife. The issue of domestic violence is brought up in the context of John Gaylord's secret from his past. He was led to believe that the woman he loved, but who married John Bennett, was beaten by her husband. At her request, he took her child, Merridy/Necia, with him and raised it as his own. He was also led to believe that the mother was bound to follow him, but she died. 
The main characters in The Barrier do not entirely correspond to those that a typical Western drama would have offered and are therefore distinct to Northwest drama. There is no "rough but valiant" hero, ${ }^{85}$ but heroism is shared instead by the old trader, who is a benevolent father figure, and the self-sacrificing French Canadian trapper. As we shall see, the character can take on various moral qualities in the stories under scrutiny in this careerography and embodies a figure typical of Northwest drama. Also the gold-diggers can be either evil or endearing. Above all, there is the girl, who, albeit pure, is not quite the "modest maiden with hidden strength in her character", ${ }^{86}$ a staple of $19^{\text {th }}$ century sentimental melodrama, neither is she the diamond-in-therough variety of girl familiar from the Western. She is courageous and frank, to be sure, but she is also reflective about what is happening to and around her, and candid in addressing and questioning patriarchal and racist social conventions. Typically, in Northwest drama, she is knowledgeable about the wild surroundings in which she was raised, and is accordingly self-reliant, yet also dreams of leading a life in more modern places in (American) society. She is representative of what Shipman called "the outdoors gal". Finally, Shipman has pointed out one more feature of what she called "Northwoods" drama: "And remember: never a mother!" 87 That is to say, if mother characters were present, they were not the outdoors girl's mother, just as Alluna does not appear to be Necia's. ${ }^{88}$ This presence of a benevolent father figure and the absence of a mother figure was shared by Northwest drama and that wellknown other sensational genre of 1910 s cinema, in which courageous and self-reliant young woman characters figured prominently, the serial queen melodrama.

Very much like sensational stage melodrama, The Barrier situated most of its dramatic crises outdoors. ${ }^{89}$ That is to say, the crises took place in the vicinity of the traders' post, on the water and on the banks of the Yukon river, and in the hills and on the trails alongside it. It is in this rough landscape that Necia spends most of her time: she explores with the gold-diggers, faces the perils associated generically with villainy, and experiences the equally typical rescue that is paired with heroism. Although the season is summer, the novel contains quite a few references to Arctic winters and their hazards. Such settings provide a range of possibilities for sensational scenes, which exploit the dangers resulting from weather changes or other forces of nature as well as from the physical vulnerability of people in rough environments.

The character of the outdoors girl is capable of both abiding by and criticizing the rules of the rough environment in which she lives, as well as those of the civilized world: in the discourse of the genre named "wilderness" and “civilization”. If the wilderness is Northwest drama's, and the outdoors girl's here and now, then civilization is situated in a not-so-near future or at a far 
spatial distance. Neither mode of existence is simply contrary to the other. In Rex Beach's novel, both the wilderness and civilization have two faces and these ambiguities are articulated in what happens to the outdoors girl. The wilderness is both good and bad to her: good in that it offers her a protective home with a gentle father and a substitute mother, and, because she grew up in it and knows it so well, a material advantage over others. The wilderness is bad in that it exposes her to the greed and the vice of what often were called "types of red blood and cold steel", that is to say, white American men from whom the setting elicits not only the best but also the worst, because they are either outlaws or proponents of laws by which woman's social and sexual dignity is denied. The two faces of the civilized world are shown in the attraction of living the life of a white man's respected wife, on the one hand, and the humiliating contempt for women of Native American or partly Native American descent, on the other. In this manner, the outdoors girl could be played as 298 an ingénue and a modern woman in alternate scenes.

\section{Nell Shipman's Options and Choices 1911-1912}

As Necia in “The Barrier” turned out to be Helen Barham's final stage role, an exploration of her professional options and itinerary is in order here. Helen Barham turned eighteen on the day that she boldly applied to the George Baker Stock Company. Her determination provided her with the role, as well as with a "Casanova":90 the manager of the company, Ernest George Montague Shipman (1871-1931), like herself a Canadian by birth but working in New York and Seattle. 21 years her senior, he was a theatrical producer and promoter with over fifteen years experience in the field. Helen Barham, already called Nell in the vernacular, became Nell Shipman on August 22, 1911; on February 24, 1912, their son Barry was born in Pasadena, California, where the couple had settled. ${ }^{91}$

Thus, at the age of 20, Nell Shipman had basically three options, the first of which evidently did not appeal to her. This was the prospect of living the life of Mrs. Ernest Shipman, raising their child and standing by her husband. Her marriage, moreover, had been motivated less by lust or love than by professional considerations, as she, with greater candor than in her memoirs, articulated in the autobiographical novel Abandoned Trails (in which the protagonist of the story is adorned with the name Joyce):

The trail to stage success lay through a man's passion. A man with influence, power and money to be expended upon herself. That was the only way. No girl, lacking money, could find the trail alone. And even money, 
Fig. III.3: Ernest Shipman.

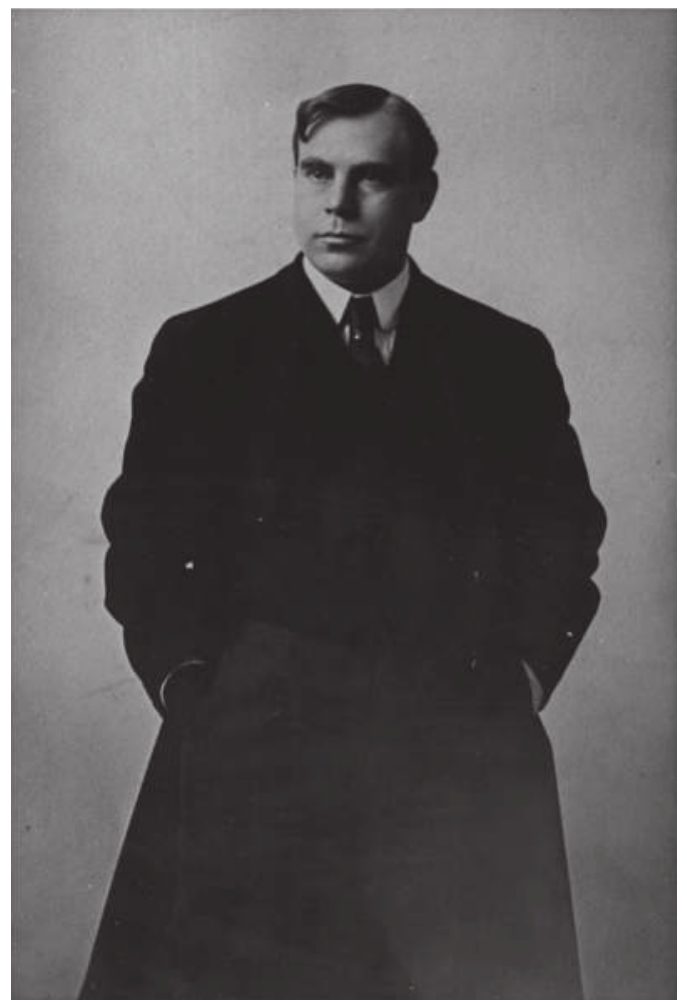

without influence and management, was worthless. Joyce must have an angel. Someone to back her, put her ahead in the show game; play her, like a pawn; make the public pay to stop, look at her and listen! ${ }^{22}$

This excerpt can be read as being more than merely a reflection on Nell's relationship with her husband Ernest. It expresses Nell Shipman's professional drive and articulates the conditions for realizing it. A public looking at her and listening, that is what made Nell Shipman tick. Her ambition was to be an actress and she had become aware that she was not capable of making it happen all by herself. Although one may disregard this as the romantic dream of a star-struck teenager, or as the inability of a woman to pursue a career independently, Shipman's later writings and actions suggest that acting was the guiding thread of her career throughout her lifetime. A paying public, moreover, enabled her to act in both senses of the word, that is to say, both as an actress and as an agent in professions such as writing and film production. What she never gave up working towards and craving, was, in the words of her son Barry, "applause and recognition" 93 for her determination and achievements. 
The weak spot in her conception of "the trail to success", however, was that she relied, time and again, on "a man's passion" in order to secure support. Despite recurrent disheartening experiences, some of which will be addressed in due course, Shipman refused to abandon that combination. It may well sound like a self-evident conclusion in retrospect, but the influence that she allowed her men and her lovers to have on her career and the considerable extent to which she made herself dependent on their professionalism or lack thereof were important factors in both Nell Shipman's successes and her failures. Ernest Shipman proved to be one of the more professional of them.

The second option for Nell Shipman, in 1912, was to pursue her stage acting career further. Although she complains in her memoirs of having been "overweight and not healthy after her bout with maternity", 94 the Shipmans initially envisioned themselves continuing in the popular theater. An attempt at a comeback with a sketch in the still-thriving vaudeville failed, however.

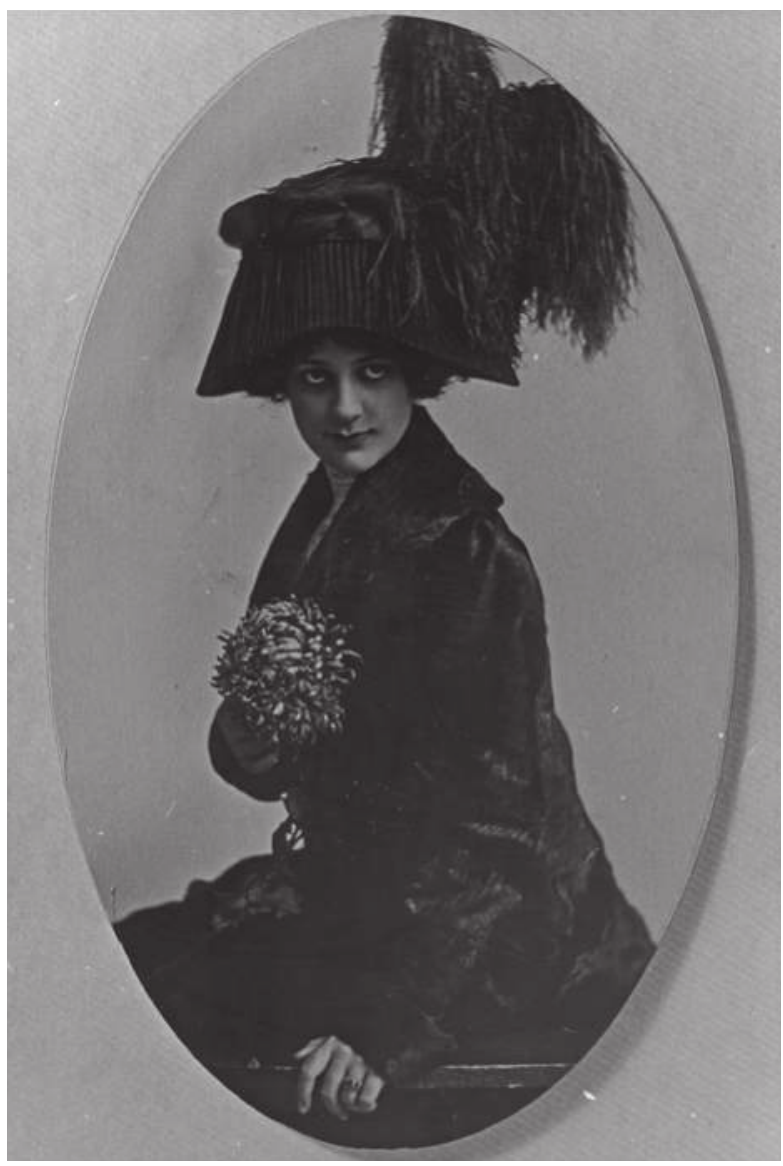

Fig. III.4: Nell Shipman c. 1912, maybe opting for vaudeville. 
Moreover, "the legit was shutting down everywhere", ${ }^{95}$ as Shipman encapsulated the situation discussed above. Not only was she herself out of work and lacking an income at the time, but her husband soon found himself in the same predicament.

During these years, many of their colleagues from the popular stage were, as was its public, switching not only to vaudeville but to the expanding film business. Among Nell Shipman's stage acquaintances who had switched over to cinema prior to 1912 were Mary Fuller and Clara Kimball Young: ${ }^{96}$ Fuller (1888-1973) had been an actress with Vitagraph and Biograph as of 1906, and with Edison as of 1909. By 1912, she was featured in her own film series, the notorious WHAT HAPPENED TO MARY?, which turned her into one of the most popular American screen stars of the early and mid-1910s. ${ }^{97}$ Clara Kimball Young (1890-1960) was with Vitagraph as of 1909 and had acted in some 24 films by the end of 1912, including the first adaptation to the screen of the melodrama UNCLE TOM'S CABIN..$^{98}$ In a 1919 interview, Kimball Young remembered that it "was hard then, eight years ago, to get stage folk into the despised pictures." 99 Similar reflections were expressed by another former stage performer, Gene Gauntier, who, by 1912, had been working as a film actress, scenario writer, producer, and critic for some six years: "like the rest of the legitimate profession I looked down on [moving pictures] with contempt and felt sure that my prestige would be lowered if I worked in them.” ${ }^{100}$ Nonetheless, she began writing and occasionally acting in movies in 1906, while also continuing to act in stage melodrama for two years. By 1908, the rivalry between stage and screen had grown so strong that Gauntier still did "not dare to speak of [her] screen work" to her stage managers and colleagues: "[a]n edict went forth that no one who worked in pictures would be employed so I kept my dark secret." ${ }^{101}$ By 1912, however, acting and other careers in the film business were becoming acceptable and gaining allure. One of the early records of Nell Shipman's entrance into the film industry was a 1912 article in which she argued for more consideration from "the foremost writers and dramatists of the present day" for this "new field, rich in promise and persistent in its demand." ${ }^{102}$

As D.J. Turner has chronicled in detail on the basis of announcements in the Moving Picture World, Ernest Shipman ventured into the so-called "film exchange", the sale and promotion of films. Following his entrepreneurial drive, he had already succeeded in selling an hour-long film of a championship boxing fight to England and to Latin American countries in 1908. Between 1913 and 1919, he was affiliated with at least four independents and one major, Universal, which hired him to sell NEPTUNE'S DAUGHTER, a 1914 feature directed by Herbert Brenon and starring Annette Kellerman. ${ }^{103}$ His talent for promotion and self-promotion has been emphasized by Peter Morris, 


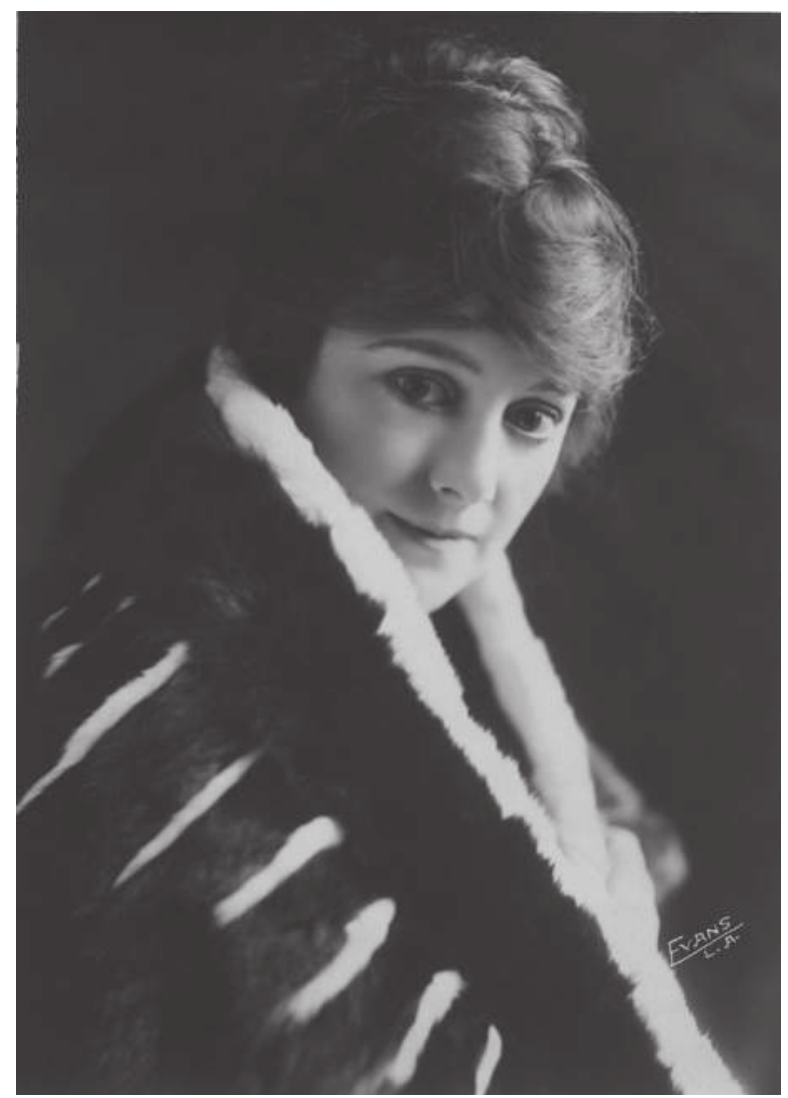

Fig. III.5: Picture postcard Gene Gauntier.

along with his frequent highlighting of the Canadian aspects of the films in which he was involved. ${ }^{104}$ Nell Shipman adopted this promotional approach for her own career, as will be illustrated by many of the instances to follow. She remembered that "Ernie [...] dreamed up what he called Ten Continents Exchanges, with letterhead addresses dotted around the world." ${ }^{105}$ Here "Ten" seems to have been a slip, in view of his nickname "Ten Percent Ernie", for the firm's name was actually Five Continents Exchanges; but, as such, one may also read in it an allusion to the phantasmagorical dimension of her husband's "promotional perspicacity". For this company, Nell Shipman "composed a list of features, presumably in work or already made: a feat less than nothing for my stoked imaginative powers." ${ }^{106}$ Ernest Shipman maintained this practice of offering both finished films and those in the making for sale throughout the 1910s, so that his 1918-1919 advertisements in the trade press also included two titles from Nell's pen, of which, as D.J. Turner has pointed out, no further trace can be found..$^{107}$ By this time, Ernest Shipman was operating as a sales 
agent under his own name and had offices in New York and Los Angeles. ${ }^{108}$ By and large, then, wife and husband went their own ways in the film business, with, as is well known, one notable exception, when both were involved in the production of BACK TO GOD'S COUNTRY in 1919.

Ernest Shipman's greatest accomplishment, according to Turner, concerned the production of films, because he had, "in four short years, from 1919 to 1922 , brought about the incorporation of five companies and produced seven feature films in Canada." ${ }^{109} \mathrm{He}$ had been engaged in film production as early as 1912, with the five- or six-reeler ONE HUNDRED YEARS OF MORMONISM produced by the Utah Motion Picture Company and directed by the leading man from "The Barrier", Norval MacGregor. ${ }^{110}$ Contemporary sources report that the working scenario for this dramatization of the history of the Mormon religion was written by Nell Shipman, even though she did not claim it as hers in her memoirs or in her 1912 article cited above (and even though the authorship was contested at the time). ${ }^{111}$ The Moving Picture World placed emphasis on the historical fidelity of the script:

A tremendous amount of data had to be worked over before the story was in shape for motion picture purpose. Nell Shipman, a Los Angeles photoplay writer, was engaged to arrange the data and prepare the working scenario. ${ }^{112}$

This was the third option for Nell Shipman in 1912, which she eventually chose: to forget, at least for the time being, about acting and to write and sell film scenarios instead. 



\section{Nell Shipman and the American Silent Cinema}

\section{NELL SHIPMAN AS A SCENARIST 1912-1917}

Few of the "yarns", "tidbits", and "outfits", as Shipman used to call her scripts from the early 1910s, can still be traced today. The Shipman filmography established by Turner shows which ones have been filmed and released and by which company. ${ }^{1}$ Thus, from 1912 through 1917, she sold scripts to various companies, including Selig, Australasian Films, the American Film Company, the Palo Alto Film Corporation, ${ }^{2}$ and, most notably, Universal. To be sure, Shipman continued writing scenarios after 1917, but, after this date, she was usually involved in the films' production, so I shall discuss them in that context. The length of her scenarios of the 1910 s varied from one reel to multiple reels and to series in several installments; the genres included historical drama, such as ONE HUNDRED YEARS OF MORMONISM Or MY FIGHTING GENTLEMAN, sensational melodrama and what Shipman called "outdoor yarns" SUch as THE PINE'S REVENGE, a drama of the Northwoods, or THE MELODY OF LOVE, a Western drama with a gold-rush motif. ${ }^{3}$ Neither of these scripts has been preserved in the format of a scenario, and none of these films is known to survive today. However, the Shipman Archive holds three items relevant to the topic: a printed synopsis of a 1912 series called THE FEMALE RAFFLES SERIES of Pноторlays; a 1916 scenario with the title "The Last Empire," which to my knowledge was neither sold nor filmed; and Shipman's novelization of the 1915 Universal series UNDER THE CRESCENT, which was based on her original scenarios. These documents will be discussed after a more general assessment of the conditions and status of script writing in the early 1910 s.

In March 1910, the Moving Picture World published an editorial item debating the status of the scenario writer, under the title "Giving Credit Where Credit is Due." On the one hand, it was observed that the public was increasingly 
curious to know the names of the main actors, while, on the other hand, "the Edison Company, Selig and other manufacturers are publishing the names of their noted authors," which included Beach and Curwood. ${ }^{4}$ The question that remained, according to the trade paper, was whether the public was as interested in the names of the scenarists as it was in those of the performers, or, in comparison to the theater, in those of the playwrights. Because within the film industry, "there does not appear to be any scenario writer who is making name and fame so that his work is extensively requested." ${ }^{5} \mathrm{~A}$ point to be inferred from this article is the hint to film producers to take the legitimate theater, which thrived on a firmly-established cult around stars and authors, as a model for change. A follow-up entry on the topic repeated the call for the scenarist to be given special mention, for the reason that the "writing of a scenario is a distinct profession." ${ }^{6}$ Nell Shipman, in her 1912 article "A Call to Arms for the Scenario Writer", arguing in the same vein, calls for an on-screen credit:

Every playwright in the legitimate drama stipulates in his contract that his name shall appear on all advertising matter, and is not the silent drama quite as worthy? [...] Let the author receive his share of fame and censure by the flashing of his name on the screen. ${ }^{7}$

By 1912, scenarios were copyrighted and, in articles and reviews, plot construction was distinguished from the drafting of a working scenario, but the acknowledgement of this distinction in advertisements or in screen credits was not common practice yet. Epes Winthrop Sargent, a scenario writer and editor at the Lubin Company, started a column, "The Scenario Writer", in the Moving Picture World in 1912 and by 1913 had renamed it "The Photoplaywright", thereby attributing some of the status of the theater playwright to the cinematic craft. His weekly column offered instructions for both aspiring and experienced scenarists and documented new developments in the craft. In January 1913, it featured Nell Shipman, who, that same month, had begun to promote herself as a "photoplaywright" in the trade paper. Her advertisement offered:

Books and Plays dramatized for camera.

Scenarios written to order for authors, playwrights, publishers, etc. Original scenarios for producers. ${ }^{8}$

Shipman presented herself as a professional scenarist from the moment that she had won first and second prizes in a scenario contest conducted by the Egan School of Drama, Music and Fine Arts in Los Angeles. ${ }^{9}$ During the year 1913, she issued at least five press releases announcing new assignments and 
projects, each time calling attention to her latest accomplishments. ${ }^{10}$ In the first of these, she proclaimed to have secured the scenario rights from wellknown novelists such as George Randolph Chester, Louis Edmont Vance, and Anna Katherina Green. In a paragraph under the heading "Mrs. Shipman is busy," Sargent commented upon the announcement: "In representing the fiction author Mrs. Shipman is a little ahead of the times, but not very far." ${ }^{11}$ Also the New York Dramatic Mirror considered Shipman to be right on the ball of the newest developments:

The growing demand for the book photodrama marks another milestone in the advance of the photoplay industry, and in keeping with this spirit of progress, it is unlikely that any more 500 or 1000 feet scenarios will emanate from Nell Shipman's pen. ${ }^{12}$

Another element of Shipman's professionalism was her insistence on the necessity of understanding "the technicalities and limitations of the camera", as she stated in her "Call to Arms". In doing so, she distinguished herself from the amateur scenario writer, for whom the market stood wide open. In The Classical Hollywood Cinema Janet Staiger contends that the changes in scenario writing practices during the silent era entailed a gradual yet systematic subdivision of tasks. If the scenario for one- or two-reelers had consisted of a plot outline, which the director transformed into images, by 1913, the plot writer and "the technical expert who specialized in translating a story into a continuity script" were two distinct functions while the director only got to see the scenario once it was "complete in every detail". ${ }^{13}$ Nell Shipman's self-promotion, in short, exposes the major shifts in scenario writing of the early 1910s: the adaptation of literary and theatrical sources, the distinction between plot construction and a continuity script, and an increasing professionalism in the craft.

The assumption that multiple-reelers required plots written by playwrights and novelists, along with the further subdivision of tasks in the scenario departments, brought about a rejection of amateur scenario writers after 1914. To "dramatize for camera", as Shipman characterized her work, became the task of a studio editor or a continuity writer. Unlike staff "men" like Gene Gauntier at Kalem, Jeanie McPherson and Grace Cunard at Universal, and Anita Loos at Biograph, Nell Shipman was never hired in this capacity and there are no indications in her writings that she ever aspired to become a studio staff member. To be sure, by 1915, she, and Ernest too, thought "that it seemed a good time to get me on the payroll," ${ }^{14}$ but in which capacity, as a scenarist or an actress, was apparently an undecided question. In her 1915 press releases, she increasingly added the designation "actress" to her profes- 
sions as "authoress" and "photo-playwright". ${ }^{15}$ At any rate, in the three years following her formal entry into the film business, Shipman continued writing scenarios on a freelance basis, but on the basis of Turner's and my own research into the trade papers, it is possible to say with certainty that only an eighth of them were actually filmed and released. Among these were, in addition to the titles already cited, the prize-winning social drama OUTWITTED BY BILLY (Selig 1912, two reels), the serial UNDER THE CRESCENT (Universal 1915, six installments of 2 reels each), and two films featuring Jack Warren Kerrigan, THE WIDOW'S SECRET and SON O' THE STARS (both Universal 1915, 2 and 3 reels respectively). A third Kerrigan film for which Shipman wrote the scenario was the aforementioned production, THE MELODY OF LOVE, which she was said to have also co-directed and acted in. ${ }^{16}$ In March 1915, her mere presence at the opening of Universal City was noticed: a sure indication that Nell Shipman had successfully established herself as a professional scenarist. ${ }^{17}$

308 A closer look at the documents in the Shipman Archive may shed some light on her scenario writing practice in the 1910s. A preserved scrapbook contains a clipping with the synopses of the series THE FEMALE RAFFLES SERIES OF PHOTOPLAYS. It is a printed copy yet lacks indications of its aim or source. Nonetheless, it states that Nell Shipman is the author and that the first episode of the series, THE MYSTERY OF THE BALL OF YARN, was copyrighted in 1912. ${ }^{18}$ Its format seems typical of a scenario of the day: it offers characters and plots and it promises enticement with blurbs like "and here follows a series of tense situations, an abduction, a chase," or "[t]his story is fraught with many exciting events"-examples of sensational scenes to be materialized during the shooting. Foreseen were ten one- or two-reelers, each featuring the main character-"a wicked female"-in a detective story. ${ }^{19}$ It was not conceived as a serial, with a consecutive story and cliffhangers, but as a series, with a separate plot in each episode. Such series films came into fashion after 1909, when Gene Gauntier initiated her GIRL SPY series, and, as was noted previously, by 1912, they were entering their heyday with WHAT HAPPENED TO MARY?, starring Mary Fuller. Characteristic of the early series and serials was the female protagonist: whether a good or a bad girl, she was always independent and intrepid. ${ }^{20}$ Shipman's main character was one of this sort, a female criminal or "Raffles" named Jess Graydon, who unremittingly succeeds in defying the detective, but who, in her turn, is most often outwitted by some little boy or poor girl, to whom is eventually given the reward for returning the jewels that Jess previously stole. According to the memoirs, only the copyrighted THE MYSTERY OF THE BALL OF YARN was actually filmed, with Nell Shipman as the protagonist and Norval MacGregor as the director. 
Shipman ventured once more into the format of a series constructed around an intrepid female protagonist with her scenario UNDER THE CRESCENT, which was released under Universal's prestigious Gold Seal brand in 1915. Each of the six two-reel episodes was a complete story in its own right and bore its own title. ${ }^{21}$ This notwithstanding, Shipman also novelized it as a consecutive story divided into "six books", which was published by Grosset \& Dunlap, 277 pages fat and containing 58 film stills. ${ }^{22}$ The heroine of this romantic adventure story was an American actress who had fallen in love with an Egyptian prince. After marrying and moving to Egypt, the princess discovers that her prince is a tyrant and a brute; she manages to escape, but the prince overtakes and imprisons her. A renewed and successful escape attempt is topped off when she finds true love, with an American.

Shipman, in contemporary publications as well as in her memoirs, claims that the story was prompted by the experiences of a real-life actress whom she happened to know. The Moving Picture World reported:

The stories are woven around the personality, and, so it is asserted, actual incidents in the life of Princess Hassan, who is credited with all sorts of odd experiences while living in Egypt. This same Princess Hassan, otherwise Ola Humphrey, is the featured player. ${ }^{23}$

Ola Humphrey was indeed a stage actress when she married the Egyptian Prince Ibrahim Hassan on April 15, 1911, and, a year later, she admitted that she wished to return to the United States because life as a princess in Egypt was close to that of a prisoner. ${ }^{24}$ The reviews do not discuss how the suggestion of actual experience was conveyed in the filmed series. Shipman's novel, by contrast, does open with an evocation of an authentic set-up, and a sleek one for that matter. The book frames the tales of the princess' experiences with a foreword, in which author and protagonist are introduced as former schooland stage-mates who meet again after the return of the princess to the United States. The foreword features an "I" who, aside from being an old friend engaging in a conversation, is also a journalist who considers writing about what the princess has told to her: "For a moment I saw a beautiful vision, dear to the heart of every writer, that of a real, throbbing, breathing, life-story laid bare under my microscope." ${ }^{25}$ Her interlocutor addresses the journalist with the soubriquet "scribe", even at the time an outdated word, which signifies that the "I" is just a medium and the princess is the veritable narrator of the story. While the conversation of the women initially suggests that we will be reading a straight reportage, towards the end of the "Foreword", a turn towards 
fictionalization is pronounced. The princess, in a written consent, eventually disclaims the truth of what she is about to tell:

I HEREBY AUTHORIZE my friend, the scribe, to set down upon paper what I shall tell her of my life in the Orient. I do not vouch for the truthfulness of what I tell. As the incense burns and the music plays, love and life are painted with glowing colors, and facts and fancies mingle with the smoke clouds of imagination. ${ }^{26}$

Before handing over this "contract" to the journalist, the princess had also adjusted the setting in which the telling of her story was going to take place:

"I have thought it all out," she said. "I have my rooms done over, as you see. To get the atmosphere, to paint the picture, I felt that I must take you, hand in hand with me, into the very essence of the Orient. Every night at midnight, for six nights, I am going, like an American Sheherazade, to tell you a story, a modern Arabian-Night story." ${ }^{27}$

It is as if the princess teaches the journalist that a "real, throbbing, breathing, life-story" cannot be told without a setting, without atmosphere and imagery, without imagination. The story results from the collaborative effort of princess and writer, which brings about the "mingling of facts and fancies", the acceptance of the fiction of truthfulness and the truthfulness of fiction. The collaboration implies an understanding of literary creativity that has operated time and again in Shipman's oeuvre. Shipman too mingles the real and the imaginative in her writing, and employs and exploits the inseparability of fiction and truth. This refusal to draw a sharp line between the real and the imaginative is a recurring principle of Shipman's work as a writer, an actress, and a filmmaker, whether in fiction or factual reportage. As I shall show, moreover, even if this principle does not always inform the topics that she selected for creative treatment or the plots that she developed, it is still discernible in her screen acting and in the cinematic style of the films she produced and directed.

The stills from UNDER THE CRESCENT published in the novel substantiate the authentication of the story just as they lend support to its make-believe. The attention of the picture-gazing recipient may well be caught by the lavishness of sets and costuming, by the variety of indoor and outdoor locations, by the number of extras employed in crowd scenes, by the restrained expressiveness of the principal cast, as well as by the graphic beauty of some of the shots, but, in the final analysis, it all comes down to one thing: these are the cinematic means of make-believe. 
Shipman, in her memoirs, acknowledges that the authenticity had been pretended to a great extent:

The mainspring of this opus was an American actress named Ola Humphrey who, as a star touring the near-East, had met and married a real, live, regular and authentic Egyptian Prince. A ready-made set-up if ever! The marriage ended conventionally in divorce. Ola was still called Princess, but no longer resided in Cairo. No matter: I changed "Hassan" to "Toussan," plunked the lady into a harem, veiled her, abused her, put her through a series of nerve-shattering adventures by stirring in parts of the British Army, added an American lover and spiced the potage with intrigue, poison, passion, dancing houris and most everything Universal's set department and wardrobe might devise. ${ }^{28}$

While she used the ready-made set-up as a basis, she changed and added whatever she thought attractive and necessary. Plot and structure seem to have borrowed from the serial queen melodrama, in which the intrepid heroine is plunked into nerve-shattering adventures from which, throughout a series of episodes, she saves herself and others. But the interweaving of the adventure story with a romance (or two) is rather reminiscent of Northwest drama. It is against this genre as a background, in my view, that the extra-textual claims to truthfulness to experience ought to be read.

The reviews of the films did not credit Shipman with the scenarios, but merely listed the names of cast members and the director, Burton King. Their reception was comprised of both criticism and praise. In addition to the aforementioned "odd experiences in Egypt", the criticism included "a disconcerting amount of mystery in the plot that may prove too much for an audience anxious to grasp the significance of many emotional demonstrations," a surfeit which was enhanced by a shortage of "subtitles which could make the action clearer". ${ }^{29}$ This comment was implicitly addressed to the scenarist of the original plot, who would also have provided the titles, as was common practice, although, of course, they may have been adjusted by the various departments responsible for them during the production of the films. ${ }^{30}$ The advice seems to have been followed, as no analogous remark is to be found in reviews of the parts of the series released subsequently. On the contrary, the review of the third episode maintained that "[t]he number is interesting, without being particularly strong in action or suspense." Disadvantage had been turned into advantage. Further praise, most notably, was expressed for "the splendor in the settings" and for "the picture [being] uncommon in its material", ${ }^{31}$ for which both producer and scenarist may share the credit. Likewise, the reception of the second episode was positive: "[t]he atmosphere of this 
series is good and the events carry the interest well." ${ }^{22}$ All further comments concerned the plot, action, performance, and graphic quality, as was standard with reviews of any film series or serial of the time. Most strikingly, the putative experiences of Princess Hassan are never taken into account-the films were read as pure fiction. The relation of the fiction to the experiences of the real-life model or to the author's observations seems to have mattered little in the films' reception. In addition, the status of the author of the scenario, even in the case of an original one such as UNDER THE CRESCENT, did not equal that of a published writer. Accordingly, Nell Shipman overcame the problem of her invisibility as the scenarist by having the story published as a novel. To top things off, she called attention to the authorial process by framing the novel within a first-person narrative.

The scenario with the title "The Last Empire" envisioned a feature film on a historical subject set at the Bahamas and in Cuba. According to Barry Shipman, his mother went to the Bahamas during the year that Ernest Shipman was employed as a business manager by the Williamson Brothers and the Submarine Film Corporation, which specialized in underwater films: "I remember her later telling me all about the 'wonderous' underwater gardens and the exciting sea-life to be found there." ${ }^{33}$ The year was $1916,{ }^{34}$ and her son therefore speculates that Nell Shipman wrote the scenario for this feature film around that time. However, the Moving Picture World reported that Shipman, in March 1917, was on the way to the Caribbean, "braving submarines and revolutions" in order "to absorb enough local color to work into a romance of the Danish West Indies," and that she would be returning to New York by July that year. ${ }^{35}$ Hence, my inference would be that the scenario was written in 1917 , most notably because of how prominently and explicitly Shipman referred to the local and historical research she had done for it. That she was making this publicity strategy into her trademark as a film scenarist, is evidenced in the introduction to the scenario: "A drama of fact and fancy, founded upon a legend of the Spanish Main and embracing the romantic periods of New World history [...]." ${ }^{36}$ The phrase "drama of fact and fancy" was taken almost literally from the foreword of Under the Crescent, and other ingredients and patterns were re-employed as well. We have an exotic locale (a subtropical island, the underwater world), royalty and the local lower class, romance and adventure. The main difference between the two scripts, however, was that "The Last Empire" was not envisioned as a series of shorts, but as a full-length feature film, which, moreover, Shipman intended to direct and supervise personally 
beginning in September 1917.37 This ambition may explain the detailed format of the scenario, which includes remarkably specific instructions for the shooting and the direction of the scenes. Barry Shipman-retired from his own lengthy career as a Hollywood scenarist by the time he rediscovered the scenario-listed them in his letter:

As well as scene numbers, location identification, players instructions and Subtitles, it gives minute CAMERA DIRECTIONS: "Panoramic", Iris and diaphragm instructions and, most interesting, "tinting", such as cool yellow, gold-enhancement, rosy sunrise, undersea green, etc.

Directions for DISSOLVES and DOUBLE-EXPOSURE SHOTS are also written in as camera instruction. The Director is told when it is to be a "large" or a "closer" shot. CAPITALIZATION is never used except for Titles and Sub Titles..$^{38}$

The abundance and thoroughness of such directions in the script are indicative of Nell Shipman's ambition to direct the film: "Iris in a long shot of ocean, coral reef and distant palm-fringed island. Tint sunset. Fade out and dissolve in title retaining dim outline of the scene and the sunset tint." ${ }^{39}$ Even more conspicuous is the very conceptualization of every scene. The situations and occurrences are conveyed with strictly visual and cinematic means. Places, characters, and incidents are described as images; atmosphere, characterizations, and actions are spelled out in terms of how they look through the camera's lens:

Scene 2. Interior of a room in the palace, showing a close view of a high backed chair placed before a diamond paned window and draped in velvet. Mariana is disc[erned] seated in the chair. She is a handsome imposing looking woman of middle age with a cold and selfish face. She looks up to someone standing behind her. ${ }^{40}$

Shipman's propensity to mix the factual with the imaginative manifests itself in the scenario of "The Last Empire" at the levels of plot and imagery alike. The imagery as evoked has a tangible quality that foreshadows Shipman's later preference for location shooting and improvisation with animals. Both the format of and the details in the scenario, then, attest to what the Moving Picture World reported: Nell Shipman, by 1917, an established scenarist, a published writer, and, as will become apparent shortly, a noted film actress, was now ready for direction too, but another three years of acting and script writing would have to pass before she fulfilled this role. 


\section{NELL SHIPMAN ACTING FOR THE CAMERA, 1915-1918}

In her communication to the press, Nell Shipman began, from early 1915 onwards, increasingly pointing out her acting competence in addition to her experience as a scenarist and a writer. An early record of this strategy is contained in the New York Dramatic Mirror of March 31, 1915, which brought to attention her current work on Under the Crescent, but which also stated that she enjoyed "a triple reputation as an authoress, photo-playwright and actress". ${ }^{41}$ Although the latter was not exactly based on experience in film, the strategy worked. In the fall of 1915, Nell Shipman landed herself a contract as an actress from the Vitagraph Company of America, for the female leading part in the Blue Ribbon Feature GOD's COUNTRY AND THE WOMAN, after the eponymous novel

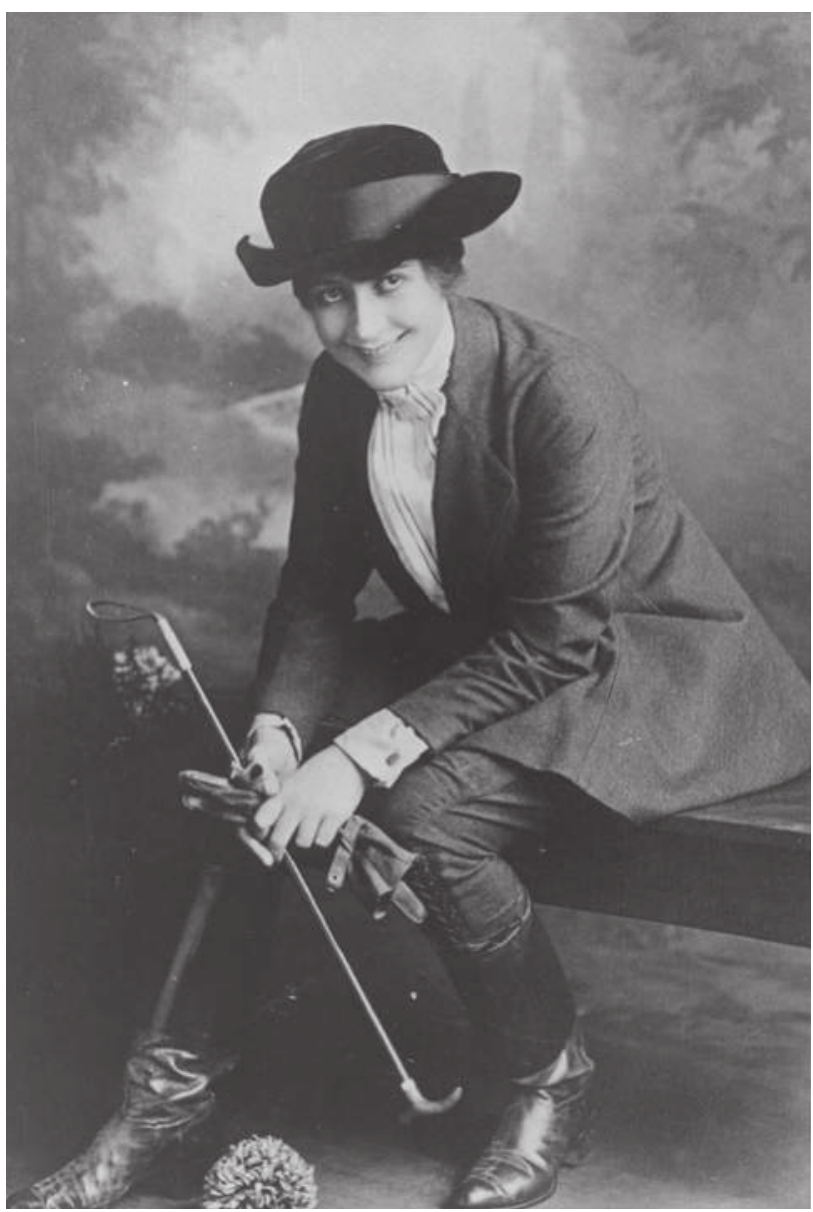

Fig. III.6: Publicity picture as an actress, c. 1916. 
by James Oliver Curwood. In January 1916, even before the film was released, Shipman was featured with a picture and a highly promotional text in the weekly column with news and gossip from the industry in the New York Dramatic Mirror conducted by Mabel Condon, a business representative for scenarists and actors, including Nell Shipman. The text extensively listed Shipman's versatile accomplishments, revamped her stage career, suggested that Curwood personally had asked to do her very best in the role of the "Woman" and allotted to her a significant function in Hollywood: "There is a big place in the industry that calls for beauty and brains. And Nell Shipman qualifies." ${ }^{42}$ This PR offensive for Shipman as an actress was crowned with an advertisement by Condon on the back cover of The Mirror of October 28, 1916, highlighting the actress in six of her leading roles, five from the stage, and one from film.

At Vitagraph, Shipman played principle roles in some ten feature films between November 1915 and November $1918 .{ }^{43}$ After two films directed by the manager of the Vitagraph studios in California, Rollin S. Sturgeon, Shipman switched over to the Fox Film Corporation in July 1916 and, in September, to the Jesse Lasky Feature Play Co., for one film each. During the following year, as we have seen, she spent some months in the Caribbean writing scenarios. ${ }^{44}$ In September 1917, the trade press published a declaration of independence that she obviously issued herself: "Nell Shipman wishes it generally known that she is not under exclusive contract to any one for either her services or her scenarios." ${ }^{\prime 5}$ By October 1917 , however, she was back at Vitagraph as an actress, to play in a new series of Blue Ribbon Features. ${ }^{46}$ In fact, within one year, by November 1918, seven of Shipman's ten Vitagraph films were produced and released, in contrast to three during her 1915/1916 affiliation with the company.

Until 1914, the Vitagraph Company had been one of the most important film producers in the United States, mainly of one- and two-reelers. ${ }^{47}$ It had built up stock companies of players and directors and had produced multiplereel films some four years before this had become standard practice. But 1916 marked the beginning of three years of financial and managerial difficulties, and, after 1917, the company lost much of its importance (to be sold eventually to Warner Bros. in 1925). In the process, the stock company system was largely replaced by the practice of hiring actors per film. Still, in the three films directed by Sturgeon in 1915/16, Shipman was cast opposite star actors William Duncan and George Holt. In August 1916, it was announced that the California branch of the firm was reducing production and that Sturgeon, as well as his scenarist and general assistant Doris Schroeder, had left, with one director, William Wolbert, remaining at the California plant. ${ }^{8}{ }^{3}$ Wolbert indeed directed Nell Shipman in her 1917 Vitagraph features, now with Alfred (Gayne) Whitman as her co-star. 
Shipman wrote none of the scenarios for the Vitagraph, Fox, or Lasky productions in which she acted. During her affiliation with the three companies, she appeared primarily in screen adaptations of literary works by, among others, George Randolph Chester and Lillian Christy Chester, Cleveland Moffatt, Wallace Irwin, and James Oliver Curwood. The continuity scenarios for these productions were all written by studio personnel.

\section{Actress at Vitagraph}

Nell Shipman began her acting career at Vitagraph as the Curwoodian heroine Josephine Adare, also known as The Woman, in GOD's COUNTRY AND THE WOMAN, the role that she associated with Necia in Rex Beach's play "The Barrier". Directed by Sturgeon, producer of "many superb photoplays of the great

316 | outdoors", from a scenario by Agnes C. Johnston, and featuring the star actors William Duncan and George Holt, the film was described in the trade press in superlative terms. The criticism in Variety that its eight reels made it too long, moreover, was acknowledged, when it, after a three week run, was edited down to seven reels, and, again, when it was re-released in a five-reel version in 1920.49 In addition to the cinematography, which provided eye-catching nature and snow scenes, it was Shipman's participation that was considered a special asset:

To close followers of the screen, "God's Country and the Woman" carries an added interest in introducing Nell Shipman, writer of many scenarios, as an actress in a leading role. Miss Shipman is as good an actress as she is a writer, which is saying much. Her beauty is of a rarely expressive type and her playing is marked by intelligence and sincerity. ${ }^{50}$

Another critic observed her flexibility:

Nell Shipman in the leading feminine role has given a thoroughly good portrayal of the character of Josephine Adare. She was delightfully attractive in the lighter moments and rose to her opportunity in the heavier emotional periods with an artistry and charm that was truly delightful. ${ }^{51}$

Employing her familiar rhetoric of understatement, Shipman herself remembered nothing about expressiveness or artistry, but instead put the emphasis on "type": 
Rollin Sturgeon was the director who hired me, not because I could act, in fact he loathed all stage performers, but I was the type: athletic, a swimmer, someone who could get around the wilderness without stubbing her toe on a pinecone. [...] To me the lure was the fact that we'd spend three months of winter in this then unknown and almost uninhabited mountain resort, that I'd act for an important company and be paid for my fun. I was to drive a team of sled-dogs, paddle a canoe, travel on snowshoes, undergo pages of Curwoodian drama in a setting which if not quite like my own Northwest was near it. ${ }^{52}$

Although still dwelling on the style of stage acting she needed to unlearn, her understatement here implies that she was a natural for such screen parts, because of her mastery of outdoor activities and her love for the Northwest. In front of the camera, she could be the type, without needing any particular acting skills. Clearly, this was yet again a way for Shipman to adopt the authenticating discourse surrounding the genre of Northwest drama, and to mix, in the context of her own oeuvre, fiction with factual experience. And yet the idea of plainly being the required type ought likewise to be connected to what Jennifer Bean has analyzed as the "technologies of early stardom", that is to say, the discursive strategies and institutional practices that shaped and were shaped by female film stardom during the 1910 ..$^{53}$

In her illuminating article, Bean assesses, historically and discursively, the otherwise often overlooked "detail" that film stardom in the United States in the early and mid-teens was largely a matter of women's stardom, which emerged in connection with a particular genre of films and a particular range of roles, namely, the action serials with their "queens of courage and daring", of which Pearl White became the archetype. Bean draws attention to the type of star constructed and promoted within this early star system, which comprised, in her words, "a particular synthesis of femininity, athletic virility, and effortless mobility", and which also applies to Nell Shipman's star persona. ${ }^{54}$ Such claims of truthfulness in the performance before the camera were understood as the opposite of what film people stereotyped as the archaic and mechanical gestures of the stage. In the same vein, emphasis was placed upon the extraordinary agility of the female performers, who were capable of deft actionsand of taking physical risks - that were unusual for women and impossible on the stage. The institutional framework of this system, moreover, included behind-the-scenes interviews, evidencing photographs, and personal testimony, which placed emphasis on the stunts done and the dangers endured by performers and crew. On the other hand, according to Bean, whatever the role or the risk involved, "a bliss jouissance [...] distinguish[ed] the star's assessment of her work." 55 These facets of early female star discourse resonate in 
Shipman's estimation of having been the type for outdoor action drama, and of having had sheer fun during the shooting.

In the pre-publicity for GOD'S COUNTRY AND THE WOMAN, care was taken to convey authentication and the hardships that had been involved. In the appropriate parlance summoned by the phrase "giving attention to every detail", it was stressed that Shipman had worn a genuine Hudson Bay blanket coat, that sled-dogs of an authentic Alaskan breed were used, and also that the film contained images of snow that would interest the students of nature. ${ }^{56}$ Likewise, it was claimed that Duncan had lived in Alaska and knew "how to handle dogs from A to Z". ${ }^{57}$ Shipman, moreover, was said to have prepared for her role with "the pleasant task to perform of reporting at the Santa Monica studio morning and evening to feed the twenty Alaskan dogs secured for [the film]." ${ }^{8}$ Other press items highlighted the location of the shooting and its conditions: that the location where the film was shot, Big Bear Valley in the 318 San Bernardino Mountains in California, could only be reached by a dog-road, that the film crew, after a storm, found themselves snowbound for two weeks, and that they, in order not to starve (or to be forced to eat the dogs), had to use the sledges and snowshoes for their own return to safety. Shipman was quoted as having concluded: "Never again if I knew it. It was too real for me." 59 Duncan was reported to have added: "Well, we were sent out to get some real northwestern hardship into the film." The result was that "the 'atmosphere' and local color of the Northland ha[d] been worked out to a degree unusual even in this day of feature films, so realistic that nature herself feels pale beside them." ${ }^{60}$ Likewise, exhibitors encouraged one another to utilize props related to the sphere of the film, such as animal skins in their lobbies, and to have real live dog-teams parade outside, in order to draw the public's attention to the theaters where the film was being shown. ${ }^{61}$ Between November 26, and December 23, 1916, finally, Nell Shipman herself was hired for making personal appearances at the film's screenings. ${ }^{62}$

If the scenario and the film, both missing today, closely followed Curwood's novel, there were hardly any scenes in which the woman could paddle, travel on snowshoes, or run a dog-sled. ${ }^{63}$ That is to say, as in any Northwest drama, there were several scenes calling for these actions, but, in the novel, they were carried out by the two men who alternately escorted the heroine: her ("half-breed") protector, Jean, and her lover, Philip, from whose perspective, moreover, both the action and the romance plotlines were narrated. Much more than was the case with Beach's Necia, in fact, Curwood's Josephine lacked narrative agency in either plotline; her agency was virtually confined to a third line in the narrative, namely, the mystery plotline built around her (and her mother's) secret.

A white woman, Josephine, was not compelled to survive the "wilderness" 


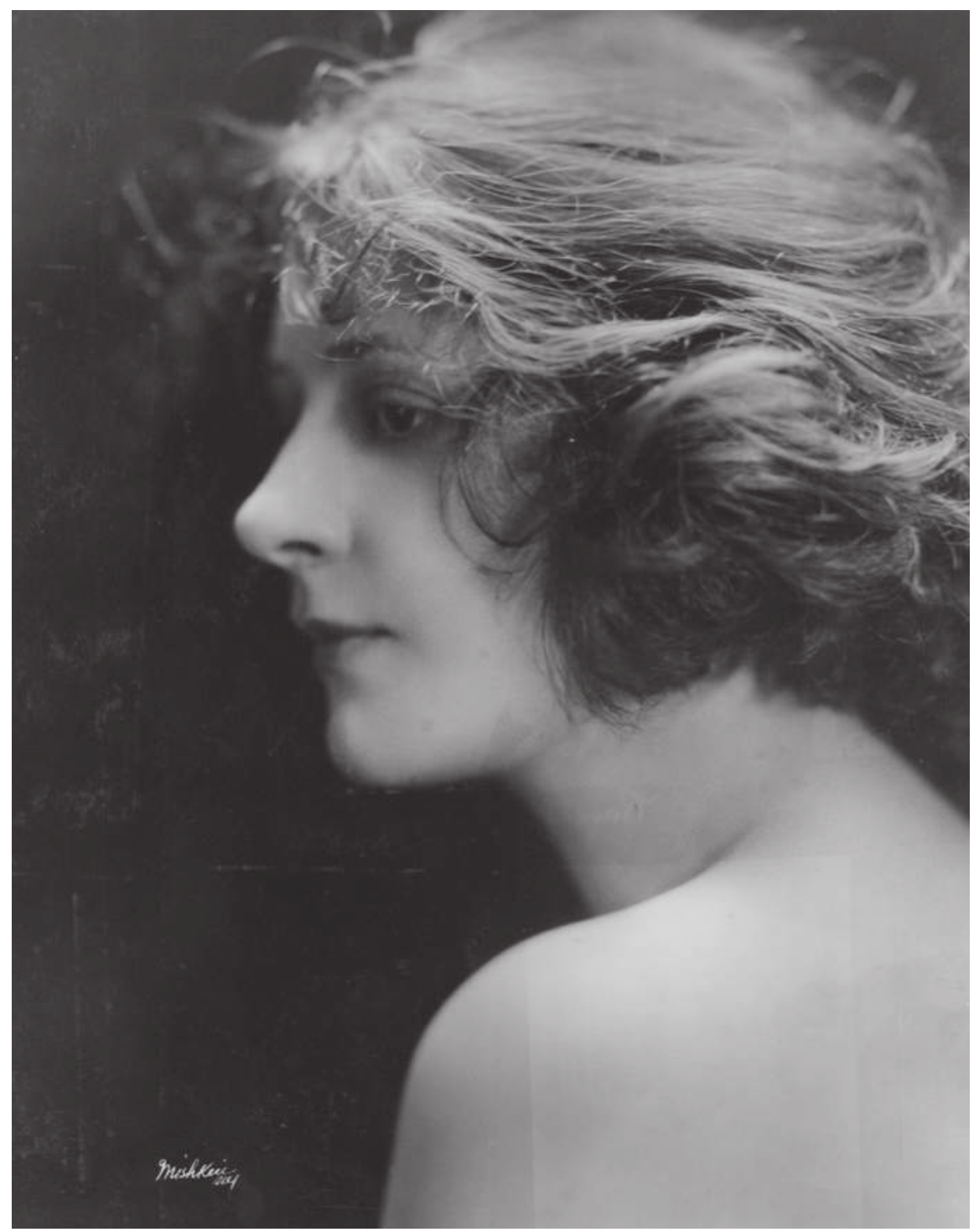

Fig. III.7: Nell Shipman as a glamorous star. 
on her own, and her doings while out in it were not quite those of an outdoors girl, but rather those of a conventional woman. We witness her combing her hair and dressing up, preparing her birthday dinner, and nursing sick children. The novel contains just one scene in which the heroine preferred to drive the dog-sled for a few miles, before and after which she had her lover run it again. The book offers her one single opportunity to take decisive action, namely at the very end, during the fight with the villain, when she calls to her sled dogs to kill him. The synopsis of the eight-reeler as published at the time of its first run confirms that the screen adaptation was fairly faithful to Curwood's plot. ${ }^{64}$ Nonetheless, it is hard to determine from it the extent to which the film followed or altered the distribution of agency and the perspectives of the characters as given in the novel. The film's synopsis merely summarize plot "events" without providing clues as to the way the narration is organized.

For Nell Shipman, the film and its successful run had initiated a culmi320 nation of favorable exposure in the film press. Vitagraph featured her in its advertisements, ranking her first in the cast lists, and her acting earned her the epithet "Vitagraph's Western Leading Woman". ${ }^{65}$ In July, the William Fox Company devoted to her a full-page studio portrait in the Moving Picture World, presenting her as a glamorous star, dressed elegantly in a backless gown and an evening hat, and gracefully framed in profile and from behind, displaying a very attractive back. ${ }^{66}$ The aforementioned advertisement on the back cover of the New York Dramatic Mirror in October 1916 showing her in a variety of roles, was accompanied by an editorial note stressing her adaptability. ${ }^{67}$ Shipman's rise to stardom within less than a year's time was lent further support when she was described as "a star in her own right" a month thereafter. ${ }^{68}$ By that time, three feature-length films with her as the female lead had been released and had met with critical acclaim and she had just concluded her fourth part in a Lasky film, in support of Lou Tellegen, which was about to open in New York.

Shipman's collaboration with Sturgeon came to an end by July 1916, and there are no indications that they planned future projects together. After his departure from Vitagraph, Sturgeon made one film for Lasky, which was released in February 1917, the very month in which he joined his former scenarist Doris Schroeder at the American Film Company, to which Nell Shipman, that same spring, sold her story "My Fighting Gentleman". The film adapted from it was directed by Edward Sloman, one of America's top directors at the time. ${ }^{69}$ Shipman's Lasky production THE BLACK WOLF was also released in February 1917, which suggests that both she and her former director were affiliated with the studio during more or less the same period of time. Asked why she had accepted a supporting part instead of having demanded a starring role for herself, she was quoted as having "realized the artistic promotion that a connection with the Lasky company contained". ${ }^{\circ}$ 
In her memoirs, Shipman remembered less about artistic promotion than about the posh treatment the studio gave the actors, and that she had a crush on Tellegen. She did mention the "savoir faire and fine directorial know-how" of her director at Lasky, Frank Reicher, and noted that it "all was so different from the slap-dash, shoot-'em-up methods common at solidly moral old Vita." ${ }^{71}$ Most salient in terms of her options and choices is the paragraph in which she recalls how she turned down the offer for a seven-year contract from the firm's general manager and treasurer, who, as she remembered correctly, was “Mr. Goldfish, not yet turned Goldwyn.” In retrospect, Shipman judged it:

Probably as silly a move a neophyte ever made. But I did not like the way they dressed their contract players. This was in the period of curly blondes with Cupid's bow mouths; and Wardrobe's main idea was to bind down a bosom with a swatch of shiny material which met yards of floaty gauze at the waistline and looked like a flowery pen-wiper. This long-legged, lanky, outdoors gal, who usually loped across the Silver Screen in fur parkas and mukluks, simply gagged at such costuming. And had the nerve to refuse it. ${ }^{22}$

The discrepancies between Shipman's retrospective account and her remarks in 1916 call for comment. She may have felt herself to be a beginner, but given her engagements and accomplishments she was one no longer. And she had thus far not "usually" moved across the screen in the costume of an outdoors girl; rather, she had done so in one film alone, GOD'S COUNTRY AND THE WOMAN. A 1917 portrait in the fan magazine Photoplay, moreover, had mentioned the film, but omitted to include a photograph in which she was clad in the garb of this type of role; instead, the illustrations showed her as an "ingenue, vamp, lead and authoress"73 In other words, if she had indeed been offered a contract by the Lasky Company, she declined to sign it, motivated by considerations other than wardrobe worries. Given the implications of her move for her further career, some speculation about what these might have been, is in order here.

If, for the sake of the argument, we accept for the moment Shipman's selfconscious opinion that she could not act, she may have then feared failure, as had happened ten years earlier, when, auditioning for Jesse Lasky's vaudeville act, she had performed so badly that she was not hired. ${ }^{74}$ Lasky, having incorporated his Feature Motion Picture Company in 1913, aimed from the start to produce feature-length films adapted from stage plays and with stage stars. ${ }^{75}$ In July 1916, he consolidated the stature of the company by forming a joint corporation with Alfred Zukor's Famous Players Company. The stage stars affiliated with the new Famous Players-Lasky Corporation included, aside 
from Tellegen, Geraldine Farrar, Wallace Reid, Pauline Frederick, and Sessue Hayakawa, while Mary Pickford and Blanche Sweet were among its most popular screen actors. ${ }^{76}$ Perhaps such illustrious company made Shipman feel timid. Yet she had little reason to, as her acting in THE BLACK WOLF did not defy the expected standard: "Lou Tellegen gives a pleasing performance, Miss Shipman charms, inspires and compels sympathy."77

It is therefore more likely that Shipman asks the reader to take her claim about wardrobe as indicative of her awareness of the type of roles she could have expected to be offered by the pretentious Lasky or Fox companies. The historical documents available, on the other hand, suggest that it was only later that she began "learning the importance of type", as she put it, namely, after she had played in her second Curwood adaptation, BAREE, SON OF KAZAN, in $1918 .^{78}$ At this earlier point in her career, Shipman placed the stress upon her versatility and not upon the type of character she preferred to play. But she 322 seems to have sensed a trend away from versatility, towards specialization and typecasting. She also may have had more confidence in her writing talent, or at least expected more secure earnings from it. In any event, my conjecture is that she feared having little say, as a contract player, in the kind of parts she would be offered, and confined to acting. And as it turned out, writing was the first thing to which she returned, once her assignment with Lasky ended.

While the general trend within the film industry of the 1910 s was towards the sub-division of tasks and specializations, by 1917, an individual's versatility was not perceived as antithetical to expertise. Particularly in connection with women's professional contributions to the hoped-for aesthetic and moral improvement of film, advertisements as well as articles created a discourse in which specialization and versatility were increasingly paired together as articulations of professional skill. With regards to specialization, I have described how discourses on acting and script writing emerged in the trade press as of 1910, and how the names of the people responsible for such tasks in film production were becoming increasingly public. By consequence, it was not only the skills involved that gained status, but the individuals who developed and adopted them as well. This applies also to female director-producers, a category included in the context of Shipman's career. Because, as it appears, quite a number of actresses and female scriptwriters from early on combined acting with script writing and/or with direction and production, and, as I have pointed out, Shipman too was ready to do so. A brief overview of the positions taken by female colleagues of Shipman's that were similar to those she to which she aspired, may illuminate the question of specialization versus versatility in relation to women's careers in American cinema of the time.

Up until this point in her career, Shipman had rarely acted in films based 
upon scenarios she had written. The same was true, to name but a few, of her old acquaintances from the stage, Mary Fuller and Clara Kimball Young, who had, by 1914, nonetheless managed to become the first and third most popular female movie stars in the United States, respectively, with Mary Pickford taking the position in between. ${ }^{79}$ Of them, it was most notably Fuller, along with other serial queens like Gene Gauntier and Kathlyn Williams, who had been instrumental in the emergence of the star discourse in the early 1910s, a time when stars, as Richard deCordova has pointed out, were dubbed "picture personalities" and the discourse on stardom focused primarily upon their professional existence, the kinds of roles they played across a group of plays and films, as well as the particular skills they developed, the hardships they endured, and the risks they took during filming..$^{80}$ From time to time, Fuller and Williams wrote their own scripts, but Fuller never, and Williams only occasionally, drew this to the public's attention. ${ }^{81}$ As compensation, the issue of versatility was applied to the variety of parts they could handle, as in a summary of Fuller's career published on the occasion of her one-film engagement with Lasky in 1917. Here, after a listing of her stage experience and the MARYseries she played for Edison, came the contention that

\begin{abstract}
Miss Fuller is likewise the star of the first multiple reel productions issued by Edison, scoring a great personal triumph by her excellent portrayal of many difficult roles. One of Miss Fuller's never to be forgotten feats was her escape from the window of the seventh story of a New York apartment by means of a rope, down which she slid in great peril. It was considered to be one of the greatest "stunts" ever attempted by a girl at that time, and Miss Fuller's blistered and aching hands were a source of great pride to the owner. ${ }^{82}$
\end{abstract}

As Jennifer Bean's analysis shows, dramatic and physical versatility were the very terms that defined cinematic performance within the early star system and physical stamina and courage were among the requisites for women to succeed in making the transition from stage to screen acting. ${ }^{83}$

Other female stars of the 1910 s combined acting with full-fledged careers in scenario-writing and called attention to this in publicity. This was even the case if they also worked in tandem with particular directors, as, for instance, Gene Gauntier with Sidney Olcott, or Grace Cunard with Francis Ford. The common knowledge that Gauntier not only performed as a leading lady but also wrote the scripts for the films that she made together with Olcott, was articulated in a 1913 review of one of the new company's films: “The story, it is fair to assume, is written by Miss Gauntier. It has the holding power of her best work." ${ }^{4}$ Similarly, a 1917 portrait of Grace Cunard outlined as many of 
her achievements that she, at Universal, had written "all of her own plays as well as tak[en] the leads in them under Francis Ford." ${ }_{5}$

Gene Gauntier was not the only actress to establish her own production company during the 1910s, to be sure, but she had been early in doing so. Clara Kimball Young left Vitagraph in 1915, and, after three years with the World Film Corporation, formed her own production company in $1917 .{ }^{86}$ Other actresses who did likewise were Florence Turner in $1913,{ }^{87}$ Anita Stewart in 1918, Ruth Roland in 1919, Alla Nazimova in 1920, and, as we shall see shortly, Nell Shipman in 1920.

In addition to such careers that combined acting and script writing or acting and production, many women in the silent cinema also ventured into film direction. Contemporary publicity stressed their versatility whenever they held additional positions in the production team. Alice Guy-Blaché, who established her own production company in 1910, was advertised by her Solax 324 Company as a producer as well as a director three years later ${ }^{88}$ In 1915 , the other renowned pioneering female director, Lois Weber, was publicized by Universal, where she held a semi-independent director's unit together with her husband Phillips Smalley, with an emphasis on scenario-writing as well as on directing: "'Scandal' Direction of Lois Weber and Phillips Smalley. [...] Written by Lois Weber, Author of 'Hypocrites. ${ }^{89}$ While this discourse may have been orchestrated in part by those whom it promoted, articles such as film reviews, portraits, and reports on business matters consistently followed the trend to distinguish women's particular and versatile qualities. In sum, the trade evinced a favorable attitude towards both capability and versatility as they were frequently manifest in women's (and men's) careers in the cinema of the time. It is in this context of a manifold and expanding range of options that we must see the fact that, by mid-1917, Nell Shipman neither wanted nor needed to choose between acting and screen writing.

Despite having announced in July 1917 that she was going independent and would personally direct her next story, Nell Shipman returned to Vitagraph as an actress by October of the same year..$^{90}$ By the middle of April 1918, four Blue Ribbon Features with Shipman in the leading role had been released, all directed by the new head director of the Vitagraph West Coast Studio, William Wolbert. Initially an actor, Wolbert had directed about a dozen features at this point and was characterized by Shipman in her memoirs as "an innovator and fine movie potential". ${ }^{91}$ His promising career was cut short in December 1918, when he, at age 35 , died in the influenza epidemic. ${ }^{92}$

The four films in which Wolbert directed Shipman-in all of which she starred opposite Alfred Vosburgh, at the time known as Alfred or Gayne Whitman-do not seem to bear the stamp of innovation; rather, each seems to be a genre exercise, that is to say, as far as can be inferred from the surviving sce- 
narios, reviews, and publicity materials. These films include a comedy, two westerns, and a romance, and, aside from the comedy, none of them seems to have provided Shipman with really exciting characters to play or acting to display. In one of the westerns, her character was said to have "more beauty than brains", and the romance centered around "an opportunistic woman who eventually returns to her rightful husband." 93 Now, wondering if these were blurbs from someone simply objecting against brainless and sinful women, as the reviewer, Edward Weitzel, declared himself to be, I turned to consult the surviving scripts in the Warner Bros/Vitagraph Archives at the University of California, Los Angeles. They confirm that these female characters were largely conventional figures, despite the fact that they were drawn from novels by well-known writers. In the western THE HOME TRAIL, Shipman played a weak and romantically afflicted school mistress; in the western CAVANAUGH OF THE FOREST RANGERS, the innocent sweetheart of a ranger; and in the

Fig. III.8: Lantern slide announcing the Vitagraph film THE GIRL FROM BEYOND.

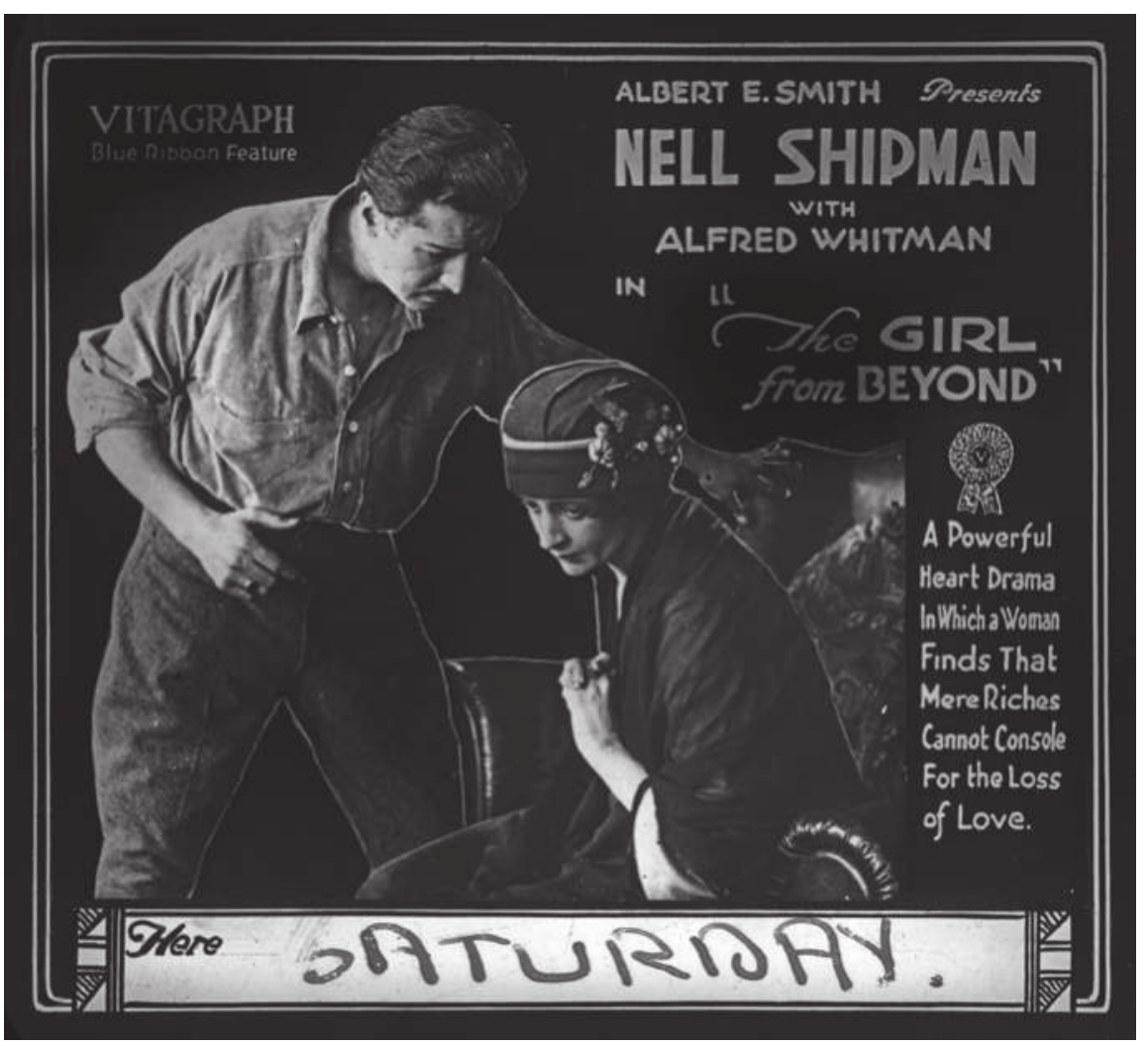


rOmance THE GIRL FROM BEYOND, the wife of a vengeful man who is healed by her love.

Even so, Shipman's acting in these films received praise in the press. "As [Cavanaugh's] sweetheart, Nell Shipman presented an appealing picture and gave a sympathetic and graphic performance." 94 In THE HOME TRAIL, "Nell Shipman contributed a vivid and sincere performance as Clara. Miss Shipman possesses unusual talents and Vitagraph appears to be successful in bringing them out." ${ }^{55}$ Weitzel furthermore notes that "Nell Shipman makes a real characterization of Clara and does her best work in the strongest scenes." ${ }^{66}$ Given the contemporary discussions about melodrama and characterization, this remark came as high praise. For, as Louis Reeves Harrison maintained, "both realism and characterization can be employed to strengthen melodrama without injury to its intensity and sensationalism." 97 In addition, Vitagraph itself repeatedly advised exhibitors to “[t]ake advantage of Nell Shipman's popular326 ity, along with Alfred Whitman, coupling with this feature their past successes in Vitagraph's westerns."98

The Vitagraph role that appealed most to Shipman's imagination was the one of the adventurous runaway in the comedy THE WILD STRAIN, which was adapted from the story "The Eighth Great-Grandparent" by George Randolph and Lillian Christy Chester. At the center of her recollections of the shooting of this film stood her work with animals: her own collie Laddie, who played Winnifred's companion, and the circus acts that she performed: a bareback "running leap" and a "Single Roman Stand", terms designating a jump and a straight standing position, respectively, on the back of a horse in motion. ${ }^{99}$ For the leap on the horse's back, a stunt-double was assigned who, however, did not succeed at the task, so Shipman was called upon to take over. In this relatively rare case, Shipman appraised her own acting: "The make-believe came alive." ${ }^{100}$ A key contribution to the make-believe was offered by the animals.

In contrast to what Shipman suggests in her memoirs, she was not "demoted to two-reelers" directly after THE WILD STRAIN, but only after four further feature-length productions at Vitagraph. That is, if "demoted" is even the right word here, for other star actors were likewise cast in the series THE WOLFVILLE TALES, which were adapted from the widely-read western short stories by Alfred Henry Lewis. ${ }^{101}$ Patricia Palmer indeed was the featured actress in the series and Shipman had only minor roles in the last three shorts that were copyrighted and released around a year after she left Vitagraph. ${ }^{102}$ If she experienced them as a setback in her career, this occurred only after she starred in another one of her Vitagraph successes, BAREE, SON OF KAZAN, a Northwest drama with animals, directed by David Smith after the eponymous novel by James Oliver Curwood.

For Shipman's career BAREE, SON OF KAZAN was a pivotal film for more 


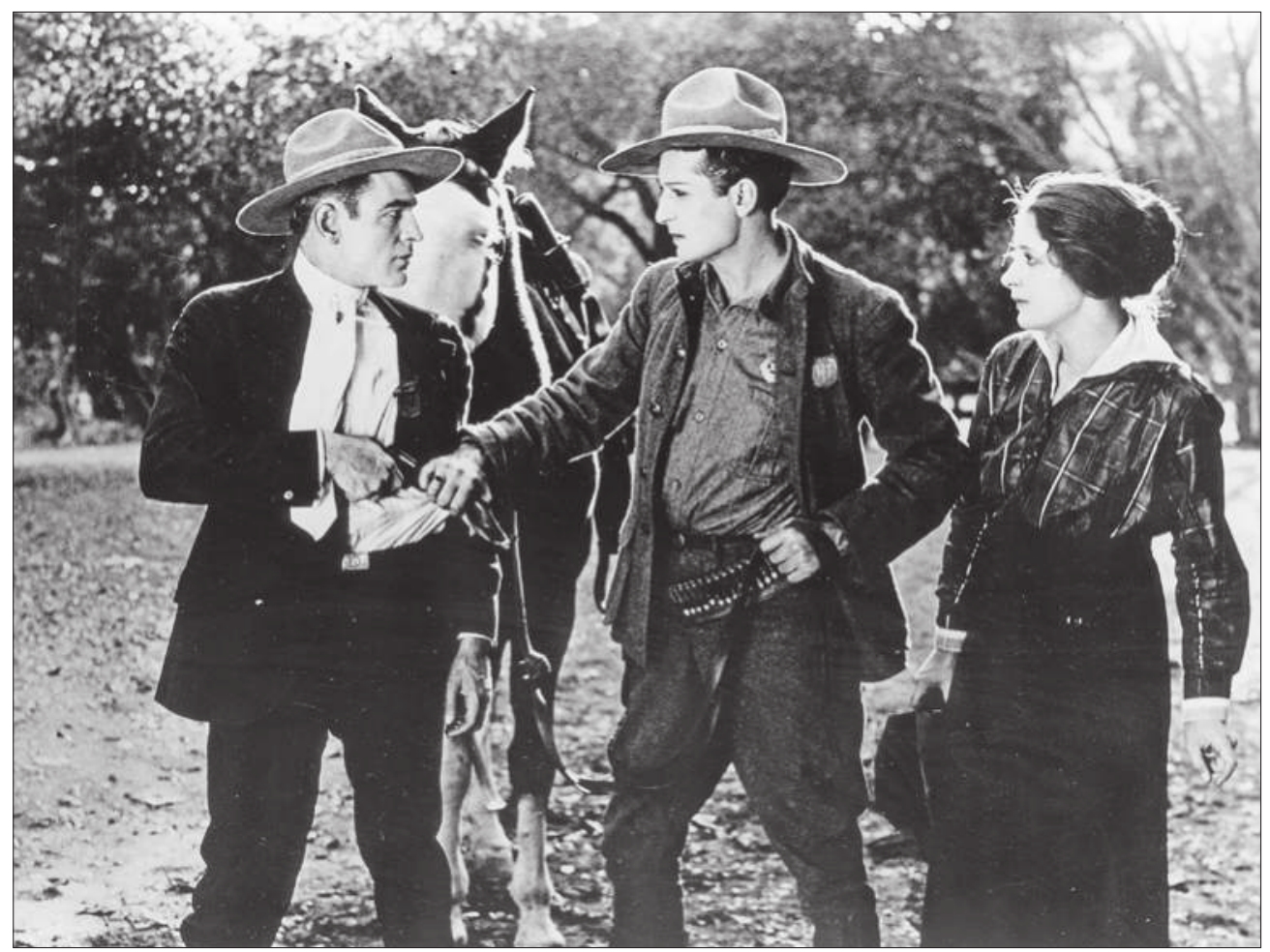

Fig. III.9: Nell Shipman in an unidentified film, maybe THE WOLFVILLE TALES.

than one reason. First and foremost, she played her second Curwood heroine in her second genuine Northwoods screen drama, and, indeed, in a film featuring more animals than any other in which she had been cast before. A second reason is that this film gave her the idea of producing her own animal pictures, as she stated in the Foreword to her memoirs:

My concern for animals acting in motion pictures began at Vitagraph during the shooting of a Curwood movie when I saw a bobcat shocked by electricity to make it hop and snarl, then doped so it would lie still. It died. [...] I made up my mind during the shooting of the Curwood book that somehow I would get my own animal cast and make actors of them without the use of whips, shouted commands, charged wires poked into them, or by boring them with some tiresome training. ${ }^{103}$

That this recollection concerned BAREE, SON OF KAZAN may be concluded from the fact that the narrative of GOD'S COUNTRY AND THE WOMAN did not feature any animals other than sled-dogs. Last but not least, both novel and 
film were an inspiration to her, as I will argue, for the scenario of BACK TO GOD'S COUNTRY. So, in my view, BAREE was the film that prompted Nell Shipman to realize definitively that this was everything she had been looking for: the type or screen persona of the outdoors girl, the adventure and romantic drama set in the Northwest, the multitude of animals, and the stories of one of the preeminent authors in the field, James Oliver Curwood. "Once more," as Shipman reminisced about BAREE further on in her memoirs, "the strange magic of Northwood's melodrama plus animals worked." ${ }^{104}$ The Moving Picture World agreed:

The picture is, for the courage of its realism, for the artistic use of suggestion mostly to keep the story vividly in its proper background, where alone it could be true, and for the touch with which the players put over their parts, a remarkable production. It seems like a living thing with the earth of the North still on its roots and the sap still flowing.

The villain of the story is a factor of a Hudson Bay Trading Post. [...] Al Garcia plays the role with splendid naturalness. The heroine, a courageous half-breed (Nell Shipman), lives in a trapper's cabin with her father (Joe Rickson), and in the course of the story has become the desire of the factor, who already has an Indian wife whom he sadly abuses. Miss Shipman's work fits into the picture's atmosphere well, and Joe Rickson carries all the mannerisms and the peculiar heartiness usually associated with a character of the type.

Baree, the dog, is the hero of many of the picture's scenes, [...] I have seen good animal pictures, but never in a story have I seen animal psychology used so intelligently and sympathetically as here. There are scenes, one of them a chase of a moose by wolves, that to me seem marvels of picture making. But the art with which the film was made in every department of it fills me with admiration. [...] It smells of pine boughs, of human beings, of dogs and sweat and blood. It is a real picture of the wild. ${ }^{105}$

No print of BAREE, SON OF KAZAN is known to be extant today. For an impression of her acting the part of the outdoors girl, therefore, we have to rely on the remark in the review cited, that her work accorded with the realism and atmosphere of the picture. Elsewhere, her affinity for the "sort of role she always does so well" was articulated: "To Nell Shipman belong the honors of having given another of her splendid characterizations. Her Nepeese was remarkably well done." ${ }^{106}$ 
Fig. III.10: Nell Shipman as Nepeese in the Vitagraph film BAREE, SON OF KAZAN.

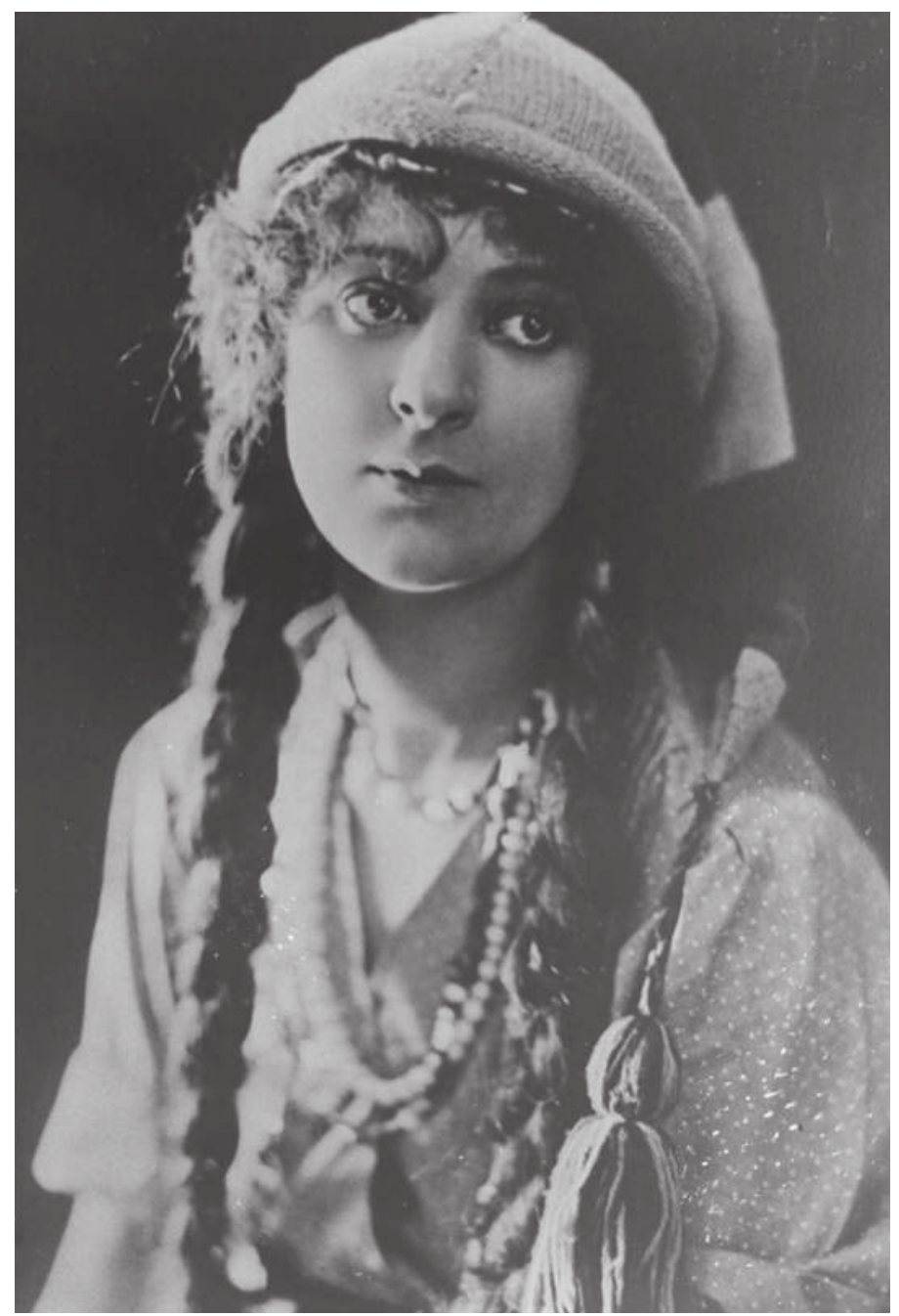

\section{James Oliver Curwood's Northwest Dramas}

Like God's Country and the Woman, Baree, Son of Kazan too is available as a literary work of James Oliver Curwood. ${ }^{107}$ Because Nell Shipman adopted Curwood's version of the outdoors girl as her favorite screen persona and had such a liking for his animal stories, it is appropriate here to continue with the generic analysis that I have set up by means of Rex Beach's novel The Barrier and also, in only two respects, have applied to God's Country and the Woman. To enable a somewhat broader assessment of Curwood's idiosyncrasies within Northwest drama, I shall take account of another of his novels, Nomads of the North. ${ }^{108}$ It is an animal story just as much as Baree, and much more so 
than God's Country and the Woman, and, as such, also akin to Shipman's third Curwood adaptation, BACK TO GOD's COUNTRY. In addition, a print of the film NOMADS OF THE NORTH is available for research. ${ }^{109}$ For the moment, I shall focus on the characters, plotlines, and other narrative devices contained in these three Curwood novels.

Each of the stories under scrutiny presents the melodramatic stock of characters and types. There is what Shipman characterized as the "Curwoodian heavy and his yen for 'it'", ${ }^{110}$ in other words, the villain with his minion who sets out to get the girl and to crudely subject her to his lust and domination. Accordingly, he serves to initiate the action-plot required by the genre, with all its journeys, abductions, perils, fights, and narrow escapes, as well as the defeat of the bad guy or guys, required on account of melodrama. As opposed to The Barrier, in Curwood's novels, the villains' wrongdoing is usually not provided with a history that might explain it, but is represented as the unmo330 tivated brutality of white men exploiting their power and imposing their own abusive laws. Even more interestingly, here, the figure of the "heavy" is usually an official or a trader quartered in a commercial outpost or a city, such that he should be associated with the civilized world, at least in its malign aspect, rather than with the side of the wilderness that brings out the worst in men. For such figures, who, in Shipman's words, "want it and want it now", ${ }^{111}$ the lawlessness of the North is not the reason but merely a pretext facilitating the pursuit of their primal drives. By consequence, the Curwoodian villain is nothing but a pervert, and an especially duplicitous one at that, for he makes use of his official position to cloak his real aims. In his case, the lack of character motivation that is typical of melodrama may produce the effect upon readers that they see the villain as he is experienced by those whom he victimizes.

The three novels likewise feature the stock characters of the benevolent father, the absent mother, Native Americans, as well as "half-breeds." The father may be old and dying (as in Nomads of the North), he may get murdered (as in Baree, Son of Kazan), or he may survive (as in God's Country and the Woman), yet he remains the caring and loving type of man who likes to see his only daughter marry, but not against her will. That the girl has to consent to the match is stated at some point or another, usually in a dialogue between the father and any of the other male characters. The mother, if mentioned at all, has passed away or is incapacitated. Most of the "half-breed" characters and Native Americans peopling Curwood's fictional universe are men, either trappers working for and dependent upon the local traders, as in the two dog stories, or faithful servants, as in God's Country and the Woman. In the latter novel, the only "half-breed" female characters are the women working in the villain's brothel and, in Baree, Son of Kazan, the only one is the outdoors girl. But even though, in this instance, she is a main character in the story, the social sta- 
tus of her mixed ethnic origin is not addressed. If the "half-breed" characters are men, their submissive presence is taken for granted, and when they are women, the issue is simply ignored.

The only daughter is an outdoors girl, of course, and she is, in Curwood's stories, more often a white woman (Josephine in God's Country and the Woman or Nanette in Nomads of the North) than of mixed ethnic descent (Nepeese in Baree, Son of Kazan). As is required by the genre, she defends her dignity and virtue against the villain, but, in Curwood's version of the outdoors girl, her courage and intelligence do not rest upon reflection about her social status as a woman. This is not even so in God's Country and the Woman, in which, nonetheless, the originating occasion for the mystery plotline is the rape of Josephine's mother by the villain in Montréal. Narratively, the consequence of the rape - the baby - is presented as bringing disgrace upon Miriam, as fostering the attitude of self-sacrifice on Josephine's part, and as accepted by her lover, Philip, as a sign of his unconditional love for her. The other stories do not include even the vaguest of hints concerning the social status of the outdoors girl. Rather, they present her stamina and ingenuity as natural requisites for surviving the wilderness in which she lives. Naturalness is further enhanced through the alliance of the girl with the animal characters. As a Curwoodian idiosyncrasy within the sub-genre of Northwest drama, this particular alliance, as Nell Shipman has maintained numerous times, constituted, for her, the main attraction of this writer's stories.

The Curwoodian outdoors girl loves animals ardently, most notably the species of the wolf-dog, whose yearnings are split between the dog's wish for a master (who is invariably white) and the wolf's longing for the wilderness. In Baree, Son of Kazan, this split is dramatized when these two yearnings come into conflict with one another, with the result that Baree learns that he is an outsider to both worlds: the wolves reject him because of the canine blood running through his veins, and men mistreat him because they fear him as a wolf. The only character who accepts the wolf-dog as he is, is the outdoors girl, who treats and loves him as a white man's dog, yet is also capable of recognizing and understanding his wild wolf side. Without making the point explicitly, Curwood's fictional universe presents the wolf-dog as a mirror to the yearnings by which women are driven: while close to nature, they too always seek a master. Similarly, the "half-breed" character is linked to the wolf-dog as an outsider figure, thus eradicating his social context and history and transferring him into the sphere of nature and biology.

The kinship of wolf-dog and woman takes on further shape in view of how each is treated by the male characters in the stories. Invariably, the lover respects and cherishes both the wolf-dog and the woman and the villain mistreats them both. The villain considers the wolf's ferocity an advantageous 
trait only insofar as he can employ it for his own purposes; through abuse and outright torture of the animal, he intends to transform it into a murderous machine, so that he can establish his power over the animal and over nature, as no other living being will be able to vanquish the beast. Towards women, the villain acts in the same way. As he sees a woman as a mere thing that he can own and enslave, he misleads and cheats her, and once he thinks he has her in his power, he abuses her both physically and psychologically. As in The Barrier, Curwood's girls only gradually come to understand the villain's intentions and techniques, yet, once they do, they resist him energetically. In their strategy to outdo the villain, the wolf-dog is usually a crucial factor, be it in his capacity of well-trained and faithful sled-dog, as in God's Country and the Woman, or on the animal's own initiative, as in Baree, Son of Kazan and Nomads of the North.

While in Curwood's novels, both civilization and the wilderness, as experienced by the outdoors girl, do have good and bad aspects, these are defined 332 differently and are allocated to other spaces than in Beach's stories. In The Barrier, the good side of the wilderness is located in the hut or the house in which the outdoors girl lives with her family, either father or husband and child, where she enjoys warmth and safety. In Curwood's novels, the hut or the house is likewise a place of shelter in the wilderness where women find refuge from the worst in men. But, from the dogs' point of view, it is also often labeled "the white men's world", and, thus, at the same time it comes to stand for the good face of the civilization for which the animal yearns. Moreover, Curwoodian girls do not aspire to a life in modern civilization, as does Necia in Beach's novel. Quite the contrary, they want to stay in the hut or the house in the midst of the wilderness, but together with a lover (and a dog) and without the threat of harassment by the villains.

In Beach's novel, the bad side of civilization relates to racism and sexism within the society from which the lover or lawman hails. In Curwood's fictional universe, it pertains to traders' posts and cities located at a certain distance, where scheming and exploitation are common practice among officials and businessmen and where the authority of government (represented by the Royal Northwest Mounted Police) is present but fails to maintain justice. The negative aspect of society, then, primarily comprises the evil suffered by woman and animal alike at the hands of the villains, as well as the helplessness of the men of the law, an incapacity that entails a rather cynical view of civilization. Here, the point is that Curwood's fictional world allocates the good and the bad faces of civilization to different places that are miles apart and thus separates them into melodramatically one-dimensional entities.

The Curwoodian wilderness, by contrast, is presented as a system that is much more balanced than this split "civilization". Its rules and laws are inspired by animal instinct, by the urge to learn and to comprehend, by the 
need to survive, and by sympathy for other species. In the conditions of the wilderness, killing is a necessity for the sincere trapper, for the Native Americans, for the outdoors girl whenever she must defend herself, as well as for the animals, rather than some perverse exercise of supremacy and power. The same holds true for ferocity: within the order of the jungle, every act of violence against another animal serves some function. Indeed, as Curwood depicts it, life in the wilds hinges upon a propriety much more refined than that of life led in civilization. The only characters who ride roughshod over it are the villains who have fled from the civilized world. By sketching a geographically and zoologically plausible world of wildlife, yet one that is, for the reader, inaccessible, Curwood veils its problems with a romanticized notion of a nature in which everyone and everything has a place and a reason.

In each of the three Curwood novels under scrutiny, the outdoors girl is not the protagonist. The character from whose perspective the events are narrated and whose thoughts and considerations are most clearly articulated, is male: either a lover or a wolf-dog. If a lover, as in God's Country and the Woman, he has returned from the Arctic north, which brought out, as it were, the best in him: he is now a fully-fledged he-man, fearless, sturdy, self-supporting, righteous, and protective of women. He is an archaic male character radiating virility. The only aspect lacking from such virility while alone in the wilderness is sexual desire for a woman and that is exactly what the romance plotline offers him. The male wolf-dog, as in Baree, Son of Kazan and Nomads of the North, is, in many respects, similar to the lover, except that the animal's desire is not sexual but canine; he yearns for a loving human master, whether woman or man, whom he will protect, and respect.

In terms of their protagonists and plotlines, Baree, Son of Kazan and Nomads of the North are very similar. Both are largely told from the perspective of the wolf-dogs Baree and Miki, respectively. Basically, they recount the animal's life-story, from his birth in the wilderness through his choice to stay with the girl and her family. Their adventures are wolf-dog adventures, showing graphically how they discover the world they inhabit. The reader follows how Baree and Miki learn to survive and to care for themselves, how they make friends or incur rejection, find help or cruelty, suffer deep loneliness or become blissfully happy. Actions draw their motivation from the coming-ofage narration, which generates a strong educational dimension to the story: each event or experience is presented as a lesson learned for life, strengthening the protagonists' ability to distinguish between good and evil, or rather, between necessity and sheer malevolence.

Despite not being the protagonist, the outdoors girl manifests some narrative agency in both animal novels. This is a consequence of the suspension of the human romance plot, which only occurs once the wolf-dog and the girl 


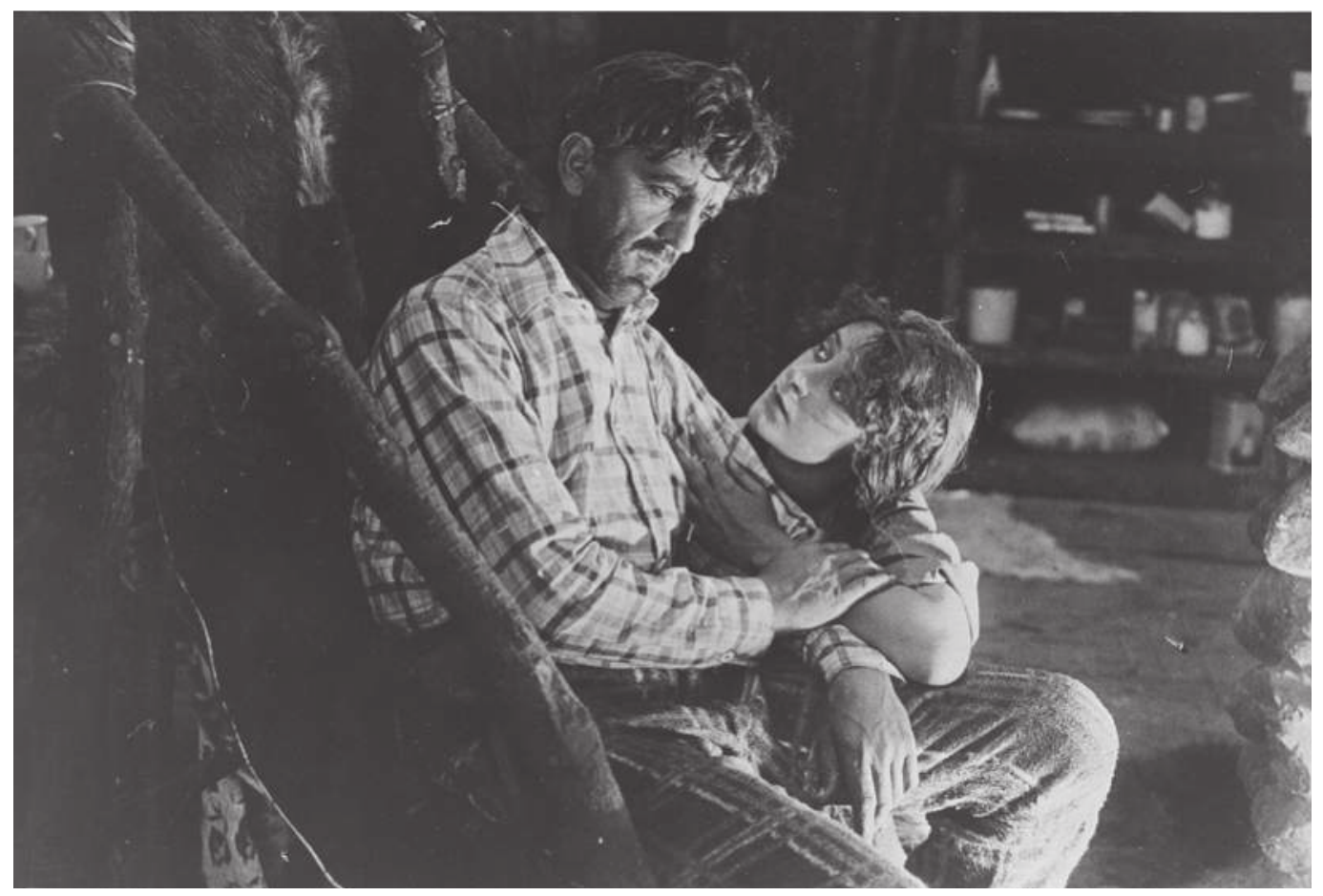

Fig. III.11: Scene from BAREE, SON OF KAZAN.

have met. For instance, Nepeese, the outdoors girl in Baree, Son of Kazan, sees her true love Carvel appear in the final four chapters of this 30-chapter novel, and he enters the story completely out of the blue.

In the preceding chapters, Nepeese had to shake off her dastardly assailant, which could count as an action plotline in its own right, parallel to the plotline of the dog's adventures. Similarly, Nanette, the girl in Nomads of the North, must first outmaneuver and indeed outlive her abusive husband before Miki, the dog, can lead her true love Challoner to the cabin where she lives with her baby. Although these stories depict such actions primarily as witnessed by the dog, the outdoors girl is allowed a certain degree of agency, a higher degree than would be the case were the lover the protagonist. Both Nepeese and Nanette, repeatedly and over extensive story time, evince intelligence and bravery in direct confrontations with the villains. It is my hypothesis that this narrative space for the agency of the outdoors girl represents an important reason why Nell Shipman chose, for her first straight collaboration with James Oliver Curwood, another one of the writer's dog tales. 


\section{Back to Nell Shipman's Career: Options and Choices 1918}

In October 1918, Shipman gave the Canadian trade press the scoop that she had asked James Oliver Curwood "to construct a big new story of wonderful outdoor life" for her. ${ }^{112}$ Shipman officially left Vitagraph on November 1, but, as she avowed in the unpublished first part of her autobiographical novel Abandoned Trails more candidly than in her memoirs, she had been laid off two months earlier. (Note that in this thinly fictionalized novel, "Lewgraphic" stands for Vitagraph and "Mason" for Curwood.)

Lewgraphic says my pictures haven't been pulling business; think they need let me "rest" until my B.O. value picks up. It's just a polite way of letting me down [...] They made money on all of the Mason's I ever did, then they trail in on the rep of pictures by grinding out a half dozen duds that have been hanging around the scenario department for years. Why wouldn't my Box Office drag flop on its fanny? ${ }^{113}$

While in the Moving Picture World no reason was given for the split between company and actress, The Canadian Moving Picture Digest - published far away from California and promoted by Ernest Shipman ${ }^{114}$ - did make note of her grievance:

Miss Shipman speaks in the highest terms of the courteous treatment and solid business facilities which are characteristic of the Greater Vitagraph Company, but she realizes that in turning out ten or twelve pictures per year there necessarily must be some stories thrown upon the screen which do not suit the personnel of the Star. ${ }^{115}$

In her memoirs, Shipman alluded to her dissatisfaction, but gave another twist to the problem:

My contract with Vitagraph ended on a high note as I informed the front office that I was not available for renewal because I had entered into partnership with Mr. James Oliver Curwood to make Independent Pictures. A dirty word to the Majors, particularly when a woman defied the Establishment. ${ }^{116}$

While making independent films perhaps amounted to "a dirty word to the Majors", it was nonetheless the order of the day in the late 1910 s and early 1920s. A consultation of Anthony Slide's The American Film Industry: A Historical Dictionary reveals over fifty independent film production companies 
launched between 1917 and 1923, and, as I have noted, there were several female stars active in them. ${ }^{117}$ If going independent was perhaps somewhat less of a heroic act for a woman, at the time, than Nell Shipman claimed it to be, and certainly less exceptional than the omission of independent women's companies from film histories seems to suggest, nonetheless the large number of independents going out of business within one or a few years does underscore that such enterprises faced an uncertain fate.

\section{THE SHIPMAN-CURWOOD PRODUCING COMPANY 1918-1920}

Whatever the trigger for Shipman's resignation from Vitagraph, Nell Shipman had taken swift action during the interval of involuntary rest from making pictures, for, on November 2, 1918, the trade press broke the news of the for-

336 mation of the Shipman-Curwood Producing Company, in which actress and writer announced their mutually exclusive cooperation, he by creating "for her new stories of tremendous scope and power, in which the North land, nature tales of wild animals and red-blooded men, will inter-weave," and she by acting only "in stories from his pen". ${ }^{118}$ Moving Picture World followed with an announcement with practically the same wording one week later. Both cited a letter that Curwood had written to Ernest Shipman:

I have watched Nell Shipman's work closely in my stories. She is the only actress in America I would sever my present profitable association to enter into affiliation with, for she is the only star who can do outdoor work and do it big. ${ }^{119}$

Ernest Shipman was hired as a business manager and sales agent for the company's first and-what appears to have been-only production, for the financing of which he incorporated the Canadian Photoplays Ltd. ${ }^{120}$ This was to remain the first and only time in the careers of both Shipmans that they would collaborate on the same film in their respective capacities of actress and production manager.

Strictly speaking, the personal association of a literary author and a screen star in a film production company was unusual, as there are, to my knowledge, no preceding instances of this in the American film industry. Coming closest, perhaps, was Bosworth Inc., a company established by the actor, director, scriptwriter, and friend of Shipman's, Hobart Bosworth, with the principal goal of adapting Jack London stories to the screen, of which, all in all, three were released in 1913 and $1914 \cdot{ }^{121}$ London, however, was not known to be personally engaged in the production of the films. Yet, taken in a broader sense, 
that is to say, in terms of the teaming up of two parties in order to combine their professional resources effectively, the Shipman-Curwood alliance may be said to have epitomized two distinct tendencies in American film production of the 1910s: the prolific duos that operated within the major companies, whether publicized as such or not, as well as the phenomenon that the incorporation of independents at the time was often guided by particular subject profiles.

Within the industry, professional partnerships had been formed from early on, but the trend, by 1918, was away from manifesting such work-arrangements publicly, as well as away from preserving their exclusivity. Whereas star and director combinations such as Gauntier with Olcott at Kalem in the early 1910s, or Cunard with Ford at Universal up until 1917, were presented as select tandems, other longstanding or periodic collaborations were not publicized as such. As far as the leading actresses were concerned, this may have been an effect of the expanding star discourse, which emphasized the players' extraordinariness, as Bean has pointed out, and featured and isolated them at the expense of other professions involved in the production of the films, as deCordova has shown. With regard to directors, the trend may signal the transition from a director-unit system of production to the central producers system implemented after 1914 and the reshuffling of power in the production hierarchy at the expense of the direction. ${ }^{122}$ Furthermore, the later collaborative teams rarely were as exclusive as the earlier ones had been. In publicity, moreover, the stars were associated with companies rather than with directors, or with scenarists for that matter. ${ }^{123}$ In this sense, Shipman's exclusive public association as a star with Curwood as the provider of stories seems to have been a little odd, yet it was not out-of-date after all.

Behind the scenes, indeed, the pervasive team-building continued with collaborations between scenarists and stars, such as, for instance, Frances Marion writing for Mary Pickford and Marie Dressler, as well as Anita Loos for Lillian Gish and the Talmadge sisters, or between scenarists and directors, with Lenore Coffee writing for Lois Weber and Jeanie MacPherson for Cecil B. DeMille, to name but a few of the most influential teams of the 1910s. The centrality of the scenarists to such collaborative efforts points to their considerable power within what Shipman called "the Establishment". As Marsha McCreadie in her study The Women Who Write the Movies has pointed out, most of the scenarists writing the films for the major companies were women. McCreadie has astutely identified an informal yet tight-knit and effective network of women writing for other women and hiring one another whenever they could. ${ }^{124}$ The idea of the existence of such an informal network sprang from a remark made by Frances Marion when she looked back at her long script writing career in 1969: 
I hope my story shows one thing. [...] While it's perfectly true that many important men [...] helped and encouraged me, it's consoling to know how many women gave me real aid when I stood at crossroads. Too many women go around these days saying women in important positions don't help their own sex, but that was never my experience. ${ }^{125}$

Shipman's writings testify neither to any awareness of, nor to affinity with this informal women's network. She never complained of women failing to help her, but, on the other hand, she hardly ever seems to have sought other women's collaboration in film production. At this point in her career, it would not have been an option, because her first choice for collaboration, the man who had thus far written the stories most suited to the screen persona she intended to monopolize, jumped at her proposal without reservations.

The Shipman-Curwood Company adopted a strict subject profile. It 338 intended to produce Northwest dramas featuring an outdoors girl, red-blooded men, and animals. Such subject-related and thematic vignettes were no anomaly among small film companies. In the early 1910s, which Kay Sloan has termed the heyday of the "social problem film", special interest groups such as labor unions and the suffragists actively participated in film production in order to advocate their causes to a movie-struck public. ${ }^{126}$ If this political edge largely disappeared with the ascendancy of the feature-length film by the mid-teens, the thematic orientation did not. Examples included the Bostock Jungle and Film Company, incorporated in 1915, which made two-reelers featuring animals, and Blazed Trail Productions, established in 1919, which focused on films with subjects set in the Canadian North Woods. Another type of subject profile was adopted by the five different companies that aspired to make films with and for black people, of which the Micheaux Film Corporation, established in 1918, is now the best-known. ${ }^{127}$ For these companies, their subject profile was an element of their rationale for going independent and carving out a niche for themselves by means of differentiation and specialization, vis-à-vis the growing hegemony of the majors.

That Curwood agreed to give Shipman the exclusive rights to the adaptation of his stories may be considered a token of his esteem for her work as an actress. With 100 best-selling stories, novels, and scenarios brought to the silver screen by 1918, the author had plentiful choice of actresses. The list of actresses that Shipman bypassed included the top stars at the time Corinne Griffith, Betty Blythe, Stella Razzato, Constance Talmadge, and, most notably, Kathlyn Williams and Anita Stewart. Anita Stewart played in some seven Curwood shorts and features from 1913 until 1917 at Vitagraph and ranked eighth in a national fan magazine poll conducted in $1918 ;{ }^{128}$ she could perhaps have posed the most serious challenge to Shipman. She formed her own 
Fig. III.12: Picture postcard Kathlyn Williams.

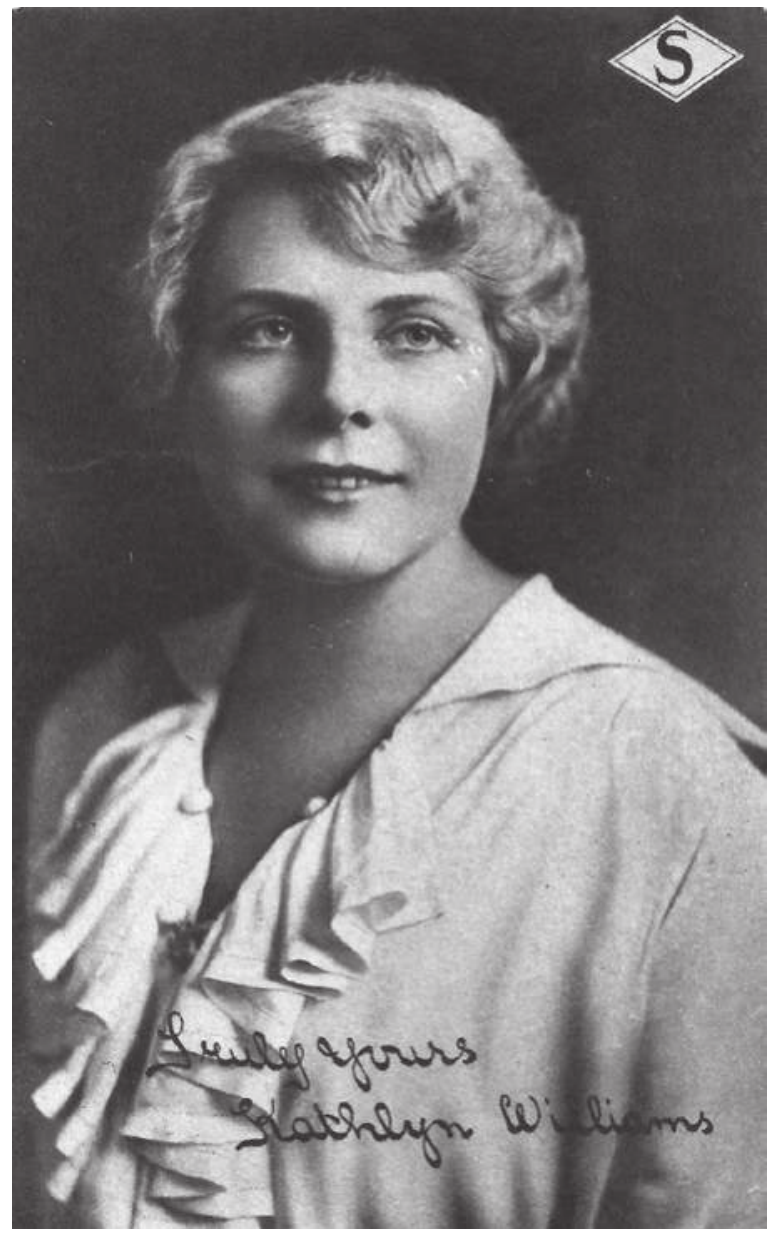

company in 1918, Anita Stewart Productions, and went on to play the lead in Vitagraph's remake of BAREE, SON OF KAZAN in 1925. On the other hand, Kathlyn Williams would have been an even more obvious candidate, as she was known as the serial queen from THE ADVENTURES OF KATHLYN and as a Northwest outdoors girl.

Williams had demonstrated in many roles that she was capable of handling wild animals in front of the camera, thus someone who was, in more than one respect, a direct forerunner of Shipman's. ${ }^{129}$ Although most of Williams' Curwoodian parts were in one- and two-reelers dating from 1913 and 1914, she played the female protagonist in the five-reeler THOU SHALT NOT COVET in 1916, for which Curwood himself wrote the scenario based on his story. Williams was also a featured actress in the screen adaptations of two 
Rex Beach works, THE SPOILERS and THE NE'ER DO WELL, in 1914 and 1916 respectively, both directed by Colin Campbell for Selig. And, last but not least, in 1917 , she too had left the company with which she had been affiliated from the beginning of her film career in 1910, the Selig Polyscope, and was, one may assume, ready for a change. ${ }^{130}$ It is not known if any of these women shared Nell Shipman's ambition to act solely in adaptations of Curwood's stories, but their work did not detract from the writer's acclaim for Shipman to be "the only star who can do outdoor work and do it big."

Within a month after the public launch of the company, the first story for production had been selected and was announced in the Canadian trade press. It was the Northwest dog tale "Wapi, The Walrus", which was already running in the November and December 1918 issues of the American monthly magazine Good Housekeeping. ${ }^{1{ }^{11}}$ Although the drawings accompanying this publication by the prominent illustrator Gayle Porter Hoskins virtually begged 340 for a further visualization into moving pictures, no indications were yet given of the story's impending adaptation for the screen. Nor did the American trade press mention that the story had been chosen, but this may have been due to a dearth of press releases from the side of the production company, as both Nell and Ernest Shipman, like so many others in and outside the trade, came down with the Spanish flu and were severely ill for several weeks in December 1918 and January $1919 .{ }^{132}$ Nonetheless, from the beginning, the relatively scarce notices in the press adopted the discourse of authentication, in compliance with the promotional rules of the Northwest genre and of early female film stardom:

Miss Shipman's Company will be taken into the North Country and the barrenness so vividly described in the story will be screened as to inject absolute realism into the picture. ${ }^{133}$

The "News of Los Angeles and Vicinity" rubric in Moving Picture World informed its readers that Nell Shipman owned nine dogs that would appear in the planned series of Curwood adaptations, including "three malamutes, three Airedales, two collies and a fox terrier". ${ }^{134}$ The discourse of authentication was maintained throughout, as many instances to follow will illustrate, and thus provided Shipman with a select chance to consolidate and elaborate her status as a star in her own right. But this status would also become an issue in a different context, one entirely absent from the contemporary press coverage: namely, the feud soon to erupt between Shipman and Curwood over the scenario and each writer's contribution to it. 
Curwood's story featured yet another dog vacillating between his ferocious ancestry and his wish to be "a white man's dog, dog of a white man's world". ${ }^{35}$ His ancestor was Tao, not a wolf but a "monstrous Great Dane", "the most powerful, and at times the most terrible" of dogs. Wapi hated men as much as they hated him, but he also obeyed them, hoping that someday he would encounter warmth and love from one of them. That was how he came into Blake's possession, "a trader in seals, whalebone-and women," ${ }^{136}$ but this man treated him even worse than the others had. Yet, through Blake, Wapi encounters Dolores, and, as is usual in Curwood's fictional universe, the recognition between beaten dog and endangered woman is reciprocal and unconditional. Their relationship offers them mutual protection: the woman protects the dog from further slavery, while the dog shields the woman from the villains who scheme to enslave her.

As this story is a short one, it contains only a single plotline: the adventure and action plot of Dolores' negotiation with Blake about escaping as well as the actual escape by dog-sled and the chase that ensues. The narrative perspective alternates between Wapi's and Dolores' and, even more pronouncedly than in those animal tales of Curwood's discussed previously, here, dog and woman share the narrative agency. Most of the characters are just as one would expect to find them in a Northwest story. Blake, the villainous trader whose vicious intentions the woman only gradually understands; Rydal, the lead villain who considers women merely something to own and to abuse; Uppy, the Inuit servant who simply does whatever he is ordered to do; Dolores, the white outdoors girl and the object of the villain's infatuation; Wapi, the dog who, with the experience of slavery and humiliation, teams up with the woman. And Peter Keith, here a husband instead of a lover, but a writer who-similar to the authors of Northwest drama-likes to go "into all sorts of places", as Curwood has Dolores explain to Blake:

"We love it-both of us - this adventuring. We have been all through the country down there," she swept a hand to the south, "on dog-sledges, in canoes, with snow-shoes, and pack-trains." ${ }^{137}$

The father is absent from the plot but is recalled by his daughter as the parent-a general - from whom she inherited her courage; a mother is not mentioned at all.

In the preamble, the life-story of the dog is not situated in an idealized wilderness, but in between the two forms of civilization that recur in Northwest drama: the cruel variety inhabited and controlled by the villains, and the good 
variety, known in Curwood's work as "the white men's world”, from which Tao comes and for which Wapi continues to yearn. As in other of Curwood's dog tales, the two aspects of civilization are situated miles apart, and their irreconcilability is enhanced in this story by a north-south antagonism. Less typical is that, here, the good face of civilization is associated with a city, Vancouver.

Of the wilderness, the story primarily illuminates its negative side: the Arctic barrens that bring out "the worst in men" and thus endanger woman and animal. The escape route taken by Dolores, Peter, and Wapi, leads them to the edge of the barrens, to the fictional Fort Confidence where the Royal Mounted Police is said to be stationed but of whom we hear nothing further. The righteous side of the wilderness is not present in the story, or mentioned only indirectly, when it is said to be what draws the white woman to her travels, and provides the writer with subject matter for his books. With the good face of the wilderness absent, the focus then shifts to civilization's good side, 342 located this time around in the south, whereas both its harmful variety and the bad side of the wilderness are situated in the north. By means of these allocations, the short story "Wapi, The Walrus" deviates from Curwood's novels: it represents wilderness and civilization as outright opposites.

The narrative of the short story obviously required elaboration to turn it into a scenario for a feature-length film. Yet before discussing the contents and form of this elaboration I shall now address the complicating circumstantial issues relevant to the controversy between Nell Shipman and James Oliver Curwood over the scenario. One reason for doing so is methodological: it allows me to demonstrate most transparently the adopted way of reading the surviving documents, viewing Shipman through the eyes of her contemporaries and inferring what is left unsaid. A second, but no less important, reason is that the conflict had shattering consequences for the collaboration, so severe that barely eight months after the establishment of the joint venture, the actress resigned from all contracts with the writer and the production company. ${ }^{138}$ The ramifications of her withdrawal would persist throughout Shipman's career.

According to her own account, Shipman was assigned to write the working scenario for the film. This is one of those claims in which we can only trust her word, as no further evidence that she actually wrote it could be retrieved. To my knowledge, the scenario itself has not survived, either in Shipman's files or in Curwood's. ${ }^{139}$ Neither was she credited for it on one of the two prints of the film used for its restoration, or in contemporary publicity or reviews. It could be argued that this lack of attribution was one of the consequences of the controversy, as the film premiered on September 16, 1919, after Shipman's resignation. Joseph Walker, cinematographer for this and various later Shipman films, mentions in his memoirs only that she 
rewrote the scenario and added various scenes during shooting, not that she had written the shooting script. ${ }^{140}$

In The Silent Screen and My Talking Heart and in Abandoned Trails, Nell Shipman maintains that Curwood was dissatisfied with her initial script, for three reasons in particular. Each of these reasons calls for critical attention, because, in the end, they obscure rather than reveal what was the problem. One of the reasons focused upon the jargon commonly used in a scenario and the requested plainness in descriptions of images and actions:

I suppose the booboo upset my non-technical partner. [...] The stuff was the same but his word painting more literate. The girl did not simply look at the man who would rape her as she came naked from the forest pool. She trembled. Her fluttering hands clothed her heaving bosom, tears, like spilled opals, coursed her pale cheeks and her hair, her bountiful, glorious hair, glistened wet from her swim with her pet bear and flowed about her alabaster shoulders like a protective mantle. ${ }^{141}$

Shipman was right that, according to the standards of 1919, such "literate word painting" was considered redundant in a working scenario. But the primary claim she makes here is that she was familiar with the specific terminology and format of a professional scenario text, whereas Curwood was not. As Tom Trusky has suggested in the notes to the third edition of Shipman's memoirs, it is rather unlikely that Curwood was incapable of reading a film script. ${ }^{142}$ In my earlier account of the developments within the profession of script writing, I pointed out that plot construction and continuity script writing were already considered to be two distinct functions by 1913. Curwood had written and sold at least 25 scenarios to various film production companies between 1911 and 1915, which implies that he must have been aware of the current and changing standards for continuity script writing. On the other hand, from 1916 onwards, he mainly furnished companies with stories and left the proper script writing largely to the studio personnel. This fits with the continuous professionalization of the craft and seems also to indicate that the technical breakdown of scenes was not Curwood's preferred occupation. If that was the case, it may clarify why Shipman managed to secure this task for the film in the first place. Nonetheless, the unlikelihood of Curwood having responded to her work in the way that Shipman said he had, seems to confuse whatever his criticisms really comprised and, at the same time, obscures Shipman's own part in the conflict. A more plausible bone of contention may have been that Shipman feared that Curwood was interfering with what would eventually be her most visible - and the only undeniable - contribution to the final picture, namely, her presence as the leading actress. At the cited point in her memoirs, 
then, we read the words not of the former star, but of the once noted scenarist writing against oblivion.

My evaluation of this as a misrepresentation of Curwood's abilities and intentions is prompted in particular by another irregularity in the memoirs, immediately prior to the passage on her technical "booboo". In the paragraph in question, Shipman characterized Curwood in these words:

James, though not physically a brawny stalwart, was publicized as a big, outdoor Game Hunter. Huge bearskins adorned his backgrounds and I'd a still of him with his foot on the head of a slain Grizzly, a picture I did not admire very much. But I did not mention my dislike of hunting $[\ldots]^{143}$

If she did not, that is unfortunate, because Curwood might have pointed out to her his change of mind in this matter. To be sure, Curwood's confession 344 of having changed from a hunter into an animal biographer may be ascribed largely to the strategies of authentication required by the Northwest genre. However, entirely to ignore its bearings on himself or on his public persona also seems a fabrication, particularly in light of the author's and the actress' joint venture. I suspect therefore, that their controversy sprang as little from his lack of professionalism with respect to film scenarios as it did from his attitude towards wild animals.

Nell Shipman's third reason for the conflict calls forth even more reservations. In her memoirs, she contends that Curwood objected to her treatment of the story because "it did go far beyond and behind 'Wapi, The Walrus"” and because, in her scenario, the girl-not the dog-took the lead. ${ }^{144}$ Now, I have argued that the girl and the dog were well-matched in terms of narrative agency in the short story, a feature that was consistent, moreover, with the Curwoodian fictional universe as known from his other animal narratives. In her roman à clef, Shipman seems, in fact, to confirm that there was no discord between her and Curwood on this point. There, she narrates how her alter ego Joyce Evons and the writer Richard Walter Mason went through the script together as the former had written it, but the latter "did not add or take away one single line". ${ }^{145}$ This became possible after the scenarist had decided to "[l]et him think that he was doing it himself!" ${ }^{146}$ This statement can be read in two ways: either Curwood did in fact require numerous changes to the scenario, or Shipman's script already resembled his work to an almost eerie extent. Could precisely such a compatibility between them as writers of Northwest plots and scenes have disturbed the big ego the author was reputed to possess?

Curwood had agreed to Shipman's cooperation in that she would act his outdoor heroines; he had envisioned her as his prototype actress, not necessarily as his favorite scenarist. Did he sense in her a potential competitor in 
the field of Northwest drama that featured animals, of which he thought himself to be (and intended to remain) the champion? And did he therefore dispute her professionalism in this field, wishing to confine her to playing roles in stories he had written? Admittedly, these are the questions of a modern-day feminist and Shipman did not ask or answer them. But her accounts of their disagreements do prompt these questions, and the aftermath of Shipman's resignation from the partnership with Curwood even more so.

During and after the production of BACK TO GOD'S COUNTRY, as the film was entitled, Shipman took sides against Curwood in what he termed "factional quarrels" and fights over her remuneration. ${ }^{147}$ Later in her life, she said outright that she had been "badly cheated on it" but did not clarify in what way or by whom. ${ }^{148} \mathrm{All}$ of this was carefully kept out of the press, but historical evidence is contained in Curwood's letter to Shipman, which, dated August 7, 1919, conveys the author's acceptance of Shipman's resignation but also his disappointment about her decision:

I think that perhaps you have made the biggest mistake of your life [...] and because of your old association with my work I cannot but regret that you have chosen another road to travel. ${ }^{149}$

The paternal and reproachful tone points to a crisis of confidence on Shipman's part, rather than on his. If we take into account their competitiveness in matters of scenario-writing skills and of proficiency in the genre, Nell Shipman may indeed have had reasons to be wary of James Oliver Curwood's intentions.

After Shipman's resignation, Curwood further fuelled their unpublicized conflict by claiming, in the trade press, an ever-larger share in the making of the film. In October 1919, in an article under the headline "Curwood Helped Produce 'Back to God's Country'," he was quoted as having declared:

I wanted to express my personal concern in [the film's] adaptation to the screen by contributing my knowledge of wild animal life and the hunting regions of California and the Arctic. ${ }^{150}$

In another article in the same issue, Curwood also took the credit for writing the parts of the animals in the film, which were considered to "contribute a novel atmosphere of realism", while Shipman was said to only have "helped the trainers". ${ }^{151}$ Advertisements, moreover, presented BACK TO GOD's COUNTRY as a film "by James Oliver Curwood", ${ }^{152}$ and thereby emphasized the possibilities for exploiting the presence of the animals in the publicity. In his column "Advertising for Exhibitors" in Moving Picture World, Epes W. Sargent 
points out a number of the most accomplished publicity ideas developed by exhibitors around the country, ${ }^{153}$ which culminated in an account of how an exhibitor at St. Paul had used animal footprints for his ingenious and successful campaign. ${ }^{154}$ The strategy turned upon the highly appealing combination of wild animals and film, which Curwood claimed exclusively as his idea but which, as we have seen, was previously utilized by Vitagraph to promote their Curwood adaptations featuring Shipman.

In a February 1920 announcement of the formation of Curwood's new production company and its first film, NOMADS OF THE NORTH, the writer affirmed "the absolute necessity of an intimate cooperation between author and director" and, now referring to BACK TO GOD'S COUNTRY, boasted of his having been "'sit[ting] in' together at every stage of the game" in order "to achieve the greatest results in picture making". ${ }^{155}$ Rather curiously, he sermonized about egotism and jealousy among authors and directors, with346 out naming or blaming anyone, to be sure, but nonetheless conveying the impression that he spoke from experience. The fact that Curwood found it necessary to legitimize the formation of his own new company with a reference to inflated self-regard and egotism, supports my thesis of the mutual competitiveness between him and Shipman. Likewise does, in my opinion, his denial of the intermediary function of the scenario between the work of the author and that of the director. On the basis of this article, readers could conclude that Nell Shipman was no longer a participant in the new Curwood company, while Hartford and Ernest Shipman still were. For this reason, it seems to me, it is not too far-fetched to read the sermon as directed to her, while she, thus indirectly addressed, was denied any means of defending herself against the insinuation. As if these various and ongoing signs of the erasure of her contributions to BACK TO GOD'S COUNTRY would not have proved bitter enough for Nell Shipman, Curwood enjoyed the support of Ernest Shipman, who, by now, had been placed "in charge of the production and sales" of the successor of the Shipman-Curwood Producing Company, the Curwood-Carver Production Company. ${ }^{156}$ During this affair, Ernest Shipman was obviously not doing much to promote his wife's career (they were officially still married); even her starring role was not always given emphasis. ${ }^{157}$ If, in the press coverage, Nell Shipman's involvement in the production of BACK TO GOD'S COUNTRY was mentioned at all, this certainly did not concern her conceptual share in the collaboration with Curwood and in the film as such.

In her roman à clef Abandoned Trails, Shipman included a few impressions of Curwood that she would omit from her memoirs. One of them hints at a ground for Shipman's distrust other than the competition between them. It suggests that Joyce was not so much bothered by Mason's criticism of her 
scenario as she was starkly disappointed with the man behind the stories she cherished:

She thought he must be as he wrote, failing to see the stereotyped hand of the cheap and popular hack behind the wordy pages she deemed so fine. She had expected to find him a composite of all his manly heroes, a climactic leading man of all leading men. Instead he was an egoist, a hen-pecked little husband-in rubbers! ${ }^{158}$

Instead of the "Author-Hero" the scenarist-actress had hoped for, she says to have encountered a "stand-offish" little "faker". If this picture of disappointment over an idol fallen from its pedestal comes anyway near to Shipman's true feelings about Curwood, it suggests that her representation of him was also motivated by professional revenge. By misrepresenting Curwood's skills and intentions in both her roman à clef and her memoirs, Shipman seems to make an effort-hardly surprising, yet admittedly meager-to beat him at his own game: she denies that he contributed anything substantial towards the artistic ideals that were as crucial to her as to his career in cinema.

Given this background, ideally scholars should have for study two drafts of the scenario proper, the initial draft written by Shipman and the text as revised after her session with Curwood. But despite-or perhaps because ofthe absence of either draft, Shipman's assertions have gone unquestioned in scholarship dealing with the issue until now. In particular, the question of the preeminence of the Girl over the dog has been widely taken for granted. ${ }^{159}$ Kay Armatage, in her monograph on Shipman, has followed suit. According to her, Shipman's

script for BACK TO GOD'S COUNTRY shifted the thrust of the plot to the woman protagonist and wove the dog into her melodramatic story of romance, villainous menace, heroic escape, and a treacherous journey across the barren snows. ${ }^{160}$

As I demonstrated in my analysis, these plotlines and elements are commensurate with the genre of Northwest drama and as exemplified in other Curwood novels and tales with which Shipman was familiar. If Shipman, in Abandoned Trails, wrote of the source story as having been "trash as a movie, a mere outline" and "a character-study" of a dog, ${ }^{161}$ suggesting that it lacked both romance and action, she was either again taking artistic license, or misrepresenting it just as she misrepresented Curwood himself. Beyond the action-plot, I have shown, "Wapi, The Walrus" also included what Armatage terms the "mutuality of the connection between dog and woman" as well as the 
alignment of "human-animal communication [...] with courageous feminine heroism" ${ }^{162}$ But these motifs, too, are attributed to Nell Shipman: "This rather complex relay of interspecies desire, it must be recalled, is the creation of the woman screenwriter and star." ${ }^{163}$ However, none of these narrative motifs can be said to be Shipman's creation as such: not only did she draw inspiration from Curwood's work, but others were also involved in the visualization of the story and the composition of the print. ${ }^{164}$ One ought at least consider that the construction of the "cinematic discourse" was shared with Shipman by a director, David Hartford, two cinematographers, Joe Walker and Dal Clawson, as well as an editor, Cyril Gardner. The film, moreover, was completed after Shipman's withdrawal from the joint venture. Both in the discursive and the pragmatic sense, then, even if Nell Shipman indeed wrote the shooting script and the intertitles, she cannot be considered to have had discursive control over the film as it was released.

348 By ascribing certain narrative elements that can be traced to Curwood's story, and specific cinematic choices that may have been made by other crew members, to the screenwriter and the leading actress, Armatage falls victim to what I like to call feminist wishful thinking. Her discussion of the film appears to be a product of a modern-day feminist scholar's wish for a historical woman's discursive control, rather than an analysis of the interplay between such a wish and the historical and discursive conditions (and the plausible extent) in the case of Nell Shipman and BACK TO GOD'S COUNTRY. When I first became acquainted with the film, I fell into this very same trap. ${ }^{165} \mathrm{I}$ admit, in retrospect, that a lack of historical knowledge and of a culturally and historically grounded conception of authorship in a popular culture as well as my sincere enthusiasm about the particular charms of the film were the reasons for my initial misreading.

With the material at hand, I shall now undertake an intertextual analysis of the surviving print of BACK TO GOD'S COUNTRY. I shall attempt to determine which plot devices and elements were transferred or adapted from the Northwest dramas from which Shipman derived her knowledge of the genre that did not spring from her own imagination but rather from Curwood's, or, for that matter, from Beach's. This will turn the focus to some narrative elements and scenes that do not necessarily accord with the formulas of the genre and the idiosyncrasies of the writers under study. A further comparison will be made with similar scenes and narrative elements in the second film made by Curwood's production company, David Hartford's NOMADS OF THE NORTH, from 1920, because of the involvement of both Curwood and Hartford, but not Nell Shipman in the film's production.

In order to work the short story "Wapi, The Walrus" into the scenario for a feature-length film of over 70 minutes, the plot needed expansion. While the 
source text basically offered an action plotline, the genre of Northwest drama called for a romantic plotline to complement it. In the film, the romance takes place prior to the adventure plot, a chronology rather unusual for Curwood's dog stories, which, as we have seen, tended to keep the lover at a distance until after the outdoors girl, practically single-handedly yet ultimately with the help of the dog, eliminates the villain. However, because Dolores and Peter are presented as wife and husband in the short story, the chronology in the film may have been prompted by the linearity of the narration and the plausibility of the order of events. The first part of the plot in its extended form, then, deals with the love story between Dolores and Peter.

The romance plotline is set in an Arcadian forest in a mild climate, whereas the adventure plotline, just as in its written source, is set mainly on a trading vessel in the cold North. The forest scenes seem to be inspired by similar scenes in Baree, Son of Kazan, in the screen adaptation of which Nell Shipman starred as Nepeese, in the same year in which the scenario for BACK TO GOD's COUNTRY was written. The romance plotline yields a series of peaceful and idyllic scenes in a most picturesque variant of forest life, where humans know how to live in harmony with the "wild things" that surround them. ${ }^{166}$ These are animals such as a raccoon, a donkey, a cub and two bears, a porcupine, and an owl, to whose parts in the film I shall return. It is not Curwood's wilderness, where fortunate events succeed unfortunate ones yet in which everything has a place and a reason, but rather his "white men's world”, the hut-on-the-heath civilization, that is depicted on the screen. The core adventure plotline set aboard the ship and the traders' post in the North, by contrast, exemplifies and visualizes rather precisely that other face of civilization in Curwood's fictional universe, in which harsh treatment of dog and woman is routine. The film fully elaborates the contrast between these two faces of civilization and likewise adopts the north-south antagonism given in the short story.

All characters figuring in "Wapi, The Walrus" were transferred to the screen. Some had their nationalities or names changed, or lost their nationalities, but their main features are maintained. The protagonists in the expanded part of the plot are Dolores, Peter, and, rather surprisingly, the "vessel master" Rydal. The latter may be classified as the story's main villain, representing the menace of "the worst in men" from which Dolores seeks refuge, but, as a character, he remains in the background in the source story. In contrast, the film's plot grants Rydal much more prominence. Seen from the perspective of plot construction and, thus, of the scenario, it is this enlargement of Rydal's part and not Dolores' that affects a change of the degree of prominence of the other characters. It affects, most notably, the part of the trader Blake, and then Wapi's. Since Wapi is diegetically linked to the character of Blake before meeting Dolores, it is the enlargement of Rydal's part at the expense of Blake's that 
holds the dog back from entering the film's action. Insofar as the plot expansion may have contributed to the controversy between Curwood and Shipman concerning the scenario, the point of contention should have been that the villain became more prominent than the dog, not the girl.

In addition to enlargements of the parts of Dolores, Peter, and Rydal, the need to extend the plot also allowed for, or probably even called for, the insertion of characters absent from the written source: not a mother, to be sure, but a father, and the aforementioned menagerie of animals. The father character in the film is a character probably modeled after the father in Baree, Son of Kazan. Both fathers are French Canadians, ${ }^{167}$ and each gets cheated and, halfway through the story, killed by the villain. The various animal characters too seem to be transferred from the plot of Baree, Son of Kazan, with one important difference: whereas, in the novel, the animals belong to the wilderness world of the dog and interact only with him, not with the human protagonists of the 350 story, in the plot of BACK TO GOD's COUNTRY, they are not connected to Wapi, but belong to, and interact with, Dolores' Arcadian forest world. Dolores is depicted here as a wilderness girl to a much greater extent than in the story. In this regard, the character was also modeled after the Nepeese of Baree, Son of Kazan.

The animals living in Dolores' Arcadian forest world do not appear merely as sylvan ornaments or props, nor as extras that make up a crowd, but are characters who play small parts and interact with the human protagonists of the two unfolding plotlines, the romance and the preparatory adventure plotline interwoven with it. In the romance plotline, for instance, we see Peter and Dolores return to the house from a first walk together, while holding hands. Dolores' father awaits them in front of the house. Dolores steps towards her father and hugs him while Peter watches the scene. The sequence may be read as showing the father's acceptance of Peter as his only daughter's lover. But it is not solely the father who has to approve of Dolores' new friend, there are others too. A raccoon leaves its water bowl and moves towards Peter, after which it puts its paws on one of Peter's calves, as if to show its affection. The fact that none of the actors seems to notice the animal or respond to its action, allows for a reading that the animals have a discourse independently from, yet no less important than, that of the human characters in the film.

The next sequence is introduced with a title, "Magic night-and the love flame kindled" ${ }^{168}$ In the hut, the father and Peter talk and smoke their pipes, and Dolores is cuddled next to Peter. Before Dolores retires to her room, Peter speaks sweet nothings to her, and she, blissfully, takes hold of his hands. There follows a close-up of an owl sitting on a branch and peering into the camera; then a cutback to Peter and Dolores holding hands, and Dolores entering her bedroom. The next shot shows Peter in front of the closed door and suddenly 
looking up. Cutback to the owl, as before. This shot is followed by a title card with a dialogue line with the owl's comment: "I am with you, old man!" The comment expresses this animal's approval of Peter.

Even though the idea of including this animal discourse may have been inspired by the interaction between Baree and his friends in the wilderness, when the animals address the humans in BACK TO GOD'S COUNTRY, the communication has a distinctive flavor. To be fair, this terrific idea may have been concocted by several craftspeople involved in the making of the film, including the author of the stories upon which the film drew, or the writer of the scenario, or the film's director, or its editor. The answer, however, cannot be deduced from the film text. An indication may be found in scenes of which Nell Shipman would prove to be especially proud in her memoirs or in her other writings; but Peter's exchange with the owl is not among them. Neverthe-

Fig. III.13: Nell Shipman playing with Little Brownie.

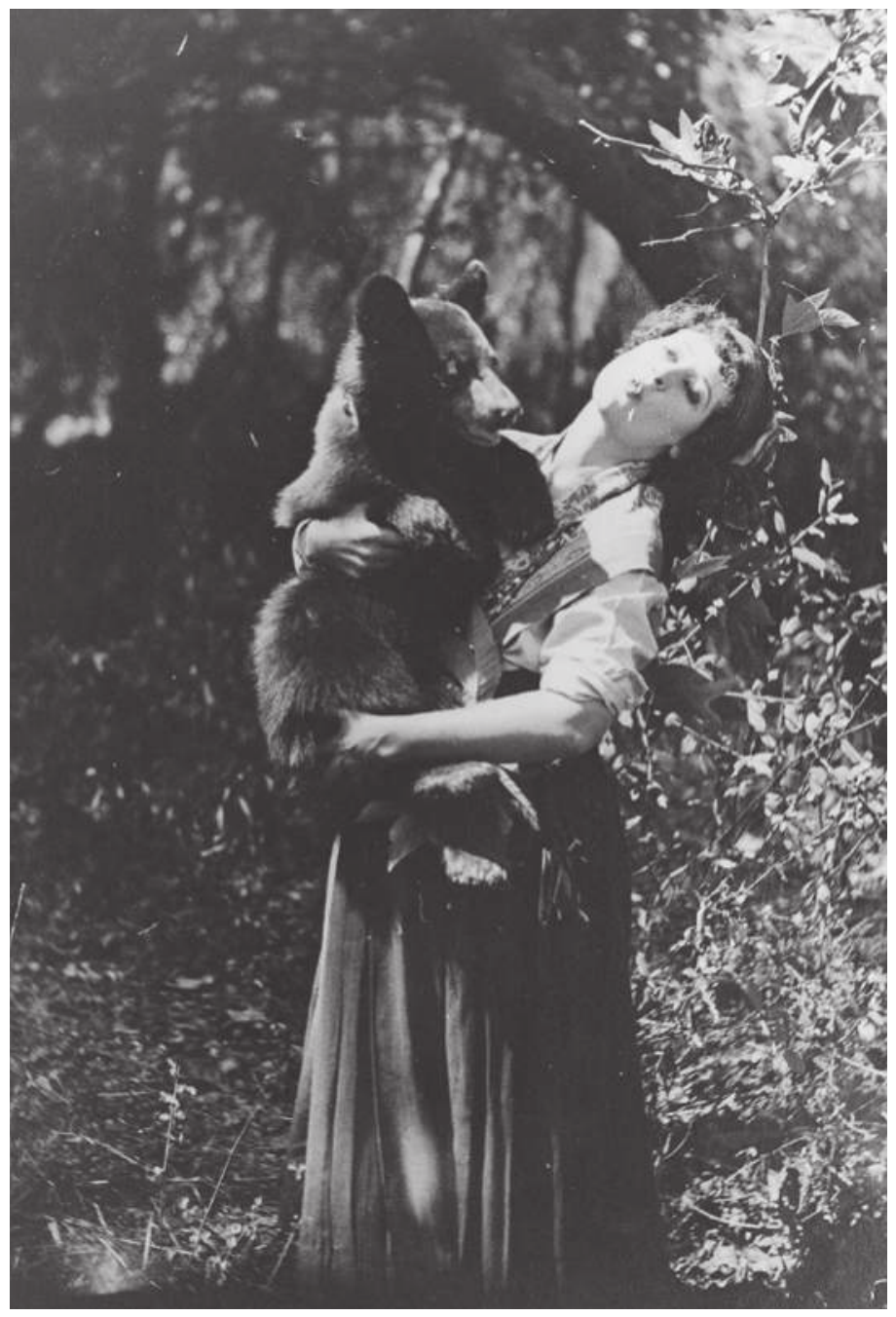


less, Shipman argues that she "thought the picture needed animal sequences to lift it from the humdrum triangle: Bad Man wants Girl, Good Man loves Girl, Saves Girl." ${ }^{169}$ One animal sequence she mentions with pride is the one with the honey-stealing bear cub on the kitchen table, which follows closely after the two scenes described. Moreover, Shipman virtually adopts in her delineation of the scene animal discourse, by emphasizing the autonomy of the performance of Little Brownie, the bear, who went "scene-stealing" and "topped her own script". ${ }^{170}$

In a published eulogy for Brownie, "This Little Bear Went Hollywood", she explicitly interprets one of the bear's actions on the movie set along these lines. While the human actors kept "gaz[ing] lovingly upon each other" so as not to disturb the little bear's "script", the animal reached up to Shipman:

Exchanging smiles with the Boy Friend, I stooped so that my face was near the cub. She flicked a mite of pink tongue and kissed my cheek, looked at my lover, bobbed her bit of head as if to say "Okay!" and then, with a flourish of her ridiculous tail, jumped down and headed for a white sugar bowl which stood exactly at the table's center. Histrionic ability! It was as if she sealed the lover's betrothal with a kiss, then turned to sweets of her own choosing. ${ }^{171}$

The corresponding shot is not included in the surviving print, in which the bear cub does her scene-stealing without the kiss, but Shipman's reading of the situation supports my thesis that the animal's approval of the human relationship was part of its discourse. Moreover, the actress and possible instigator of the animal sequences was only one of those who were ready to acknowledge the animal's "script" right on the spot. Instrumental to its materialization into an accomplished take was the cinematographer Joe Walker, who was capable, according to Shipman, of capitalizing on a haphazard occurrence. ${ }^{172}$ Yet, even if the scene originated from Little Brownie's "script" and Walker's proficiency, it was Nell Shipman who articulated the autonomy of the animal's performance. Such autonomy, as we saw with the raccoon's performance, is, in my reading, one of the conditions for the occurrence of an independent animal discourse in BACK TO GOD'S COUNTRY.

Another indication of who may be held accountable for this animal discourse, can be drawn from the Curwood-Hartford production NOMADS OF THE NORTH, which was shot one year after BACK TO GOD'S COUNTRY and likewise directed by David M. Hartford. ${ }^{173}$ Shipman was not involved in its production, nor was the editor Cyril Gardner or the cameraman Joe Walker. ${ }^{174}$ But, based upon the dog-story by Curwood, it involves various animal scenes featuring the bear cub Neewa and the dog Brimstone (as he is called in the film; in the story, 
he is named Miki). NOMADS OF THE NORTH includes a shot like the one of the raccoon approving of Peter as Dolores' lover: it shows Neewa mounting and Brimstone licking Nanette's lover's leg while the couple reunites. As this is a question of the actions of the actors and hence of the mise-en-scène, one may assume that the idea ought to be ascribed to the director, or, if it was a matter of capitalizing on a chance occurrence, to the cinematographer. NOMADS OF THE NORTH also encompasses independent animal-to-animal exchange and human-to-animal communication, including a sequence with a honey and scene-stealing bear cub on a kitchen table that is almost a quotation from BACK TO GOD's COUNTRY. But, beyond the shot with Neewa and Brimstone, the film does not offer a recurrent and independent animal discourse. My conclusion, then, is that neither Curwood nor Hartford ought to be credited with the idea, which leaves only Walker, Gardner, or Shipman its possible creators.

This same possibility of attributing the animal discourse to Walker, Gardner, or to Shipman, in fact, arises vis-à-vis another sequence that Nell Shipman has mentioned in her memoirs as one of her favorites and that is part of the expanded plotline featuring the villain. It concerns the famous bathing scene with a full-grown bear in the forest, a scene not found in the short story and hence created for its screen adaptation. The scene is famous because it was used in the publicity for the film. ${ }^{175}$ Shipman recalls it because she believedwrongly, as it happens - that she had been the first actress in American cinema to act in the nude. ${ }^{176}$ In the context of the hypothetical scenario that I delineate here, the scene helps to shape the character of the "man-beast" Rydal, ${ }^{177}$ who is outlined, in succession, as a murderer (killing a Mountie who tries to arrest him for another murder), a voyeur (peeping at Dolores while she is frolicking with the bear and bathing in a pool in the forest), and a fraud (dressing up in the Mountie's uniform and pretending to be wounded, so that Dolores' father will offer him shelter). In accord with generic consistency, these actions lead to the villain's molestation of the girl and murder of her father, after which the girl manages to escape-for the time being, at least. In this way, the bathing scene, or more appropriately the "voyeur sequence", forms part of the preparatory adventure plotline interwoven in the romance plotline. But what renders it pertinent to my discussion of the animal discourse in the film is the interaction between the bear and the villain.

Practically the entire voyeur sequence was edited so as to represent the perspective of the villain, who spies on the woman frolicking and bathing, and to motivate the villain's subsequent action, his attempt to "see more of that girl". ${ }^{178}$ Apart from this point of view, this sequence also provides for a new portion of animal discourse. The actions involved seem an amalgamation of several similar scenes from Baree, Son of Kazan but the comparison discloses one difference: whereas in Baree, Son of Kazan Nepeese herself shoos away the 


\section{DON'T BOOK}

"BACK

TO GOD'S

COUNTRY"

Unless

You want to prove that the Nude is NOT Rude

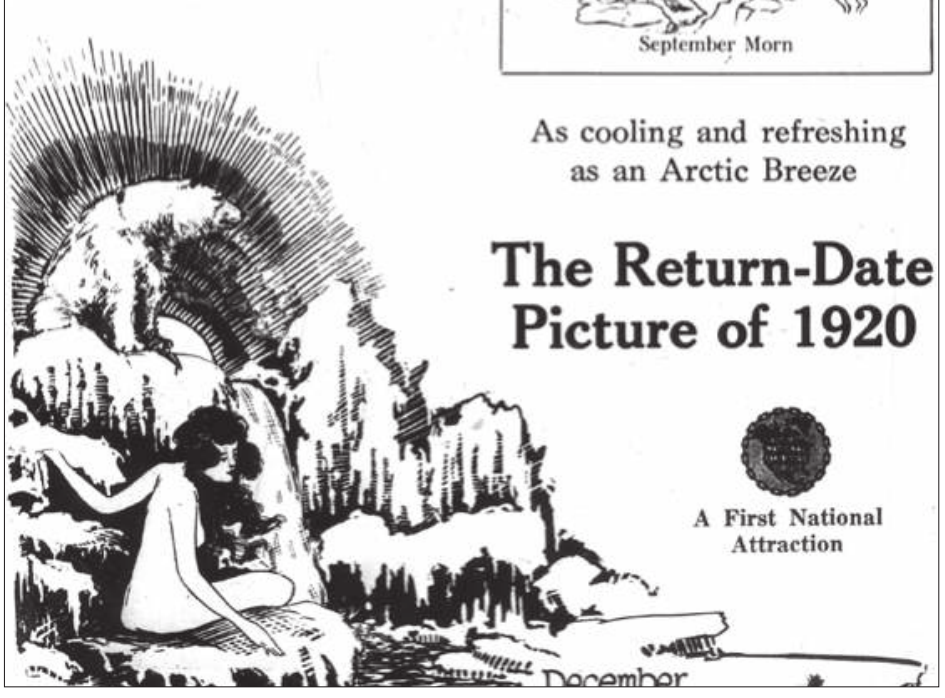

Fig. III.14: Advertisement BACK TO GOD'S COUNTRY emphasizing the bathing scene and the presence of animals.

villain, in BACK TO GOD'S COUNTRY, it is the big bear who is granted such a heroic action.

Right after the intertitle "The hidden pool", a shot framed by the branches of bushes shows a river flowing. The framing can be read as a visualization of the word "hidden" from the intertitle. In the following two shots, we see Dolores, dressed in a bathing wrap and playing in the river with the full-grown bear; they are safe by the hidden pool and entirely comfortable together. The subsequent shot shows the villain Rydal and an accomplice (another character added for the sake of extending the plot) approaching through the bushes and delighted by the sight of Dolores. After this, the shots of Rydal are crosscut with those of Dolores playing, bathing, and swimming of which Nell Shipman was so proud. It continues thus until the film reminds us of that other player present on the scene-the big bear-, who looks up at Rydal as he has almost reached the spot where the animal is resting on a rock by the riverbank. 
A counter-shot shows a startled Rydal backing away, and a consecutive shot reveals his accomplice laughing at him. In the next shots, the bear remains at his spot, Rydal flees, and the accomplice continues to laugh. These are followed by two shots of interaction between Dolores and the bear: Dolores waves and splashes water at the animal on the rock. Just by looking at the villain, the bear has chased him away and has protected Dolores from the danger she sensed but of which she was not fully aware; this is yet another instance of an independent animal discourse.

How to link the romance and the adventure plots together or, even better, how to intertwine them, must have posed a challenge to Nell Shipman as a scenarist. This problem was most likely also of concern to James Oliver Curwood, whose stories usually thrived on compelling plot-constructions. His novel Baree, Son of Kazan seems to have been taken as a model for the extension of the plot for the film in more than one regard. As we have seen, characters such as the father and the animals were inspired by it, as a setting like Dolores' Arcadian forest world also was. But, in addition, the very construction of the plot of Baree, Son of Kazan seems to have been copied too. In the novel, the main villain, McTaggart, seizes Nepeese quite early on, and, about half-way through, is thrashed off by the girl; he then withdraws for some narrative time but returns at the plot's climax, where he is eventually defeated, this time around with the decisive help of the dog, who comes to the heroine's rescue only in this late instance. The plot of BACK TO GOD'S COUNTRY discloses a similar set-up: the main villain Rydal assaults Dolores early on in the film, withdraws for some length of story-time, and is defeated in the end. Thus, in, both the film and the novel, the romance plotline is complemented by a preparatory adventure plotline, which motivates the menace that the girl expects from the villain and leads to the resolution. Like Nepeese, moreover, Dolores too shakes off her assailant practically single-handedly; and, just like Baree, Wapi too appears on the scene to help the woman only as a last decisive resort. Whether these well-tested plot and character-constructions were a result of clever copying on the part of the scenario writer, or were, on the other hand, suggested by Curwood himself, we shall probably never know; but the parallels between the novel and the film are too obvious to be ignored.

In the film, the transition from the romance to the adventure plot proper is made by one brief sequence motivating the actions to come. According to the intertitle, the sequence is set "a year later" and it shows Peter and Dolores at their "city home" in Montréal. ${ }^{179}$ With the mail in her hand, Dolores rushes towards Peter, but holds back once she notices that he is busy writing in his room. She peeps through the keyhole, sinks down on the floor, yawns, and begins to long "for the wild things she loved, praying for the day when the forests will claim her again". ${ }^{180}$ This title introduces and clarifies a multiple- 
frame shot combining two long shots: one showing Dolores with a cub and two bears by a river, a second showing Dolores musing in her city home, as in the preceding shot. The second shot is reduced in size and inserted at the bottom in the middle of the first. At the left edge of the frame, we see Dolores cuddling with the bear cub, on the right edge, we see one bear sitting on a rock, and the upper edge shows another bear swimming. In the reduced shot, the action goes on: the door behind Dolores opens and shows Peter leaving his work-room, discovering Dolores sitting on the floor and laying his hand on her shoulder. There follows a dissolve into a full-screen long shot showing Peter sitting behind Dolores, while she wipes away a tear and begins talking to him. She then shows him the piece of paper (a telegram from the Canadian Department of the Interior summoning Peter to sail on a trading ship) and makes him agree that, after this journey, they will return to her old home and, in his words, "find Cubby, even if he's grown up. And all the others. And I'll 356 | never take you away from them, Dolores." ${ }^{181}$ The sequence closes with a medium long shot of Dolores and Peter hugging each other on a bench in their city home. None of this is contained in Curwood's short story. The setting of the scene is rather out of tune with the sub-genre of Northwest drama and Curwood's fictional universe, in which cities usually represent places where harm is done to women and to animals, so I find it improbable that Curwood suggested it. In her memoirs, moreover, Nell Shipman has laid claim to the design of the dream sequence, asserting that the cinematographer "Joe Walker went along with [her] notion." ${ }^{182}$ But what best supports the hypothesis that Nell Shipman created this city home and dream sequence is its central function of rendering plausible the transition to the adventure-plot and building a bridge for the film to reach narrative closure.

The preparatory adventure plotline centering around Rydal involves two distinct sets of scenes created for the screen adaptation. In addition to the sequences interwoven in the romance plot that are set at the forest, such as the voyeur sequence, there is a series of five sequences set aboard the ship before it gets caught in the ice. They can count as a visual elaboration of what, in Curwood's story, Dolores tells Blake about her husband and herself, namely, that they love "adventuring [...] all through the country" and by every means of transportation. ${ }^{183}$ Yet, more immediately, they are visualizations of what, in the story, Blake tells Dolores about Rydal. One of these sequences visualizes a characterization that is mentioned rather casually in Curwood's story: that Blake is a trader in sealskins, whalebone, and women ${ }^{184}$ (in the film's intertitle this is rephrased as "furs, whalebone-and other things"). ${ }^{185}$ The sequence shows the crew having a party with Inuit women and abusing them, but we also see Dolores try to intervene and protect one of the women against her assailant, whereupon Rydal intervenes in support of his men. Whereas the abuse of 
the Inuit women was implied in the written source, Dolores' action was neither foreseen nor hinted at in it. Basically, then, the five sequences unfold and stage, for the most part, things that had been suggested in Curwood's story, with one exception: Dolores' interference on behalf of the Inuit woman. Even if such issues of women's social dignity and trans-ethnic bonding were alien to Curwood's fictional universe, this was not the case with the sub-genre per se-to that, my discussion of Rex Beach's novel The Barrier has borne witness. To Nell Shipman, they were a concern as well, as her book Under The Crescent confirms.

The plot of BACK TO GOD's COUNTRY employs yet another device for linking the two main plotlines, one that involves the dog's role. Very much as in the written source, the film opens with a preamble recounting the fates of the dog Tao and subsequently switches to introducing Wapi as Tao's "throwback" and as Blake's ferocious Great Dane. ${ }^{186}$ These two sequences comprise the five opening minutes of the film, which, in contrast to the written story, then abandons the dog to veer into the romance and the preparatory adventure plotlines. However, in order to bridge the gap of almost 50 minutes of screening time before the dog finally meets Dolores and takes his part in the action-plot, a sub-plotline was created. This plotline is invoked through a series of separate shots, followed by scenes of Wapi fighting other dogs and being whipped by Blake. It begins after almost 38 minutes of screening time with a medium long shot showing and an intertitle stating, that "Wapi awaits his appointed hour." ${ }^{187}$ The intertitle and shot are, with intervals of half a minute of different action, followed by three long shots of Blake's trading post with the dog chained to it, which present Wapi alert (looking up), Wapi waving his tail, and Wapi on guard (laying down), respectively. The dispersion of the shots effectively suggests the dog's waiting through the passing of story time. In addition, these shots are not simply long shots, but each has an iris that emphasizes the dog's varying bodily expression. The irises do not move in or out (as at the beginning and end of sequences or scenes), but are held in one position, though it is a different one in each shot. As far as I know, this is a rare usage of this particular cinematographic device, of which it is unfortunately impossible to reconstruct whose idea it was, whether the scenarist's, the director's, or, in this case, the cinematographer's. What makes the use of the iris strikingly appropriate is that the dispersion of shots can be read as suggesting Wapi's waiting to meet Dolores, while the iris-on-hold might represent the dog's waiting to enter the action-plot of the film. This is yet another example of animal discourse on a textual level and this time it is elaborated in a distinct sub-plotline meant to link together the worlds the film depicts as so far apart.

Only after about 52 minutes of screening time does the film plot reach the moment in which the vessel is frozen in ice and Dolores is able go ashore 
in order to befriend Wapi and to make her first appeal to Blake. In the following nearly 20 minutes, the action in the film sustains the action in "Wapi, the Walrus". It constitutes the part in which the woman and the dog share the narrative agency. Dolores tends to Peter in their cabin aboard the vessel; Wapi tears himself loose from his chain (and from Blake) and runs to Dolores to stay with her; Dolores tries a second appeal to Blake and overhears him and Rydal plotting her abduction; Dolores confronts Blake about his attempt to deceive her by using two dog-sleds instead of one, shoots at him, and escapes with Peter and the Inuit driver on one of the sleighs; Wapi follows them, but so does Rydal with the second sleigh; there is the chase of the two teams and the loss of the gun; Dolores urges Wapi to turn and attack Rydal's sled-dogs; Wapi succeeds in doing so; and Dolores and Peter reach Fort Confidence, followed, a few days later, by Wapi, wounded yet alive and happy to come "home", the word that both concludes the short story and is used in one of the last interti358 tles of the film. ${ }^{188}$

The final three minutes of the film offer two more scenes not included in the written story. One of them recounts the fate of Rydal. In Curwood's story, Rydal is left "shouting and cursing", having been able to do no more than fire twice "at the retreating shadow" of Wapi "before it disappeared." And both his servant and his dogs "failed to respond to Rydal's command when he pointed to the red trail that ran out under the stars." ${ }^{189}$ This image is strong enough: without assistance, the man is defeated. What defeated him was what Dolores chose as her weapon: Wapi, referred to as the killer in both story and film. Yet neither in the story nor in the film does Wapi kill Rydal. Nor do, in the film, the members of the Royal Mounted Police, despite the fact that one of them boasts at Fort Confidence that they soon will have the villain. In the end, Rydal simply drowns in a hole in the ice; the RMP remains just as inept as in any other Northwest story by Curwood. Given this generic idiosyncrasy, one could read Rydal's death by drowning as constituting an escape from institutionalized law and order as easily as one could see in it the definitive elimination of a villain who had attained such prominence in the film plot that allowing him to survive had become impossible.

In the film, Dolores' "home" is "the old dream ... COME TRUE"190_that is to say, not her city home, but the home recollected in her dream about her former place in the forest and her "wild things." We first see the same multiple-frame image repeated, then there are shots of the pool where she used to bath, of puppies, squirrels, and baby birds in the vicinity of the wooden house. Next, there is a medium long shot of Dolores and Peter sitting at a table; he is busy writing, she is embroidering. After a tender glance over the table down towards the floor, she invites Peter to take a look as well. He gets up and seesa phlegmatic Wapi, blinking good-heartedly, and, right next to him, a baby on 
a blanket. In "Make-Believe Land", ${ }^{191}$ even the most ferocious beast may have "dreams - hope, happiness, things to live for in a new, a white-man's world". ${ }^{192}$ If Wapi had found in a woman someone to fight for, ${ }^{193}$ rather than against, he then found "things to live for" in this woman's idyllic hut on the heath. ${ }^{194}$ In accordance with Curwood's fictional universe, Wapi's fate, not unlike Baree's, was to be a guardian in an idyllic wilderness world that was only extant in popular stories and films of the time.

This intertextual comparison has rendered obvious that not only the adventure but also the romance plotline, as well as the settings and the characters, including the animals, were all closely modeled after the formulas of the genre of Northwest drama generally and in accordance with Curwood's treatment of it in particular. The plot construction may also have been inspired by one or another of Curwood's tales and novels. Moreover, I have demonstrated that the dog's and the woman's heroic parts and their narrative agency both draw upon the short story; and that the animal-human relationships between dog, woman, lover, and villain mirror, in many respects, those in other dog stories by Curwood. The woman's heroic part may have constituted one of the attractions of Curwood's animal stories for Nell Shipman, as I have conjectured, but this does not transform her, even if she did write the shooting script for the film, into its author.

The parallels between story and screen adaptation even apply to the intertitles, which, in Armatage's opinion, "stand for Shipman's authorial voice”. ${ }^{195}$ Although the film depicts the dog's character in less psychological depth than does the written source, it nonetheless devotes five (of a total of 87) intertitles to Wapi's attitudes and feelings about the human beings. These intertitles are drafted in words reminiscent of Curwood's style and phrasing: ${ }^{196}$ Even the one title in which the relation between dog and woman is directly articulated: "A new miracle of understanding roused by the touch of a woman's hand", ${ }^{197}$ still relates to sentences in the story:

For the first time Wapi felt the caress of a woman's hand, soft, gentle, pitying, [...] One slim, white hand was stroking his face so gently, and she was speaking to him in a voice so sweet and soft that it stirred like wonderful music in Wapi's warped and beaten soul. ${ }^{198}$

If, as Armatage does, one cares to read into the cited intertitle and into the relationship between Dolores and Wapi a "rather complex relay of interspecies desire", one nonetheless cannot maintain that it emanated from Nell Shipman's imagination rather than from James Oliver Curwood's pen. If what the print of the film presents us with today indeed has followed the script as written by Nell Shipman, my analysis, to begin with, suggests that the scenarist 
was a perfect copyist of Curwood's fictional universe and the popular writer's plots and phrasing. Given their competition and feud at the time, however, one might just as well consider whether the film instead testifies to the eventual inclusion of the revisions Curwood proposed when he and the scenarist "went to the mat" 199 over the script, and whether those revisions were more extensive and drastic than Nell Shipman would ever prove willing to admit.

Yet the method of intertextual comparison and inference does permit to point out, with due caution, the contributions Shipman may have made as a scenarist to BACK TO GOD'S COUNTRY. This caution concerns, most notably, the animal discourse as well as the sub-plot of Wapi waiting. To be sure, it is highly tempting to ascribe the construction and the insertion of these elements to Nell Shipman, particularly given her long-standing concern for animals in her professional and personal life. But it may just as well have been Cyril Gardner who edited the film in this way in order to maximize the potentialities of 360 the animals beyond fulfilling a mere function as sylvan props or extras. In any case, the question is to what extent such animal discourse became a recurring feature of the films that Nell Shipman herself wrote, produced, and directed, an issue to be pursued later in this careerography.

Such a reservation is far less pertinent to the two other sequences singled out above, namely, the sequence in which Dolores intervenes on behalf of the Inuit woman, and the city home and dream sequence. The sequence in which Dolores defends the Inuit woman against her assailant could have been cut out at the editing table without violating narrative plausibility; indeed it seems to exhibit, as Armatage has noticed, "an abrupt shift of tone". ${ }^{200}$ I agree with this observation insofar as, in this sequence, a view of woman emerges that is alien to Curwood's fictional universe. In this writer's work, as we have seen, solidarity against the worst in men is in evidence among family members or between the dog and the woman, but not among strangers or, with even lesser likelihood, between a white woman and an Inuit prostitute. But, in Shipman's fictional universe, and in Beach's, as I have shown, solidarity among women, even of different ethnicities, could occur.

The city home and dream sequence, by contrast, is far from redundant within the plot, yet it is equally out of tune with the genre that the film otherwise exemplified. In this scene, Dolores is first and foremost a white middleclass woman bored with her domestic life as somebody's wife, even though that somebody is an adventurer and a writer. What she longs for is not her husband's adventuring, as in Curwood's story, but a chance to make her own dream come true. The point of this sequence, in my opinion, is that the female character is endowed with an agency that goes beyond her heroic actions of self-defense prompted by the adventure plotline: she is a woman who consciously dreams and assertively works towards the materialization of her (day) 
dream. The actual visualization of the dream in the film attests to this reading, and the film's closure further confirms it by allowing the dream to come true subsequent to the happy ending of the adventure plot. Compared to the written story, then, it is not the dog who is the central character yearning for a home but the woman, a change that represents a major shift of narrative perspective. This very shift of perspective, I surmise, and, hence, the two sequences in which it becomes manifest, can be credited only to Nell Shipman as the scenarist. And it may also be that these two scenes are the sole remnants of what once was the source of the conflict over the script between Shipman and Curwood.

Yet another reading of the daydream sequence is possible. The dream of the female character is a correlative of Nell Shipman's own aspirations at the time she wrote the scenario. She articulated them in an article, written probably during or immediately after drafting the scenario, and published in February 1919, the month before the shooting of BACK TO GOD'S COUNTRY began:

And now: My Dream. It is a very real one to me. It is that some day I may go up into Canada, to the waterways of the Hudson Bay territory, to the great plains of the Middle West, and to the mountains and forests of the coasts, and make big human outdoor pictures. ${ }^{201}$

Nell Shipman too was a white middle-class woman on the verge of realizing her dream, namely, of producing outdoor films and starring in them. To point out this parallel, however, leads beyond a simple conflation of fictional character and biographical data, because it also holds at the level of discourse. If we understand Dolores' outdoors home-with-animals as Nell's outdoors films-with-animals, it reminds us of the inclusion of the "scribe" in Under the Crescent, a fictionalized character that stands, as I have argued, for the refusal to draw a sharp line between the real and the imaginary, which is the recurring principle of Nell Shipman's work as a writer, an actress, and a filmmaker. I argue that it is in the city home and the dream come true sequences that Nell Shipman as the scenarist of BACK TO GOD'S COUNTRY most convincingly can be retrieved, even if we only catch a glimpse of her.

\section{Nell Shipman Acting with Animals}

It is necessary to return once more to Kay Armatage's discussion of the film, now, however, from an angle other than that of Shipman's possible authorial investment in it. Armatage assigns to the dog "the traditional melodramatic function of the [...] heroic lover", who must save the imperiled heroine. ${ }^{202}$ "The 
dog at its most heroic," she argues, "functions merely as the agent of the woman's desire." ${ }^{203}$ In this reading, the woman-dog relationship in the film is narrowed down to a classical opposition of active hero and passive heroine; in the process, the animal's drives and yearnings are limited to cravings projected onto it by human beings. Furthermore, Armatage detects an "instinctive rapport" 204 between woman and dog, thus invoking both a conventional anthropomorphism and ideas of women being closer to nature and to animals. To be sure, Armatage analyzed both of these tendencies as discourses at work within the filmic text, but this does not preempt her own analytic move of projecting human desire and sexuality onto an animal character and its yearnings. BACK TO GOD'S COUNTRY, as I contend against Armatage's assessment, is neither domestic melodrama nor classical Hollywood cinema. In spite of its city home sequence, it is outdoors action melodrama, because of its action-driven narrative, its episodic structure, its non-psychological construction of char362 acter, its incapacitated hero, and its animal and female heroism. By reason of all this, it allows, and in my opinion calls, for readings drawing upon the historical and contextual frameworks developed to understand more kindred genres, including the 1910 s women's action melodramas scrutinized by Ben Singer and Jennifer Bean. And, as the latter suggests, these films are not about unconscious desire for a lost object:

If there is desire to be had in the "nerve-wracking" genres of early action, adventure, crime and comedy films, perhaps it is best formulated as the desire not to desire: that is, the yearning to catapult forward and beyond oneself, to stunt fearlessly and without hesitation. ${ }^{205}$

Unlike desire, yearnings such as these may be shared by human beings and animals, and, to a large extent, they seem to motivate the actions and relationships of Wapi and Dolores in BACK TO GOD's COUNTRY. But, in order to see things this way, Bean also argues, a different idea of identification is required, namely, a mimetic identification that takes shape "as an imitation by one 'self' of an 'other". ${ }^{206}$ "Mimesis", she argues,

stresses the reflexive, rather than reflection; it brings the subject into intimate contact with the object, or other, in a tactile, performative, and sensuous form of perception, the result of which is an experience that transcends the traditional subject-object dichotomy. ${ }^{207}$

In my reading of the characters of the film, I have also stressed the reflexive that is in play, as well as the tactile, performative, and sensuous forms of their contacts with one another. For these reasons, I will continue to speak in terms 
of dog-woman solidarity, narrative agency, animal discourse, and animalhuman communication.

The representations and narrative functions of the animal characters in BACK TO GOD'S COUNTRY seem to be an accomplished rendition of a concern that Curwood and Shipman shared-as I have argued, contrary to Shipman's contention that they did not-namely, that animals ought to be treated and seen as animals, and this perhaps even more so in fiction than in real life. In his stories, Curwood carefully saw to it that the thoughts, yearnings, and understanding of his animal protagonists and characters remain within the realms of their physical and mental capacities, regularly reminding the reader of this concern throughout the course of his tales. Shipman, in her turn, wanted the animals to "act" naturally: none of them had to perform tricks or special acts (as in a circus or on-stage), but each of them just got to "do" whatever they would have done anyhow: a dog, to lie down, wait, snarl, lick, run, keep guard, be stroked and caressed; a bear, to rear, swim, play, lick honey, climb onto a table, empty a sugar bowl; and so forth. In Shipman's recapitulation:

On this, my first independently made picture, my theory was being put into practice. There were no cages except those the animals slept in. And no whips, no charged prodders, no limbered guns in case a Cat became fractious - my pet notion that even to think of a gun connotated fear and was communicable to an animal. In other words, freedom! Wildlife at large in its natural habitat, moving naturally about its business of living, untrained to do human-inspired tricks but peacefully reacting to what interested it: virtue rewarded with petting, gentle speech and Honey Sticks. ${ }^{208}$

This is also, I assume, why both Curwood and Shipman were interested primarily in wild or semi-wild animals, not in pets or cattle. In other words, each was aware of, and acknowledged in her or his work, what Donna Haraway has called "relations of significant otherness", that is to say, relations in which actors of two different species-one human, one animal-are understood as agents in a game of companionship and bonding. ${ }^{209}$ For Haraway, crossspecies companionship takes material shape in processes of learning and working together, in being attuned to one another, with each companion species performing its own specific tasks according to its capacity and pleasure. Observation, interaction, and communication are central to the processes involved, and it is in this sense that I prefer to understand the gestures and utterances of the raccoon, the owl, the bear cub, and Wapi's waiting, helping, and fighting for something, as well as Dolores' responding to and interacting with him in BACK TO GOD'S COUNTRY.

If Nell Shipman uses the term "natural" as in the quotation above, she 


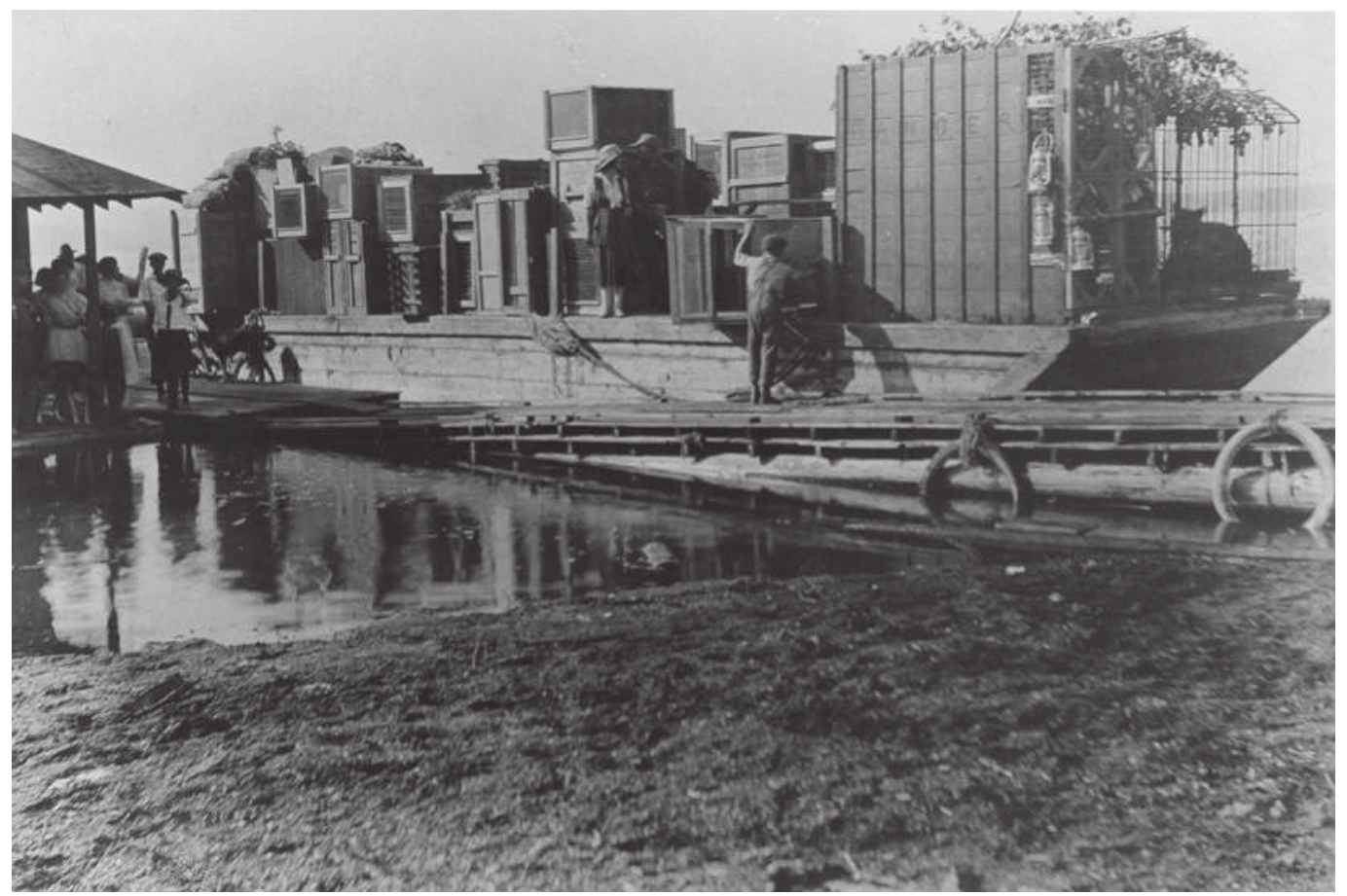

Fig. III.15: The cages with Shipman's animal collection on the move.

refers, in my view, to the companion species' character or specific talents, and not to Nature as a system opposed to Culture or, for that matter, to civilization. For her part, Haraway speaks in terms of "naturecultures" inhabited jointly by companion species, and makes a point of distancing her politics and philosophy from more puritan views on nature, ecology, and animal welfare. ${ }^{210}$ I should like to make the same point for Nell Shipman's ideas and practices vis-à-vis animals and nature, and keep them apart from purist ecologist interests and wildlife preservation politics, then or now. This for the reason that there is no evidence that she was ever involved in organizations for matters of ecology or animal relief, although, in the 1910 s and 1920s, such organizations did exist. ${ }^{211}$ Or, just to name a further option, she could have initiated a lobbying effort against the mistreatment of animals in the film industry; but, to my knowledge, she never did so. Instead, she began to buy several of the animals she had worked with during the shooting of BACK TO GOD'S COUNTRY, including, to begin with, the bear cub, little Brownie, and her sister Goldie, later on a "variety of little folks", and, eventually, the two Great Danes employed for the role of Wapi, Tresore and his brother Rex. ${ }^{212}$ Thus, she established her own collection of non-domestic and semi-domesticated animals. The collection was reported to consist of over 70 animals by $1922 .{ }^{213}$ 
Yet Shipman's menagerie was not simply the result of an eccentric star's excessive hobby. The animals were employed in support of her favorite screen persona of the outdoors girl. They were entitled to work with her and to act, preferably as "animal actors", as they used to be called, alongside and with the leading actress in her film productions. If, as Haraway maintains, being engaged in working together and accomplishing things is the name of the game, Shipman both practiced and reflected upon cross-species companionship long before the expression was coined. The ideas advanced by Haraway correlate in many cases with Shipman's when she wrote animal stories from her experience. For instance, in recounting her first acting experience together with a bear, Shipman explained how she approached the animal:

I was acting with a free, large bear who might bite, hug or merely swat. [...] While I relaxed in her embrace I knew my theory was okay, and that it was a fifty-fifty deal between human and animals. Had there been a seedling of fear in me I would have felt it sprout [...] It could lie in the deepest, darkest thought-cell but would communicate. It simply was not there.

[...] No personal bravery in this, just a fact of communication. ${ }^{214}$

Just as Haraway's Manifesto invites humans into the kennel, ${ }^{215}$ Shipman's anecdotes bid us entrance to her zoo, which she used to call, rather tellingly, the "Animal Company". Shipman's memoirs, published writings, and other reminiscences abound in accounts of Tresore's and Brownie's conduct, their cleverness, and, precisely, their companionship. In her rhetoric, the emphasis, moreover, is always placed upon agency and specific talents, and upon interaction and communication. This is how Shipman described Brownie to an interviewer of the Los Angeles Times:

She can afford to have individuality and temperament.

When Brownie is corrected, she seeks out the farthest corner, sits down dolefully and places her two forepaws up to her eyes and actually cries. She is not obstinate or contrary, nor does she sulk, but she expresses very plainly that her feelings have been hurt. However, she is soon coaxed out of it, and the next instant she is romping about like a child.

[...] She is very fond of fruits and vegetables, but has never had meat. She loves candy, but not cheap candy: she prefers chocolates. She will swear if she is neglected, sing when she is petted, and cry when she is scolded. ${ }^{216}$

In the scholarship inspired by the rediscovery of her work beginning in the mid-1980s, little has been said about the way in which Shipman acted 


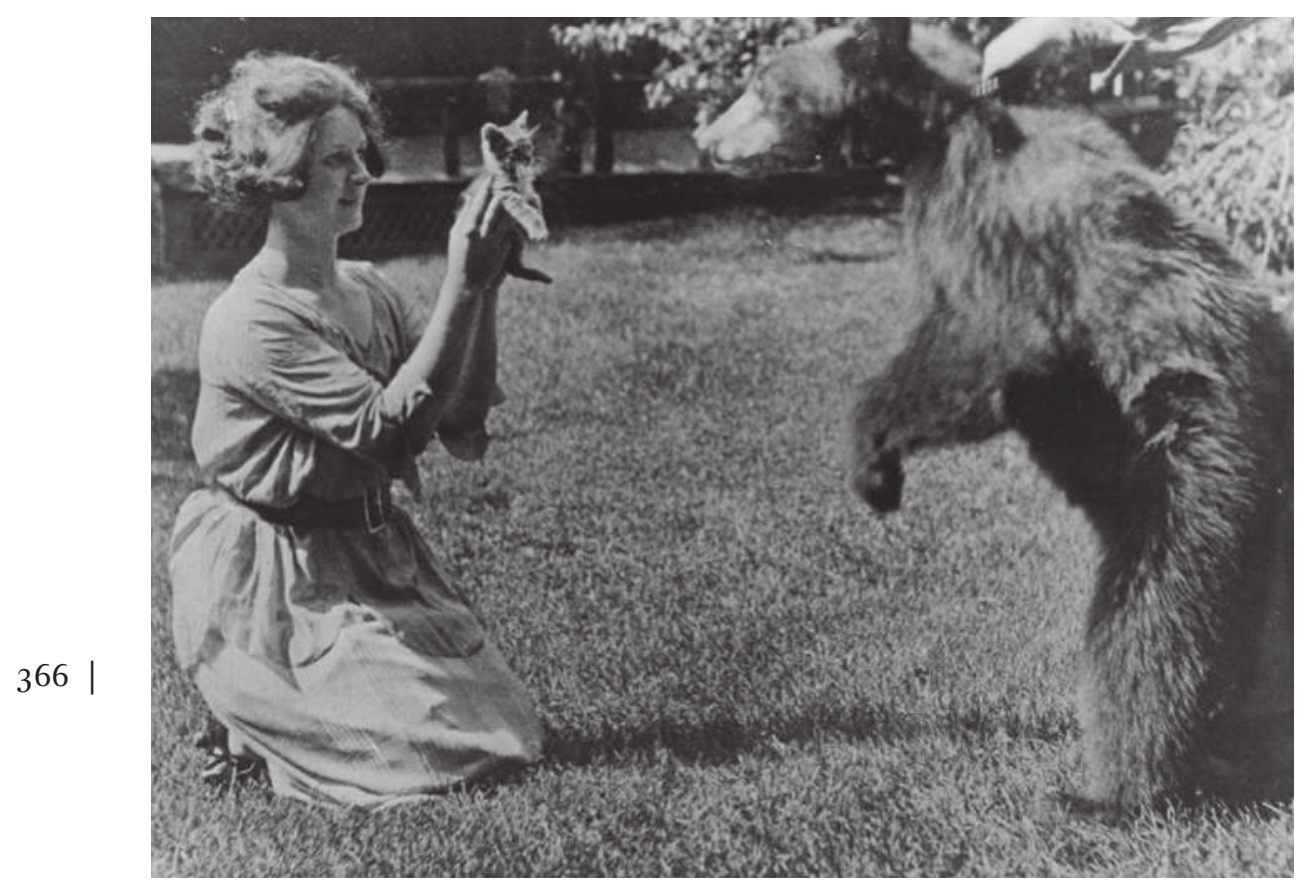

Fig. III.16: Brownie making the kitten's acquaintance.

the role of Dolores. The survival of prints of BACK TO GOD'S COUNTRY and the fact that, for a long time, it was the only one of "her" films known to be extant, have not quite elicited reflection upon this contribution of the actress to the film. Sometimes, her strong performance is merely mentioned without further discussion, elsewhere it is noted that she had made a "memorable heroine" with her "Junoesque presence", her "talent evident throughout" along with her spontaneity in the scenes with the animals, which "could only have grown from an essential sympathy". ${ }^{217}$ Given that most assessments of Shipman's oeuvre focus on her work as a director and producer, her acting is usually treated as a secondary matter, not as an issue pertinent in its own right. This holds particularly for feminist scholarship, which tends to connect the questions of cinematic aesthetics to its overarching arguments about discursivity and signification. Feminists usually note Shipman's comfort with her own body and her ease with animals, but then discuss how these relations define Dolores' femininity in the film. In this corpus of critical literature, Armatage appears to stand alone when she detects essentialist connotations in Shipman's relationship with her body, 
with animals, and with nature. In contrast, the French critic and theorist Françoise Audé, for instance, has credited Shipman with effecting "an ethical and bodily emancipation", ${ }^{218}$ and her German colleague, Annette Brauerhoch, similarly contends that the actress' very closeness to her body and to animals helps to create "a playful distance [...] vis à vis generic conventions, role patterns and gender clichés”. ${ }^{219}$ As my analysis has suggested and will continue to maintain, however, the latter views also stretch things a bit too far, leading into the direction of a putative liberation from and resistance to conventions and clichés. As the very production, distribution, and success of BACK TO GOD'S COUNTRY demonstrates, at the end of the 1910 s such conventions and clichés were more open to variation than is often assumed. And, as my examination of Shipman's and Curwood's aspirations with the film suggests, they did not pursue an ideological critique, but, rather, aimed at revivifying tried and trusted formulas.

Still, in my discussion of Shipman's acting, I wish to retain the concept of playful distance as suggested by Brauerhoch. In BACK TO GOD'S COUNTRY, the presence of the animals and the mirth generated by their discourse break the absorption in the melodramatic story of girl, villain, and lover, and call forth a pleasurable awareness of the acting and the gaze-a playful distance to some of the artificial means of cinematic make-believe. While the concept of the cinematic gaze is a critical tool deployed by, and of special concern to, present-day feminists, there are no indications that it functioned that way for Nell Shipman or her contemporaries. Her manner of acting the heroine's role, in contrast, indeed figured extensively in the discussions of the pleasures the film provided to audiences and to the actress herself.

Despite Ernest Shipman's emphatic publicity campaign in which a choice of rave blurbs about the film (but none about its star) were cited, ${ }^{220}$ the contemporary American film press was not unanimously positive about BACK TO GOD'S COUNTRY, and, if a particular trade paper was not impressed, it usually did not bother to say much about the acting. In Variety, the film is called a "meller of the real old-fashioned kind" and the dog that played Wapi was considered "by far one of the best actors in the picture". ${ }^{221}$ The New York Dramatic Mirror was charmed by the action and particularly by Little Brownie's performance on the table, which sent "the audience into loud exclamations of delight", but found nonetheless that "the picture contains a lot of typical picture stuff, the inevitable struggle between the man and the girl where he treats her rough." ${ }^{222}$ Neither one said anything about Shipman's performance at all. The most favorable review, to my knowledge, appears in the Moving Picture World, which states that the picture was "excellently acted" and that "Nell Shipman's impersonation of the heroine gains greatly by the skill and nerve she displays in several physical stunts." ${ }^{223}$ In other words, the appreciation of 
Shipman's part largely depended on the appreciation of the genre: if critics enjoyed it, they also liked her way of acting. ${ }^{224}$

Trusky's concise overview of Shipman's life and career mentions that she usually served as her own double in the stunts required by the films in which she played. ${ }^{225}$ Although by no means exceptional in her time, and, most notably, a common practice in the kindred genre of the serials, this is one of the things Shipman took particular pride in, according to her memoirs, in which she seems to recall every single stunt she ever did. Another actress may indeed have needed a double for the scenes in which Dolores had to cast herself into a fast streaming river in order to try to save her father from drowning. Yet, as was repeatedly stated in the papers, Shipman was a good and enthusiastic swimmer. ${ }^{226}$ Acting with a full-grown wild animal must have appealed to her to such an extent that she not only wrote the bear into that particular scene, but most likely would never have accepted that someone else stand in for her.

368 The scenes that most poignantly create a playful distance are those in which Nell Shipman acts together with the animals. Here, as in performing her own stunts, truthfulness is the keyword, because whoever knows about the sincerity of animals would have to agree that few actresses could have excelled in the ease that Shipman displayed in scenes with her non-human co-actors. The actress met most of them only shortly before or even during the film's shooting, and, yet, she touched and petted each of them as if she had known them forever, hugging and kissing the dog and the bear, giving orders or coaxing, and the animals responded accordingly. They licked honey and rubbed noses, sniffed around and ambled about, glanced at their human co-actor, and seemingly did what she told them to do. They visibly felt perfectly comfortable in her proximity and she genuinely enjoyed their company. In this manner, credibility was created, but comedy too (the bear cub), as well as a playful cinematic commentary on the romantic (the raccoon, the owl) and the heroic (the dog) narratives.

Beyond the stunt work and the animal scenes, Shipman's acting style was likewise based on truthfulness whenever scenes allowed her to be "in action": when she walked, talked, climbed a rock, teased an animal or a lover, argued and struggled with the villain, and so forth. Faithful to the genre, the film abounds in scenes requiring such action and agency. What seems particularly striking today is Shipman's ostensible "non-acting" in such scenes, her matter-of-fact way of doing whatever has to be done, from laying a table to splashing water at a bear. In such action scenes, her gestures and movements are quick, agile, cheerful, and down-to-earth.

Despite the preeminence of action in it, the scenario also requires that Shipman evoke specific states of mind using facial expressions. These states of mind include various modes of happiness, such as daydreaming, amorous- 
ness, and merriment, as well as modes of unhappiness, such as boredom, suspicion, and confusion. Usually captured in a medium shot or medium close-up of Shipman alone, she often communicates such mental states by rather inexpressive miens, sometimes even merely with a blank face, letting the narrative context, the editing, or the intertitles do the signifying work. This restrained acting goes along very well with her seeming non-acting in the action scenes.

Another way of expressing states of mind, and, in this case, two different ones at the same time, was play-acting, for which the scenario of BACK TO GOD's COUNTRY offered Nell Shipman at least two occasions. One was set in the cabin aboard the vessel. Dolores pretends to the helpless Peter to be light-hearted and intrepid. Unseen by Peter but visible to us, she switches back and forth from one mood to the other. Her play-acting has an important narrative function: it enables the character to take action, constituting its narrative agency. A second occasion occurs when Rydal invites-or rather, imposes upon-Dolores to visit him in his cabin. At first, the villain is busy trying to keep up appearances, but he is in fact too drunk already. He offers Dolores a drink, which she declines, enticing him instead into pouring one for himself. She remains resolute throughout, but preserves a friendly demeanor, even after he prevents her from leaving his room. She resorts to offering him more drinks. As a result of her double-dealing, he eventually falls asleep and she can finally exit: thus does play-acting restore her narrative agency again.

To communicate emotions, Shipman uses both facial expressions and gestures. Feelings of terror, despair, pain, remorse, and horror are conveyed through relatively emphatic attitudes, ranging from lowered to wide eyes and corresponding facial contortions, or from stretched-out arms to the whole body gone limp. These are the intense and temporarily distressing emotions of melodrama, narratively motivated by situations of peril, physical threat, and impasse, which, in the film, are not emphasized only by Shipman's manner of acting but also by means of editing: they are shown in repetitive shots that are intercut with some action, or with shots of relatively long duration (lasting from five to sixteen seconds) often placed at the end of a scene. Their length, compared to the overall editing pace of the film, for which shots were cut down to an average of two to three seconds, and their placement at the end of a scene lends them extra poignancy. Their narrative function, of course, is to maintain the suspense and to sustain our interest in the action to come. ${ }^{27}$

My assessment of Shipman's acting in BACK TO GOD'S COUNTRY opens up a new perspective upon her remark that she could not act. Earlier in this careerography, I argued that her modesty concerning her acting skills may have been prompted by the vantage points of the film actress looking down upon the popular stage actress and of the once-noted screen star writing 
against film-historical oblivion. For one thing, it ought to be obvious from my analysis that she could act, and "do it big," to quote Curwood, by lending the character of the outdoors girl a convincing degree of stamina as well as considerable intensity. Furthermore, Shipman's commitment to truthfulness in her acting, through doing her own stunt work, her ostensible non-acting, and, most notably, her play with the animals, suggests that something else is implied in her modesty, namely, a preference as regards the practice and style of screen acting. For the actress, truthfulness had become something more than a requirement belonging to the authentication discourse of Northwest drama and to film star discourse. After the shooting of BACK TO GOD'S COUNTRY, she no longer said: "It was too real for me," as she had done after cast and crew had been snowed in during the filming of GOD'S COUNTRY AND THE WOMAN in California. Instead, she declared, upon her return from Lesser Slave Lake, northwards of 55 degrees north latitude where the snowbound

370 | scenes of BACK TO GOD'S COUNTRY were shot: "I enjoyed it up there. [...] I don't mind saying that I am wild to get back!" ${ }^{228}$ Because of these statements, as well as the commitment to truthfulness, I would suggest that Shipman adopted authentication as a practice to inform her manner of acting and, as shall become apparent shortly, her film production too. By turning truthfulness into a trademark of her screen persona, Nell Shipman sought to claim the outdoors girl as her specialty and to enact her as the prototype of a woman whose stamina, sensitivities, and pleasures she increasingly came to embrace as her own.

\section{Nell Shipman's Options and Choices, 1919-1920}

At the peak of her acting career by the fall of 1919, Nell Shipman had a choice of options, but her ambitions and experiences restricted them. As a screen actress, she had a proven talent for a variety of roles, but she primarily aspired to the type of the outdoors girl. As an outdoors girl, she had proven to be able to "do it" on the level of stardom, but the persona limited her chances of returning to any of the majors, which had not permitted her to capitalize on this typecasting. As the Curwoodian heroine, she had shown that she could do it "big", but as she had "annoyed" the author by withdrawing from their mutually exclusive contract, there were few opportunities left for her to play such a role again. For freelance scenarists, moreover, the market was long closed, as we have seen; Shipman's aim of combining script writing with acting was a practice only still current among independents, if at all.

In terms of professional collaboration, moreover, Nell Shipman not only separated from Curwood, but from her husband Ernest as well. Out of the con- 
troversies at the end of the production, two factions had emerged: on one side Curwood, Hartford, and Ernest Shipman, and on the other, Nell Shipman, her new love Bert Van Tuyle, and Joseph Walker. It is hard to say whether, or how, Nell Shipman's new relationship with Van Tuyle and her subsequent divorce from Ernest influenced these quarrels. In her roman à clef, Nell Shipman suggests that Van Tuyle, "with the diplomacy of an Army Mule", had confronted Ernest Shipman about his unfairness in the management of the finances, which led to a clash of personality between them and thus initiated the faction-forming. ${ }^{229}$ She herself apparently entertained a mistrust of her husband in these matters as well. In the Los Angeles newspapers, she was reported to have given as her reason for the separation that her husband collected her salary without leaving her any money for herself. ${ }^{23^{\circ}}$ Although the divorcees kept in touch privately, they never collaborated professionally again. Instead, Ernest Shipman went on to work side-by-side with Curwood on the publicity campaign for BACK TO GOD'S COUNTRY, and was hired in the same capacity by the writer's new company, incorporated in January 1920, for the film NOMADS OF THE NORTH. ${ }^{231}$

On the other hand, with the production and filming of BACK TO GOD's COUNTRY, Nell Shipman had made a number of experiences that she could use to her advantage. She had witnessed how an independent production was carried out and what was necessary to make it a success. She had once more experienced what on location shooting could contribute to atmosphere and pictorial quality. Quite significantly, moreover, she had discovered that her "theory" of acting worked, and this, as I have argued, concerned not only her acting with the animals but also her conception of a role in its entirety, as something based upon truthfulness. Last but not least, Nell Shipman had observed (and not for the first time) how replaceable the director of a film could be: according to her own and Walker's accounts, in some of the action scenes shot in Alberta and in some of the animal scenes shot in California, it was not Hartford but Bert Van Tuyle who carried out the task.

Van Tuyle, according to Walker, had had little experience in filmmaking but was eager to learn more about it. He had money and, during the war, had helped Walker to obtain financing for a short subject for the Red Cross, in exchange for which he requested lessons in directing:

Van Tuyle was a go-getter. He learned the few basic rules of directing in short order. I noted, however, that [...] he lacked a certain artistry he would need to ever be big time; but what he lacked in artistry he made up for in drive and enthusiasm. ${ }^{232}$ 


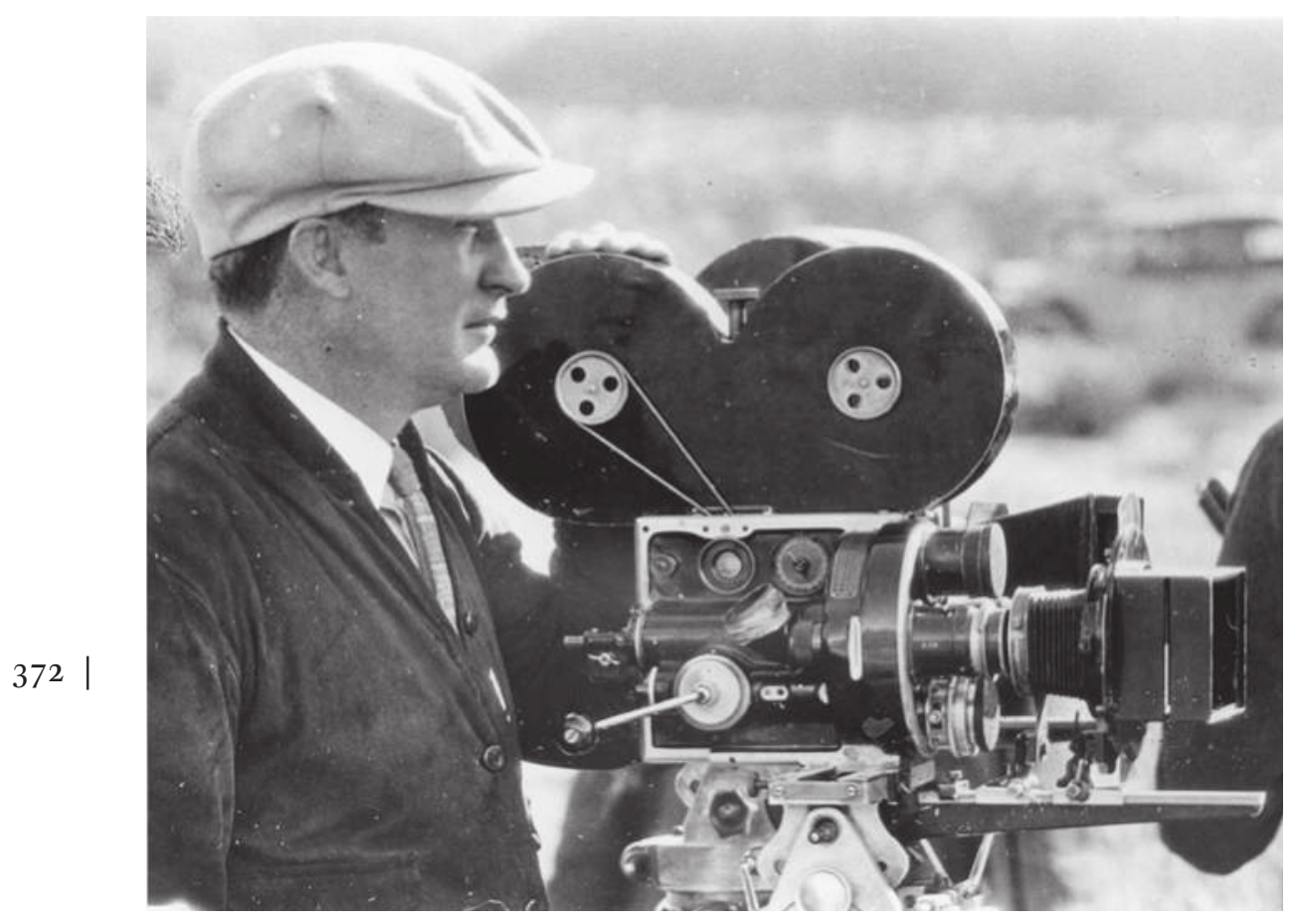

Fig. III.17: Nell Shipman's devoted cinematographer, Joseph. B. Walker.

In addition, Van Tuyle had claimed the director's credit, while, in fact, most of the work had been done by Walker, who, however, as he aspired to be a cinematographer, not a director, was willing to keep the secret. That is how Bert Van Tuyle was "named production manager" for BACK TO GOD'S COUNTRY, "with a chance to direct the action scenes". ${ }^{233}$ Among the scenes he directed was the one in which Dolores befriends with Wapi, which, as planned, would be filmed in two shots, one with the ferocious Tresore and one with his gentle brother Rex:

We started the scene. [Arling] began his beating attempt and the dog responded ferociously to his aggressive action. It became frightening to watch. We were about to cut the cameras and make the switch to the gentler dog, when Nell cried out suddenly, "Keep the cameras going, boys. Do you hear? No matter what happens-don't cut!” (...)

Nell rushed into the scene, protesting the driver's brutality, then threw her arms around the ferocious dog. We stared horrified; no one dared to speak. (...) With the dog's face close to hers, Nell's lips moved as 
though murmuring friendly and comforting words. The dog looked her in the eye. Then slowly he lowered his head, allowing her to stroke him.

(...) Several feet of film rolled through the cameras on this shot before Bert Van Tuyle said quietly:

"We've got it. Cut." ${ }^{234}$

Walker's conception of the task of the director evoked in this account is not limited to his judgment that Van Tuyle lacked artistry. Admittedly somewhat biased, because his point of view is the cameraman's, he nonetheless describes directing on the set as a function that is subservient to the interaction between the camera and the actors in front of the lens. Thus the crucial instruction-"No matter what happens-don't cut!"-came from the actress, not the director. Yet Shipman's various anecdotes about Van Tuyle's directing may be no less biased, for they are told from the point of view of the actress, but they still testify equally to the direction's having had such a secondary role and the cinematography a primary one. She made the point in her memoirs:

I wonder if there is any question in the minds of all people dedicated to Blunderland as to who, from [Griffith's cameraman] Billy Bitzer on, the real magicians have been? They made us. ${ }^{235}$

For Nell Shipman, the real magicians were not the directors but the cameramen. Her conception of directing, then, did not imply creative control, as one would have expected in the field of independent filmmaking. For her, the magic of film was created between camera and acting, and directing was an activity in the service of precisely that creativity and interaction. In my opinion, this conception of the relationships among direction, cinematography, and acting clarify three of Nell Shipman's choices that determined her future filmmaking practice: to continue working with Joe Walker behind the camera, to appoint the inexperienced but pragmatic Bert Van Tuyle as "her" director or co-director, and, most significantly, never to claim the direction credit of her films for herself alone.

\section{NELL SHIPMAN WRITING, DIRECTING, ACTING IN AND PRODUCING FILMS 1920-1925}

In August 1919, while wondering if she would ever touch a penny of the money she was entitled to, and cut off from her former business partnerships, Nell Shipman, not yet 27 years old, practically started from scratch. She had no doubt about her plans for the near and distant future. She also recalled feel- 
ing "very free" ${ }^{236}$ after the divorce and painted a picture of buoyancy, of fun with Brownie, and of frantic activity. In addition, she was eager to keep Joe Walker busy and to prevent him from joining another company. ${ }^{237}$ The historical record shows that she accomplished at least four endeavors during the year that followed: she wrote the synopsis for and acted in a car commercial THE TRAIL OF THE ARROW; she wrote a two-reel animals-and-children adventure comedy, A BEAR, A BOY AND A DOG (also known as SATURDAY OFF); she expanded the idea of the car commercial into the five-reel comic action film SOMETHING NEW; and, finally, she founded her own film production company, Nell Shipman Productions, Inc. in October 1920. ${ }^{238}$

The company was established in order to produce Shipman's own God's Country film, THE GIRL FROM GOD'S COUNTRY, of which no prints are known survive. Its films were to be directed or co-directed by Van Tuyle, edited by Nell Shipman, and each was copyrighted and financed by a different backer. ${ }^{239}$ All

374 were shot in California, and Joseph Walker cranked the camera, although in the case of A BEAR, A BOY AND A DOG, he also claims to have directed portions of the film..$^{240}$ Both this film and somETHING NEW are irresistibly funny. Each can be considered as a witty send-up of popular silent-film genres of the 1910s: A BEAR, A BOY AND A DOG makes mockery of crime films; SOMETHING NEW of car commercials, westerns, and, most notably, serial queen melodrama. While the overall comic tone is a novel element in Shipman's oeuvre, nonetheless, each of the extant films does exemplify the artistic conceptions and ideas about film production that I have ascribed to her thus far.

\section{A BEAR, A BOY AND A DOG}

The three characters of the title, played by Nell Shipman's bear Brownie and Barry Shipman's dog Laddie, joined by Sunny Howard, a vaudeville child actor provided by the film's backer, William $\mathrm{H}$. Clune, are introduced, in an intertitle, as victims of "the shackles of grown-up inhumanity", from which, at the very same moment, each on his or her own decides and manages to escape: the bear from a cage in the zoo, the dog from a pole to which it has been leashed, and the boy from helping his mother while his peers go to the movies. In the intertitles, both bear and dog are granted speech; Brownie, still in her cage, sighs about her fate: "And this on a September Day with the wind whispering in the wildwood." The dog Laddie barks, while still leashed, "I want my liberty!" and, while trying to free itself from the collar, remembers: "If you scrooge back your ears, this doesn't hurt ... much." Animal discourse materialized! In the further unfolding of the plot, the bear evinces autonomous narrative agency—not only does she push open the door of her cage (for "Opportunity even 
knocks at cage doors," as a title tells us), but she dashes off, follows the tempting smell of Saturday baking, enters a house, makes a mess of the table, and eats her fill, culminating in an intertitle: "Bless my Wool and Whiskers, but I am full." Nonetheless, she remains alert enough to leave the place just at the moment that the lady of the house, Henry's mother, returns from the market. The parallel editing of the lady returning and the bear banqueting concludes with a shot of the arrival of the one and the departure of the other, thus comically emphasizing the animal's autonomy: while the woman enters the door in the left half of the frame, Brownie jumps out of the window in the right-the simultaneity and opposition creating the comic effect.

In order not to be recognized, Henry, the boy, disguises himself as a criminal after having decided to take his Saturday off. Perfectly "in character", he leaves the house by climbing out of the window, whereupon a title comments: "He could go out the regular way, but that would spoil it." The lampoon of the crime-film genre has begun and it continues with the help of two "real" burglars visiting the house after both the mother and Henry have left and while Brownie is feasting in the kitchen. The noise chases the thieves away and they escape by sliding down the drain-pipe, as in a crime series. Further on in the story, it is autonomous animal agency that helps to catch the criminals. One of them, on the run, is tripped by the dog and the bear, who use the rope with which they are bound together as a tool: a crime successfully fought with mischief-as in a Feuillade children's comedy!

Spectators knowledgeable about the treatment of animals in the film industry may read the scene with the rope in yet another way, namely, as a send-up of the techniques by which, for instance, horses are downed on film sets. Because the rope is used by animals to tackle men, rather than vice versa, it may be read as a tongue-in-cheek comment on such practices. Fans of BACK TO GOD'S COUNTRY, moreover, might discover at least one reference to it, in the form of an ironic reversal of Dolores' dream. While Dolores, in her city apartment with her husband, dreamed of her Arcadian forest home with the animals, Henry, with Brownie and Laddie free but hungry in the woods, longs for home and for his mother offering them supper. And while Dolores' dream was bound to come true, Henry's wish does so only in part: he eventually returns, but without his new friends. In terms of the plot, then, the film only half fulfills its subversive promise of rebellion against "the shackles of grown-up inhumanity". While the threesome from the title does catch the criminals, and are otherwise up to some harmless mischief, each of them eventually returns or is returned to the "inhuman" captivity from which he or she sought to escape. To be fair, with this, the plot is neatly rounded off; but, on the other hand, such an ending effectively undoes the potential legitimacy of the naughty protest of the three escapees. 
Cameraman Joseph Walker has suggested that the film was not intended to be a comedy, but that Shipman rewrote the script and edited the film as a comical subject once she had watched the rushes of a hilarious sequence featuring Brownie and Henry right after their first meeting. ${ }^{241}$ Henry climbs a tree in fright, but is followed immediately by the bear, who fails to halt upon reaching the boy and instead just clambers over him and further up the branch. In fact, the one who was scared was the bear (having been chased into the tree by noises made by Van Tuyle), not the boy. But, apart from this artistic license, ${ }^{242}$ Walker's anecdote underscores what I have pointed out as Nell Shipman's conception of where the magic of film is created, that is, between camera and actors and nowhere else. And, as soon as that magic turned out to be more comic than had been foreseen, Shipman rewrote and edited the entire film to exploit serendipity.

SOMETHING NEW and THE TRAIL OF THE ARROW

Although referred to by Shipman as a commercial made "between pictures", ${ }^{243}$ SOMETHING NEW was, and certainly in retrospect is, much more worthy of note than that. ${ }^{244}$ For the film's scenarist, star, co-director, and editor, it may have been no more than a quickie and a detour from her aim to make and act in Northwest drama, but the film as preserved and its reception call for a fuller consideration than the autobiographer's casual treatment of it would encourage. For one thing, at the time, as well as 60 years, the film has been seen as a fiction film starring Nell Shipman, not as a mere commercial for the Maxwell automobile, although the latter was indeed also featured. ${ }^{245}$ It was promoted as a "Motor Drama”, a "Melodramatic Photoplay", and an "Auto-Photodrama”, and the contemporary press emphasized its romance and sensational thrills as well as "the novelty of the use of the motor car instead of a horse in a country where there are no boulevards or even rough mountain roads." ${ }^{246}$ For another thing, as I shall argue, the film can be considered as - all at once-continuing, deviating from, and reworking some of the narrative devices and production concerns central to Shipman's work and career.

As Shipman's second production, it was another film with an overall comic tone. It opens and ends with shots of a woman sitting behind a table with a typewriter. The setting is in the open: table and chair are placed beneath a huge tree. In the opening sequence, the writing woman is said to be searching for "an inspiration" to write "something new", and she is shown seeing things as if they were happening before her very eyes. Her thoughts and reflections are directed to the spectators who are watching her ponder and find her topic. Inasmuch as we recognize two of Shipman's production concerns - the use of 
outdoor settings and the use of observation to create fiction-it is as if Shipman were asking spectators to identify this pre-diegetic writing woman with herself. ${ }^{247}$

In the subsequent sequences, a shift occurs, which further specifies the writing woman's ideas about the plot. She now enters the diegesis as "The Writing Lady herself", who selects and presents a series of generic elements. She needs, in consecutive order, a setting "beyond the border, in that land of Rogues and Romance, Mystery and Murder-Mexico!"; and then THE HERO, and a "Good old Yankee" called "Dad"; that she "craves ATMOSPHERE, real, red and RAW," including "Danger" provided by a gang of bandits; and, last but not least, that "Old George FATE is helping a hand". In addition, she repeatedly emphasizes her presence by commenting ironically upon the action, as, for instance, after she has made the hero at first sight fall in love with the heroine: "(Nothing new about that, but who would change it?);" or, when introducing the bandits and their leader: "(He doesn't look dangerous, but look at his gang.)" At the point when the diegetic Writing Lady, in a second twist, turns into the GIRL of her own tale and is about to be caught in a perilous situation, she self-mockingly tells the dog: "I wanted 'Atmosphere' and I'll say I am getting it." Whereupon the Writing Lady merges into her story's character of the imperiled girl and victorious heroine. The framing device is invoked again in the conclusion, when the diegetic Writing Lady strikes her final note: "Now the MORAL is: Be it MOTOR-or MAID-THERE IS ALWAYS SOMETHING NEW!" Girl has changed back into Writing Lady, who is granted the last word and the last laugh. This sequence and the entire film are completed with a shot of the pre-diegetic writing woman bent over the table, laughing her head off, beaming and looking straight into the camera. The intertitles' direct address, eventually performed in the acting as well, convey both her pleasure and her pride. The employment of this meta-discourse renders SOMETHING NEW in fact truly new within Shipman's cinematic oeuvre, as well as singular, because she would never utilize it as explicitly in any of her subsequent films. ${ }^{248}$ Today, this feature makes the film particularly rewarding to scrutinize from feminist film-historical points of view.

In the tale presented by the pre-diegetic writing woman and written down by the diegetic Writing Lady, the atmosphere becomes so "real" that she herself gets caught up in the romance and the perils she concocts. The Girl she turns into, however, is not the sylvan outdoors girl of Northwest drama, but the imperiled and intrepid automobile-driving heroine of the less archaic women stunt melodramas. Suspended as in the stunt serials, ${ }^{249}$ there is a romance, with "hero Bill" who owns, according to the intertitles, apart from "the smile", also "a dog and a posh car". The indispensable perils include a kidnapping and a car ride through the desert, in which the car is initially driven by the 


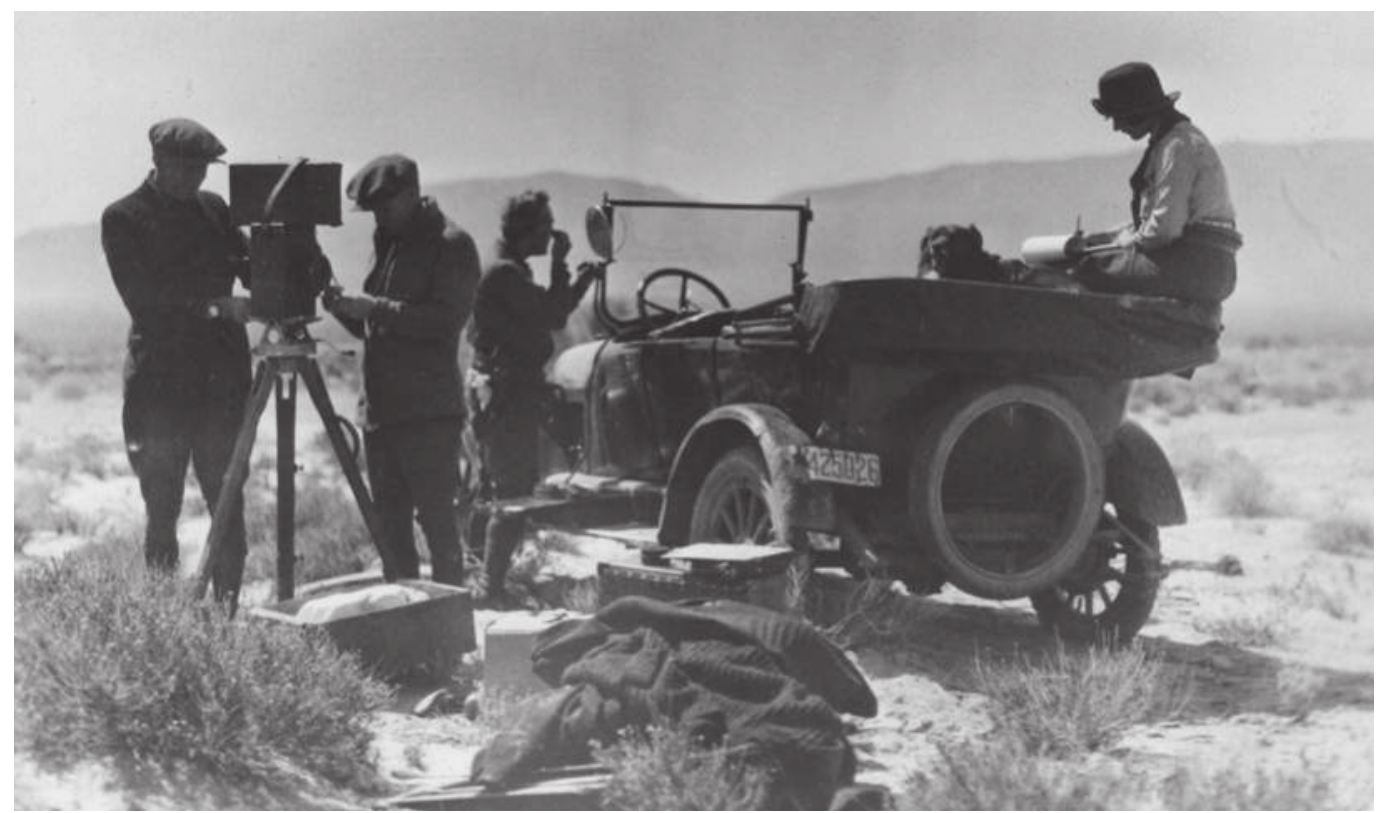

Fig. III.18: Set photo from SOMETHING NEW. Nell Shipman rewriting the scenario with Laddie at her feet.

hero, but eventually by the heroine too. The writing woman or Writing Lady is not only new to the genre as she frames and constructs the melodramatic plot and its types, but her presence likewise assumes responsibility, in an autoreferential spiral, for the scenario and production of the film. Because all of these roles and functions in the making of SOMETHING NEW were performed, in both senses of the word, by Nell Shipman herself.

The writing woman can be seen as Shipman's reworking of the scribe from the foreword of her 1915 novel Under the Crescent. Both are present as a fictional first-person narrator giving shape to the story within the story, which, as we have seen, cannot be told without a setting, types, "atmosphere", and imagination, and in which the adventures and perils of a woman in the desert are featured. Both first-person narrators, moreover, employ direct address in order to engage readers-spectators in the fabrication of the story. The scribe in the novel, however, is a serious character assigned the task of authenticating the narrative, but who then remained outside of it, and disappeared as a selfeffacing medium behind the character starring in it. The writing woman in the film, in contrast, reappears as the heroine of her story, and not only presents it beforehand but comments upon it repeatedly, and, despite suggesting otherwise, has it on a string right to the very end. Present as the tale's instigator, composer, and protagonist, her textual task is no longer the authentication of the fiction, but rather, and this is significant, to emphasize its fabrication 
as well as to satirize generic elements and fictional characters, her own not excluded. Her self-confident direct address and her entrance into the diegesis and seeming loss of control over the story, effectively represent, and provide, the dual pleasure that readers-spectators derive from sensational stage melodrama, that is to say, an apperceptive awareness - of genre, in this case, rather than medium-alongside absorptive realism. By 1920, however, American cinema had come to favor stylistic devices that obscured the product's fabrication and fostered the spectator's absorption. The film's foregrounding of a writer went against the classical cinema's demand for stories with an invisible or implied narrator. The fact that Nell Shipman cast herself in the role of the woman who writes the film's story points to the level of the film's production. In other words, if her previous starring role of the wife of a writer is taken into account, as well as the erasure of her contribution as a scenarist to BACK TO GOD'S COUNTRY, her self-casting could likewise be thought of as an unabashed and even confrontational gesture. Considering that she was the producer-scenarist and star, the film seems to have been not only a promotional item for a brand of car, but also an act of self-promotion on the part of Nell Shipman.

If authentication was not a concern at the level of the text, it nonetheless informed, to a large extent, the production conditions, the style, and the contemporary reception of the film. Main object and result of this authentication was not the human heroine and her vicissitudes, but the mechanical heroine and her success in blazing a trail through the desert landscape. For the film, a sample of the 1920 Maxwell automobile, an open touring car, was made available to Shipman and Van Tuyle, who steered it "over rocks bigger than itself, up canyons hub-deep in sand. And we [...] really drove!” During the shooting, they had a mechanic at hand to mend the car and they took Laddie, "the collie who bear-sat for Brownie, [...] along on the Maxwell's wild rides". ${ }^{250}$ Both the producer-actress and the director-actor had a history of automobile driving and had performed stunts with the vehicles, while cameraman Joe Walker had a record of car commercials, including one for an earlier Maxwell model, made in September 1918, and one for an Essex, shot in August 1919. ${ }^{251}$ In the latter, THE TRAIL OF THE ARROW, Shipman too had been involved as a scenarist and an actress. Van Tuyle had been a secretary of an automobile club and a rally driver before he got involved in film production. Shipman, moreover, had made it into the columns of the Los Angeles Times in previous years as a car driver for commercial and philanthropic purposes, each time with a different and explicitly identified brand of automobile and was asked to comment upon its qualities. ${ }^{252}$ The articles invariably promoted both the brands of car and women's driving, which had been the object of campaigns throughout the 1910 in all sorts of media, including newspapers and cinema. Women's car- 
driving was nonetheless represented within the boundaries of conventional femininity, most notably by means of tropes of passivity (e.g., easy control, no worries). As Ben Singer has pointed out, two of the prevailing prejudices against women as car-drivers hinged on their alleged lack of physical coordination and their putative cognitive inadequacy to concentrate or to do two things at one time. ${ }^{253}$ Even if Shipman in her newspaper comments seemed to have reckoned with such prejudices, her on-screen representations of women driving zealously rebuffed them-both in SOMETHING NEW and in its predecesSOr, THE TRAIL OF THE ARROW.

Driving in an Essex in August 1919, Shipman was reported to have undertaken, in the company of her friend Marjorie Cole, a "dashing auto trip [...] through the roughest mountain section and the most arid desert region of the Southwest." ${ }^{254}$ The film made of this trip, which is not known to be extant today, was referred to as a "motion picture record" in the press ${ }^{255}$ rather than as the 380 semi-fictional commercial a synopsis by Nell Shipman indicates. ${ }^{256}$ Shipman's synopsis for THE TRAIL OF THE ARROW called for automobile stunts and comic situations as a result from a wager made by two men over women's driving abilities. This wager, moreover, was taken for real in the press coverage. ${ }^{257} \mathrm{The}$ plot of THE TRAIL OF THE ARROW and its publicity emphasized that women were no less-or even more-capable than men in the performance of stunts with cars. Shipman's synopsis, moreover, outlines the trip from the perspective of the intrepid women, who has to deal not only with rugged desert landscapes and a time limit, but also with "[o]bstacles [...] that are not the work of nature", but of the opposing contender. ${ }^{25}$ Thus, the women not only triumph over the car or the rough terrain but over a man "sarcastic" and "desperate" about their capabilities, as Shipman phrased it. However, the synopsis eventually allows him to be "a good loser", ready to take his "hat off to the Woman Driver" and to state that women "have a right to vote and drive automobiles, and do anything their hearts desire". ${ }^{259}$

In her synopsis, then, Shipman, modelled her women drivers after the myriad action heroines who had been showcasing daredevil automobile driving (and other stunts) on-screen during the 1910s in the genre Ben Singer has coined the serial-queen melodrama. ${ }^{260}$ The women are not only capable of driving a car over the most trying trails, but also of mending it in case of trouble. The heroines accomplish a task even the most experienced desert driver would have found troubling. Likewise, there may have been what Singer calls "a fashion interest" in the mise-en-scène, ${ }^{261}$ as Shipman has the women change at a certain moment from "their regular feminine apparel" into "the overalls brought in case of tire trouble" ${ }^{262}$ Furthermore, we have the role reversal that Singer observes in scenes with car chases, with the women growing ever more determined and the sarcastic man increasingly desperate and helpless. Lastly, 
Shipman's script obviously employs an overtly feminist discourse spread by the women's movement and the campaign for women's suffrage, which was likewise not uncommon in serial-queen melodramas. ${ }^{263}$ If parity and mobility were key terms in the women's liberation movement of the 1910s, Shipman's story for THE TRAIL OF THE ARROW supported it.

SOMETHING NEW features Shipman again as a champion desert car-driver, yet, in this film, her companion was male. The stake of the bet was different as well: it no longer advocated women's abilities in traditionally masculine positions, but proposed the less politicized issue of the old versus the new, of organic versus mechanic horsepower and endurance. The writing woman's tale, moreover, contains more of the old than of the new. Although these plot elements and choices yield a film less militant than its predecessor seems to have been, SOMETHING NEW can still be read as making another case for women's independence and mobility through the devices of the Writing Lady and of the Girl's stunt driving. Yet this case for independence and mobility, I argue, has less to do with the social and political demands of the women's movement, than with what Brauerhoch aptly has called "the adventure in the mind" ${ }^{264}$ that is to say, Shipman's professional aspirations as a writer, a scenarist, and an actress. In this regard, it is significant that Shipman decided to drive the car over barely accessible desert tracks. Her stunts in the middle of nowhere, in my reading, refer to a realm of make-believe yet, nonetheless, draw upon observation of reality. And so does her portrait of the woman writing regular action melodrama, getting carried away with it yet nonetheless emphasizing the process of its fabrication. "All fantasy, see?"265 Through presenting the producer-actress' artistic notions of popular fiction-film writing, SOMETHING NEW provides nothing short of Nell Shipman's credentials: a humorous self-portrait as a writer and an actress seeking and enjoying professional independence and mobility in the popular literature and the popular cinema of her times.

What, then, is the role of Laddie, the dog, in this auto-referential Nell Shipman film? By and large, Laddie's part seems nondescript in SOMETHING NEW, certainly when compared to animal parts in preceding and subsequent Shipman films. Although the dog is spoken to by the human characters, he is granted no speech or thoughts of his own in the intertitles, and, while he is present in the car in many shots of it, only three sequences provide for independent animal agency and more or less scene-stealing performances. If the animal is by no means a protagonist, then, the question is what significance his presence acquires at the level of the text. A closer look at the three sequences in which Laddie's role becomes prominent, may direct us towards an answer.

In the first sequence, Laddie functions as a token of hero Bill to the Writing Lady: "Love my dog, love me" says the intertitle. In the second sequence, 
the Writing Lady and Laddie are caught up in an attack by bandits. For help, she writes a note and fastens it to Laddie's collar. The Writing Lady is now fully "in character" as the Girl, which is further attested to by her abduction at the hands of the villains. Slipping inside the story has meant losing control and independence. In these sequences, then, the dog's function is to support the woman in her struggle against becoming an object of masculine aggression as well as of male heroism. The drama is that the animal is as yet unable to prevent her from being "carried away with her own out-pourings". ${ }^{266}$ But this is drama with a wink, because the meta-discourse of the Writing Woman reminds us of what we are watching: a witty lampoon of melodramatic fiction and its heroines and heroes.

While our heroine is carried away, literally and figuratively, Laddie is granted his one narratively indispensable sequence in SOMETHING NEW. The dog undertakes an autonomous action by dashing off to fetch Bill and running 382 into the hero outside a deserted village. The car stops, Laddie sits down to be stroked by Bill and invited into the car, and delivers the message. Thus end Laddie's major sequences and narrative task: to ensure that the hero helps save the Girl. In other words, he fulfills the task to restore male heroism for the sake of the sensational story within the story, which, from this point onwards, takes over the film's plot.

His subsequent trek through the desert is intercut with two parallel actions. One shows the bandits with the girl on the horses and on their increasingly rough and wearisome trail; the other shows Bill arriving at Dad's ranch, finding it and the village deserted, and preparing to return empty-handed. He turns the car around and drives off, which is intercut with two shots of Laddie leaping swiftly over rocks and through sage bushes- his route obviously carefully choreographed by the directors, as he runs towards and past the camera in a winding course reminiscent of the mise-en-scène of galloping horses in westerns.

In the remaining scenes of the film, Laddie's actions are confined to riding in the backseat of the open car while it drives through the rocky wasteland. To be sure, the dog sometimes dives away into the car and pops up again, and is often ostentatiously busy keeping his balance. The collie's rather servile demeanor in the presence of the hero is somewhat puzzling. Should we read in this an avowal that, in Shipman's view, dogs, or animals generally, relate to men in a different manner than to women? That men's bonding with animals is based upon the latter's subservience rather than upon the reciprocity of companionship with which women relate to them? If that sounds a bit too generalized or hypothetical, nonetheless Shipman may have drawn upon her own store of observations of the animals and the men she had come to know. Consider, for instance, the question of why she chose Laddie to play this part, 
and not a larger and more virile-looking dog like Tresore or Rex. While pragmatic considerations may provide the main answer to this question-for each of those long-legged, stately Great Danes it would have been far less "natural" to hold his poise in the back seat of the car as it rattled along than it would be for the agile and graceful collie-it would not surprise me had Shipman, aware of how actors had "to look it" in fact reckoned with the difference the collie's appearance would make. ${ }^{267}$ For the long-coated Laddie, although a hedog, does not look macho at all, but rather the opposite. In the company of the hero, then, the dog undergoes a sex-change, so to speak: in order not to further undercut male heroic agency in the melodramatic plot, he takes up a de-sexed if not feminized position.

The dog's ornamental presence in the scenes of the hero and the car ally him with that other non-human character featured in the film, namely, the Maxwell touring car. In the narrative, it is treated semantically as a dutiful animal or a loyal girlfriend. Referred to as "she" by the Writing Woman, the car is eventually declared to be the "real heroine". In several instances, the hero addresses the Maxwell as if it were a living being, sharing his thoughts with it: "Little car, it's up to you!" or "I reckon we're licked, little car.” The girl treats "her" likewise, comforting the automobile when they seem to have gotten stuck: "You've fought the good fight, little brave car, but you cannot save us-now!" This title is cut into a medium close-up of the girl in profile with her cheek against the grill of the car, the grill fully filling the frame, the trademark as a signature visible above the girl's head. With great affection, the girl strokes and caresses the car's nose as if it were another devoted Wapi. The closing image tops this off by giving "her" the cinematographic treatment of which a screen heroine is worthy. In a shot taken from a steady camera, in a straight-on angle and at a low height, the car rolls towards the lens, moving from a medium long shot to an extreme close-up position. With this shot, the front acquires face-like features - its headlights two large eyes, its grill a nose, its license plate a mouth, its wheels the ears. Although unable to speak, the car is made into a film character and becomes a star in her own right.

Moreover, the car is endowed with independent agency in the mise-enscène. There is one moment in which it even continues to motor on its own, the hero at the wheel having collapsed due to exhaustion and pain, the girl standing at his side facing backwards and shooting at the bandits pursuing them. To be sure, the car has to be stopped by the girl in order not to run into a rift, but it had been "acting" without anyone controlling it. Its "acting" is shown even more convincingly in the multiple and lengthy shots in which it is driven through the desert landscape. It makes its way through bushes and cacti, over rocks and boulders, bumping and jumping-one only wonders when its high wheels will break off, or how much longer it will take before it 
collapses entirely. Its driver, whether the hero or the girl, seems to have little bearing on the car's own stamina and endurance. It is awesome and hilarious to watch. The magic between acting and camera is at work again, and the direction and editing in service of that magic renders the Maxwell car, in this regard, a heroine in her own right.

In her various roles in SOMETHING NEW, Nell Shipman displays a whole range of acting capabilities, from comedy to melodrama acting, from horseriding with hands bound behind her back to stunt-driving, from a pensive writer to the imperiled and intrepid action heroine, and from a woman indifferent to men's advances to a caring companion and loyal pal. As in BACK TO GOD'S COUNTRY, moreover, she is most persuasive when she is in action and does things as though neither acting nor camera were involved. Her aptitude in play-acting, furthermore, she employs to comic ends. But what she most definitely does not act, is the intimacy of a loving woman, as she had, for 384 instance, in the city home sequence in BACK TO GOD'S COUNTRY. Shipman's part in SOMETHING NEW downplays sexual appetite and attraction in favor of companionship or attitude of "being game". The role she assumes vis-à-vis him is one of helping each other out, caring for one another, and taking over if the other is unable to keep going. Thus, their relationship is about mutual encouragement, joint accomplishment, and, at some points, shared despera-

Fig. III.19: The Maxwell touring car, another nonhuman character in SOMETHING NEW.

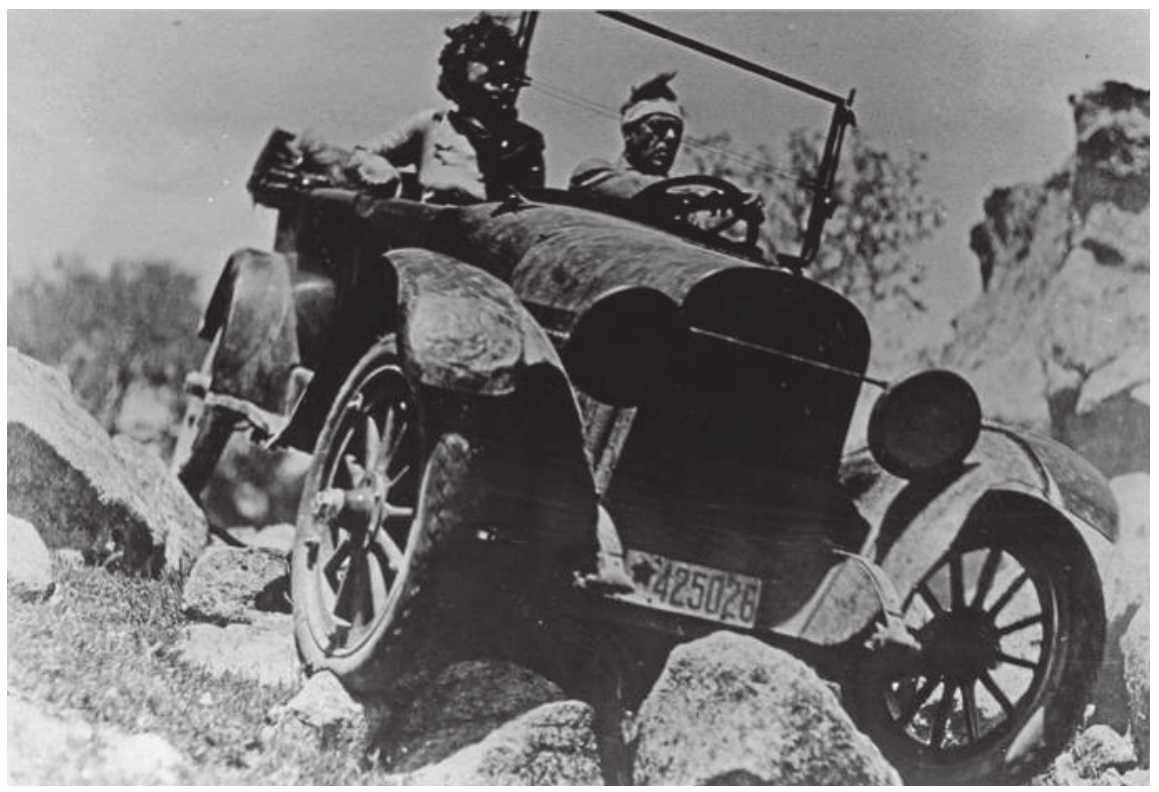


tion; but, as acted both by her and by Van Tuyle, it is not about passion, from either side. They do exchange caresses and tender gestures, of course, but whenever they touch it is to comfort and sooth one another. There is not one intimate kiss, nor passionate hug, nor desiring glance. The Girl's most enamored touch-crooning, as Trusky terms it ${ }^{268}$ - is directed towards the Maxwell, not the hero. Shipman's acting makes clear throughout the film what the diegetic Writing Lady had stipulated at the beginning: while hero Bill possesses sex appeal, neither Lady nor Girl would respond to it. They have other things to do. If we consider that the hero and the girl do not end up as a married couple or family in this film, we may conclude that the Girl, right to the very end, evades heterosexual attraction. And, if we remember that the Girl's crooning concerned a "she", we might well wonder if we have not witnessed a discreet lesbian love scene.

The only kind of masculine appetite represented in SOMETHING NEW is filthy and menacing. It is attributed to the bandit chieftain, a stereotyped Mexican. The scene in which he assaults the Girl displays the full range of the bandit's illicit intentions and dirty tricks and exposes the physical brutality of the villain's lust, as he pushes the Girl backwards over the table, puts one knee on the tabletop as if to mount her, claws her shoulder with one hand, while she cries: "No! No!" Her cries are heard by Bill, but before he arrives at the den, the Girl manages to stop her molester by smashing a bottle over his head. The brutality of masculine lust as depicted in this sequence contributes to the narrative motivation of the Girl's evasion of heterosexuality.

Am I arguing that Shipman's Girl in SOMETHING NEW ought to be seen as a closeted dyke? Yes and no. A denunciatory portrayal of villainous masculine lust was a must in the genre of melodrama that Shipman had embraced as her own, even if this requirement was met more poignantly in Northwest drama than in the serial-queen variety. The Girl's crooning to the car, moreover, is, in the first place, a joke about automobile fetishism and, in the second, a terrific shot meant to direct attention to the brand-name in such a way that no spectator of either sex would overlook it. But the film's emphasis on female-male companionship and its nullification of heterosexual attraction adds to the narrative context of the Girl's character and, to this particular shot, a dimension of potential radicalization. It is from this potentiality, in my opinion, that today's scholars derive the notions of feminist resistance and liberation as well as of insubordination and exuberance. It also might well have been for this reason that Shipman, in her reminiscences, asserts that it was "all fantasy", and that "none of it ever really happened", contradicting the strategy of authentication of film production and promotional discourse that she usually employed. She was setting the record straight in her memoirs, literally and figuratively, and that record would not include feminist resistance or politics, let alone a call 
upon women to abandon heterosexuality. Despite the lip-service she paid, in her 1919 self-portrait “Me”, to “'Feminism,' 'Socialism,' and other 'Isms'”, ${ }^{269}$ still I cannot see Nell Shipman as a filmmaker led by the conviction to support a cause. Shipman did not make films to put out statements or a message, but for the fun, for the fame, and to earn money. To the extent that she would assert that women "had a right to do everything their hearts desired", this emanated from pragmatism and from her own experience, and it depended on the spirit of the times, the discourses of which Nell Shipman was an astute interpreter and appropriator. At the time of the making of SOMETHING NEW - and THE TRAIL OF THE ARROW, for that matter-it was a promotional plus for film stars to ally themselves to the women's liberation and suffrage movements, but, by the end of the 1960s, when Shipman was recording her career, this was no longer, or rather not yet again, the case. The film buffs and collectors of the $1960 \mathrm{~s}$ were devoted to interests other than women's empowerment through femi386 nism, and Shipman, in old age still as sensitive as ever to the requirements of self-promotion, was delighted to be seen and read as the once-noted silent film star, the Queen of the Dog Sleds. It is in this context that her blushing at "fixing herself a tricky conclusion" ${ }^{270}$ is best understood. The auto-referential, tongue-in-cheek boldness pervading the entire film is precisely the reason why Nell Shipman's quickie, adorned with the most apt title someTHING NEW, strikes feminist-and lesbian and gay viewers today as the most self-assertive and flamboyant film in her oeuvre. ${ }^{271}$

\section{THE GIRL FROM GOD'S COUNTRY}

Shipman's first film under the official banner of her own company, and her last film produced and shot in California, was intended, as the title suggests, to exploit further her favorite screen persona and the, as she called it, "publicity sobriquet" of the outdoors girl. Given that no print of the film is known to survive, scrutiny must be satisfied with para-textual material such as synopses, reviews, advertisements, film stills, and, of course, the memoirs of Shipman herself and her cinematographer, Joseph Walker. Nonetheless, these documents enable me to explore the two most urgent questions posed at this point in Shipman's career: To what extent did THE GIRL FROM GOD'S COUNTRY agree with Shipman's production concerns, her preferences in genre, and her promotional strategy as a star? And did Shipman's outdoors girl differ from Curwood's model, and if so, in what respects?

The opening scenes of the story were set in the Northwest, but shot in California's Kings River Canyon, just east of Fresno. ${ }^{272}$ These scenes are, in fact, the sole ones in Shipman's post-Curwood productions that were explicitly set 
in a supposed Canadian part of the region. They did, of course, feature wild animals:

In an early reel of this varied production Miss Shipman introduces some very amazing wild animal work. She pets and feeds leopards, bears, wild cats - in fact, everything from a skunk to a lion. ${ }^{273}$

While the animals themselves were real, they were not brought out to the location, which, coming from Los Angeles, took a trip of almost three days to reach, two of them on horseback, ${ }^{274}$ and on which no animals other than Laddie were allowed in order to protect the local fauna. ${ }^{275}$ Thus, the scenes with Shipman petting wild animals were shot elsewhere. The major part of the story was set in "the palatial home of a Californian millionaire, an aeroplane factory, a burning hangar" and it culminated in a trans-Pacific flight and a landing in Japan. ${ }^{276}$ In contrast with Northwest drama, then, the story was largely situated in modern and moneyed society, not some sort of remote or idyllic wilderness locale, and no character in it, apparently, dreamed of returning to the Canadian Northwest where it all had begun. As one paper wrote, it was "a northwest yarn to a certain extent". ${ }^{277}$

Shipman cast herself in dual roles in the film, as a dark-haired outdoors girl and as a blonde millionaire's daughter. At a textual level, her double casting may have added to the credibility of the characters, who were supposed to believe, for most of the story-time, that they were half-sisters. Shipman's aspiration was "to achieve the ultimate of an actor's desire: twin characters shot in double exposure". ${ }^{278}$ She surely inspired Joseph Walker to creative cinematography with this idea, much like she had done with the dream sequence in BACK TO GOD'S COUNTRY. ${ }^{279}$ As for herself, she probably expected to employ, once again, her versatility in acting, and perhaps hoped to keep open an escape-route from being typecast as the outdoors girl, while, at the same time. maintaining that the latter was the screen persona she wished to play most dearly.

"We did the airplane stuff at a small airfield situated among the beans in the heart of what today is real estate's Eighth City of Cibola," Shipman recalled. She went on to explain that they had actually flown, much like they had actually driven the car through the desert: although they did not fly over the ocean, but "over the Santa Monicas", the mountains northwest of Los Angeles and bordering the Pacific Ocean. The aerial shooting was done in two "Jennies", single-seater biplanes used during the war, flying "practically wing-tip to wingtip". One of them carried a pilot and Joe Walker with his camera, and the other a pilot and Nell Shipman, standing and "act[ing] for the alongside cameraplane". ${ }^{280}$ 


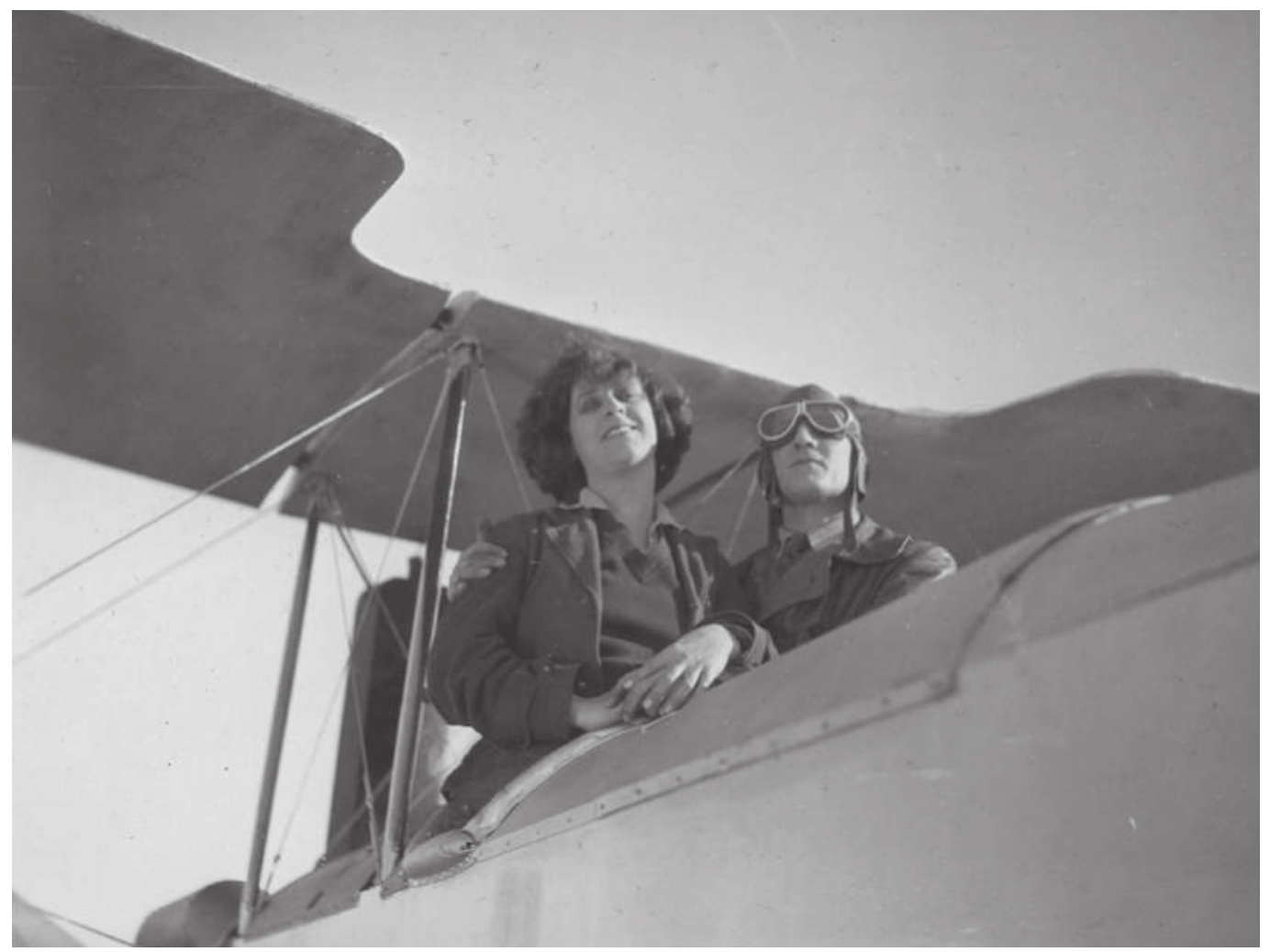

Fig. III.20: Nell Shipman and a pilot in one of the "Jennies" in THE GIRL FROM GOD'S COUNTRY.

As with previous productions, this is only one of several stunts Shipman and her co-actors performed for the film, of which quite a few were, if we may take her word for it, rather risky to carry out, but, as usual, fun to do. ${ }^{281}$ The synopses suggest that the film contained at least two scenes in which she rescued a man from drowning, namely, her alleged father and her blinded sweetheart. Shipman's own point about the stunts was that "[n]o audience nowhere no time could holler 'Double!'," 282 obviously a condemnation to her mind, although it, much like the on-location shooting, was considered a precarious and inefficient practice in the film industry of the early 1920s. Of this she was well aware, at least in retrospect:

That I wrote the scenario for myself and presented myself with not only unlimited flying time but many weeks on location in the High Sierras at Kings River Canyon, must be considered sheer opportunism. ${ }^{283}$

She also knew that it was not very economical: 
The overhead was running near $\$ 10,000$ per day and Mr. Clune [the president of Nell Shipman Productions and an investor in the film] came to visit his show wearing a long face. The syndicate was carrying a sizable insurance on the star and I sometimes fancied I detected a speculative gleam in my backer's eye. I might be more valuable dead. ${ }^{284}$

For the film's interiors, moreover, an expensive mansion was built at the former Selig studio, then owned by Louis B. Mayer, in Los Angeles. According to Shipman, there were even further reasons why "the budget was slopping over", including the purchase of animals "all of no use to our North American wildlife films, but so cute!", her wardrobe "to stun the eye", and the fancy lamps with which the mansion was decorated. ${ }^{285}$ Hence, she more or less admits that, at the time, her own and Van Tuyle's attitudes had been to stretch the budget beyond its limits. This may also be inferred from the inconsistency of initially characterizing the production as "(for those days) high-budgeted", but then again as "under-budgeted", without being more exact about the matter. ${ }^{286}$

A reasonable indication for the amounts involved may be derived from an article that, although it viciously defames Van Tuyle, illuminates a series of production circumstances and problems that Shipman's memoirs do not deny, but rather recount with less blaming and shaming. The only person mentioned as a spokesman in the anonymous article was David Hartford, which renders these allegations trustworthy to a certain extent, that is to say, from a professional point of view, but they are less so if the old competition between Curwood and Nell Shipman as well as the possible rivalry between Ernest Shipman and Bert Van Tuyle as producers and as Shipman's lovers are taken into account. The piece depicts Van Tuyle as a producer promising over and over again "to put over a big feature for eighty thousand dollars", but then spending "twice that amount". ${ }^{287}$ Even if the latter figure was exaggerated in order to humiliate Van Tuyle, 80,00o dollars does sound like a probable budget, albeit a tight one.

The production schedule and the length of the film also exceeded what they had planned. Shipman, who did the editing herself, matter-of-factly recounted that, during the summer, she "cut and ran and re-cut until the footage was down to a reasonable 12,000 feet." ${ }^{288}$ The article mentions nearly four months for the editing and an approximate length of 9,ooo feet, but additionally suggests that both had not been agreed upon. ${ }^{289}$ For market requirements, it should have run to 7,000 feet, as this was the length in which it would eventually be distributed and that suited the standard slot of "a top half of dual bookings" in film exhibition of the time. Shipman and Van Tuyle, however, refused to edit the film accordingly, whereupon the president of the financing syndicate, W.H. Clune, took it out of their hands and had it reedited by 
another, hitherto unknown, editor. "Murdered, slaughtered, senseless", Shipman cried melodramatically in her memoirs about this non-director's cut of her movie. ${ }^{290}$ Her dismissal as an editor may have hurt, but, even more so, I assume, did the subsequent breakup of her first production company and the damage to the reputation of Van Tuyle, to begin with, and to Nell Shipman too, most notably in her functions as the film's co-producer and co-director. It was an outcome that Shipman certainly dreaded, for she concludes her description of this episode in her career with the comment:

Was I black-balled in the business? I really don't know for certain. I do know I was spanked, that henceforth I heard strange, sharp sounds as if some doors down a long corridor were slammed shut. ${ }^{291}$

This admittedly still largely oblique impression of the production circum390 | stances of Shipman's feature film THE GIRL FROM GOD'S COUNTRY, prompts nonetheless the conclusion that the couple's tenacity in the conflict about the editing and its follow-up cost them something more important than money. That is to say, they lost part of the professional goodwill on which Nell Shipman's film productions had thrived up to that time. In the context of this careerography, the most urgent question prompted by the events is: to what extent did the film justify the commotion? For want of a surviving print, this question can be answered only in part.

All synopses and reviews, whether favorable or critical about the film, agreed as to the serial-like structure of the plot. Variety, as usual when concerning Shipman's films, was downright disapproving, while Wid's Daily and the ever-supportive Moving Picture World gave the same characteristic and much more affirmative response. ${ }^{292}$ All three discuss the seven-reel version, not Shipman's original cut, which she defended with the consideration that "perhaps it never boasted much sense but it did hang together." ${ }^{293}$ I tend to give her the benefit of the doubt for this claim, on account of the editing of her other films. If, in SOMETHING NEW, much of the footage of the car rides is lengthy and repetitive, the narrative of that film, with its various layers and convolutions, did hang together amazingly well. And, as I shall argue, the narrative construction of Shipman's subsequent film, THE GRUB-STAKE, can be considered to be the proof of the pudding in this regard.

The point of the assessments of THE GIRL FROM GOD'S COUNTRY as a condensed serial is that the romance plotline seems to have given way to the action scenes, which, moreover, "piled thrill upon thrill," to quote the publicity. ${ }^{294}$ The film was supposedly, as Shipman summarized the criticism, 
so overloaded with twin stories for the twin heroines, so crammed with frenetic action that no character ever stopped to be. It leaped from one episode into the next: dog sleds to airplanes, earthquakes to snowslides. ${ }^{295}$

The romance between Neeka, the "half-breed" girl from the North, and a French aviator gone blind is of minor importance compared to the issues of parentage, mistaken identity, business competition, deception, and bravery that otherwise motivate the characters' narrative agency. In the synopses and reviews, there is no mention of a scene of sexual assault by one of the villains; rather, their villainy takes the form of fraud (on the part of the millionaire airplane builder) and espionage (on the part of his butler), which, moreover, are not directed against the Girl. In this set-up, it seems, it is Neeka's confidence in the butler that is abused, not her sexuality or femininity.

With a French Canadian father and a Native American mother, Shipman's Neeka appears to be another version of Beach's Necia and Curwood's Nepese. The alliteration of their names, which was, in general, a stylistic favorite of Shipman's, lends material support to this thesis. ${ }^{296}$ As is common in Northwest dramas, part of the plot revolves around the question of her descent: presumed to be a daughter of the fraudulent millionaire (whose real daughter she resembles like a twin sister), she eventually turns out to be the child of his brother, an inventor who partially had lost but later on regains his memory, and from whom the millionaire stole his invention. Here again we have the benevolent but helpless father and absent mother, as they belong to both of the relevant genres. The difference may be that this father is not eliminated in the narrative, but, rather, is restored in his paternal function, which, however, the girl has proved, reel after reel, not to need. It is difficult to say to what extent Neeka's status as an illegitimate child and a "half-breed" girl was addressed (as Necia's status was in Beach's play and Nepese's was not in Curwood's novel). Shipman's synopsis suggests that in the northern scenes, Neeka's grandfather seeks "revenge for the affair in which his daughter paid the penalty", a formulation also found in the Variety review. ${ }^{297}$ But then the granddaughter's status would only be at issue indirectly, and, by the end of the film, accordingly, the man's abandonment of the Native American mother and her child no longer appears to be held against him. Given the film's frenetic action and its motifs of dishonesty and mystery, there seems to be little room for exploring the social context in any depth. Armatage may have a point when she assumes that racial differences could have played a role in Neeka's relationship with her presumed half-sister, the millionaire's white daughter, Marion, when they quarrel about "social blunders". ${ }^{298}$ The Wid's Daily summary adds that they clash in many scenes, and suggests that the opposition 
in play was one between "primitive instincts" and urbane manners. Whereas in Shipman's synopsis the Marion character is noted only for how closely she resembles Neeka, the memoirs speak of them merely in antitheses: "the blonde and the brunette, confronting one another", "Neeka, the half-breed gal" against the "snooty-nosed, patrician Blonde", ${ }^{299}$ and so forth. The vocabulary employed suggests bald oppositions between "civilization" and "wilderness" and between a good and a bad character, rather than issues of ethnicity; nor does the surviving film-still representing Shipman in her dual role point to the topic. ${ }^{300}$ The still shows, in the left half of its frame, a timid but proud Neeka, facing the camera but looking angrily to her left, and in the right half, a supercilious Marion with a hunched shoulder and her arms akimbo, the latter gesture rendering her prissiness vulgar rather than chic. Their costumes too indicate character and class differences, not racial ones. On the other hand, the film was promoted as "something different" for "people growing a bit tired 392 | of problem plays”, which suggests that no social aspects were articulated at all. ${ }^{301}$ Nor does Walker's account respond to the question of the social issues; rather, he suggests that the film concerned rivalry among women, resulting from the fact that both girls were in love with the same man. ${ }^{302}$ Much depends, then, on the means with which the blonde pursues her aim, while it is also important to note in this context that it is not she but the mountain girl who eventually "gets" the guy. In these characterizations and narrative structures, we may recognize the generic conventions of Northwest drama, but it remains unclear to what extent the social issues potentially raised by the genre elaborate on in this particular film.

Having cast herself in both of the parts, Shipman's personal sympathy was with the "half-breed" girl. One sign of this affinity may be that Shipman had made the blonde Marion character a member of a hunting party, and we know how the scenarist felt about that particular sport. The affinity was also noticed by contemporary viewers:

The part of Neeka, the half-breed, is better suited to the talents of Miss Shipman than that of Marion Carslake, the society girl. The spirit of the former role is entered into by the live wire Nell and played with gusto. ${ }^{303}$

In addition, the Neeka character seems to have been the heroine of the story in terms of morals as well as of narrative agency: an honest girl with guts, performing sensational acts of stamina and bravery for the sake of others and being rewarded for it with romantic love.

Generically speaking, THE GIRL FROM GOD'S COUNTRY seems to have been a mixture of Northwest drama and serial-queen melodrama. Rooted in an Arcadian but also violent wilderness world, the Neeka character soon exchanges it 


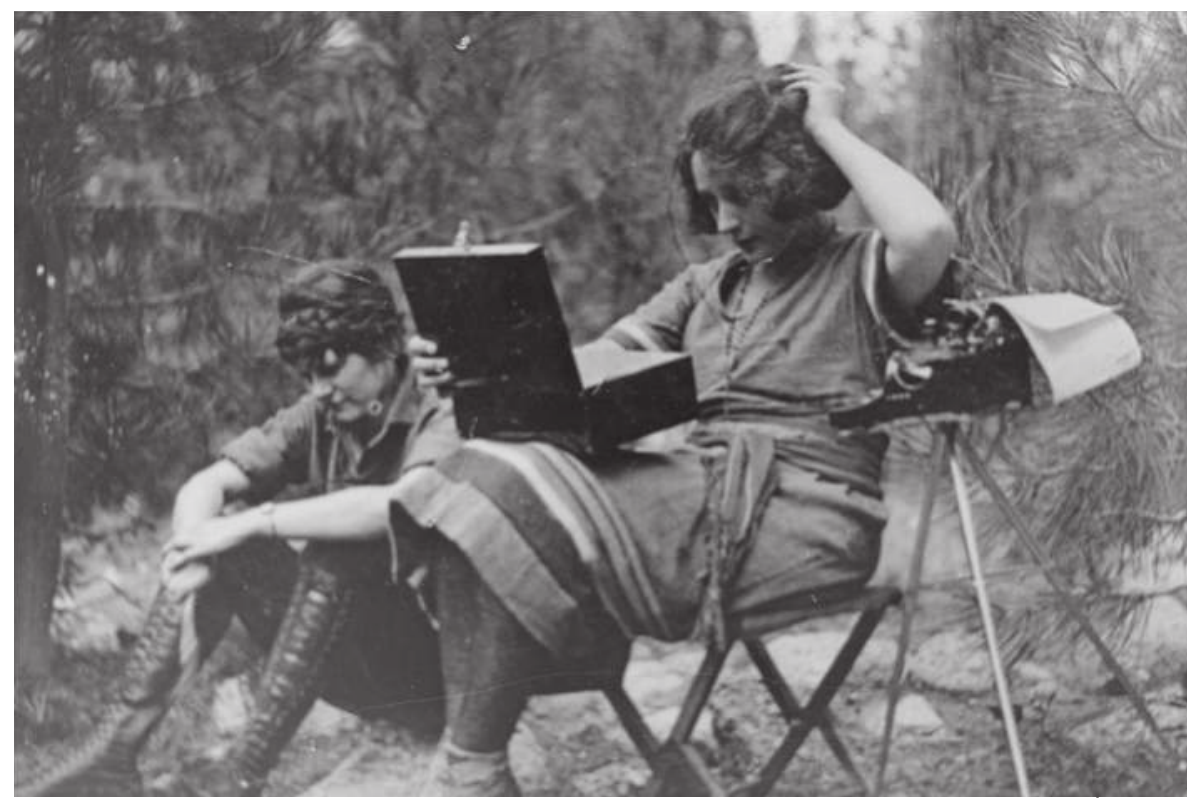

Fig. III.21: Nell Shipman preparing for playing Neeka in THE GIRL FROM GOD'S COUNTRY.

for so-called civilized society, which, in its turn, is saturated with dishonesty, competition, betrayal, and wealth acquired at the expense of others. With her sincerity and courage, however, Neeka helps her father and her beau and thus succeeds in making a difference to the morals of this white men's world. None of the documents available furnishes a clue about the blonde Marion's fate. But, to the extent that we learn about Neeka and her readiness to live and survive in the modern world, she seems to be a younger sister of Beach's Necia more than of Curwood's Nepese, who did not leave the wilderness. And, unlike Curwood and Shipman's joint creation of Dolores, Neeka does not seem want to return there: she heads far away with her lover, over the Pacific to Japan.

\section{“I packed my Toys and Moved North."}

In this casual sentence, which, in the memoirs, follows immediately after the "doors [...] slammed shut" remark cited above, there resonates much of what Nell Shipman continued to stand for and to believe in. First of all, she refused to throw in the towel, once again licked her wounds, and started over to pursue further her aspirations in filmmaking. To this end, she contacted-late in 1921 or early in 1922 - her co-actor from BACK TO GOD'S COUNTRY, Wellington Playter and his wife Dorothy, who ran a film "studio on the outskirts of Spokane, Washington, sometimes known as 'Minnehaha' because it was near a 
park of that name." Shipman's proposal to produce and shoot a film there was welcomed by the owners of the "mostly idle Studio". ${ }^{304}$ This was to be her next feature, THE GRUB-STAKE, produced in 1922 and released in 1923. Secondly, in this production, she once more employed her "toys", which I have identified as the genre of Northwest drama and the screen persona of the outdoors girl, the animal actors, cinematographer Joseph Walker, and her lover Bert Van Tuyle in the role of producer and co-director. ${ }^{305}$ And thirdly, she at last secured the Pacific Northwest for the outdoor settings:

The scenery was a spill-over of Yukon Territory as I remembered it when I acted in Alaska for Charlie Taylor and later when we journeyed to northern Alberta for the Calgary-financed BACK TO GOD'S COUNTRY. The mountains were high, the winters severe, the forests lush with towering timber and tangled brush; no neatly spaced park land as in the [Californian] Sierra but stuff to whack your lens into! THE GRUB-STAKE must be the Klondike, all the stories rolled into one, out-servicing Service, outbeaching Beach. ${ }^{306}$

Shipman may have already written an outline for the script before she arrived in Spokane in February; she developed it further during the few weeks before the start of the shooting in March 1922.307 She wrote another outdoors girl part for herself, revived various figures from her time in Alaska in her plot, and incorporated elements from her youth in Seattle as well as experiences from her time as a popular stage actress in the 1900s in her script, all subjects that I will discuss extensively. First, a discussion of the reception of the Shipman Co. in Spokane is in order here, because it clarifies some points about the production practices of Shipman and Van Tuyle, which heretofore could be predominantly inferred.

Thrilled by the promising arrival of a Hollywood star and "her" manager and director, Spokane newspapers chronicled the fundraising process and the progress of the production of THE GRUB-STAKE. On February 8, 1922, it was announced that the company planned to spend "at least $\$ 110,000$ in Spokane making its first picture", ${ }^{308}$ and on the $17^{\text {th }}$, it was stated that the official contract would be signed between Shipman's company and the production syndicate the following day, who deposited $\$ 135,000$ and $\$ 150,000$, respectively. The estimated budget for the first "super feature" had risen to $\$ 120,000$ and shooting was planned to start "in about two weeks". ${ }^{309}$ Apparently, Van Tuyle had also held up the prospect of making about fourteen films during their first year there, for which he would need thirteen staff assistants and about 75 extras. The reporter seemed to be unaware of the unrealistic nature of this production schedule, perhaps blinded by the prospect of the employment pos- 
sibilities it promised. On March 1, the names of the crew members and actors were provided, which included several previous collaborators of Shipman's, including cameraman Joe Walker, the animal trainer Felix "Doc" Graff, and the actors from THE GIRL FROM GOD'S COUNTRY Lillian Leighton, George Berrell, and Walt Whitman. ${ }^{310}$ For insiders too, it must have looked impressive, as these and other actors listed had substantial records in the film industry. ${ }^{311}$

One week after this, the newspaper reported that shooting had begun, which was then followed by a period of relative silence for six weeks. On the 19th of April rushes from THE GRUB-STAKE and portions of THE GIRL FROM GOD'S COUNTRY were shown at the Minnehaha Studio to an unexpected "crowd of 200 investors", apparently to everyone's satisfaction..$^{312}$ Two months later, the paper ran a full-page feature on the oldest actor in the crew, George Berrell, with stills from THE GRUB-STAKE in his part of Malamute Mike. ${ }^{313}$ On August 26, five and a half months after the beginning of the shooting, it was reported that a large part of the film had been completed, that the actors playing in the "dramatic sequences" had returned to Los Angeles, and that Nell Shipman, along with Van Tuyle and the animals, sojourned at Priest Lake, Idaho, in order to shoot the animal sequences. ${ }^{314}$

Nothing was said of the length of the shooting period, but there was mention of trouble with the financing syndicate: "Spokane investors raised about $\$ 117,000$," whereas, according to the article, \$140,000 would have been necessary to complete the film. Shipman and Van Tuyle had therefore taken over the financing and secured \$25,000 to complete "the animal stuff at Priest Lake" (and the editing, it must be assumed, which had to be done in Los Angeles, and for which Shipman ultimately would have to pawn what remained of her family heirlooms). The article concluded with the way in which the profits would be shared: half going to Shipman and Van Tuyle (who were reported to have been working without a salary), a quarter to the special investors, and a quarter to the original stockholders. This division was then adjusted, according to an article of December 18: the original stockholders would no longer share in the profits - "if any"- but would instead merely have their money refunded, because they were said to have "failed to raise the amount specified in the original contract". ${ }^{315}$ Here, it was not disclosed who had advanced this idea. The expenditure of the production was now established as "about $\$ 120,000$ " and it was "expected to 'gross' $\$ 600,000$ " in total. This information was provided by J.H.C. Reynolds, an investor in THE GRUB-STAKE as well as the treasurer of the Nell Shipman Productions Syndicate, who had visited Van Tuyle and Shipman in New York where they were trying to sell the film. Reynolds further informed readers that the film had been cut down from 55,000 feet of original material to 11,000 feet and then, in three more steps, to $7,000 .^{316}$ Moreover, Shipman and Van Tuyle were expected back in Spokane after the holidays, to start work 
on a new picture. On January 8, finally, the paper broke the news that the film had been sold to a states' rights distributor.

If this sounds like a happy ending, it was not. The financial problems precipitated a clash not only with the stockholders but also with the actors, who had not been paid for the final two weeks of work. Shipman justified not doing so in this way:

They'd had a long engagement, been well-quartered and paid top salaries for their work so I did not feel guilt over the two weeks owed. Soon as we'd got the picture edited and its distribution arranged we'd collect a sizeable advance and pay off everybody. This was pretty much the way BACK TO GOD'S COUNTRY ended its shooting schedule, the Company broke and the animal sequences still to be made. ${ }^{317}$

396 What she either forgot or preferred not to mention is that faith in Van Tuyle was faltering, not only among the actors who had witnessed the schedule and financing problems with THE GIRL FROM GOD'S COUNTRY, but also among the Spokane backers. According to a letter to the editor written by Reynolds and printed in The Spokesman-Review, the defamatory article (referred to above) had been preceded by "warning letters from Los Angeles" that had reached "several prominent people in Spokane before Mr. Van Tuyle started operations here", and in response to which the latter never had given "satisfactory explanations". "This information from Los Angeles was the real cause of the inability of the finance company to secure sufficient funds for to complete the picture," Reynolds disclosed. ${ }^{318}$ This would imply that, from the beginning, there had been seeds of caution and suspicion, that neither Van Tuyle nor Shipman had known how to allay adequately. In her novel Abandoned Trails, Shipman suggests that they chose the strategy of denial:

A Los Angeles enemy caused the circulation of a scurrilous bit of libel; a "page," supposedly copied from an entirely fictitious Movie Journal, privately printed and distributed. There was no tracing to its source and the thing, widely spread, did untold damage. ${ }^{319}$

After the picture's completion, then, Reynolds too charged Van Tuyle with mismanagement, inefficiency, and the waste of funds, and he added that further "evidence of mistakes can easily be had from every member of the cast and about 90 percent of the staff." ${ }^{20}$ His confirmation that the suspicion was wellfounded is all the more remarkable, as he was one of the people who had consistently acted against it, most notably by filling the office of treasurer of the financing syndicate and by privately providing part of the $\$ 25,000$ additional 
funding to initiate the film's production. It seems that he was also contented with the film as it had turned out, because he assured readers: "Notwithstanding all this, the scenery, photography, animals and the acting of Miss Shipman and others, mark the picture as a superproduction." ${ }^{21}$ In June of that year, the treasurer let Spokane know that the "financial difficulties of the film producers were likely to be adjusted." ${ }^{22}$ Here he said to have heard (!) that the film had been in distribution since "about" March 1, but also remarked that he had not yet received any figures from Van Tuyle about how it was doing at the box office. (It was released on February 18, 1923 in Portland and Spokane, where it was held over for a second week.) ${ }^{323}$ Although still expressing his full confidence in a good outcome, Reynolds rebuked Van Tuyle for his evasiveness in providing financial data and for his inflexible attitude towards the stockholders, who had not accepted his decree that they would be reimbursed their investment instead of sharing in the profits. The sum total of production costs by then was estimated at \$150,000-the highest figure mentioned in the entire coverage.

A surprisingly unflattering picture of Van Tuyle emerges from this coverage, a picture that does not accord with Shipman's depiction of his personality and attitude in her "factual" memoirs yet resembles, in several respects, the Van Tuyle character, Dirk, in her (semi)-fictional novel Abandoned Trails. In the memoirs, precisely in the context of the making of THE GRUB-STAKE, she states that she considered him to be

the Top Top Banana. Bert Van Tuyle deserved the title. Here was a man! A ready laugh, an ability to face down discomforts and the anthills of problems built up in all moving picture productions. [...] He was capable and owned a pair of hands able to build things, as my father built them. [...] He had small patience with foibles and fusses. The big laugh, the gay backslap: "Forget it and let's make motion pictures! Let's get going!" was his cry. [...] Such was Bert, very much loved, admired, obeyed for many moons. ${ }^{324}$

From the coverage in The Spokane-Review, however, he seemed to be someone capable of offending and repelling even the most devoted and benevolent business associate. In Abandoned Trails, Shipman portrays Joyce's partner in life and in business accordingly:

[T] he woman was far from being blind to his mistakes, his tyranny and the Dutch obstinacy which, time and again, brought them to the brink of ruin. (...) Three times he had come to an impasse in the business relations of the companies formed to finance Joyce's pictures and three 
times she had stood by him, against the others and, in the end, thrown up the sponge; lost everything for which she toiled and walked out, empty-handed.

It may have been love, or its finer facet-loyalty. Perhaps again, it was that dear bought Pride which would not admit poor judgment. ${ }^{325}$

The tyranny mentioned here related to their professional skills, beliefs, and positions in filmmaking, as is demarcated in this dialogue:

[He:] "Before we start shooting we've got to settle, once and for all, who is who. There was trouble all through the last picture. A scene is all set, the script-your own, which you've written, so you ought to know what you want! - calls for such and such action. I have the actors lined up, rehearsed, everything ready. Then you open up; want this changed, some398 t thing else done differently. It makes me look-well, like a heel. I want to know, right now, before we start on this Spokane picture, do I direct or do I not?"

[She:] "You do. You always have. You know that. But..." she clasped her hands, nervously. "I love it so. The story, the producing of it; seeing it come to life. I can't keep off. I know the typed words say this and that but when the actors are there, working it out bit by bit, they seem like clay. I've got to mold. I must make changes. Why, I'd die if I saw the thing photographed any other way, even if I do have to alter my written ideas. It isn't doubting your ability or judgement. You must know that!" ${ }^{26}$

By this point in the novel, Shipman had made it clear that the woman indeed doubted his ability, lying to her partner only so as not to send him into another fit of rage. She acted accordingly:

Despite all her promises and the frequent internecine warfare it caused, Joyce continued to intrude upon the picture's direction. Once on the set, (...) she seemed to throw discretion to the winds and consider only the work in hand. It bred an unhealthy state of turmoil which was rapidly transmitted to the cast and, from them, via gossipy channels, to the stockholders. "The picture," it was predicted, "will never be finished." ${ }^{327}$

The seeds of suspicion, then, were not only nourished by problems with the budget and the schedule, but also by the atmosphere on the set and the quarrels between the two "Top Bananas". Their unresolved work hierarchy is discernible still today from the convoluted opening credit titles of the print, which read as follows: "Bert van Tuyle presents NELL SHIPMAN in [...] Writ- 
ten by Miss Shipman. Directed by Bert van Tuyle, in collaboration with the author."

There are several points to be drawn from the agreement between the Spokane paper coverage and Shipman's fictionalization of her experiences. First, Van Tuyle's inveterate lack of diplomacy and flexibility affected his relations with external business partners and internal associates alike: Shipman was also subjected to this. Secondly, Van Tuyle's personality and business attitude were an important factor in the downfall of the various Nell Shipman film producing companies, regardless of whether Shipman was willing in retrospect to avow to it or not. Van Tuyle's intentions may not have been dishonest or malicious, but he lacked the tact and the finesse to reach sensitive decisions without giving people the feeling that they were being misled or cheated. Thirdly, and this may be the most important point, Nell Shipman and Bert Van Tuyle had entirely different, if not opposing, conceptions of film direction. For him, it was a function of control and an expression of status, while, for her, it was, as we have seen and as the dialogue further attests to, a function in the service of the magic between acting and cinematography. Even aside from issues of male dominance or personal competition, as Shipman represents them, such different conceptions could not but clash, if they are considered from a perspective of how production matters affect aesthetics. After all, the particular vividness of the imagery in Shipman's films, still perceptible today, results precisely from her specific working methods. And fourthly, albeit not blind to the record of conflicts and to Van Tuyle's conduct, Shipman mostly blamed herself for the consequences. In her fictional account, it was she who failed to admit "poor" judgment, who questioned the man's ability to direct films, who forgot about "discretion" on the set and hence occasioned the turmoil. It is important to notice this blaming of herself, because she also did so in her factual recounts. Hence, it can be singled out as a recurrent trope in the stories of her past, one that has, to my mind, a dual function. Inasmuch as Shipman portrays herself as a victim, the offender was not Van Tuyle and his personality but her own misjudgments and her inability to counteract them. To blame herself is simultaneously to render her as co-responsible, thus enabling her to illustrate her own views about filmmaking. Bearing this dual function in mind may shed a different light on her account of the further "events" that eventuated in the failure of THE GRUB-STAKE to fulfill the promise of its title.

THE GRUB-STAKE never provided the grub for the Minnehaha Studios and the Nell Shipman Company for which it had been undertaken so energetically. This failure flowed only indirectly from the way in which the film was produced and had nothing at all to do with its inherent qualities, such as genre or aesthetics. If Shipman may be believed, it was even unrelated to Van Tuyle's propensities as a manager and a producer. Having come down sick, he stayed 
in the hotel while she attended the screening of the film for potential distributors. ${ }^{328}$ After the screening, no one seemed to show any interest. Therefore, they sold the film to the first distributor to call, Fred Warren, whose previous company had released THE GIRL FROM GOD'S COUNTRY, and who now ran the American Releasing Corporation.

That same afternoon more calls came to the Astor from every one of the major distributors, the best offer from Metro. They liked the picture, thought it saleable, were surprised and, I thought, miffed to find it already sold. "I thought you didn't like it," I explained. "You didn't say..." "Don't be silly, Sweetie, we never say anything at a Trade showing. You must know that!" 329

Metro's was "the best offer", according to Shipman, because it entailed an 400 | advance with which to pay the unsettled bills, whereas the American Releasing Corporation only offered a contract on a percentage basis. Thus, it was her inexperience in sales that caused the film to go to the wrong distributor. However, the difficulty with the distributor was not that it did not offer an advance, but that it went into bankruptcy, as Shipman would learn in January 1924, apparently before they had received any of the revenues since its release in February the previous year (thus explaining Van Tuyle's silence about this to the backers in Spokane: he himself probably lacked the information and the money). This fact, however, Shipman relayed only in the context of another anecdote told 36 pages further on in her memoirs. Once again, the trope of self-blame with its twofold rationale was at work. It allowed her to point out that she had been able to produce a saleable print.

\section{THE GRUB-STAKE as Nell Shipman's Magnum Opus}

Perhaps in response to the assessment of her previous film as a Northwest yarn only to a certain extent, Shipman provided THE GRUB-STAKE with an explanatory subtitle - "A Tale of the Klondike"-and expanded the Northwest drama to encompass more than half of the story-time. However, differently than did Beach or Curwood in their stories, Shipman mixed in other types of melodrama, most notably a more city-based and a more sensational variety of it, as they are manifest in THE GIRL FROM GOD'S COUNTRY and in SOMETHING NEW, respectively. The first half-hour of the 88 minute film centers on a white-slavery plot largely set in the towns of Seattle, Washington, and Dawson City, Alaska, and in interior spaces such as an art studio and a dance hall. Though of the Pacific Northwest by geography, the events and crises of this 
plotline are situated in urban environments. This plotline is concluded with a sequence that lasts twelve minutes, in which events simultaneously occur at different locations depicted in parallel edited scenes, marking the transition to the outdoor action plotline, the dance hall sequence. The more strictly Northwest part of the film, with its action and romance plotlines, runs for the following 40 minutes of screen time, and is set primarily outdoors, on snowy trails in a forest, in a lush valley, and in and around rustic cabins in remote wilderness locales. This part concludes with a second sequence with parallel edited events, which, due to the intrepidity of the heroine and its cliff-hanging scene, is reminiscent of a serial installment rather than a Northwest drama. The Northwest genre, in the strict sense, is finally invoked once again in the brief scene of the happy ending, lasting less than one minute, set in the proverbial hut on the heath, and that closes off the romance plotline: the happy family sequence.

Despite its action-driven narrative and episodic structure, and its three plotlines, the plot's construction is solid and clear. We are shown, in order, a poor girl seeking to improve her situation; an older rich man tricking her into marriage but only so as to exploit her as a dance hall hostess; the girl escaping with a dog-sled but getting lost in the wilderness; the girl first afraid but then cared for and accommodated by the wilderness' inhabitants; the girl being retrieved by her soon-to-be lover but finding herself in the vexed position of being married to a man she does not love; the girl facing an arrest warrant for dog theft although what she had taken from her counterfeit husband was only what he was unwilling to give despite having promised it to her; and, finally, the girl managing to get rid of her husband and liberating herself for the true love of her life. Already from this scanty synopsis, it may be clear that the story hinges on "things" and "people" not being what they initially seem or pretend to be. Central to the plot's construction is the fact that the actions are motivated by the perceptions the characters have of one another, and by the changes in this perception resulting from their doings or from the interference of others. In my analysis, THE GRUB-STAKE is a film about appearances and perceptions and I will explore in the following how these issues pervade the film's construction at every level.

Thanks to its setting, the film largely comes across as Northwest drama. The gold-seekers territory is adorned with captions such as "the Lost Valley" and "at the end of the rainbow", situating the wilderness part of the story, in line with the generic conventions, in the world of literary fantasy. In the intertitles, moreover, not only the place but also the time of the action is indicated: "As the old last Century made way for the young Twentieth, there loomed to the north of us a land of golden promise...."- -ALASKA!" Set a quarter of a century back in time, THE GRUB-STAKE presents itself as Northwest drama with 
a historical dimension and simultaneously indulges its overall fictional and generic core. ${ }^{330}$

In terms of the film's production, Shipman pursued the usual strategy of authentication. The Seattle and Dawson City interiors were shot in the Minnehaha Studios in Spokane, Washington, but the winter and spring scenes were filmed on location at the Little Pend Oreille River, Tiger, and Ione, Washington, and the summer scenes around Priest Lake, Idaho. ${ }^{331}$ Shipman did the stunt work herself, included a choice of animals to co-act with her, and selected actors who "looked their parts". In addition, she drew upon observations made in her youth and upon her recollections of people she had known.

The characters of THE GRUB-STAKE include the set of types common to the genre. Thanks to the film's emphasis on appearances and perception, however, these figures come across as much less predictable and more multi-faceted than their models in Beach's and Curwood's stories. This applies most nota402 bly to the outdoors girl Faith Diggs, the villain-in-disguise Mark Leroy, and to the "hard-boiled He-woman", Dawson Kate. Supporting characters, such as the Royal Mounted Police Officer, the villain's Chinese valet, the tragicomic Malamute Mike, the old Skipper, and the lover Jeb are more one-dimensional by comparison. Yet a closer look reveals that they too have been given traits or undergo transformations that stretch their generic typification. It is in the similarities with and the variations on the generic types in THE GRUB-STAKE that Shipman's idiosyncrasies in the application of Northwest drama can be discerned.

Compared to Curwood's Royal Mounted Police Officers, Shipman's Mountie does arrive in time but, without giving it a moment's thought, sides with the villain-in-disguise, Mark Leroy, throughout most of the film. The character of the Mountie represents the self-evident alliance of the law with masculine power, yet Shipman's plot grants him the opportunity to change his opinion on the basis of his own observations in the scene in which he spots the approaching party of Leroy, his henchmen, and their hostage Malamute Mike. Mike shouts to the Mountie, "Claim jumpers! Claim jumpers!" after which he is shot by Leroy. "That was murder, Leroy" the officer tells the now-exposed imposter. The Mountie plays no role in the concluding cliffhanger sequence and the rescue of the girl, which is indeed in line with Curwood's treatment of the type as useless when law enforcement would really matter. Shipman, nonetheless, inserts a final shot of him at the end of the sequence, which shows him with Malamute Mike in his arms, who, unexpectedly surviving, now asks him: "Did we lick' em?” The Mountie nods and gives him a friendly smile. He has learned that his perception was amiss and that truth and justice can be on the side of those whom he, taking things at face value, would believe to be in the wrong. 
The Chinese valet also undergoes a change, but, in the opposite direction, that is to say, from relatively sympathetic to plainly sly and murderous. Once again, this has to do with perception. The Chinese valet's big scene comes at the point when Faith is in her Seattle home with the Skipper confronting their hopeless situation. The scene is built upon an accumulation of things turning out differently than what they had initially seemed to be, engendering a series of moments of comedy and relief in alternation. In this scene, Faith expects the landlord, who will collect the rent that she cannot pay, but after having opened the door, she sees a bulky sack and, behind it, the Chinese valet. This is already in itself a relief for her, yet believing that the sack contains dirty laundry - another thing that differs from what it seems-she considers it "a gift from heaven". She bursts into elated laughter, and jokes: "I guess John is going to celebrate Chinee New Year and wants me to do his work", which is

Fig. III.22: Characters and items turn out different than they first seemed in THE GRUB-STAKE. Here is the Chinese valet with the bulky sack, which does not contain dirty laundry, but part of the grubstake.

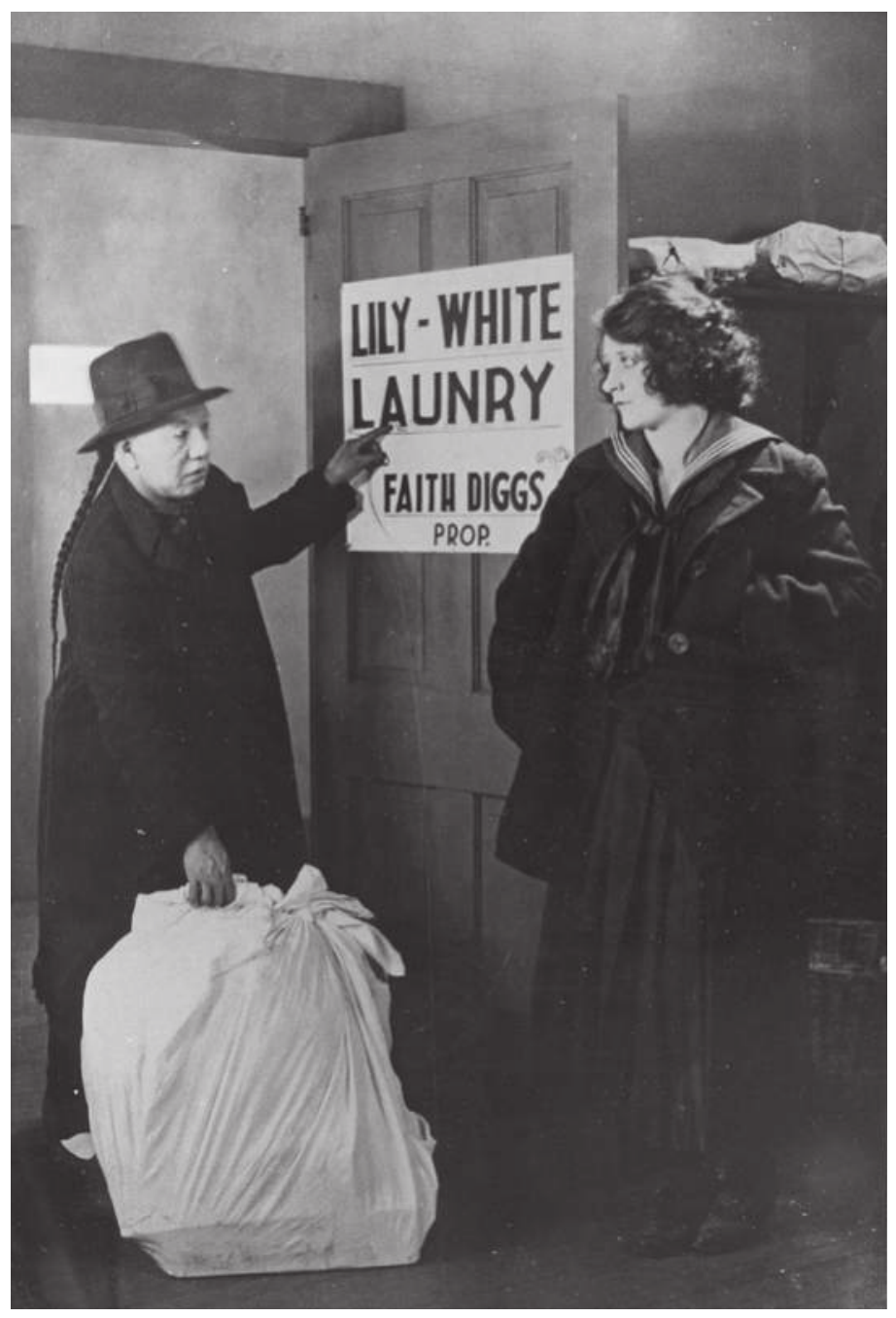


answered affirmatively by the Chinese man with nods and smiles. Her comment is a response to his words as conveyed by the preceding intertitle, which shows four scattered Chinese ideograms surrounded with exclamation and question marks. The effect of this intertitle is very comical, for it graphically expresses an immigrant's attempt to communicate and also, by its punctuation, his own sense of irony about his language not being understood. Faith's joking interpretation of the Chinese man's words, moreover, evinces an awareness of his cultural background and suggests some solidarity with one another's social positions, inasmuch as they both do the dirty work for other people. Her laughter, in this scene, is not at his expense, although for his part he can only be laughing at her (supposing that she is aware of the contents of the sack), yet it does not come across that way. The scene then proceeds with Faith's discovery of what the sack really contains: a beautiful leather coat as part of the grubstake that she had requested of Leroy. This is another item that 404 is different from what it first had seemed to be; and it marks the turning point in the plot in which Faith begins to trust Leroy.

In the remainder of the film, the Chinese valet's actions are reduced to carrying out his master's order to poison the Skipper, in much the same way how, for instance, the Inuit servant in BACK TO GOD's COUNTRY was ordered by Rydal to kill Peter. Why Shipman chose an Asian character may have had to do with authentication, in terms of both the narration and the production of the film. There was a substantial Asian immigrant population at the turn of the century living along the Pacific coast (as the Chinese character in BACK TO GOD'S COUNTRY also suggests). Thus, the use of the name John, which was a slang term for a Chinese man, as well as the visual invocation of the stereotype of the Chinese launderer, may have been inspired by observations from Shipman's youth. Furthermore, Shipman knew the actor, Ah Wing, also known as Ah Fong, from her Vitagraph film THE GIRL FROM BEYOND, and may have written the part with him in mind. None of this, however, prevented her from rendering his part in a fashion that was, by and large, as stereotyped and racist as the way in which the Mexican villain in SOMETHING NEW or the Inuits in Curwood's tales were depicted. Because Faith's relieved laughter with the Chinese valet in THE GRUB-STAKE is embedded in a scene in which nothing is what it seems and which hinges on, as Trusky writes, "a business even dirtier than the laundry we expect," $33^{2}$ the potential of Faith's joke and the humorous intertitle to expose racism is largely neutralized.

Malamute Mike does not undergo a change but remains the same odd character throughout the film. What changes, however, is the other characters' and the spectators' perception of him. His physical demeanor, his dreamy persistence, and his frequent bouts of drunkenness lend his presence a comic flavor, as if he were the local loony tolerated by everyone but taken seriously 
by no one. Not only does he recall Beach's clumsy but ultimately fortunate gold-digger character "No Creek Lee", he also has a likeness of the man whom Shipman had met on the boat from Fairbanks back to Seattle, at the time when Charles Taylor wrote "The Girl from Alaska" for her:

There were two passengers who did not play the round game on board. [...] The other was Malamute Mike - the name for real, not made upand he was crazy too. He dragged a length of rope on the end of which he was certain was his lead sled dog. "Cummon, now you malamute!" he'd say, tugging on his empty rope. Pranksters thought it fun to tie the rope to a handy rail. I made it my business to untie it whenever I could. Then I'd have a long talk with Mike about his malamute and his gold mine. This was the first treasure to be prospected, located and someday, mined by a would-be chronicler of malamutes and gold mines. ${ }^{333}$

Shipman's sympathy and compassion for this man and his lost malamute lives on in the character as she had written and filmed it and that the actor, George Berrell, was to embody on-screen, looking like a toothless bum, and carrying his ever-present rope. It becomes apparent, for instance, in the manner in which the character is introduced. In the dance hall, where he, as usual, stands boasting of his mine and his dog, other visitors do not respond with aggression or harassment but with amused teasing and eventually by petting his invisible dog. It also becomes apparent in Walker's double-exposure shot included in this scene. This is a medium close-up of Mike's legs into which his all-white dog is blended as if it really were there, representing the man's vision. And, last but not least, Shipman's empathy with the character of Malamute Mike is evident in the narrative functions she assigned to him in her plot. For one thing, she has him, precisely by virtue of his drunkenness and his distracted attitude, prevent the Skipper from being poisoned by the Chinese valet and lead him and Faith on the trail away from Leroy; thus, enabling the outdoor action plot to commence. Furthermore, he is the one who seeks help for the Skipper and then for Faith, that is to say, who leads Jeb to them, bringing the lovers together and enabling the romance plotline to unfold. Hence, he is like Laddie in SOMETHING NEW: unimportant at first sight, but indispensable to major twists and turns in the plot when considered attentively. Finally, it is Malamute Mike who brings about a general change of mind and situation, for the plot fully vindicates his activities as a gold-prospector. For two-thirds of the film, skepticism about his claims predominates among the characters, expressed most notably by Dawson Kate, who admits: "I fell for his 'lost mine' story. He's drinking up the last of the grub-stake I give him." However, in the final half-hour of the film, both malamute and mine are returned 


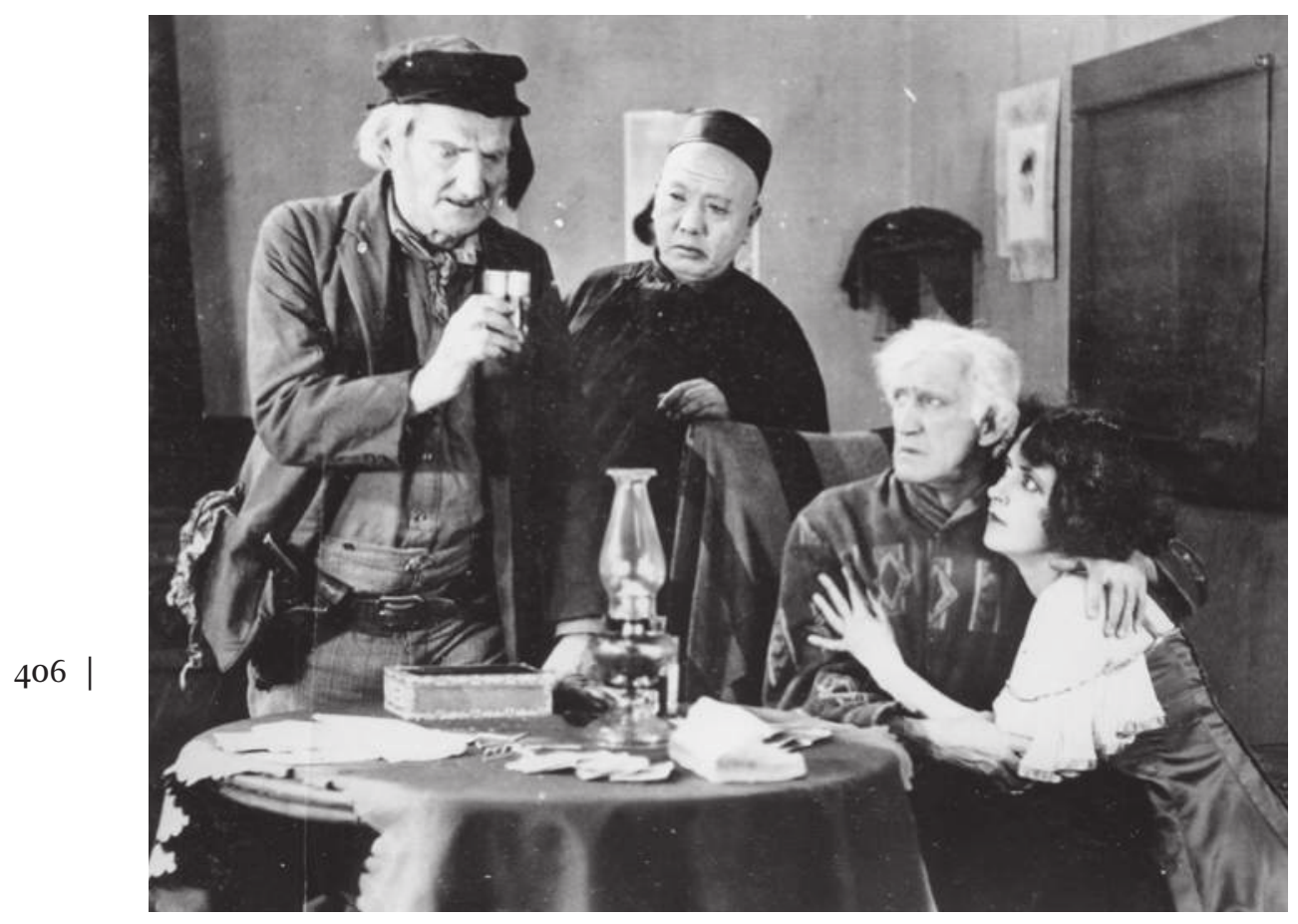

Fig. III.23: Malamute Mike prevents the Skipper from being poisoned by the Chinese valet.

to him, whereby the others are prompted to avow how wrong their perception of him had been.

The character of Skipper Diggs corresponds to the Northwest drama's fatherly figure who is benevolent but of little help in solving the girl's problems. As in Curwood's stories, he is ineffective not just due to physical feebleness, but first and foremost, because of his blindness regarding, and his incapability to cope with, the issues of sexual harassment with which young women were confronted. ${ }^{334}$ But, although he is a paternal figure, he might as well be the girl's "grandpa", as Shipman would consistently refer to him in her memoirs. ${ }^{335}$ His age, behavior, and social status as a retired sailor, consolidate this, and the filmic text seems to refuse to clarify whether he is her father or not. Even if Shipman unintentionally leaves the relationship vague, it fits this film astonishingly well as yet another instance of questioning appearances of a character. However, unlike the father figures in Curwood's animal stories, and very much like the father in Shipman's THE GIRL FROM GOD'S COUNTRY, the Skipper survives the villain's schemes against him. In THE GRUB-STAKE, 
moreover, Shipman's script takes his survival even a step further, allowing him a love of his own, a plot element to which I shall return in the context of my discussion of the character of Dawson Kate.

According to Shipman, the character of Jeb, the hero-lover, was inspired by an artist she had known in Fairbanks; but, in terms of her oeuvre, he brings to mind the writer-lover in BACK TO GOD'S COUNTRY. His artistic aspirations can be read as another sign of THE GRUB-STAKE's preoccupation with changing and varying perceptions. Shipman had envisioned "the artist-lead" to "be strong, protective, gentle and tall," ${ }^{36}$ and the actor, Hugh Thompson, indeed "looks it", while he also creates one drawing in the film, of Faith together with Brownie, and treats animals gently. His heroic actions, however, are almost as restricted as those of his predecessor: he strolls through the woods and the valley to find the girl and the gold mine, fights Leroy's men with his bare fists, kills the Chinese valet, and grips the arm of the girl while she hangs from the precipice. To be sure, "stalwart Jeb" is only briefly incapacitated in the action (gunned down by the villain), and at no point does he need nursing by the girl or to be saved by her; but he does not become more protective or heroic than this. And, as usual in a Curwood or Shipman tale, he does not rescue the girl outright or entirely by himself.

The most salient difference from Curwood's Peter, is that Shipman has given her Jeb a social background, as the son of a single parent working parttime as a dance hall hostess. If this sounds more like Beach's approach to his characters, it is not so with respect to the unconventionality of the background, which is presented in a matter-of-fact fashion. Unlike Beach's Meade, Jeb does not undergo a mental change prior to the inevitable Northwest drama ending in which the girl's "past" turns out to pose no problem and the primacy of heterosexual love is restored. What is more, the necessity for such a change of mind on his part is thwarted each time by the interference of Faith, who, to begin with, tells a lie so that Jeb may continue to believe his mother to be the Dawson postmistress, and then "solves" the problem of her already being married by "accidentally" killing her husband. In THE GRUB-STAKE Shipman made the hero-lover into a rather one-dimensional supporting character, as in Curwood's animal tales. ${ }^{337}$

By far, the most complex figure among the supporting characters in THE GRUB-STAKE is Dawson Kate. Her social position recalls that of Beach's Native American Alluna; they are both clever, respected, tough women, caring mothers loved by their children, but in the Golden West nonetheless confined to the sexual service of men, whether unpaid as a Native American concubine or paid as a dance hall hostess. Shipman mentions Dawson Kate as another one of the real-life persons from her time in Alaska who "came back into her plot", and she adorns her, without clarifying further, with the sobriquet "Heart-of-Gold 
in dance hall finery". ${ }^{33^{8}}$ In the name, there resonates the proverbial Klondike Kate, an epithet used by several Katherines and Kathleens from Dawson, including a vaudeville dancer who was involved with Alexander Pantages in the early 190os, Kathleen Eloisa Rockwell. ${ }^{339}$ Legend has it that this woman grubstaked Pantages so that he could start his vaudeville chain, but that he married another woman and failed to return the money. Their attachment, reputedly, ended about 1905 in a legal suit for breach of promise. ${ }^{340}$ In her Dawson Kate character, Shipman revives the employment in the turn-of-thecentury entertainment business of the grubstaking or Heart-of-Gold motif.

Shipman's script and film provides the character of Dawson Kate with two spatially and temporally separate appearances, which can nonetheless be summarized in one line: she is a single working parent. During the winters, she works in the city, and, when the weather warms up, she returns to the cabin in the woods to manage her adult son's household and to care for 408 anyone who comes by in need of help. Nothing is revealed about her past: in what conditions she bore her son, whether she had been unmarried, divorced, or widowed. She works, moreover, not just in order to earn a living, but also in order to send her son to art school-motives stemming both from motherly love and from a free spirit. Only the nature of her work as a dance hall hostess is presented, to a certain extent, as a problem, for she hides it from her son and pretends instead to be employed as a postmistress. But, in good Northwest drama tradition, the ending resolves all problems, this one not excluded, with the help of true love.

Dawson Kate's character acquires new dimensions in each of the three plotlines of the film. In the dance hall scenes, she is a sincere but dyed-inthe-wool and somewhat vulgar woman; in the outdoor action scenes at and around the cabin in the woods, she appears as a heartwarming and caring yet also jocose mother figure. The characterization with which she, in the dance hall scenes, is initially introduced, "Dawson Kate, hard-boiled He-woman", applies most pertinently to the penultimate cliff-hanger sequence in which she is unmasked as a liar (although they are but white lies), ${ }^{341}$ tells Faith she cannot have Jeb, and holds off Leroy's cohorts to protect her son. Lillian Leighton, at the time a reputable character actress with long experience, plays the part with the apt mimicry, bodily persuasiveness, and comic sense necessary to fill the character's full complexity. Even today, the imagery still attests to how fond the actress and the filmmaker(s) were of the true-to-life character of Dawson Kate. ${ }^{342}$ A closer look at some of the scenes mentioned may illuminate the details of acting and mise-en-scène that made this character the embodiment of the central themes of the film, appearances and perception, and, in line with this, observation. The actress' expression and body language throughout the dance hall scenes lend the character a streetwise air; but her 


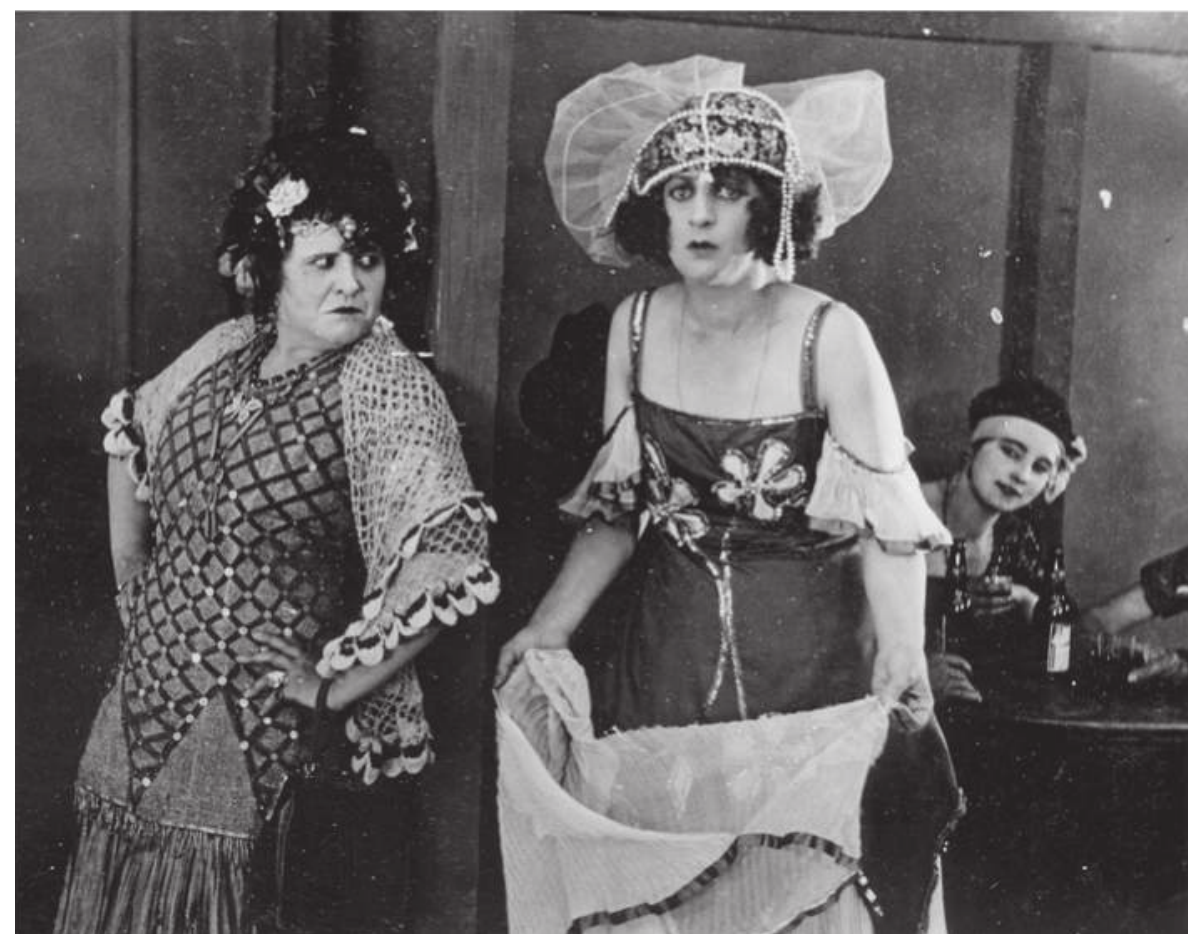

Fig. III.24: Dawson Kate reveals to Faith and to the viewers of the film that the dance hall provides the cover for gambling and prostitution.

narrative function is to observe and comment on other customers' behavior, thus revealing to viewers, and to Faith, the gambling and prostitution for which the dance hall provides a cover. The tone of her dialogue lines is sardonic (when speaking of the object of her sharp eye and tongue) and candid (when directly addressing the person). The contrast between the knowing Kate and the naïve Faith is played out to the extreme in the scenes in which the two are together, but, towards the end of the sequence, it vanishes and is replaced by a mutual confidence and understanding. Faith has come to share Kate's perception and view of things, and translates this into action: she decides to escape.

In a second introduction, the film presents us a Kate entirely different from the dance hall hostess with her talent for observation and for getting to the heart of the matter. At the cottage in the woods, she is a self-ironic, goodhumored, and warmhearted caretaker of a household, her son, and guests. The warmth and mirth that marks the relation between mother and son, seems to derive from Shipman's own carefree and playful bond with her son Barry, which highlighted creativity and humor and was less concerned with doing the chores or finishing homework for school. ${ }^{343}$

In the cliff-hanger sequence towards the end of the film, Kate has taken 
on the task of defending Mike's claim, a notice pinned to a tree, against the claim jumpers. She observes one of Leroy's henchmen trying to steal the note and fires her gun at him. A counter shot shows the man hit in his arm and running off, and a concluding shot shows Kate again, expressing anger, pugnacity, and, with her arms akimbo again, satisfaction about her solo action and achievement. All shots of her are frontal, and, by the zeal in her facial and bodily expressions, she communicates to viewers her pleasure in her successful action, even if it remains unnoticed by other characters in the film. A little later, Kate is shown leaving the bushes and running towards Jeb, who is fighting one of Leroy's men. The others stand by as if watching a wrestling match, and Kate capitalizes on the situation by covering them with her pistol. After awhile, she is shown cheering on Jeb while still holding the other men covered. Her cheering, however, has a comical effect, for she thereby joins the audience transfixed by the fight. Her next action is to order Jeb to "go 410 | to the girl," who, followed by Leroy, is climbing up the mountain side. From this point on, the focus of the group's attention is no longer the men's fight, but the girl's climbing up the mountain to their right and then her dangling from the edge at great height. Kate ceases to hold the men at bay (she puts the gun back in the holster) and joins them in their function as a public watching the sensational action. A frenzied crowd, they cheer on Faith and Jeb on the mountain's edge. Thus, Dawson Kate is restored to her narrative function of observing other people's behavior. The difference is that now her responses to it, unlike the dance hall scenes, are not addressed to diegetic characters but are acted straight into the camera and hence address us, the film's spectators. Critical perception is no longer conveyed, but plain emotional involvement. In the six shots of Kate dispersed throughout the climax of the action, she displays a range of emotional responses: fear and panic, excitement and relief, and all of it in an exalted, now comic, now dramatic mode. So, much like the diegetic Writing Woman in SOMETHING NEW, Dawson Kate abandons her astute observations just as soon as she becomes a character in sensational melodrama; yet, like her writing predecessor, she does not forego a knowing wink that calls forth an apperceptive awareness on the part of the audience. It is true that Shipman did not give her Dawson Kate character an extra-diegetic part; but, had she done so, it might well have been the one of the Perceptive Woman.

In the scenes in which Kate nurses the Skipper, it becomes more and more obvious that they are growing to like each other greatly. The initiative in this is never his; it is always Kate who pampers him. When they are shown fondly embracing each other, after the climax of the cliff-hanger scene, it therefore looks as though their union is beneficial to her; much as in Faith's case, the alliance enables her to escape from providing sexual services to men and to 
follow her own heart and yearnings instead. The final sequence of the film attests to the parallel. Preceded and followed by a series of shots of single (!) parent animals with offspring, two medium shots of the Skipper and Kate are counter-cut with one medium long shot of Faith and Jeb standing by a cradle. The first shot shows the Skipper alone, seated in a chair and knitting, a humorous reversal of the closing shots of BACK TO GOD'S COUNTRY in which Dolores embroiders. From his left, a hand enters the frame and pats his arm. The second medium shot includes in its frame the owner of the hand, Kate, who nudges her neighbor with her elbow and nods towards something in front of her, miming a "look at that!" As is consistent with the character of Kate, the emphasis is on her perceptions, and the following shot shows what she sees: Faith and Jeb by the cradle and looking down into it. Despite what Kay Armatage maintains, I have not found a pan in the sequence, nor are the two shots the ending shots, and, hence, the four human characters are not "joined together in one space". ${ }^{344}$ Rather, the human characters appear as separate couples, and each is immersed in her or his own perception of things. The suggestion of what Armatage calls "the ideal family", that is to say, a father, a mother, children, and grandchild, is further undercut by the embedding of these shots in the imagery of single parent animals, which refers back, with a wink and with sympathy, to Kate's social status. To the degree that this closing sequence could be considered to represent Shipman's ideal family, it would not be the conventional family triangle but an extended and unruly variant of it, encompassing multiple histories, generations, species, love bonds, and points of view. But, given the formulaic heterosexual happy ending inherent to the genre of Northwest drama, I would hesitate to read the sequence as representing Shipman's view of things. What I would instead highlight in this final constellation is what is added to the formula: that two of the supporting characters, the Skipper and Dawson Kate, were allowed a love and a happiness of their own.

THE GRUB-STAKE offers a multitude of animal characters and agency, and also a bit of animal discourse, albeit in a different manner than BACK TO GOD'S COUNTRY or A BEAR, A BOY AND A DOG. The animal characters include the white Malamute Yukon (Shipman's dog Lady), Brownie (Shipman's now grown-up bear), and a myriad of unnamed sled-dogs, raccoons, coyotes, beavers, marmots, badgers, porcupines, deer, skunks, and owls. To begin with the latter: they all live in the Lost Valley where Faith arrives after getting lost in the woods, or, as the narrator tells us: "For years, Dame Nature has ruled the Lost Valley and her forest children have lived in perfect peace, unmolested and unafraid." What they are unafraid of is "this wanderer from another world", who "stumbled upon this haven, and found here the love and sympathy denied her by human hearts." But the forest children are not always kind to each other: 


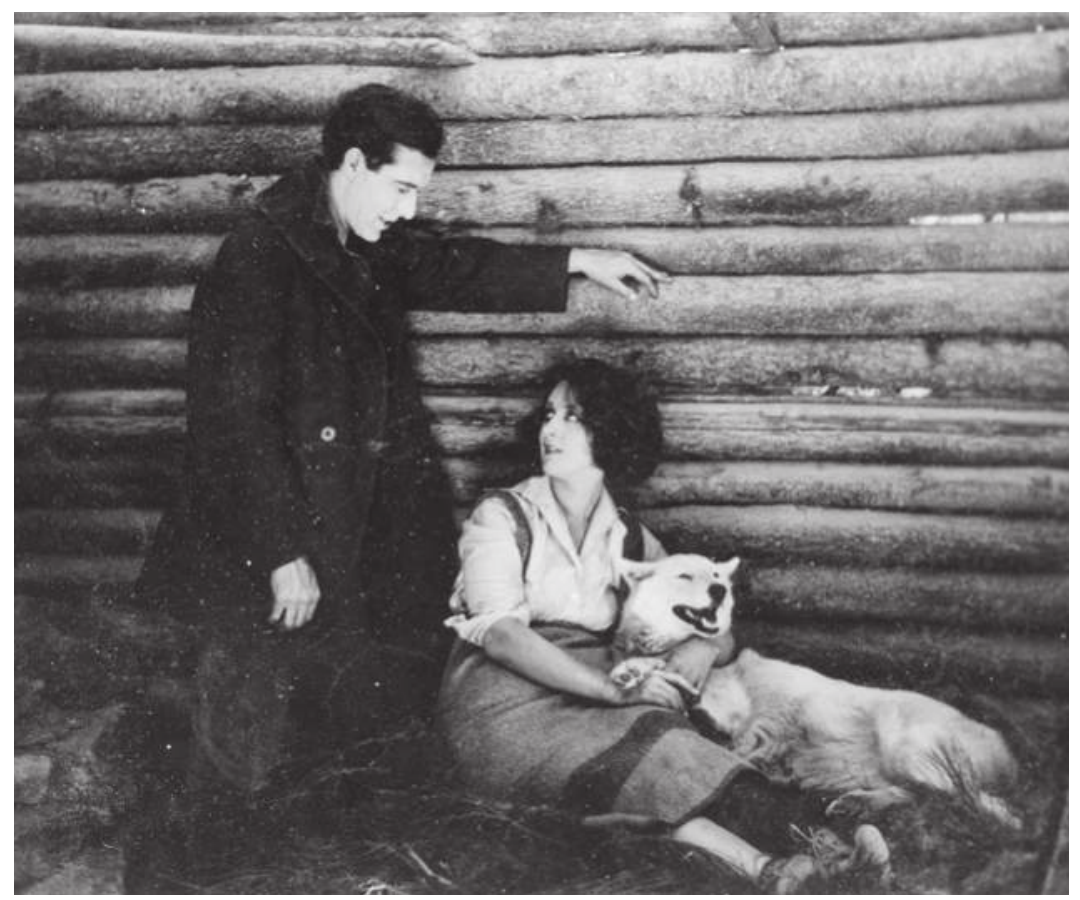

Fig. III.25: Faith with Mike's Malamute Yukon and her lover Jeb in Mike's hut.

the raccoons catch frogs and fight with one another over their prey, the coyotes have reason to act as "[a]nxious parents", the dog chases the skunks from their hide-out, and even the friendly bear "goes fishing" from time to time. The sled-dogs are, as previously noted, released into the wilderness "from whence they came", as in a revision of the ending of Shipman's animal short in which bear and dog were returned to their human owners and captivity. Albeit not by dialogue lines, but in the implied narrator's texts, still we are told what even these supporting animal characters are doing, thinking, and yearning for: yet another form of the stylistic device of animal discourse.

The two main animal characters, the dog Yukon and the bear Brownie have an independent narrative agency. Mike's white Malamute is present in the film beyond her ornamental disembodied mode. She appears to have survived on her own, guarding Mike's hut in the Lost Valley, yet another character different from what it initially seemed: she is not dead. When Jeb and Faith arrive there, they are welcomed by the dog, and, after they have entered the hut, she chases the skunks away, cleaning up the place for her visitors. The owls examine the newcomers in silence, but blink in greeting. When Jeb has gone back home to break the good news while Faith is staying at the cabin awaiting his return, Yukon sits watchfully in front of her. The medium shot 
shows the back of the dutiful dog's head in the center at the lower edge of the frame, with Faith sleeping in front of her; thus, it represents the dog's point of view. The leading part among the animal characters is reserved for Brownie, who puts the initially frightened Faith at ease with a kiss, then "cares for her helpless human sister", introduces her to the other forest inhabitants, and teaches her how to survive on berries and honey "from Nature's sweet shop". Most of this is shown in five consecutive sequences around two-thirds of the film.

As Wapi in BACK TO GOD's COUNTRY and Laddie in SOMETHING NEW, some of the animals return in the closing sequence of THE GRUB-STAKE. After the shots of single parent animals, including Yukon with a large litter of pups and the shots of the human family members, there follows a medium shot of the door to the dwelling set ajar. Through it, Brownie peeks her nose, withdraws while looking behind her as if expecting to be followed, then reappears in its opening and enters the room. The subsequent shot takes on the bear's point of view by filming her from behind while she approaches the cradle and puts her front paws on its edge. Here, significant otherness is acknowledged in the animal's agency and perception. Only then, and hence from the animal's perspective, is a shot of the baby inserted into the sequence, which invokes a playful gaze at the human tableau. Next, Brownie drops back down onto her feet, returns to the door, and goes to exit, while Faith watches her with a questioning look. There follows a shot of Brownie exiting through the door, another one of Faith and Jeb wondering about what is going to happen next, and then one of them approaching the door and looking outside. Thus, human-animal communication is substantiated in observation and acting upon it. The three closing shots of THE GRUB-STAKE show, in order, Brownie with one of her cubs outside the cabin, the human couple watching them from the doorstep, and two cubs alone in a blossoming little tree. Although Shipman mixed up the order of the shots, she otherwise remembered this, which she called a "sockeroo finish", accurately and articulated her impression of the sequence's closing images: "It was as if Brownie said, 'There. You folks had one! Lookit what I did!'”345

To round out this analysis, I will now consider the two main characters, the villain and the girl, in that order. We have seen how, in Beach's and Curwood's stories, villains-in-disguise appeared who at first acted well-behaved, while the girl only gradually discovered their actual intentions and, from that moment onwards, decidedly and heroically resists and combats them. A copy of this plot pattern can be detected in the relation of villain and girl in Shipman's THE GRUB-STAKE. However, the seemingly suave villains in The Barrier and in "Wapi, The Walrus" were not the main but the subsidiary villains and the impression they made on the girl was presented as a sign of her naïveté 
rather than as an element of the character's complexity. Shipman, in contrast, made the villain-in-disguise the main exponent of the type in her scenario and, in addition, a character oscillating between malignity and candor in his feelings of lust. By his role as the girl's husband, she also makes him a chief protagonist of the first and the final plotlines of her story.

In order to render it plausible that Leroy's character would appeal to the girl just as much as he had appalled her at the outset and again towards the end, Shipman elaborated upon his attractive sides much more than Northwest drama would conventionally have permitted. To be sure, his villainy is constructed from the repertory of tactics adopted by any Northwest villain, that is to say, pretense, double-crossing, treacherous conspiracy with other men, violent assault on powerless people, and sexual harassment of the girl. This aspect is enacted primarily in the interaction and dialogues of Leroy with supporting characters. But Shipman did not supply his villainy with the 414 generic excuse that the Arctic brings out the worst in men and allows them to set their own laws in remote wilderness locales. Instead, her scenario and film situates his operations largely in the "civilized" world, the turn-of-the century northwestern towns of Seattle and Dawson, and in a context of women striving for economic independence. In addition, she ascribes to him an intention no viewer would accept as an excuse: taking advantage of the girl's beauty, poverty, and spirit of enterprise. However, in order not to render the girl for her part completely silly or opportunistic when she trusts and then marries the man, the plot, the direction, and the acting make it plausible that he had genuinely attractive traits as well, above and beyond their narrative function of masking his villainous intentions. It was, I assume, to this end that Shipman and the actor, Alfred Allen, granted the character various moments in which his considerate attitude seems to be sincere, if not a sign of outright infatuation. In the scenes between him and the girl, his suavity is not revealed as feigned, with the narrative effect that Faith can never be sure if her suspicions are entirely right. Viewers are kept informed about his false pretense primarily by those scenes in which he interacts with other characters as well as by the moments in which he does not hide it because he knows or thinks himself to be out of range of the girl's vision and perception. The insertion of shots showing behavior or facial expressions unnoticed by other characters in the story, is a cinematic device also applied to his character.

Leroy's masculine lust, moreover, is presented not solely in its brutality, as was the case with the chief villains in most of the narratives discussed previously, but so as to provide glimpses of an adoration that the man can barely control and that, at the end of the film, becomes his Achilles' heel. Because, having told the girl after his first attempt to harass her, "You're strong, you're worth fighting for," he, eventually, on the mountain edge that will not hold 
them both, finds out how right he was and how he has underestimated her strength. There are many moments of such ambiguity stemming from the vacillation between disguise and candor. The cliff-hanger sequence, moreover, contains another example that illustrates how this ambiguity was sustained by means of the direction, the acting, and the editing. At its center is a shot of Leroy approaching Faith, who, with her back to the ravine and her arms spread, is awaiting him as though to embrace, but in fact is planning to fall down and drag him along. In a previous shot of Faith, we see her inviting him to come closer, with an expression of hatred and rage on her face, which her persecutor, however, seems not to notice. The shot of Leroy shows his face expressing both disbelief and desire, which signals to Faith and to the viewer that, however the situation may develop, the villain is at the girl's mercy and not the other way around. This is the moment in which the film reveals the narrative purpose of adding touches of candor to the villain's character: not only do they motivate the girl's confidence in him, they also encourage her heroic resistance against his virile power.

The persistent ambiguity in the characterization of the villain is also intriguing for a reason other than its narrative function. One wonders whether some real-life characters may have entered Shipman's plot in the form of traits lent to Leroy. Those knowledgeable about Shipman's partners in business and marriage may well discern at least one allusion to Curwood in the depiction of Leroy. When he wishes to flatter Faith, Leroy praises not her bodily or facial features, but her beautiful hair. As Shipman wrote in her memoirs, Curwood "was a kook on the subject" ${ }_{346}$ and her natural wealth of hair had been one of the reasons for declaring her to be the ideal Curwood screen heroine. Now, in THE GRUB-STAKE, Leroy proclaims her the ideal model for advertising his hair tonic. Moreover, when Curwood asked Shipman to show him her hair during the shooting of BACK TO GOD'S COUNTRY, she could only refuse to satisfy his curiosity, for she had lost her hair due to the Spanish flu; and in order to escape from a "fate worse than death: a disclosure, an unveiling, the fading of a dream", she had avoided revealing what was left of it, or, for that matter, from acknowledging that she wore a wig. ${ }^{347}$ In THE GRUB-STAKE, Faith likewise denies Leroy this pleasure: she goes for a haircut, an act that, at the level of the plot, was motivated by the possibility of selling the hair and raising some of the money she badly needed. The scene ends with one of Leroy's acts of candor: he admits to knowing nothing about hair tonic, implying that it was just an excuse to invite her to his place out of genuine interest.

What is more, in his supportive and considerate attitude, Leroy eerily seems to fit the description that Shipman gives, in the unpublished first part of her roman à clef, of her ex-husband Ernest, in which she avows that a girl needed the passion of a man with influence, power, and money to find the 
"trail to stage success". ${ }^{348}$ In Leroy, Shipman created another man with power and money and with influence in the entertainment business, albeit a shadier branch than the one in which Shipman's ex-husband was involved. And the girl, lacking money, expected him to expend it on her, while she accepts his, clearly inescapable, proposal of marriage not quite out of love, but in order to secure his economic support in her professional and private life. ${ }^{349}$ There is also a parallel in the age difference between the respective couples, as Ernest too was much older than Nell. Last but not least, pretense notwithstanding, Leroy's marriage to Faith turns out to have been legal after all, which, in the plot, is the final time Leroy will once again be given the benefit of the doubt, and yet another of the many things that turn out quite differently than what they seemed at first to be.

From her experience with Bert Van Tuyle, Shipman appears to have drawn the theme of jealousy, again doing so in a way that bolsters not the villainy 416 but the ambiguity in the character of Leroy. Aboard the boat to Dawson, one of the male passengers tells Leroy that "I'll bet someone will marry that girl before she even gets to Dawson." There follows a shot showing Leroy heading towards the girl, who is in conversation with some young men. She explains to Leroy that she has "been working up trade for my laundry" and shows him a note with an address; Leroy takes the paper from her hand and throws it overboard; she mimes to him something like "it's not what you think," and he asks her to marry him. The motivation of this proposal seems to be a genuine jealousy rather than his hidden agenda of exploiting her as a dance hall hostess. It is necessary to point out that I do not suggest here that Shipman adorned Leroy with character traits borrowed from her partners in life and business in order to make a statement about them. That which makes Leroy a traitor and an exploiter has little to do with his obsession with hair, his jealousy, or even his marriage. Rather, these elements pertain to his attitude of support and infatuation, and, in the narrative, they function in part as a disguise over his villainy and in part as offering glimpses of candor and hence adding to the complexity of his character. By the same token, they make the character of the girl look less silly and add substance to her fight against him, as he is neither a plain villain nor just a villain-in-disguise, but her legal husband and, it may be, even a genuine admirer. I would argue, therefore, that Shipman's recourse to traits of men she knew is a sign of her strategy of authenticating the fiction, much as she does in handling the characters of Dawson Kate and Malamute Mike, and much as she does with the female protagonist of her story, Faith Diggs, who, as I will argue, is embellished with traits taken from Shipman herself, without, however, really resembling her.

With respect to the three plotlines, Faith' characteristics in two of them do agree with the type of the Northwest outdoors girl, Shipman's favorite screen 
persona. However, vis-à-vis her role in the white slavery plotline, she obviously drew from a source other than a generic one, namely, from her observations and experiences in the trade of popular entertainment at the beginning of the nineteenth century. As we have seen, she herself used to be a poor girl, and a working girl as well, albeit as a popular stage actress. At a young age, Shipman also married an older, influential, and (sometimes) wealthy man, indeed in the expectation that he would support her in building a career. In contrast to her own history, however, she has Faith choose a man working in the wrong trade, and, by this narrative element, makes her main character more naïve than she herself probably ever was, and the villain of her story more exploitative than she (hopefully) would consider any man in her life as ever having been. She also has Faith, again in contrast to her own history, abandon her aspirations for economic autonomy when faced with marriage. The same can be said about the character's name. It is true that, like her fictional creation, Shipman did have faith in her husband and thus had reason to be badly disappointed with him; but she differed from her insofar as she herself had no religious faith. ${ }^{35^{\circ}}$ I could go on comparing the traits of the scenarist-actress to those of the character she wrote and acted, but it all boils down to one conclusion: there are at least as many similarities as there are differences between the fictional Faith Diggs and the Nell Shipman I have researched, in terms of both their personalities and their experiences. As suggested above, moreover, Shipman transferred some of her own dispositions-her history in popular entertainment, her playful style of mothering, the preoccupation with observation and perception evinced by her literary and cinematic oeuvre- to the fictional character of Dawson Kate. In other words, Faith is as autobiographical as Leroy, or Kate for that matter, are biographical; all are figures in Shipman's plot, while some of the facets of their characters are drawn from real life in much the way that the locations, the animals, or, on occasion, the automobiles are. This is done for the sake of authenticating the fiction, but it is fiction or make-believe that their inclusion ultimately aims to serve.

Thus, what can be considered as a novelty compared to Beach's, Curwood's, or even Shipman's previous treatments of the outdoors girl, is that, at the outset, the character of Faith is a working girl in urban society at the turn of the century, unaware of the idealized wilderness to which the narrative trajectory will lead her. Faith did not grow up in an idyllic hut on the heath, and she initially feels helpless and desperate in the land "ruled by Dame Nature", stubs her toe (in an ironic self-depiction of Shipman as an actress), and shudders at the big brown bear upon which she stumbles. What attracts her to Alaska is the prospect of "starting fresh" in a business of her own. Her history is situated precisely in those towns and cities that are designated as civilization in Northwest fiction and where the villains usually operated their dirty 
businesses, but in which the story itself was not set. By means of the character of Faith and her encounters, an emphasis that is unconventional for the subgenre is placed upon the nature of this business and upon the way in which it affects women, literally in the plural: the poor and innocent girl, as well as the tough mistress and single mother she may sooner or later become. Thus, this working girl, in both senses of the term, has good reason to lose herself in another, a more caring and loving world. Its attraction consists in the fact that she is emotionally and socially motivated to prefer it to the degrading fate that so-called civilization has in store for women under the rule of treacherous and exploitative men. This grounding of the character of Faith in a specific historical society can be seen as an effort to revise the otherwise perhaps archaic sub-genre, even though the revision eventually results in a deep pessimism in Shipman's scenario. The function of this pessimistic "history" of the outdoors girl Faith, I argue, is not to make a statement about the civilized world or about 418 marriage, but firmly to motivate the girl's drive to find a way out of poverty and misery.

A noteworthy aspect of Faith's misery as presented in the white slavery plotline is the connection between elegant feminine dress and the sexual exploitation of women. In it, one can read a sampling of "do nots" so as not to end up as a prostitute: do not display your beautiful hair and body to people other than artists; do not accept the most stylish fur parka as part of an investment, for it is meant to lure you into dependency; do not have your husband dress you up for he will sell you to other men. Ironically enough, Shipman has Leroy tell Faith, in the Dawson dance hall, "You cannot judge by the clothes up here."

It is also notable, in this context, that Faith made Dawson Kate's acquaintance because her unwieldy dancing partner, chosen and approved of by Leroy, has torn her gown by stepping on it, whereupon Kate takes Faith to the dressing room reserved for the hostesses. And it is significant, I would argue, that it is precisely in the dressing room that Kate reveals to Faith that she is about to be exploited as a dance hall hostess. This is underscored in the costumes the women are wearing, which, if seen together, make manifest a similarity: each has a large zigzag pattern, and Kate's and Faith's are variations on the pattern but basically alike. In the film, Shipman has Kate articulate Faith's appearance by her sneering remark "I believe you're almost as innocent as you act." By using the words "believe," "almost," and "act" in a single sentence, she hints at guise and appearance, yet also presupposes that agency comes from two sides: from the onlooker and from the one who is acting. Hence, Faith's elegant feminine attire is presented as something she dons for a change and yet out of which she ought quickly to change if she wants to escape from the exploitative perception she will be subjected to while wearing it. The film 


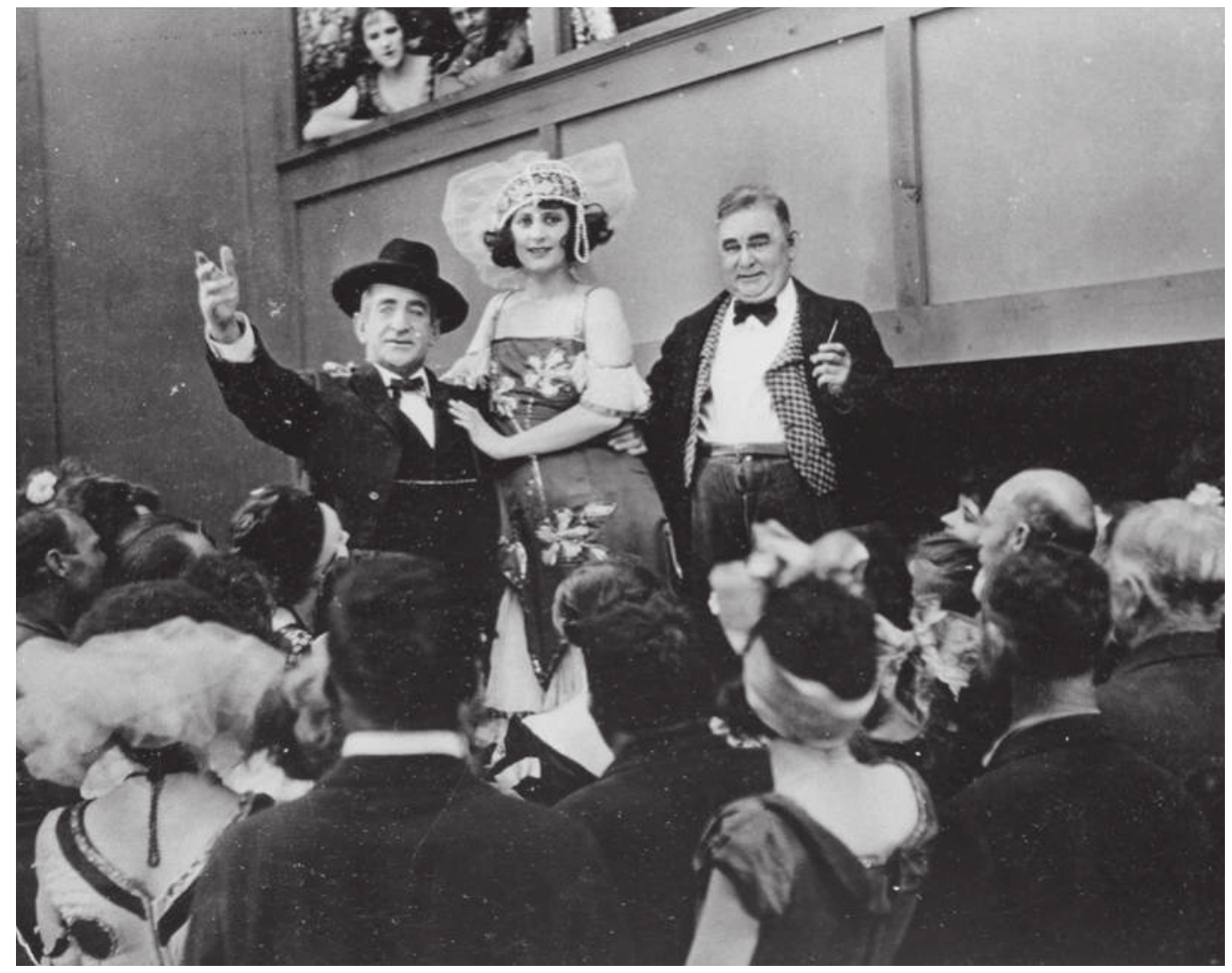

Fig. III.26: Villain-in-disguise Leroy presents Faith to the dance hall patrons and warns her: "you cannot judge by the clothes up here."

lucidly presents this relation between feminine dress and exploitation, and thus extends its focus on the perceptions of women, in both senses, from the character of Dawson Kate to Faith's.

When read with a focus on perceptions of women, it seems as if Shipman, in the first part of her film, investigates how perception relates to narrative agency. Under what conditions does the perception of Faith obstruct her agency, and when does it prompt it? In the opening sequence, set at the art studio where Faith acts as an artist's model and where Leroy arrives as a customer to buy supplies for "a painter-fellow up in Alaska"-who later turns out to be $\mathrm{Jeb}$ - the problem is laid out. Faith poses for a group of painters, including at least one woman, wrapped in a piece of cloth that leaves her shoulders bare and is tightly wound around her body as if she were to represent a mermaid, revealing her shapely form but also making it difficult for her to move her legs. Neither the indecency nor the immobility seem to cause problems as long as 
they are perceived to be at the service of art. When the customer arrives, the female painter asks Faith to stand in for the momentarily absent shop owner. She hesitates on account of her attire, then covers herself with a kind of blanket that she has to hold up with one hand, and enters the store. The scene first focuses on how her modeling costume hampers her agency: the supplies Leroy asks for are placed on a high shelf, so that she not only has to climb a little stepladder, but must also reach high above her head to a pile of large, flat boxes and pull one out one-handedly; yet in order to grasp it, she needs to use her other hand as well, and the blanket consequently slips from her shoulders. The expression on her face speaks volumes in terms of perception: no man should see her like that. Because the film shows, in medium closeup, her shocked response to the exposure of her risqué costume, it seems to suggest that indecency is in the eye of the beholder, not in a woman's attire. The following shot of Leroy's face, however, seems to undercut this reading: 420 it shows him lowering his eyes and glancing at her worn-out footwear, thus noticing her poverty and not the indecency of her attire. While the relation between perception and agency is not yet clearly marked out in this scene, it nonetheless provides an introduction to the idea that they are connected.

In a further scene with Leroy, the relation is clarified. Faith is visiting Leroy after having had her hair cut and is listening to his "Golden Stories of the land of the long snows." The series of shots, interspersed only with a closeup of pieces of gold in her hand and with dialogue titles spelling out Faith's thoughts or questions, shows him watching her, whereas she, contrary to what one would expect in a dialogue situation, rarely looks at him. Instead, she looks straight ahead, past the camera, and sometimes her glance strikes the lens. In the latter case, she mimes getting an idea, but, otherwise, her expression varies: from musing about some imaginary place, to hopefulness followed by resignation, or to hesitation followed by enthusiasm for her own idea. It is Shipman's conception of the magic created in the interaction between herself and Joe Walker's camera that takes on a narrative significance in these scenes. The effect of him watching her yet her looking somewhere else than at him, is that we not only see her as she appears in his perception, but also witness how this confines her to imagining and dreaming, which do constitute a form of narrative agency, to be sure, but not necessarily one that will entail consequences for the course of the action. This is what the remainder of the whiteslavery plotline seems to suggest: the more Faith adapts to Leroy's perception of her, the less it corresponds with her perception of things. Giving up her own perception, however, also implies abandoning her capacity for independent agency. And it takes another woman to restore both the perception and the agency of the female protagonist and allow her to become the outdoors girl.

Once Faith has made the transition to the outdoors girl, her character 
becomes a classic of its kind. Perception at first is not at issue, but narrative agency. With a grim face, she drives the dogsled, hauls it up after it capsizes, gathers wood, traverses hip-deep snow drifts, climbs rocks, and performs all the stunts that are further necessary. The sled rides are framed in eye-catching shots by Joe Walker with their trademark choreography of movement of the photogenic chains of dogs speeding across the snow-covered landscape, and edited to relatively long duration (one takes up to fifteen seconds), summoning from the viewer an aesthetic awe that accords with the empathetic awe generated by the girl's physical feats.

The Lost Valley sequences, however, pick up the reflections on perception and who is to be held accountable for it, the perceived or the perceiver. They contain a small sub-plot, which moves through, first, Faith's fearful reactions to the wild animals she encounters, then her companionship with Brownie who shows her the world in which she has arrived but that is still "unaware of visitors", then the animals' acceptance of her, and, last but not least, her pleasure in watching cubs "on mischief bent" or big bears sparring for her amusement. It is in this idealized wilderness world that Faith is finally imbued with Dawson Kate's capacity for observation and, interestingly enough, it is observation in which the direction of the look between animals and humans is reversed. Now it is she who observes the animals' doings. Unlike Kate, Faith looks at the animals' doings not with a critical perception and wariness, but rather with an eagerness to learn from them how to survive and how to behave kindly towards one another. Faith does not observe the animals as an outsider, but with the aim of living and communicating with them, much as the young wolf-dogs had done in Curwood's stories, and, eventually, she derives delight and mirth from the sight. Once again, if there is a problem, it resides in the eye of the beholder.

In the cliff-hanger sequence, finally, Shipman drafted an action scene for Faith of bare-handed struggle with Leroy that crowns all the thrills of the preceding scenes, and in which, as Armatage has also noted, she performs fantastically, as an actress fighting "tooth and nail [...]. She lands many blows, bites Leroy on the wrist when he has her in a headlock, and throttles his neck in close-up." ${ }^{351}$ In the fight, Faith is reminiscent of a wild animal showing off all the "pent fury, hate and Cat power" ${ }^{32}$ she could bring to bear. For this performance, Shipman and her co-star Alfred Allen seem to have rehearsed before the camera every possible move and action that could communicate the man's incapacity to handle the girl's fury and give her an advantage. This not only adds to the scene's intensity, but also accords with the ambiguity in Leroy's character as described earlier, as if he were impressed or even outclassed by Faith's strength and determination. It renders her stamina more credible, but also makes the ending of the fight the more disconcerting and shatter- 
ing: Leroy grabs Faith's arms, loosens her grip on his throat and, in one easy motion, flings her into a corner, as if he had only been playing along with her power game and was now restoring the situation to his order or perception.

Armatage has pointed out that camera and editing in THE GRUB-STAKE tend not to privilege one character's point of view in the classical manner, that is to say, through point-of-view shots, corresponding camera angles, and eyeline matching, but instead that they rely on a "narrational omniscience of the camera gaze". ${ }^{353}$ There are indeed many scenes in which the camera seems to register interactions between characters rather than to side with one of them. However, I would argue that the text employs other means to establish character perspective or to solicit the viewers' involvement and empathy. Take, for instance, the sequence in which the Mountie reveals Kate's profession as a dance hall hostess. The dialogue is between Kate, the Mountie and Jeb, but there is significant non-verbal interaction among them and with Faith as well.

422 A first close-up in the scene shows Faith in semi-profile, with a very angry and dogged expression (angry with Kate, who has told her that she cannot have Jeb). A second close-up, inserted after the Mountie's revelation and Jeb's disbelief in response to it, shows Faith's face frontally with a knowing expression, then turning her head from the Mountie to Jeb, and then registering shock. While the interaction and dialogue continue between the Mountie and Jeb, Faith is shown, in another close-up, first observing them with a worried look on her face, and then with a hateful smile, raising her upper lip like a spitting cat. It is true that her action seems to be directed at no one in particular, but this is not the case in the following five shots. In the first, a medium close-up of Kate and the Skipper, Kate is shown glancing at Faith, which is followed by another close-up of Faith smiling scornfully and then looking at the Mountie, who, likewise in close-up, answers with a satisfied grin. The fifth and final shot of the series shows Faith again in close-up, now frowning and looking straight ahead of her. It is her preparation for the lie she is going to tell Jeb, namely, that she used to get her mail from his mother. In other words, by Faith's active observing and listening, and by the framing and editing of her responses to what is said and done, not to mention her diegetic interfering in the latter in the form of a lie, she simultaneously summons spectators to become absorbed in the diegesis and shares with us her perception of the scene. This twofold manner of addressing viewers is a recurrent stylistic device in THE GRUB-STAKE, and it constitutes Shipman's answer to the problem of woman's perception. 
For Nell Shipman, there were no other options or choices than to go on, to shoot new films, and to try to make a profit on them, so that she could settle her bills and begin afresh. To that end, she planned a series of two-reelers, LITTLE DRAMAS OF THE BIG PLACES, and shot, during the course of 1923 and 1924, four of them, of which one remained unfinished, according to D.J. Turner's filmography, while three others have been retrieved by Tom Trusky. ${ }^{354}$ All were shot in and around Lionhead Lodge at the northern tip of Priest Lake, Idaho, where Shipman and Van Tuyle, as of April 1923, had established a home and a permanent movie camp, including the menagerie with dozens of animals. In her memoir she described the place in ecstatic terms:

Fig.III.27: Cast and crew of one of the LITTLE DRAMAS, THE LIGHT ON LOOKOUT. Standing, from left to right: Daddy Duffill (cast), Dorothy Winsloe (cast), Bert van Tuyle (co-director), Nell Shipman (co-director and cast), Bobby Newhard (camera), Ralph Cochner (cast). Squatting in the front: Barry Shipman (cast) with Laddie.

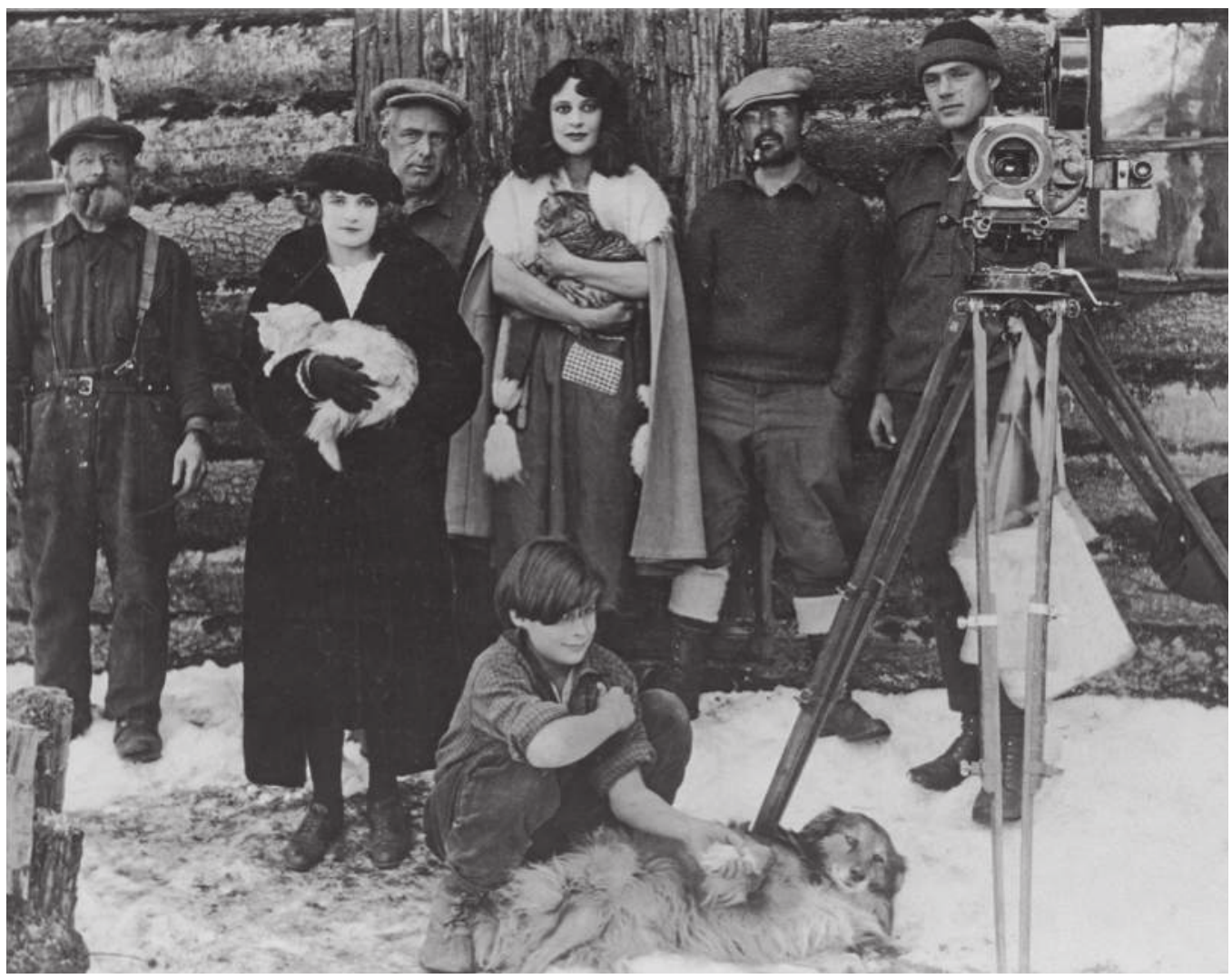


Did you ever come to a place and instantly recognize it as your Ultima Thule, the one spot in all God's world where you belonged, where your roots could go deep into soil which would forever nourish you, where inspiration and spiritual blessing welled up from the earth to top the tallest Tamarack, spread to the encasing bowl of the sky, return on every waterway to feed you everlastingly? Such a spot, so it seemed to me, was Priest Lake, Idaho. ${ }^{355}$

Unfortunately, however, Lionhead Lodge would turn from an Ultima Thule into her Waterloo. The events leading to the sad ending of her silent film career were chronicled by herself in three versions: a largely factual account published in 1925 in the Atlantic Monthly, "The Movie That Couldn't Be Screened," the novelization in Abandoned Trails in 1932, and the recollection in The Silent Screen and My Talking Heart. At the time, everything went wrong 424 that could go wrong for Nell Shipman. She made a little money with personal appearances and screenings of THE GRUB-STAKE and THE GIRL FROM GOD'S COUNTRY, but not enough to pay her debts, let alone to satisfy the investors. She sold some of the shorts to a distributor, Selznick Distribution Corporation, but this company too went bankrupt in December 1924, leaving her with empty pockets once again..$^{356}$ Financially, the Nell Shipman Company had lost its credibility, and it would hardly have been possible, as its star and directors must have sensed, to engage new crew members with such a history of unpaid remuneration. What is more, they ran so short of money that they could hardly feed the company's non-human and human members. It is in this context that Shipman spoke of "going Curwood all the way",357 that is to say, becoming the outdoors girl for real and trying to survive in the wilderness. But the whole idea was becoming an ordeal instead of fun. Socially, they were in trouble because Bert Van Tuyle had engaged in a local feud between two ship owners vying for the lucrative transport over the lake and had refused to pay to one of them the company's outstanding debts. ${ }^{35^{8}}$ When this man poisoned Shipman's Great Dane Tresore, she felt downright threatened. ${ }^{359}$ Privately, to make things worse, Shipman's relation with Van Tuyle was turning into hell. In her factual account and her memoirs, she excused his jealousy and increasingly obsessive attitude in view of the maddening pain he suffered from gangrene in his toes, which he refused to have treated on account of the money it would have cost. In her fictional account, by contrast, she paints a picture of outright psychic and physical abuse, as he blamed her for his misery: not only did she flirt with other men, but he had also contracted the frostbite during the shooting of BACK TO GOD'S COUNTRY. When Van Tuyle, around Christmas 1924, went berserk from the pain and threatened to kill her, Shipman initially attempted suicide by drowning, as her heroine Faith had, only to be rescued 
by her son Barry. Later, mother and son decided to escape, snowshoeing and dog-sledding over the frozen lake like an outdoors girl in real life. Alone, she headed for New York, telling herself:

I must go back, to the animals, to movie making, but alone. First, I must [...] try to refinance. I'd planned a picture. Not a bumbling little Short but a real Feature with which I could recoup, state the long-awaited comeback. It was to be called "The Purple Trail" and I'd play my old time GIRL FROM GOD'S COUNTRY role. ${ }^{360}$

It would not turn out that way, as we now know. Shipman's company was bankrupt, and she would never see Lionhead Lodge again, nor any of the animals, including Laddie and Brownie. Nell Shipman's thirteen-year career as a scenarist, actress, producer, director, and editor in the silent cinema was over.

\section{EPILOGUE}

In New York, Shipman soon began a nine-year relationship with a painter, Charles Ayers, with whom she had twins in 1926 and traveled to Spain, whereupon she picked up her writing career and went on to publish several novels and stories. In 1928, she also wrote, produced, and acted in a play, "Are Silent Screen Stars Dumb?", a satire on the film industry's policy to refrain from employing silent film actors. However, she never again acted for a camera, although one of her stories was filmed, in 1935, starring Gary Grant and Myrna Loy in WINGS IN THE DARK, and, in 1947, she, albeit uncredited, wrote and produced, together with her fourth and last lover, Amerigo Serrao, another feature film, THE STORY OF MR. HOBBS. ${ }^{361}$ Yet, as her papers in the archive at Boise State University attest, Nell Shipman never gave up planning new and larger pictures, and writing and rewriting their scenarios, until the end of her life in 1970. 



\section{In Conclusion}

As my careerographies treat Adriënne Solser, Musidora, and Nell Shipman individually, I wish to highlight, in conclusion, some of the insights into the work of women in the silent cinema in Europe and the United States that their parallel careers may offer.

The three careers, in the first place, draw attention to the significance of female performers on the silent cinema of the 1910s. Adriënne Solser, Musidora, and Nell Shipman epitomize the creative and artistic contributions of actresses to the well-liked characters they brought to the screen. These contributions were far more influential than the phrasing "directed by" has suggested in retrospect. This may explain why even acclaimed actresses were so casual in asserting the direction credit for themselves: claiming the direction was not a signature of discursive control for them, but rather an appreciation of the collaboration of actress, cinematographer, and director. Actresses knew exactly how they co-created, in interaction with the camera, the appealing screen roles accredited to "their" directors. The inclusion of film direction and production in the careers of these actresses, then, ought not just be considered a legitimate means to capitalize on their accomplishments and fame; it can also be seen as a sign of shifts in acting styles at the end of the $1910 \mathrm{~s}$ by consequence of impending requirements such as photogénie and diegetic acting. Like other actresses of the era, Solser, Musidora, and Shipman consolidated their grips on the roles and styles they preferred through establishing their own film production companies and co-directing the films in which they were featured.

A second communal aspect is the versatility, adaptability, and competences required by the range of métiers available to women in the booming popular stage and cinema of the first decades of the twentieth century. They switched from popular stage acting to screen acting, and ventured into scenar- 
io writing, production and direction. They selected established stage genres and excelled in them after transferring them to the screen. Musidora and Shipman also astutely attuned their self-promotion and public personas to such requirements; through fictional and non-fictional statements, they engaged in the public discourse that shaped the field even long after their careers in the film business had ended. In the films that the three wrote and directed, they adorned the generic figures with individual traits and concerns, attempting to make them relevant to a new audience and to make them, to a tasteful extent, self-referential. One of my particular pleasures has been to detect the self-irony about stardom on the popular stage and in the cinema, and about popular genres and formulas that each exhibited in her comic roles and films: they provide delights of female wit and professional self-knowledge.

In the capacity of film producer and director, these women took great entrepreneurial and professional risks to realize their ambitions. They did 428 not work under the umbrella of an established studio or film production company, but operated on a self-supporting basis. Solser and Musidora invested large amounts of private money, while Shipman had to find and to satisfy backers. It was essential to secure the collaboration of competent and loyal crew members. If the chemistry worked, they were idolized, but when things worked out differently than envisioned, their reputation and creditworthiness was at risk. For each film anew, Musidora and Shipman needed to find a distribution company that would care to make the most of it, while Solser held the distribution in her own hands through making her live performance an indispensable component of it. I found it particularly wry to observe the impact of sheer bad luck on their endeavors. Yet, in the same vein, they can be seen as the precursors of the independent women filmmakers of the 1970s and after.

Adriënne Solser, Musidora, and Shipman each carved out a niche for herself in the mass entertainment of the early twentieth century and left an imprint on it as competent and clever craftswomen. It is this imprint that I have detected and that I wish to cheer and to share. 



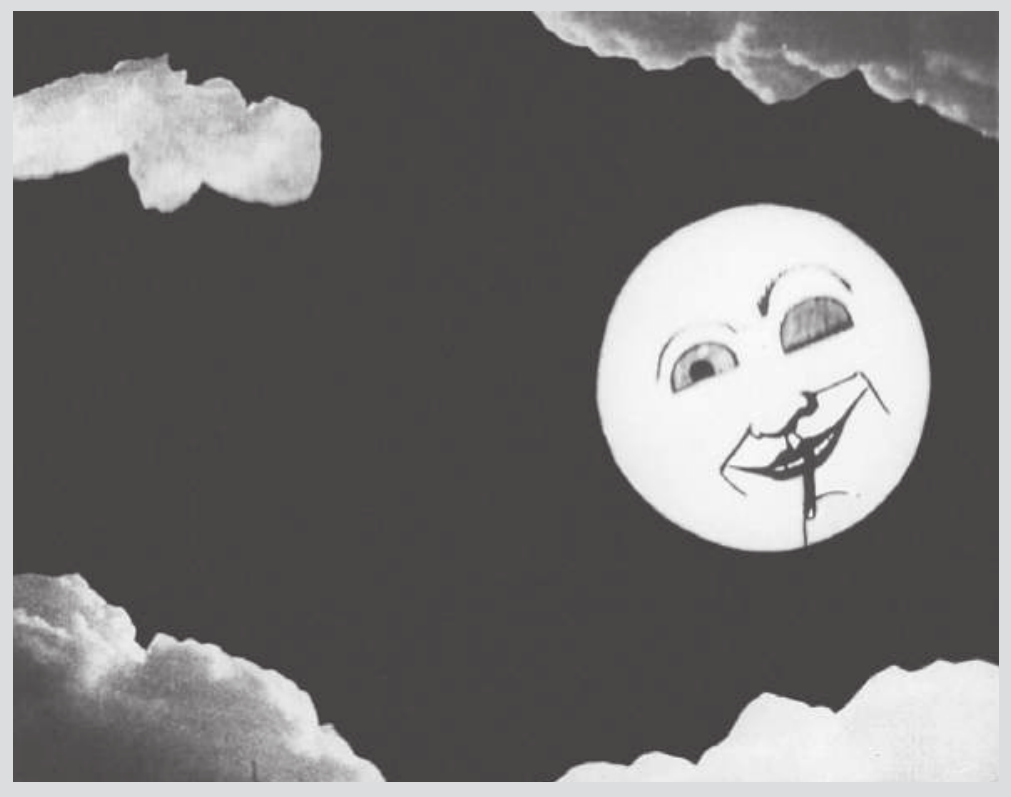

Winking moon. Animated image from BET NAAR DE OLYMPIADE, EYE Filmmuseum. 


\section{ABBREVIATIONS}

AAS

AFI

BHV

BiFi

BNF, DAS

BvG

CÉCR

$\mathrm{CRH}$

$\mathrm{IMDb}$

$L C C$

$M P W$

NSA

$N W C$

NYDM

RO

RSR

SAA

TIN

UDNP
Archief Adriënne Solser en Lien d'Oliveyra, EYE Filmmuseum, Amsterdam

American Film Institute

Bibliothèque historique de la ville de Paris

Bibliothèque du Film, Cinémathèque française, Paris

Bibliothèque nationale de France, Département des arts du spectacle, Paris

Centraal Bureau voor Genealogie, The Hague

Le Cinéma et l'Écho du cinéma réunis

Fonds de la Commission de Recherche Historique de la Cinémathèque française

Internet Movie Database

Le Courrier cinématographique

Moving Picture World

Nell Shipman Archive, Albertsons Library, Boise State University, Boise, Id.

Nieuw Weekblad voor de Cinematografie

New York Dramatic Mirror

Collection Rondel

Radio Suisse Romande

Stadsarchief Amsterdam

TIN-collectie, Bijzondere collecties UVA Uitvoerende Kunsten, Universiteit van Amsterdam, (former Theater Instituut Nederland), Amsterdam

Utah Digital Newspaper Project 



\section{NOTES}

\section{INTRODUCTION}

1 Thomas Elsaesser, "General Introduction. Early Cinema: From Linear History to Mass Media Archeology.” In: Thomas Elsaesser with Adam Barker (eds.), Early Cinema. Space Frame Narrative (London: British Film Institute 1990), 5.

2 Elsaesser, "General Introduction," 3.

3 Ibid.

4 Cited ibid.

5 Giuliana Bruno, Streetwalking on a ruined map. Cultural Theory and the City Films of Elvira Notari (Princeton, New Jersey: Princeton University Press 1993).

6 Bruno, Streetwalking, 12.

$7 \quad$ Eric de Kuyper, "Het theater als trauma." In: E-View 1 and E-View 2, 1999 (Dutch translation of "Le Théâtre comme mauvais objet" in: Cinémathèque, 11, 1997) at: http://comcom.uvt.nl/eview/991/kuijper.htm

8 Marsha McCreadie, The Women Who Write the Movies (New York: Birch Lane Press 1994), 7.

9 Anita Loos, The Talmadge Girls, (New York: The Viking Press 1978), 6.

10 Heide Schlüpmann, "Asta Nielsen and Female Narration: The Early Films." In: Thomas Elsaesser (ed.), A Second Life. German Cinema's First Decades (Amsterdam: Amsterdam University Press 1996), 118-22.

11 Bruno, Streetwalking, 3.

12 Ibid., 151.

13 Ibid., 149.

14 Robert Stam, Subversive Pleasures. Bakhtin, Cultural Criticism, and Film (Baltimore and London: The John Hopkins University Press 1989), 14.

15 Ibid.

16 Ibid., 57 
Ibid., 14

Mikhail Bakhtin, Rabelais and his World. Translated [from the Russian] by Hélène Iswolsky (Cambridge, Mass., The M.I.T. Press 1968), 224.

9 For a detailed list of holdings see http://library.boisestate.edu/Special/Finding Aids/fa81.htm

Nell Shipman, The Silent Screen and My Talking Heart: An Autobiography, (Boise, Idaho: Boise State University Hemingway Western Studies Series, 2001), 3. A selection of Shipman's papers has been published in Tom Trusky with Alan Virta (eds.), Letters from God's Country. Nell Shipman: Selected Correspondence and Writings, 1912-1970 (Boise, Idaho: Boise State University Hemingway Western Studies Series, 2003).

1 Francis Lacassin, Musidora. Anthologie du cinéma 59 (November 1970), 441-504; Patrick Cazals, Musidora. La dixième muse (Paris: Henri Veyrier 1978).

22 Musidora mentions the donation in correspondence with Henri Langlois of July 10, 1945 and July 29, 1945, preserved at the BiFi, Fonds Musidora. At times, she took the films out for screenings when lecturing. That she was creating a file on Colette, she reported in her tribute to Colette, Musidora, "Colette et le Cinéma Muet. Souvenirs de Musidora,” L'Écran français, 241 (February 13, 1950), reprinted in Cazals, La dixième Muse, 195-99.

\section{ADRIËNNE SOLSER ON THE DUTCH POPULAR STAGE}

Dominique Jando, Histoire mondiale du music-hall (Paris: Éditions Universitaires Jean-Pierre Delarge 1979), 7 . The director of the Amsterdam Flora Variété Theater, F. A. Nöggerath Sr., produced and directed three films in 1899, which were screened during variété programs. See: Geoffrey Donaldson, OfJoy and Sorrow: A Filmography of Dutch Silent Fiction (Amsterdam: Stichting Nederlands Filmmuseum 1997), 51-52. However, these were not the first Dutch film productions, nor the first films to be screened in the programs at the Flora: Nöggerath created a fixed slot for film in his shows from March 1896 onwards. See: Ansje van Beusekom, Kunst en amusement:Reacties op de film als een nieuw medium in Nederland, 1895-1940 (Haarlem: Arcadia 2001), 26.

3 One of the notebooks, "Couplettenboek van Adriënne Solser, soubrette”, with verses dating from 1904 through 1916, contains a list with names of German theaters, directors, and, sometimes, honoraria. It is unclear whether this was the record of a few months' work or the result of a series of inquiries. The source for Solser's stay in Belgium is Piet Hein Honig, Acteurs- en kleinkunstenaarslexicon:Drie duizend twee honderd namen uit honderd jaar Nederlands toneel (Diepenveen: Honig 1984), 865. 
“Flora-Theater, Amsterdam: Albert Bol,” De Kunst, 11 June 1910.

“Soesman's Casino," De Kunst, 24 August 1912, 749.

6 Ibid.

7 A marriage certificate issued by the Municipality of Rotterdam on November 2, 1876, listed another sister, Jeannette Johanna (1855-unknown), but her name does not come up in the variété context; this certificate is held in the file Solser Family (no. 620) in the TIN-collection at the University of Amsterdam (hereafter TIN). Nor does her name appear in the files of the Bureau voor Genealogie (hereafter BvG). I thank Peter Christiaans for checking this information.

The annual awards for theater acting, issued today in the Netherlands, are named in their honor: the Theo d'Or for actresses, the Louis d'Or for actors.

9 The children were born in different towns in the province of Zuid-Holland. (For this information, I wish to thank John Willemsens.)

10 J., "Michel Solser $\dagger$," Algemeen Handelsblad, 30 August 1893; H., "In en om den Schouwburg: Michel Solser $†$," De Telegraaf, 30 August 1893.

11 See: Nathan Heyman Wolf, “Adriënne Solser,” De Kunst, 26 April 1919, 357-58. Unfortunately, this article contains errors concerning Solser's career, which suggests that this claim may be equally dubious.

12 According to the Marriage Certificate, File Solser Family. These dates concur with those provided by the BvG.

13 J.H. Rössing, "Lion Solser †," Het Leven, 10 August 1915, 1000.

14 Jacques Klöters, Honderd jaar amusement in Nederland (Den Haag: Staatsuitgeverij 1987), 17-18.

15 According to the Marriage certificate, File Solser Family.

16 Klöters, Honderdjaar amusement, 58.

17 G.H.J., "Chrétienni en Solser: Interview," Weekblad "Algemeen Belang," 31 December 1892, 9 and "Michel Solser $\dagger$," De Telegraaf, 30 August 1893.

18 Alex de Haas, 't Was anders: Leven en levenskring van De Heer J. H. Speenhoff, dichterzanger (1869-1945) (Rotterdam and Den Haag: Nijgh \& Van Ditmar 1971), 29-30.

19 T. K. Looijen, Een geschiedenis van Amsterdamse theaters: Wie kwam er nou niet in de Nes? (Nieuwkoop: Heuff, Amsterdam: Uniepers 1981), 40-43. In Dutch entertainment histories, the sketch is often referred to as "De Artiestenrevue", but this was not its title when it was performed at the Vic.

20 Ibid. For a detailed description of the Nes in its years of glory, see also Joost Groeneboer, "Schouwburgen en vermakelijkheden in de negentiende eeuw" in: Joost Groeneboer and Hetty Berg (eds.), ... Dat is de kleine man ...: 1oo jaar joden in het Amsterdamse amusement, 1840-1940 (Amsterdam: Joods Historisch Museum; Zwolle: Waanders 1995), 69-70.

21 Samuel Falkland, Algemeen Handelsblad, 4 February 1911, newspaper clipping page 18168 A in the Collection Hartkamp at the Stadsarchief Amsterdam (hereafter SAA). 
22 Collection of program leaflets from the Grand Café-Concert Victoria (code U oo.1376), SAA.

23 See: advertisements for the Grand Café-Concert Victoria, Algemeen Handelsblad, 1 December 1887, 8 October 1888 and 26 October, 1888.

24 Advertisements for the Grand Café-Concert Victoria, Algemeen Handelsblad 1 February 1889) and 1 January 1890.

25 Looijen, Amsterdamse theaters, 40.

26 See: advertisements for the Karseboom Cabaret at The Hague, Haagsche Courant 24 April 1919 and 29 April 1919.

27 See: Weekblad Cinema en Theater, no 40, n.d.(1924), n.p., and no. 45, n.d.(1924), n.p.

28 See: Nathan Heyman Wolf, “Variété-Tooneel: Peter Gronen, 1882-1899-1912," De Kunst, 19 October 1912, 45-47.

29 Solser formed an occasional and short-lived duo with Marinus de Wilde in 1918. 436 See: the advertisement for the Theater Astoria, Rotterdam, Rotterdamsch Nieuwsblad, 27 December 1918.

30 See: the advertisements in Rotterdamsch Nieuwsblad, 14 October 1887 and Algemeen Handelsblad 18 October 1888, as well as a review of the annual fair in Rotterdamsch Nieuwsblad, 15 May 1889, in which it is stated that Michel and Josephine made the public cry with laughter with their comical scenes and duos. I have found no documentation to confirm the assumptions of some historians that Adriënne also played in duos with Michel or with Chrétienni.

31 H., "In en om den Schouwburg: Michel Solser †" and Rössing, "Lion Solser †," 1001. According to the BvG, Johannes Solser died two months before his son Michel, in August 1893, at the age of sixty, but Engelina Solser-Hartlooper passed away in 1920, at the age of eighty-five.

32 Adriënne Solser played the part of Queen Scaroline in "Juffrouw Sans-gêne" and of Emilie Roerbek in the one-act-comedy "Jochem Pezel," both on the program for January 1895; she had the supporting part of a night-bird in the operetta “"n Amsterdamsche Hartjesdag” in April 1900. See: the collection of program leaflets from the Frascati-Schouwburg 1879-1922 (code T 728129), SAA. The titles of the operettas in which she is reported to have played are listed by Wolf, "Adriënne Solser," 357.

33 Another child was born in 1912. The BvG lists four children. A problem results from a comparison of the obituaries for André Boesnach, Solser's son, with the newspaper reports of his funeral: whereas the obituaries list three sisters and two brothers-in-law, the reports mention a brother who thanked those present for attending. For the obituaries, see Nieuwe Schiedamsche Courant, 22 March 1928 and Schiedamsche Courant 22 March 1928. For reports of the funeral, see “André Boesnach †: De begrafenis," Nieuwe Schiedamsche Courant, 24 March 1928; “Stadsnieuws, André Boesnach †," Nieuwe Schiedamsche Courant, 26 
March 1928; and "Begrafenis André Boesnach," Schiedamsche Courant, 26 March 1928.

34 Honig, Acteurs- en kleinkunstenaarslexicon, 865.

35 See: the advertisement for the Vauxhall Doelen, Rotterdam, Rotterdamsch Nieuwsblad, 11 August 1902; and "De Kermis," Rotterdamsch Nieuwsblad, 15 August 1902.

36 Son of one of the first comedians of Dutch variété, Nico de Haas, Alex (18961973) took up the craft in 1914, first as piano-humorist, composer, and entertainer, later also as writer of radio-revues and film scripts (Honig, Acteurs- en kleinkunstenaarslexicon, 359). The last three decades of his life were dedicated to documenting the early Dutch entertainment business, and to writing about its history from the perspective of a contemporary insider. I thank Leo Akkerman for making me aware of the collection of Alex de Haas' scrapbooks at the TIN.

37 Alex de Haas, "Hoe mooi het was en hoe lang geleden," De Groene Amsterdammer, 30 January 1954, clipping in Haas' scrapbooks.

38 See: the advertisements for the Karseboom Cabaret in Haagsche Courant, 24 April 1919 and 29 April 1919, announcing her jubilee.

39 Haas, Speenhoff, 21.

40 M. O. Nocle, "Moment-Opname no. 64, Soubrette... !," Theatergids, 17 March 1917, 11.

41 Program leaflet "Grand Café-Concert Victoria." Anna Judic was a French diseuse of the stature of her contemporary Yvette Guilbert.

42 Solser married Neumann Wittkower on March 15, 1893, and divorced him on September 27, 1894. On May 27, 1893, a daughter was born: Rebecca Rachel. The date of Solser's second marriage, with Louis Joseph Boesnach, is unknown, but, as already mentioned, she left with him for Pretoria in 1895, where they had two children: Andreas Louis and Adela Michelina. Solser divorced Boesnach on April 22, 1909, and married Salomon d'Oliveijra on March 22, 1912. The date of their divorce is likewise unknown, but it must have been before March 11, 1925, when he remarried. On August 13, 1912 she gave birth to her last child, Engelina Jeannette. (Source: BvG.)

43 Historians consider the fairgrounds - together with the circuses — as the cradles of the variété. According to Klöters, Honderd jaar amusement, 14, fairs were originally markets where goods - material and immaterial — from the foreign and the new world were imported, including entertainment. When, by the end of the nineteenth century, they had lost this function on account of the rise of middle class and of consumer society, they were believed to be sites of immoral and indecent behavior for the working class and accordingly abolished (Ibid., 36): in Amsterdam in 1876, in Rotterdam in 1908. At the time, café-concerts were gardens around the city in which, during the summer months, foreign performers were on the bill (Ibid., 34), of which the name Vauxhall Doele, in its reference to 
the London Vauxhall Gardens, is reminiscent. See also: Charles Albert Cocheret, Openbare vermakelijkheden: Een Rotterdams tijdsbeeld, 1875-1925 (Rotterdam: Donker 1955), 72.

44 Nocle, "Soubrette... !," 11.

45 Haas, Speenhoff, 21.

46 Klöters questions both men's and women's image-building alike, placing it in the context of the social and sexual practices and norms within the actors' community, which differed from those in the rest of Dutch society. See Klöters, Honderd jaar amusement, 172.

47 Ibid., 58.

48 Ibid., 100; emphasis mine.

49 Louise Fleuron (1877-1943) began in 1898 and remained popular throughout the 1910s, after which she turned to the legitimate stage and the operetta (Alex De Haas, "In memoriam Louise Fleuron," Cinema en Theater, 15 January 1943, 438 in file Louise Fleuron no. 212, TIN). Louisette (1882-1965) first appeared in 1900 in the Circus Carré in Amsterdam (according to the collection of program leaflets at the SAA) as a "pupil" of Chrétienni, with whom she scored repeated triumphs until their separation in 1915. She continued her career as a solo revue and variété artiste or in collaboration with her husband Armand Haagman, and earned herself the epithet "the Dutch Mistinguett" (Roeland van Ruyven, "Louisette," De Hollandsche Lelie, 10 September 1930, 179; press-clipping in Particulier Archief Louisette (code 389/12), SAA).

50 Women's "genres" in French music-hall were, among others, chanteuses, gommeuses, and diseuses. See Philippe Chauveau and André Sallée, Music-hall et caféconcert, (Paris: Bordas 1985) 14; and my careerography of Musidora in Part II of this book.

51 Encyclopaedia Britannica, s.v. "soubrette," at: http://www.britannica.com/eb/ article-9068785.

52 Van Dale Groot woordenboek der Nederlandse taal, twelfth revised edition,1992, s.v. "soubrette."

53 Haas, Speenhoff, 28.

54 Haas, "In memoriam Louise Fleuron."

55 Ibid.

56 Ruyven, "Louisette," 179.

57 Introducer, “Uit de Residentie,” De Komeet, 16 March 1925.

58 Klöters, Honderd jaar amusement, 56. See also his discussions of the careers of Louise Fleuron (Ibid., 67) and Emilie Culp (Ibid., 75 ff.).

59 Emilie Culp made her debut in Rotterdam and passed away in the midst of her career, in 1902 (Ibid. 75.)

$60 \quad$ Rotterdamsch Nieuwsblad, 21 November 1891. 
61 Van Dale 1992, s.v. "Hartjesdag." See: the collection of program leaflets from the Frascati-Schouwburg from 1879-1922, SAA.

62 R., "Kunst en Wetenschappen: Frascati - Een Amsterdamsche Hartjesdag," Algemeen Handelsblad, 17 April 1900.

63 Klöters, Honderdjaar amusement, 66.

64 Advertisement for the Grand Théâtre Amsterdam, De Kunst, 16 November 1912, 111.

65 In Rotterdam, Carl Pfläging operated the Doon or Place des Pays-Bas from 18831891, the Tivoli-Wintertuin from 1892, and opened his first class hall the CircusVariété or Circus Pfläging in 1895. After his sudden death in 1904, it was run by his wife, Mrs. Pfläging-Hradetzky until 1907, when the former comic and later revue manager Henri ter Hall took over, to be succeeded from 1914 until 1929 by Marius Spree. The other major player in Rotterdam was the former variété performer Samuel Soesman, who worked his way up from operating the notorious Salon des Variétés to running the second largest variété-theater in town, the Casino, beginning in 1898. After Soesman's death in 1911, the direction was taken over by his brother, the one-time duettist Philip Soesman, until the variété and revue star Louis Davids succeeded him during the early nineteen-twenties. In The Hague, Boekholt began operating the Scala, in 1901. One legendary variété-theater of Amsterdam was the Flora Variété Theater, which flourished under the direction of Franz Anton Nöggerath, Sr. from 1893 until his sudden death in 1908. Once again, a wife took over, Mrs. Lilli Nöggerath-Alscher, while their son Franz Anton Nöggerath, Jr. continued the film business. In 1928, the film distributor Jean Desmet bought the Flora and turned it into a cinema. (See: Ivo Blom, Jean Desmet and the Early Dutch Film Trade (Amsterdam: Amsterdam University Press 2003), 325.) Other popular locales were the Grand Théâtre, under the direction of the Van Lier brothers, Isidore, Lion, and Joseph from 1905 to 1912; the Paleis voor Volksvlijt under various directors, including Pfläging from Rotterdam, and Frits van Haarlem, Sr.; and the Panopticum, managed during the 1910 s by former bandmaster Sol. J. Kinsbergen. The variété palace of Amsterdam that enjoyed the highest reputation, however, was the former circushall Carré, under the management of Frits van Haarlem, Jr., between 1899 and 1913, and thereafter under the direction of the widow Elisa Maud Carré-Adams, who was usually featured in the program with her famous Lipizzaner horses. While many variété managers earned their good reputations with the help of a supportive family environment, the involvement and competence of their wives only became clear once the women were widowed.

66 Haas, Speenhoff, 87.

67 “Tooneel: Lion Solser †," De Telegraaf, (August 3, 1915); newspaper clipping in Personalia Persdocumentatie Lion Solser, SAA. 
68 Adriënne Solser-Willemsens (1872-1962), daughter of the operetta baritone Jos Willemsens (1844-1928) and sister of the actress and soubrette Isabella Kaart-Willemsens (1876-1939), moved in 1888 from Belgium to Amsterdam. She worked as a soubrette with Gustave Prot until she married Lion Solser in 1899 and joined the Ensemble Solser en Hesse, with which she remained active until 1920. See: Honig, Acteurs- en kleinkunstenaarslexicon, 1040. Anna HesseSlauderof (1861-1933) sang in a chorus and in the variété, for instance at the Vic with the Solsers, before she married Piet Hesse and joined the Ensemble Solser en Hesse, with which she stayed until 1924. See Ibid., 848.

69 The advertisements in Rotterdamsch Nieuwsblad indicate that during the early 1910 Solser was defeated in this regard by Louise Fleuron.

$70 \quad$ Haas, Speenhoff, 87.

71 Klöters, Honderdjaar amusement,121.

72 Giovanni, "Kunst en Wetenschappen, Grand Théâtre, Ueberbrettl-avond,"

440 Algemeen Handelsblad, 17 May 1903. The principal performers were actress Julia van Lier-Cuypers, the comedian pianist Jules Boesnach, and actor and director Louis Chrispijn, Sr.

73 M. O. Nocle, "Moment-Opname no. 29, Klein-Tooneel," Theatergids, n.d. 1916, 13-14.

74 For these dates, see Honig, Acteurs- en kleinkunstenaarslexicon, 869 (for Speenhoff), 630 (for De la Mar), and 734 (for Pisuisse). Speenhoff's "Het Kleine Tooneel" of 1909 ought not to be confused with Eduard Verkade's theater company "Klein Tooneel" of 1915 and 1916. For Verkade, see ibid. 954.

75 See Alex de Haas, De Minstreel van de mesthoop: Liedjes, leven en achtergronden van Eduard Jacobs, pionier van het Nederlandse cabaret, 1867-1914 (Amsterdam: De Bezige Bij 1958). See also: Klöters, Honderd jaar amusement, 121; and Honig, Acteurs- en kleinkunstenaarslexicon, 462.

76 Jeanne Reyneke van Stuwe, Madame Nicotine (Amsterdam: L. J. Veen, 1921), 58.

77 Ibid., 79-80.

78 “Variété-Tooneel," De Kunst, 9 August 1913, 715. Various critics contended that cabaret in the French sense did not exist in the Netherlands, such as L. Essing in his column "Amsterdamsche Dramaturgie," Theatergids, n.d. 1916, 5 or an anonymous reviewer of Reyneke van Stuwe's Madame Nicotine, "Hollandsche Kleinkunst," Cinema en Theater, n.d. 1922, 10.

79 M. O. Nocle, "Centraal Theater: Verkade's Klein Tooneel,” Theatergids, n.d. 1916, 1 .

80 See: Nathan Heyman Wolf, "Variété-Tooneel: "La Sylphe” in Flora," De Kunst, 1 February 1913, 270-72; and Nathan Heyman Wolf, "Variété-Kunst: "Sacrifice," Mimodrama door Meina Irwen,” De Kunst, 20 July 1912, 665.

81 Rido, "Revueparade," De Telegraaf, 10 April 1954; clipping in file Rido (no. 546), TIN. 
See: the advertisement for the Casino Variété Soesman, Rotterdamsch Nieuwsblad, 2 June 1909. According to Haas, Speenhoff, 93, the sketch premiered in 1906.

83 Ibid.

84 Advertisement for the Casino Variété, Rotterdamsch Nieuwsblad, 2 June 1911.

85 Advertisement for the Theater Panopticum, De Kunst, 18 April 1914, 456; and a review of the evening, De Kunst, 18 April 1914), 455. Another review appeared anonymously in Algemeen Handelsblad, 17 April 1914); clipping held in Collection Hartkamp, (P 18053 B), SAA.

86 Martin Liket, “Eén-acters," Theatergids, 2 March 1918, 14.

87 Klöters, Honderdjaar amusement,125.

88 Liket, "Eén-acters," 14.

89 There had been a promising future as an actor in store for Nap de la Mar (18781930) when he, at age twelve, had an accident that partially paralyzed one of his arms and, as his necrologists have it, shattered his father's dream of an impressive acting career for his son. Instead of the legitimate stage, then, in 1903, De la Mar chose the world of variété and operetta, but decided to turn to non-comic parts in the legitimate theater during the 1920s. Therefore, it was assumed that the latter was what he had really wanted and that his twenty years of involvement in the popular theater was just a detour prompted by his slight disability. Already in 1930, apparently, theater critics were no longer aware of how popular and respected "low" theater culture had been during the 19oos and 1910s. See the obituaries by Frits Lapidoth, G. Zalsman Jr., and Pieter Koomen, "Nap de la Mar $\dagger$,”; unidentified and undated newspaper clippings in file Nap de la Mar (no. 439), TIN.

90 "Variété-Tooneel: Bioscope-Theater, Kempinski," De Kunst, 21 May 1910, n.p.

91 See: the advertisement in Rotterdamsch Nieuwsblad of 1 February 1916.

92 "Bioscopisme en Tooneel," De Kunst, 26 April 1913, 1.

93 The cast lists provided by Donaldson, Joy and Sorrow, 79-83 of films with and by Caroline van Dommelen mention, among others, her brothers Jan and Louis van Dommelen, Johan Kelly, Dirk Lageman, Louis Chrispijn Jr., Jan Buderman, and the ladies Cateau Mertens-de Jaeger, Jopie Tourniaire, Tilly Lus, and Caroline's sister-in-law Ansje van Dommelen-Kapper. See also: Honig, Acteurs en kleinkunstenaarslexicon, s.v.

94 Geoffrey Donaldson, "Caroline van Dommelen," The Silent Picture, Summer 1972, 33-34, and "Wie is wie in de Nederlandse film tot 1930: Dommelen, Johannes Sebastianus Engelbertus van (Jan)," Skrien, Winter 1986, 39. To Donaldson goes the honor of saving Caroline van Dommelen, as the first Dutch woman to direct films, from oblivion. See also: Annette Förster, s.v. "Caroline van Dommelen,” Women Film Pioneers Project at wfpp.cdrs.columbia.edu/ pioneer/caroline-van-dommelen-2/. 
95 Ansje van Beusekom, "De dubbele salto tussen 'De Nieuwe Prikkel' en DE JANTJES," Jaarboek Mediageschiedenis, (Amsterdam: Stichting Mediageschiedenis 1997), 185 .

96 Caroline van Dommelen, "Vijfentwintig jaren tusschen de coulissen: Toneelmémoires,” Het Leven, 5 April 1921, 435.

97 Dries Krijn, Bonte pracht, vederdracht: Geschiedenis van de revue in Nederland (Zutphen: Walburg Pers 1980), 13.

98 Beusekom, Kunst en amusement, 28; Donaldson, Joy and Sorrow, 52-53. All English translations of the titles of Dutch silent films are borrowed from Donaldson.

99 Beusekom, "De dubbele salto," 179.

100 Beusekom, Kunst en amusement, 43.

101 Advertisement for the Cabaret Metropole, Rotterdamsch Nieuwsblad, 2 February 1914.

442 | 102 N. N., De Theatergids, 22 March 1913, 2.

103 See the advertisement for the Olympia Palace, De Kunst, 9 July 1910.

104 Julia Culp was related to Emilie Culp and Cato Culp.

105 “Anna Klaasen," Theatergids, n.d. 1917, 16. Anna Klaasen (1881-1944) was an actress at the Koninklijke Vereeniging het Nederlandsch Tooneel until 1912, but during the war, she entertained the audience as a soubrette. In 1919, she left for the Dutch East Indies, where she continued to perform. Honig, Acteurs- en kleinkunstenaarslexicon, 507.

106 For Rika Davids, see Krijn, Bonte pracht, 74, and Honig, Acteurs- en kleinkunstenaarslexicon, 197; for Mina de Cock, Krijn, ibid. 132, and ibid. 173; for Roosje Köhler-van Gelder, ibid. 315; and for Mimi Boesnach, Krijn, Bonte pracht, 48, 64, and Honig, Acteurs- en kleinkunstenaarslexicon, 86.

107 Nathan Heyman Wolf, “Oorlogs-cabaret-programs," De Kunst, 2 December 1916, 103-04.

108 Heintje Davids soon would become more of a revue-star than a soubrette like Solser, as a consequence of her collaboration with her husband Rido/Philip Pinkhof, who wrote many successful revues in the 1910 .

109 Haas, "In memoriam Louise Fleuron."

110 M. v. A., "Nederlandsch Panopticum-Theater en nog wat," De Theatergids, 18 April 1914, 1; "Stadsnieuws: Scala," Haagsche Courant, 8 April 1915; "Kom j'eens kijken, zàg?," Het Vaderland, 2 May 1916; “Kinematografie: Alberts Frères,” De Kunst, 23 November 1912, 126; “Variété-Tooneel: Scala, Den Haag,” De Kunst, 10 April 1915, 351.

111 "Specialiteitenvoorstelling," press clipping from Pak me mee, 2 March 1910, in the scrapbook of Rob du Mée, "Recenties etc. betreffende de voorstellingen in Variété Flora," running from November 16, 1909 to October 1,1910 (hereafter: scrapbook Rob du Mée I). I thank Ansje van Beusekom for providing me access 
to this source. Chanteuse à diction was an alternative name for voordrachtskunstenares or diseuse.

112 The terms appeared in this order: Rotterdamsch Nieuwsblad, 3 October 1908, (advertisement for the Casino Variété); Rotterdamsch Nieuwsblad, 2 June 1909, (advertisement for the Casino Variété); Rotterdamsch Nieuwsblad, 2 June 1911, (advertisement for the Circus Variété); De Kunst, 2 November 1912, 80 (advertisement for the Casino Variété); De Kunst, 16 November 1912, 111 (advertisement for the Grand Théâtre); De Theatergids, 17 May 1913, 7 (advertisement for the Beurs-Bioscoop); De Kunst, 18 April 1914, 456 (advertisement for the Panopticum); in an article by Wolf, "Oorlogs-cabaret-programma's," De Kunst, 2 December 1916, 104 and in "Adriënne Solser," De Kunst, 19 April 1919, 346.

113 Klöters, Honderd jaar amusement, 97.

114 See: the advertisement for the Rozen-Theater, De Theatergids, 10 January 1914, 4; and the advertisement for the Cabaret Metropole, Rotterdamsch Nieuwsblad, 2 February 1914, respectively.

115 “De Revue 1918, Casino-Variété, Rotterdam,” De Kunst, 12 October 1918, 20.

116 From the "Couplettenboek van Adriënne Solser, soubrette," Archief Adriënne Solser en Lien d'Oliveyra, Folder 1, EYE Filmmuseum (hereafter: AAS). The Dutch text reads: "Ik wou dat ik een snijboon was. [...] Ik hoefde nooit alleen te gaan, want ' $\mathrm{k}$ werd steeds afgehaald." The pun derives from the double meanings of the words "snijboon" and "afhalen." In Dutch, "een snijboon" generally means a string-bean, but when referring to people it designates someone as being an oddball. The verb "afhalen" means "to fetch" when referring to people, but "to top and tail" when referring to beans. Another example of a nonsense verse is "Een bitter-zoete geschiedenis" (A bitter-sweet story), "Repertoire Adriënne Solser," Folder 5, AAS.

117 From the "Couplettenboek van Adriënne Solser."

118 "Couplettenboek Adr. Solser," p. 8, Folder 10, AAS. This is one of two notebooks equipped with an index, albeit incomplete, and one of the few in which the pages are numbered.

119 Ibid.

120 Ibid.

121 Letter from Adriënne Solser to the Board of Film Censors, November 24, 1932, Dossier Centrale Commissie voor de Film Keuring, EYE Filmmuseum.

122 "Amsterdam in de Blommetjes" (Amsterdam celebrates), revue written by Rido and performed by Chrétienni and Louisette. See, Rido, "Revue-Parade. 'Amsterdam in de Bolommetjes', De Telegraaf, 23 January 1954; clipping in file Rido.

123 Contained in a notebook without a headline, Folder 17, AAS.

124 See "De vrouwen voor het eerst ter stembus," Het Leven, 3 May 1921, 565.

125 From the notebook without a headline. In Dutch, the line reads: "door de vrouw de tweede kamer/nog " $n$ beste kamer wordt.” The pun is on the Dutch word 
"kamer," which means a chamber or house of parliament, but more generally for a room in the home, the realm of woman. The "beste kamer" is the finest room in the dwelling.

126 Ibid.

127 See M. v. A., "Uiltje-revue," De Theatergids, 13 March 1915, 6-7.

128 Uiltje, "Voor en achter het voetlicht," Uiltje, 10 April 1920, 257-58. The writers using the alias Uiltje, G. Blok and David Orobio de Castro, edited their own satirical weeky.

129 Consider, for instance, "Rijk en arm," in the "Couplettenboek van Adriënne Solser, soubrette."

130 From "De dief," in "Repertoire Adriënne Solser."

131 Traditionally, in the Netherlands, Sinterklaas or Sint Nikolaas (St. Nicholas) brings presents on 5 December, the eve of his birthday.

132 Ibid.

444 | 133 Ibid.

134 From “De Baanwachteres,” Ibid., and in "Repertoire Adriënne Solser.”

135 From "Vrouwelijke Politiebeambte," a sketch with songs, verses and prose, in "Couplettenboek van Adriënne Solser, soubrette" and in "Repertoire Adriënne Solser." It is probably dated to 1916.

136 In Dutch: "dat is de eerste politieagent die ze niet kunnen oplichten, en dat geeft ons de verzekering dat bij de keuze van de eerste vrouwelijke Agenteuse ze niet te licht bevonden is." In Dutch, "oplichten" can mean "to cheat" or "to lift up," and "te licht bevinden" means to be deemed not good enough or not heavy enough.

137 From “De lieve mannen,” in “Couplettenboek van Adriënne Solser, soubrette."

138 Ibid.

139 From "Komaan, wees zoo verlegen niet," Ibid.

140 From "De arme soubrette," in "Repertoire Adriënne Solser."

141 "From "De Nachtvlinder," Ibid.

142 "De mannen begrijpen ons niet," in "Couplettenboek Adr. Solser."

143 From "De liefste van allen," in "Couplettenboek van Adriënne Solser."

144 "De mannen begrijpen ons niet."

145 Signed J. Decb., 1907.

146 Signed T. W. Gebing.

147 Ibid.

148 "Repertoire Adriënne Solser."

149 From "De nachtvlinder," ibid.

150 See Klöters, Honderdjaar amusement, 68.

151 Jeanne Reyneke van Stuwe was one of the few female copy-writers I have come across.

152 Ruyven, "Louisette," 179; emphasis mine. 
153 Henri Bergson, Le rire: Essai sur la signification du comique, Paris: Félix Alcan 1912:142; id., Laughter: An Essay on the Meaning of the Comic, (trans. Cloudesley Brereton and Fred Rothwell) at: http://www.gutenberg.org/etext/4352

154 Advertisement for the Rozen-Theater, Nieuws van den Dag, 30 August 1915. The show was reviewed by M. v. A., "Rozen-Theater," De Theatergids, 4 September 1915, 3-4; and Anonymous, "Stadsnieuws: Rozen-Theater, Weet je moeder 't al?," De Telegraaf, 2 September 1915.

155 Advertisement for the Rozen-Theater, Het Leven, 5 October 1915, 1270.

156 “De Revue 1918: Casino-Variété, Rotterdam,” De Kunst, 12 October 1918, 20.

157 Advertisement for the Rozen-Theater, De Theatergids, 10 January 1914, 4; and advertisement for the Cabaret Metropole, Rotterdamsch Nieuwsblad, 2 February 1914.

158 “Variété-Tooneel: Scala, Den Haag," De Kunst, 10 April 1915, 35.

159 "Stadsnieuws: Scala," Haagsche Courant, 8 April 1915.

160 “Adriënne Solser," De Kunst, 19 April 1919, 346.

161 Haas, Speenhoff, 178.

162 "Duettenboek," Folder 10, AAS. The notebook is undated, but in view of the other verses in it and the revue after which it follows, this entry must have stemmed from the mid-1910s.

163 In Dutch: "wat ik laat zien is geen kuitenparade, geen asem in ballingschap, maar echte ware volksstukken waar de kouwe rillingen van over je rug loopen.” "Asem" means breath in Dutch, but the word is used here as a pun on an illiterate pronunciation of the name Adam. "Adam in Ballingschap" (Adam in Exile) is a classical play by Joost van den Vondel, which was parodied by Solser en Hesse.

164 "Bet en Hein aan het tooneel," in "Couplettenboek van Solser en De Wilde" (dated Rotterdam, December 16, 1918), Folder 2, AAS.

165 See: Guus Rekers, “De Boubers en het ‘bouberen'.” In: G. J. de Voogd (ed.), Facetten van vijftigjaar Nederlands toneel, 1920-1970 (Amsterdam: Moussault 1970), 99.

166 G. P. M. Knuvelder, Handboek tot de geschiedenis der Nederlandse letterkunde, vol. 4: De geschiedenis van de Nederlandse letterkunde van 1875 tot 1916 (Den Bosch: Malmberg 1977) does not include Bouber's work.

167 Esther de Boer-van Rijk (1853-1937) began acting in 1873 and remained with the legitimate theater throughout her long career. The list of plays she was cast in takes up three columns in Honig, Acteurs- en kleinkunstenaarslexicon, 803-4. She also acted in various films by Maurits Binger, Alex Benno, and others.

168 See Knuvelder, Handboek 4,384.

169 Of these poets, the most important representative is Gerbrand Adriaenszoon Bredero, writer of the farce "De Spaansche Brabander" (1618), about common people's life in Amsterdam, which has become one of the classical works in the Dutch theater. See: Knuvelder, Handboek tot de geschiedenis der Nederlandse let- 
terkunde, vol. 2: De geschiedenis van de Nederlandse letterkunde van 1567 tot 1766 (Den Bosch: Malmberg 1977), 219-25.

170 R., "Kunst en Wetenschappen: Frascati - 'n Amsterdamsche Hartjesdag," Algemeen Handelsblad, 17 April 1900.

171 Piet de Rooy, "Toen zijn de mannen uithuizig geworden: De sociaal-culturele verandering van Amsterdam, 1864-1929." In: Groeneboer and Berg (eds.), Dat is de kleine man, 10. During the 1960 and 1970 s, the Jordaan was a quarter where many students and artists lived, but it has since been gentrified into a neighborhood for the nouveaux riche.

172 Bert Hogenkamp, "Film: een even kostbare als kostelijke tijdmachine.” In: Wim Visscher (ed.), Amsterdam in de film: Een filmografie van 1896 tot 1940 (Amsterdam: Gemeentearchief Amsterdam; Zwolle: Waanders 1995), 21-22.

173 Nathan Heyman Wolf, "Bleeke Bet," De Kunst, 18 May 1918, 409.

174 Barbarossa, as quoted in "Lion Solser †," De Telegraaf.

446 | 175 Krijn, Bonte pracht, 83. Gustave Prot, Sr. operated the Frascati-Schouwburg from 1879 until 1895, which mainly produced comic operettas by and with the three K's: the comedians Kreeft, Kelly, and Kiehl. From 1895 through 1912, Gustave Prot, Jr. joined the direction, generating a new heyday for the theater with racy French comedies of the Palais Royal type. See: Klöters, Honderd jaar amusement, 117.

176 Spree spent the last ten years of his life as director of the Circus Schouwburg in Rotterdam, where he staged the famous "Rooie Sien" (Red Sien) in 1918, with his second wife Sophie Spree-te Mijtelaar in the principal role. Klöters, Honderd jaar amusement, 177 .

177 "Het Amsterdamsche Volkstheater," De Prins, 10 August 1901, 64; press clipping in the file Marius Spree (no. 633), TIN.

178 "Het Tooneel," unidentified press clipping dated 1902; file Spree.

179 “Marius Spree," Bekende Rotterdammers: Biografisch Maandschrift, January 1927, 220.

180 "Het Tooneel," file Spree.

181 "Marius Spree," Bekende Rotterdammers, 224.

182 "Jan Smees" played during November 1919 at the Circus Schouwburg in Rotterdam, with Spree's second wife Sophie Spree-te Mijtelaar in the principal role. At the Plantage-Schouwburg, Spree's first wife Jeanne Spree-Monch used to play the principal female roles.

183 Krijn, Bonte pracht, 16.

184 Klöters, Honderd jaar amusement, 109. The actors were the operette-komiek Jan Grootveld and the actress Geertruida André-Meeuwissen, who were otherwise not involved in the Jordaan genre.

185 Krijn, Bonte pracht, 23.

186 See Knuvelder, Handboek 4, 384, 388. 
187 Johan Kelly, the director and comic lead of " "n Amsterdamsche Hartjesdag” at the Frascati-Schouwburg, was another writer-actor.

188 J.H. Rössing, "Lion Solser $†$," 1000.

189 Klöters, Honderdjaar amusement, 89.

190 This was the revue "Weet je moeder 't al?" (Does your mother know it already?), performed in the Rozen-Theater during August and September 1915. It was advertised in Nieuws van den Dag, 30 August 1915; reviewed in De Telegraaf, 2 September 1915; and in De Theatergids, 4 September 1915, 3-4.

191 Aaf Bouber-ten Hoope (1885-1974) began acting in 1900. During the 1910s she was attached to the Plantage-Schouwburg where she played in typical melodramas and volksstukken. Before joining her husband's ensemble in 1918, she performed in revues with Ter Hall and Rip. From 1919 onwards, she took parts in Jordaan-komedies. Between 1915 and 1953, she acted in nineteen movies, including several adaptations of volksstukken. See: Honig, Acteurs- en kleinkunstenaarslexicon, 438.

192 Krijn, Bonte pracht, 108.

193 "Jan Grootveld †: Populair artist uit den tijd van Reijdings revues," unidentified newspaper clipping dated 24 April 1939 (code AA 2000.81), SAA.

194 M. v. A., "Hollandsche Schouwburg: Holl. Operettegezelschap Nap de la Mar, Bleeke Bet, schets in 3 bedrijven," Theatergids, 6 April 1918, 4.

195 Otto Zeegers, "Rhapsodie no. 36: Hóóg de Jordaan!,” De Theatergids, 23 January 1915, 4 .

196 Rido, "Revue-Parade: Solser en Hesse op dreef in "Heb je 't Kind al gezien?", De Telegraaf, 27 March 1954; newspaper clipping in file Solser Family; and Rido, "De Boubers: Deel I, Van enthousiast toeschouwer op het schellinkje tot toneelschrijver is een lange, en moeilijke, weg," De Telegraaf, December 1955; newspaper clipping in file Bouber.

197 "Lion Solser †," Rotterdamsch Nieuwsblad, 5 August 1915.

198 "Jan Grootveld †".

199 Rössing, "Lion Solser †," 1001: Solser and Hesse were stage partners for eighteen years.

200 "Lion Solser $\dagger$, , De Telegraaf.

201 They did so, for instance, at Christmas 1909: see the advertisement for the Frascati-Schouwburg in De Kunst, 25 December 1909.

202 Tom., "Hollandsche Schouwburg. Ensemble Solser en Hesse," De Theatergids, 5 September 1912, 1 .

203 De Kunst wrote on “Kom j'ook naar de bruiloft van Mietje?" (Will you be coming to Mietje's wedding too?): "It was surprisingly good, very amusing, no high art - no art even; but in terms of entertainment very well done, and in terms of performance excellent." "Amusementskunst: Mietje's 50ste Bruiloft," De Kunst, 28 October 1911, 63-4. 
204 Rössing, "Lion Solser †," 1000.

205 "Ensemble Solzer (sic) en Hesse," Nieuws van den Dag, 3 September 1910.

206 Rido, "Revue-Parade. Solser en Hesse op dreef".

207 Otto Zeegers, "Rhapsodie no. 38 (De Triumf van de visch)," De Theatergids, 31 January 1915, 4 .

208 See: J. H. Rössing, “Tooneel," Nieuws van den Dag, 8 September 1915; “Mevrouw Hesse's Jubileum," De Kunst, 12 February 1916, 226-7; and the advertisement for the Rozen-Theater in Theatergids, n.d. November 1917, 17.

209 Rido, “De Boubers: Deel 1," De Telegraaf, n.d. December 1955; newspaper clippings held in file Bouber and file Rido. This was the first of a seven-part series on the careers of Herman and Aaf Bouber, running through January 1956.

210 M. v. A., "Bleeke Bet," Theatergids, 13.

211 Aaf Bouber's engagement with the playhouse occurred while the latter was under the direction of Colnot and Poons, who took over the direction from Stoel and Spree in 1912.

212 Rido, "De Boubers: Deel I."

213 Rido, “De Boubers: Deel IV,” De Telegraaf, n.d. December 1955-January 1956, file Bouber and file Rido, TIN. This happened for two reasons in particular: the enormous success of "De Jantjes," and Bouber's managerial mistakes at the Rotterdam Circus Schouwburg under the direction of Marius Spree, which almost drove him bankrupt.

214 Rido, “De Boubers: Deel II," De Telegraaf, n.d December 1955-January 1956, file Bouber and file Rido, TIN.

215 Rekers, “De Boubers en het "bouberen”, 101, lists a certain Lien Solser as the actress playing Mooie Neel, but a person with that name never existed to my knowledge. Mooie Neel was played by Tine van der Werff (or Werf), an actress formerly engaged by Stoel and Spree and the Ensemble Solser en Hesse. See: Theatergids, 21 April 1917, 14; and Honig, Acteurs- en kleinkunstenaarslexicon, 1029.

216 Rido, "De Boubers: Deel II."

217 Wim Visscher, "Ruwe bolster, blanke pit: Jordaan-film, een populair genre," Ons Amsterdam, October 1991, 248-52.

218 Wolf, "Bleeke Bet," De Kunst, 18 May 1918, 409.

219 See: Donaldson, Joy and Sorrow, 274 and Giovanna Fossati, From Grain to Pixel. The Archival Life of Film in Transition (Amsterdam: Amsterdam University Press 2010), 250. The restoration of ZEEMANSVROUWEN as a sound film was motivated by the knowledge that it was meant to be that way, whereas technical difficulties prevented its completion at the time. Instead of the first Dutch sound film production, it thus became the last silent film production. The dialogue was reconstructed with the help of lip-reading and intertitles.

220 See for a discussion of DE JANTJEs Beusekom, "De dubbele salto," 179-200 and 
Clara Pafort-Overduin, “De Jantjes: hogerop via het cabaret?" In: Madelon de Keizer and Sophie Taes (eds.), Moderniteit, modernisme en massacultuur in Nederland, 1914-1940, Vijftiende Jaarboek van het Nederlands Instituut voor Oorlogsdocumentatie (Zutphen: Walburg Pers 2004), 165-83.

221 "Premières etc.," NWC, 14 September 1934.

222 Rido, "De Boubers. Deel II."

223 The actors Willem Munnik and Johan Siliakus appeared in Jordaan revues and in individual acts such as "Mie en Ko." See: Honig, Acteurs- en kleinkunstenaarslexicon, 679.

$224 \mathrm{~N}$ [athan] H[eyman] W[olf], "Amusementskunst: Kee van de Lindengracht naar Parijs," De Kunst, 12 May 1917, 384.

225 Liket, "Volksstukken," 13-4. The "Jan Salie-geest” was coined by satirical writer Potgieter and indicated a lack of spirit and energy considered typically Dutch.

226 See: Mikhail Bakhtin, Rabelais and His World (Bloomington: Indiana University Press 1984), 12.

227 Reyneke van Stuwe, Madame Nicotine, 72-73.

\section{ADRIËNNE SOLSER AND THE DUTCH SILENT CINEMA}

1 See, among others: Beusekom, Kunst en amusement, 13.

2 She may have watched moving pictures in South Africa, as in 1895-1899 they were shown widely in South African music-halls too. See: Guido Convents, s.v., South Africa, in: Richard Abel, Encyclopedia of Early Cinema (Abingdon, Oxon: Routledge 2005), 598.

3 Beusekom, Kunst en amusement, 31 and "De dubbele salto," 187.

4 Beusekom, Kunst en amusement, 32-33.

5 See: the advertisements for the Variété Flora Amsterdam in De Kunst, 10 January 1914, 240, and 18 April 1914, 455. The Dutch term bioscope, which is spelled bioscoop today, is still the equivalent for the English word cinema as it indicates the location where films are screened and viewed.

6 Beusekom, Kunst en amusement, 41.

7 See: the advertisements for the Cinema Palace in De Theatergids, 1 March 1913, 4; for the Plantage Bioscope in De Kunst, 4 January 1913, 222; and for the Cinéma de la Monnaie in De Kunst, 1 March 1913, 350. See also: Blom, Jean Desmet, 123-4, in which he states that continuous film screenings remained the rule in cinemas in Amsterdam up until 1914.

8 See: the advertisements for the Casino Variété Soesman in Rotterdamsch Nieuwsblad, 6 June 1904, 2 March 1908, 2 June 1909, and 2 October 1909; in De Kunst, 2 November 1912, 80; and the advertisement for the Flora Variété Amsterdam's program running from 1 to 15 March 1917; held in the scrapbook Rob du Mée II. 
9 See also: Cobi Bordewijk, “'Prachtvol gekleurd doch zeer boeiend', Jaarboek Mediageschiedenis, 8, 1997, 153-77, who surveyed this phenomenon in the city of Leiden.

10 For an account of the Dutch discussion on cinema as art versus cinema as entertainment, which took place in the Netherlands during the 1920s, see Beusekom, Kunst en amusement, chap. 4.

11 See: "Variété-Tooneel: Gemengde programma's," De Kunst, 1 March 1913, 351; "De intrede van Film en Bioscoop in Nederland," NWC, 11 October 1935; "Kinematografie: Alberts Frères,” De Kunst, 23 November 1912, 126; and Beusekom, Kunst en amusement, 43.

12 N. H. Wolf, "Pathé Frères: Louis Justet," De Kunst, 27 December 1913, 205.

13 Het Vrije Tooneel and Het Vroolijk Tooneel took turns at the Bioscope-Theater from January through March 1910. During this period, two jubilees were celebrated there of other performers who played particular roles in Adriënne Solser's career: Solser en Hesse in December 1909, and Alex Benno in January 1910. See: the scrapbook Rob du Mée I.

14 Beusekom, Kunst en amusement, 53. See also: the reports of cinemas opening in Amsterdam by Violet, "Bioscope Tavenu," De Theatergids, 12 October 1912, 5; and M. v. A., "Cinéma-Palace," De Theatergids, 28 December 1912, 1.

15 See: the advertisement for the Bioscope-Theater in De Kunst, 13 August 1910 and the scrapbook Rob du Mée I.

16 Ibid. and "Bioscope-Theater," Nieuws van den Dag, 3 September 1910.

17 See: the advertisement for the Bioscope-Theater in De Kunst, 11 March 1911.

18 Beusekom, Kunst en amusement, 50.

19 Advertisement for the Bioscope-Theater in De Kunst, 1 March 1913, 350. The film was not specified beyond being a Gaumont drama in two acts.

20 See: the advertisement for the Bioscope-Theater in Theatergids, 17 August 1918, 4 , in which the live act was set in smaller typeface than the film title; as well as the program for the Bioscope-Theater from 17 to 23 March 1922, contained in the scrapbook Rob du Mée II.

21 M. v. A., "Bioscoop Theater: Directie: F. A. Nöggerath," Theatergids, 16 February 1918 , 16. Jules Boesnach (1883-1927) was a very popular piano playing humorist of the second generation, who performed together with his wife Bertha Boesnach. He was related neither to Mimi Boesnach, nor to Solser's ex-husband Joseph Boesnach. See: Klöters, Honderd jaar amusement, 99.

22 M. v. A., "Bioscoop Theater: Directie: F. A. Nöggerath," Theatergids, 20 October $1917,16$.

23 Reviews in De Telegraaf, 3 September 1910; and De Komeet, 16 September 1910; held in the scrapbook Rob du Mée I.

24 Blom, Jean Desmet, 77-80. This information is based upon an advertisement of the films available for rental in De Komeet, 31 December 1909. See also: Ibid. 
227-32, and the advertisement for the Bioscope-Theater in De Kunst, 4 January 1913, 222.

25 N. H. Wolf, “F. A. Nöggerath's Films: Bioscope-Theater, Amsterdam,” De Kunst, 21 August 1920, 642.

26 See: Donaldson, Joy and Sorrow, 79 and 131-2, respectively.

27 Advertisement for the Bioscope-Theater in De Kunst, 21 June 1913, 605.

28 N. H. Wolf, "Het Film-Mimodrama: De Geschiedenis van een Pierrot, BioscopeTheater, Dir. Nöggerath, Amsterdam,” De Kunst, 4 July 1914, 619-20.

29 Scrapbook Rob du Mée II. The Cunard-Ford serials were not the first to reach the Netherlands, but they were released at a time when the serial genre had permeated Dutch cinema. They were preceded by, to name a few, FANTôMAs (Gaumont 1913), and UNDER THE CRESCENT (Universal Gold Seal 1915), and they reached the Netherlands around the same time as did THE EXPLOITS OF ELAINE (Pathé 1915) and LES VAMPIRES (Gaumont 1915-16). For an overview of serials shown in the Netherlands, see Rudmer Canjels, "De Serial in Nederland: 1915-1925," Tijdschrift voor Mediageschiedenis 4, 1 (2001), 108-28, and his Distributing Silent Film Serials. Local Practices, Changing Forms, Cultural Transformation (New York and Abingdon: Routledge 2011).

30 For an overview of Dutch film distribution and its links to film exhibition during the early 1910s, see: Blom, Jean Desmet, 232-7.

31 See: the advertisement for the Thalia-Bioscoop-Theater in Rotterdamsch Nieuwsblad, 24 August 1912. In March 1915, SEVERo TORELLI, featuring Musidora, was screened and complemented by a live performance by Albert Bol, and in February 1916, Adriënne Solser was featured "in her entirely new repertoire" together with an otherwise unspecified film called COLLIN'S DAGBOEK. See: Rotterdamsch Nieuwsblad, 11 February 1916. Nöggerath, Abraham Tuschinski continued to combine staged and screened acts even well into the 1920s. See: Beusekom “De dubbele salto," 196. At Tuschinski's Rotterdam cinemas Thalia and Nieuw Olympia, Alex de Haas was engaged as the comic performer at the piano from 1920 through 1928; see the scrapbooks in the Collection Alex de Haas at the TIN.

32 Advertisements in various issues of Rotterdamsch Nieuwsblad (1913). The performers belonged to the later generation of Dutch comedians.

33 Advertisement for the Grand Théâtre in Algemeen Handelsblad, 14 November 1912; repeated in the issues of 21 November 1912 and 23 November 1912, the latter with a change of the feature film title. In De Kunst, 23 November 1912, 123, there ran an advertisement that explicitly stated: "Adriënne Solser soubrette, extended run." Alberts Frères were the regular summer exhibitors at the Grand Théâtre beginning in 1909. See: Beusekom, Kunst en amusement, 35 . “Kinematografie: Alberts Frères," De Kunst, 23 November 1912, 126.

35 The Tip-Top-Theater opened in March 1914 with a program of music, humor, 
and film. I base my case upon a systematic survey of the advertisements in De Kunst between 1909 and 1916 and in De Theatergids between 1912 and 1915 .

36 “Variété-Tooneel: Gemengde programma's," De Kunst, 1 March 1913, 351.

37 Around the turn of the century, the Rembrandt Theater was a variété-theater that mainly presented foreign attractions. The Rembrandt Theater already began to include films in December 1903. For this information, I drew from the advertisements in Algemeen Handelsblad. Under the direction of Max Gabriel from 1910 through 1914, the theater became known for staging operettas starring, among others, Piet Köhler. During the war, film was again included, and ,in 1919, it was bought by the UFA and turned into a cinema, which continued to include live acts during the 1920s. See: the file "Specialiteitentheaters, Rembrandt Theater" (file T 732.110), SAA. De Vereeniging opened in May 1893 as a café-concert and was the place where Louis Davids made his debut. When showing films during the 1910s, it was renamed the Beurs-bioscoop. Bellevue was the former café-concert Maison Stroucken where Michel Solser, together with Chrétienni, gave three exceptional presentations of "De Revue Artistique" in 1892. In 1910, it began including film in its program, but eventually returned to staged entertainment. See: the illustration in Klöters, Honderd jaar amusement, 53.

38 "Specialiteitenvoorstelling: Apollo-Theater," Pak me mee, 2 March 1910; clipping in scrapbook Rob du Mée I.

39 N. N., "Rozen-Theater," De Theatergids, 22 March 1913, 2.

40 Advertisement for the Rozen-Theater in De Theatergids, 10 January 1914, 4. The advertisement for the same program in De Kunst, 10 January 1914, 240, however, did single out the opéra comique "De List van Pierrot" typographically.

41 Advertisement for the Beurs-Bioscoop in De Theatergids, 17 May 1913, 7.

42 M. v. A., "Theater "De Vereeniging”," De Theatergids, 20 May 1913, 1.

43 Nevertheless, De Theatergids can be considered among the forerunners of Dutch film criticism, in the footsteps of De Kunst, whose pioneering role has been pointed out by Beusekom, Kunst en amusement, 75 .

44 Beusekom, Kunst en amusement, 53.

45 M. O. Nocle, “Moment-Opname no. 112: Repertoire kiezen," Theatergids, 20 April 1918, 4.

46 Advertisements in Rotterdamsch Nieuwsblad during September and October 1915.

47 Beusekom, Kunst en amusement, 88.

48 For instance, in an advertisement for Cinema Imperial in Rotterdam in Rotterdamsch Nieuwsblad, 14 June 1915.

49 Advertisement for the Cinema Pathé-Tivoli Bioscope in Rotterdamsch Nieuwsblad, 25 September 1916. In December 1918, the Bioscoop Luxor Theater showed JOE DEEBS, ZIJN BESTE VRIEND (Joe Deebs, His Best Friend) along with a further extensive program and variété and the Princes-Theater supplemented 
DE HELD MACISTE, ALS BEVRIJDER (The Hero Maciste, the Liberator) with two variété acts. Advertisements in Rotterdamsch Nieuwsblad, 27 December 1918.

50 Advertisement for the Nieuw Olympia Theater in Rotterdamsch Nieuwsblad, 4 June 1917. The page of advertisements in the same newspaper of October 4, 1918, announces Lucien, the Gentleman on Stage, at the Cinema Royal, Willy Derby and Les Niotnaz (a transformation dance-act) at the Thalia-Theater, and Sophie Smith and Raf Kapper at the Nieuw Olympia Theater.

51 See, for instance: the advertisements for the Cinema Royal and Thalia in Rotterdamsch Nieuwsblad, 4 October 1918.

52 "Variété in de bioscoop," Kunst en Amusement, 27 October 1922, n.p.

53 Bordewijk, "Prachtvol gekleurd," 153-77.

54 “Kinematografie: Alberts Frères,” De Kunst, 23 November 1912, 126.

55 This sketch is the third monologue in the notebook that includes the revue by Uiltje, “Kom j'eens kijken, zàg?, from May 1916, but was obviously written prior to that. (Folder 10, AAS).

56 Ansje van Beusekom, "The Rise and Fall of the Lecturer as Entertainer in the Netherlands: Cinema Exhibition Practices in Transition Related to Local Circumstances, "Iris 22 (Autumn 1996), 131-44.

57 Frank van der Maden, "De komst van de film." In: Karel Dibbets and Frank van der Maden (eds.), Geschiedenis van de Nederlandse film en bioscoop tot 1940 , (Weesp and Antwerpen: Wereldvenster 1986), 26 ff.

58 N. H. Wolf, “Kinematografie: Explicatie,” De Kunst, 4 January 1913, 222.

59 Ibid.

60 Ibid., 223.

61 N. H. Wolf, "Kinematografie: Explicatie (III)," De Kunst, 1 March 1913, 351.

62 Wolf, “Kinematografie: Explicatie," 223.

63 I agree with Ansje van Beusekom's observation that lecturing with films seems to have been a man's job. One woman who was mentioned in advertisements was Nelly Nieuwstraten, a lecturer and piano player at the Amsterdam Odeon in 1912. See: Beusekom, "Rise and Fall of the Lecturer," 141-42, note 4. However, the advertisements in Kunst en Amusement of 1920 and 1921 do show a remarkable number of female pianists and singers active in film accompaniment.

64 See: Chef van Dijk, "De Explicateur (Slot)," Nieuw Weekblad voor de Cinematografie, 31 October 1924 (hereafter: NWC); and Beusekom, "Rise and Fall of the Lecturer," 136.

65 Chef van Dijk, "De Explicateur (II)," NWC, 2 October 1924.

66 M. O. Nocle, "Moment-Opname no. 103," Theatergids, 16 February 1918, 13.

67 Max van Wesel, “De Explicateur," De Lichtstraal, n.d. July 1918, 2, reprinted from De Filmwereld, 15 June 1918.

68 Ibid.

69 Beusekom, Kunst en amusement, 88. 
Dijk, "De Explicateur (Slot).”

71 Ibid.

72 Ruud Bishoff makes the point that Alberts Frères', i.e., the Mullens' fiction film production has been neglected in Dutch film studies largely because it did not seem to be in line with their later non-fiction. See: Ruud Bishoff, "De zwijgende speelfilm.” In: Dibbets and Van der Maden (eds.), 65. Here I wish to emphasize that while their production did include fiction, it was mainly comic fiction.

73 Donaldson, Joy and Sorrow, 55 and 61 respectively. The latter film is one of the few to have been preserved.

74 Ibid., 71.

75 See: Beusekom, Kunst en amusement, 26.

76 See: Geoffrey Donaldson, "Wie is wie in de Nederlandse film tot 1930," Skrien, (Winter 1983-84), 35; Krijn, Bonte pracht, 107; and Donaldson, Joy and Sorrow, 66. Donaldson mentions Heintje Davids as being the duet partner of Louis, whose activity in that field, however, was only launched a year later, in 1907, in the Ter Hall revue "Doe er 'n deksel op!" (Put a Lid on It!) at the Circus Variété in Rotterdam. See: Krijn, Bonte pracht, 108.

77 For details of their tours, see Donaldson, Joy and Sorrow, 77.

78 Undated and unspecified British and American press clippings held in Particulier Archief Louisette. She visited the USA with the act for the first time in 1913. See: Ruyven, "Louisette."

79 Ibid.

80 From the American press clippings in Particulier Archief Louisette.

81 In 1924, when Solser made and accompanied her film BET, DE KONINGIN VAN DE JORDAAN (Bet, The Queen of the Jordaan), Louisette performed the act again, including newly-shot film inserts with her husband Arnold Haagman. See: Donaldson, Joy and Sorrow, 238.

82 The slang word "blom" signifies both flower and young woman.

83 File "Specialiteitentheaters, Circus Carré," (T 738039), SAA.

84 “Circus Carré,” Nieuws van den Dag, 8 September 1908.

85 Van Haarlem mounted two more revues with film inserts: BIJ CARRÉ (1903), with shots of the audience entering for the revue "Amsterdam Bovenal," also starring. Chrétienni and Louisette, and UTRECHT BOvenAL (Utrecht Above All,1912), an Utrecht adaptation of the Flora revue "Amsterdam op hol!" (1910). See: Donaldson, Joy and Sorrow, 55 and 88.

86 Geoffrey Donaldson, "Wie is wie in de Nederlandse film tot 1930: Nöggerath, Franz Anton (Senior)," Skrien, 128 (Summer 1983), 34; and Bishoff, "De zwijgende speelfilm," 58 .

87 F. A. Nöggerath, Ons bioscopisch bedrijf voorheen en thans (Amsterdam: Nöggerath 1911).

88 Donaldson, Joy and Sorrow, 54 . 
89 Starring, most notably, the Dommelens and the Bouwmeesters.

90 In Donaldson, Joy and Sorrow, 78, the film is listed under the name of the revue and ascribed to the direction of Léon Boedels. The revue, however, was directed by Louis Chrispijn, Jr., the jeune premier of Gustave Prot.

91 Isidore Zwaaf (1873-1940) began his career at age 21 and collaborated for many years with Sam Soesman's brother Philip, before he switched to the revue in 1910 and became the leading actor in all the revues at the Flora written by Rido. One of his famous acts was "De Artiestenrevue," after the sketch "De Revue" by Michel Solser, which was made into a film by Alex Benno in 1926, with Zwaaf as Philipje and Adriënne Solser's daughter Adèle Boesnach as one of the actors interviewed. Aside from this, Zwaaf was an operette comedian. See: Honig, Acteurs- en kunstenaarslexicon, 1059; and Donaldson, Joy and Sorrow, 260.

92 Rido, "Revue-parade: Het publiek kwam driemaal naar dezelfde revue kijken," De Telegraaf, 10 April 1954; press clipping, file Rido.

93 Ibid.

94 M.v. A., "Theater Panopticum," De Theatergids, 29 September 1913, 1. Under review was a re-use of the film insert in "Amsterdam op hol!" for the act "Zwaaf is zoek” (Zwaaf's gone missing), in Rido's anthology-revue “Uitzoeken maar!!” (Just take your pick!).

$95999+1$ was directed by Louis Chrispijn Jr., son of the later Hollandia director Louis H. Chrispijn Sr., and co-produced by Film-Fabriek F. A. Nöggerath in conjunction with Het Vroolijk Tooneel, a company featuring the former Prot actor Jan Buderman.

96 Donaldson, Joy and Sorrow, 74.

97 "Filmspel," De Kunst, 14 November 1914, 1. For a detailed description of Linder's "bioscoop-stukje” (short cinema piece) "Député," see Leo Faust, "Kunst te Parijs," De Kunst, 4 July 1914, 624-6.

98 Other revues by Rido and with Zwaaf that made use of film inserts, were "Rotterdam op hol!," mounted in the Casino Variété in Rotterdam, and "Een schandaal” (A Scandal), in the Flora, both in 1912. See: Donaldson, Joy and Sorrow, 86 and 92, respectively.

99 With Zwaaf, he produced WILLEM GAAT MELK HALEN (Willem Fetches the Milk) (Ibid., 87-88); with Kelly and Lageman, DE GEBROKEN SPIEGEL (The Broken Mirror) (Ibid., 84); and with Buziau, DIE VERWORFENE (The Female Outcast) (Ibid. 84), A HELPING HAND (Ibid., 88), JOPIE GAAT TROUWEN (Jopie Is Going to Get Married) (Ibid., 94), and ATTRACTIVE ARCHIBALD (Ibid., 98). Lageman was also the author of the verwisselingskomedie (comedy of errors) DE PANTOFFELHELDEN (The Henpecked Husbands), whose actors are unknown (Ibid., 94).

100 The titles are as follows: MIE EN KO UIT DEN JORDAAN MET DE GEVONDEN DAMSCHAT (Mie and Ko from the Jordaan in Amsterdam With the Recovered Dam Treasure), with the Jordaan duo Mie and Ko, i.e., the actors Willem Munnik and 
Johannes Siliakus, but otherwise very little is known about this missing film (Ibid.,162); ER WAREN EENS DRIE HOEDEN (Once Upon a Time There Were Three Hats) (Ibid., 174); and AMERICAN GIRLS (Ibid., 181).

101 Louis Bouwmeester in Het Vaderland, quoted in De Theatergids, 5 September 1912, 1.

102 See: Bishoff, "De zwijgende film," 67-90.

103 Peter Delpeut, "A Cinema of Accidental Incidents: Dutch Fiction Films 18961933, a Review." In: Donaldson, Joy and Sorrow, 11-31.

104 See: Bishoff, "De zwijgende film," 76

$105 \mathrm{M}[\mathrm{ax}] \mathrm{v}$ [an] W[esel], "Filmkunst ... Volkskunst," NWC, 29 February 1924.

106 Ibid.

107 See: Ruud Bishoff, Hollywood in Holland. De geschiedenis van de Filmfabriek Hollandia 1912-1923 (Amsterdam: Uitgeverij Thoth 1988), 93.

108 Beusekom, Kunst en amusement, 91-2.

456 | 109 “Alex Benno's jubileum,” De Komeet, 1 January 1910; clipping in the scrapbook Rob du Mée I.

110 Benno's remark, made vis-à-vis KEE EN JANUS NAAR PARIJS (Kee and Janus Go to Paris) and BLEEKE BET, in the interview "Over de Hollandsche film: In gesprek met Alex Benno.” In: Herman van Lee and Sjoerd Broersma, De wonderen der filmwereld (Utrecht: Lewandowski 1926), 12.

111 P[iet] K[loppers]., "Passage-Bioscoop: Kee en Janus naar Parijs," Algemeen Handelsblad, 13 January 1924; my emphasis.

112 "Cinema de Munt," Kunst en Amusement, 15 April 1921.

113 The tramp's actual name was Cornelis de Gelder, and he had earned his nickname in 1916 when he was hired to advertise the revue "Hadt-je-me-maar" by Nap de la Mar. See: Donaldson, Joy and Sorrow, 206; and the advertisement for the Circus Schouwburg in Rotterdamsch Nieuwsblad, 1 December 1916.

114 "Cinema de Munt," Kunst en Amusement, n.p.

115 Marcel Westhoff, "Alex Benno, exponent van de vooroorlogse Nederlandse film," Historisch Tijdschrift Holland, 29, 4-5 (1997), 276.

116 The latter two functions are not mentioned in Westhoff's essay, but can be supplied on the basis of press clippings held at the EYE Filmmuseum, file biographical clippings, Alex Benno: "Hoe de Nederlandse film ontstond," unspecified press clipping dated 2 March 1934; and Rido, "Pionier van de Nederlandse film: Alex Benno," undated and unspecified press clipping.

117 For an overview and discussion of the Hollandia output, see: Bishoff, "De zwijgende film," 67-90.

118 Donaldson, Joy and Sorrow, 131, mentions Benno as the possible director of BET TREKT DE 100.000. For the credits of the MIJNTJE EN TRIJNTJE-series, see ibid. 109 and 115, and for the farce DE VERWISSELING ONDER HET BED, 125.

119 Advertisement in Kunst en Amusement, 25 November 1921 as cited in Westhoff, 
"Alex Benno," 282.

120 See: Bishoff, "De zwijgende film," 88; and "Hollands filmindustrie herleeft!," NWC, 2 November 1923.

121 See: Bishoff, "De zwijgende film," 104.

122 See: ibid., 112 and the advertisement for Actueel Film in NWC, 5 January 1923.

123 Benno directed and produced ORANJE HEIN in 1925, initiated and co-scripted with the director Jaap Spyer the sound version of DE JANTJES in 1934, co-directed with Richard Oswald the sound version of BLEEKE BET in 1934, and directed and produced AMSTERDAM BIJ NACHT (Amsterdam at Night), adapted from Bouber's play “Ronde Ka", in 1937. On top of these, Benno directed and produced DE ARTIESTENREVUE in 1926. See also: NWC, 4 January 1935.

124 Lee and Broersma, "In gesprek met Alex Benno," 12.

125 See: Bishoff, "De zwijgende film," 93-97.

126 Ibid., 86.

127 See: "Fabricage en Handel: Verfilming “De Jantjes", Kunst en Amusement, 10 February 1922; "De films van de week: 'De Jantjes'”, Kunst en Amusement, 24 March 1922; “Bioscoop.” De Telegraaf, 26 March 1922; and “Witte Bioscoop: 'De Jantjes'," Algemeen Handelsblad, 27 March 1922.

128 "Bioscoop," De Telegraaf.

129 “'De Jantjes' voor de filmlens," Cinema en Theater, n.d. 1922, 8. In 1934, a soundfilm adaptation of the play was directed by Jaap Speyer, in which Heintje Davids played the role of Na Druppel.

130 "De films van de week: 'De Jantjes'."

131 See her photograph included in the article "De Jantjes voor de filmlens," 8.

132 Donaldson, Joy and Sorrow, 219.

133 See: “Witte Bioscoop. "De Jantjes”, "De Telegraaf, 26 March 1922, which maintains that the play's plot was faithfully followed, but that many scenes were added.

134 Beusekom, "De dubbele salto," 195.

135 "Premières: Kee en Janus naar Berlijn,” NWC, 5 January 1923, 4.

136 Pruis was a gentleman humorist who had also worked with Bouber and De la Mar.

137 Lee and Broersma, "In gesprek met Alex Benno," 11-12.

138 "Premières: Kee en Janus naar Berlijn," 4.

139 See: Donaldson, Joy and Sorrow, 239; and Algemeen Handelsblad, 13 January 1924 .

140 "Premières: Kee en Janus naar Berlijn," 4.

141 Lee and Broersma, "In gesprek met Alex Benno," 12.

142 It is difficult to tell to which film the still belongs. Yet it seems that Piet Köhler features in it, because the picture was published alongside an article referring to Köhler and Solser reappearing as a comic duo in another film. See: M., "Filmland: Onder den rook van Amsterdam," Weekblad Cinema en Theater, n.d. 1924. It is therefore unlikely that it stems from Solser's own production of BET, DE 
KONINGIN VAN DE JORDAAN, to which both Bishoff, "De zwijgende film," 90, and the EYE Filmmuseum have ascribed the still. See also: Annette Förster, Ladies First: Een programma met films van vrouwelijke cineasten (Amsterdam: Nederlands Filmmuseum 1992), 28.

143 "Kee en Janus naar Parijs," Cinema en Theater, n.d. 1923, 3.

144 "Kee en Janus naar Berlijn," Kunst en Amusement, 15 December 1922.

145 "De Moulin Rouge," Cinema en Theater, n.d. 1923, 3.

146 For Kee and Bet characters before 1920, see, for instance, "Groen-maken," a prose monologue and verse, in the "Couplettenboek van Adriënne Solser, soubrette;" "Duettenboek van Solser en De Wilde;” and the prose monologues "Bolle Bet als 1ste vrouwelijke Schotsche Hooglander" and "Bolle Bet gaat naar 't toneel" in "Duettenboek."

147 “Thalia-Bioscoop," Het Vaderland, 24 February 1923.

148 "Premières: Kee en Janus naar Berlijn," 4.

$45^{\mid} 149$ 415”Mooi Juultje van Volendam," Kunst en Amusement, 18 October 1924, 511.

150 "Premières: Kee en Janus naar Berlijn," 4

151 "Van de verhuurkantoren: Kee en Janus naar Parijs," NWC, 11 January 1924.

152 "Passage-bioscoop: Kee en Janus naar Berlijn," De Telegraaf, 7 January 1923.

153 See: the advertisement from Alex Benno-Actueel Film for KEE EN JANUS NAAR BERLIJN in NWC, 9 February 1923, 24; and for KEE EN JANUS NAAR PARIJS in $N W C, 29$ February 1924. For details of these films' runs, see also: Westhoff, "Alex Benno," 285.

154 Donaldson, Joy and Sorrow, 219.

155 Also to contemporaries, see Cinema en Theater, which twice used the term 'verbazend' (surprising) when referring to the popularity of KEE EN JANUS NAAR PARIJS with the public. See: Cinema en Theater, n.d. 1923, 3 .

156 These were the current economic crisis and the high cost of tickets, as a result of high rental prices and the entertainment tax; moreover, it was an exceptionally hot summer that year. The consequence was that cinemas and distribution offices had to close. See: "De malaise in het filmbedrijf," Kunst en Amusement, 9 June 1922.

157 Beusekom, Kunst en amusement, 139.

158 "Premières: Kee en Janus naar Parijs," NWC, 18 January 1924.

159 Ibid.

160 Ibid.

161 Lee and Boersma, "In gesprek met Alex Benno," 12.

162 Ibid., 14.

163 See: "Passage-Bioscoop: Kee en Janus naar Berlijn,” De Telegraaf, 7 January 1923; and P. K., "Passage-Bioscoop: Kee en Janus naar Parijs," Algemeen Handelsblad, 13 January 1924. One positive review was "Thalia-Bioscoop," Het Vaderland, 24 February 1923. 
164 Jules Suikerman, "De débacle der Nederlandsche filmindustrie," letter to the editor, $N W C, 22$ February 1924. This same Jules Suikerman, incidentally, had no qualms - after Benno left the Dutch Film Co.—about initiating the Hollando-Belgica Film Mij. "Eureka” together with André Boesnach and Adriënne Solser in September 1924, nor about continuing to make farces under its aegis. See: “Ons eigen land: Adriënne Solser's laatste film,” NWC, 12 September 1924 .

165 "Het film-blijspel,” NWC, 29 February 1924.

166 "Uit de studio's," NWC, 1 February 1924.

167 Westhoff, "Alex Benno," 285. Benno continued his career in directing and producing films just as energetically. After 1934, when economic and political circumstances made filmmaking impossible, he concentrated on distribution prior to the Second World War, and on exhibition afterwards. He died in 1952.

168 For an overview of Frenkel's career, see Bishoff, "De Zwijgende film," 91-98.

169 Advertisement by the Dutch Film Co. for AMSTERDAM BIJ NACHT in NWC, 25 April 1924 .

170 Ibid.

171 "Premières: Amsterdam bij Nacht," NWC, 25 April 1924. The star of the film was Annie Bos, the only true film diva of Dutch silent cinema.

172 “Union-Bioscoop: Amsterdam bij Nacht," Algemeen Handelsblad, 20 April 1924.

173 Donaldson gives two more synopses of feature films with Jewish characters: for WEERGEVONDEN (Found Again 1914) by Louis Chrispijn Sr. and for DIAMANT (Diamond 1916) by Johan Gildemeijer, see: Donaldson, Joy and Sorrow, 131 and 147 , respectively.

174 Hetty Berg, "Joden en Jodinnen aan het tooneel: Het joodse aandeel in het Amsterdamse amusement" in: Groeneboer and Berg (eds.), Dat is de kleine man, 43 .

175 See: Donaldson, Joy and Sorrow, 247.

176 “Union-Rialto-Passage: Het Hollandsche Circus," De Telegraaf, 18 October 1924.

177 “Unionbioscoop, Passagebioscoop en Rialtotheater: Het Hollandsche Circus," Algemeen Handelsblad, 19 October 1924.

178 See my discussion of possible dates for Solser's debut on stage at the beginning of this careeropraphy.

179 Beusekom, "De dubbele salto," 195, too has noted that BET, DE KONINGIN VAN DE JORDAAN may be considered an extended soubrette act.

180 As Beusekom has analysed it, three views dominated the discourse on cinema in the Netherlands during the mid-1920s: a derogatory view based upon the notion of cinema as posing a danger to culture and society, which prevailed in the press; the view of the new generation of intellectual critics, who embraced film fragments and experimental aspects that heralded a new art; and a more popular view of cinema as entertainment for the masses, which, however, was 
given less articulation in the press than in the creative attitude of cinema programmers. See: Beusekom, Kunst en amusement, 137.

181 See: Jan Klopper, “Jordaan, Kismet en de Kritiek,” Kunst en Amusement, 9 August 1924, 381. L. J. H. Jordaan was one of the new generation of critics and criticised by Klopper in this article for having accused the popular film KISMET of deceiving good taste. A tirade from the Jordaan against comic film was also published as a supplement.

182 See: Beusekom, Kunst en amusement, 136.

183 Advertisement for the Hollandia-Belgica Film Mij. "Eureka” in NWC, 12 September 1924, and 3 October 1924 . With respect to the name of this film company, note that, by December, when BET, DE KONINGIN VAN DE JORDAAN was released, the term "Hollandia" had been changed into "Hollando." See: NWC, 5 December 1924 .

184 “De film-studio 'Eureka': Hollywood in Schiedam," Schiedamsche Courant, 22 September 1927, back page. Boesnach stated that he also had been to Berlin, Vienna, and Rome during his eleven years of apprenticeship in film studios. In one of his obituaries, it was said that he had entered the studios at age eighteen, that is to say, in 1914. See "A. Boesnach †," Schiedamsche Courant, 22 March 1928.

185 This possible intent of Solser's to establish the company for her son's sake, was suggested to me by the Dutch filmmaker Anouk Sluizer, who has done research for a film on Solser and who, for that aim had spoken to the late Stien Hanou, the life companion of Lien d'Oliveyra.

186 See: "Huldiging Adriënne Solser," NWC, 20 March 1925; and the advertisement for the Hollando-Belgica Film Mij. "Eureka" in NWC, 1 May 1925.

187 "Bet Zit in de Penarie," NWC, 14 January 1927.

188 See: the scrapbook "Recentie-boek van Adriënne Solser voor de film: BET NAAR DE OLYMPIADE (Bet to the Olympic Games) begonnen te Groningen Vrijdag 28 October 1932" (Folder 25a), AAS.

189 “Ons eigen land. Adriënne Solser's laatste film," NWC, 12 September 1924. It is unclear for how long Suikerman remained affiliated with the company, but beginning with the advertisement in $N W C$, 3 October 1924, his name no longer appeared in the advertisements.

190 Advertisement for the Hollandia-Belgica Film Mij. "Eureka" in NW C, 12 September 1924 .

191 The Eureka advertisement in NWC promised the release of two films by the French director Jacques de Baroncelli.

192 Press release cited under the title "Hollando Belgica Film Mij. ‘Eureka',” NWC, 15 January 1926.

193 See: the Eindvonnis (Final Ruling), dated 19 June 1929, in Verdict Case 239/1928, Audiëntiebladen Civiele Procedures, Zeeuws Archief Middelburg. 
Two film titles, of which positive prints were listed as belonging to the inventory, corresponded to those advertised: DE KLOKKENLUIDER VAN MIDDERNACHT (The Midnight Bell-ringer) and DE POOLSCHE JOOD (The Polish Jew). Those were listed as films by the French director Jacques de Baroncelli, yet only the first title can be matched to those in his filmography in the IMDb (LE CARILLON DE MINUIT 1922).

194 “Opening Eureka Studio te Schiedam,” NWC, 23 September 1927.

$195 N W C, 9$ September 1927.

196 See: "De filmfabricage," NWC, 30 December 1927.

197 Advertisement about BET, DE KONINGIN VAN DE JORDAAN in NWC, 21 November 1924; and in Kunst en Amusement, 6 December 1924. See also: Donaldson, Joy and Sorrow, 264-6.

198 "Stadsnieuws: Moeilijkheden bij de Eureka," Schiedamsche Courant, 20 October 1928.

199 See: the contract between the Smits heirs, Boesnach, and Solser, in Civiele Dossiers 1928, no 569, docket number 239, Zeeuws Archief Middelburg.

200 Agreement between Hadima and Boesnach, dated 31 August 1927, in Civiele Dossiers 1928.

201 Verdict case $239 / 1928$. The last advertisement for the film is in $N W C, 19$ August 1927.

202 “P. W. A. H. Hulsman †," NWC, 9 May 1941. I thank Geoffrey Donaldson for pointing out this article to me. In his filmography of Dutch silent film, he states that the co-direction credit was given to Hulsman only on the film print, not in further contemporary documentation such as advertisements or reviews.

203 See: "Henk Alsem," NWC, 12 June 1925.

204 IMDb and other internet sources do not contain any information on Gauthier's career.

205 See: Donaldson, Joy and Sorrow, 247.

206 See: Klöters, Honderdjaar amusement, 195

207 Beeckman had written the music for De la Mar's revue "Hadt je me maar" of 1916. Eric Winter, “Eugène Beeckman,” Weekblad Cinema en Theater, n.d. 1928.

208 “Trianon Theater: Bet Trekt de 100.000," Haagsche Courant, 30 January 1926.

209 See: Honig, Acteurs-en kunstenaarslexicon, 695.

210 Ibid., 638.

211 Donaldson has listed her as the editor of Solser's first BET-film in 1924, but this seems unlikely as Lien d'Oliveyra was only twelve years old at the time. Here, he refers to her as sixteen years old, which was her age at the time of the final BETproduction.

212 "Kijkjes in de Schiedamsche filmkraamkamer," Schiedamsche Courant, 17 May 1928. 
213 "Uit de pers: Belangstelling voor Filmkunst," NWC, 20 May 1925. This item included a reprint of an article by L. Willing in Het Vaderland that had argued for better information and thus for not advertising every film as a wonderful film or of definitely first quality, as such platitudes failed to educate the audiences to appreciate films for their particular qualities.

214 Advertisement for Actueel film in NWC, 9 February 1923.

215 Advertisement for the Dutch Film Company in NWC, 11 January 1924.

216 Advertisement for Eureka in NWC, 12 September 1924.

217 Advertisement for Eureka in NWC, 29 May 1925.

218 Advertisement for Actueel film in NWC, 9 February 1923.

219 Advertisement for BET, DE KONINGIN VAN DE JORDAAN in NWC, 21 November 1924.

220 Advertisement for Eureka in NWC, 21 January 1927.

221 Advertisement for Eureka in NWC, 25 February 1927.

462 | 222 A certain agreed-upon degree of bluff was permitted as a public-relations strategy, it was stated [probably the editor, Pier Westerbaan]: “Nog even een woord over "waardering”, , (II) NWC, 14 October 1927, cover page.

223 Advertisement Eureka in NWC, 30 January 1925.

224 See: "Algemeene Vergadering van den Nederlandschen Bioscoopbond," NWC, 12 March 1926.

225 See: "Opening Eureka Studio te Schiedam," NWC, 23 September 1927.

226 Neither Alex Benno nor Theo Frenkel, Sr., nor the cinema managers who had benefited thus far from Solser's BET-series, but only the secretary of the NBB and the director of the Rotterdam division of the organization, André de Jong, cared to be present. See "Stadsnieuws: Opening Film-Studio 'Eureka', Nieuwe Schiedamsche Courant, 23 September 1927, front page; "Stadsnieuws: De filmstudio 'Eureka' geopend," Schiedamsche Courant, 23 September 1927; "Opening Eureka Studio te Schiedam," NWC, 23 September 1927; and the "Gastenboek Opening Eureka September 1927" (Folder 2), AAS.

227 “Nog even een woord over 'waardering”, (I), NWC, vol. 5, no. 53 (September 30, 1927), cover page.

228 See: "Nog even een woord over "waardering", (II) cover page.

229 See: [probably Fraper], "Cinema: Inauguration," Paris Jeudi, 22 September 1927; [probably Fraper], "Dernière Heure: Inauguration,” Le Courrier Cinematographique, 24 September 1927; and Charles Le Fraper, "Lettre de Hollande," La Patrie, 25 September 1927; press-clippings held in the scrapbook "Gasten- en recensieboek opening Eureka” (Folder 3), AAS.

230 [Probably Westerbaan], "Nederland in de oogen van een Franschman," (I) NWC, 11 November 1927 , cover page.

231 "Nederland in de oogen van een Franschman," (II), NWC, 25 November 1927, cover page. 
232 See: De Filmwereld, 15 September 1927, 9; clipping in "Gasten- en recensieboek opening Eureka."

233 "Nog even een woord over 'waardering'", (II), cover page.

234 "Algemeene Vergadering van den Nederlandschen Bioscoopbond,” NWC, 12 March 1926.

235 See: "André Boesnach †," Schiedamsche Courant, 22 March 1928; “André Boesnach †," Nieuwe Schiedamsche Courant, 21 March 1928; and "André Boesnach †," NWC, 23 March 1928.

236 In the November 24, 1932 letter to the Board of Censors, Solser expressed her despair: "How I survived those four years with my little daughter, God alone knows."

237 See: the advertisement for N.V. Studio Eureka in NWC, 20 July 1928. According to the advertisement, the film was booked until the middle of November.

238 See: Eindvonnis in Verdict Case 239/1928.

239 A former comedian of the revues of Ter Hall, a brother of Piet Köhler and the husband of Roosje Köhler-van Gelder, Johan Köhler planned to venture into the production of commercials at Schiedam.

240 Cover of Kunst en Amusement, 15 December 1922.

241 Cover of $N W C, 30$ October 1925.

242 Advertisement for BET, DE KONINGIN VAN DE JORDAAN in NWC, 21 November 1924.

243 "Passage-bioscoop: Bet, de Koningin van de Jordaan," De Telegraaf, 22 November 1924 .

244 Ibid.

245 From the speech by André de Jong, quoted in Het Vaderland and cited in NWC, 20 March 1925.

246 "Bet trekt de 100.000," NWC, 22 January 1926; emphasis mine.

247 Ibid.

248 “Trianon Theater: Bet zit in de penarie," Haagsche Courant, 26 February 1927.

249 See, for instance: Nieuwe Tilburgsche Courant, 17 February 1943, and other clippings held in the scrapbook "Recentieboek van Adriënne Solser van de film: BET NAAR DE OLYMPIADE begonnen te Groningen Vrijdag 28 October 1932" (Folder 25a), AAS.

250 “Adriënne Solser," Nieuwe Rotterdamsche Courant, 29 October 1933; clipping in ibid.

251 "Pandora, Hoogstraat," Schiedamsche Courant, 10 September 1927.

252 "Filmnieuws," De Alkmaarsche Courant, 26 August 1933; clipping in "Recentieboek.”

253 This association led to an interesting juggle with words when one journalist tried to comprehend the performance: "We have in fact seldom seen a silent film that is nonetheless a talkie." "Bet wil naar de Olympiade," Nieuws van den Dag, 11 March 1933 . 
254 "Een bezoek aan de 'Eureka'-studio," Nieuwe Schiedamsche Courant, 11 May 1928, front page.

255 "Keurbioscoop," Twentsche Courant, 24 April 1934.

256 "Bet trekt de 100.00o," NWC, 22 January 1926. This took place during a screening at the Trianon Theater in The Hague.

257 Delpeut, "A Cinema of Accidental Incidents," 15.

258 Ibid., 16.

259 Ibid.

260 Ben Singer, "Female Power in the Serial-Queen Melodrama: The Etiology of an Anomaly," Camera Obscura 8.1 22, 90-129; partly revised in Melodrama and Modernity: Early Sensational Cinema and Its Contexts (New York: Columbia University Press 2001).

261 See: the advertisement for Eureka Film Production, under the headline "In voorbereiding productie 1927-1928," De Filmwereld, 15 September 1927; clipping in

464 | "Gasten- en recensieboek."

262 Advertisement for Eureka in NWC, 21 January 1927.

263 "Bet zit in de penarie," NWC, 14 January 1927.

264 Middelburgsche Courant, 2 August 1933; clipping in "Recentieboek."

265 De Twentsche Courier, 24 April 1934; clipping in ibid.

266 Quite well done by the actor Hugo Blum.

267 "Beurstheater," Nieuwsblad van het Noorden, 18 May 1935; clipping in "Recentieboek."

268 One of these bears the title Duo Solser, which Solser probably formed with Felix Swart Verwer, an actor who was mentioned in the 26 March 1935 reviews of the performances in Groningen. It contains a song about people who say things behind your back that they would not tell you to your face, which, with the history of Eureka Studio in mind, is rather heartbreaking.

269 From "Dat zal ik lekker doen," undated, in untitled notebook (Folder 12), AAS.

270 Undated and unidentified newspaper clipping in "Gasten- en recensieboek."

\section{MUSIDORA ON THE FRENCH POPULAR STAGE}

1 Musidora, letter to Georges Sadoul, quoted in Histoire Générale du Cinéma. Le Cinéma devient un Art 19o9-1920. Volume 2. La Première Guerre Mondiale (Paris: Denoël 1951), 341; Sadoul's Biography of Musidora held at the Bibliothèque du Film (hereafter : BiFi) (GS.A.220); Francis Lacassin, Musidora. Anthologie du Cinéma 58, November 1970, 443; Philippe d'Hugues and Michel Marmin, Le Cinema Français. Le Muet (Paris: Éditions Atlas s.a., 1986), 106; Johan Daisne, "Souvenirs gantois à la mémoire de Musidora,” La Flandre libérale, 26 January 1958, 4. 
Patrick Cazals, Musidora. La dixième muse (Paris: Éditions Henri Veyrier 1978), 13 gives 1884, which seems an erratum.

2 Jennifer Waelti-Walters, Feminist Novelists of the Belle Époque. Love as a Lifestyle (Bloomington and Indianapolis: Indiana University Press, 1990), 4.

3 “Notre vedette Musidora," Ciné-Revue 5, 1923, 1. This text follows, almost verbatim, Musidora's self-presentation for an undated four-page publicity folder issued by impresario Charles Baret, pasted between clippings from 1921 and 1922 in the Musidora scrapbook "Biographie-Critique" held at the Bibliothèque Nationale de France, Département des Arts du Spectacle (hereafter: BNF, DAS), Collection Rondel (RT 9736).

4 Henri Fescourt, La Foi et les montagnes ou le 7e Art au passé (Paris: Éditions Montel 1959), 93.

Georges Coulonges, La Chanson et son temps. De Béranger au juke-box (Paris: Les Éditeurs français réunis 1969), 36.

Waelti-Walters, Feminist Novelists, 4 . The first women's rights congress was held in 1878 .

7 Lacassin, Musidora, 444; Cazals, La dixième muse, 13.

8 Musidora interviewed by Dominique Chantal, "Les avez-vous oubliées? Musidora, ancêtre des pin-ups," Détective, 14 October 1957, 6-7.

9 G.L., "Musidora devient Mme Clément Marot," Le Journal, 21 April 1927.

10 Musidora to Sadoul, Histoire Générale, 341.

11 Charles Rearick, Pleasures of the Belle Époque. Entertainment \& Festivity in Turn-ofthe-Century France (New Haven and London: Yale University Press 1985), 85-89.

12 Musidora to Sadoul, Histoire Générale, 341; Lacassin, Musidora, 444; Cazals, La dixième muse, 14.

13 Musidora, letter to Pour vous, 8 June 1938, 6. See, for the Parnassians: Encyclopaedia Universalis France s.a. 1995, www.ed4web.collegeem.qc.ca/prof/rthomas/ textes/parnasse.html, s.v. "parnasse".

14 Chantal, "Ancêtre des pin-ups," 7.

15 "Notre vedette Musidora," 1.

16 Musidora to Sadoul, Histoire générale, 342; Lacassin, Musidora, 445.

17 Musidora's self-presentation, Baret publicity folder.

18 Gautier was one of the most widely read writers, poets, and playwrights of nineteenth-century France and was, in his fiction, an exponent of literary Romanticism, but nonetheless highly regarded by the Parnassians. See: the web sites "Théophile Gautier: sa vie, son oeuvre 1811-1872" at: http://mercator.ens. fr/home/letourne/gautier/biographie.html and "17. Gautier, Nouvelles (1845)" at: http://buweb.univ-angers.fr/PRESSES/Godenne/Nouv17.html.

19 Musidora in conversation with Renée Carl, minutes of the Commission Recherches Historiques (hereafter: $\mathrm{CRH}$ ) conducted by the Cinémathèque française, interview 043, (1946), BiFi. 
20 Daisne, "Souvenirs gantois", 4. See also: Daisne's tribute to Louis Feuillade and JUDEX, Kroonfilms van Altijd (Gent: Snoeck-Ducaju \& Zoon 1950) and his correspondence with and writings about Musidora 1950-1958 preserved in Fonds Johan Daisne, Universiteitsbibliotheek Gent.

21 Musidora, "Les beaux visages de France. Colette," lecture given on October 20, 1945 at the Génie français, transcribed and printed in Cazals, La dixième muse, 181-93; and "Souvenirs sur Colette," three conversations with Musidora conducted by Jean Thévénot for Radio Suisse Romande, broadcast in June 1950. (Tape courtesy Archives Radio Suisse Romande (hereafter: RSR)). The Swiss radio programs slightly differ from the French draft as published in Cazals. Neither Musidora's nor Cazals' statements seem always reliable when it comes to dates.

22 Musidora, "Les beaux visages," 183.

23 Judith Thurman, Secrets of the Flesh. A life of Colette (London: Bloomsbury 1999), 466 xiv.

24 Thurman, A life of Colette, xvii. (Emphasis Thurman)

25 Thurman, A life of Colette, 111.

26 Thurman, A life of Colette, 114.

27 Musidora, "Souvenirs sur Colette," first conversation RSR.

28 Colette, Mes Apprentissages. Ce que Claudine n'a pas dit (Paris: Ferenczi 1936), 145. Colette used to quote her friend Polaire phoneticly, thus reproducing her Algerian accent.

29 Colette, Mes Apprentissages, 151.

30 Bibliothèque Nationale (ed.), Colette (Paris: Bibliothèque Nationale de France 1973), 15-16.

31 Thurman, A life of Colette, 89.

32 Colette, Mes Apprentissages, between 144 and 145 .

33 Cazals, La dixième muse, 16. A non-Claudine attribute are the shoes Musidora wears. See also: the picture of the statuette of Claudine by Georges Coudray, in: Bibliothèque Nationale (ed.) Colette, 11.

34 Cazals' caption suggests that Musidora was fifteen when the picture was taken, but, given that she was preparing for her finals, seventeen seems more likely. The book in her hands, moreover, was probably not Fortunio, but one of the Claudines.

35 According to Lacassin, Musidora toured the French provinces in "Claudine à Paris" for three months in the summer of 1911 (Musidora, 446). Cazals has included a poster of a representation of the play with Miss Musidora at the town of Laon, dated February 13, 1911, which, however, announced that it concerned "One single and extraordinary performance" (La dixième muse, 18). Musidora also inquired with Johan Daisne about her having played "Claudine à l'école" in 1911, 1912, or 1913 in the Belgian town Gent, but, despite his investigations into 
programs and newspapers, no trace of the performance could be found. Neither Musidora nor Colette mentioned the fact in their published references to each other.

36 Colette, quoted in Musidora, "Les beaux visages," 184.

37 Ibid., 183.

38 For the French radio, she said 1906 (Cazals, La dixième muse, 183); for the Swiss, 1908.

39 Colette entered into a relationship with a woman, Missy, also known as SophieMathilde-Adèle-Denise de Morny, Marquise de Belboeuf, in March 1905. The legal divorce between Colette and Willy was announced in 1910. Thurman, $A$ Life of Colette, 154 and 204. Colette's letter is published in Colette, Un bien grand amour. Lettres à Musidora 19o8-1953 (Paris: L'Herne 2014), 28-29.

40 Thurman, A Life of Colette, 259.

41 The friendship lasted until Colette's passing in 1954. It has often been suggested that they also had a sexual relationship, particularly during the months shortly before and after the outbreak of the war, when they shared an apartment and formed a threesome with the actress Marguerite Moreno. (See, for instance: Thurman, A Life of Colette, 259.) I would have loved to unearth confirmative documentation for such a romance, but have found only those usually cited in this context: Colette's remark about Musidora "showing her ass" and Musidora's evocation of her "deep but chaste love" for Colette. In my view, even Musidora's sermon to Willy does not do: the adulating rhetoric may attest to Musidora's infatuation with Colette, or otherwise her cleverly taking advantage of men's (and Willy's) fascination with lesbian sex, but it does not evince that it ever manifested. During the war years, as also Musidora recounted, Colette was deeply in love with Henry de Jouvenel.

42 Musidora, "Les beaux visages," 181-2.

43 Thurman, A life of Colette, 162.

44 Joë Bridge, "Après la répétition générale de la revue "Ça grise” à Ba-ta-clan," Comoedia, 6 April 1912, 4. I thank Sabine Lenk for drawing my attention to Comoedia.

45 Louis Delluc, "La chatte amoureuse," Comoedia Illustré, 1 May 1912, 611. Delluc was a critic of music-hall before he turned to film criticism. See : Jacques Legrand (ed.), Chronique du Cinéma (Boulogne-Billancourt: Éditions Chronique 1992), 923 .

46 Musidora, "Les beaux visages," 185.

47 Cited and translated in Thurman, A Life of Colette, 194.

48 Chantal, "Ancêtre des pin-ups," 6; Fescourt, La foi, 93, Sadoul, Histoire Générale, 243. The program lists her in the part of La Môme Torchon (The Dishrag Chick). See: Comoedia, 11 September 1910), 6. The play "La Loupiote" had been written by Arthur Bernède after the homonymic novel by Aristide Bruant. 
Lacassin, Musidora, 445, Cazals, La dixième muse, 17.

50 Comoedia, 15 July 1910, 2, in its column "Informations," actually a collection of excerpts from press releases issued by the theaters, noted about the vaudeville play "La nuit de noces" (The Wedding Night) that it was "the triumph of guffaw". Neither Jeanne Roques nor Musidora are mentioned in the column.

51 See: the advertisements on the program page of Comoedia, 11 September 1910, 6.

52 Chantal, "Ancêtre des pin-ups," 6.

53 Musidora played the part of Salopette in this "grand detective drama in five acts and eight tableaux", but was not singled out in the very positive review in Comoedia. See, for an announcement: Comoedia, 1 October 1910, 4; for the cast list the advertisement ibid., 6; and for the review Comoedia, 5 October 1910, 4. Including the performances at the annexes of the Theatre Montparnasse, the piece ran until 20 October 1910.

468 | 54 Playing the role of Lyane in this vaudeville, pièce militaire à grand spectacle (military spectacle play) or fantaisie militaire, which was written by two of the most renowned revue authors, Celval and Charly. Musidora was first noticed by a critic of Comoedia. See : Harry Whist, “A Ba-ta-clan. 'Zizi' 'Le Matricule 607'," Comoedia, 5 October 1912, 4.

55 Louis Delluc, “Un coup de téléphone,” Comoedia Illustré, 5 November 1913, 126.

56 The play began its three month run on 7 November 1913. During the final two weeks of January 1914, Musidora took on the principal role of Odette, but this change of cast did not prompt renewed critical attention.

57 Paul Reboux, “Théatre Municipal du Châtelet. L'Insaisissable Stanley Collins,” Le Théâtre, December (II) 1913, 23. See also : Georges Casella, "L'Interprétation," Comoedia, 8 November 1913, 2.

58 Delluc (probably), introduction to Musidora's self-portrait "Variations sur le Cinéma,” Le Film, 15 April 1918), 7.

59 J.M. Thomasseau, "Feuilleton et théâtre" in: Michel Corvin (ed.), Dictionnaire encyclopédique du théâtre (Paris: Bordas 1995), 333.

60 J.M. Thomasseau, "Boulevard du Crime" in Dictionnaire, 119.

61 Not to be confused with American vaudeville, which, in French, was captioned with the anglicism music-hall. See : Dominique Jando, Histoire mondiale du music-hall (Paris: Éditions Universitaires Jean-Pierre Delarge 1979), 7.

62 Olivier Barrot and Raymond Chirat, "Ciel, mon mari!" Le théâtre de boulevard (Paris: Gallimard 1998), 33.

63 M. de Rougemont, "Foire (le théâtre de la)" in: Dictionnaire, 338-39.

64 Michel Corvin, "Boulevard (le théâtre du)" in: Dictionnaire, 119.

65 Casella, "L'Interprétation,” 2.

66 Ibid.

67 Corvin, "Boulevard, (le théâtre du)," 118. 
See, for instance: the review of Le matricule 607 by Harry Whist, "Moulay-Hafid nous parle du 'Matricule 607'," Comoedia, 31 August 1912, 1-2, in which the same terms were used to praise the performances of the comic actors.

69 “Au Ba-ta-clan. 'Ça grise!'," Comoedia Illustré, 15 February 1912, 2.

70 Fantaisie is a work of imagination in which the artistic creation is not subjected to formal rules. Le Petit Larousse illustré 1992, s.v. "fantaisie."

71 Humble, "Le programme est renouvelé fort heureusement," Comoedia, 28 September 1912), 4 .

72 Ibid.

73 Joë Bridge, "Vous savez?... nous ouvrons çe soir..., " Comoedia, 30 August 1912, 4.

74 Whist, "A Ba-ta-clan. 'Zizi'," 4.

75 Philippe Chauveau and André Sallée, Music-hall et café-concert (Paris: Bordas 1985), 16; Jando, Histoire mondiale du music-hall, 21; Rearick, Pleasures, 83 even gives a number of 264 .

76 Jean-Jacques Meusy, Paris-Palaces ou les temps des cinémas 1894-1918 (Paris : CNRS Éditions 1995), 114.

77 Louis Laloy, "Music-halls et chansonneries," Revue musicale S.I.M., 1 January 1914,47 .

78 See, for an analysis of audience stratification along the lines of class, status, and gender: Rearick, Pleasures, most notably his chapter 4: 84-116.

79 Louis Laloy, “Cabarets et music-halls," Revue musicale S.I.M., 15 February 1913, 53 .

80 Chauveau and Sallée Music-hall et café-concert, 16.

81 'F(ernand) R(ourvray), "Fursy donne une soirée de vrai Café-Concert," Comoedia, 23 October 1912, 4 .

82 See: Annuaire des artistes-Paris 1921-1922.

83 See also: Paul Adrian, "Cinéma et music-hall." In: Chauveau and Sallée, Musichall et café-concert, 34-35.

84 Chauveau and Sallée practically omit considering the first two decades of the twentieth century in their articles. See also: J.M. Thomasseau, "Music-hall" in: Dictionnaire, 17.

85 Louis Laloy (1874-1944) was a leading music critic and scholar, who co-founded the Parisian section of the Société Internationale de la Musique (S.I.M) and the periodical La Revue musicale S.I.M. (See: Deborah Priest, Louis Laloy on Debussy, Ravel and Stravinsky (Aldershot, England and Brookfield Vt.: Ashgate Publishing 1999).) The aim of his articles on the importance and qualities of music-hall and revue was to win prejudiced readers over, while the reviews in Comoedia were clearly written for fully informed devotees. Curnonsky (1872-1956) was the nom de plume of Maurice Edmond Sailland, who had begun his career in 1896 as a ghostwriter for Willy, turned to music-hall journalism in the mid-19oos, and abandoned it for writing on gastronomy in the 1920s, for the latter of which he 
is best remembered. (See: L'Association des amis de Curnonsky, Curnonsky et ses amis (Paris: Edgar Soete Librairie 1979)).

86 Louis Laloy, "Cabarets et Music-Halls," Revue Musicale S.I.M., 15 March 1913, 54.

87 A typical music-hall program could, for instance, be found in 1909 at the Folies-Bergère on which Curnonsky offers a closer look. He watched daredevil équilibristes (tight-rope walkers), a group of cyclists, a dance act by a dozen of pretty women with "admirable" legs, and the extraordinary "kinemacolor". Next followed a one-act drama, one performance with dogs, and one with horses, which the observer thought much less fun for the animals than for the audience, and a ballet featuring the dancer Stacia Napierkowska. The evening was closed off with two sketches, one comic and one dramatic, played by entertainers and mimes, as well as a tour de chant by "notre Mayol national", the vedette of the program. Curnonsky, "La semaine au music-hall," Paris qui chante, 17 October 1909, 2.

470 | 88 Laloy, "Cabarets et Music-Halls," (15 March 1913), 56.

89 Ibid. 54 .

90 Laloy, "Cabarets et music-halls," (15 February 1913), 55.

91 Laloy, "Cabarets et music-halls," (15 March 1913), 53.

92 Curnonsky, "La Revue des Revues. Le Music-Hall pendant la guerre," Le Théâtre, September 1919, 28-32.

93 Ibid.; Annuaire des artistes-Paris 1921-1922, 264 (Alhambra) and 287 (Olympia).

94 Ibid. 264.

95 Coulonges, La chanson, 41.

96 Thérésa (1837-1913) began her career singing sentimental songs at the Divan Japonais, but saw little success until the accidental discovery of her comic talent in 1862. She was not particularly beautiful and gained weight over the years, but used those features to the advantage of her comedy and to destroy every suggestion of feminine coquetry. Her stage persona brings to mind Adriënne Solser's, both in terms of the character she impersonated and the elements with which it was constructed. See also: Kelley Conway, Chanteuse in the City. The Realist Singer in French Film (Berkeley, Los Angeles, London: University of California Press 2004), 37-41.

97 Coulonges, La chanson, 35 .

98 Jando, Histoire mondiale du music-hall, 21.

99 Chauveau and Sallée, Music-hall et café-concert, 12 ; Conway, Chanteuse in the City, 34 .

100 Coulonges, La chanson, 29. See also: Yvette Guilbert, La Chanson de ma vie (Paris: Grasset 1927), 60-67 and 132.

101 Chauveau and Sallée, Music-hall et café-concert, 12.

102 Coulonges, La chanson, 44.

103 Colette, Mes apprentissages, 164. 
104 Ibid. 149

105 See also: Curnonsky, "La semaine au music-hall," 2.

106 Chauveau and Sallée, Music-hall et café-concert, 121.

107 Guilbert, La chanson de ma vie, 64.

108 Laloy, "Music-halls et chansonneries," 46.

109 See also: Curnonsky, "La semaine au music-hall," 2.

110 Laloy, "Cabarets et Music-Halls," (15 March 1913), 57.

111 Lacassin gives another title, "J'adore ça" (I Love It), a revue mounted at the Bata-clan in the winter of 1911-1912, but neither the cast list of the program leaflet (BNF, DAS, RO 18287) nor the one published in Comoedia, 8 November 1912), 6 include Musidora's name.

112 BNF, DAS, RO 18287 (“Ça grise!”; "La Revue de Ba-ta-clan”), RO 18311 (“Bien, Marie!... “), RO 18340 ("La Revue de l'Amour”; "La Revue Galante”).

113 Sallée, for instance, mentions Colette's writing before her acting in music-hall and categorizes her under the label "comédiens de passage", actors making guest appearances, and hence suggests that her music-hall acting was just a brief stint away from her real profession. However, Colette worked as a mime for six years. See: Chauveau and Sallée, Music-hall et café-concert, 26.

114 Joë Bridge, Nos Vedettes, (Paris: private publication, 1922; Bridge's songs were published in the early 1910 s in Paris qui chante and his reviews in Comoedia.

115 Program booklet "Ça grise!."

116 Song text in program booklet "Ça grise!."

117 Max Viterbo, “Au Perchoir. La Revue ‘Hop!...' En deux actes, de MM Jean Bastia et Paul Clérouc,” Comoedia, 8 October, 1919), 3.

118 Joë Bridge, "Après la répétition générale de la revue 'Ça grise’ à Ba-ta-clan,” Comoedia, 6 April 1912, 4.

119 In 1911-1912, Mistinguett was affiliated with the Folies-Bergère and Andrée Spinelly with the Cigale. Eve Lavallière was a leading lady of the boulevard theater.

120 Georges Talmont, "La Revue de Ba-ta-clan. Deux actes et trente tableaux de MM. Celval et Charley," Comoedia, 25 October 1912, 4.

121 Curnonsky, "Aux Folies-Bergère. 'La Revue de l'Amour'. Vingt-trois tableaux de MM. Quinel et Moreau," Comoedia, 9 February 1914, 1.

122 Curnonsky, "Music-Halls et Cafés-Concerts. Folies-Bergère," Le Théâtre, February (II) 1914, 20.

123 Curnonsky, "Aux Folies-Bergère. 'La Revue de l'Amour." 1.

124 Curnonsky, "Music-Halls et Café-Concerts. Folies-Bergère,” 21.

125 'Curnonsky, “Aux Folies-Bergère. 'La Revue Galante.' Trente-trois tableaux de MM. Lemarchand et Rouvray," Comoedia, 5 April 1914, 4.

126 Thomasseau, "Music-hall," 17.

127 Lacassin, Musidora, 448.

128 Cazals, La dixième muse, 102. 
129 Chauveau and Sallée, Music-hall et café-concert, 140-41. See also: Jando, Histoire mondiale du music-hall, 37, and Charles Castle, The Folies-Bergère (London: Methuen 1982), 97.

130 Guilbert, La chanson de ma vie, 93. (literally: into Paris; meaning: away from Montmartre, where the Divan Japonais was located as well as towards the renowned café-concerts of Paris.)

131 Castle, Folies-Bergère, 97.

132 Chauveau and Sallée, Music-hall et café-concert, 141.

133 Curnonsky, "La semaine au music-hall, “ 15.

134 “Spectacles et Concerts. Soirée Parisienne," unidentified paper clipping, 6 November 1912, (BNF, DAS, RO 18287)

135 Rasimi directed the Ba-ta-clan from 1910 through 1926. Further female directors were: Mme Varin (Ambassadeurs, 1840-1874); Thérésa (Alcazar d'Hiver, 1885-1893); Mme Varlet (Gaiété Rochechouart 1874-1915); Mme Roissu (Scala, 1876-1884); Mme Allemand (Scala 1884-1894; Eldorado 1887-1894; FoliesBergère 1886-1894); the widow Dorfeuil (Concert Mayol 1904-1907); and the widow Marchand (Scala 1901-1905).

136 Talmont, "La Revue de Ba-ta-clan," 4.

137 Laloy, "Cabarets et music-halls," (15 February 1913), 55. Laloy was also defending music-hall against moralists like the senator Béranger, who conducted a crusade against the tradition académique. See: Jando, Histoire mondiale du music-hall, 114.

138 Louis Aragon, Projet d'Histoire Littéraire Contemporaine (Paris: Gallimard 1994), 8-9. The passage was written in 1922-1923, according to Roger Garaudy, L'Itinéraire d'Aragon, (Paris: Gallimard), 1961:26.

139 Laloy, "Cabarets et music-halls," (15 March 1913), 53.

140 A view incited by Laura Mulvey, "Visual pleasure and narrative cinema," (1974) reprinted in: Karyn Kay and Gerarld Peary (eds.), Women and the Cinema. A critical anthology (New York: E.P. Dutton 1977), 412-28.

141 Laloy, "Cabarets et music-halls," (15 March 1913), 53.

142 Bibliothèque Nationale (ed.), Colette, 54.

143 Ibid., 56-57.

144 Thurman, A life of Colette, 171.

145 Castle, Folies-Bergère, 99.

146 Thurman, A life of Colette, 182.

147 Ibid., 163.

148 Annette Förster, "De verering van een schim. Musidora en de overlev(er)ing van Irma Vep," Tijdschrift voor Mediageschiedenis 1, 1, 1998: 5-31 Translated into German as "Schwärmerei für einen Schatten. Musidora und das Nachleben von Irma Vep," montage/av, 8, 2, 1999: 51-76.

149 Talmont, "La Revue de Ba-ta-clan," 4. 
150 Laloy "Cabarets et music-halls," (15 February 1913), 56.

151 Ibid. 55 .

152 Ibid 56 . The incapability to offend distinguished the revue à grand spectacle from the short revue as it survived in the cabaret of the time, of which Laloy noted that it was much less respectful towards politicians and other authoritative figures, because, in contrast to the masses frequenting music-hall, the elite frequenting the cabaret did not have faith in authorities. Laloy, "Music-halls et chansonneries," 54 .

153 Celval et Charley, Ça grise!, verses and monologues. (BNF, DAS, RO 18287 (2)).

154 Celval et Charley, Bien, Marie!..., verses and monologues (BNF, DAS, RO 18311 (3)).

155 Georges Talmont, "A Ba-ta-clan. Bien... Marie!.... Revue en vingt-quatre tableaux de Celval et Charley," Comoedia, 23 March 1913, 1.

156 Fernand Rouvray, "La soirée," Comoedia, 23 March 1913, 1.

157 Talmont, “A Ba-ta-clan. Bien, Marie!...”, 1.

$15^{8}$ Celval et Charley, Bien, Marie!....

159 Curnonsky, "Aux Folies-Bergère. 'La Revue de l'Amour'. Vingt-trois tabelaux de MM. Quinel et Moreau,” Comoedia, 9 February 1914, 1.

160 Talmont, "A Ba-ta-clan. Bien... Marie!...,” 1. See also: Talmont, “'La Revue de Ba-ta-clan'. Deux actes et trente tableaux, de MM. Celval et Charley,” Comoedia, 25 October 1912, 4; "Spectacles et Concerts," 6 November 1912, n.p.

161 Harry Whist, "La Presse entière constate le formidable succès de la Revue de Ba-ta-clan," Comoedia, 12 May 1912, 5.

162 Curnonsky, "La Revue de l'Amour," 1.

163 Curnonsky, "La Revue Galante," 3.

164 Curnonsky, "Music-Halls et Cafés-Concerts," Le Théâtre, April (II) 1914, 21.

165 Curnonsky, "La Revue de l'Amour," 1.

166 The film constituted the ninth tableau of "La Revue Galante" and was announced to be featuring the artistes of the Folies-Bergère. No print of it is known to survive. The revue was also preceded with non-fiction films by the French Film Company Éclair, which were not discussed in the reviews. See: Program booklet of "La Revue Galante" (BNF, DAS, RO 18340 (3)).

167 Curnonsky, "Music-Halls et Café-Concerts. Folies-Bergère, 'La Revue Galante'," Le Théâtre, April (II) 1914, 21.

168 Curnonsky, "La Revue Galante," 3.

169 About Sarah Duhamel, only scant and scattered information can be retrieved. From Chauveau's "Dictionnaire Historique" it can be distilled, that she, in 1895, performed in a revue at Le Divan Japonais, and, between 1897 and 1899, was a member of the troupe of the Fourmi. After the turn of the century, she performed at the Libre-Échange and at the Casino de Tourelles, all café-concerts. (Chauveau and Sallée, Music-halls et café-concerts, 142, 158 and 164). When 
exactly she traded the stage for the screen is unclear. Lacassin mentions that in the ROSALIE-series, which was released between March, 31, 1911 and June, 13, 1913, she usually played a cleaning woman, but that does not hold for the surviving films ROSALIE ET SA PHONO (Rosalie and Her Phonograph) and ROSALIE ET SES MEUBLES FIDÈLES. In the first one, she has a maid, suggesting a (petit) bourgeois milieu, and, in the second, she is poor, but no job indications are given. In a third surviving film, ROSALIE ET LÉONTINE VONT AU THÉÂTRE (Rosalie and Léontine Visit the theater, 1911) she plays a melodrama spectator, which marks her-and her friend-as lower class (See: Thomas Brandlmeier, "Lachkultur des Fin de siècle.” In: Slapstick \& Co. Frühe Filmkomödien/Early Comedies (Berlin: Stiftung Deutsche Kinemathek and Argon Verlag GmbH 1995), 23.) In addition to Rosalie, Duhamel played the lead in an eleven-part Éclair-series, PÉTRONILLE, directed by Georges Rémond between November, 8, 1912 and March 1915. See : Francis Lacassin, Pour une contre-histoire du cinéma (Lyon: Institut Lumière/ Actes Sud 1994), 142, 148, and 152 ; and Richard Abel, The Ciné Goes to Town. French Cinema 1896-1914 (Berkeley, Los Angeles, London: University of California Press 1994, 391-392). Abel's research discloses that Duhamel likewise starred in four films with Little Moritz, which were released in the summer and fall of 1911.

170 Abel, Ciné, 62. The stop-motion technique was also used for ROSALIE ET SA PHONO, in which Rosalie demonstrates the magic of her new gramophone, which prods her and her maid into dancing the quick-step, and the furniture and other objects in the room as well. (Abel, Ciné, 391).

171 Curnonsky, "La Revue Galante," 3.

172 Musidora, "La Vie d'une vamp," Ciné-Mondial, 12 July 1942, n.p.

173 Curnonsky, "La Revue Galante," 3.

174 "Music-Halls, Cafés-Concerts, Cabarets, Cirques, etc.," Comoedia, 7 February 1914), 4 .

175 Stage photo published in Le Théâtre, December (II) 1913, 23.

176 Program leaflets of "Ça grise!” and "La Revue de Ba-ta-clan."

177 Picture collection Musidora in Bibliothèque Nationale de France, Département des Arts du Spectacle, 4e Ico Per. (Iconographie Personnalités). Most of the pictures in this collection are of later date.

178 Lacassin, Musidora, 450 and 455.

179 See: http://www.flickr.com/photos/r3dqu33n/55845899/. I thank Ivo Blom for making this picture available to me.

180 Musi-chat was a stray cat that Musidora had given shelter at her dressing room at the Ba-ta-clan. "Music-Halls, Café-Concerts, Cabarets, etc.," 4.

181 In April 1916, Musidora was the vedette of the revue "C'est Maouspoilpoil!" (That is very classy!) by Jean Bastia in the Scala (BNF, DAS, RO $18423(2,3)$ ); in January 1919, she appeared in Bastia's revue "French spoken" in the cabaret Le 
Perchoir (BNF, DAS, RO 18517 (1)); at the same venue, she performed in Bastia's "La revue 'Hop'!..." in October 1919 (Comoedia, 8 October 1919), 3 and BNF, DAS, RO 18517 (1)); and, in May 1921, she replaced the vedette of Magre's play "L'Arlequin” (Musidora, “Journal d'un jour,” Ève, 1 May 1921, 3).

182 Musidora, "La tranchée de toile peinte," Fantasio, 1 March 1916, 712. Her last story for the magazine was "Le snob au cinéma," Fantasio, 1 December 1916, 289 -90.

183 Alain and Odette Virmaux (eds.), Colette at the movies. Criticism and Screenplays (New York: Frederick Ungar Publishing Co. 1980), 210.

184 "Music-Halls, Cafés-Concerts, Cabarets, Cirques, etc.," 4.

\section{MUSIDORA AND THE FRENCH SILENT CINEMA}

1 The date cannot be established more exactly from the documentation at hand. The synopsis of one of Musidora's first films with Feuillade, LE CALVAIRE, was deposited for copyright in April 1914, and features her as "the famous music-hall dancer”. (BNF, DAS, Dossier Gaumont Scénarios (Code G3431 (03374), Gaumont Hallmark (20 April 20 1914), Depot legal 1623/1914). Part and synopsis seem to have been tailored and conceived to introduce Musidora as a Gaumont actress. Advertisements with stills from the film that picture Musidora in her role were published from the end of May 1914. (See: Le Courrier Cinématographique, 30 May 1914, 26-27; hereafter: $L C C$ ) SEVERO TORELLI, another Feuillade film, but with Musidora in a supporting part only, was advertised two weeks earlier, but without stills, so that it remains unclear if she was already cast in it or added to it later on. (See $L C C, 16$ May 1914, 1.) Musidora's self-presentation, Baret publicity folder. See also: "Notre vedette Musidora," 1.

3 The exact date of the end of her affiliation with Gaumont is irretrievable, and neither Lacassin nor Cazals mention it. In February 1917, it was announced in the trade press that she just had signed a contract with the film company of André Hugon. See : L’Opérateur, untitled note, LCC, 24 February 1917, 12.

4 For Alice Guy-Blaché's career and oeuvre see Alison McMahan, Alice Guy Blaché. Lost Visionary of the Cinema, (New York and London: Continuum 2003).

5 Only in April 1916, coinciding with the release of the seventh episode of LES VAMPIRES, SATANAS, Feuillade's name as the director of the series was revealed in the booklets recounting the stories of the various installments, which he had co-authored with Georges Meirs and which were published halfway the series. See: Anonymous, "Les Vampires en roman," Le Film, 15 April 1916, 23, and Alain Carou, "Le Film au coin du feu. Feuillade et les «Romans-cinéma»." In: 1895. Revue de l'association française de recherche sur l'histoire du cinéma, numéro hors série Louis Feuillade (October 2000), 228. 
Marcel Levesque, "De 1913 à 1918. Cinq ans à la maison Gaumont avec Louis Feuillade, Souvenirs personnels de Marcel Levesque," Archives, 8 (November 1987), 4 .

7 Levesque, "Cinq ans," 6.

8 Fescourt, La Foi, 81.

9 Renée Carl, "Vedette du cinéma français d'avant-guerre conte quelques souvenirs, Pour Vous, 15 June 1938, 7; Levesque, “Cinq ans,” 8.

10 Chantal, "Ancêtre des pin-ups," 7.

11 Quoted without source reference in Lacassin, Musidora, 451-52.

12 Letter from Feuillade to Musidora, written from the front between March and July 1915, printed in Cazals, La dixième muse, 31.

13 These were not Musidora's very first screen appearances. As already noted, she had acted in a Pathé Film inserted in the revue at the Folies-Bergère. In 1913, moreover, she had played in a propaganda film for the anarchist film corporation Le Cinéma du Peuple, which was shown at community centers. Directed by the stage actor and her colleague from the Châtelet, Raphael Clamour, the film, LES MISÈRES DE L'AIGUILLE (The Miseries of the Needle) made a case against the exploitation of women home workers. While acting under her real name Jeanne Roques, she offers the screen presence of Musidora: seemingly natural, reliant on the expressivity of her face and her eyes. A print is held at the Cinémathèque française and was shown at Il Cinema Ritrovato in Bologna 2014. See also: Isabelle Marinone, “Les Misères de L'Aiguille” film muet d'Armand Guerra” (the male actor in the film) at http://raforum.apinc.org; Lacassin, Musidora, 448, Cazals, La dixième muse, 19, and Laurent Mannoni, "Le Cinéma du Peuple." In: Richard Abel (ed.), Encyclopedia of Early Cinema (Abingdon, Oxon: Routledge 2005), 123.

14 Musidora, "La Vie d'une Vamp."

15 Fescourt, La Foi, 94.

16 Fescourt did not mention the title of the tableau, but Musidora referred to her Virginie-part in this context and not to the "Tangomaniaque," which, moreover, seems not to correspond with the dance described by Fescourt. It might well be that Fescourt mixed up his recollections with another performance Musidora did in the revue "Hop!...," in the cabaret Le Perchoir in October 1919, in which she indeed enacted a plant while wearing a silken bodysuit that made her dance appear quite sensual according to contemporary critics.

17 Fescourt, La Foi, 94.

18 Musidora, "La Vie d'une Vamp."

19 Fescourt, La Foi, 94.

20 Musidora reconfirmed that her debut had been in SEVERO TORELLI at a session of the CRH in 1946 (See: minutes BiFi, CRH 043, 9.) In "La Vie d'une Vamp", however, Musidora points out a scene from LE CALVAIRE as the one in 
which Feuillade tested her screen qualities, which should imply that this film, although released after, was shot before SEVERO TORELLI.

21 Gaumont advertisements and program leaflets, for instance, announce PEINE D'AMOUR and GUIGNOL with the predicate. These films were not directed by Feuillade, according to the filmography established by Lacassin. (Francis Lacassin, Maître des Lions et des Vampires. Louis Feuillade, (Paris: Pierre Bordas et Fils 1995), 308-12). See: advertisement LCC, 6 June 1914), 1 and program leaflet Gaumont-Palace 30 April 1915 at Bibliothèque Historique de la Ville de Paris, Fonds Actualités, Dossier Gaumont-Palace (hereafter BHV).

22 Musidora, "Mes projets: Être la Méchante Femme," Le Film, January 1920, n.p.; "Informations. Au ‘Gaumont-Palace' SEVero torelli," Comoedia, 6 June 1914, 4.

23 The print is held at the Cinémathèque française. It has a length of 1026 metres, lacks title cards and tinting, but seems complete as far as the scenes are concerned.

24 Abel, Ciné, 302-25.

25 "Au Gaumont-Palace. SEVERO TORELLI," 4.

26 Fescourt, La Foi, 92.

27 Ibid.

28 Ibid.

29 Yvette Andreyor, "Yvette Andreyor par elle-même," Le Film, 3 December 1918, 18.

$30 \quad$ Fescourt, La Foi, 95.

31 J.-L. Croze, "Cinématographes," Comoedia, 6 June 1914, 4. The play had been staged at the Odéon and the Renaissance. Advertisements LCC, 16 May 1914, 1 and Ciné-Journal, 16 May 1914, 8.

32 BNF, DAS, Dossier Gaumont scénarios no. G3431, Gaumont Hallmark (31 March 1914), Dépot légal 1276/1914.

33 LCC, 30 May 1914, IV.

34 See: picture in Lacassin, Musidora, 450; Jacques Richard, "Une troupe à géométrie variable" in: 1895. Revue de l'association française de recherche sur l'histoire du cinéma, numéro hors série Louis Feuillade (October 2000), 236, and BNF, DAS, Iconographie Personalités, Musidora, (4e SW 12153).

35 Musidora interviewing scriptwriter Nora Januxi for the CRH of the Cinémathèque française, undated minutes BiFi, CRH 041, 9. Musidora stated that the actors were dressed in all costume films, but for contemporary films they ought to have their own wardrobes and very often change dress.

36 Musidora, "La Vie d'une Vamp."

37 Advertisement and synopsis can be found in $L C C$, 30 May 1914, 26-7 and in the inlay, III and IV, respectively. Synopsis also at BNF, DAS, Dossier Gaumont Scénarios, no. G3431 (03374), Gaumont Hallmark (20 April 1914), Dépot légal 
1623/1914. The publicity booklet contains the Gaumont Hallmark (11 June 1914), Dépot legal 2324/1914.

38 Lacassin, Musidora, 451.

39 Ibid., 497.

40 Preserved at the Cinémathèque Gaumont, Neuilly-sur-Seine.

41 Abel, Ciné, 41.

42 Fescourt, La Foi, 74, 80 and Carl, "Vedette du cinéma français," 7.

43 Quoted in Alain Carou, "Art et imitation sur une bande de la série 'le Film esthétique’ et son procès.” In: 1895. Revue de l'association française de recherche sur l'histoire du cinéma, numéro hors série Louis Feuillade (October 2000) 39.

44 Quoted in Jacques Champreux, "La Vie telle qu'elle est.” In: 1895. Revue de l'association française de recherche sur l'histoire du cinéma, numéro hors série Louis Feuillade (October 2000) 63-72.

45 Quoted in Carou, "Art et imitation," 39.

478 | 46 Quoted in Champreux, "La vie telle qu'elle est," 63. Translation from Richard Abel, French Film Theory and Criticism 1907-1939, vol. 1, 1907-1929 (Princeton, New Jersey: Princeton University Press 1993), 54. Abel also clarifies the name of Rocambole: "Rocambole evolved from arch criminal to fearless detective as the hero of some thirty adventure novels written by Ponson du Terrail in the middle of the nineteenth century. Here he is used to stand in for all of the adventure heroes of the French séries (criminal, detective, western) which were so popular from 1907 to 1914." The Rocambole books were filmed in 1914-1915 as a four-part series by Georges Denola for the SCAGL. (Abel, Ciné, 49, Lacassin, Maître 123.) Marcel Levesque recollected how Feuillade himself, ironically enough, acquired the title Ponson du Terrail du Cinéma because of his serials. (Levesque, "Cinq ans," 3.)

47 Richard, "Une troupe," 247.

48 Fescourt, La Foi, 91.

49 Quoted in Champreux, "La vie telle qu'elle est," 63-72. Translation quoted from Abel, French Film Theory and Criticism, 54 .

50 Quoted from the publicity material and included in Jacques Champreux, "Les Films à épisodes de Louis Feuillade" in: 1895. Revue de l'association française de recherche sur l'histoire du cinéma, numéro hors série Louis Feuillade (October 2000) 191.

51 Arthur Bernède, Louis Feuillade "Les Auteurs au Public," Le Film, 16 December 1916), 16 and Ciné-Journal, 26 May 1917, 11.

52 Abel, Ciné, 301, 328.

53 In a survey of the film historical reception of Feuillade's oeuvre, I have argued that the focus on his authorship and on a reassessment of his crime series in terms of film aesthetics and cinematic specificity primarily has sprung from the urge to right a wrong presumably done by critics and filmmakers of the postwar 
avant-garde that publicly charged Feuillade for wasting his talents by working in mass production and popular film. His extensive work beyond the crime series is only recently an object of film historical research. Annette Förster, "Dellucs Unrecht: Die Forschung zu Louis Feuillade und seinem Werk," Kintop, 10, (2001), 193-200.

54 Richard Abel, French Cinema: The First Wave 1915-1929 (Princeton, New Jersey: Princeton University Press 1984), 80; Emmanuelle Toulet, “Une année de l'édition cinématographique Pathé: 1909” in: Pierre Guibert (ed.), Les Premiers Ans du Cinéma Français (Perpignan: Institut Jean Vigo 1985), 136.

55 Abel, Ciné, 249-250.

56 Meusy, Paris-Palaces, 231.

57 Abel, Ciné, 334.

58 Thurman, A Life of Colette, 130. Philippe Chauveau names her Emilie Bouchaud, Chauveau, and Sallée, Music-hall et café-concert, 145.

59 Jacques Charles, "Polaire," De Gaby Deslys à Mistinguett (Paris: Gallimard 1933), 204.

60 Colette, Mes apprentissages,148.

61 Curnonsky, "La semaine au music-hall," Paris qui chante, 27 February 1910), 2.

62 Curnonsky, "La revue des revues," 31.

63 Chauveau and Sallée, Music-hall et café-concert, 166. Mirande wrote operettas and comic plays for, among others, the Concert Mayol during the 1910s. In 1916, Polaire acted in a film by the director of melodramas and comedies, André Hugon, LE MASQUE DU VICE (The Mask of Vice).

64 Abel, Ciné, 123.

65 Other actors include Armand Numès, Gaston Sylvestre, and Maria Fromet. See: the catalog of Il Cinema Ritrovato at Bologna 1999, 7.

66 Thurman, A Life of Colette, 130.

67 Abel, Ciné, 78 describes the 1904 DANSE DES APACHES (Apache Dance) as serving "to display the power of an underworld tough guy through his rough, abusive handling of a female partner."

68 Chauveau and Sallée, Music-hall et café-concert, 169. See, for an extensive discussion of Mistinguett's career and roles: the chapter "Music Hall Miss" in Conway, Chanteuse in the City, 58-83.

69 Chauveau and Sallée, Music-hall et café-concert, 156, 131.

70 Ibid., 124, 133, 170.

71 The number and list of titles has yet to be established. See, for a tentative filmography of Mistinguett D'Hugues and Marmin: Le Muet, 163 and 56 as well as the website http://filmstarpostcards.blogspot.com/2010/og/postcard-friendship-friday-mistinguett.html.

72 Abel, Ciné, 214-15.

73 Toulet, “Une année”, 138. 
74 The films listed here are extant today, the first two at the EYE Filmmuseum, the third at the British Film Institute Film Archive, and the fourth at the National Film Center, The National Museum of Modern Art, Tokyo. The latter three films were rediscovered by Mariann Lewinsky for Il Cinema Ritrovato, Bologna 2010.

75 Abel, Ciné, 235.

76 Deviant from this practice was the publicity for two vaudeville films released in September and December 1916, respectively. In the publicity for them, the label ciné-vaudeville was alternated with indications such as "comédie" or "comédie comique”, (Ciné-Journal, 27 May 1916), 26), although in reviews they were invariably referred to as ciné-vaudeville or even vaudeville play.

77 Marcel Levesque, "Par lui-même," Le Film, 3 December 1917), 6-8.

78 These figures are based upon my count of relevant titles in the filmography of Feuillade established by Lacassin, Maître, 308-12. They do not entirely correspond with Lacassin's count of a sum total of 32 titles on p. 130, nor with the 480 number given by the catalog of the nineteenth Giornate del Cinema Muto at Pordenone/Sacile (2000:25), which is 30 ciné-vaudevilles. Laurent Le Forestier, “Feuillade et les cinévaudevilles, ou le paradoxe de la théâtralité," in: 1895. Revue de l'association française de recherche sur l'histoire du cinéma, numéro hors série Louis Feuillade (October 2000) p. 73-87 gives no sum total but discusses two series of ciné-vaudevilles: the 1913-1914 series, La Vie drôle, and the 19211922 series, La Belle humeur. I do not consider the latter series because it did not feature Levesque nor Musidora.

79 I thank Jacques Champreux, Feuillade's grandson and a committed researcher of his oeuvre, for informing me in 2000 that an unrestored print of this film was held at the Cinémathèque Gaumont. The print was restored by the Cineteca di Bologna and shown at Il Cinema Ritrovato 2011.

80 For advertisements announcing the film's release, see: Le Film, 23 December 1916, 18, Ciné-Journal, 27 January 1917, 22-3, Le Cinéma et l'Écho du cinéma réunis, 19 January 1917, 3 (hereafter: CÉCR). A print is held at Lobster Films, Paris.

81 Musidora, "Mes projets."

82 Le Forestier, "Feuillade et les cinévaudevilles," 78.

83 Levesque, "Cinq ans," 4.

84 Le Forestier, "Feuillade et les cinévaudevilles," 74.

85 Ibid., 78.

86 D'Hugues and Marmin, Le Muet, 6o-61; Fescourt, La Foi, 84.

87 Abel, Ciné, 390.

88 Ibid., 219.

89 Le Forestier, "Feuillade et les cinévaudevilles," 77.

90 A print was screened at the Giornate del Cinema Muto 2000 at Pordenone/Sacile and is held at the Cinémathèque française. 
BNF, DAS, Dossier Gaumont Scénarios (Code G3431) gives as date of drafting December 24, 1914, as date in the Gaumont Hallmark January 4, 1915, Dépot légal no. 58/1915.

92 G. Dureau mentioned the film's banishment from the screen in his article on film and censorship in Paris in Ciné-Journal, vol. 8, no. 7 (May 1, 1915), p. 7.

93 Lacassin, Maître, 309 mentions the initial title BOUT DE ZAN ET LE BOCHE.

94 The same uncertainty holds for another film from the series in which Musidora was reputedly cast, the comédie patriotique BOUT DE ZAN ET LE POILU (Bout de Zan and the French soldier in The Great War) (1915).

95 See: the listings of the programs at the Gaumont-Palace in Comoedia, for instance 6 June 1914, 4 and 21 June 1914, 4. Furthermore: D'Hugues and Marmin, Le Muet, 79, Fescourt, La Foi, 96-103 and Abel, Ciné, 407.

96 For Prince and Perret see D'Hugues and Marmin, Le Muet, 54 and 79, respectively.

97 Abel, Ciné, 419.

98 Ibid., 425.

99 Notes for LE COUP DU FAKIR, handwritten by Feuillade, BiFi, Fonds Feuillade.

100 Guillaume Danvers, "La présentation hebdomadaire," Le Film, 2 December 1916, 10.

101 Ibid., p. 29.

102 Curnonsky, "Music-Halls et Café-Concerts," Le Théâtre, February (II) 1914, 20.

103 Toulet, "Une année," 137.

104 Meusy, Paris-Palaces, 262.

105 The play is mentioned in Paris-Palaces on p. 261, but without specification of the film or the filmmaker. The film has been listed in Alice Guy filmographies established by Victor Bachy, Alice Guy-Blaché (1873-1968). La première femme cinéaste du monde, (Perpignan: Institut Jean Vigo 1993), 42 and by McMahan, Alice Guy Blaché, 76, whose research shows that it was shot in the summer of 1896 and screened for the public as of 14 November 1896.

106 Meusy, Paris-Palaces, 261.

107 Fescourt, La Foi, 91.

108 Meusy, Paris-Palaces, 262.

109 Adrian, "Cinéma et music-hall," 34.

110 Abel, Ciné, 55.

111 Legrand, Chronique, 123 and 127, Abel, Ciné, 31.

112 Program advertisement in the column "Cinematographes," Comoedia, 21 June 1914, 4 .

113 Program advertisement in the column "Cinematographes," Comoedia, 29 June 1914, 4 .

114 François Garçon, Gaumont. A Century of French Cinema (Paris: Gallimard 1994), 20. 
115 Program brochure LE COUP DU FAKIR/DEUX FRANÇAISES, Gaumont 1914-1915, BHV.

116 See: advertisement of the Gaumont-Palace program in CÉCR, 2 June 1916, 6 and program flyer Gaumont-Palace, 3-8 March 1917, BHV.

117 Adrian, "Cinéma et music-hall," 34; Gustave Fréjaville, "Le cinema et les spectacles (au music-hall)," Les Cahiers du mois, Cinéma, October 1925, 109-15.

118 Toulet, "Une année” 135.

119 Garçon, Gaumont, 19.

120 Abel, Ciné, 60.

121 J.M. Thomasseau, "Le Vaudeville" in: Dictionnaire encyclopédique du théâtre, 898

122 Henri Bergson, Le Rire. Essai sur la significaton du comique, Paris: Félix Alcan, Éditeur 1912. (Laughter: an Essay on the Meaning of the Comic, translation Cloudesley Brereton and Fred Rothwell at: http://www.gutenberg.org/etext/4352.) Unless indicated otherwise, I refer to the French original.

482 | 123 Ibid., 10.

124 Ibid., 78.

125 Ibid., 37.

126 Ibid., 31.

127 Ibid., 52.

128 Ibid., 90.

129 Ibid., 98.

130 Ibid., 92.

131 Ibid., 94.

132 Ibid., 96-7. L'ARROSEUR ARROSÉ was one of the first comic films ever made, by the Lumière Brothers in 1895, and brought to the screen a well known music-hall motif.

133 Bergson, Le Rire, 98.

134 Le Forestier, "Feuillade et les cinévaudevilles," 74.

135 Levesque, "Cinq ans," 5 .

136 Synopsis LE COUP DU FAKIR in program flyer Gaumont 1914-1915, BHV.

137 Synopsis LE COLLIER DE PERLES, held at BNF, DAS, Dossier Gaumont scénarios, no. G3643, Gaumont Hallmark (15 April 1915), Dépot légal 597/1915.

138 Le Forestier, "Feuillade et les cinévaudevilles," 79.

139 Edmond Floury, "Gaumont," LCC, 8 September 1917, III (summary section).

140 Notes for LE COUP DU FAKIR, Fonds Feuillade 2, BiFi.

141 Ibid.

142 Synopsis LE COUP DU FAKIR, BHV.

143 Ibid.

144 Ibid. Le Forestier has observed a similar sketchiness in the notes for a cinévaudeville LA SOURIS BLANCHE (The White Mouse) that is in the possession of Jacques Champreux; Le Forestier, "Feuillade et les cinévaudevilles," 79. 
145 Ibid.

146 Ibid. The paradox that Le Forestier observes is a shift from theatricality to a more modernist cinema aesthetics and liberty in mise-en-scène techniques and organisation.

147 Levesque, "Cinq ans," 10.

148 Le Forestier, "Feuillade et les cinévaudevilles," 73-87.

149 The following analysis is based upon the synopses of: TU N'ÉPOUSERAS JAMAIS UN AVOCAT at BNF, DAS, Dossier Gaumont scénarios G3488, Gaumont Hallmark (4 May 1914), Dépot légal 2150/1914; DÉBROUILLE TOI! at BNF, DAS, Dossier Gaumont scénarios G3824, Gaumont Hallmark (4 July 1917), Dépot légal 1908/1917; LE COLLIER DE PERLES at BNF, DAS, Dossier Gaumont scénarios G3643, Gaumont Hallmark (15 April 1915), Dépot légal 597/1915; LES FOURBERIES DE PINGUIN at BNF, DAS, Dossier Gaumont scénarios G3761, Gaumont Hallmark (18 April 1916), Dépot légal 708/1916; LE SOSIE at BNF, DAS, Dossier Gaumont scénarios G3647, Gaumont Hallmark (15 April 1915), Dépot légal 595/1915; L'ESCAPADE DE FILOCHE at BNF, DAS, Dossier Gaumont scénarios G3633, Gaumont Hallmark (22 March 1915), Dépot légal 146/1915; LA PEINE DU TALION at BNF, DAS, Dossier Gaumont scénarios G3782, Gaumont Hallmark (18 July 1916), Dépot légal 1207/1916; LES FIANÇAILLES D’AGÉNOR at BNF, DAS, Dossier Gaumont scénarios G3752, Gaumont Hallmark (31 March 1916), Dépot légal 579/1916; MON ONCLE at BNF, DAS, Dossier Gaumont scénarios G3827, Gaumont Hallmark (4 August 1917), Dépot légal 1909/1917; SI VOUS NE M’AIMEZ PAS at BNF, DAS, Dossier Gaumont scénarios G3783, Gaumont Hallmark (28 July 1916), Dépot légal 1550/1916.

150 Simounet, "Les nouveautés de la semaine," CÉCRs, 9 June 1916, 3.

151 Fescourt, La Foi, go.

152 Corvin, "Boulevard (le théâtre du)," 118-19.

153 Synopsis LES FOURBERIES DE PINGOUIN.

154 Ibid.

155 Synopsis SI VOUS NE M'AIMEZ PAS.

156 Synopsis LE COLLIER DE PERLES, printed in program flyer Gaumont Palace, Season 1914-1915, BNF, DAS, file RK 1033 bis.

157 Jacques Richard's brief acting descriptions in the 1895 special issue on Feuillade shows that, in fact, most of the members of his troupe had stage acting or dancing experience. Richard, "Une Troupe," 237-68.

158 Levesque, "Cinq ans," 10.

159 Richard, "Une Troupe," 251; D’Hugues and Marmin, Le Muet, 73.

160 Louis Delluc, “Marcel Levesque," Le Film, vol. 5, no. 99 (February 4, 1918), reprinted in: Louis Delluc and Pierre Lherminier, Cinéma et Cie (Paris: Cinémathèque française 1986), 61.

161 See also: Levesque "Par lui-même," 6. 
162 Levesque, "Cinq ans," 8.

163 See: advertisements for LES FOURBIÈrES DE PINGOUIN Ciné-Journal, 20 May 1916, 11; for LES FIANÇAILLES D'AGÉNOR Ciné-Journal, 27 May 27 1916, 26; for LA PEINE DU TALION Le Film, 25 November 1916, 4; and for LAgOURDETTE GENTLEMAN CAMBRIOLEUR Le Film, 2 December 1916, 4.

164 In addition, Levesque performed at the Théâtre Michel, the Comédie Marigny, the Gaiété, as well as at the Ba-ta-clan, in a vaudeville play by Cottens and Veber, La Dame du Commissaire and the Théâtre Albert Ier in a crime story adapted to the stage by Yves Mirande. For Levesque's further career, see: D'Hugues and Marmin, Le Muet, 73, and Richard, "Une Troupe," 251-52.

165 See: the Gaumont advertisement announcing Nouvelle Série de Vaudevilles in Ciné-Journal, 20 May 1916, 10 and idem listing all his ciné-vaudevilles produced So far in CÉCR, 11 August 1916, 4, as well as in Le Film, 12 August 1916, back page. The accent aigu on the first "e" was only rarely used, for which reason I 484 have chosen to write his name without it.

166 Edmond Floury, "Les Films tels qu'ils sont," $L C C$, 20 June 1914, 16.

167 Interim, "Les Nouveautés de la Semaine," CÉCR, 9 June 1916, 3.

168 Guillaume Danvers, "La Présentation hebdomadaire," Le Film, 18 November 1916, 18.

169 Edmond Floury, “Gaumont. DÉBROUILLE-TOI!. Cinévaudeville,” LCC, 8 September 1917, III; “Film,” "Courrier de l'Étranger. La Suisse,” CÉCR, 19 October 1917, 2.

170 Louis Delluc, "Notes pour moi," Le Film, 12 November 1917) and "Le cinéma existe," Le Film, 5 November 1919, reprinted in: Delluc and L'herminier, Cinéma et Cie, 153 and 264, respectively.

171 Albert Bonneau, "Un genre presque disparu. Les Films comiques," Cinémagazine, 24 August 1923, 267.

172 Henri Falk, "Les rois de l'écran. Lévesque," Le Crapouillot, 1 July 1920, 16.

173 Lacassin, Maître, 311.

174 Ibid., 310-11.

175 A prominent moralist was Ballot, who in, Hebdo-Film, signed the section "Échos et indiscrétions" and who wrote against the crime films in Hebdo-Film, 1, 3, and 8 April 1916, 3. Hebdo-Film's editor-in-chief André de Reusse openly disputed Ballot's vision in his editorials and opening articles. Other adepts of the moralist stance included Gustave Féry, film critic of L'Oeuvre, J. Ernest-Charles of L'Opinion, and Edouard Julia of Excelsior.

176 L'Intérimaire, "Les Films de la semaine," Hebdo-Film, 23 December 1916, 12.

177 [Louis Feuillade], synopsis MON ONCLE, LCC, 25 August 1917, IV.

178 Musidora, "La Vie d'une Vamp," and Lacassin, Maître, 210.

179 L'Intérimaire, "Les Films de la semaine," Hebdo-Film, 9 December 1916, 10.

180 See: Le Film, 2 December 1916, 4; Ciné-Journal, 2 December 1916, 23; and CÉCR, 8 December 1916, 5 . 
181 Except for the advertisements for TU N'ÉPOUSERAS JAMAIS UN AVOCAT, none of those for the ciné-vaudevilles listed her name. Sometimes, she was present in the stills, as in those for LA PEINE DU TALION and MON ONCLE.

182 Program flyer Pie... Ouit! in La Pie qui Chante in September 1916, BNF, DAS, RO 18420. Likewise, she was on the top of the bill in La grande revue sensationelle in the Concert Mayol in July 1917 as well as in the revues Comme une fleur in the Théâtre des Capucines in January 1918 and La Cigale réchante in La Cigale in April 1919. BNF, DAS, RO 18449, 18468 and 18502.

183 Advertisement Gaumont in Ciné-Journal, 2 December 1916, p. 23.

184 L'Intérimaire, "Les Films de la semaine," 10 and Interim, "Les nouveautés de la semaine," Le Cinéma et l'Echo du cinéma réunis, 8 December 1916, 5.

185 The scene was mentioned in Interim, "Les nouveautés de la semaine," 5.

186 Lacassin, Maître, 311. Both films were released in December 1916.

187 A still from LA PEINE DU TALION, in which Levesque pulls her hair up and she makes an extremely surprised face, suggests that she used physical comedy at other occasions. See: advertisement Gaumont in Ciné-Journal, 25 November 1916), 34. The still has been reprinted in Lacassin, Maître, 132, but there it has been ascribed to another ciné-vaudeville, incorrectly so, apparently.

188 Feuillade continued making serials until his death in 1925.

189 In April 1916, Musidora acted in the costume in Jean Bastia's revue "C'est maouspoilpoil" at the Scala; in October 1917 she reappeared in it in a sketch that she wrote, "Le maillot noir", and staged at the Théâtre Saint-Denis; in November 1917 , she wore the suit in the revue "C'est une affaire" at the Gaité-Rochechouart and, in December of that same year, in the music-hall's next revue with the telling title "Le dernier exploit de la vampire", in which she also appeared in a pink bodysuit. Likewise, she wore a silver-gray suit in a transvestite role at La Cigale, in the revue "La Cigale rechante" that premiered on 23 April 1919.

190 Förster, "De verering van een schim," 25.

191 Musidora, “Mes projets," n.p.

192 The sessions on Feuillade are most notably CRH 068 and 069. Musidora occasionally - but each time very briefly - mentioned two of the films she directed and produced, POUR DON CARLOS (BiFi, CRH 037) and SOLEIL ET OMBRE (BiFi, CRH 051).

193 Lacassin, Musidora, 458-9 and 69.

194 Cazals, La dixième muse, 36-7.

195 Richard Roud, "Louis Feuillade and the serial.” In: Richard Roud (ed.), Cinema: A Critical Dictionnary. The Major Film-makers, Volume 1 (New York: The Viking Press 1980), 354.

196 Monica Dall'Asta, "Il costume nero da Zigomar a Musidora.” In: Monica Dall'Asta, Guglielmo Pescatore and Leonardo Queresimo (eds.), Il colore nel cinema muto (Bologna: Mano 1995), 167-8. 
197 Vicki Callahan, Zones of Anxiety: movement, Musidora, and the crime serials of Louis Feuillade (Detroit, Michigan: Wayne State University Press 2005), 37.

198 Ibid., 40.

199 Ibid., 85 .

200 Ibid., 92.

201 Eva Warth, "Moving Bodies," Tijdschrift voor Mediageschiedenis, 2, 1, (June 1999), 148.

202 Förster, "De verering van een schim," 8.

203 Abel, The first wave, 74; Roud, "Feuillade and the Serial," 351.

204 For a discussion about how the exploits and the chase of Bande à Bonnot became tragic and heroic in the media coverage, see: Annette Förster, "Amusing the Audience, Defying Authorities. Female Criminals in the Silent Cinema," e-book in English language accompanying Winfried Pauleit, Christine Rüffert, a.o. (eds.), Public Enemies. Film zwischen Identitätsbildung und Kontrolle (Berlin: Bertz+Fischer 2011), 25-36.

205 Levesque, "Cinq ans," 4.

206 Abel, The First Wave, 222.

207 See: Levesque, "Cinq ans," 4 and François de la Breteque, "L'Inspiration méridionale dans l'oeuvre de Feuillade," Les Cahiers de la Cinémathèque. Louis Feuillade, 48 (1988), 29-36. Mazamet is a town in the county of Tarn, a county next to the Hérault where Feuillade came from. (Le Petit Larousse illustré 1992, s.v. "Mazamet.")

208 Musidora's top-right signature on the poster as it is displayed in the film suggests that it was her own design.

209 Video released by Waterbearer Film.

210 See: Levesque, "Cinq ans," 6 about HOTEL DE LA GARE.

211 Musidora speaking at the 4 April 1952 session of the CRH, according to the minutes CRH 070, 37-38, held at the BiFi.

212 As Nathalie Leplongeon has argued in her highly illuminating analysis of the narrative organization of LES VAMPIRES, this direct address is not the remnant of an earlier mode of cinematic representation, but a choice of aesthetics and communication that brings the film in line with popular narrative arts like serial novels, vaudeville plays, and melodramas. She considers the device a cinematic transcription of the contact and the complicity with the audience established by such popular arts. See: Nathalie Leplongeon, "Les Vampires de Feuillade, une logique de transition,” in: Jean A. Gilli, Michèle Lagny, Michel Marie, Vincent Pinel (eds), Les vingt premières années du cinéma français (Paris: Presses de la Sorbonne Nouvelle 1995), 268.

213 Musidora, "Vingt ans de vie cinématographique en vingt minutes," radio lecture transcribed and printed in Cazals, La dixième muse, 205.

214 Letter from Musidora to Georges Sadoul, quoted in Sadoul, Histoire générale, 342. 
215 Musidora, "Le Prince des Ténèbres," theater play in one prologue and three acts, written in 1952. The text of the prologue is printed in Cazals, La dixième muse, 134 .

216 Musidora, "Dialogues de jadis," Cahiers du Cinéma, November 1964, 43.

217 Musidora interviewed by Jean Thévénot for RSR (18 November 1947).

218 Lacassin writes that it was designed by the couturier Paul Poiret, but does not disclose his source for this information (Maître, 208). Musidora indeed wore designs by Poiret, who, moreover, belonged to Colette's circle of friends. In addition, the suit would have matched Poiret's interests, because his creations are well-known for liberating the woman's body from the corset and for using smooth, flowing, and elastic materials in underwear instead. To my knowledge, however, Musidora never mentioned Poiret's design of the suit.

219 Chantal, "Ancêtre des pin-ups," 6-7.

220 Napierkowska switched to film around the same time as she performed at the above prestigious places, that is to say, around 1909, when she was invited by SCAGL-director Albert Capellani. At Gaumont, she worked with Feuillade and Jacques Feyder. In 1921, she played the protagonist of the legendary L'ATLANTIDE by Jacques Feyder, to which I will return.

221 This artistic standard was set by Loïe Fuller, who, since 1892, had presented her dance acts at the Folies-Bergère. "La Dance Serpentine" and "La Dance du Feu" were neither routine nor regular dance, but compositions of bodily movements, flowing veils, and choreographed colors, in which the eye was attracted to the performance of physical strength and ephemeral beauty. See: Giovanni Lista, Loïe Fuller. Danseuse de la Belle Époque (Paris: Éditions Stock 1994).

222 See, for a discussion of this tradition: Dall'Asta, "Il costume nero," 164-81.

223 Abel, Ciné, 367 mentions that it was missing. I had a chance to view the print as restored by Cinémathèque française in 1998 and shown at Il Cinema Ritrovato in Bologna 1999. This print runs 1059 meters or 45 minutes screening time and is probably incomplete. It was shown again at the same festival in 2010, together with ZIGOMAR PEAU D'ANGUILLE (a print from the British Film Institute National Archive) in the program "Le donne avventurose del muto" curated by Mariann Lewinsky and Monica Dall'Asta.

224 D'Hugues and Marmin, Le Muet, 69, Abel, Ciné, 367.

225 Guérin reported that Feuillade gave him full freedom in framing and lighting. See: CRH o69 (24 November 1951) and Sadoul, Histoire générale, 198 (footnote).

226 There is a fan letter from a soldier with a drawing of Irma Vep in her suit in which the pubic hair shines through the cloth. See : Lettres d'admirateurs à Musidora 1915-1919, Fonds Musidora, BiFi Paris. See also Förster, "De verering van een schim," 14 .

227 Musidora, Le prince des ténèbres, 135. 
228 In the session of the CRH devoted to LES VAMPIRES and Feuillade, Musidora explained that she never saw the film in the cinema in the 1910s, because she was too busy working, acting for the camera, and rehearsing stage performances in daytime, and performing on stage at night. BiFi, CRH o56 (30 June 1948).

229 Abel, Ciné, 367.

230 M.P. Sales agency advertized in March 1915 that THE HAZARDS OF HELEN, starring Helen Holmes, was available for exhibition. See: Ciné-Journal, 15 March 1915, 20. October that year the advance of Pearl White, also known as Elaine Dodge, set off with LES MYSTÈRES DE NEW YORK (The Mysteries of New York), a compilation of THE EXPLOITS OF ELAINE, THE NEW EXPLOITS OF ELAINE, and THE ROMANCE OF ELAINE made for the French market. The French title played up the association with the 1842 serialized novel Les Mystères de Paris by Eugène Sue. The first American serials, with Kathlyn Williams, had reached France a few months before the war broke out, according to Albert Bonneau, "Le Film à épisodes, "Cinémagazine, 27 July 1923, 125, and Selig advertized them in CinéJournal of May 1914. In the USA, the serial queen vogue dated from the early 1910 , and was at its peak by the mid-1910s.

231 Musidora interviewed by Jean Thévénot for RSR (18 November 1947).

232 André de Reusse, "Encore une censure?...," Hebdo-Film, 27 May 1916, 2.

233 Edouard Julia, "L'Influence du cinéma," article from Excelsior reprinted in Le Film, 5 June 1914, 18.

234 “Échos, Informations, Communiqués,” Le Film, 17 March 1916, 22.

235 René Delbost, "Les nouveautés de la semaine," CÉCR, 12 May 1916, 3.

236 Guillaume Danvers, "Nouveau Spectacle," Ciné-Journal, 11 December 1915, 18.

237 Le Voyeur, "Les Films de la semaine,” Hebdo-Film, 1 April 1916, 4 ; Le Voyeur, "Les Films de la semaine," Hebdo-Film, 17 June 1916, 4.

238 Le Voyeur, "Les Films de la semaine," Hebdo-Film, 11 March 1916, 4.

239 Ibid.

240 Le Voyeur, "Les Films de la semaine," (1 April 1916), 4

241 Le Voyeur, "Les Films de la semaine," (11 March 1916), 4.

242 Le Voyeur, "Les Films de la semaine," (17 June 1916), 4.

243 Guillaume Danvers, "Nouveau spectacle," 18.

244 According to Lacassin, the production period of LES VAMPIRES ran from the third week of August 1915 through the first of March 1916. (Maître, 204)

245 The earliest mention of the publication that I have come across was in the rubric “Échos, Informations, Communiqués," Le Film, 15 April 1916, 23.

246 Lacassin, Maître, 210.

247 “Les Vampires en roman,” Le Film, 15 April 1916, 23 ; Jacques Yvel, "Les drames policiers," CÉCR, 12 May 1916, 1.

248 A.P., "Cinéma en province: Le Mans," CÉCR, 12 May 1916, 2; "Courrier de l'étranger: Alexandrie," CÉCR, 16 June 1916, 2; José Rogès, “Courrier de l'étran- 
ger," Le Film, 8 July 1916, 24 (reporting from Barcelona); Edouard Petit, "Courrier de l'étranger: La Suisse," CÉCR, 9 February 1917, 2.

249 For an overview of papers appearing and reappearing during the war, see: Abel, French Film Theory and Criticism, 95.

250 See: Le Voyeur's review of LES EXPLOITS D'ELAINE in "Les Films de la Semaine," Hebdo-Film, 22 July 1916), 9-10 and Musidora's own story "Le Moyen” in which she gave her fictional alter ego the telling name Pearl Dora (Le Film, 23 September 1918, 5-6).

251 Musidora, "Les Dangers du Cinéma," Fantasio, 1 July 1916, 11. Brunoy was a town in the outskirts of Paris. The clip is available at: http:/www.youtube.com/ watch?v=_5Fzy8RVYfU\&feature=related "Fragmento de Les Vampires".

252 Musidora, “Comme j'ai passé sous un train," CÉCR, 21 July 1916, 2; Paris Midi, 9 August 1916; L'Action, 20 July 1916, and Siècle, 10 August 1916.

253 Musidora, "Petit cours à l'usage de ceux qui voudraient devenir vedette de cinéma," Filma, 15 January 1920, 1.

254 Musidora, "Le snob au cinéma," Fantasio, 1 December 1916, 289.

255 Ibid., 290.

256 Musidora, "La Vie d'une Vamp."

257 Musidora, "Le snob au cinéma," 290.

258 Ibid., 289.

259 The distinction between diegetic and extra-diegetic acting is borrowed from Heide Schlüpmann, "Asta Nielsen and Female narration: The Early Films” in: Thomas Elsaesser (ed.), A Second Life. German Cinema's First Decade, (Amsterdam: Amsterdam University Press 1996), 118-22.

260 Musidora, "Mes projets."

261 Callahan, Zones of Anxiety, 91-103.

262 Ibid., 95.

263 For this reason, Callahan sees in Daisy a reference to the American serialqueens (Zones of Anxiety, 103).

264 Advertisements in Le Film, 16 December 1916, n.p. and in Ciné-Journal, 5 May $1917,11$.

265 "Présentation. Judex," Ciné-Journal, 28 December 1916, 14.

266 Constant Larchet, “Judex,” Le Film, 13 December 1916, 11.

267 Léon Druhot, "Presentation Gaumont," Hebdo-Film, 20 January 1917, 9.

268 Voittout [Edmond Floury], "Critique Cinématographique," LCC, 3 February 1917, 14; "La Présentation Hebdomadaire," Le Film, 12 February 1917, 17.

269 Simounet, "Les Nouveautés de la semaine," CÉCR, 2 February 1917, 3.

270 Larchet, "Judex," 11.

271 Musidora, "Mes projets."

272 "Échos," Ciné-Journal, 20 January 1917, 4.

273 P. Simonot, "Chacals," Hebdo-Film, 8 November 1917, 14. 
274 Supplement à Hebdo-Film, 20 July 1918, 2 and 15 March 1919.

275 Arlecchino, “M. André Hugon. Compositeur de Films," La Cinématographie française, 30 November 1918, 25.

276 André de Reusse, "Présentation Pathé,” Hebdo-Film, 19 March 1919, 12.

277 Delluc (probably), introduction to Musidora, "Variations sur le Cinéma," 7.

278 Lacassin, Musidora, 495; Virmaux (eds), Colette at the Movies, 209.

279 Early December 1916, MINNE was advertized as newly released in three trade papers: Ciné-Journal, 2 December 1916, 41, Hebdo-Film, 2 December 1916, 11, and Le Film, 2 December 1916, 9. The latter two mentioned Musidora as the lead actress and Films Lumina as the production company, yet none specified a director. Neither did any of the follow-up advertisements in Le Film, 23 December 1916, 10 and in Ciné-Journal, 13 January 1917, 18, after which the title vanished from the Films Lumina advertisements. None of these papers, moreover, ran reviews of the film, neither was it mentioned in a 1918 overview article on Jacques de Baroncelli, director of Lumina Films and, according to Lacassin, also of MINNE. See: Arlecchino, "Monsieur Jacques de Baroncelli. Compositeur de Films," La Cinématographie Française, 23 November 1918, 10-11. Musidora used omitted the title from her self-presentations, so that Lacassin's conclusion (Musidora, 495) that the film was either never made or never finished, seems justified.

280 The French term scénario refers to plot outline, while adaptation rather refers to scenario.

281 In her retrospective radio lectures and article on Colette, Musidora claimed the co-adaptation and co-direction of LA FLAMME CACHÉE. To underpin her point, she cited from articles in Le Monde and Le Théâtre of 2 November 1918, but not from any film periodicals, which, moreover, did not pick up the news. Musidora, “Colette et le Cinéma Muet," L'Écran français, 13 February 1950, 8-9; reprinted in Cazals, La dixième muse, 195-99.

282 Musidora, "Vicenta," Comoedia Illustré, 15 February 1920, 207; advertisements of distributor Union Éclair for viCENTA predicted "Musidora will achieve a triple success as the author, director and the protagonist." Ciné-Journal, 3 April 1920, 40.

283 Advertisement Union-Éclair in LCC, 3 April 1920, 15.

284 Ibid.

285 Advertisements of Dulac's production company Films DH, for instance for LA VRAIE RICHESSE (True Richness) in Ciné-Journal, 6 January 1917, 48 and for VENUS VICTRIX in Ciné-Journal, 20 January 1917, back page. See also: Arlecchino, “Madame Germaine Albert-Dulac. Compositeur de Films," La Cinématographie Française, 16 November 1918, 31.

286 According to Tami Williams, Dulac's first article on cinema was "Mise en scène," Filma , 15-31 July 1918, 2, reprinted from Le Film, 19 November 1917. See: 
Williams' C.V. of Dulac in the issue entirely devoted to the filmmaker of Kinemathek, 39, 93 (October 2002), 117, published on the occasion of the retrospective and international symposium "L'invitation au voyage - Germaine Dulac" organized in 2002 by the Kinothek Asta Nielsen in Frankfurt am Main. See also: Tami Williams, Germaine Dulac. A Cinema of Sensations, (Urbana, Chicago and Springfield: University of Illinois Press, 2014).

287 Colette, "A Short Manual for the Aspiring Scenario Writer" in: Virmaux (eds), Colette at the Movies, 46-55; Musidora, "Petit cours," 1.

288 See: Virmaux (eds.), Colette at the Movies, 13 and 20. Colette stopped writing for Le Film because there was no money in it; she was succeeded by Louis Delluc, who was almost immediately appointed editor-in-chief of the paper.

289 Virmaux (eds.), Colette at the Movies, 59.

290 Ibid.

291 See, for an excellent overview of the various positions of critics and aspirations of filmmakers of the time and the overlaps and the divergencies in their views: Abel, French Film Theory and Criticism, 95-124, and for an historical reassessment of the convoluted uses of the term then and later, Frank Kessler, "Fotogenie en fysionomie," Versus, 1 (1991), 64-80.

292 Colette, "L’Envers du Cinéma," Femina, September 1917, Le Film, 8 October, 1917 and Filma, 15 December 1917 and reprinted and retitled "Les Coulisses d'un Film" in Cinéa, August 26, 1921, 8. Translation by Sarah R.W. Smith quoted from Virmaux (eds.), Colette at the Movies, 68.

293 Ibid., 69-70.

294 Ibid., 71-2.

295 Abel, French Film Theory and Criticism, 110.

296 Musidora, "Variations sur le Cinéma," 7.

297 Ibid., 8.

298 Louis Delluc, “La Vagabonde," Le Film, 25 February 1918, 13.

299 Musidora, "Petit cours," 1.

300 Ibid.

301 Ibid.

302 Abel, French Film Theory and Criticism, 110.

303 Musidora, "Colette et le Cinéma Muet," 195-99.

304 Cinéa was a deluxe weekly, modelled after the prestigious Comoedia Illustré, which, according to Abel, (French Film Theory and Criticism, 197), for at least a year and a half after its inception on 6 May 1921, functioned as the primary forum of debate on independent film art in France.

305 Cinéa, 8 July 1921, n.p. The photograph was reprinted in Legrand, Chronique, 191.

306 The dog was Musidora's own and it also plays a small comic part in Musidora's film POUR DON CARLOS, after the novel by Pierre Benoit, which I shall discuss 
shortly. According to Lacassin, Musidora, 483, its name was Lacsalé, after Benoits novel Le Lac salé, which Musidora intended to adapt to the screen as well, but the project never materialized.

307 Louis Delluc, "Metteurs en scène français," in: Louis Delluc and Lherminier, Cinéma et Cie, 124; originally published in Le Film, 1 October 1917.

308 Louis Delluc, "Judex (Bruxelles)" in: Delluc and Lherminier, Cinéma et Cie, 92; originally published in Paris-Midi, 6 July 1919. Delluc is not very consistent in his judgment, because, in the previous year, he had applauded JuDEx for its innovative imagery, beautiful landscapes, modernist set-dressing, and for the comic character of Cocantin as played by Levesque. See: his "Notes pour moi" in: Delluc and Lherminier, Cinéma et Cie, 177, originally published in Le Film, 29 April 1918. Delluc did not write anything specific on LES VAMPIRES, and may not even have seen it, because his interest in film emerged in the fall of 1916, after having seen THE CHEAT, while LES VAMPIRES had closed its first run early that summer. His crusade, as can be concluded in retrospect, predominantly concerned the serials made by Feuillade after JUDEx.

309 Musidora, "Variations sur le Cinéma," 8.

310 Musidora, "Mes projets." In 1919, after Delluc had left Le Film, the periodical turned from a weekly into a monthly.

311 V. Guillaume-Danvers, "Musidora," Cinémagazine, 22 July 1921, 7

312 "On dit que...," Filma, 1 December 1919), 7.

313 Lacassin, Musidora, 474 notes that he had been unable to retrieve official documents for the company's establishment.

314 Ibid.

315 Musidora, "Vicenta," 207.

316 Ibid.

317 Ibid.

318 Nyctalope, “Union-Éclair," La Cinématographie française, 17 April 1920, 60.

319 Colette to Musidora, cited in "Colette et le Cinéma Muet," 195-99.

320 Musidora, "Vicenta," 207.

321 Lacassin, Musidora, 475.

322 Musidora, "Mes projets."

323 That is to say, this is how one plot summary depicts the character, which, moreover, seems to correlate with Musidora's view on it. See: André de Reusse, "Les Présentations. Union-Éclair," Hebdo-Film, 3 April 1920, p. 4.

324 Lacassin, Musidora, 475-76 cites from a Nice newspaper, and from an article by Delluc in his Le Journal du Ciné-Club. The latter periodical was, according to Abel, French Film Theory and Criticism, 197, an inexpensive and unpretentious alternative to Le Film. Le Film itself and most other film periodicals that I have examined, did not run a review of VICENTA. The reviews cited by Lacassin were highly critical of the film, most notably on its intelligibility, whereas the review 
from the trade paper La Cinématographie française was mild on that point and stated that there were better scenarios but also worse ones. Cazals, La dixième muse, 75 summarizes one single, favorable, assessment of Musidora's acting and the film's imagery published in L'Oeuvre, yet without reference details.

325 I thank Frank Kessler for making me aware of the rediscovery of a nitrate print of this film at the Centre National de la Cinématographie (CNC), Bois d'Arcy, France, in a deposit from the Cinémathèque de Toulouse.

326 Jean-Luc Croze announced the intended adaptation to film of Benoit's novel, including crew and cast, in his column "Informations" in Comoedia, 17 April 1919, 3. According to Lacassin, Musidora, 495, viCENTA was shot in July, August and September 1919.

327 Musidora, “Comment j'ai tourné POUR DON CARLOS," Lectures pour tous, undated and unpaginated clipping, private collection. In this text, she mentions a friend who introduces her to Benoit. Without disclosing his name, she answers him (in a dialogue format) that she knows L'Atlantide to be filmed. This is a more extensive account of how she came to shoot the film than the excerpts from it published under the same title in the women's magazine $\grave{E} v e, 30$ January 1921), 10. The unnamed friend was probably Feyder, who is reported to have wanted Musidora for his film but was forced to cast Stacia de Napierkowska in her place (Abel, The First Wave, 156). Musidora knew Feyder from her Gaumont time, as she acted in his parody on serials LE PIED QUI ÉTREINT (The Foot that Clutches, 1916) and apparently was still in touch with him, as she was with other Gaumont filmmakers, including Marcel L'Herbier and Henri Fescourt. See also: Marcel L'Herbier, La Tête qui tourne (Paris: Éditions Pierre Belfond 1979), 20-21; Fescourt, La Foi, 95. I thank Theodore van Houten for bringing L'Herbier's autobiography to my attention.

328 The novel was published in June 1920 by Albin Michel. Since his debut in 1918, Pierre Benoit (1886-1962) used to write one novel a year (with the exception of 1943-1947), all romance and adventure stories, with a heroine whose name invariably had the initial A. See: Bernard Vialatte (President of the Association des Amis de Pierre Benoit), "Pierre Benoit, écrivain français et académicien dans le calme du Quercy qu'il a tant aimé” at: http:/www.quercy.net/hommes/ pbenoit.html and http:/www.roman-davontures.info/auteurs/france/francais2. htm.

329 Musidora, "Mes projets."

330 Lucien Wahl, “Films d'aujourd'hui. Pour Don Carlos,” Cinéa, 16 December 1921), 5 .

331 "Pierre Benoit. Pour Don Carlos," Le Film, June 1920, n.p.

332 Daisne, Kroonfilms, 8. See, for a biography and bibliography of Daisne's extensive oeuvre Studiecentrum Johan Daisne at: http://www.daisne.bewoner.antwer pen.be/jdgiog_n.htm. As of 1950 until her death in 1957, he corresponded with 
Musidora, and, in 1951, invited her to visit Gent. (Universiteitsbibliotheek Gent, Dossier Musidora).

333 J. Trébor, "Agence Générale Cinématographique. 'Pour Don Carlos', " CÉCR, 21 October 1921.

334 Musidora, "Comment j'ai tourné," and Lacassin, Musidora, 480. Based on correspondence now irretrievable, Lacassin assumes that Musidora initially felt a bit overruled by this demand, but, as indeed her published accounts attest to, eventually happily accepted the contribution as it did not hamper her project; moreover, she assigned De Lasuen/Lasseyne as the co-director for her next film, SOLEIL ET OMBRE.

335 Musidora, "Comment j'ai tourné."

336 D'Hugues and Marmin, Le Muet, 91. See also: the catalogue of Le Giornate del Cinema Muto, Pordenone/Sacile 2005:55-80.

337 See: André Antoine, "Propos sur le cinématographe," Le Film, December 1919. The article details the distinct techniques of theater and film. Translated into English as "A proposal on the Cinema" in: Abel, French Film Theory and Criticism, 191.

338 Ibid., 96.

339 Ibid., 102, D'Hugues and Marmin, Le Muet, 92. By 1921, when Fabris performed in the Jaques Charles revue Avec le Sourire at the Casino de Paris, the culte $d u$ maillot gave way to veritably nude dancers. Jaques Charles had introduced the nude dancer at the music-hall in 1919, although he regretted the "innovation" in retrospect. See: Chauveau and Sallée, Music-hall et café-concert, 27 and 133 .

340 Lacassin, Musidora, 495.

341 Abel, French Film Theory and Criticism, 96.

342 Le Petit Larousse illustré 1992, s.v. Daudet, Alphonse.

343 Louis Delluc, "Antoine travaille" in: Delluc and Lherminier, Cinéma et Cie, 1986:66-67, reprinted from Le Film, 25 February 1918.

344 Abel, The First Wave, 96.

345 Musidora, "Comment j'ai tourné."

346 See, for a discussion of films set in various southern French regions: Abel's chapter in The First Wave (94-138).

347 Musidora, "Comment j'ai tourné."

348 Louis Delluc, "Pour Don Carlos," Paris-Midi, 22 October 1921, reprinted in: Louis Delluc and Lherminier, Cinéma et Cie, 259-60.

349 Both Lacassin (Musidora, 495) and Cazals (La dixième muse, 214) give 2400 meters for the film's length, without specifying if this concerns the initial or the revised cut. According to a short notice by André de Reusse, "Agence Générale Cinématographique. Pour Don Carlos," Hebdo-Film, 22 October 1921), 57, the released print measured 2000 metres. The information that the film was shortened by one fifth is derived from Legrand, Chronique, 188 ; if indeed, the length 
given by Lacassin and Cazals concerns the initial cut. Projected at a speed of 18 frames per second, 2400 meters would take 127 minutes screening time, that is to say, a bit over two, but not nearly three hours, as Lacassin (Musidora, 481) and Cazals (La dixième muse, 82) unanimously suggest.

$35^{\circ}$ This length was measured on the editing table when I viewed the unrestored nitrate print in March 2001 at the CNC. To my regret, I have never been able to see the film in projection, let alone with musical accompaniment. Neither was a video copy of it available for closer scrutiny. Another print of the film held at the Cinémathèque française was not available for research, but I was notified (by telephone in May 2001), that it was more incomplete and had no intertitles at all.

351 Scenario POUR DON CARLOS, BiFi, Fonds Musidora B1 (3).

352 Musidora, "Comment j'ai tourné "Don Carlos", Ève, 30 January 1921, 10. The painter was Guy Amont, according to this article, but a publicity leaflet held at the BNF, DAS (code 4 e RK 7565) assigns it to Pierre Labrouche. It represents a mountain village, with a church and white timbered houses. According to JeanLouis Meunier, who has published and annotated Musidora's radio lectures on the writer Pierre Louÿs, Labrouche was a painter and etcher from Bayonne, a town in the Basque Pyrenees, and a friend of Musidora's. See: Musidora, Souvenirs sur Pierre Louÿs (Muizon: Éditions “À L'Écart” 1984), 32 (footnote 10).

353 De Reusse made the remark, as well as Colette, in a private note to Musidora quoted in Lacassin (Musidora, 483). But Colette may have responded to the initial cut, as she also asks if the film had been shortened already.

354 Musidora to Johan Daisne, cited by Daisne in "Souvenirs gantois," 4.

355 Musidora interviewed by Jean Thévénot for RSR.

356 Germaine Dulac's 1928 adaptation of a Benoit novel in her film LA PRINCESSE MANDANE (Princess Mandane) likewise has two women leave the man who loves them both and take off together, albeit it does not constitute the very end of the film, but of a dream. A rare opportunity to watch this film was the 2002 retrospective of all extant films by Dulac: both her well-known avant-garde work and her extensive popular oeuvre to which LA PRINCESSE MANDANE belongs. The retrospective was organized by the Kinothek Asta Nielsen in Frankfurt am Main. "Pour Don Carlos," Cinéa, 16 December 1921, 5.

358 Musidora to Pierre Benoit, undated, cited in Cazals La dixième muse, 79-80.

359 Lucien Wahl, "Pour don Carlos," Cinéa, 28 October 1921, 15.

360 Quoted in Lacassin, Musidora, 483.

361 Colette to Musidora, ibid.

362 The print does not contain a single moment representing Lucille's view on things, or a scene explaining her instantaneous commitment to the cause and unconditional closeness to Allégria. Neither did the novel, as one critic pointed out, "Pierre Benoit. Pour Don Carlos," Le Film, June 1920, n.p. 
363 The action unfolds as follows: Allégria slaps a soldier and a lieutenant in the face; she is then pushed down by the latter, who, thereafter, gets stabbed by Maypur. A possible explanation would be that the situation is hopeless and that the men are ready to give up, whereas she orders them to hold out; another explanation could be that she has gotten angry for not finding Olivier. The unrestored nitrate print does not, or no longer, contain indications for what the narrative logic may have been.

364 Scenario POUR DON CARLOS; "Pour Don Carlos," 5.

365 R.H., "Le succès du jour. Pour Don Carlos d'après le roman de Pierre Benoit," Hebdo-Film, 22 October 1921, 50.

366 Ibid.

367 "Pour Don Carlos," 7.

368 According to Lacassin (Musidora, 495), Musidora and Lasseyne made a short in between the two feature films, UNA AVENTURA DE MUSIDORA EN ESPAÑA (An Adventure of Musidora in Spain), which was intended and shown as an introduction to a play, but which is not known to survive. A print of SOLEIL ET OMBRE is held at the Cinémathèque française.

369 Abel, The First Wave, 153. Other Spanish films mentioned by Abel are LA FÊTE ESPAGNOLE (The Spanish Feast, 1920), directed by Germaine Dulac from a scenario by Delluc, and, most notably, the box-office hit EL DORADO (1921), directed by a friend of Musidora's, Marcel L'Herbier.

370 In 1920-21, when Musidora became acquainted with Antonio Cañero/Baena (1885-1952), he was the owner of a "ganaderia" (bull breeding farm) and practiced bull fighting only at benefit festivities. In 1922, the year that SOLEIL ET OMBRE was made, Cañero began his career as a professional rejoneador, which he pursued until his retirement in 1936. He was the second most famous bull fighter of Cordoba behind the legendary Manolete (Manuel Rodriguez Sanchez). See: Museo Taurino, Cordoba, and http://www.ayuntcordoba.es/ayunta/html/ ilus/canero.htm.

371 See, for instance, Agustín Jurado: “Musidora y Antonio," El Dia de Cordoba, 16 May 2010, Toñi Caravaca, “Anonio Cañero, rejoneador y actor,” El Mundo, 12 May 2010 and M. Roso, "Cañero, rejoneo de cine," $A B C$, 9 May 2010. These articles were written on the occasion of a program of Musidora's films with Cañero presented by the Cineteca de Andalucía.The latter article also points out the sites where the film was shot.

372 Also Callahan included the publicity still of this shot in her Zones of Anxiety, 115. Her caption erroneously states that it shows Juana imprisoned.

373 Maria Star was the nom de plume of the writer, art collector, and Maecenas baroness Ernesta Stern, who presided over a literary salon in Paris that was frequented by illustrious artists such as the writer Marcel Proust, the composers Reynaldo Hahn and Gabriel Fauré, the paintress Madeleine Lemaire, and the 
soprano Lina Cavallieri. The style of her novels was said to be vivid and clear, with a novel imagination and a moving knowledge of the human soul. See: Jean Bouscatel, "Ernesta Stern/Maria Star Chévalier de la Légion d’Honneur," Ève, 17 October 1920, 3 and André de Fouquières, “Mme Ernesta Stern,” www.apo phtegme.com/ROULE/stern.pdf.

374 Publicity booklet SOLEIL ET OMBRE, Universiteitsbibliotheek Gent, Fonds Johan Daisne, Dossier Musidora.

375 Lacassin, Musidora, 486.

376 www.youtube.com/watch?v=52ut-CBSGBg.

377 Musidora, “Grandes enquêtes d'Ève: Comment je suis devenue 'Torera', Ève (September 28, 1924), clipping in scrapbook "Musidora," BNF, DAS, BiographieCritique (RT 9736).

378 It has often been suggested that Musidora's fascination with bull fighting stemmed from Louis Feuillade, who was an aficionado as well. On the basis of the interview in $\grave{E} v e$, however, I doubt this, because Musidora explained that she had had to learn the passion: "It is a passion which begins with abomination, abhorrence, anxiety, and which results in enthousiasm and the most immense excitement."

379 Musidora, Paroxysmes. De l'Amour à la Mort (Paris: Éditions Eugène Figuère 1934).

380 For instance, chapter 24, p 177-193 cites diary fragments, and Musidora explains in a footnote that they follow Flora's notes to the letter, but the friends and the stage performances mentioned are Musidora's; chapter 25 is set in BoisLe-Roi, where Musidora's mother lived and her father Jacques Roques was buried as described on p. 206; and chapter 26 is dedicated in a footnote on p. 207 to Clément Marot, Musidora's husband at the time when she wrote the novel.

381 Lacassin, Musidora, 488-9; Cazals, La dixième muse, 87-8.

382 Musidora, Paroxysmes, 179.

383 Jacques Durand, "SoleIL ET OMbRe," in: Philippe Arnoud (ed.), La Persistance des images, (Paris: Éditions de la Cinémathèque française 1996), 62.

384 Callahan, Zones of Anxiety, 113.

385 Vicky Callahan, "Screening Musidora: Inscribing Indeterminacy in Film History," Camera Obscura, (2001), 76.

386 María Camí-Vela, “Mujeres, toreros e identidad en el cine español: Sol y sombra (1922) de Musidora,” in: Consejería de Cultura y XI Congreso de la Asociación Española de Historiadores de Cine (eds.) Savia nutricia. El lugar del realismo en el Cine Español II (Córdoba: Filmoteca Andaluza 2006), 43-46 The print is held at the Filmoteca española in Madrid and bears the title L'ESPAGNOLA.

387 This may be a consequence of some historical fallacies put forward by Callahan and reproduced by Camí-Vela, which need correction because they concern Musidora's filmmaking practice and the functions she took in it. Callahan 
suggests that Musidora directed ten films, only two of which are known to be extant today, SOLEIL ET OMBRE and LA TERRE DES TAUREAUX. ("Screening Musidora," 59, Zones of Anxiety, 112.) As my research shows, POUR DON CARLOS also survives, and this latter film, as well as SOLEIL ET OMBRE, were co-directed by Jacques Lasseyne. Although it is hard to distinguish this co-director's contributions, there is no reason to doubt that they have been significant, because Musidora chose to work with him again after their first joint effort, and because she attributed the full direction to him in the contemporary publicity, however incomprehensible this may seem in retrospect. Of the lost seven titles, only two feature films can, more or less safely, be attributed to Musidora as their director or co-director, namely VICENTA (direction) and LA FLAMME CACHÉE (co-direction with Roger Lion), while LA MAGIQUE IMAGE was a short homage to Louis Feuillade directed by Musidora in 1950. Camí-Vela ("Mujeres, toreros," 43 note 2) further lists, on the basis of Lacassin's filmography, but without the due cautions this historian has put forward, the feature films MINNE, which, as we have seen, most likely was never made; MAM'ZELLE CHIFFON, which was directed by André Hugon; and LA VAGABONDE, which was directed by Eugenio Perego. As noted before, LE MAILLOT NOIR was a filmed insert in a sketch in a revue and UNA AVENTURA DE MUSIDORA EN ESPAÑA was a filmed introduction to a stage performance.

388 Lucien Wahl, "Soleil et Ombre," Cinéa, 20 November 1922), 7, Anonymous, "Présentations," Ciné-Journal vol. 16, 12 August 1922, 26.

389 "Les Présentations," Hebdo-Film, 12 August 1922, 24. This particular title, however, misses from the surviving print.

390 Vicki Callahan, "Screening Musidora," 75-76.

391 Lacassin, Musidora, 489. As Lacassin told me, there was no film print accessible at the time of his research. I have also found no reviews, only two very brief announcements written by Musidora to Cinémagazine, 26 October 1923, 145 and 11 April 1924), 67, and the above cited text by Musidora as part of the five-page publicity folder with pictures tied in in $\grave{E} v e$.

392 Callahan, "Screening Musidora," 76.

393 Ibid., 59.

394 Ibid., 75 .

395 Ibid., 76.

396 See also: “Musidora nous écrit," Cinémagazine, 11 April 1924, 67.

397 Scenario LA TERre des taureaux, BiFi, Fonds Musidora, Boîte 1 (3).

398 This may have been intended for live performance.

399 All titles with her first person narrative, moreover, have a first letter richly decorated with drawings, whereas the other titles are plain text.

400 See: http://www.flickr.com/photos/confetta. I thank Ivo Blom for drawing my attention to existence of this postcard. 
"La Magique Image," L’Écran français, 23 October 1950, 3.

402 Musidora, "Arlequin et Arabella," published in serial form in twelve daily installments in Comoedia, beginning on 26 December 1928, 4 and ending on 9 January 1929, 4 .

\section{NELL SHIPMAN ON THE AMERICAN POPULAR STAGE}

See: J.W. Sayre, “Will produce play here," Seattle Star, 26 October 1909, reissued at: www.sos.wa.gov/history/newspapers.

Nell Shipman, The Silent Screen and My Talking Heart: An Autobiography, 3rd edition (Boise, Idaho: Hemingway Western Studies Centre, Boise State University, 2001), 23-24. (Hereafter: Screen\&Heart). In these memoirs, Shipman alternates between the first and the third person when referring to herself.

3 Ibid., 21.

4 Ibid., 20.

$5 \quad$ Kay Armatage, The Girl from God's Country. Nell Shipman and Silent Cinema (Toronto, Buffalo, London: University of Toronto, 2003) 53, writes in the biographical timeline that the family migrated to the United States in 1904. Tom Trusky notes that Arnold Foster Barham was a resident of Victoria, British Columbia, between 1891 and 1898 (Screen\&Heart, 165-66, note 1.) See also: Shipman's curriculum vitae, held in The Nell Shipman Archive in the Albertsons Library at Boise State University (hereafter: NSA), MSS 81, Box 1, Folder 2. In the unpublished first part of her autobiographical novel Abandoned Trails, "She Bear", Shipman indicates that the move to the vicinity of Seattle took place when she was nine years old, that is to say, in 1901. NSA, MSS 81, Box 6, Folder 1, 37.

6 Her name was mentioned in the announcement of an event organized by the school in 1906. See: “Christmas in Stageland," Seattle Star, 25 December 1906. See also Screen\&Heart, 5 .

7 See: Eric Sorensen, “Driven by Entrepreneurial Zeal: Seattle's Rise above Portland" at: http://seattletimes.nwsource.com/news/local/seattle_history/articles_ rise.html. The population almost tripled between 1900 and 1910, from 80,671 to 237,194 inhabitants.

8 See: Eric Flom, "Seattle's Early Movie Theatres - A Snapshot History,” at: http:// www.historylink.org/_output.CFM?file_ID=3257.

9 Screen\&Heart, 5 .

10 Ibid., 19.

11 Nell Shipman, “Me," Photoplay, February 1919, reprinted in: Nell Shipman, Letters from God's Country: Nell Shipman, Selected Correspondence and Writings, 1912-1970, selected and edited by Tom Trusky, with the assistance of Alan Virta, 
(Boise, Idaho: Hemingway Western Studies Centre, Boise State University, 2003) 324 .

12 "Yorkville - At Yale," New York Dramatic Mirror, 19 October 1907, 3. Further reviews include "Art in a Rah Rah Drama," New York Sun, 11 October 1907; NSA, MSS 99, Box 8 Folder 2 ascribes it to New York Evening Standard; "At Brooklyn Theaters," Brooklyn Daily Eagle, 20 October 1907. These New York newspapers are reissued at: www.fultonhistory.com/Fulton.html.

13 Shipman, "Me," 324, and Screen\&Heart, 14. In the unpublished first part of her autobiographical novel Abandoned Trails, Shipman mentions performances in Idaho, Montana, North and South Dakota, Nebraska, Iowa, and Connecticut. NSA, MSS 81, Box 6, Folders 1, 56 and 60.

14 “The Academy - 'At Yale'," Washington Herald, 3 December 1907, reissued at: www.sos.wa.gov/history/newspapers.

15 Nell Shipman, "Fade In," unpublished autobiographical manuscript (which, given the address on it, was probably written in 1962), 6; NSA, Box 5, Folder 1.

16 Ben Singer, Melodrama and Modernity: Early Sensational Cinema and Its Contexts (New York: Columbia University Press 2001) 53.

17 See: John Frick, “Introductory Essay,” at: http:www.lib.virginia.edu/speccol/ exhibits/theatre/essay.html.

18 "An Astonishing Revival," NYDM, 29 June 1907, 6.

19 Singer, Melodrama and Modernity, 163.

20 “Miss Barham Popular," Lewiston Morning Tribune, 29 October 1908, reissued at: http://news.google.com/

newspapers.

21 “Grow in popularity," Lewiston Morning Tribune, 13 November 1908.

22 Screen\&Heart, 19.

23 Letter from the Alaska Historical Library to Nell Shipman upon her requesting the exact dates of her sojourn in Alaska, dated 24 May 1968; NSA, MSS 81, Box 1, Folder 41.

24 "Drama is The Thing," Dawson Daily News, 3 July 1909, reissued at: http://news. google.com/newspapers.

25 John F. Logan, "Portland, Ore.," NYDM, 20 November 1909.

26 Screen\&Heart, 22.

27 Ibid., 21.

28 "New Leading Woman," Salt Lake Herald-Republican, 3 January 1910, reissued at Utah Digital Newspaper Project (hereafter: UDNP), http;//digitalnewspapers.org; C. E. Johnson, "Salt Lake City, Utah,” NYDM, 22 January 1910.

29 Ibid. 13.

30 "Grand," Deseret Evening News, 8 February 1910, reissued at UDNP;.

31 Walker O'Loughlin, “Amusements," Salt Lake Telegram, 14 February 1910, reissued at UDNP. 
33 Singer, Melodrama and Modernity, 178.

34 See: Perry N. Verkroff, "Motion Pictures and the Drama in America," MPW, 23 July 1910, 186; James McQuade, "Chicago Reports Many Variations in Picture Shows," MPW, 15 July 1916, 413-15; the website of the Alliance of Theatrical Stage Employees IATSE, http://www.iatse.lm.com; and Encyclopaedia Britannica, s.v., "theatrical production" and "theatre, history of," at: www.britannica.com.

35 Glenmore Davis, "The Moving-Picture Revolution," Success Magazine, April 1910, 240, quoted in Singer, Melodrama and Modernity,164.

36 Ibid.

37 Flom, "Seattle's Early Movie Theatres".

38 Screen\&Heart, 26.

39 After a terrible audition, she was not hired by Jesse L. Lasky, probably in 1907 (Ibid., 17-18).

40 Daniel Statt, “Pantages, Alexander (1876-1936)," at: http://www.historylink.org/ output.CFM?file_ID=2999

41 Unspecified Seattle newspaper clipping, NSA, MSS 99, Box 3, Folder 10. The date of 15 February and the day of the week, a Monday, are given in the program, but not the year, which has been furnished to me by the Head of Collections of the Boise State University Library, Alan Virta. See, for an extensive discussion of the program: Eric L. Flom, Silent Film Stars on the Stages of Seattle: A History of Performances by Hollywood Notables (Jefferson, N.C.: McFarland \& Company Inc. Publishers, 2009), 162-164.

42 Kenrick, "A history of the Musical." See also: Charles Musser, The Emergence of Cinema: The American Screen to 1907 (New York: Scribner's Sons, 1990), 298. That this was the aim is now disputed, but its having such an effect was borne out by Shipman's own experiences.

43 Screen\&Heart, 27.

44 Shipman mentions in her memoirs stops at Sacramento and Reno, and I have retraced performances in Tacoma, Washington, in early March, as well as an engagement in San Francisco at the end of the month. See: Screen\&Heart, 28; Tacoma Times, 2 March 1909) and Seattle Call, 21 March 1909, reissued at "Washington Historic Newspapers," www.sos.wa.gov/history/newspapers.

45 Screen\&Heart, 29.

46 Ibid., 30.

47 Letter from Shipman to Murray Summers, editor of Filmograph, dated 25 March 1969, NSA, MSS 81, Box 3, Folder 21. See also: letter from Shipman to Gordon Sparling, 3 June 1968, NSA, MSS 81, Box 3, Folder 18.

48 Typewritten copies, NSA, MSS 81, Box 1, Folder 2.

49 These vicissitudes include, firstly, her separation from her husband Ernest Shipman, which she mentions in a letter to Gordon Sparling, 8 March 1967, NSA, 
MSS 81, Box 3, Folder 18, as having occasioned the loss of the press books of BACK TO GOD'S COUNTRY; secondly, when she left everything behind in Priest Lake, Idaho in December 1924; and thirdly, the trunks with memorabilia stolen from her home in Cabazon, California on the day of her funeral, in January 1970. See: Alan Virta, introduction to The Nell Shipman Collection, at: http://library. boisestate.edu/Special/FindingAids/fa81.htm and Tom Trusky's note 151 to her memoirs, 187 .

$50 \quad$ Nell Shipman, “This Little Bear Went Hollywood,” Good Housekeeping, January 1931, 30-31 and 168-71 (photocopy in NSA, MSS 81, Box 5, Folder 15); and "The Movie That Couldn't Be Screened," Atlantic Monthly, March 1925, 326-32, and April 1925, 477-82 (photocopy in NSA, MSS 81, Box 5, Folder 5).

51 Further autobiographical fiction includes the two Alaska novels about a stock company actress in the early 190os, "Little Lost Lady" (NSA, MSS 81, Box 8, Folder 4, 5) and "The Naked North” (NSA, MSS 81, Box 8, Folder 6). See: Virta, "The Nell Shipman Collection."

52 Letter to Gordon Sparling, 3 June 1968, reprinted in: Shipman, Letters, 311.

53 See: Carolyn Heilbrunn, Writing a Woman's Life (New York: Ballantine, 1988), 11-31.

54 Screen\&Heart, 20.

55 Letter to Georgia B. McManis, 8 September 1966, in: Shipman, Letters, 281.

56 See: letter to Roi Uselton, 31 March 1968, in: Shipman, Letters, 297; and Barry Shipman, "Afterword," 211.

57 Shipman's letter, dated 12 October 1968, to the editor of The Classic Film Collector, Thomas Fullbright (NSA, MSS 81, Box 2, Folder 22), and her letter, dated 28 March 1968 to her friend Archibald Stone, quoted in: Barry Shipman, "Afterword," 212, both mention the other books. For the date of completion, see ibid., 217, and the letter to his mother, 3 February 1969, which includes his rave review of her memoirs, reprinted in Shipman, Letters, 309-10.

58 Letter to Thomas Fullbright, 2 March 1969, NSA, MSS 81, Box 2, Folder 3.

59 Letter to Roi Uselton, 31 March 1968, in: Shipman, Letters, 297.

60 Letter from Gordon Sparling to Nell Shipman, apparently citing her own words, quoted in: Barry Shipman, "Afterword," 211.

61 The connection between writing against film-historic oblivion and the choice for a personal perspective from which to tell reminiscences has also been pointed out by Amelie Hastie in the memoirs of Alice Guy-Blaché. However, as Hastie shows, while Guy-Blaché opens her account rather humbly, the overall tone appears to be quite self-assured, claiming labor, positions, innovations, and films. See: Amelie Hastie, "Circuits of Memory and History. The Memoirs of Alice Guy-Blaché.” In: Jennifer M. Bean and Diane Negra, A Feminist Reader in Early Cinema (Durham \& London: Duke University Press, 2002), 35. Screen\&Heart, 49-50. 
63 Ibid, 16.

64 Ibid., 2-3.

65 The advertisement displays six pictures of Shipman in leading roles. It is held in the NSA as a photo, donated by Shipman's son Barry (NSA, Series VIII, Photos). It was originally published on the back cover of the NYDM, 28 October 1916.

66 Screen\&Heart, 34.

67 See: “The Barrier' here next Tuesday night," Laramie Republican, 13 September 1911, reissued at UDNP. The article announces Helen Barham as Necia, but it is illustrated with a picture of Eleanor Haber. In subsequent performances Haber, invariably plays the role.

68 Screen\&Heart, 32.

69 "Theatre," Evening Standard Ogden, 2 March 1911, 2, reissued at UDNP.

70 Shipman, "Me," 324: my emphasis.

71 I gathered the term Northwest drama from the generic indicators employed in the American Film Institute Catalog, in which most of the films adapted from stories by London, Beach, or Curwood are identified as being "drama” or "melodrama" in their main category and for further specification given the label "Northwest". The catalog categorizes several Shipman films under these same rubrics.

72 Earle Labor, "Jack London" in: A Literary History of the American West, 381-97, at: http://www2.tcu.edu/depts/prs/amwest/pdf/wlo381.pdf.

73 Letter to Thomas Fulbright, 19 November 1968 (NSA, MSS 81, Box 2, Folder 22), on "Get the Woman," also known as “M'sieu Sweetheart," Shipman's serialized novel in McGall's Magazine, June to September 1930.

74 The internet page (at: http://www.litrix.com/sec11.htm) of the Litrix Reading Room lists, aside from seven titles by London, three titles by Beach and two by Curwood, as well as two by Robert Service—"the spellbinder of the Yukon"—and one by William Macleod Rain.

75 Netstate, "People of Alaska," at: http://www.netstate.com/states/peop/ak_peop. htm, and "Rex Ellingwood Beach," at: http://www.netstate.com/states/peop/ people/ak_reb.htm.

76 See: the Olin Library at Rollins College, Archive and Special Collections, "Rex Beach, 1877-1949," at: http://www.rollins.edu/olin/archives/beach.htm; "WellKnown Writers Turning to a New Field - That of Writing Film Scenarios,” MPW, 29 January 1910, 120; AFI Catalog and IMDb.

77 The first adaptation to film was done in 1914, by Colin Campbell for Selig, featuring Kathlyn Williams, William Farnum, and future BACK TO GOD's COUNTRY actor Wheeler Oakman. See: Speelfilmencyclopedie 1992, 107; AFI Catalog and IMDb.

78 See: the list of Curwood's films compiled by the Shiawassee District Library, at: http://www.sdl.lib.mi.us/curwood3.htm. 
79 See: the Olin Library, "Rex Beach."

80 Shiawassee Regional Chamber of Commerce, "James Oliver Curwood," at: http://www.shianet.org/community/tour/joc.html. See also: Byron Anderson, "Biographical Portrait. James Oliver Curwood," at: http://www.foresthistory.org/ publications/fht/fhtspringfall2003/curwood.pdf.

81 See: Ross, "The Northern Boundary," for the authentication of Northwest stories; and Gerald W. Haslam, "The Western Story" in: A Literary History of the American West, 152-58, especially 155 f., at: http://www2.tcu.edu/depts/prs/ amwest/pdf/wlo152.pdf, for other Western authors who wrote from experience and observation.

82 Garff. B. Wilson, Three Hundred Years of American Drama, $2^{\text {nd }}$ edition (Englewood Cliffs: Prentice-Hall 1982), 136, as quoted in Maguire, "Western American Drama”, 207.

83 Rex Beach, The Barrier (New York: Harper and Bros., 1908), reissued at: http:// www.litrix.com/barrier/ barrioo1.htm.

84 I am aware that the expression "half-breed" is now perceived as offensive, but I will retain it in this text-between quotation marks-because of its historic and racial specificity, that is to say it refers to the descent of a child from a Native American woman and a white man.

85 Wilson, Three Hundred Years of American Drama, 136, as quoted in Maguire, "Western American Drama ," 207.

86 Ibid.

87 Screen\&Heart, 48.

88 The exception to this rule, in fact, is Curwood's God's Country and the Woman, but in this story the character is, as we shall see, completely dysfunctional in her role of the mother.

89 See: Singer, Melodrama and Modernity, 157.

$90 \quad$ Screen\&Heart, 32.

91 See: D.J. Turner, "Ernest Shipman: Some Notes," Griffithiana, March-September 1992, 147-48; and Screen\&Heart, 36. Trusky, in note 32 on p. 166, refers to a Los Angeles Evening Herald article of 1920 concerning their divorce for the information about the date of what was to be their first marriage, as well as about the second, which, for legal reasons, took place two years later.

92 Shipman, "She Bear," 76.

93 Barry Shipman, "Afterword," 210.

94 Screen\&Heart, 38.

95 Ibid., 36 .

96 In a 1919 interview, Kimball Young recounted that, by 1908-1909, she was affiliated with the T. Daniel Frawley Stock Company in Seattle. This confirms Shipman's memories of Kimball Young having played in town by the time Shipman 
returned broke and very disheartened (Screen\&Heart, 26).

97 Fuller stayed with Edison until 1914, when she, out of dissatisfaction with the company's promotion of her series THE ACTIVE LIFE OF DOLLY OF THE DAILIES, switched to Universal, where she first acted in two-reelers and then, in 1915, made her feature-film debut in the Civil War drama UNDER SOUTHERN SKIES. After ten more features, she abruptly ended her screen career in 1917. See: Billy H. Doyle, The Ultimate Directory of Silent Screen Performers (New York: The Scarecrow Press, 1995), 23-26; and Buck Rainey, Those Fabulous Serial Heroines: Their Lives and Their Films (Metuchen and London: The Scarecrow Press, 1990), 30719.

98 IMDb. In 1915, after over 80 leads in Vitagraph films, including GOODNESS GRACIOUS opposite Sidney Drew (a satire on THE PERILS OF PAULINE), Kimball Young switched over to the World Film Corporation, with which she remained for two years. In 1916, she went independent, later making the transition to the talkies; she retired in 1943.

99 Ray. W. Frohman, "Clara Kimball Young," Los Angeles Herald, 29 October 1919; reissued by the internet newsletter Taylorology at: http://www/public.asu. edu/ ialong/Taylor36.txt.

100 Gene Gauntier, "Blazing the Trail,” Woman's Home Companion, October 1928, 7; reissued by David Pierce at: http://www.cinemaweb.com/silentfilm/4_blaze1. htm.

101 Gene Gauntier, “Blazing the Trail," Woman's Home Companion, November 1928, 134 .

102 Nell Shipman, "A Call to Arms for the Scenario Writers," West Coast Magazine, 12 December 1912, reprinted in: Shipman, Letters, 316.

103 Turner, “Ernest Shipman," 148.

104 Peter Morris, Embattled Shadows: A History of Canadian Cinema, 1895-1939 (Montreal: McGill-Queen's University Press, 1978), 95-126, chap. 4, “Ten Percent Ernie."

105 Screen\&Heart, 38.

106 Ibid.

107 These were the seven-reelers THE COAST GUARD PATROL and THE TIGER OF THE SEA. See: D.J. Turner, “Nell Shipman Filmography”, Screen\&Heart, 193-94.

108 "Ernest Shipman Secures Several New Productions," MPW, 10 August 1918, 870.

109 Turner, "Ernest Shipman," 147.

110 Screen\&Heart, 42. See also: IMDb and AFI Catalog, which claims that the feature was a documentary. The film was the directorial debut in cinema of the stage actor and director Norval MacGregor (1862-1933), who would direct over 20 films before 1927, including, for Selig, three James Oliver Curwood stories: SECOND CHILDHOOD (1914), CATS (1915), and THE LADY KILLER (1915). (See: the list of Curwood's films compiled by the Shiawassee District Library, at: http://www. 
sdl.lib.mi.us/curwood3.htm.) MacGregor's screen acting debut, moreover, was in 1914, in THE SPOILERS, adapted from Rex Beach's story, and by 1924 he had played in a dozen more films.

111 Shipman was hired to rework an earlier scenario. See: "To Revise Scenario", NYDM, 4 December 1912, 30. MPW published a protest from one Harry A. Kelly, who claimed for his part to have written the scenario which "was faithfully followed from the start to the finish." See: "Doings at Los Angeles," MPW, 15 February 1913,667 . “Doings at Los Angeles,” MPW, 18 January 1913, 251.

\section{NELL SHIPMAN AND THE AMERICAN SILENT CINEMA}

See: Turner, "Filmography," 193-207.

$506 \quad 2$ This company is mentioned in a report of Shipman's doings and in an item on the search for a title for her second script for it, in $M P W, 4$ November 1916, 682, and 25 December 1915, 2373, respectively. I thank D.J. Turner for sharing this additional information with me.

3 Jon C. Mirsalis, "The Films of Lon Chaney, Sr.," at: http://members.aol.com/ ChaneyFan/filmog.htm, and “The Pine's Revenge," at: http://members.aol. com/ChaneyFan/66.htm; and $M P W, 25$ September 1915, 2062 and 2177. The screenplay was adapted from Shipman's story "The King”s Keeper." For THE MELODY OF LOVE see J. Van Cartmell, "Along the Pacific Coast", NYDM 9 September 1915, 30. The film was initially entitled "The Troubadour of El Dorado."

4 “Giving Credit Where Credit is Due,” MPW, 12 March 1910, 269.

5 Ibid.

6 Emar, "Concerning Scenarios," $M P W$, 9 July 1910, 76.

7 Shipman, "A Call to Arms," 317.

$8 \quad$ Clipping held in NSA, MSS 99, Box 8, Folder 7.

9 “Young Woman Wins Prizes," NYDM, 27 November 1912, 30; Advertisement, Los Angeles Times, 10 November 1912, III 14. Her script "Sold to the British" won first, "Outwitted by Billy” won second prize.

10 See: "Represents Noted Authors”, NYDM, 8 January 1913, 27; "Engage Nell Shipman," NYDM, 12 February 1913, 28; "Nell Shipman Company,” NYDM, 26 March 1913, 23; "Nell Shipman in New York,” NYDM, 20 August 1913, 29; "Lucky Nell Shipman,” NYDM, 26 November 1913, 38.

11 Epes Winthrop Sargent, “The Photoplaywright," MPW, 25 January 1913, 357.

12 "Represents Noted Authors," NYDM, 8 January 1913, 27.

13 Janet Staiger, "The Hollywood mode of production to 1930." In: David Bordwell, Janet Staiger, and Kristin Thompson, The Classical Hollywood Cinema: Film Style and Mode of Production to 1960 (New York: Columbia University Press, 
1985), 146.

14 Screen\&Heart, 41.

15 See, for instance: "Personal. Nell Shipman," NYDM, 31 March, 1915, 5, and Esther Hoffmann, "Life in Harem Made into Play by Movie Actress," Tacoma Times, 31 March 1915. The article included a portrait with the caption "Nell Shipman, Actress and Playwright."

16 See: J. Van Cartmell, "Along the Pacific Coast," NYDM, 16 October 1915, 30. The initial title of the film was THE TROUBADOUR OF EL DORADO." Review in $M P W$, 17 June 1916, 2063.

$17 M P W, 27$ March 1915, 1908.

18 Neither Trusky nor Turner has traced the copyright number. A notation in Shipman's handwriting at the margin of the clipping reads: "1st movie N.S., 1st Prize, 1st Scenario Contest Ever Held. Tally was the judge.” Although Tally was a member of the jury, and Shipman indeed won first and second prizes at the Egan School contest, this was hardly the first scenario contest ever held, as such contests were already ubiquitous by 1912 . None of the synopses from this series won a prize.

19 Screen\&Heart, 42.

20 See: Singer, Melodrama and Modernity, Bowser, Transformation, and Janet Staiger, Bad Women. Regulating Sexuality in Early American Cinema (Minneapolis: University of Minnesota Press, 1995).

21 Lynde Denig, “'The Purple Iris': Princess Hassan Appears in First Picture in the 'Under the Crescent' Series, Produced by Universal,” MPW, 22 May 1915, 1271.

22 Turner, "Filmography," 195.

23 Denig, "Purple Iris," 1271.

24 See: NYDM, 26 April 1911) 14, for the marriage date, and "Reflections," NYDM, 3 April 1912, 10, for Ola Humphrey's wish to regain her "American" freedom.

25 Nell Shipman, Under the Crescent (New York: Grosset \& Dunlap, 1915), xviii.

26 Ibid, xix-xx.

27 Ibid.

28 Screen\&Heart, 39.

29 Denig, "Purple Iris," 1271.

30 Further criticism was directed at the cinematography in the second episode, which rendered scenes "a little darker than was perhaps intended", whereas the cinematography in the fourth episode was positively acclaimed. See: "Universal Film Mfg. Company, Specials,” MPW, 12 June 1915, 1779, and 26 June $1915,2097$.

31 Ibid., and Denig, "Purple Iris," 1271.

32 "Universal Film, Specials," 1779.

33 Barry Shipman's letter to the Boise State University Library, 7 April 1988; NSA, MSS 81, Box 14, Folder 5. 
34 See: Morris, Embattled Shadows, 103; Turner, "Ernest Shipman," 148; and $M P W, 30$ December 1916, 1966.

35 See: "Nell Shipman Sails for West Indies," $M P W, 31$ March 1917, 2112; and "Nell Shipman Returns from West Indies," MPW, 7 July 1917, 99.

36 Nell Shipman, "The Last Empire," cover sheet; NSA, MSS 81, Box 14, Folder 5.

37 "Nell Shipman Returns from West Indies," 99. She actually returned already on 22 April. See also: “Nell Shipman Returns," New York Clipper, 27 June 1917, n.p., reissued at: www.fultonhistory.com/Fulton.html

38 Barry Shipman's letter to the Boise State University Library, 7 April 1988. Capitalizations and quotation marks are his.

39 Shipman, "Last Empire," second page.

40 Shipman, "Last Empire," third page.

41 "Personal. Shipman," 5.

42 Mabel Condon, "Pacific Coast Studio News and Gossip," NYDM, 29 January 1916, 44. The revamping of the stage career concerned that she had been acting under the direction of Belasco and that she had been leading her own company in Alaska for two years. None of this seems to have happened.

43 "News of Los Angeles and Vicinity - Nell Shipman Leaves Vitagraph," MPW, 9 November 1918; clipping held in NSA, MSS 99, Box 8, Folder 7; and "Nell Shipman is a Canadian," Canadian Moving Picture Digest, 19 October 1918, 5; NSA, MSS 99, Box 8, Folder 3 .

44 See: $M P W, 23$ September 1916), 1985; and "Nell Shipman Returns from West Indies," 99.

45 "Nell Shipman Independent," MPW, 8 September 1917, 1558. The same declaration was printed some days earlier in "Nell Shipman Succeeds," NYDM, 1 September 1917, 21.

46 “Back With Vitagraph,” NYDM, 20 October 1917, 20.

47 See: Anthony Slide, The American Film Industry. A Historical Dictionary, (New York: Limelight Editions, 990), 374 .

48 “Vitagraph Lessens Production," MPW, 19 August 1916, 1230, and 18 November 1916, 1022.

49 Jolo, "God's Country and the Woman," Variety, 28 April 1916, clipping held in NSA, MSS 99, Box 8, Folder 19. See also G.P. von Harleman and Clarke Irvine, "News of Los Angeles and Vicinity - GOD's COUNTRY AND THE WOMAN continues," MPW, 19 August 1916, 1230-31; and Turner, "Filmography", 197.

$50 \quad$ Lynde Denig, "God's Country and the Woman," $M P W, 6$ May 1916, 985.

51 E[ditor, William R. Kane], "Feature Films," NYDM, 29 April 1916, 29.

52 Screen\&Heart, 47-48.

53 Jennifer M. Bean, "The Technologies of Early Stardom and the Extraordinary Body," Camera Obscura, 48 (2001), 9-56.

54 Bean, "Technologies," 11. 
Ibid., 34. (Her emphasis)

56 “News of Los Angeles and Vicinity,” MPW, 11 December 1915, 1996.

57 “News of Los Angeles and Vicinity,” MPW, 6 November 1915, 1057.

58 Paul Hubert Conlon, "In and Around the West Coast," New York Clipper, 17 November 1915, 43.

59 "Snowbound Party Back From Near-Starvation," Los Angeles Times, 10 January 1916, III; NSA, MSS 99, Box 8, Folder 5. The MPW rubric "News from Los Angeles and Vicinity" ran a practically integral reprint of this article: see 22 January 1916, 578. Further reports include J. Van Cartmell, "Pacific Coast Studio News," NYDM, 18 December 1915, 33; “'God's Country and the Woman' (Vitagraph),” $M P W, 29$ April 1916, 828; and Mosgrove Colwell, "Snow Stuff in the Orange Belt," Motion Picture Magazine, November 1916, reprinted in: Shipman, Letters, 318-21.

60 Quotation from an unidentified New York newspaper cited in an advertisement in $M P W, 20$ May 1916, 1286-87.

61 See, for instance: G.P. von Harleman and Clarke Irvine, "News from Los Angeles and Vicinity," MPW, 8 July 1916, 237.

62 "Nell Shipman," NYDM, 9 December 1916, 23.

63 The novel, God's Country and the Woman (New York: A.L. Burt 1915) is available as a Project Gutenberg Etext, at: http://www.gutenberg.org/etext/4585.

64 "Stories of the Films - God's Country and the Woman," MPW, 6 May 1916, 1404. The adaptation diverged on one point: in the film, Jean, the "half-breed", was killed in the fight with the villains, whereas in the novel he survived his injuries.

65 See, for instance: the full page advertisement for the film in $M P W, 13$ May 1916, 1108; and the advertisement for her second film with the company, THROUGH THE WALL, MPW, 30 September 1916.

66 Advertisement, $M P W, 15$ July 1916, 495.

67 "The Girl on the Back Cover," NYDM 28 October 1916, 24.

68 "Nell Shipman Returns East," $M P W, 4$ November 1916, 682.

69 See: $M P W, 2$ December 1916, 1334, and 10 February 1917, 853; and Turner, "Filmography," 198.

$70 \quad$ "Nell Shipman Returns East," 682.

71 Screen\&Heart, 43.

72 Ibid., 44 .

73 “A Jill of All Trades," Photoplay, April 1917, 38; NSA, MSS 99, Box 8, Folder 2.

74 Screen\&Heart, 18. 
“New Feature Company: Jesse L. Lasky, Vaudeville Producer, Latest to Head Organization for Production of Features," MPW, 20 December 1913, 1417.

76 "Two Large Feature Companies Combine," $M P W, 15$ July 1916, 434; and see the Lasky Corporation's advertisement ibid., 361.

77 George Blaisdell, “The Black Wolf,” MPW, 24 February 1917, 1208.

78 See: Shipman, “Me," 324.

79 This ranking was the result of a popularity poll in the fan-magazine Motion Picture Magazine of October 1914, as described and cited in Richard Koszarski, An Evening's Entertainment: The Age of the Silent Feature Picture, 1915-1928 (Berkeley and Los Angeles: University of California Press,1994), 259. The list included both male and female stars, and the first five spots were filled as follows, in descending order: Earle Williams, Kimball Young, Pickford, J. Warren Kerrigan, and Fuller.

80 See: Richard deCordova, Picture Personalities: The Emergence of the Star System in America (Urbana and Chicago: University of Illinois Press,1990), in particular the chapter "Picture Personalities."

81 See: the filmographies in Rainey, Those Fabulous Serial Queens; and in Bodeen De Witt, "Frances Marion. Wrote the Scripts of Some of the Milestone Movies," Films in Review, February 1969, 71-91 and March 1969, 129-52; as well as Richard Willis, “Kathlyn the Intrepid," Photoplay, April 1914, reissued by Bruce Long (ed.), Taylorology, 48 (December 1996), at: www.uno.edu/drcom/Taylorology/Taylor48.txt

82 "Mary Fuller to Support Lou Tellegen," MPW, 27 January 1917, 534.

83 See: Bean, "Technologies," 19.

84 George Blaisdell, “'In the Power of the Hypnotist”: A Strong Three-Part Gauntier Players' Picture Recently Released by Warner's Features," MPW, 1 November 1913, 499 .

85 "Picture Personalities,” $M P W, 27$ January 1917, 522.

86 "Popular Picture Personalities," MPW, 24 February 1917, 1183. However, Kalton C. Lahue, Ladies in Distress (South Brunswick: A. S. Barnes, 1971), 328, gives the year 1918.

87 Larry Trimble, “Concerning Florence Turner," MPW, 6 December 1913, 1157.

88 Quoted from the Solax advertisement in $M P W, 1$ November 1913, 548.

89 Quoted from the Universal advertisement in $M P W$, 19 June 1915, 1881.

90 "Back With Vitagraph," NYDM, 20 October 1917, 20.

91 Screen\&Heart, 62.

92 IMDb.

93 Edward Weitzel reviewing THE HOME TRAIL, MPW, 6 April 1918, 130, and reviewing THE GIRL FROM BEYOND, $M P W, 20$ April 1918, 587.

94 H.D.R., "Current Feature Photoplays Passed in Review," NYDM, 2 March 1918, 18. 
95 H.D.R., "Current Feature Photoplays Passed in Review," NYDM, 30 March 1918, 18.

96 Weitzel, “The Home Trail,” 130

97 Louis Reeves Harrison, “Up-to-Date Melodrama,” MPW, 13 April 1918, 216.

98 "Advertising Aids for Busy Managers," MPW, 20 April 1918, 436.

99 Screen\&Heart, 62-63.

100 Ibid.

101 See: C.S. Sewell, “The Wolfville Tales,” MPW, 8 June 1918, 1332.

102 See: Turner, "Filmography," 200; and the release schedules in MPW, 13 September 1919, 1710.

103 Screen\&Heart, i.

104 Screen\&Heart, 63.

105 Hanford C. Judson, “'Baree, Son of Kazan': Remarkable Vitagraph Picture of the Far North - Will Surely Make a Sensation,” MPW, 8 June 1918, 1470.

106 Harry A. Gibbs, Fritz Tidden, Frederick James Smith, Helen D. Reid, "The Picture and Ideas for Playing It,” NYDM, 1 June 1918, 778.

107 The novel, Baree, Son of Kazan (New York: Grosset \& Dunlap,1917) has been reissued as a Project Gutenberg Etext at: http://www.gutenberg.org/etext/4748; for my discussion I have consulted a Dutch translation, De Zoon van Kazan (Amsterdam: De Geïllustreerde Pers, 1963).

108 This novel (New York: Grosset \& Dunlap, 1919), is likewise available as a Project Gutenberg Etext, at:

http://www.gutenberg.org/etext/4704.

109 I thank D.J. Turner for making a videotape of NOMADS OF THE NORTH available to me.

110 Screen\&Heart, 58.

111 Ibid., 77.

112 "Nell Shipman is a Canadian," Canadan Moving Picture Digest, 19 October 1918, 5.; NSA, MSS 99, Box 8, Folder 3

113 Nell Shipman, "Abandoned Trails I," 125-26; NSA, MSS 81, Box 6, Folder 2.

114 See: Turner, "Ernest Shipman," 149.

115 "Nell Shipman is a Canadian," 5; NSA, MSS 99, Box 8, Folder 3.

116 Screen\&Heart, 63.

117 The entry "Women Filmmakers" (in Slide, The American Film Industry, 391-92) does not distinguish between filmmakers and producers, so the women's film production companies go unnoticed in it. This is all the more surprising, as the same author had, in 1977, published one of the first, and for long afterwards still one of the very few, surveys of American women directors and producers of the silent era. See: Anthony Slide, Early Women Directors (South Brunswick: A.S. Barnes, 1977). 
"Stories of Plays and Players. Shipman-Curwood Productions," Canadian Moving Picture Digest, 2 November 1918, 19; NSA, MSS 99, Box 8, Folder 3; "Shipman-Curwood Co. Formed on Coast," NYDM, 2 November 1918, 660.

119 See: "Curwood and Nell Shipman Form Producing Company," MPW, 9 November 1918, 678; and NSA, MSS 81, Box 2, Folder 13 for the original typewritten letter.

120 Morris, Embattled Shadows, 105 and 108; Turner, "Ernest Shipman," 150.

121 See: George A. Katchmer, Eighty Silent Film Stars: Biographies and Filmographies of the Obscure to the Well Known (Jefferson, N.C.: McFarland, 1991), 91-109; and W. Stephen Bush, “The Sea-Wolf," MPW, 5 November 1913, 480.

122 See: Staiger, "The Hollywood Mode of Production," 134-37.

123 See: Koszarski, An Evening's Entertainment, 188.

124 Marsha McCreadie, The Women Who Write the Movies: From Frances Marion to Nora Ephron (Secaucus, N.J.: Carol Publishing, 1994) especially the chapter “The Pioneers," 3-66. See also Lizzy Francke, Script Girls. Women Screen Writers in Hollywood (London: British Film Institute, 1994).

125 Quoted in DeWitt, “Frances Marion.” See also Cari Beauchamp, Without Lying Down: Frances Marion and the Powerful Women of Early Hollywood (New York: Scribner, 1997).

126 See: Kay Sloan, The Loud Silents: Origins of the Social Problem Film (Urbana and Chicago: University of Illinois Press, 1988).

127 Slide, The American Film Industry, 213. Further African-American companies listed by Slide are the Ebony Pictures Corporation, active between 1918 and 1922 (ibid., 104), the Democracy Film Company, beginning in 1919 (ibid., 90), Sack Amusement Enterprises, which lasted from 1920 until 1970 (ibid. 295), and the Reol Motion Picture Company, which ceased to operate in 1921 (ibid., 286). See also: Pearl Bowser, Jane Gaines, and Charles Musser (eds.), Oscar Micheaux and His Circle: African-American Filmmaking and Race Cinema of the Silent Era (Bloomington: Indiana University Press, 2001).

128 Koszarski, An Evening's Entertainment, 261.

129 See, for a discussion of Williams' early films with wild animals: Annette Förster, "Actresses Interacting With Animals in the Silent Cinema." In Sabine Nessel, Winfried Pauleit a.o. (eds), Animals and the Cinema: Classifications, Cinephilias, Philosophies (Berlin: Bertz+Fischer GbR, 2012), 66-86

130 De Witt, "Frances Marion," 74. Williams did, however, not go independent, but signed a non-exclusive contract with Paramount.

131 Reprinted in a 1920 collection of Curwood's short stories, "Wapi, The Walrus" was re-baptized with the title of the film made from it, BACK TO GOD's COUNTRY: James Oliver Curwood, Back to God's Country and Other Stories (New York: Grosset \& Dunlap, 1920), 9-53. In the following citations I shall refer to its 
magazine publication: Good Housekeeping, November 1918, 17-20, 109-114, and December 1918, 36-39, 106-109.

132 Nell Shipman's recovery was reported in $M P W, 25$ January 1919, 475. She also lost her mother to the influenza epidemic in those weeks.

133 "Nell Shipman Selects Two Canadian Stories," Canadian Moving Picture Digest, 7 December 1918, 17.

134 “News of Los Angeles and Vicinity," MPW, 16 November 1918, 728.

135 Curwood, “Wapi," 20.

136 Ibid.

137 Ibid., 112.

138 See: the letter from James Oliver Curwood dated 7 August 1919 responding to her withdrawal; published in: Shipman, Letters, 325-26.

139 See: the letter from the Bentley Historical Library at the University of Michigan to Tom Trusky, stating that they hold material on only two of the films he asked for, viz., NOMADS OF THE NORTH and THE YELLOW-BACK; NSA, MSS 99, Box 8, Folder 7 .

140 Joseph B. Walker A.S.C. and Juanita Walker, The Light on Her Face (Hollywood: The ASC Press, 1984) most notably chapter 7, "Keeping Them Down On the Farm," 74-133.

141 Screen\&Heart, 69.

142 Trusky in Screen\&Heart, 171.

143 Screen\&Heart, 69.

144 Ibid., 68.

145 Nell Shipman, Abandoned Trails (New York: The Dial Press, 1932), 38.

146 Ibid., 36 .

147 Letter from Curwood to Shipman.

148 Letter to Georgia B. McManis, her literary agent at the time, dated 8 September 1966; in: Shipman, Letters, 281.

149 Letter from Curwood to Shipman.

150 "Curwood Helped Produce "Back to God's Country”," MPW, 4 October 1919, 102.

151 “Wild Animals Play Parts in Curwood-Carver Film,” MPW, 4 October 1919, 115.

152 See, for instance: $M P W, 4$ October 1919, NSA, MSS 99, Box 8, Folder 9; and 24 July 1920, 42.

153 Epes Winthrop Sargent, "Advertising for Exhibitors," MPW, 8 November 1919, 855; and 15 November 1919, 331.

154 "Animal Tracks Duplicated by Paint Brush Awaken Great Curiosity and Produce Good Results With the Box Office,” MPW, 20 December 1919, 992.

155 "James Oliver Curwood Forms His Own Company to Picturize His Own Novels," $M P W, 21$ February 1920, 1243. 
156 See: the advertisement in $M P W, 22$ May 1920, 1030; and "It was a Merry Holiday, Declares Ernie Shipman," MPW, 10 January 1920, 272. The surviving print, too, introduces the film as being presented by the Curwood-Carver Company.

157 Ernest Shipman may have had a personal motive for devaluing his wife's contributions to the production: Walker recounts (Light, 97) that Nell, earlier that year, had fallen in love with the film's on-location business manager, Bert Van Tuyle, and was no longer making a secret of it after they returned from Lesser Slave Lake, following the filming of the winter scenes. The Shipmans separated on 18 April 1919, and the divorce was finalized in May 1920, according to both the Los Angeles Times and the Los Angeles Evening Herald (issues of 12 May 1920), reprinted in: Shipman, Letters, 327.

158 Shipman, Trails, 38-39.

159 See: Turner, "Ernest Shipman," 151; and Morris, Embattled Shadows, 106.

160 Armatage, Girl, 78.

514 | 161 Shipman, Trails, 35.

162 Armatage, Girl, 96-97.

163 Ibid., 108.

164 Tom Trusky also argues that the film cannot be considered as having been created by Shipman, in "The Light on Lookout: Racism, Homophobia \& Utopia in the Films of Nell Shipman," an unpublished paper, portions of which were presented at the Second International Conference Women and the Silent Screen, held at the University of California at Santa Cruz, November 2001, under the title "A Little Hand for the Villains: Same-Gender Touching in the Feature Films of Nell Shipman."

165 See: my article, "What's Up, Dog?," Nederlands Filmmuseum Themareeks, November 1992, 4-32; available also in a German version, Cinemazoo, Cinema, 42, 1997, 33-49.

166 The expression appears in title 10 of the film, but not in Curwood's story.

167 Hence Dolores' surname Lebeau, which would be later given to the villain in NOMADS OF THE NORTH.

168 Title 11.

169 Screen\&Heart, 77. Of course, it is the girl who saves both the man and herself.

170 Ibid., 80 and 81.

171 Shipman, "This Little Bear Went Hollywood," Good Housekeeping, January 1931, 166.

172 See: ibid., and Screen\&Heart, 80. Shipman also recalled that Van Tuyle was directing the scene and that he whispered "cut" too early but that Walker "did not hear or went deaf in that ear". See also: my discussion of A BEAR, A BOY AND A DOG further on.

173 BACK TO GOD'S COUNTRY was shot in 41 days between the middle of March and early June 1919, NOMADS OF THE NORTH between the end of April and the end 
of June 1920. I owe this information to a letter of 24 November 2000 from D.J. Turner.

174 Ibid. Also see "Cyril Gardner (I)" in the IMDb.

175 See, for instance: the advertisement in $M P W, 24$ July 1920, 421.

176 Screen\&Heart, 77. Trusky justly maintains in his note on p. 172, that Annette Kellerman's nude scene in A DAUGHTER OF THE GODS dated from three years before Shipman's.

177 Title 17.

178 Title 21.

179 Title 28.

180 Title 29.

181 Title 31.

182 Screen\&Heart, 75 .

183 Curwood, "Wapi," 112.

184 Ibid., 113.

185 Title 6.

186 The expression "throwback" appears in both the story and the film's intertitles; Curwood, "Wapi," 17 and title 4.

187 Title 32.

188 Title 85, after Dolores has welcomed the dog at Fort Confidence: "Wapi - dear old Wapi - we're going home - home - and you are going with us.” Likewise Curwood, "Wapi," 109: "For Wapi, the Walrus, forty years removed from Tao of Vancouver, had at last come home."

189 Ibid.

190 Titles 68 and 87, respectively.

191 Quoted from title 22, which ascribes the term to the writer Peter. In her memoirs, Shipman often uses the expression as well, for instance: "The makebelieve came alive" (Screen\&Heart, 63).

192 Curwood, "Wapi," 109.

193 Title 81 reads: "Fighting at last the greatest of all fights - for a woman."

194 Curwood, "Wapi," 109.

195 Armatage, Girl, 108.

196 Early on, the titles inform the spectator that Wapi is "a white man's dog in a brown man's land" and an "alien without friends, hating the men who understand nothing of the magic of kindness and love;" and, later on in the film, they state that he is on "the trail of the white woman — the first friend Wapi the Killer has ever known," aware of "the swift-approaching menace of the men and beasts he hates." .

197 Title 56.

198 Curwood, "Wapi," 20.

199 Screen\&Heart, 69. 
200 Armatage, Girl, 105.

201 Shipman, “Me,” 325.

202 Armatage, Girl, 108.

203 Ibid., 109.

204 Ibid., 96.

205 Bean, "Technologies," 47.

206 Ibid., 45.

207 Ibid., 46.

208 Shipman clarified: "The Honey Stick was just that, a stick dipped in honey and used to lure sweet-tooth animals to a quick starting point and not to waste time." (Screen\&Heart, 76)

209 Donna Haraway, The Companion Species Manifesto:Dogs, People, and Significant Otherness (Chicago: Prickly Paradigm Press, 2003). I thank Rosi Braidotti for bringing this text to my attention.

516 | 210 See: Haraway, Companion Species, 6.

211 Armatage provides a historical overview of such organizations in Girl, 296-99.

212 For a full list, see: Screen\&Heart, 95.

213 Trusky, in his footnote 119 in ibid., 183, adds that, "the size of Shipman's zoo is sometimes trebled by memory or desire."

214 Screen\&Heart, 78; my emphasis.

215 Haraway, Companion Species, 3.

216 “Sensitive Bear," Los Angeles Times, 11 September 1921; NSA, MSS 99, Box 8, Folder 5 .

217 William K. Everson, "Rediscovery," Films in Review; 40, 4 (1989), 229-31 and Morris, Embattled Shadows, 108.

218 Françoise Audé, "Femmes du Siècle de Colette," Positif 326 (April 1988), 55.

219 Annette Brauerhoch, "La Belle et la Bête," Frauen und Film, 47 (September 1989), 37.

220 See: the First National advertisements for the film in $M P W, 4$ October 1919, n.p.

221 Fred, "Back to God's Country," Variety, 1 March 1920; NSA, MSS 99, Box 8, Folder 19.

222 "At the Capitol - Unusual First National with Nell Shipman," NYDM, 8 January 1920, 40.

223 "Reviews Taken from Our 'Strike Bulletin', Back to God's Country," MPW, 20 December 1919, 1013. Due to a printers' strike from 11 October through 1 November, the trade paper had seen its publication interrupted and had only issued short reviews on type-written pages. These reviews were then reprinted in this regular issue.

224 Compare also D.J. Turner's examination of reviews of the film in his article on Ernest Shipman, which deals with several more instances, including those appearing in Canadian and British papers, among which there is one in which 
the role of Dolores was considered to be the best Shipman had ever done. Turner also notes, as an explanation for the unusually denigrating tone of the review in Variety, that the editor was reputed to dislike Ernest Shipman. See: Turner, "Ernest Shipman," 154.

225 Tom Trusky, "Nell Shipman: A Brief Biography," Griffithiana 32/33 (September 1988), 254.

226 See, for instance: "News from Los Angeles and Vicinity," MPW, 5 August 1916, 933 and "Medal for heroism for Nell Shipman, Movie Star," The Watchan and Southron, 27 December 1919, n.p., which reported that she had saved already three people from drowning because of her "aquatic ability".

227 It is worth noting that the music for the film composed by Lindsay Cooper significantly influenced my perception of Shipman's acting. With the music, the acting seemed much more measured than without.

228 "In the Land of 'Long Night', Picture Play Magazine, September 1919, in: Shipman, Letters, 326.

229 Shipman, Trails, 63.

230 “Nell Shipman, Actress, Wins Divorce," Los Angeles Evening Herald, 12 May 1920; in: Shipman, Letters, 327.

231 See: "James Oliver Curwood Forms His Own Company to Picturize His Own Novels," MPW, 2 February 1920, 1243. According to Peter Morris (Embattled Shadows, 110), Ernest Shipman was also involved in a consecutive CurwoodCarver production, THE GOLDEN SNARE (1921).

232 Walker and Walker, Light, 80.

233 Ibid., 88.

234 Ibid., 96-97. Walker erroneously wrote "Playter" while in fact it was Arling who played Blake. I thank D.J. Turner for the correction.

235 Screen\&Heart, 80.

236 Ibid., 94 .

237 Ibid., 111.

238 “Nell Shipman's Next to be 'Girl from God's Country'," MPW, 21 August 1920, 999; and "Nell Shipman Enters Production Field with Company of Her Own," $M P W, 9$ October $1920,802$.

239 See: Turner, "Filmography," 202; and his article, "Who was Nell Shipman and Why is Everyone Talking about Her?," The Archivist, 110 (1995), 31.

240 Walker and Walker, Light, 111. He also recalled it as being a one-reeler, which it is not.

241 Ibid., 112.

242 Which indeed, shows, as soon as one has become aware of it, from the rush with which the bear climbs upwards.

243 Screen\&Heart, 86. 
244 My discussion of this film draws from and revises a paper I gave at the Screen Studies Conference at Glasgow in 1996, "Nell Shipman: A Career Like a Serial Queen - Or: 'None of It Ever Really Happened!’.”

245 Discussions of the film as a fiction film include Paolo Cherchi Usai and Lorenzo Codelli (eds.), Sulla via di Hollywood, 1911-1920 (Pordenone: Edizioni Biblioteca dell'Immagine 1988), 514-15; Brauerhoch, "La Belle et la Bête," 36-45; William H. Drew, Something New: Speeding Sweethearts of the Silent Screen, 1908-1921 (@1997), chap. 10, at: http://www.welcometosilentmovies. com/features/sweethearts/chap10.htm; Trusky, his unpublished paper; Kristen Whissel, "On Something New: Nell Shipman, New Technologies and the New Woman in Motion," paper presented at the Women and the Silent Screen Conference, Santa Cruz 2001; and Armatage, Girl, chap. 4.

246 “Nell Shipman in 'Something New' Daring," Los Angeles Examiner, 7 October 1921; NSA, MSS 99, Box 3, Folder 37 (Marjorie Walker Folder); other articles on the film in the same file include "Auto Wins in Film Battle With Horse," Los Angeles Evening Herald 15 October 1921; “'Something New' at Philharmonic,” Los Angeles Evening Herald, 9 October 1920; and “'Something New' Rightly Named," Los Angeles Examiner, 10 October 1921.

247 The picture on the cover of Trusky's edition of her correspondence is a frame enlargement taken from these shots.

248 Another appearance of Shipman as a writer-figure can be found in her 1924 short subject THE TRAIL OF THE NORTH WIND, in which, however, "the writing girl”, Dreena, remains entirely diegetic and is missing the meta-layers resulting from playing with the diegetic and the extra-diegetic writing woman in SOMETHING NEW.

249 See: Shelley Stamp, Movie-Struck Girls (Princeton, New Jersey: Princeton University Press, 2000).

250 Screen\&Heart, 85.

251 See: the coverage in the Los Angeles Times and the Los Angeles Examiner of 18 and 21 September 1918, and 10 August 1919; NSA, MSS 99, Box 8, Folder 5. Walker's 1918 Maxwell film is paired with Shipman's SOMETHING NEW on the Idaho Film Collection DVD.

252 "A Pretty Scene and a Beautiful Car in Beverly Hills District," Los Angeles Times, 10 June 1917; NSA, MSS 99, Box 8, Folder 5; "Movie Star Has Record," Los Angeles Times, 17 November 1918, V13; NSA, MSS 99, Box 8, Folder 5 .

253 Singer, Melodrama and Modernity, :235.

254 “Nell Shipman on Dashing Auto Trip,” Los Angeles Times, 10 August 1919) and “Devil's Punch Bowl in Danger," Los Angeles Times, 24 August 1919; NSA, MSS 99, Box 8, Folder 5 .

255 “Win Wager in Fierce Battle," Los Angeles Times, 14 September 1919; NSA, MSS 99, Box 8, Folder 5. 
256 The synopsis is printed in: Shipman, Letters, 327-30. Although it was copyrighted in 1920, according to the NSA, the synopsis was obviously written before the shooting of the film, for it includes a note: "Many comedy situations may be worked in during the trip as we meet the existing conditions."

257 "Devil's Punch Bowl."

258 Shipman, "Synopsis," 330.

259 Ibid.

260 See: his groundbreaking article, "Female Power in the Serial-Queen Melodrama: The Etiology of an Anomaly," Camera Obscura 22 (January 1990), 90-129, which has been republished in a revised form in his Melodrama and Modernity.

261 Singer Melodrama and Modernity, 224.

262 Shipman, "Synopsis," 330.

263 Singer, Melodrama and Modernity, 239.

264 Brauerhoch, "La Belle et la Bête," 42.

265 Screen\&Heart, 87; my emphasis.

266 Ibid.

267 I do not believe that budgetary reasons played a role in the choice. The film was not made "on a shoestring", nor was it an "extreme example of low-budget production" (Armatage, Girl, 153). According to identical pieces in the Los Angeles Times and the Los Angeles Evening Herald of 15 and 16 October 1921, respectively, "The picture cost over $\$ 28,000$ to produce, in spite of the fact that it was filmed within less than 150 miles of Los Angeles," and the producers were apparently proud of the amount, as if to suggest that no expense or trouble had been spared. This budget came to over 40 percent of the production costs of BACK TO GOD'S COUNTRY, which had amounted to $\$ 67,000$, according to D.J. Turner (see: his letter in Griffithiana 46-47 (1993)). As Richard Koszarski contends, it is of little use to try to establish an average budget for film production at the time, because production costs varied widely and increased substantially in the postwar years. But even at a major company like Universal, in 1921, a fivereeler could be produced for a bit over $\$ 34,000$, so for an independent like Nell Shipman Productions and for a film like SOMETHING NEW, with its original scenario, modest cast and crew, and nearby locations, $\$ 28$,ooo did not necessarily represent an extremely low budget. See: Koszarski, An Evening,s Entertainment, 111-13.

268 Trusky, unpublished paper.

269 Shipman, "Me," 324.

270 Screen\&Heart, 87.

271 See, for a further discussion of the issue: Annette Förster, "Humorous Reflections on Acting, Filmmaking and Genre in Comic Film Productions by Adriënne Solser, Musdiora, and Nell Shipman,” in: Sofia Bull, Astrid Söder- 
bergh Widding (eds.), Not So Silent. Women in Cinema before Sound (Stockholm: Acta Universitatis Stockholmiensis 2010), 314-24.

272 See: Turner, "Filmography," 203; and Screen\&Heart, 88-89.

273 "Plenty of Action and Thrills in Colorful Picture," Wid's Daily, 18 September 1921, 9; NSA, MSS 99, Box 8, Folder 4.

274 See also: the photograph of the company on their way to the location; NSA, Series VIII: Photos.

275 Screen\&Heart, 87.

276 Jessie Robb, "Newest Reviews and Comments: 'The Girl from God's Country'," $M P W, 24$ September 1921, 448.

277 Fred., "Girl from God's Country," Variety, 18 November 1921, in: Shipman, Letters, 332-33.

278 Screen\&Heart, 87.

279 In his memoirs, he proudly describes the solution he came up with to conceal the fuzziness on both sides of the dividing line between double exposure images: having the blonde wear a boa. See: Walker and Walker, Light, 126-27. See also: the still from the film showing Shipman in her dual role, Screen\&Heart, no. 25 .

280 Screen\&Heart, 91-92.

281 See, for instance: her stories of the earthquake and the burning hangar (Screen\&Heart, 93), as well as of the wrangler named Keith and the canoe in the rapids of Kings River (Screen\&Heart, 90-1).

282 Screen\&Heart, 89.

283 Ibid., 87.

284 Ibid., 92.

285 Ibid., 101-102.

286 Ibid., 88 and 99, respectively.

287 “Bert Van Tuyle Again Promotes Film Capital for N. Shipman," unspecified newspaper clipping, hand-dated 1922, found in the files of the Spokane newspaper The Spokesman-Review ; NSA, MSS 99, Box 8, Folder 10. See also: Trusky's footnote 88 in Screen\&Heart, 174-75. There is no evidence for the budget having amounted to the princely sum of \$250,000, as Armatage, Girl, 161 believes. There was an announcement in the trade press that the Shipman Company was incorporated with a "paid-in capital of $\$ 250,000$ ", but it is unlikely that the budget set for the company's first film matched the entire sum. See: "Nell Shipman Enters Production Field with Company of Her Own,” MPW, 9 October 1920, 802.

288 Screen\&Heart, 94.

289 "Bert Van Tuyle Again Promotes Film Capital."

290 Screen\&Heart, 102.

291 Ibid., 103. 
292 Fred., "Girl from God's Country," 332; "Plenty of Action and Thrills in Colorful Picture," Wid's Daily, 18 September 1921, 9; Jessie Robb, “Newest Reviews and Comments: “The Girl from God's Country”, MPW, 24 September 1921, 448.

293 Screen\&Heart, 102.

294 Advertisement for THE GIRL FROM GOD'S COUNTRY, ibid., 361.

295 Screen\&Heart, 101.

296 "How I have always loved alliteration!," she exclaims in her memoirs (Screen\&Heart, 99).

297 Nell Shipman, "The Girl from God's Country," synopsis dated 28 September 1921, published in: Letters, 2003:331; and Fred., "Girl from God's Country," 332.

298 A term used in the summary in the AFI Catalog and quoted in Armatage, Girl, 162 and 182.

299 Screen\&Heart, 99 and 88, respectively.

300 NSA, Series VIII, Photos.

301 Anonymous, "Plenty of Action and Thrills in Colorful Picture," Wid's Daily, 18 September 1921, 9.

302 Walker and Walker, Light, 126.

303 Robb, "The Girl from God's Country," 448.

304 Screen\&Heart, 103.

305 Shipman also "packed" her ten year old son Barry, but he was a "toy" for private use, as he played only in one film, the 1923 two-reeler THE TRAIL OF THE NORTH WIND. See: Turner, "Filmography," 205.

306 Screen\&Heart, 103. Robert W. Service (1874-1958) was another Northwest fiction-writer, poet, and novelist, whose ballads were published in 1907 under the title The Spell of the Yukon. Shipman recited his verses during her three-week tour of "personal appearances" in support of THE GRUB-STAKE in Oregon and other states (see: Screen\&Heart, 124.)

307 See: Trusky's footnote 119 to Screen\&Heart, 182; and The Spokesman-Review, 8 March 1922; NSA, MSS 99, Box 8, Folder 17.

308 "6o Years Ago," Spokane Chronicle, 11 February 1982, reprint of a short item from the issue of 8 February 1922; NSA, MSS 99, Box 8, Folder 17.

309 "Film Syndicate Names Officers," The Spokesman-Review, 17 February 1922, 7; NSA, MSS 99, Box 8, Folder 17. Shipman, in her memoirs, mentions a budget of \$180,000, which was “the lowest since BACK TO GOD'S COUNTRY”, but both the amount and the comparison seem to result from her difficulty in recalling "facts and figures" (Screen\&Heart, 101).

310 "Shipman Staff Here Monday," The Spokesman-Review, 1 March 1922, 6; NSA, MSS 99, Box 8, Folder 17.

311 Lillian Leighton (1874-1956) had been a film actress since 1910 and would act in over 150 films until 1940. George Berrell (1849-1933) had been a film actor 
since 1915 and would act in almost 50 films before 1927 . Walt Whitman (18591928) had been a film actor since 1915 and would act in some 60 films before 1924. Cecil K. Van Auker (unknown-1938) had been a film actor since 1916 and would act in seventeen films through 1923. Ah Wing, also known as Ah Fong (1851-1941), had been a film actor since 1917 and would act in seven films through 1923; he had been cast together with Shipman in Wolbert's THE GIRL FROM BEYOND (1918), and THE GRUB-STAKE was his final film part. The actors with whom Shipman had no previous working experience, Alfred Allen (in the role of the prospector-villain) and Hugh Thompson (in that of the hero-lover), were no less esteemed. Allen (1866-1947), who had been a film actor since 1915, would act in over 100 productions before 1931. Thompson (1887-unknown) likewise had been a film actor since 1915 and would act in over 40 productions before 1926. (Source IMDb)

312 "Film Made at Minnehaha," The Spokesman-Review, 20 April 1922, 7; NSA, MSS 99, Box 8, Folder 17.

313 "Berrell, Now in Movies, Recalls Long Career on Stage," The Spokesman-Review, 25 June 1922; NSA, MSS 99, Box 8, Folder 17.

314 "Miss Shipman at Priest Lake," The Spokesman-Review, 26 August 1922, 5; NSA, MSS 99, Box 8, Folder 17.

315 “Report Spokane Film Marketed,” The Spokesman-Review, 18 December 1922, NSA, MSS 99, Box 8, Folder 17.

316 The British print recovered by Trusky runs to eight reels or about 8.000 feet, and the AFI Catalog mentions 6,408 or 8,061 feet.

317 Screen\&Heart, 109.

318 J.C.H. Reynolds, "Says Van Tuyle Bungled Film," The Spokesman-Review, 24 March 1923, 5; NSA, MSS 99, Box 8, Folder 17.

319 Shipman, Trails, 110.

320 Reynolds, "Van Tuyle Bungled Film," 5.

321 Ibid.

322 J.C.H. Reynolds, “"Grubstake” Coin Outlook Good,” The Spokesman-Review, 9 June 1923, 6; NSA, MSS 99, Box 8, Folder 17.

323 See: Turner, "Filmography," 203.

324 Screen\&Heart, 110.

325 Shipman, Trails, 123.

326 Ibid., 106.

327 Ibid., 110.

328 Ibid., 113.

329 Ibid., 115 .

330 Only twice were temporal and seasonal plausibility overlooked. Namely, when the girl in a pinafore dress sets out to collect firewood in the snow, and when she, in the springtime, finds a berry bush. 
331 See: Trusky's footnote 119 to Screen\&Heart, 182-83.

332 Ibid.

333 Ibid., 23.

334 The father in BAREE, SON OF KAZAN, in his dying hour, asks the girl to marry the man whom she distrusts and fears as a brute, because he would rather see her protected by marriage than alone; the father in BACK TO GOD'S COUNTRY lets himself be double-crossed and eventually killed by Rydal, too naïve to see through the villain's disguise and to recognize his intentions concerning the girl.

335 Screen\&Heart, 101-104.

336 Ibid., 103.

337 Compare, for instance, the same actor's role in Oscar Apfel's comedy PHIL FOR SHORT (1919), in which Thompson plays the lead of a woman-hating teacher of Greek, who is seduced by a younger, beautiful, and permissive female colleague. Because initially they make an improbable match, his character has to go through several changes, from fearing women and sexuality to a transitional vacillation between feelings of attraction and of awkwardness, to feeling jealousy, and eventually to taking pride in and enjoying the girl's beauty and personality. (The film was included in Le Giornate del Cinema Muto 2004 at Pordenone/Sacile.)

338 Screen\&Heart, 103.

339 See: "Klondike Kate," at: http://www.geocities.com/Heartland/Bluffs/8336/ yukon_kate.html and Daniel Statt, "Pantages, Alexander (1876-1936)," at: http://www.historylink.org/output.CFM?file_ID=2999.

340 See: Elizabeth Beckett and Sarah Teel, “Klondike Kate,” at: http://library.thinkquest.org/11313/Gold_Rush/

kate.html and "Who was Klondike Kate?,” at: http://nancysworld.net/Rothrock/ KlondikeKate.html.

341 The narrative motif of telling white lies is, in this scene, connected directly to the women's interests in a male-dominated society. Kate has to live with the lie to her son that she has a honorable job. In the plot, she also lies to the Mountie when she denies knowing anything about the dog-thieves. At this point in the story, her lying may be not just in Faith's or her own interests, but also in her son Jeb's and the Skipper's. Furthermore, it is strongly suggested, when she play-acts before the Mountie her disapproval of dog-stealing, that she doubts whether she would consider the act to be theft in this case. In the penultimate sequence of the film, in which Faith lies to Jeb that she knows his mother from the post office, the reciprocal interest of the women is emphasized once again. The plot contains not the slightest suggestion that lying such as this is reprehensible; on the contrary, it is presented as a necessity for women in order to survive in the incriminating situations that result from the law's alliance with male power. 
342 The sources about Klondike Kate mention at least seventeen women in the turn-of-the-century Northwest who adopted the tag for themselves, which points not only to the extent to which a fictional character like Dawson Kate could be nonetheless true to life, but also to how many real life women could identify with it. Moreover, on account of Nell Shipman's sympathy for the character, it may come as no surprise that she, after having created the part for the screen, befriended Belle Angstadt, a woman cut from the same cloth as Dawson Kate. In her memoirs, Shipman fondly featured her Idaho friend in a characterization that, in many ways, also applies to the fictional character of her film: "Maybe I was imitation Western folklore but Belle was the real thing. And Aunt Belle, as she was known and loved throughout the region, once shot a man. Now, gunning down a Bad Hat, in fiction, is the bread-and-butter of our trade. [...] But, as a make-believe shooter, the story fascinated me. I longed to ask the real life heroine how it felt to really kill someone. But never dared. There was 524 that about Belle to make one step gently [...] Usually in winter she lived in a Priest River cottage with a mended front door, wrote squibs and verse for the local newspaper, fed, cheered and consoled every friend and, it can be said, was the greatest, biggest 'heart of gold' to step from the real life pages of wild West romance." (Screen\&Heart, 124-25).

343 See: Screen\&Heart, 115-19, for a very fond account of Barry's life during this period in her career, when the boy was not with her most of the time.

344 Armatage, Girl, 236.

345 Screen\&Heart, 107-108.

346 Ibid., 105.

347 Ibid., 71.

348 Shipman, "She Bear," 76.

349 Trusky too has pointed out this similarity in motivation for marrying a man with power and money; his unpublished paper.

350 Barry Shipman informed me of this during our conversation.

351 Armatage, Girl, 225.

352 From the caption of a photograph of Nell with a scared kitten, included in the section of illustrations, "Helen Barham becomes Nell Shipman," between pp. 50 and 51 of Screen\&Heart, photograph no. 13.

353 Armatage, Girl, 250.

354 See: Turner, "Filmography," 204-06. The filmography lists only THE LIGHT ON LOOK OUT and THE TRAIL OF THE NORTH WIND to be extant. However, after the third edition was published, the third LITTLE DRAMA, WHITE WATER, has been rediscovered by the George Eastman House, as well as the opening title cards of the fourth, WOLF'S BRUSH. See also: Trusky, Tom. "Nell Shipman." In Jane Gaines, Radha Vatsal, and Monica Dall'Asta, eds. Women Film Pioneers Project. Center for Digital Research and Scholarship. New York, NY: Columbia 
University Libraries, 2013. Web. 27 September 2013. <https://wfpp.cdrs. columbia.edu/pioneer/ccp-nell-shipman/>.

355 Screen\&Heart, 108.

356 Slide, The American Film Industry, 195.

357 Screen\&Heart, 111.

358 See: Trusky's note 126 to Screen\&Heart, 184.

359 See: Trusky's note 158 to Screen\&Heart, 188-89.

360 Screen\&Heart, 157.

361 For a brief discussion of the film, see: Armatage, Girl, 343-46. 



\section{CAREER OVERVIEWS}

\section{ADRIËNNE SOLSER}

187318 February: born in Rotterdam as Engelina Adriana Hartlooper; acknowledged as Engelina Adriana Solser through the marriage of her mother Engelina Florina Hartlooper with Johannes Solser on 2 November 1876.

1883-1886 Performs with the parental troupe in the province of Zuid-Holland 1886 Solo debut of her brother Michel Solser at the Place des Pays Bas, Rotterdam.

1889 Performs at the Café-Concert Victoria, Amsterdam, in a sketch by Michel Solser.

1893 March: marries Neumann Wittkower. 22 May: gives birth to Rebecca Rachel Wittkower.

189427 September: divorces Wittkower. 22 October: Michel Solser dies of tuberculosis.

1895 January: performs at the Frascati Schouwburg, Amsterdam, in a parody operetta and a farce featuring her brother Lion Solser.

1896 Marries the pharmacist Dr. Louis Joseph Boesnach; moves to Pretoria, South-Africa.

12 January: gives birth to Andreas Louis (André) Boesnach;

18975 July: gives birth to Adela Micheline (Adèle) Boesnach.

1900 April: performs at the Frascati Schouwburg, Amsterdam, in a comic operetta.

1902 September: solo performance as chanteuse internationale at the Vauxhall Doele, Rotterdam.

1904-1912 Solo performances at the Casino Variété Soesman in Rotterdam, as $\mathrm{Hol}^{-}$ landsche soubrette, voordracht soubrette, koepletzangeres, humoriste, or karakter soubrette. 
1910-1915 Ensemble Solser \& Hesse scores triumphs with Jordaan farces.

19122 March, Amsterdam: marries Salomon d'Oliveijra. 13 August: gives birth to Engelina Jeannette (Lien) d'Oliveijra 16 November-30 December: solo performance in a mixed variety and film program by Albert Frères at the Grand Théâtre, Amsterdam.

1913 May: solo performance as Neêrlands 1e Cabaret-Artiste and member of the cast of a Carmen parody at De Vereeniging, Amsterdam.

1914 January and February: solo performance as Neerlands eerste soubrette at the Rozen-theater, Amsterdam and the Cabaret Metropole, Rotterdam.

1915 April: solo performance at the Scala, The Hague.

May-July: stand-in for Lion Solser.

3 August: Lion Solser dies of suicide.

September-October: performance in a Jordaan-revue by Rido and solo performances in the mixed film and variety program at the Rozen-Theater, Amsterdam.

1916 May: solo performance in a revue by Uiltje at the Bouwmeester Theater, The Hague.

1917 June: solo performance as soubrette after film screening, Nieuw Olympia Theater, Rotterdam.

1918 October: act of a fish monger in a revue by Ter Hall at the Casino Variété, Rotterdam.

December: performs with Marinus de Wilde at the Astoria Theater, Rotterdam.

1919 April: celebration of the 30 year stage jubilee of the populaire karakterhumoriste at the Karseboom Cabaret, The Hague.

1921 April: performance in a sketch and actress in a short film, DE DROOM VAN HADT JE ME MAAR, at Cinema de Munt, Amsterdam. Prod. Satiriek Film Cie, Dir. Alex Benno, Cast Cornelis van Gelder, fragment of $161 \mathrm{~m}$. preserved at EYE.

1922 Supporting role in DE JANTJES (release 17 March). Prod.: FilmfabriekHollandia (Alex Benno \& Fred. Penley), dir. Maurits H. Binger \& B.E. DoxatPratt, cast Beppie de Vries, Johan Elsensohn, Louis Davids a.o.; fragments of $165 \mathrm{~m}$. preserved at EYE.

1923 Featured actress of and performances as a lecturer with KEE EN JANUS NAAR BERLIJN (release 5 January). Prod.: Actueel-Film (Alex Benno \& Fred Penley), dir. Alex Benno, cast Kees Pruis.

1924 Featured actress in and performances as a lecturer with KEE EN JANUS NAAR PARIJS (release 11 January). Prod.: The Dutch Film Cy (David Sluizer), dir. Alex Benno, cast Piet Köhler; Supporting role in AMSTERDAM BIJ NACHT (release 18 April). Prod.: The Dutch Film Co (David Sluizer), dir. Theo Frenkel sr., cast Henriëtte Davids, Louis Davids, Piet Köhler a.o.; 
Supporting role in CIRQUE HOLLANDAIS (release 17 October). Prod.: The Dutch Film Co (David Sluizer), dir. Theo Frenkel sr., cast Louis Bouwmeester, Aaf Bouber-ten Hope, Piet Köhler, a.o..

September: incorporation of Solser's production and distribution company Hollando-Belgica Film Mij. "Eureka," managing directors André Boesnach \& Jules Suikerman; Featured actress, co-director (with Pierre Hulsman) of, and live performance with BET, DE KONINGIN VAN DE JORDAAN (release 21 November). Prod.: Hollando-Belgica Film Mij. "Eureka" (André Boesnach \& Jules Suikerman), cast Jan Nooy, Beppie Nooy-Blaaser. Preserved at EYE. Performances throughout the country.

1926 Featured actress, co-director (with Pierre Hulsman) of, and live performance with BET TREKT DE 100.000. (release 15 January). Prod.: HollandoBelgica Film Mij. "Eureka” (André Boesnach), cast Henk Livermore, André Boesnach a.o. Performances throughout the country and in a sketch with Charles Braakensiek in the interval.

1927 Featured actress of and live performance with BET ZIT IN DE PENARIE. (release 27 February). Prod.: Hollando-Belgica Film Mij. "Eureka” (André Boesnach \& Jan Smits), dir. André Boesnach, cast Eugène Beeckman, Alex de Meester, Beppie Nooy-Blaaser a.o. Performances throughout the country and in a Hawaiian sketch in the interval.

22 September: Opening of film studio "Eureka" in Schiedam; owner Adriënne Solser, managing director André Boesnach; cinematographer Fernand Gauthier; production assistant Lien d'Oliveijra. Solser and Boesnach also run a film school.

192821 March: André Boesnach dies of influenza; Featured actress, producer of and live performance with BET NAAR DE OLYMPIADE (release 13 July). Prod."Studio Eureka Film," dir. Theo Frenkel Sr., cast Alex de Meester, Rinus de Wilde a.o.; Print length 1749 m, 1548 m. preserved at EYE. Performances throughout the country. October: Film studio "Eureka" sold.

1929-1930 Solser runs Pension Liena in The Hague.

1931-1934 Solser tours with BET, DE KONINGIN VAN DE JORDAAN and BET NAAR DE OLYMPIADE and her live performances in the Dutch provinces.

1934-1943 minor roles in the sound films HET MEISJE MET DEN BLAUWEN HOED (dir. Rudolf Meinert), SUIKERFREULE and HET LEVEN IS NIET ZO KWAAD (both dir. Haro von Peski), as well as in IK FLUIT IN DE HOOP DAT JE ZULT KOMEN (dir. Gerard Rutten).

194329 November: Adriënne Solser dies in a hospital in Doetinchem. 


\section{MUSIDORA}

188923 February: born in Paris as Jeanne Roques, sole child of the composer Jacques Roques and the painter Marie Porchez, also known as the feminist editor Marie Clémence.

1900s education in literature, drawing, and sculpting (at art school) and performance (at the Conservatoire du Chanson). Beginning of lifelong friendship with Colette.

191011 September-17 November: supporting parts in a crime drama, a popular drama, and the revue at the Théâtre Montparnasse.

1911 February and March: role of Claudine in "Claudine à Paris" in Belgian and French province towns.

21 October-November: performs in the revue at the Théâtre Montparnasse.

$530 \quad 19126$ April-1 June 1913: performs in three revues and a farce at the Ba-ta-clan.

1913 5-19 November: supporting part in a play by André de Lorde starring Max Dearly at the Renaissance theatre.

20 November and December: supporting part in a spectacle play at the Chatelet.

1914 Featured actress in LES MISÈrES DE L'AIGUILLE (release 18 January). Prod. Cooperative le Cinéma du Peuple, dir. Raphaël Clamour, cast Jeanne Roques, Armand Guerra (print preserved at the CF).

7 February-30 June: performs in two revues at the Folies Bergère. Acts in the film insert LA VILLE DE MADAME TANGo (Prod. Pathé Frères), which constitutes the $9^{\text {th }}$ tableau of "La Revue Galante"; April-June: actress at Gaumont, dir. Louis Feuillade in dramas starring Renée Carl: SEVERO TORELLI (print preserved at the CG) and LE CALVAIRE; In a ciné-vaudeville starring Marcel Levesque: TU N'ÉPOUSERAS JAMAIS UN AVOCAT. August 8: Outbreak Great War; November-December: actress at Gaumont, dir. Gaston Ravel in patriotic dramas and comedies: SAINTE ODILE, LES TROIS RATS, LA BOUQUETIÈRE DES CATALANS, LES LEÇONS DE LA GUERRE, LA PETITE REFUGIÉE.

1915 Actress at Gaumont, dir. Louis Feuillade in ciné-vaudevilles starring Marcel Levesque: LE COLONEL BONTEMPS, LE COUP DU FAKIR, L'ESCAPADE DE FILOCHE, LE SOSIE, TRIPLE ENTENTE, LA BARRIÈRE, LE FER A CHEVAL, LE COLLIER DES PERLES; In patriotic dramas by Feuillade: L'UNION SACRÉE, CELUI QUI RESTE, DEUX FRANÇAISES, FIFI TAMBOUR, LES NOCES D'ARGENT; by Ravel: LE TROPHÉE DU ZOUAVE, LE GRAND SOUFFLE; by Léonce Perret: L'AUTRE DEVOIR, UNE PAGE DE GLOIRE (print preserved at the CNC); In a children's comedy by Feuillade: BOUT DE ZAN ET LE POILU; In LE CRYPTOGRAMME ROUGE, episode III of the crime series LES VAMPIRES by Feuil- 
lade (print preserved and reissued on DVD by the CF). As of 25 August: performs in the revue at the Moulin de la Chanson and as of 5 November: performs in the revue written by Albert Willemetz and Sacha Guitry starring Raimu at the Palais Royal.

1916 Actress at Gaumont, dir. Louis Feuillade in ciné-vaudevilles starring Marcel Levesque: LES MARIÉS D'UN JOUR, LES FOURBIÈRES DE PINGOUIN, LES FIANÇAILLES D'AGÉNOR, LE POÈTE ET SA FOLLE AMANTE, SI VOUS NE M'AIMEZ PAS, LA PEINE DU TALION, LAGOURDETTE GENTLEMAN CAMBRIOLEUR (print preserved at the CF); Role of Irma Vep in episodes IV to X of the crime series LES VAMPIRES: LE SPECTRE, L'ÉVASION DU MORT, LES YEUX QUI FASCINENT, SATANAS, LE MAÎTRE ET LA FOUDRE, L'HOMME DES POISONS, LES NOCES SANGLANTES (prints preserved and reissued on DVD by the CF); In a parody on crime series dir. Jacques Feyder: LE PIED QUI ÉTREINT (print preserved at the CF). As of February: performs in the revue at La Pie Qui Chante. As of 29 April: performs in the Irma Vep suit in the revue by Jean Bastia at the Scala.

October: in the revue at La Pie Qui Chante; December: preparations for the drama MINNE, after L'Ingénue libertine by Colette, directed by and starring Musidora. Probably never accomplished.

1917 Actress at Gaumont, dir. Louis Feuillade: in the role of Diana Monti in the crime series JUDEX (12 episodes, print preserved at the CRB, reissued on DVD by Waterbearer); in part I of the benefit film C'EST POUR LES ORPHELINS: LE RÉVEIL DE L'ARTISTE (print preserved at Lobster Films), and in the ciné-vaudevilles MON ONCLE and DÉBROUILLE-TOI.

28 July-end of September: performs in the revue at the Concert Mayol; Featured actress of the drama CHACALS, prod. and dir. André Hugon (release 5 October). Cast: André Nox, Louis Paglieri, M. Byon a.o. As of 1 October: acts in and directs a short film LE MAILLOT NOIR, shown in the play with the same title at the Bobino.

9 November-end of December: in two revues at the Gaiété-Rochechouart, using her Irma Vep suit.

1918 As of 8 January: performs in the revue at the Théâtre des Capucines; Featured actress and co-scenarist of LA VAGABONDE, prod. Film d'Arte Italiana, dir. Eugenio Perego, after the novel by Colette (release $22 \mathrm{March}$ ). Cast: Luigi Maggi, Ernest Treves, Rina Maggi; Featured actress of the drama JOHANNÈs, FILS DE JOHANNÈs, prod. and dir. André Hugon (release 19 July). Cast: André Nox a.o.

1919 Featured actress of the drama MAM'ZELLE CHIFFON, prod. and dir. André Hugon (release 28 March). Cast: Suzanne Munte, Kitty Hott a.o.. As of 23 April: performs in the revue at La Cigale réchante; As of July: in the revue at the Théâtre du Pré-Catalan. As of October: in the revue at Le Perchoir. 

LA FLAMME CACHÉE, after a scenario by Colette (release 5 March). Cast: Maurice Lagrenée, Jean Yonnel a.o.March-May: performs in a popular play at the Théâtre Albert I; Featured actress, director, producer and scenarist of the drama VICENTA (release 15 May). Cast: Jean Guitry, Girau-Rivière, Lancien a.o. As of 8 November: in the revue at La Pie Qui Chante

1921-1922 Performs in vaudevilles and melodramas on a tour organized by the impresario Charles Baret. Performs with chansons at the Omnia; Featured actress of the drama LA GÉOLE, co-prod.(with Cines) and dir. Gaston Ravel (release 15 July). Cast: René Navarre, André Nox, Georges Colin a.o. September: performs in the revue at La Pie Qui Chante. 4-22 November 1921 (Madrid) and 4-9 November (Genève): performs in a pantomime written and directed by herself, "El dia de Musidora"; Featured actress, producer and co-director (with Jacques Lasseyne) of the Spanish-French drama POUR DON CARLOS, after the novel by Pierre Benoît (release 16 December 1921, unrestored print of the Cinémathèque de Toulouse held at the CNC). Cast: Abel Tarride, Janvier, Stéphane Weber, Paul Clérouc, Jean Darragon, Jean Signoret, Jean Guitry, Miss Chrysias, Simone Cynthia a.o.

1922 March-4 May: performs in a play by Jean Bastia at Le Perchoir; Actress in the second episode of LA JEUNE FILLE LA PLUS MERITANTE DE FRANCE, directed by Germaine Dulac (release 16 June); Featured actress, co-director (with Jacques Lasseyne), producer and scenarist of the Spanish-French drama SOL Y SOMBRA/SOLEIL ET OMBRE, after the novella L'Espagnole by Maria Stern (release 6 October). Cast: Antonio Cañero, Paul Vermoyal, Simone Cynthia, Miguel Sanchez. Print preserved at the CF.

192327 January-end of April: performs in the revue at La Pie Qui Chante.

1924 Featured actress in double roles, director, producer, and scenarist of the mixed stage and film comedy LA TIERRA DE LOS TOROS/LA TERRE DES TAUREAUX (release 3 June 1924, print preserved at the CNC). Cast: Antonio Cañero. Writes (with Nora Januxi) and performs "Le Bluff", a one act play as an epilogue to LA TIERRA DE LOS TOROS. As of 22 June: performs in a melodrama by Jean Mathieu.

1925 As of 11 January (Macon): performs in a comedy "Une femme trop parfaite", written in collaboration with Nora Januxi. October-November: performs in her tour de chant at the Scala.

192626 February: is proclaimed Reine du Cinéma; Minor role in LE BERCEAU DE DIEU, directed by Fred Leroy-Granville (release 15 June).

192720 April: marries the doctor Clément Marot (divorce 1944).

1928-1950 Performs in and writes comedies, operettas, and plays for the popular stage, such as "La Vie Sentimentale de George Sand" (premiere 23 Novem- 
ber 1946 at the Théâtre de l'Humour). Published as a book with illustrations by the author (Paris: Ed. La Revue Moderne, 1946).

1928 Novel Arlequin et Arabella serialized in Comoedia (26 December 1928-9 January 1929) and published as En amour tout est possible in 1929 (Paris: Ed. Eugène Figuière).

1929 Gives birth to a son, Clément Marot, Jr.

1934 Novel Paroxysmes. De l'amour à la mort (Paris: Ed. Eugène Figuière).

1939 Collection of poems Auréoles.

1942 Publication of "La Vie d'une Vamp", reminiscences in weekly installments about her work with Feuillade at Gaumont, in Ciné-Mondial 12 June to 24 July 1942.

1946-1957 Coordinates, conducts, and transcribes the interviews of the Commission des Recherches Historiques, an oral history project about French silent cinema instigated by Henri Langlois at the Cinémathèque française.

1950 Actress, director, producer, and scenarist of the short film LA MAGIQUE IMAGE, shown at the Festival d'Antibes. Cast: Pons-Magdelina, Renée Chappaz.

195710 December: Jeanne Roques/Musidora dies in the hospital of Bois le Roi of heart failure.

\section{NELL SHIPMAN}

189225 October: born Helen Foster Barham in Victoria, British Columbia, Canada. Stage name Helen Barham; as a scenarist, film actress, director and novelist Nell Shipman.

$\mathbf{\pm 1 9 0 1}$ moves with parents and brother to the vicinity of Seattle, Washington.

1905-1906 Dancing and acting lessons at the Egan School of Music, Drama and Fine Arts, Seattle.

1907 October: female lead in "At Yale" (author Owen Davis) at the Yorkville Theatre, New York and the Majestic Theatre, Brooklyn; December: in Washington D.C.

1908 October-November: member of the National Stock Company; ingénue in "An Arkansas Romance" and female lead in "What women will do" at the Binnard Theatre, Lewiston, Idaho.

1909 February: acts in the comedy playlet "According to the code" (author and producer Dave Williams) at the Pantages Theatre, Seattle. July-November: member of the Taylor Stock Company of Charles A. Taylor; female lead in "Yosemite" in Dawson City, Yukon, Canada and "The Girl from Alaska" at the Portland Theatre, Portland, Oregon. 
1910 January-February: leading woman of the Sutton Players of Dick Sutton; female lead in "The Punkin Husker", "The Night Before Christmas”, "A Girl Engineer", "In a Woman's Power", and "For her Sake" at The Grand Theatre, Salt Lake City, Utah.

1911 January-May: member of the American Amusement Company (general manager: Ernest Shipman); leading role of Necia in "The Barrier" (author Rex Beach). Performances in Oregon, Utah and Washington.

22 August: Helen Barham marries Ernest Shipman and uses the name Nell Shipman. Moves to California.

191224 February: gives birth to Barry Shipman.

November: first and second prizes in a scenario contest of the Egan College, Los Angeles with Sold to the British and Outwitted by Billy. Prod. SeligPoliscope Company, dir. Edward J. LeSaint (release 21 November 1913). December: "A Call to Arms for the Scenario Writers", a plea for fair prices and credits for scenarists, published in West Coast Magazine; scenario ONE HUNDRED YEARS OF MORMONISM for the Utah Moving Picture Company. Dir. Norval MacGregor (release 3 February 1913).

1913-1914 Self-promotion as a professional scenarist, preferably of literary adaptations. Scenario for THE SHEPHERD OF THE SOUTHERN CROSS produced in Australia by Australasian Films. (Dir. Alexander Butler, release June 1914).

1915 Scenarist of the series UNDER THE CRESCENT (six two-reel episodes), prod. Universal Film Manufacturing Co. (Dir. Burton King; release 1 June 1915). Under the Crescent, the novel with $5^{8}$ production stills, published by Grosset \& Dunlap. Scenarios sold to Universal for the actor/director J. Warren Kerrigan: the melodramas THE WIDOW'S SECRET and GOODBEY SUMMER, the Indian drama SON O'THE STARS and the heroic western drama THE MELODY OF LOVE aka THE TROUBADOUR OF ELDORADO. Shipman reputedly acted in and (co-?)directed the latter. Scenarist of the drama of the Northwoods THE PINE'S REVENGE, adapted from her original story The King's Keeper, prod. Universal (dir. Joseph de Grasse, cast Cleo Madison, Lon Chaney a.o.; release September 1915). Represented by Mabel Condon as a scenarist and an actress. Scenarios sold to the American Film Company and the Palo Alto Film Company. Actress at Vitagraph playing the female lead in GOD's COUNTRY AND THE WOMAN after the novel by James Oliver Curwood (dir. Rollin S. Sturgeon, cast a.o. William Duncan; release 24 April 1916).

1916 Actress at the Fox Film Corporation in THE FIRES OF CONSCIENCE (dir. Oscar C. Apfel, cast William Farnum, Gladys Brockwell a.o., release 25 September 1916); at Vitagraph in THROUGH THE WALL and THE MYSTERY OF LAKE LETHE (both dir. Rollin S. Sturgeon, cast a.o. William Duncan, George Holt, Corinne Griffith; release 2 October 1916 and January 1917, 
resp.) and at the Jesse L. Lasky Feature Play Co. in THE BLACK WOLF (dir. Frank Reicher, starring Lou Tellegen; release 12 February 1917).

1917-1918 Leading actress in Vitagraph Blue Ribbon Features opposite Alfred Whitman, dir. William Wolbert: the comedy THE WILD STRAIN (release 14 January 1918), the outdoors drama CAVANAUGH OF THE FOREST RANGERS (release 25 February 1918), the Western drama THE HOME TRAIL (release 25 March 1918), and the melodrama THE GIRL FROM BEYOND (release 15 April 1918); dir. David Smith in: BAREE, SON OF KAZAN (after the story by James Oliver Curwood; release 27 May 1918) and A GENTLEMAN'S AGREEMENT (release 29 July 1918); dir. Albert W. Hale in three WOLFVILLE TALES: TOAD ALLEN'S ELOPEMENT, THE TRIALS OF TEXAS THOMPSON, and THE WASHERWOMAN'S WAR (release September 1919).

November 1918: forms the independent Shipman-Curwood Production Co. with the exclusive right to adapt Curwood stories featuring Nell Shipman.

1919 Scenarist and leading actress in BACK TO GOD'S COUNTRY, after Curwood's short story "Wapi, the Walrus", prod. Canadian Photoplays for the Shipman-Curwood Production Co., dir. David Hartford, cinematographers Dal Clawson, Joseph B. Walker, cast Wheeler Oakman, Wellington Playter, a.o.; release 16 September 1919. Preserved at the Canadian National Television, Film and Sound Archive and reissued on DVD by The Idaho Film Collection/Hemingway Western Studies Centre, Boise State University. August: resigns from the Shipman-Curwood Production Co. (Probably) scenarist and actress in the promotional film THE TRAIL OF THE ARROW, dir. Tuyle, cinematographer Walker, cast Marjorie Cole.

1920 May: divorces Ernest Shipman

1920-1921 Scenarist and supporting actress in A BEAR, A BOY AND A DOG, also known as SATURDAY OFF, dir. Tuyle, cinematographer Walker, cast "Sonny" Howard, Margaret Mann, release 1921. Preserved and reissued on DVD by IFC/HWSC, BSU; Scenarist, leading actress, and co-director (with Tuyle) of SOMETHING NEW, cinematographer Walker, cast Tuyle a.o., release 10 October 1921. Preserved and reissued on DVD by IFC/HWSC, BSU; Establishment of Nell Shipman Productions Inc. Scenarist, leading actress, co-director (with Tuyle) and producer of THE GIRL FROM GOD'S COUNTRY, cinematographer Walker, cast Edward Burns, George Berrell, Walt Whitman, Lillian Leighton a.o.; release 11 September 1921. Print preserved and reissued on DVD by IFC/HWSC, BSU.

1922 February: moves with Tuyle and son Barry to Spokane, Washington; Scenarist, leading actress, co-director (with Tuyle) and producer of THE GRUB-STAKE , cinematographer Walker, cast Hugh Thompson, Alfred Allen, George Berrell, Walt Whitman, Ah Wing, Lillian Leighton, Lloyd 
Peters a.o.; release 18 February 1923. Preserved and reissued on DVD by IFC/HWSC, BSU; August: Shipman Film Company and zoo move to Upper Priest Lake, Idaho.

1923 April: THE GRUB-STAKE caught in the bankruptcy of the American Releasing Company and generating financial problems for the Shipman Film Company; Until July 1924: building the "studio-camp" Lionhead Lodge on Mosquito Bay.

1924 Scenarist, leading actress, co-director (with Tuyle), and producer of LITTLE DRAMAS OF THE BIG PLACES, a series of two-reelers: THE TRAIL OF THE NORTH WIND, THE LIGHT ON LOOKOUT, WHITE WATER, WOLF'S BRUSH, and THE LOVE TREE. Cinematographer Robert S. Newhard, cast a.o. Daddy Duffill, Aubrey Overmeyer, Dorothy Winsloe, Ralph Cochner, Belle Angstadt, Lloyd Peters, Barry Shipman. The first three preserved and reissued on DVD by IFC/HWSC, BSU.

Autobiographical account “The Movie That Could n't be Screened” sold to Atlantic Monthly, published in three installments March-May 1925.

31 December: Shipman flees from Bert Van Tuyle and leaves Lionhead Lodge behind.

1925 January: escape to New York; April: relationship with Charles Austin Ayers, painter (until 1934); Barry joins them. The Animal Collection auctioned to satisfy financial claims.

June 16: forty animals shipped to the San Diego Zoo.

1926 Lives with Ayers in Spain.

3 May: gives birth to twins, Charles and Daphne Ayers; Returns to the US, lives in Sarasota, Florida. Novel "The Tamiami Trail” serialized in Florida newspapers.

1928 May: author, leading actress and producer of "Are Screen Stars Dumb?", one-act play about the advent of sound film and attempt to make a comeback as an actress. Staged at the Olympia Theatre in Miami.

1929-1935 Lives alternately in California and New York.

1930 Novel Get the Woman (Dial Press); as "M'sieu Sweetheart" in six installments in June-July published in McGalls Magazine; Children's book Kurly Kew and the Tree Princess (New York: Dial Press).

1931 January: Brownie's biography “This Little Bear Went Hollywood," published in Good Housekeeping.

1932 Autobiographical novel Abandoned Trails (New York: Dial Press).

1935 Co-author (with Philip D. Hurn) of the original story of WINGS IN THE DARK, production Paramount, director James Flood, cast Cary Grant, Myrna Loy; Co-author (with George Palmer Putnam) of the novel Hot Oil (New York: Greenberg Publishing Co.). 
1939-1960 Relationship with Amerigo Serrao, alias Peter Locke/Arthur Varney/Grover Lee, film producer. Several scenarios remain unrealized, with the exception of THE STORY OF MR. HOBBS also known as THE CLAM-DIGGER'S DAUGHTER, production Mid-Century Pictures Corporation, director Lorenzo Alagia (Serrao), cast Jack Hardwood, Frances Helm, a.o. release January 1947. Incomplete print at BFI, London.

197023 January: Nell Shipman dies at her home in Cabazon, California. 



\section{ACKNOWLEDGEMENTS}

At the cradle of this project stood Heide Schlüpmann, professor emerita of the Johann Wolfgang Goethe University in Frankfurt am Main. As a friend and colleague in feminist film studies and history, she inspired the choice for actresses and women filmmakers in the silent cinema; as one of my PhD-supervisors, she provided invaluable guidance and encouragement throughout the research and writing processes. Over the past decade, Schlüpmann involved me in projects about women and silent cinema, that she, together with Karola Gramann of the Kinothek Asta Nielsen, organized. This sustained my research on women on the popular stage and the silent cinema.

In the period that this was a research project, Rosi Braidotti's heartening enthusiasm and committed questions nourished my intellectual confidence, and Thomas Elsaesser's solid comments and constructive criticism encouraged me to elaborate my approach. A generous scholarly climate was offered in post-graduate seminars, during which staff members and $\mathrm{PhD}$ students presented their works-in-progress. For thought-provoking feedback I am particularly indebted to Rosemarie Buikema, Esther Captain, Maaike Meijer, Baukje Prins, Jann Ruyters, Anneke Smelik, Berteke Waaldijk, and Gloria Wekker at the former department of Women's Studies in the Arts at Utrecht University; to Ansje van Beusekom, Ivo Blom, Bernadette Kester, Alison McMahan, Patricia Pisters, Michael Punt, Peter Verstraeten, and Michael Wedel at the department of Media Studies at the University of Amsterdam; and to Frank Kessler, Bregtje Lameris, Sonja de Leeuw, Judith Thissen, William Uricchio, André van der Velden, Nanna Verhoeff, and Eva Warth at the department of Media Studies at Utrecht University. Special thanks are due to Karel Dibbets, who kept a watchful eye on the project from its earliest phase and acted as a most challenging discussion partner throughout.

Especially inspiring was the opportunity provided by the department of Media Studies and the Research Institute for History and Culture (OGC) at Utrecht University to organ- 
ize, together with Eva Warth, the first Gender and Silent Cinema Conference 1999, which launched the biannual Women and the Silent Screen Conferences (WSS). Eva Warth's knowledge of feminist film studies, her intellectual generosity, and her energizing spirit encouraged me to explore the full scope of the field. My work significantly benefitted from the interdisciplinary exchange and collaboration with archives boosted by the WSS conferences. For thoughtful response and enriching conversations, I wish to thank Kay Armatage, Jennifer Bean, Vicki Callahan, Monica Dall'Asta, Angela Dalle Vacche, Victoria Duckett, Jane M. Gaines, Tami Williams, and Shelley Stamp. I am particularly grateful to Victoria for her enduring interest in my work.

For financial support, travel grants, and defraying material expenses in the research and initial writing phase, I am grateful to the Netherlands Organization for Scientific Research (NWO) and the Research Institute for History and Culture (OGC) of Utrecht University. For compensation for travel costs to present portions of my work at confer540 ences, I am obliged to the Women Film Pioneers Project (WSSC II, 2001), to the University of Stockholm (WSSC V, 2008), and to the Royal Netherlands Embassy in Montréal, Quebec (Pratiques Orales du Cinéma, 2010).

As this book is based on archival research, the assistance and commitment of archivists and librarians was vital. The institutions that offered occasions to view films and to consult documentation are acknowledged in the introduction of this book. Here, I wish to express my gratitude to the staff members of the archives and libraries for facilitating the research. Special thanks are due to individuals whose generosity and encouragement had a significant impact. At the then Nederlands Filmmuseum, Eric de Kuyper and Peter Delpeut gave me the opportunity to curate a program with and explore films made by women in the silent era at a time that these were hardly shown in film museum programs. This research became the initial trigger for my project. The late Tom Trusky of the Hemingway Western Studies Center and Alan Virta of the Albertsons Library shared their Nell Shipman collection with great enthusiasm. Tom never grew tired of talking about Shipman, advised me to always "stay tuned" for more finds or thoughts and was a dear friend in and beyond "Shipmania". I am also grateful to D.J. Turner and the late Micheline Morisset, who kindly made available to me their list of Shipman-related articles in The Moving Picture World, that proved a real timesaving aid. With regard to Musidora, I wish to thank Frank Kessler for making me aware of an extant print of her film POUR DON CARLOS and to thank Eric Leroy at the Centre Nationale de la Cinématographie for allowing me to view this precious nitrate copy from the Cinémathèque de Toulouse. I am particularly indebted to Emmanuelle Toulet for her valuable suggestions for researching Musidora's popular stage career at the Département des Arts du Spectacle. This documentation opened my eyes for the interaction between stage entertainment and silent cinema. 
Outside of these institutions, I thank Sabine Lenk for sharing contacts to inquire about Musidora's archive and Patrick Cazals for his information about Musidora's son, the late Clément Marot. Many thanks also to Ivo Blom for sharing contacts from his extensive international network. Marianne Hietbrink, Edward Schenk, and the Parisian film collector Jean Bloch were always willing to listen to enthused reports about my archival discoveries. To Peter Delpeut and Mark-Paul Meyer, I am grateful for their interest in the progress of the project and its publication.

Of crucial importance for my understanding of silent cinema are the two archival festivals held annually in Italy. Le Giornate del Cinema Muto in Pordenone offered retrospectives of films by André Antoine and Louis Feuillade at the right moment, and at Il Cinema Ritrovato in Bologna, I learned from the programs that Mariann SträuliLewinski curated focusing on silent film actresses and women filmmakers. Over the years, Mariann has become a cherished companion in archival research. I likewise wish to thank Gianluca Farinelli and Guy Borlée for the opportunity, in 2011, to present a tribute to Musidora, that highlighted the actress' comic acting.

Colleagues and friends who read the originally extensive manuscript provided astute commentaries. For relevant remarks and questions, I thank Richard Abel, Madeleine Bernstorff, Ansje van Beusekom, Patrick Cazals, Richard Dyer, Germain Lacasse, the late Francis Lacassin, Eric Leroy, David Mayer, Mariann Sträuli-Lewinsky, D.J. Turner, Tineke de Vaal, Hildegard Westbeld, and Paul van Yperen. My anonymous readers supplied much appreciated comments and suggestions.

Many of the pictures in this book informed my research and argument. For access and permission for publication, I am grateful to Cheryll Oestreicher and Jim Duran from the Special Collections and Archives at the Albertsons Library of Boise State University; to Véronique Chauvet from the Iconothèque of the Cinémathèque française; to Melanie Hérick from the Musée Gaumont; to Gonneke Janssen from the TIN-collection at the UVA Special Collections; to Annette Schulz from the EYE Filmmuseum; as well as to Ivo Blom and Paul van Yperen.

I particularly thank the board of Framing Film, Giovanna Fossati, Leo van Hee, Frank Kessler, Patricia Pisters, Dan Streible, and Nanna Verhoeff, for their resolve to include this book in the series; many thanks also to Jeroen Sondervan, Kristi Prins, and Chantal Nicolaes of Amsterdam University Press (AUP) for their commitment to this publication.

For native speaker corrections I am obliged to Pete Purnell (in Part II) and Jack Ben-Levi (in Part I and III). Jack added an extra quality by translating Solser's verses on rhyme. I thank Danielle Carter for the smooth copy-editing of the final text. 
Annette Apon performed more than one vital role in the development of this publication. Her expertise as a filmmaker made her the ideal sounding board during the research and writing processes. As an editor, she rigorously cut down the text to its present size. She supplied the idea for the cover image. Above all, she offered encouragement and backing whenever I needed it. Without her love and loyalty this book would not have come to fruition. 


\section{ILLUSTRATION CREDITS}

Fig. I.2, I.3, I.5, I.6, I.8: TIN-collectie, Bijzondere Collecties UVA Uitvoerende Kunsten, Universiteit van Amsterdam; Fig. I.4, Stadsarchief Amsterdam; Fig. I.7, I.11, I.13-20, I.22, I.23, page 430: EYE Filmmuseum.

Fig. II.1, II.11, II.12, II.17, II.18, II.21-31, page 134: Cinémathèque française; Fig. II.2, II.5: Paul van Yperen/Ivo Blom, private collection; Fig. II.3: Clément Marot, private collection; Fig. II.4, II.8, II.15: Collection Musée Gaumont; Fig. II.9, II,14, II.16, II.19, II.20: Cinémathèque française/Musée Gaumont.

Fig. III.1-4; III.6; III.9-11; III.13-27; page 280: Boise State University, Albertsons Library, Special Collections and Archives, Nell Shipman Archive, MSS 081, photo numbers 267, 1022, 193, 194; 210, 309, 266; 201, 007; 172, 208, 260, 207, 164, 1054, 220, 139, 241, 238, 252, 236, 088; Fig. III.7: MSS 258; Fig: III.8: MSS 251; Fig. III.5, III.12: Paul van Yperen/ Ivo Blom, private collection. 



\section{INDEX}

Abandoned trails (a. Shipman) 499n 5 , 50on13, 536

on Bert van Tuyle $396-8,424$

on Curwood 335, 343, 346, 347

on Ernest Shipman 298

Abel, Richard $174,178,180-3,185^{-}$

7, 191, 214, 224, 240, 242, 250,

263, 464n169, 478n46, 479n67,

491n304, 492n324, 493n327,

496n369

Actueel Film: and Adriënne Solser's production company 108, 109, 111, 113. See also Benno, Alex

Adrian, Paul 190

Ah, Wing (Fong) 404, 522n311, 535

Ainé, Mévisto: and Musidora 138

Alhambra (music-hall, Paris) 148

and film 190

Musidora at 153

Allen, Alfred 414, 421, 522n311, 535

Allen, Robert 12

American Releasing Company (Fred

Warren) 400

AMSTERDAM BIJ NACHT 104, 105, 457,

528

Andreyor, Yvette: in JUDEX 170, 174, 232

career of $477 \mathrm{n} 29$
Andriot, Josette: in PROTÉA 220, 222, 223, 223Fig.II.17, 225

Antoine, André 186, 199, 251, 252, 494n 337

Aragon, Louis 156

ARLÉSIENNE, L': and POUR DON CARLOS

250-2

Arling, Charles 372, 517n234

Armatage, Kay 347, 348, 359-62, 366, 391, 411, 421, 422, 499n5, 519n267, 5200287

ARTIESTENREVUE, DE 111, 435ng1

Asta, Monica Dall' 212

ATLANTIDE, L' 249, 493n327

and POUR DON CARLOS 251, 256,

$487 \mathrm{n} 220$

Atlantide, $L^{\prime}$ (a. Benoit) 249

Audé, Françoise 367

Australasian Films 305,535

AUTRE VICTOIRE, L' 178

BACK TO GOD'S COUNTRY 17,303 , 354Fig.III.14, 371, 372, 424, 502n49, 512n131, 514n173, 519n267, 521n309, 523n334, 535 and A BEAR, A BOY AND A DOG 375 
and Shipman's shooting script 328, 341-9, 352, 355-61

and SOMETHING NEW 369,384

and THE GIRL FROM GOD'S

COUNTRY 387

and THE GRUB-STAKE 393,394 ,

396, 404, 411, 413, 415

animals in $329,349-51,351$ Fig.

III.13, 353, 354, 357, 361-5, 365Fig.

III.16

Shipman's acting in $\quad 365-70$

Baker, George (Baker Stock Company, American Amusement Company): Barham/Shipman with 293, 298

546 | Bakhtin, Mikhail 14, 15, 71

BALLET DU FEU, LE 189

BANNELINGEN, DE 11

Barbarossa (H.C. Schröder) 38, 60, 129

BAREE, SON OF KAZAN 295, 322, 326,

334Fig.III.11, 535

and animals 327,333

and BACK TO GOD'S COUNTRY 349-

51, 353, 355, 359, 523n334

Baree, son of Kazan (novel): stock

characters in 329-32

the outdoors girl in $328,329 \mathrm{Fig}$.

III.10

Barham, Helen (stage name of Helen

Foster Barham/Nell Shipman )

283, 285-9, 292-4, 298, 503n67, 533

Baroncelli, Jacques de 237, 46on193, $490 n 279$

Barrier, The (a. Beach): characters in

$295^{-7}$

and Curwood's characters 329,

330,332

and Shipman's characters 357,

413

play $293,294,298,303,534$

See also Beach, Rex
Bastia, Jean 166, 474n181, 485n189, 531,532

Ba-ta-clan (music-hall, Paris): Musidora at $145,146,151-3,155,160-2,164$, 167Fig.II.7, 182, 193, 530

Beach, Rex: and The Barrier 293-5, 298, 306, 316, 318

and Curwood's fictional universe

332, 340, 348, 357

and Shipman's characters 360, 391, 393, 394, 400, 402, 405, 407, 413, 417, 503n71, 503n74, 534

See also Curwood, James Oliver

Bean, Jennifer 317, 323, 337, 362

BEAR, A BOY AND A DOG, A 535; animal discourse in $374^{-6}$

BÉBÉ APACHE 186

Beeckman, Eugène 110, 111Fig.I.18, $461 \mathrm{n} 207$

Benno, Alex 83, 92, 93Fig.I.13, 94, 455ng1

and Solser's performance 105-7 and volksstukken (folk plays) 95, 97-100, 102-4

See also Actueel Film; KEE EN JANUS films

Benoit, Pierre: and POUR DON CARLOS 249-57, 491n306, 493n327-n328, $495 \mathrm{n} 356,532$

Berg, Hetty 105

Bergson, Henri: on laughter 55, 102, 130, 161, 192, 193, 202

Bernardin de Saint-Pierre, Henri 172 Berrell, George 395, 405, 521n311, 535 BET films: and popular stage culture 106, 107, 111, 121, 131 and comic acting $127-9$ and Solser's film company 108-10, 112, 114, 116

and Solser's live act 115-7, 119-21, 132 
and the Bet character 122-6, 128

crews and casts of 110,111

early film devices in 130, 131

marketing of 113,114

BET NAAR DE OLYMPIADE 109, 110, 116, 119-29, 122 Fig.I.21, 126Fig.23, 131, 529. See also BET films

BET TREKT DE 100.000 108Fig.I.17, 110, 113, 114, 116, 125, 529. See also BET films

BET ZIT IN DE PENARIE 109,

111Fig.I.18, 115, 116, 124, 124Fig.I.22, 529. See also BET films BET, DE KONINGIN VAN DE JORDAAN

(BET I) 61, 106, 107, 109, 112Fig.I.19, 116, 118Fig.20, 11923, 125, 126, 128, 130, 454n81, 458n142, 459n179, 529. See also BET films

Beusekom, Ansje van 43, 96, 103, 434n2, 452n43, 453n63, 459n18o Binger, Maurits 89, 91, 92, 94, 95, $445 \mathrm{n} 167,528$

Bioscope-Theater (cinema and theater, Amsterdam) 74-6, 79, 81, 89, 450 13

Bishoff, Ruud 454n72, 456n117, $456 \mathrm{n} 167$

BLACK WOLF, THE 320,321

Shipman in 322

BLEEKE BET: film 69, 94, 95, 103, 105

play $62,63,68,70,96$

Boesnach, André: and the Eureka studio 107-16, 108Fig.I.17, 124, 437n42, 459n164, 46on184, 527, 529

Boisyvan 257

Bonnefoy, Nini 265

Bosetti, Roméo: and comic subjects 163

Bosworth, Hobart 336
Bouber, Herman, and Jordaan comedies: history of $58,59,62-4$, 67-70

characterisation of $94,96,97,104$, 106, 131, 448n213, 448n215

See also BLEEKE BET, DE JANTJES

Bouber-Ten Hoope, Aaf 69, 105, 447n191; 448n211. See also Bouber, Herman

Bout de Zan (René Poyen): and Feuillade 170, 185, 186, 190, 198, 481n94, 530

in LE REVEIL DE L'ARTISTE 201

in LES VAMPIRES 215,216

BOUT DE ZAN ET L'ESPION 186

Bouwmeester, Louis: on stage 28,41 and film acting 89, 105

Braakensiek, Charles: and Dutch lecturing 81, 120, 529

Brauerhoch, Annette 367,381

Bret, Suzanne Le 186, 202

Bridge, Joë 152, 471n114

Bruno, Giuliana 12, 14

Buderman, Jan: Dutch stage comedian 68, 441n93, 455n95

Bunink, J. Werumeus 62

Buziau, Johan: revue star and film actor 89, 455n99

Cabaret Metropole (Rotterdam): Solser at $44,56,528$

Café-concert Victoria (Amsterdam):

Solser at 31Fig.I.4, 32-4, 48

Michel Solser at 29, 30

Callahan, Vicky: on SOLEIL ET OMBRE 212, 231, 232, 269 ON LA TERRE DES TAUREAUX $270-2$

CALVAIRE, LE 176, 179, 180, 475n1, 530 Musidora in:177, 178

Camí-Vela, María 269, 270 
Cañero, Antonio: and Musidora 263, 267-9, 271-4, 276, 496n370-n371

Carl, Renée: at Gaumont 170, 174, 176, 186, 199, 465n19, 476n9,530

Casino de Paris 251, 494n339

Mistinguett at 182

Casino Variété (variété-theater, Rotterdam): Solser at 38, 40, 41, $64,73,439 n 65,527$

CAVANAUGH OF THE FOREST RANGERS 325

Shipman in 325,326

Cazals, Patrick: on Musidora 17, 18, 140, 142, 211

548 CHACALS 236,531

Chaplin, Charlie: imitation of

126Fig.I.23, 131

Colette on 242

Musidora referring to 138

Châtelet (Théâtre du, Paris): Musidora at $143,145,228,229,241,530$ Raphaël Clamour at $476 \mathrm{n} 13$ Stacia de Napierkowska at $\mathbf{2 2 2}$ Chauveau, Philippe 146, 155, 438n5o Chester, George Randolph and Lillian Christy Chester 307, 316, 326 Chrispijn, Louis H. Sr: film director 90, 94, 44n72, 441n93, 455n95, $459 n 173$

Chrysias, Ginette: Musidora on 246, 532

Cigale, La (café-concert, Paris): Musidora at 241, 485n182, 531 Circus Carré (variété-theater, Amsterdam 64, 78, 438n49, $439 n 65$

film at $73,84,454 \mathrm{n} 85$

Circus Pfläging (variété-theater, Rotterdam) 439n65

Solser at 38

CIRQUE HOLLANDAIS $105,110,111,529$
Clune, William H. 374,389

Coffee, Lenore 337

Cole, Marjorie: and THE TRAIL OF THE ARROW 380, 381

Colette: Musidora's friendship with 18 , 139-42, 467n41, 530 and mime 145 , 159Fig.II.5 in Musidora's essays 434n22, 466n21, 466n27, 490n281 in the Parisian revue $151,152,154$, 157, 158, 471n113 on French music-hall 166, 168, 175 on Musidora's acting 236, 237, 248, 249, 257, 261, 272, 278, 491n292, 495n 353 on photogénie 238-42, 246, 491 288

on Polaire $149,150,466 n 28$

on scenarios $530-2$

COLLIER DE PERLES, LE 196, 202, 203, 530

Concert Mayol (café-concert, Paris): Musidora at 479n63, 485n182, 531

Condon, Mabel: and Shipman's publicity 315,534

Coppée, François: and Feuillade 175

Corvin, Michel 144

COUP DU FAKIR, LE 190, 198, 530 and Feuillade's working procedure 194

Cresté, René 232

Croze, Jean-Luc 228, 493n326

Culp, Cato: and the Dutch variété 44 , $74,438 n 59$

Culp, Emilie: and the Dutch variété 32, 37, 438n $58-n 59$

Culp, Julia: and the Dutch variété 44 , 442n104, 438n 59

Cunard, Grace 76, 307, 323, 337, $451 \mathrm{n} 29$ 
Curnonsky (Maurice Edmond Sailland): on the Parisian revue 147,154 , $155,162-4,181,188,238,469 n 85$

Curwood, James Oliver: and God's

Country and the Woman 295, 306, $315^{-8}$

and Baree, Son of Kazan 322, 326-8

and Beach 329-33, 335

film adaptations of $504 \mathrm{n} 88$, 505n110, 534, 535

Shipman's experiences with 347 , 348, 371, 389, 415, 424

See also Shipman-Curwood Producing Company

Daisne, Johan: and Musidora 139, 250, 255, 466n 35

Danvers, Guillaume 226, 228, 229

Daudet, Alphonse 251

Davids, Heintje: in the revue 28,45 , $442 n 108$

as film actress $457 \mathrm{n} 129$

Davids, Louis 27, 32, 37, 39, 45, 84, $439 n 65,452 \mathrm{n} 37$

and Jordaan comedies 68

film actor $69,89,95,528$

Davids, Rika 26,32 ; in the revue 45 ,

$84,442 n 106$

Davis, Owen 285, 533

Dearly, Max 182, 530

DÉBROUILLE-TOI! 194, 196, 202, 531

DeCordova, Richard 323, 337

Decourcelle, Pierre 181, 183

Delluc, Louis: on music-hall 141, 143, 199

on film 201, 238, 241, 242, 244,

245, 251-3, 479n 53, 491n288, 492n308, 492n310, 496n369

Delpeut, Peter: and Solser 89, 120, 121

Derval, Louise 236
Divan Japonais, Le (cabaret, Paris) 155, 47n96, 473n169

DOCTORESSE, LA: Mistinguett in 183

Dommelen, Caro(line) van: as stage actress 28, 41, 45 and film directing $42,43,76,89$, 441n93-n94

Dommelen, Jan van: stage actor, film actor and director $28,76,89,90$, 441n93, 455n89

Dommelen, Louis van: stage and film actor $28,68,89,441 \mathrm{n} 93,455 \mathrm{n} 8 \mathrm{~g}$

Donaldson, Geoffrey 20, 83, 87, 89, 90, 94-6, 110

Donnay, Maurice 160

DROOM VAN HADT-JE-ME-MAAR, DE:

Solser in 93, 94

Duhamel, Sarah: and RosALIEcomedies 473n169, 163

Dulac, Germaine 238, 495n 356

Dumas, Alexandre 234

Duncan, William 315, 316, 318, 534

Durand, Jean 185, 199

Dutard, Charles 151, 152, 161

Eldorado (café-concert, Paris) 148, $472 \mathrm{n} 13$

Polaire at 140, 182

Elsaesser, Thomas 11,12

Envers du music-hall, L' (a. Colette) 166, 239

épouvante, L: Mistinguett in 183

ESCAPADE DE FILOCHE, L' 196, 530

Falkland, Samuel: on Michel Solser 30

FEMALE RAFFLES SERIES OF

PHOTOPLAYS, THE 305, 308

Féry, Gustave 206, 484n175

Fescourt, Henri: on Feuillade 172, 175, 179, 180, 189, 197

on Renée Carl 174 
Feuillade, Louis 17, 168-71, 170Fig.II.8, $475 \mathrm{n} 5,477 \mathrm{n} 21,478 \mathrm{n} 46,478 \mathrm{n} 53$, 48on $78,585 \mathrm{n} 188$ and ciné-vaudeville $18,144,183-5$, 187, 192-9, 202-9, 214-8, 530, 531 and crime series 19, 139, 210-2, 250,274 and JUDEX 190, 231-3, 233Fig. II.18, 234, 235, 235Fig.II.19, 466n.20, 531 and LE CALVAIRE 176, 177, 181, $475 \mathrm{n} 1,53 \mathrm{O}$ and LES VAMPIRES 158,217 Fig. II.14, 220Fig.II.15, 531

and Marcel Levesque 199-202, 213 and Musidora's acting 172,178 , 203, 204, 209, 210, 220-2, 224, 227 and popular stage genres 171,178 80, 186, 190, 191, 195, 213 and SEVERO TORELLI 173-5, 475n 1,530 and stage actors 199, 208, 213 Musidora's recollections of 210 , 229-31, 245, 248, 278, 220, 221, 224, 476n2o, 488n228, 533

Feydeau, Georges 161, 192, 193, 196, 199

Feyder, Jacques: at Gaumont 169, 249, 487n220, 493n327, 531

FIANCÉE RECALCITRANTE, LA: Mistinguett in 183

Film d'Art 178, 180, 181, 183 Film d'Arte Italiana (Pathé Italy) 239, 531

Film Fabriek F.A. Nöggerath See Nöggerath, Franz Anton Sr. and Jr. Filmfabriek-Hollandia See Binger, Maurits FINANÇAILLES D'AGÉNOR, LES 203, 531 FLAMME CACHÉE, LA $236,237,248$ Fig.

II. 22, 248, 490n281, 498n387, 532
Fleuron, Louise 26, 32, 36, 37, 45, 46, $54,56,62,74,438 \mathrm{n} 49$ in mixed programs $39,62,74,75$, 79

Flora (variété-theater, Amsterdam) 64, 439n65

film at $43,73,74,76,84,87,88$, 434n2, 449n5, 454n85, 455n91, $455 \mathrm{ng} 8$

Folies-Bergère (music-hall, Paris):

Musidora at 145, 146, 151-5, 161-5, 172, 176, 180, 182, 188, 189, 530

Loïe Fuller at 471n119

Mistinguett at $470 n 87$

Stacia de Napierkowska at $\mathbf{2 2 2}$

Ford, Charles 211

Ford, Francis See Cunard, Grace

Forestier, Laurent le: on Feuillade's ciné-vaudevilles $184,185,187,193-$ $5,480 n 78$

FOURBIÈRES DE PINGUIN, LES: and LES VAMPIRES 203, 204

Fraper, Charles le 114, 115

Frascati-Schouwburg (theater, Amsterdam): Solser at 32,60, 70, 436n32, 446n175

Frenkel, Theo Sr. 91, 92, 104-6, 109, 110, 116, 127, 132, 462n226, 528, 529

Frondaie, Pierre 161

Fuller, Loïe 487n221

Fuller, Mary 293, 301, 308, 323, 505n97, 510n79

Fursy, Henri 146, 147

Gaiété-Rochechouart (music-hall, Paris) 472n135, 484n164

Musidora at 531

Gaines, Jane 512n127

Gardner, Cyril: and the editing of BACK TO GOD'S COUNTRY $348,352,353$ 
Gaumont (production company):

Musidora at $17,75,169,172-5$, 183, 206, 210, 231, 236, 249, 475n 3 , $493 n 327$

comic film production at $184-7$, 199, 201

production climate at 170,171 publicity profile of $178-80,199$, 200, 206, 207, 227

See also Feuillade, Louis: cinévaudevilles; Perret, Léonce;

Levesque, Marcel

Gaumont, Léon 170, 178. See also

Gaumont (production company)

Gaumont-Palace: and mixed programs 173, 176, 190, 191, 194

Gauntier, Gene 301, 302Fig.III.5, 307, $308,323,324,337,505$ n10o

Gautier, Théophile 138, 139, 465n18

Gilmore, Paul: Barham/Shipman with 285

GIRL FROM BEYOND, THE 325Fig.111.8, 522

Shipman's role in 326, 404

GIRL FROM GOD'S COUNTRY, THE 374, 386, 388Fig.III.20, 395, 396, 400, $424,425,535$

and Northwest drama 392

and THE GRUB-STAKE 390,406

animals in 387

production of 389,390

reviews on 390,391

scenario of 388,389

Shipman's roles in 387,393 Fig.

III.21, 391, 392

GOD'S COUNTRY AND THE WOMAN:

294, 295, 314, 370, 534

and Shipman's career 323,324

and Shipman's stardom 319Fig.

III.7, 320-2

animals in 320,327
God's Country and the Woman

(novel): characters in $330-3$,

504n88, 509n64

locations of 318

reviews of 316,317

Shipman on $294,318,321,370$

the outdoors girl in 320,329

Grand Theatre (Salt Lake City, Utah):

Barham/Shipman at 287, 288, 534

Grand Théâtre (variété-theater, Amsterdam): Solser at 38,76

Grandais, Suzanne 187, 199

Grootveld, Jan: and the Jordaan

audience $63,64,446 \mathrm{n} 184$

GRUB-STAKE, THE 394, 406Fig.III.23,

521n306, 522n311, 535

animals in $411-4$

character perspective in $\mathbf{4 2 2}$

characters in: 402-6, 403Fig.III.22

and the Dawson Kate character

407-11

and the Faith character 417-21,

419Fig.III.26

and the Leroy character $414-6$

funding and shooting of 394, 395

plot construction of 400, 401

relation star-director of 398,399

sale of $396,397,400$

Guérin, Georges 224, 487n225

Guilbert, Yvette: French diseuse 39, 40, 150, 155

Guitry, Jean: Musidora on 246, 532

Guitry, Lucien: and Musidora 251

Guitry, Sacha 531

Guitty, Madeleine 199

Guy, Alice (Alice Guy-Blaché): at

Gaumont 169, 189

Haarlem, Frits van jr. 84, 87, 439n65, $454 \mathrm{n} 85$

Haarlem, Frits van Sr. 84, 454n85 
Haas, Alex de: on Dutch variété comedians $33-6,38,48,437 n 36$

Habrekorn, Gaston 155

Hall, Henry ter: and the Dutch revue 47, 56, 89, 111, 447n191, 454n76, 463n239, 528

Haraway, Donna 363-5

Harrison, Louis Reeves 326

Hartford, David 348, 352, 353, 371, 389, 535

Hartlooper, Engelina 28, 436n31, 527

Hayakawa, Sessue 322

Colette on 241, 242, 257

Hermann, Fernand 179,181

552 Hesse, Piet See Solser, Lion: duo Solser and Hesse; Ensemble Solser and Hesse

Hesse-Slauderof, Anna 37, 64, 66, 440n68. See also Solser, Lion, the Ensemble Solser en Hesse

Heyermans, Herman : and Dutch socialist drama $30,41,58,59,63$ Hogenkamp, Bert: on Jordaan films 60 Hollando-Belgica Film Mij "Eureka” (Eureka studio) See Boesnach, André

Hollandsche Schouwburg (theater, Amsterdam) 61, 62 and Bouber's "Bleeke Bet" 63, 64 Solser and Hesse at 68 HOME TRAIL, THE: Shipman in 325 , 326

Hugon, André 236, 246, 475n3, 479n63, 498n 387,531

Hulsman, Pierre 110, 127, 130, 461n202, 529

Humphrey, Ola 309, 507n24

IK FLUIT DAT JIJ ZULT KOMEN 133,529 Ingénue libertine, $L^{\prime}$ (a. Colette) 236, 531 Iribe, Marie-Louise 256
Irwin, Wallace 316

Jacobs, Eduard: and Dutch cabaret 3941, 440n75

Jacques-Charles: and the revue 181 JANTJES, DE: film 69, 94, 95,102-

$4,457 \mathrm{~N} 123$

play 62,68

Solser in 96

Januxi, Nora: and Musidora 178, 477n 35,532

Jasset, Victorin-Hippolyte 222, 224

Jeanne, René 211

JOHANNÈS, FILS DE JOHANNÈS 236, 237Fig.II.20, 246, 531

Colette on Musidora in 247

JUDEX 18, 171, 182, 190, 210, 234, 250, 265,531

and the Diana Monti-character

231, 232, 235.II.19

comic elements in 213

disguise in 204, 205, 212, 232, 233Fig.II.18

intended audience of 179,180

Musidora's acting in 235

Musidora's defence of 245

popular stage conventions in $\mathbf{2 3 3}$, 234

reception of 234, 235, 492n308

Judic, Anna: French diseuse 30, 34, 48, 437n 41

KEE EN JANUS NAAR BERLIJN 94, 95, 979, 101, 103, 104, 528. See also KEE EN JANUS-films

KEE EN JANUS NAAR PARIJS 94, 97-100, 100Fig.I.15, 101Fig.I.16, 528. See also KEE EN JANUS-films, Benno, Alex

KEE EN JANUS-films 94, 95, 97-9 and Solser's stage and screen presence 102 
box-office success of 103, 106 episodic structure of 100, 101 marketing of 113

mixed response to 104,116

Kelly, Johan 59, 89, 441n93, 446n175, 447n187

Klaasen, Anna: and the Dutch variété 44, 45, 442n10 5

Klöters, Jacques: on the Dutch variété 28, 29, 33, 34, 37, 46, 62, 437n 43, $438 n 46$

Köhler, Piet: stage comedian 45,68 , 452n37, 457n142

in AMSTERDAM BIJ NACHT 104, 105, 463n239, 529

in KEE EN JANUS NAAR PARIJS 97, 98Fig.I.14, 103, 528

Krijn, Dries: on the Dutch revue 43 , 61,62

Kuyper, Eric de 12

Labiche, Eugène: and French stage vaudeville 183, 187, 192, 193, 199

Lacassin, Francis: and Musidora's archive 17,18 as a music-hall actress 165 on her qualities 178 on her stage debut 142 ON LA FLAMME CACHÉE 237, 248 ON LA TERRE DES TAUREAUX 271 , 272

On LA VAGABONDE 237

On LES VAMPIRES 211, 244, 227;

487n218

On MINNE 237, 490n279

on Musidora playing "Claudine" 466n35

on Paul Montel 208

on POUR DON CARLOS 494n349, 495n353

ON SOLEIL ET OMBRE $\quad 265,494$ n 334 on the ciné-vaudevilles 184 on the ROSALIE-series 474n169 On UNA AVENTURA DE MUSIDORA EN ESPAÑA 496n368 On VICENTA $245,247,492 n 324$, $493 n 326$

LAGOURDETTE GENTLEMAN CAMBRIOLEUR 18, 184, 194, 531 and LES VAMPIRES 204-6

Musidora in 203, 205-9, 231

Laloy, Louis: on the Parisian revue 18 , 146, 147, 150, 155, 157, 160, 164, 238, 469n85

Langlois, Henri 18, 211, 434n22, 533 Lasky, Jesse (Jesse L. Lasky Feature Play Company, Famous Players-Lasky) 315, 316, 320, 321, 323, 501n39 Lasseyne, Jacques (Jaime de Bourbon) 250, 252, 270, 494n334, 496n368, $498 \mathrm{n} 387,532$

Lavallière, Eve 153, 471n119

Leighton, Lillian 395, 408, 521n311, 535

Léontine 208, 474n169

LEVEN IS NIET ZO KWAAD, HET 132, 529 Levesque, Marcel: in Feuillade's cinévaudevilles 170, 181, 184, 187, 1935, 197Fig.II.12, 199-202, 203Fig.

II.13, 204-9 in JUDEX 234, 476n6, 478n 46 , 485n187, 492n308, 503, 531 in LES VAMPIRES 210, 213-6, 218, 226

stage career of $199,484 \mathrm{n} 164$

Lewis, Alfred Henry 326

Liket, Martin 41, 70, 71, 90

Linder, Max: and mixed stage and screen performances $89,189,190$, 455ng7

L'Ingénue libertine (a. Colette) 236, 531

Lion, Roger 237, 532 
Lisbonne, Maxime 155

LITTLE DRAMAS OF THE BIG PLACES

423, 423Fig.III.27, 536

London, Jack: and Northwest drama

294, 295, 336, 503n71, 503n74

Loos, Anita 13, 307, 337

Lorde, André de 161, 530

Louisette 32, 35, 37, 39, 49, 50, 55,

85Fig.I.11, 438n 49

and mixed stage and screen

performances $84-6,88,445 \mathrm{n} 81$,

$454 n 85$

and Solser 87,130

Louÿs, Pierre 278

MacGregor, Norval 303, 308, 505n110, 534

MacPherson, Jeanie 337

MAGIQUE IMAGE, LA 278, 498N387, 533

Magre, Maurice $166,475 \mathrm{n} 181$

Mann-Bouwmeester, Theo 28, 41, 89,105

Mar, Josefien de la: in BET NAAR DE OLYMPIADE 110

Mar, Nap(oleon) de la 28, 441n89 and volksstukken (folk plays) 40, 41, 62, 68, 70, 74

Marion, Frances 337,338

Mathé, Edouard 202, 205

Maurik, Justus van $61,62,65$

Mayol 149, 470n87 and Concert Mayol 472n135, 479n63, 485n182, 531

McCreadie, Marsha 13, 337

McMahan, Alison 475n 4

Meester, Alex de: in BET NAAR DE OLYMPIADE $111,127,529$

Meirs, Georges $207,227,475^{n} 5$

MEISJE MET DEN BLAUWEN HOED, HET 132,529

Méliès, Georges 163
MELODY OF LOVE, THE 305, 308, 534

Mérat, Albert 138

Meusy, Jean-Jacques 146, 181

MINNE 236, 237, 490n279, 531

Mirande, Yves: and film 182, 479n63, $484 n 164$

Missy (Sophie-Mathilde-Adèle-Denise de Morny): and Colette 157, 467n39

Mistinguett: and the apache dance (valse chaloupée) 153,183 and film acting 181, 183, 236 music-hall career of 182, 471n119, 479n68, 479n71

Moffatt, Cleveland 316

MON ONCLE: and JUDEX 205, 531

Monca, Georges 183

Montel, Paul: in LAGOURDETTE CAMBRIOLEUR 208

Morris, Margie: and Louis Davids 68, 69, 95

Moulin Rouge (music-hall, Paris) 156

Colette at $157,15^{8}$

in KEE EN JANUS NAAR PARIJS

100Fig.I.15, 102

Mistinguett at 182

Mullens, Willy: and lecturing 80, 81 and comic fiction $89,454 \mathrm{n} 72$

Musset, Alfred de 166

MY FIGHTING GENTLEMAN： 305 and Shipman's story 320

MYSTÈRES DE NEW YORK, LES:

Gaumont's competition with 227, $228,488 n 230$

MYSTERY OF THE BALL OF YARN See THE FEMALE RAFFLES SERIES OF PHOTOPLAYS

Napierkowska, Stacia de: danser and film actress 181, 222, 470n87, 487n220, 493n 327 
NE'ER DO WELL, THE 340

Nell Shipman Productions:

incorporation of 374,535

and THE GRUB-STAKE 389,395 ,

519n267

See also Reynolds, J.H.C.

Nielsen, Asta: and acting 13, 489n259 and Dutch mixed programs 44,76 , 78,82

Nieuw Olympia Theater (cinema and theater, Rotterdam): Solser at 79, 451n31, 453n5o, 528

Nöggerath, Franz Anton Sr. and Jr. 43, 434n2, 439n65

and Dutch comic film production $84,87,88,455$ n95

and mixed programs $74-6,451 \mathrm{n} 31$ NOMADS OF THE NORTH $330,346,348$, $514 \mathrm{n} 173$

and Curwood's novel 329,330

and Ernest Shipman 371

animal discourse in 352,353

characters and plotlines of $331-4$

Nooy, Jan: in BET, DE KONINGIN VAN DE JORDAAN 111, 112, 127, 529

Nooy-Blaaser, Beppie: in BET, DE KONINGIN VAN DE JORDAAN 111, 112,529

Oakman, Wheeler 77, 535

Olcott, Sidney See Gauntier, Gene

Oliveyra, Lien D' 19, 112, 431, 46on185, $461 \mathrm{n} 211$

Olympia (music-hall, Paris) 155, 161

Musidora at 148

Polaire at 181

ONE HUNDRED YEARS OF MORMONISM $303,305,534$

"Op hoop van zegen": play 59

OUTWITTED BY BILLY 308, 506n9, 534
Palais Royal (vaudeville theater, Paris)

187, 446n175

and Levesque 181, 193, 199, 200,

207

Musidora at 531

Paleis voor de Volksvlijt (variété-theater, Amsterdam) 29, 439n65

Panopticum (variété-theater, Amsterdam): Solser at 38, 41, 42, 77, 439n65

Pantages Circuit (vaudeville chain, US) See Pantages, Alexander

Pantages, Alexander: Barham/Shipman with $285,288-91,408,533$

Paroxysmes. De l'Amour à la Mort (a.

Musidora): and SOLEIL ET OMBRE 267-9

Pathé: films with Musidora 162, 239, 253, 531

Gaumont's rivalry with 171,178 , 186, 197

See also Duhamel, Sarah

PEG VAN DEN CIRCUS 76, 124

PEINE DU TALION, LA 187, 203Fig.II.13, 485n181, 485n187

Perchoir, Le (cabaret, Paris): Musidora at $475 \mathrm{n} 181,476 \mathrm{n} 16,531,532$

Perego, Eugenio 237, 239, 531

Perret, Léonce: and comic subjects

169, 178, 186, 187, 199, 200, 530

Pfläging, Carl 29, 38, 439n65

Pie qui chante, La (cabaret, Paris):

Musidora at 207, 485n182

PINE'S REVENGE, THE 305, 534

Pisuisse, Jean Louis: and Dutch cabaret $39,42,440 n 74$

Pit, Jet: and Adrienne Solser's live act 19, 120

Plantage-Schouwburg (theater, Amsterdam) 6o, 61, 111, 446n182 audience of 105 
Jordaan comedies at $67,447 \mathrm{n} 191$

Lion Solser at 64

Playter, Wellington 393, 535

Polaire (Emilie-Marie Bouchard-Zouzé):

and the Claudine character 140

in films 182, 218, 479n63

in French music-hall 181

in the French café-concert 149, 150, 151Fig.II.2, 466n28

Ponson du Terrail, Pierre Alexis $478 \mathrm{n} 46$

Porchez, Marie 137, 530

POUR DON CARLOS 18, 249, 253, 254Fig.II.23, 485n192, 491n306,

493n327, 494n349, 495n362,
$498 n 387,532$

Musidora in: 257-63; Pour Don

Carlos (a. Benoit) 249, 250, 255,

256

Musidora's approach to 250,252 , 255,256

Prince/Rigadin (Charles Petitdemange) 181, 183, 186, 187

PRINCESSE MANDANE, LA 495n 356

Prot, Gustave: and volksstukken 6o, 64, 440n68, 446n175, 455n9o, 455n95

PROTÉA 222

and the black suit 223, 233Fig.

II.17, 224

character of 224, 225

Pruis, Kees: stage comedian 79 actor in KEE EN JANUS NAAR BERLIJN 97, 98, 110, 457n136, 528

Querido, Israel 62

Raimu 152, 531

Rasimi, Bénédicte $155,472 \mathrm{n} 135$

Ravel, Gaston: and Musidora 169, 178, 530,532
Reusse, André de 253, 484n175, 494n349, 495n353

RÉVEIL DE L'ARTISTE, LE $18 ; 184,531$

Levesque in 200

Musidora in 203, 204

Reyding, August 43,61, 63

Reyneke van Stuwe, Jeanne: on Dutch cabaret 39, 40, 71, 90, 444n151

Reynolds, J.H.C.: on financing THE GRUB-STAKE $395-7$

Rido (Philip Pinkhof): and Jordaan revues $28,49,55,62,63,65$, 67-70, 87-9, 111, 528, 442n108, 455n91,455n94, 455n98 on Jordaan comedies 68,70 on Jordaan sketches 65,67

Roques, Jacques 137, 138, 497n38o, 530

Roques, Jeanne (Musidora's given name) $137-40,468 \mathrm{n} 50,476 \mathrm{n} 13$, 530,533

ROSALIE ET SES MEUBLES FIDÈLES 163 , 464n169

Rössing, J.H. 65

Roud, Richard 211-3

Rozen-Theater (cinema-variété theater, Amsterdam): Solser at $44,55,56$, $63,67,68,77,528$

RUSE DE MISS PLUMCAKE, LA:

Mistinguett in 183

Sadoul, Georges: on Musidora 211, 220 Sargent, Epes Winthrop 306, 307, 345 SATURDAY OFF See A BEAR, A BOY AND A DOG

SCAGL (Société Cinématographique des Auteurs et Gens de Lettres) 178, 180-3, 478n46, 487n22o

Scala (café-concert, Paris) 147, 472n135 Musidora at $153,475 \mathrm{n} 181$, 485n189, 531, 532 
Scala (variété-theater, The Hague):

Solser at $38,113,439 n 65,528$

Schlüpmann, Heide 13

Schmitz, Tony: and the Jordaan revue $40,56,62,110$

Schroeder, Doris 315,320

Scribe, Eugène: and French stage vaudeville 192

Selig 305, 306, 488n230 and Beach adaptations 340, 503n 77 and Curwood adaptations $505 \mathrm{n} 110$ and Shipman's scenario Outwitted by Billy 308

See also Beach, Rex; Curwood, James Oliver

Serrao, Amerigo 425, 537

SEVERO TORELLI 173, 173Fig.II.9, 174, $180,451 \mathrm{n} 31,530$

Musidora in $175,176,476$ n 20

Shipman, Barry 298; on Nell Shipman: 16, 291, 299, 312, 313, 374, 409, 423Fig.III.27, 425, 521n305, $524 \mathrm{n} 343,534^{-6}$

Shipman, Ernest: and Nell Shipman 298, 299, 299Fig.III.3, 370, 371, 415, 416, 501n49, 514n157, 535 and BACK TO GOD'S COUNTRY 335 , 336, 340, 346, 367, 516n224 and film promotion $312,517 \mathrm{n} 231$ and theatrical manager 298,534 Shipman-Curwood Producing Company 336-40, 345, 346, 371, 389 and "Wapi the Walrus" 361-3 and Baree, Son of Kazan $355^{-7}$ and NOMADS OF THE NORTH $349-53$ and the shooting script of BACK TO GOD'S COUNTRY 341-4 See also Curwood, James Oliver, Shipman, Ernest.
Singer, Ben: on serial queens 123 on stage melodrama $286,287,362$, 380

Slide, Anthony $335,511 \mathrm{n} 117$

Sloan, Kay 338

Smith, David 326, 535

SOLEIL ET OMBRE 18, 263, 264Fig.II. 25 and II. 26

and Paroxysmes, de l'amour à la mort 267-9

Musidora in 265, 266Fig.II.27, 267, 268Fig.II.28, 269, 270

Solser, Johannes $28,436 n 31,527$

Solser, Josephine 28, 30, 32

Solser, Lion $27,28,30,32,37,527,528$; and cross dressing 65 , 66Fig.I.8, 67Fig.I.9 and Bouber's Jordaan comedies 67-9; Solser in the tradition of 97, $105,116,117,123,445 \mathrm{n} 163$ and Jordaan sketches $\quad 62-6$ and the Bet-persona 70 and the duo Solser en Hesse 26, 32,41 and the Ensemble Solser en Hesse $38,64,45$ on 13

Solser, Louis 28

Solser, Michel 29, 29Fig.I.3, 32, $45_{2 n}$ 37, 527; at Café-concert Victoria (Amsterdam) 30, 31 and DE ARTIESTENREVUE 455n91 Solser-Willemsens, Adriënne 38, 440n68. See also Solser, Lion SOMETHING NEW 374, 390, 404, 519n267, 535 and Laddie's role in 381, 382, 405, 413 and Shipman's roles in $384-6$ and the car's role in 383,384 , 384Fig.III.19 and women's car driving $379-81$ 
the comic tone of $376,377,410$ the writing woman in 378,378 Fig.

III.18

SON O' THE STARS 308,534

SOSIE, LE 196, 202, 531

Souvestre, Pierre and Marcel Allain 179

Speenhoff, Koos and Césarine

Speenhoff-Prinz: and Dutch

cabaret $39-42,71,74$

SPOILERS, THE 340, 506n110

Spree, Marius: and volksstukken (folk plays) $61-4,67,70,94,439 n 65$, 446n176, 446n182, 448n213, $448 \mathrm{n} 215$

558 | Staiger, Janet 307

Stam, Robert 14

Star, Maria (Ernesta Stern) 263, $496 n 373$

Stewart, Anita 324

in Curwood films 338,339

STORY OF MR. HOBBS, THE 425

Sturgeon, Rolin: Shipman on 292, 315-

7, 320, 534

Sue, Eugène 488n230

SUIKERFREULE 132, 529

Sutton, Dick (Sutton Stock Company, Sutton Players): Barham/Shipman with $285-8,290,291,534$

Tarride, Abel 251, 532

Taylor, Charles A.: Shipman's recollections of $283,285-7,289-91$, 294, 405, 533

Tellegen, Lou 320-2, 535

TERRE DES TAUREAUX, LA 18, 247,

498n387, 532

and live acts 277

and Musidora's self-presentation

271-6, 275Fig.II.29, 276Fig.II.30

Théatre Montparnasse: Musidora at

142, 468n 53,530
Thérésa (Emma Valladon): and the French café-concert 148, 149, 470n96, 472n135

Thompson, Hugh 407, 522n311, 523n 337, 535

THOU SHALT NOT COVET 339

Thurman, Judith: on Colette 139-41, 158

Tip-Top Theater (cinema-variété theater, Amsterdam) 77, 452n35

Toulet, Emmanuelle 183, 190, 191

TOURNÉE DES GRANDS DUCS, LA: Polaire in 182

TRAIL OF THE ARROW, THE 374,379 , 535

and women's rights 381,386

Shipman's synopsis of 380

Trusky, Tom 16, 343, 369, 385, 404, 423, 499n 5, 502n49, 504ng1, 507n18, 514n164, 515n176, 516n213, 518n213, 524n349

TU NÉPOUSERAS JAMAIS UN AVOCAT 195, 198, 485N181, 530 and ciné-vaudeville 196 Levesque's role in 202 Musidora's role in 203 Turner, D.J.: on Shipman, Ernest 301$3,516 \mathrm{n} 224,519 \mathrm{n} 267$ Nell Shipman filmography 305 , 308, 423, 506n 2, 506n17

Tuschinski, Abraham: and mixed programs 76, 79, 451n31

Tuyle, Bert van: Shipman's relationship with $371,372,423,424,514 \mathrm{n} 157$ as actor 385 as managing producer 379 , 389, 390, 394-400, 416, 423, 424, 5200287 as Shipman's co-director 373, 374, $376,514 \mathrm{n} 172,535,536$ 
Uiltje (David Orobio de Castro and G.

Blok): and the Jordaan genre 50,

444n128, 453n 55,528

UNDER THE CRESCENT $305,308,310$, 311

Under the Crescent (a. Shipman) 309, 310,312

Union-Éclair 237, 245

Universal: and Shipman's scenarios

293, 301, 305, 308, 309, 534

and Cunard, Grace 324,337

and Fuller, Mary 505n97, 519n267

and Weber, Lois 324

VAGABONDE, LA 166, 236, 237, 245,

498n387, 531

Colette on the shooting of $238-40$

Delluc on 241

Musidora on 241

Vagabonde, $L a$ (a. Colette) 166, 236

VAMPIRES, LES 18, 171, 190, 210, 235,

475n $5,488 \mathrm{n} 228,488 \mathrm{n} 244,530,531$

and the afterlife of the Irma Vep

character 210, 211, 218, 531

and the apache dance 182Fig.II.15,

220

and the black body suit 155 ,

156Fig.II.4, 158, 212, 220-4

citation of 276,277

comic elements in $213-8$

Musidora's acting in 230, 231,

486n212

Musidora's writings on 228-31,

245,278

parody of 184, 203-6, 209

popular stage conventions in 218 -

25

reception of $225^{-8}, 492 \mathrm{n} 308$

Vas-Diaz, Herman: and Dutch lecturing 82

Vermoyal, Paul 263, 532
VICENTA 237, 238, 245, 490n282, 492n324, 498m387, 532

Musidora on 246-9

Vitagraph: at the Bioscope-Theater (Amsterdam) 75

Anita Stewart at 338,339

Clara Kimball Young at 301, 505n98

Mary Fuller at 301

Shipman in the publicity of 315 , $318,320,326,327,346$

Shipman on $290,292,335,336$

Shipman's affiliation with 295,

314-6, 324

See also individual film titels

Wague, Georges: and mime 141, 158, 159Fig.II.5

Walker, Joseph: cinematographer of BACK TO GOD'S COUNTRY 342,348 , 352, 353, 356, 371-4,372Fig.III.17 of A BEAR, A BOY AND A DOG 376 Of THE GIRL FROM GOD'S COUNTRY 386, 387, 392 of THE GRUB-STAKE $394,395,405$, 420, 421, 514n157, 514n172 of TRAIL OF THE ARROW and SOMETHING NEW 374,379

"Wapi, the Walrus" (a. Curwood): and

Northwest drama 340

and Shipman's shooting script 344, 347-9, 358, 359

characters in $341,342,349$

woman-dog relationship in 341

Warth, Eva 212

Weber, Lois 324, 337

Wedekind, Frank: and Dutch cabaret 41

Weitzel, Edward 325, 326

Wesel, Max van 90 
Westhoff, Marcel: on Alex Benno 94, 104

WHAT HAPPENED TO MARY? 301,308 . See also Fuller, Mary

White, Pearl 201, 225, 228, 242, 317, $488 \mathrm{n} 230$

Whitman, Alfred (Gayne) 315, 326

Whitman, Walt 395, 522n311

WIDOW'S SECRET, THE 308, 534

Wilde, Rinus de: and Solser 111, 125, 426n29, 445n164, 458n146, 528, 529

WILD STRAIN, THE 535; Shipman's role in 326

560 | Williams, Dave 285, 289, 533

Williams, Dave (National Stock Company): Barham/Shipman with 285, 289, 533

Williams, Kathlyn and the outdoors girl 323, 338, 339Fig.III.12, 488n230, 512n130, 503n7 and wild animals $339,512 \mathrm{n} 129$

Willy (Henri Gautier-Vilars) 139-41, 166, 467n41, 469n87

WINGS IN THE DARK 425,536

Wolbert, William: at Vitagraph 315 , 324-6, 522n311, 535

Wolf, Nathan Heyman 45, 46, 69, 70, 74, 81, 435n11, 436n 32

WOLFVILLE TALES, THE 326,327 Fig. III.9, 535

Young, Clara Kimball 301, 323, 324, 504n96, 505n98, 510n79

Zidner, Paul: and Musidora 152, 152Fig.II.3, 162, 164 ZIGOMAR, PEAU D'ANGUILLE: and the black suit 222, 223

Zwaaf, Isidore: and film inserts in revues 88, 89, 455n91, 455n94, 455n98-n99 